
ME D D E L L S E R
O M
$G R \oslash N L A N D$

\title{
Nipisat - a Saqqaq Culture Site in Sisimiut, Central West Greenland
}

Anne Birgitte Gotfredsen and Tinna Møbjerg

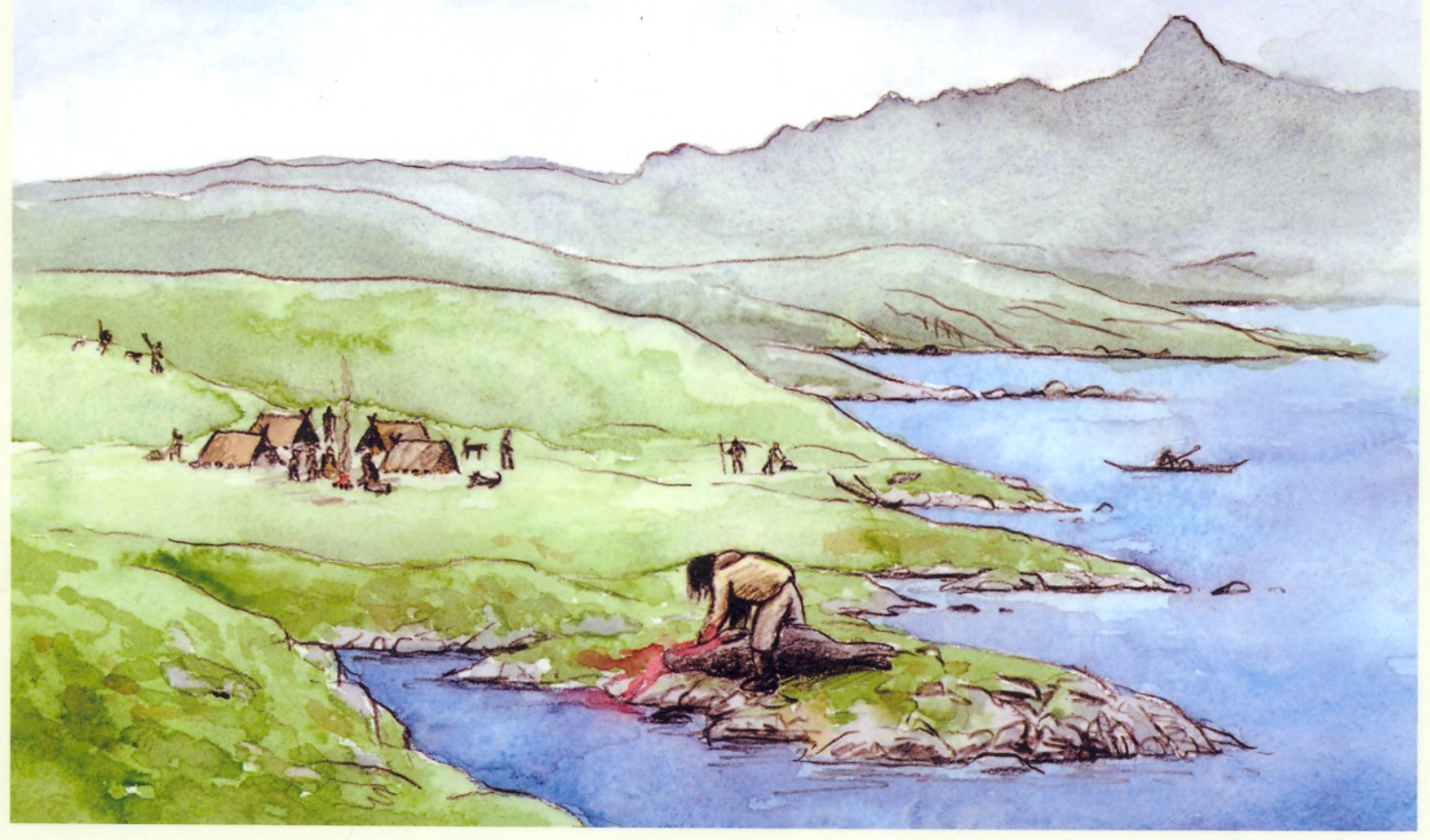


Museum Tusculanum Press - University of Copenhagen :: www.mtp.dk :: info@mtp.dk

Published in cooperation with Sisimiut Museum and SILA, the Greenland Research Centre at the National Museum of Denmark.
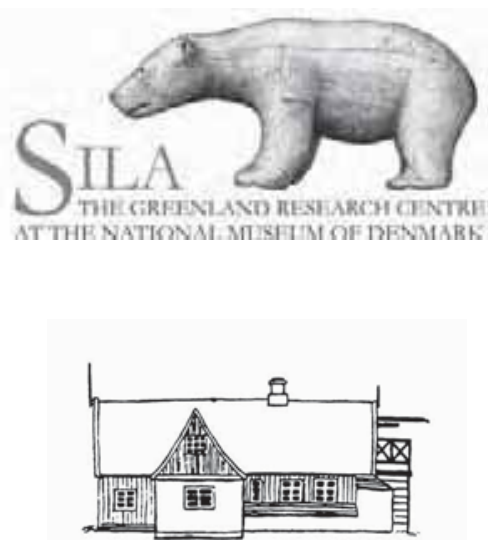

SISIMIUT KATERSUGAASIVIAT SISIMIUT MUSEUM 


\section{Nipisat - a Saqqaq Culture Site in Sisimiut, Central West Greenland}

Anne Birgitte Gotfredsen and Tinna Møbjerg

- with a contribution by Kaj Strand Petersen and Ella Hoch

Meddelelser om Grønland · Man \& Society 31 
Gotfredsen, A.B. and Møbjerg, T. Nipisat - a Saqqaq Culture Site in Sisimiut, Central West Greenland. Monographs on Greenland | Meddelelser om Grønland, vol. 331 (ISSN 0025-6676)

Man and Society, vol. 31 (ISSN 0106-1062)

(c) 2004 by SILA and Danish Polar Center (ISBN 87-90369-73-4)

ISBN 978-87-635-1264-0 (Museum Tusculanum Press)

elSBN 978-87-635-2626-5 (Museum Tusculanum Press: unchanged PDF-version of print edition)

Publishing editor Kirsten Caning

Printed by Special-Trykkeriet Viborg a-s

No part of this publication may be reproduced in any form without the written permission of the

copyright owners.

Front cover: A Saqqaq Culture Site in Sisimiut as imagined by $\mathrm{J}$ ørgen Mührmann-Lund.

Back cover: A Saqqaq family by their hearth and midden. Drawing J ørgen Mührmann-Lund.

\begin{abstract}
About the series
Monographs on Greenland | Meddelelser om Grønland, (ISSN 0025 6676) has published scientific results from all fields of research in Greenland since 1878. The series numbers 345 volumes comprising 1253 titles. Publisher since 2008 is Museum Tusculanum Press, University of Copenhagen.
\end{abstract}

In 1979 Monographs on Greenland | Meddelelser om Grønland was developed into a tripartite series consisting of Bioscience (ISSN 0106-1054), Man \& Society (ISSN 0106-1062), and Geoscience (ISSN 0106-1046). Hence Monographs on Greenland | Meddelelser om Grønland was renumbered in 1979 ending with volume no. 206 and continued with volume no. 1 for each subseries. As of 2008 the original Monographs on Greenland | Meddelelser om Grønland numbering will be continued in addition to the subseries numbering.

Scientific Editor (Man \& Society):

Dr. Hans Christian Gulløv, The National Museum of Denmark, Ny Vestergade 10, DK-1471 Copenhagen K, Denmark. Phone (+ 45) 3347 3220, fax (+ 45) 3347 3330, hans.christian.gullov@natmus.dk

Scientific editor (Bioscience)

Dr. Reinhardt Møbjerg Kristensen, University of Copenhagen, Natural History Museum of Denmark, Universitetsparken 15, DK-2100 Copenhagen Ø, Denmark, Tel. +45 353 21118, fax +45 353 21010, rmkristensen@snm.ku.dk

Scientific editor (Geoscience)

Dr. Svend Funder, University of Copenhagen, Natural History Museum of Denmark, Geological Museum, Øster Voldgade 5-7, DK-1350 Copenhagen K, Denmark, Tel. +45 353 22363, fax +45 353 22325, svf@snm.ku.dk

\title{
Publisher
}

Museum Tusculanum Press, University of Copenhagen

126 Njalsgade, DK-2300 Copenhagen

Tel. +45353 29109, Fax. + 4535329113

info@mtp.dk :: order@mtp.dk

www.mtp.dk

\section{Distribution}

In North America and Europe Monographs on Greenland - Meddelelser om Grønland is sting distributed by Museum Tusculanum Press' distributors in those regions: ISBS, Gazelle, and Édition Picard.

Distributor contact details.

Subscribe to news about the series through Museum Tusculanum Press newsletter: www.mtp.dk/newsletter

List of MoG publications from 1979-

List of MoG publications from 1878-1979

\section{Guide to Authors}

\section{www.mtp.dk/MoG}




\section{Contents}

\section{Abstract 7}

\section{Acknowledgements 9}

\section{Chapter 1}

\section{Cultural background 11}

by Tinna Møbjerg

History of the Sisimiut District 12

Archaeological surveys 14

Chronology of the Sisimiut District 15

\section{Chapter 2}

Natural characteristics of the Sisimiut District 16

by Anne Birgitte Gotfredsen

Geography 16

Climate 16

Vegetation 18

Fauna 18

Sea mammals 18

Sea birds 20

The interior 21

Nipisat upon the arrival of humans 23

\section{Chapter 3}

The Nipisat site 24

by Tinna Møbjerg

The excavation 24

Stratigraphy and ${ }^{14} \mathrm{C}$ dates 27

Comments on the stratigraphy and dating 34

Dwelling features 37

\section{Chapter 4}

Description of the tool inventory 43

by Tinna Møbjerg

Unclassifiable tools 44

Hand tools 54

Tools for hunting and fishing 69

Household utensils 83

Comments on formation processes, activity areas and tool inventory 87

\section{Chapter 5}

The faunal assemblage 91

by Anne Birgitte Gotfredsen

Sampling methods 91

Preservation of the bones 91

Articulation of the bone elements 92

The bone analysis 92

Quantification 93

Seasonal indicators 94

Characteristics of the faunal assemblage 95

\section{Chapter 6}

Fish 96

by Anne Birgitte Gotfredsen

Factors affecting the species composition 96

Cod 96

Other fish species 101

The importance of fishing at Nipisat 101

\section{Chapter 7}

Birds 102

by Anne Birgitte Gotfredsen

Hunting in coastal waters 102

Fulmars and shearwaters 102

Great cormorant 104

Eiders 112

Sandpipers and snipes 116

Arctic skua 116

Gulls 116

Auks 119

Hunting in terrestrial and fresh water habitats 125

Divers 125

Geese 126

Ducks 131

Swans 132

Rock ptarmigan 136

Common raven 136

Owls 138

Gyrfalcon 138

Food preparation, consumption and storage of birds 138 Change in the bird composition over time 139 


\section{Chapter 8}

\section{Mammals 142}

by Anne Birgitte Gotfredsen

Marine mammals 142

Polar bear 142

Walrus 143

Seals 149

Whales 160

Terrestial mammals 164

Arctic hare 164

Dog 165

Arctic fox 168

Caribou 168

Temporal trends in the mammalian fauna 188

\section{Chapter 9}

\section{Cultural position of the Nipisat site 192}

by Tinna Møbjerg

Nipisat and other sites in the Sisimiut area 192

${ }^{14} \mathrm{C}$-dating the phases of the Saqqaq Culture 192

Beach ridge chronology 194

Choice of lithic raw material 195

Typology - presence and absence of types 197

Dwelling structures 199

Concluding remarks on the cultural history

of the Sisimiut area 200

Nipisat compared to sites in other regions of

Greenland 201

Nipisat's relation to sites in Canada and Alaska 205

\section{Chapter 10}

Discussion and conclusions 207

by Anne Birgitte Gotfredsen and Tinna Møbjerg

Climatic and cultural sequences 207

Interaction between humans and the environment 207

Exploitation of non-living resources 208

Technology 209

Settlement patterning 210

Social organisation 213

Concluding remarks 214

\section{Appendix 1}

Description and position of cut marks on bird

bones and their interpretation 215

Eiders 215

Gulls 215

Geese 216

\section{Appendix 2}

Holocene marine fauna and shoreline studies in the Sisimiut Area 218

by Kaj Strand Petersen and Ella Hoch

The molluscan assemblages - recent and subfossil 218

The subfossil molluscan assemblages 226

The relative sea-level curve from the Sisimiut area 227

Comments on the records of boreal molluscs in

Greenland 229

References 231 


\section{Abstract}

Gotfredsen, A.B. and Møbjerg, T. 2004. Nipisat - a Saqqaq Culture Site in Sisimiut, Central West Greenland. Meddelelser om Grønland, Man and Society 3I. Copenhagen, Danish Polar Center. 243 pp.

From 1989 to I994, more than $200 \mathrm{~m}^{2}$ were excavated at the Saqqaq site of Nipisat, situated on a small island $\mathrm{I}_{5} \mathrm{~km}$ south of Sisimiut. The excellent preservation conditions for organic material, and the fact that some of the stone artefacts were not previously known from the Saqqaq Culture, were the main reasons for the excavation. More than 70,000 bone fragments, 20,000 flakes and I,000 artefacts were recovered.

A total of 33 dates, making this site one of the best dated in the entire Arctic, reveal that Nipisat was occupied continuously for nearly I,500 years. Although protruding bedrock disturbed the stratigraphy and several lenses of crushed shells interrupted the layers, three different chronological phases could be identified. Phase I is dated by eight ${ }^{14} \mathrm{C}$ dates ranging from 2020 to $\mathrm{I} 74 \mathrm{O} \mathrm{BC}$ (cal). Phase 2 partly overlaps, but is mainly younger than phase I and dated by five ${ }^{\mathrm{I} 4} \mathrm{C}$ dates to $1860-\mathrm{I} 325 \mathrm{BC}$ (cal). Phase 3 is dated by I6 ${ }^{14} \mathrm{C}$ dates to I3IO-8Io BC (cal). One date was very young (520 BC (cal)) and problematic because of extreme oscillations of the ${ }^{\mathrm{I} 4} \mathrm{C}$ curve. From phase I there is a mid-passage structure with a box-hearth. A ring of flagstones surrounds the structure. From phase 2 there is a well-defined box-hearth. There was no clear outline of a tent ring surrounding the hearth, which could be due to later disturbances in phase 3. No dwelling structures were recognised from phase 3. Instead several sherds of soapstone were recorded, indicating the use of blubber for light or cooking. From phase I and 2 the tool types are well known from other Saqqaq sites in Greenland and Arctic Canada e.g. small harpoon endblades, projectile points, knife blades, scrapers, burins etc. and needles, flint flakers, harpoon heads, wedges etc. But from phase 3 previously unknown types were recorded. A new tool kit for sea mammal hunting is seen in the very sturdy harpoon or lance head made of antler. In addition there are many different kinds of barbed leisters or spears. New types of bevelled harpoon heads, bevelled knife blades and bevelled projectile points, all made of killiaq (silicified slate), were also registered.

The faunal assemblage of Nipisat yielded 28,823 identified bone fragments representing at least 42 species of fish, birds and mammals. The fish remains, comprising c. $2 \%$ of the faunal material, consisted nearly entirely (98\%) of fairly large sized cod (Gadus morhua). The bird remains comprise c. $47 \%$ of the material and derive from at least 24 bird species. Gulls are the dominant group (c. $54 \%$ of the bird remains) followed by eider ducks (Somateria spp.) (24\%) and Branta spp. (I3\%) presumably barnacle geese (Branta leucopsis), while auks (Alcidae) were found in lower frequencies. The most spectacular finds, however, were skeletal remains of subadult great auks (Pinguinus impennis) from the oldest phase. A total of 60 presumed whooper swan (Cygnus cygnus) remains constitute the hitherto largest, northernmost and oldest occurrence in Greenland.

At least I4 mammalian species were identified revealing a surprisingly large proportion of caribou (Rangifer tarandus) (51\% of the mammal remains) for a coastal site. Seals accounted for $45 \%$, with the common seal (Phoca vitulina) as the absolutely dominant component. Other marine mammals were walrus (Odobenus rosmarus) and harbour 
porpoise (Phocoena phocoena), which played an important but minor role. Polar bear (Ursus maritimus) hunting was documented by the presence of four fragments from the youngest phase. Saqqaq people were accompanied by fairly large and robust dogs (Canis familiaris).

Nipisat, the first larger Saqqaq site to be excavated from the Open Water Area was a coastal site and through all occupation phases the game animals of the surrounding waters and fjords were hunted. For more than a millennium, the site was visited briefly from time to time, at least during spring, summer and early autumn. Staging geese were captured during spring. In June and July the breeding birds were exploited for their eggs and easily accessible young, as documented by large numbers of juvenile gull bones in particular. The common seal hunting specialised on immature individuals caught primarily during their first summer on the breeding grounds. The inhabitants at Nipisat also hunted caribou on the mainland. The age structure and sex distribution of the caribou remains primarily reflect stalking. Selected body parts, especially the fore and hind legs and the heads, were transported to the island for raw material, meat filleting and further processing for marrow extraction and fat rendering.

The exploitation of fauna through the entire occupation period was remarkably constant with respect to choice of game animal and the selected age groups. Although eiders were more abundant in phase I (36\%) than in phase 3 ( $17 \%)$ while gulls increased from 43 to $61 \%$ in the same time period. The same trend was found valid for geese, which increased over time while the importance of auks decreased. Harbour porpoise seem to have decreased while walrus increased in relative importance through time. Caribou seem to be of greater importance in phase 3 with $55 \%$ compared to $45 \%$ in phase I. The slight shift in preferred resources may be explained by fluctuating abundance and availability of the game species combined with the development of new hunting tools.

Based on the new investigations in the Sisimiut District, the gap between Saqqaq and Dorset Culture in Central West Greenland has been diminished. Although resource exploitation at the site seems to have been very stable through all three phases, there are aspects of cultural change bridging the transition from Saqqaq to Dorset Cultures. The introduction of bevelled tools, sturdy harpoon or lance heads and the abandonment of the bow and arrow in phase 3, show cultural affiliation with Dorset technology. This is also true in terms of lithic raw material preference, the introduction of soapstone artefacts and the absence of dwelling structures with a well-defined box-hearth. At the same time it looks like, the central occupation area for the Saqqaq Culture shifted southwards from the Qeqertarsuup Tunua area towards Sisimiut and Nuuk.

Keywords: Early and late Saqqaq culture; specialised seasonal site; dwelling structures; soapstone artefacts; hunting gear; caribou hunting; walrus hunting; bird exploitation; young common seals; consistency in exploitation patterns.

Anne Birgitte Gotfredsen, Zoological Museum, University of Copenhagen, Universitetsparken I5, DK-2Ioo Copenhagen $\emptyset$, e-mail: abgotfredsen@snm.ku.dk

Tinna Møbjerg, Herning Museum, Museumsgade 32, DK-740o Herning, e-mail: tinna@herningmuseum.dk

Ella Hoch, Midtsønderjyllands Museum, DK-65io Gram, Denmark

Kaj Strand Petersen, Geological Survey of Denmark and Greenland, Øster Voldgade Io, DK-I350 Copenhagen K, Denmark 


\section{Acknowledgements}

The authors are very grateful to the curators of Sisimiut Museum - Finn Erik Kramer, Anne Mette Olsvig, Søren Thuesen, Hans Christian Vorting, Pauline Knudsen and Klaus Georg Hansen - for their cooperation, which has permitted us to work with the PalaeoEskimo material from 1990 up to the present day. We are also grateful to the Greenlandic Air Service, which financed the investigation at Asummiut.

The investigation at Nipisat was financed by Dronning Margrethes og Prins Henriks Fond, Augustinus Fonden, the Commission for Scientific Research in Greenland, N.A.P.A., De Grønlandske Kommuners fond til arkæologiske unders øgelser, Grønlandsflys og SAS's Rejsestipendieordning and Børne- og kulturforvaltningen, Sisimiut Kommune.

We also want to express our warmest thanks to all the people who participated in the excavation of Nipisat and Asummiut in 1989-1995, and to Nalunnguafiup Atuarfia and Knud Rasmussenip Højskolia for the loan of equipment. Many thanks to Naja and Hans Henrik Petersen, Pia and Gaba Lennert, Lars and Anne Mette Olsvig and Karin Sinclair Strøm for their great hospitality throughout the excavation periods.

We thank Aarhus Universitets Forskningsfond for a grant used to register and digitize data from the excavation. The work was done by Anna Lindebo Leth, Department of Prehistoric Archaeology, Moesgård, Aarhus University. Also thanks to Torsten Madsen, Jens Andreasen and Mads Holst of the same department for valuable assistance with computer analyses.

Thanks to Jørgen Mürhmann-Lund, Moesgård Museum, for his excellent drawings depicting the life of the Nipisat peoples, his work was supported by Grønlands Hjemmestyre, Direktoratet for Sundhed og Forskning.

Dronning Margrethe II's Arkæologiske Fond and Dronning Margrethes og Prins Henriks Fond are thanked for a grant used to digitize the data and create spread sheets. Kristine Stub Precht, Department of Prehistoric Archaeology, Moesgård, Aarhus University carried out this troublesome work. Hanne Kolding made the fine maps and edited the artefact drawings, done by Niels Levinsen, The Danish National Museum,
Copenhagen, and Geert Brovad, Zoological Museum, University of Copenhagen, took most of the photographs. Sönke Hartz, Schloss Gottorp, Slesvig, placed his slides from the excavation at our disposal. To these people we express our sincere thanks.

We also thank Jan Heinemeier, Niels Rud and Vibeke Jensen of the AMS ${ }^{14} \mathrm{C}$ Dating Laboratory, Aarhus, and Kaare Lund Rasmussen and Uffe Rahbek of the ${ }^{\mathrm{I}} \mathrm{C}$ Dating Laboratory, Copenhagen, for their help with the dates.

Both authors are very grateful for a grant in 199598 under the programme Man, Culture and Environment in Ancient Greenland from the Danish Research Councils' special programme in support of Arctic research, TUPOLAR. Sisimiut Museum is also thanked for supporting the initial and final phase of the analyses financially. Also our warmest thanks to SILA, the Greenland Research Centre at the Danish National Museum for financial support in the terminal phase of the project.

Bjarne Grønnow, SILA, and Finn Kramer, Nordsjællands Folkemuseum, are thanked for their valuable comments on earlier drafts of the manuscript and Hannah Jones is thanked for her revision of the language.

Anne Birgitte Gotfredsen: Part of the faunal analysis was supported by grants from The Danish Natural Science Research Council, The Danish Research Council for Humanities and The Commission for Scientific Research in Greenland. The Zoological Museum, University of Copenhagen gave me access to the $\mathrm{Ni}$ pisat material and the comparative collections. Jeppe Møhl let me have access to unpublished data from Itinnera (Portion B) and Inge Bødker Enghoff allowed me to use unpublished regression diagrams on cod total lengths. My colleagues at the section of Quaternary Zoology, Zoological Museum, participated in good and productive discussions. David Boertmann, National Environmental Research Institute, gave many useful comments on chapter 7. To these Institutions and persons I extend my sincere thanks. Finally I am grateful to my husband Carl Christian 
Kinze for constructive criticism of earlier versions of the manuscript (Chapters 2, 5, 6, 7 and 8) and for his and my son Jacob's patience and support.

Tinna Møbjerg: The analysis of the artefact material took place at the Department of Prehistoric Archaeology, Moesgård, Aarhus University and at Moesgård Museum. I am grateful for having been able to use the facilities of these institutions and for all the fruitful discussion with my colleagues, special thanks goes to my room mates from 1995 to 2002, Helle Vandkilde, Ulla Odgaard and Anne Bjerrekær. I also wish to express my warmest thanks to my husband Ivan Bundgaard and my three children: Kasper, Sanne and Anders for their never-failing love and support.

Finally we are grateful for constructive criticism and helpful comments on the manuscript from the two referees. 


\section{Chapter 1}

\section{Cultural background}

This monograph presents the results of an investigation of Nipisat I (registered at Sisimiut Museum with the number SIK 534), a Saqqaq site located in Sisimiut municipality in Central West Greenland (Fig. I, no. 39). In the following, the site is referred to as Nipisat, meaning lumpfish (Cyclopterus lumpus) due to the shape of the island.

Discovered in 1989, the site is one of the first known in this part of Greenland that has produced substantial assemblages of lithic and organic materials spanning a period of nearly I500 years beginning around 2000 BC. The time gap between Saqqaq and Dorset Culture has thus been decreased in the Sisimiut area (Fig. 2)

The oldest phase at Nipisat shows clear affinities to other Predorset sites all over the Eastern Arctic and

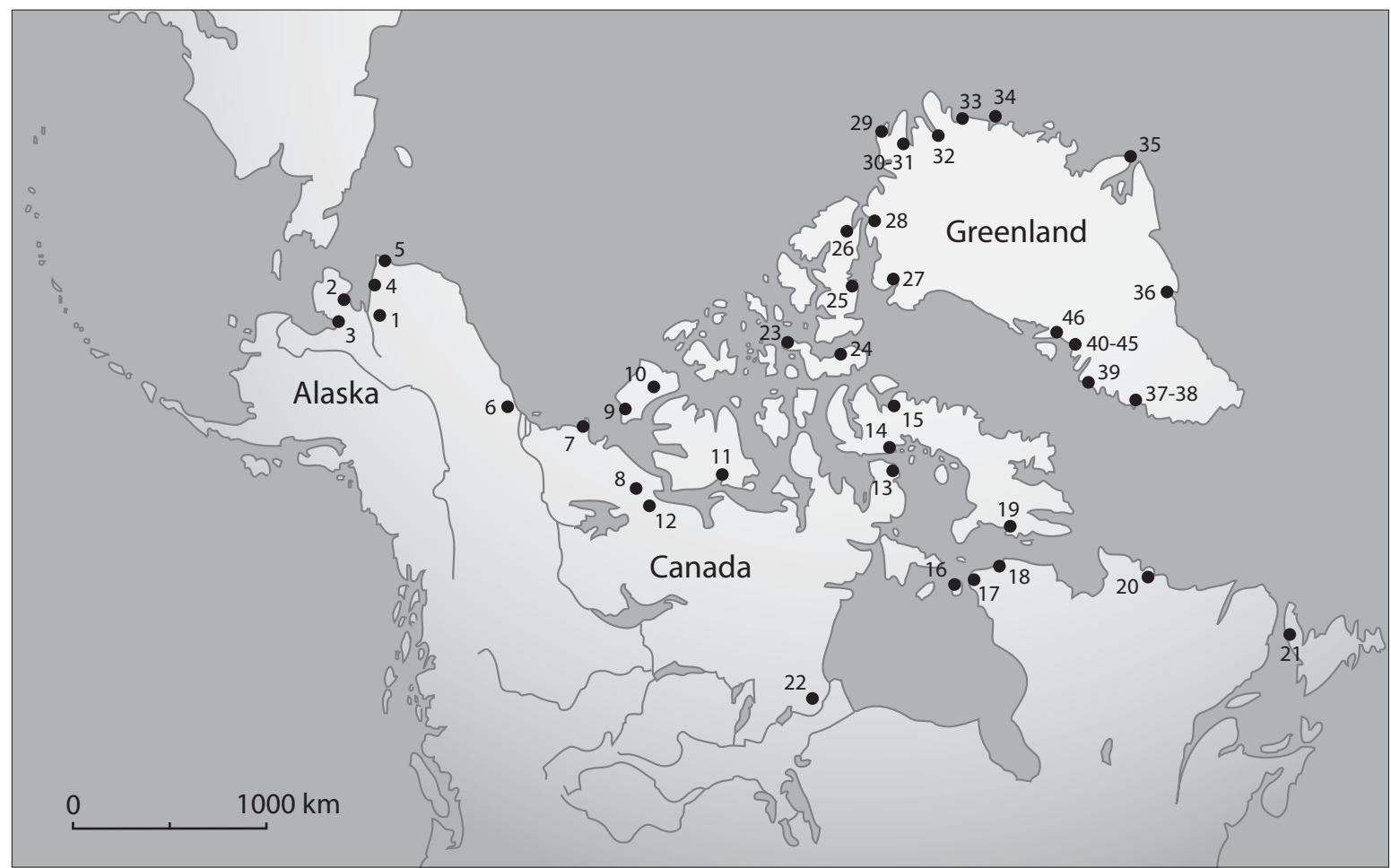

Fig. 1. Early Palaeo-Eskimo sites mentioned in the text (partly after Harp 1958, 1997; Mary-Rousseliére 1976; McGhee 1970; Plumet 1994).
1. Onion Portage
2. Trail Creek
3. Cape Denbigh
4. Cape Krusenstern
5. Point Hope
6. Engigsticiak
7. Crane
8. Dismal II
9. Lagoon
10. Umingmak
11. Ekalluk River
12. Bloody Falls

13. Igloolik

14. Kapuivik

15. Mittamatalik

16. Arnapik

17. Ivujivik

18. Tyara

19. Closure

20. Saglek Bay

21. Port au Choix

22. Thyazzi

23. Port Refuge

24. Devon Island

37. Nunnguaq

38. Itinnera

39. Nipisat

40. Annertusuaqqap Nuua

41. Niivertussannguaq

42. Tupersuai

43. Qeqertasussuk

44. Qajaa

45. Sermermiut

46. Saqqaq 


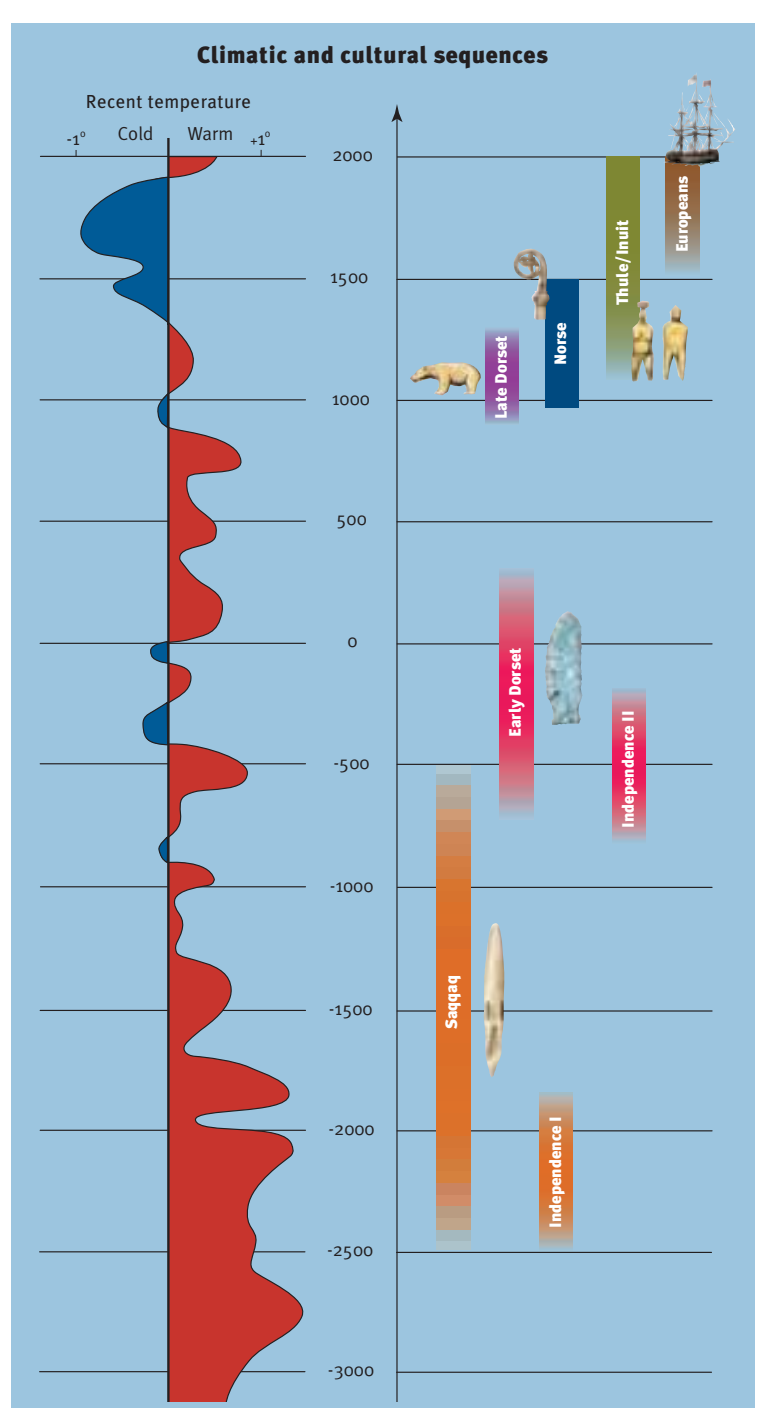

Fig. 2. The sequences of climatic and cultural events in Greenland (climatic sequences adapted from Fredskild and Böcher 2001:61).

is without doubt related to the oldest sequence of the Arctic Small Tool tradition (Dekin 1976) known from Cape Denbigh (Fig. I, no. 3) in Alaska to Illoqqortoormiut (Fig. I, no. 35) in East Greenland.

From Greenland there are no close parallels to the youngest phase at Nipisat, although several artefacts suggest links with the western Canadian Arctic. Sites such as Buchanan at Ekalluk River (Fig. I, no. II) on Victoria Island (Taylor 1967), Lagoon (Fig. I, no. 9) on Banks Island (Arnold 198I) and Crane (Fig. I, no. 7) at Cape Bathurst Peninsula (Le Blanc 1994) show clear similarities. There are even certain resemblances to Choris and Norton Cultures of Alaska (Fig. I, nos. I-5) (Anderson 1988; Giddings 1964, 1967).

\section{History of the Sisimiut District}

In the interpretation of archaeological data, ethnographic analogies are often used to elucidate resource exploitation, settlement pattern and social organisation. This is done more or less implicitly. How do we know about tool types if we do not use our knowledge from ethnography? How can we explain different hunting methods without using ethnohistorical information? However, it is our responsibility not just to extrapolate from the present back into the past, but to use the analogies as an idea bank for archaeological interpretation.

Historic information about the Sisimiut area has been collected over nearly 400 years (Bendixen I92I; Bobé I92I; Gad 1967, 1969, 1976, 1984). In the year I605, the Danish King Christian IV sent out an expedition led by James Cunningham and Godske Lindenow to rediscover the Norse settlements in Greenland. They did not succeed in finding the Norse Settlements, but were the first Danish expedition to return safe and sound. James Hall, from Hull in England, participated as a pilot and mapped the fjords Itilleq, Isortoq and South Kangerluarsuk. In I606, Hall returned to the area and abducted five native Greenlanders who were brought to Copenhagen. On the next visit in 16I2, James Hall was recognized as one of the abductors and was killed by the natives (Bobé 19ı6; Haarløv et al. I980:19; Høiris et al. 2002:266-268).

In 1652-54, David Danell was sent out by the Danish King Frederik III. Following Hall's maps he explored Itilleq fjord and found winter houses made of whale ribs covered with turf (Gulløv I997:89-97).

The famous Norwegian/Danish missionary Hans Egede tried to visit the area in I724, but was forced back due to bad weather. On his behalf, however, a small mission station was established at Nipisat in I725, only to be abandoned the next year because of starvation (Fig. 3). Soon after, it was burned down by Dutch whalers. In 1729 governor C.E. Paars re-established a colony at Nipisat. Two years later it was again abandoned due to raiding by Dutch whalers (Haarløv et al. 1980:60-64, figs. 67-69).

In 1756 , on behalf of the Danish authorities, a trading station was established at Ukiivik (Sydbay). Ukiivik was only used as a hunting site in the summer and no Greenlanders lived there in the wintertime. Therefore, Niels Egede established an alternative trad- 


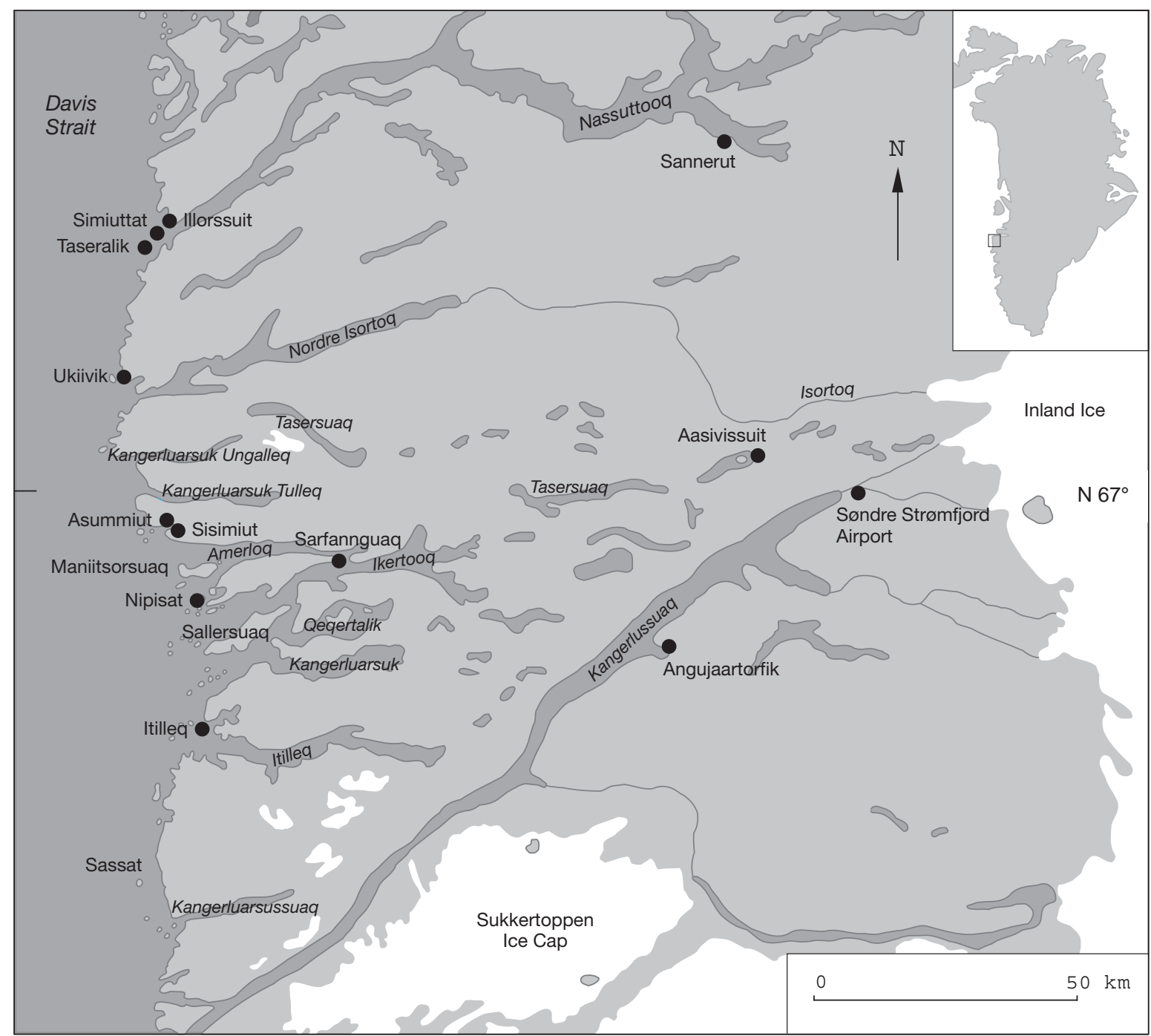

Fig. 3. The Sisimiut region with place names used for identifying important migration routes and congregation localities of terrestrial and marine species.

ing station at Asummiut in I759. In I763 a mission station was also established close by and the missionary H.C. Glahn lived here for four years (Olsen I958).

The trading station at Ukiivik was moved to the present location at Sisimiut in 1764 and, until I767, both Asummiut and Sisimiut were occupied (Fig. 3). In I767 it was decided to abandon Asummiut and the buildings were moved to Sisimiut and rebuilt (Thuesen 1997).

Glahn served as missionary in Asummiut from I763-67 and in Sisimiut from I767-69. Thanks to his diaries, important information concerning social organisation, settlement patterns, material culture and resource exploitation has been preserved (Ostermann I92I). This information, combined with missionary E.
Thorhallesen's account of his visit to Sisimiut in I774I775 (Bobé I9I4) has contributed to our detailed knowledge of the annual cycle in the area during the $\mathrm{I} 8^{\text {th }}$ century. Like Pastor O. Fabricius, they described cultural history as well as the behaviour and, in particular, the exploitation of game animals (Fabricius I8I8).

In more recent times, many expeditions (Haarløv et al. 1980) from different scientific disciplines have visited the Sisimiut area. Thanks to these expeditions and to the local colonial managers and missionaries, this is one of the most thoroughly described areas in Greenland concerning resource exploitation, settlement structures and social organization during the latest phase of the Thule Culture. 


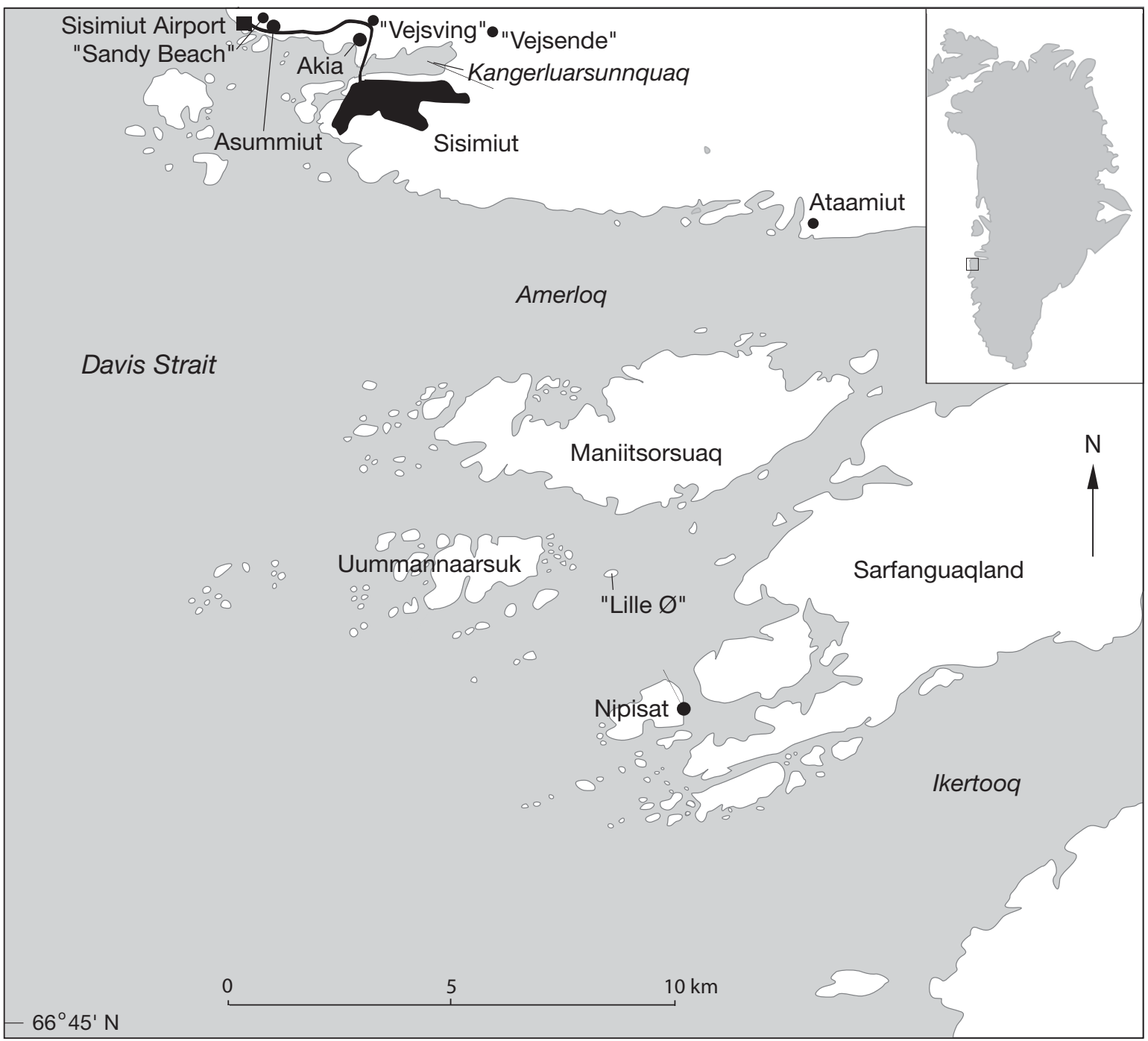

Fig. 4. Map of the Sisimiut District with the three Saqqaq sites: Asummiut, Akia and Nipisat (marked with large dots) and the geological samples (marked with small dots) (see Appendix 2).

\section{Archaeological surveys}

Research has continued in more recent times with a focus on the prehistory of Greenland. In 1976 and 1977 the "Committee for a Conservation Act for Greenland" supported comprehensive investigations of the natural and cultural environment of Sisimiut. The purpose of this study was to create a foundation for legislation concerning the protection of natural features and prehistoric monuments.

J. Meldgaard (The Danish National Museum) and H.C. Petersen (Principal of the Knud Rasmussen Folk High School in Sisimiut) both participated in the investigations, which concentrated on the coastal area
(Haarløv et al. I980; Meldgaard 1980). In 1978 and I980 the large caribou-hunting camp Aasivissuit was investigated and, in addition, there was a comprehensive general survey of the inland area (Grønnow et al. I983).

In $1984-85$ the National Museum of Greenland continued these inland investigations in connection with the hydraulic power project at Tasersuaq (Kapel I984, 1986). In 1985 Sisimiut established its own museum and since 1987 research concerning the PalaeoEskimo cultures has been particularly successful with more than Ioo Palaeo-Eskimo sites identified. Although research has been intensified in the inland area, very few traces of Palaeo-Eskimo sites have been 
registered here compared with the number of sites found at the coast (Appelt et al. 1992; Gabriel et al. 2002; Kapel 1996; Kramer 1996a; Odgaard 2003; Pind et al. 1991; Secher et al. 1987; Schilling 1996).

The knowledge of Palaeo-Eskimo cultures in the area derives primarily from surface collections and test pits. However, between 1989 and 1996 three sites were excavated (Fig. 4). Akia, just north of Sisimiut, was excavated in 1989-9I (Kramer 1996a, b). The site of Nipisat (excavated between 1989 and 1994) has revealed new information concerning tool typology, resource exploitation and dwelling structures of the Saqqaq Culture due to the excellent preservation conditions for organic material (Kramer 1994, I996 a, b; Kramer and Jones I992; Gotfredsen 1992, I996, I998, 2002; Møbjerg I995a, b, I997b, I998, I999). In I994 it was decided to build a new airport in Sisimiut, only 2 kilometres from the city at Asummiut. Four discrete units from the Saqqaq Culture were excavated in this rescue programme, which revealed the same chronological sequences as Nipisat (Møbjerg 1997a, I998; Møbjerg and Grummesgaard-Nielsen I996, I997a, b).

\section{Chronology of the Sisimiut area}

The cultural sequences in Sisimiut begin with the Saqqaq Culture around $2500 \mathrm{BC}$ and continue to at least $800 \mathrm{BC}$. There is one very young date from Nipisat (520 BC), coinciding with a plateau on the calibration curve, indicating a date between 760-4Io + I stdv. BC. This young ${ }^{\mathrm{I}} \mathrm{C}$ date from Nipisat means that the gap between the Late Saqqaq Culture and the Early Dorset Culture in the Sisimiut area has been reduced. Unfortunately, there are still very few ${ }^{\mathrm{I} 4} \mathrm{C}$ dates (only three) from the Early Dorset Culture, lying between 4IO and I80 BC (Kramer 1996a; Grønnow et al. 1983). At present there are no traces of either the late phase of the Dorset Culture or any permanent occupation by the Norse settlers in the Sisimiut area. So it seems as though this part of Greenland was abandoned for more than 500 years. There is one early date from the Thule culture at Aasivissuit, IIoo $\mathrm{AD}$, but it was not until 300 years later that the Thule culture was massively represented in the area by winter houses, tent rings and burials (Møbjerg and Grummesgaard 1997a) (Fig. 2).

The investigations of Nipisat, Akia and Asummiut were first and foremost carried out to elucidate the cultural history of the Sisimiut municipality. Due to the excellent preservation conditions at Nipisat it has, however, been possible to increase our understanding of the Saqqaq Culture throughout Greenland. Nipisat and Asummiut provide evidence of definite changes over time in the Saqqaq Culture and three chronological phases can be identified. However, at many sites in the area, only one of the phases is represented. Nipisat can therefore be used as a guideline for studying changes not only in tool typology, but also changes in social structures, resource exploitation and settlement patterning from the first occupation around $2000 \mathrm{BC}$ up to the time of abandonment.

First and foremost, this publication concerns the excavations at Nipisat and the analysis of the archaeological data including organic as well as inorganic materials. The results from the investigations at Asummiut and Akia will also be incorporated, however, in order to reach a better understanding of the Saqqaq Culture. 


\section{Chapter 2}

\section{Natural characteristics of the Sisimiut District}

\section{Geography}

Bordered to the north by Nassuttooq (Nordre Strømfjord), to the south by Sukkertoppen Ice Cap and to the west and east by the Davis Strait and the Inland Ice Cap respectively, the Sisimiut region constitutes the most extensive ice-free area in West Greenland, with an east-west extension of up to $180 \mathrm{~km}$ and an area of approximately 30 ooo square kilometres (Fig. 3). During the last Ice Age, huge glaciers formed the landscape, creating lakes and u-shaped valleys often running in an east-west direction. Numerous fjords branch deeply inland and lakes are often connected to rivers forming continuous waterways from the Ice Cap to the coast. The coastal zone is predominantly mountainous with peaks often reaching altitudes of more than Iooo $\mathrm{m}$ above sea level, while the rocks inland are more rounded and worn down by erosion caused by repeated advances and retractions by the huge glaciers. In the vicinity of the Ice Cap, the area is influenced by the transportation and deposition of large amounts of sediment, especially silt from the glaciers, creating extensive plains.

\section{Climate}

The Sisimiut region is part of low arctic Greenland. The arctic climate, defined by a mean July temperature below $10^{\circ} \mathrm{C}$, is often subdivided into a high arctic and a low arctic zone (Heide-Jørgensen and Johansen 1997). The boundaries between these climatic zones are governed by factors such as ice cover and water temperatures (at sea) (e.g. Salomonsen i98ra) and the distribution of plant communities (on land), with a zone boundary close to $72^{\circ} \mathrm{N}$ on the west coast (Bliss and Matveyeva 1992). Because of its very wide ice free zone, the Sisimiut region spans two extremes of climate sub-types.

At the coast, the climate is characterized by marine influence, being wetter, cloudier, and receiving more precipitation and fog than the continental sub-type inland. The mean summer temperatures near the coast are about $3^{\circ} \mathrm{C}$ lower than inland and the variability of precipitation between years is up to $3-400 \%$ (Heide-Jørgensen and Johansen 1997). The North Atlantic Drift, an extension of the Gulf Stream, branches off at the Irminger Current off South Greenland and proceeds south of Nunap Isua (Kap Farvel) carrying relatively warm and saline 'Atlantic water' into the Davis Strait, thus creating the West Greenland Open Water Area of Southwest Greenland. The Sisimiut region is situated at the northern boundary of the Open Water Area, which has the characteristics of a polynia (Boertmann 200I), remaining ice-free during winter (Fig. 5). Westerly storms, however, may force the accumulating sea ice from the Davis Strait, The West Ice, into the fjords connecting it to the fast ice. If this situation prevails for a long time, it may have detrimental consequences for the numerous wintering marine and coastal birds. During summer, the stretch of coast is normally free of 'Storis' coming from the Arctic Ocean with the East Greenland Current down the east coast of Greenland and up the West Greenland coast with the West Greenland Current. In gener$\mathrm{al}$, there is an outflow of air from the ice sheets during winter and an inflow from the oceans during summer, determining the prevailing wind directions of the various seasons (Heide-Jørgensen and Johansen 1997).

Inland the climate is characterized as continental and arid with temperature differences between mean of coldest and warmest months up to $28^{\circ} \mathrm{C}$ and an annual precipitation not exceeding $200 \mathrm{~mm}$ (Haarløv et al. 1980). Variability in annual precipitation is rarely more than I00\% (Heide-Jørgensen and Johansen 1997). Usually the snow falls at the end of September and thaw commences at the beginning of May. During winter, inland areas will sometimes be virtually snow free, due to the low precipitation and frequent storms. The Ice Cap has a significant influence on the inland climate by e.g. generating the characteristic warm dry Foehn winds often causing snowmelt. If thaw is followed by subsequent frost, an ice crust forms and cov- 

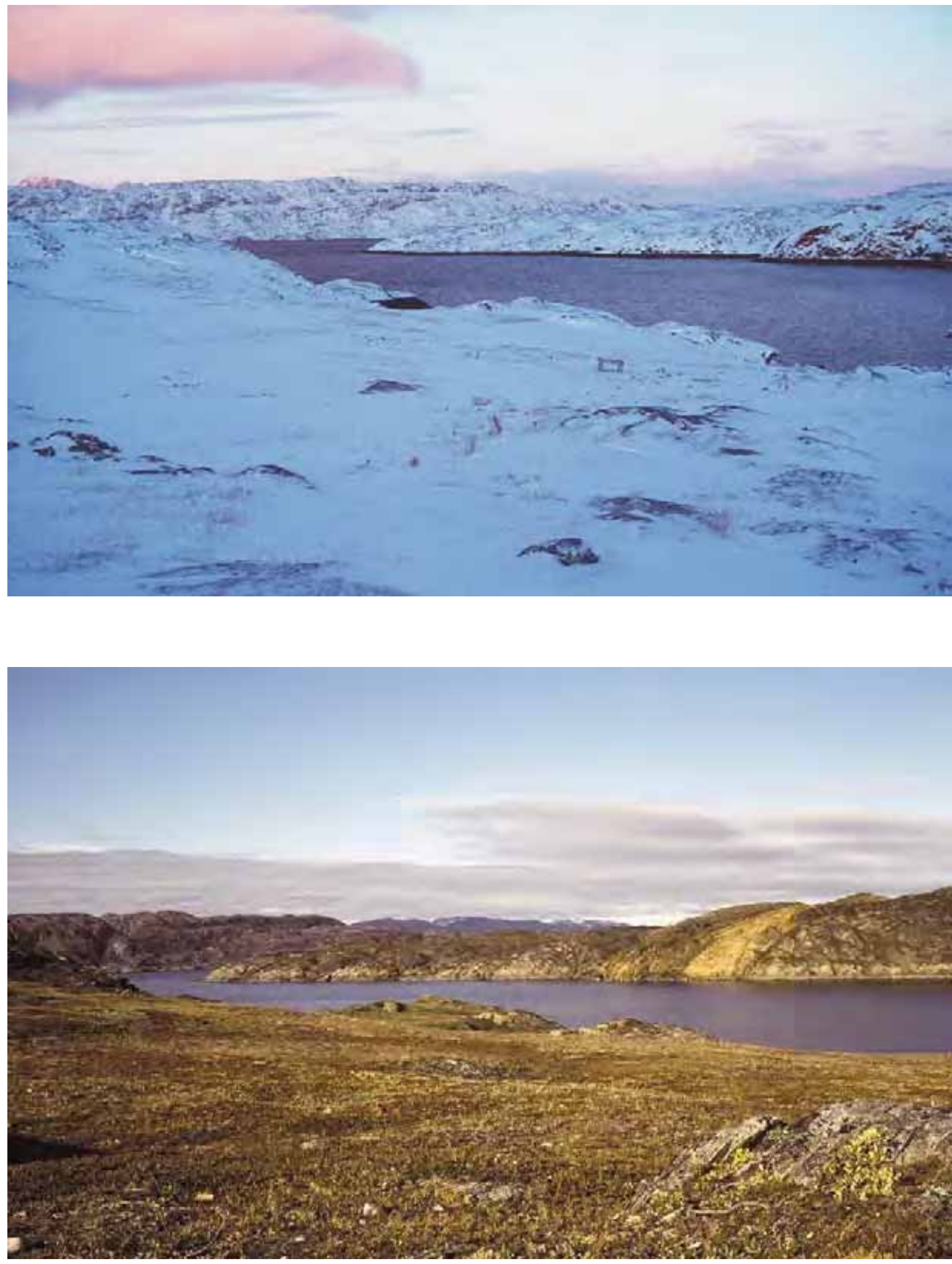

Fig. 5. The island of Nipisat is situated in the Greenland Open Water Area and the narrow sound northeast of the island facing Sarfannguaqland is kept open by the current year round. The ice-free conditions make the sound attractive for seal species, which avoid fast ice, such as common seals and bearded seals. Photo: (Winter-February) Pauline Knudsen (Summer-August) Anne Birgitte Gotfredsen. 
ers the vegetation with catastrophic effects for terrestrial herbivores (e.g. Vibe 1967; Meldgaard 1986). On the other hand, geese such as white-fronted geese (Anser albifrons flavirostris) may benefit from early snowmelt that will expose the vegetation. The geese move their nesting sites closer to the high plateau lakes and take advantage of the abundance of food and a better protection against arctic foxes (Fox and Stroud I988).

\section{Vegetation}

Inland dwarf scrub heaths are a characteristic vegetation type. Moist dwarf scrub heaths predominate on north facing slopes and are dominated by northern willow (Salix glauca) and dwarf birch (Betula nana), often together with narrow-leafed Labrador-tea (Ledum palustre), whortleberry (Vaccinium uliginosum) and Lapland rose-bay (Rhododendron laponicum) (Secher et al. 1987). In the valleys, willow 'woods' consisting of trees up to 3-4 m can be found near streams (Secher et al.1987) together with a variety of wet habitats such as ponds with e.g. common mares tail (Hippuris vulgaris), lush marshes with common cotton-grass (Eriophorum angustifolium) and loose-flowered alpine sedge (Carex rariflora) as the dominating species, growing together with dwarf scrubs. In the valleys, in some of the moister areas, grassland with wood reeds (Calamagrostris spp.) and meadow grasses (Poa spp.) are common. On south facing slopes the risk of drying out during summer favours dry dwarf scrub heaths, which often constitute a transition to a steppe environment with sedge (Carex supina), Balfours's meadow grass (Poa glauca) and wormwood (Artemesia borealis) as predominating species.

The vegetation closer to the coast is more exposed to southwesterly winds often prevailing during summer, resulting in a lower and less lush dwarf scrub heath. Wind erosion along the fjords makes the vegetation cover lower and sparser than would otherwise be expected from humidity and nutrition levels (Heide-Jørgensen and Johansen 1997). The predominating vegetation types at Nipisat today are dwarf scrub heath with dwarf birch and Arctic willow (Salix arcti$c a$ ), interspersed with well-drained lichens and herb vegetation.

\section{Fauna}

Some native species of the Sisimiut region have disappeared completely or become very scarce as breeding species in Central West Greenland during modern times, e.g. the common seal (Phoca vitulina concolor) (Teilmann and Dietz 1994) and some coastal bird species (see Boertmann 200I). It was thus necessary to obtain information on the fauna in the $19^{\text {th }}$ and the first half of the $2 \mathrm{O}^{\text {th }}$ century from historical accounts. One should be cautious in extrapolating from ethnographic knowledge of Neo-Eskimo historic Inuit to the Palaeo-Eskimo cultures concerning areas such as hunting technology and hunting methods. In the present study, therefore, the ethnographic and historical information is used primarily to extract detailed knowledge of the habits and distribution of game animals in the Sisimiut area. This information was obtained from diaries of colonial administrators and missionaries. The distribution of some species may have changed through time and, for many arctic species, population size is known to fluctuate (Vibe 1967; Meldgaard 1986) and thereby to some extent change the habits of the species in question. Still, the physiological needs of the animals are unaltered and, in that sense, the use of ethnographic and historical parallels is still valid. What may have changed is the exact timing of arrival and departure of migrating species. In the Sisimiut area, for instance, the timing of arrival and departure of the Atlantic walrus (Odobenus rosmarus rosmarus) has changed during the $2 \mathrm{o}^{\text {th }}$ century (Born et al. 1994). Prolonged growth season and early melting of snow would indeed have favoured an early arrival of some species, e.g. breeding geese (Heide-Jørgensen and Johansen I997:37).

\section{Sea mammals}

All five Greenland seal species are known from the Sisimiut area. Harp seals (Phoca groenlandica) (being lean after the breeding season) arrive in June on their northwards 'lean migration' following the capelin (Mallotus villosus), which seek into shallow waters in the fjords to spawn. During autumn from October, the harp seals return on their 'fat migration' before they leave Greenland. Subadults, however, may winter in Greenland waters (Vibe 198I). Ringed seals (Phoca 


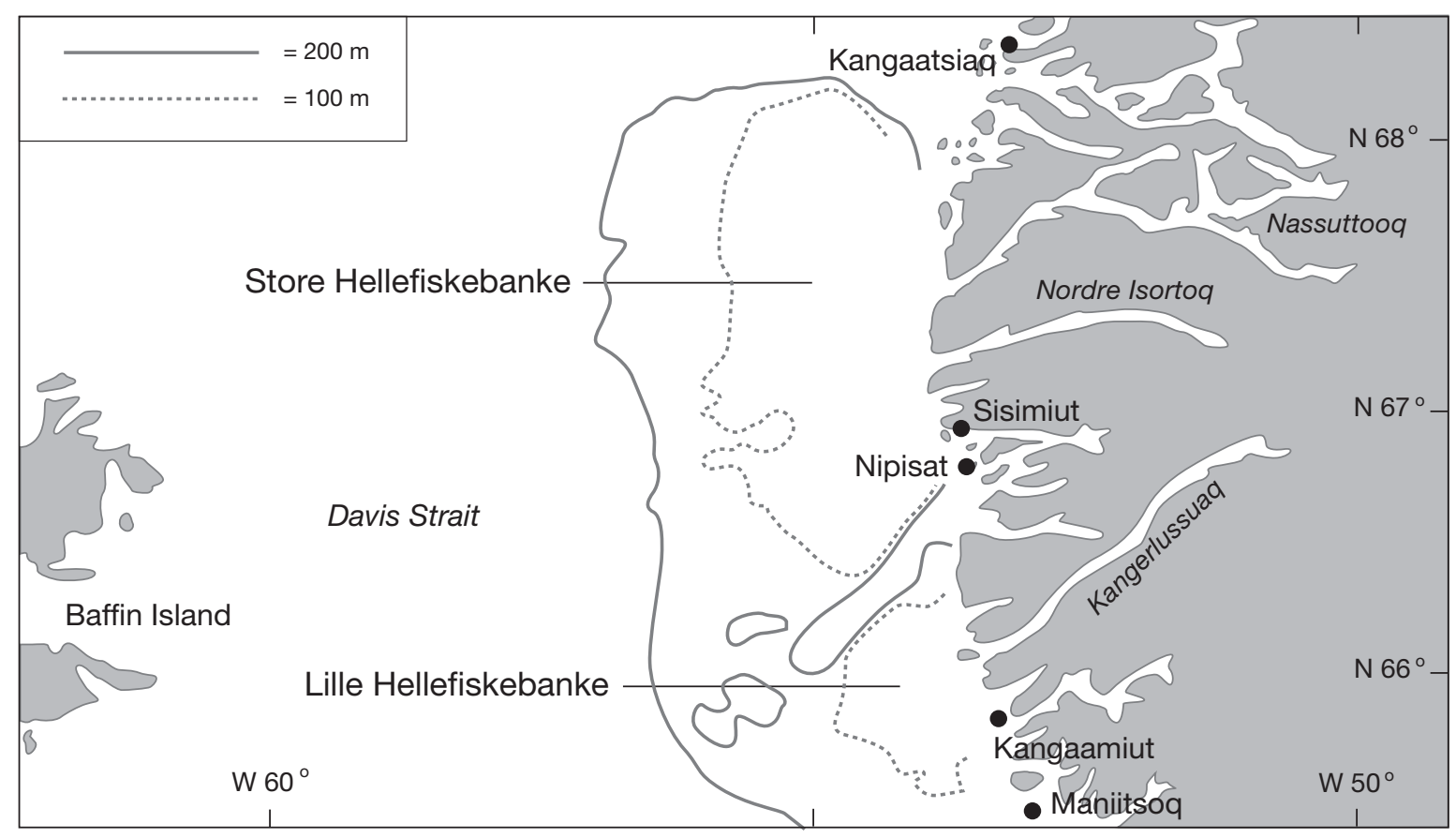

Fig. 6. General map of the coastal part of the Sisimiut region with the bordering districts of Kangaatsiaq to the north and Maniitsoq to the south. The deep fjords and shallow banks off the coast are important foraging areas for numerous sea birds and mammals.

hispida) breed on the fast ice and their primary breeding grounds are situated north of the Open Water Area (Vibe 198I), however, they occur through out the year in the Sisimiut area. The common seal generally avoids winter ice and does not make breathing holes in fast ice (King 1983). They are gregarious and tend to haul out on easily accessible rocky shores or sandy beaches to breed and moult (King 1983). Common seals are not migratory, however some movements do occur from feeding areas and haul-outs in bays and rivers during the ice-free months, towards the ice edge and ice-free areas along the coast during winter. Fabricius (Helms I92I) stated that common seals were widely distributed near the coast, especially close to islands and in the fjords, and bred at Sassat south of Itilleq (Winge 1902; Müller 1906). In the Nipisat area a year-round presence of common seal would therefore have been possible. The hooded seal (Cystophora cristata) prefers deep water and pack ice and is not so often found associated with firm ice (King 1983). Hooded seal is the seal species occurring near the coast for the shortest period of time and it occurs less abundantly in the Sisimiut District compared to the southern districts (Müller 1906; Bendixen 192I). The hooded seals occur on their 'fat migration' in spring (April-May) and in autumn on their 'lean migration' after moulting (September-October) (Vibe 198I). Bearded seals (Erignathus barbatus) gather in the productive waters of the ice edge and light drifting pack ice with open leads. They are able to maintain breathing holes in thin ice but avoid fast ice (King 1983). They are normally solitary animals and occur year round in the waters of Sisimiut District, often in shallow areas (Müller 1906). Walruses used to haul out on land at several now abandoned places along the Central West Greenland coast (see Born et al. 1994). Taseralik at the mouth of Nassuttooq was a famous location, with large concentrations of moulting walruses during September and October (Helms 1921:47; Müller 1906:240) (Fig. 3). The shallow banks off Sisimiut still offer good foraging possibilities during winter and spring (e.g. Freuchen I92I; Vibe 1956) (Fig. 6).

Nipisat Sound was a well-known whaling locality (Fig. 7). On his visit in I723, Egede heard accounts of 'large whales of the right kind, possessing large baleens' (Bobé I92I:92) presumably Greenland right whales (Balaena mysticetus). Even before the arrival of Egede, Inuit hunters and Dutch whalers exploited the 


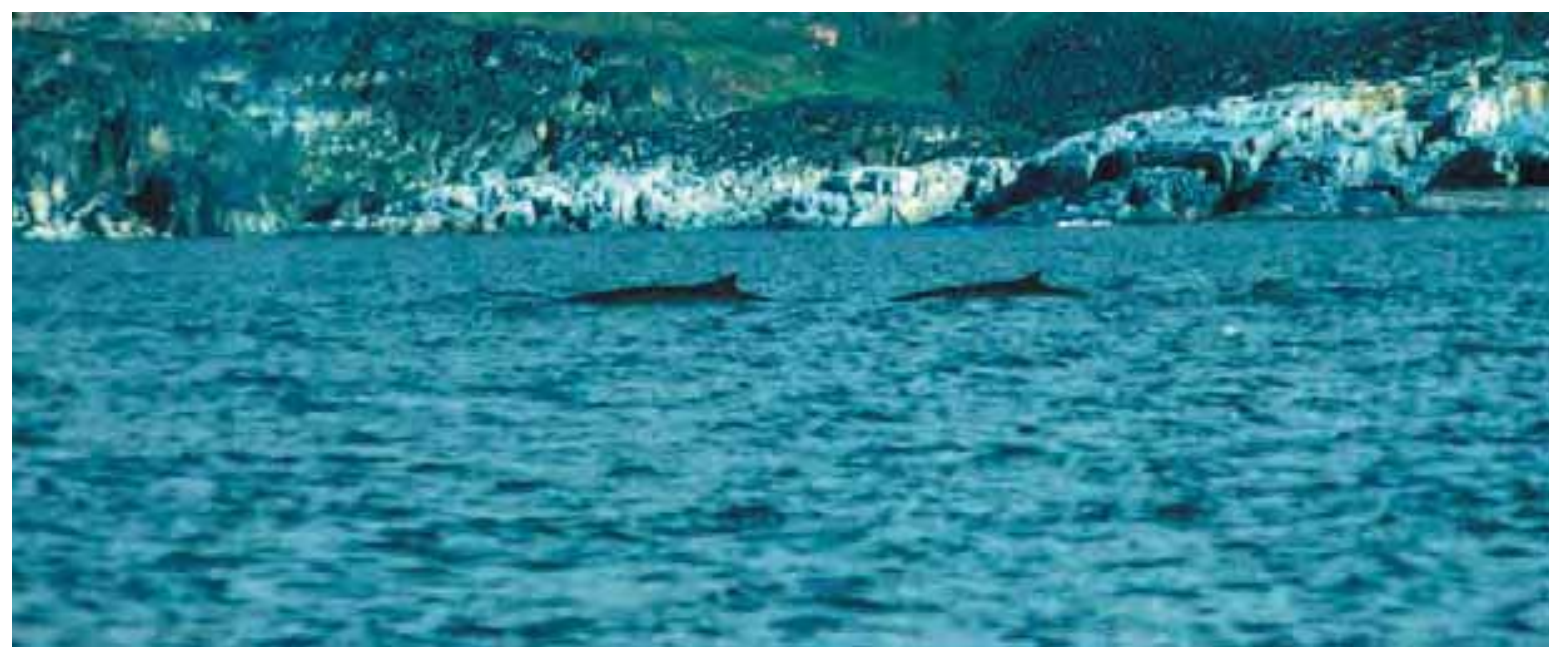

Fig. 7. The sound between Nipisat and Sarfannguaqland has, in recent and historical times, been known as a preferred passage for migrating seals and whales and was probably also an important locality during Saqqaq times. Here passing fin whales (Balaenoptera physalus). Photo: Reinhardt Møbjerg Kristensen.

large whale species occurring in the area. Several small coastal cetaceans, namely the white whale (Delphinapterus leucas) and the harbour porpoise (Phocoena phocoena), once occurred or still occur in the district. The distribution of the white whale is governed by the expansion and retraction of the ice edge. Today they occur along the west coast up to c. $73^{\circ} \mathrm{N}$, with a main distribution between $62^{\circ} \mathrm{N}$ and $66^{\circ} \mathrm{N}$ (Heide-Jørgensen I994). The harbour porpoise is a typical species of the Open Water Area, being abundant close to the coast during the summer in pursuit of capelin, and migrating off the coast in winter.

\section{Sea birds}

Today several species of breeding birds have more or less abandoned the coastal stretch of Central West Greenland as breeding places (Salomonsen 1967; Frimer and Nielsen 1990; Boertmann 200I). For centuries Sisimiut District was a major breeding area for the common eider (Somateria mollissima) (Salomonsen 1974); the great fishing banks, e.g. Store Hellefiske Banke (Fig. 6), off the coast of Sisimiut offer good foraging possibilities for both species of eiders. The narrow strait at Sarfannguaq attracted numerous blacklegged kittiwakes (Rissa tridactyla) to forage on capelin (Jensen I885; Müller 1906) and they used to breed quite numerously in Ikertooq Fjord (Bendixen
I92I:23). But also the razorbill (Alca torda) and a few Brünnich's guillemot (Uria lomvia) reportedly bred especially in Ikertooq Fjord (Winge I898). Several cliffs named after the great cormorant (Phalacrocorax carbo) (in Greenlandic Oqaatsoq) indicate nesting and resting cliffs in the area, and the species was known to breed on the western side of Qeqertarsua in Qeqertalik Fjord (Fig. 3) (Bendixen 1921:23). In the Nipisat area, good breeding possibilities for glaucous gull (Larus hyperboreus), black-backed gull (Larus marinus), and Iceland gull (Larus glaucoides) existed (Müller 1906; Bendixen 1921:23).

The Open Water Area, with relatively ice-free waters and numerous small islands and islets, is an attractive wintering area for millions of Greenland seabirds. But also Canadian, Scandinavian and even Russian breeding birds migrate to the West Greenland coast (Boertmann 200I). From October Brünnich's guillemots gather to winter at the great fishing banks off the West Greenland coast (Falk and Durinck 1992). The entire Greenland population of great cormorant and black-backed gull, together with a large part of the Greenland population of red-breasted merganser and both species of eider, winter in the area as well as some of the Greenland glaucous and Iceland gulls. Several of the Greenland fresh water species, e.g. white-tailed eagle (Haliaeetus albicilla), harlequin duck (Histrionicus histrionicus) and Greenland mallard, also winter in the Open Water Area. 


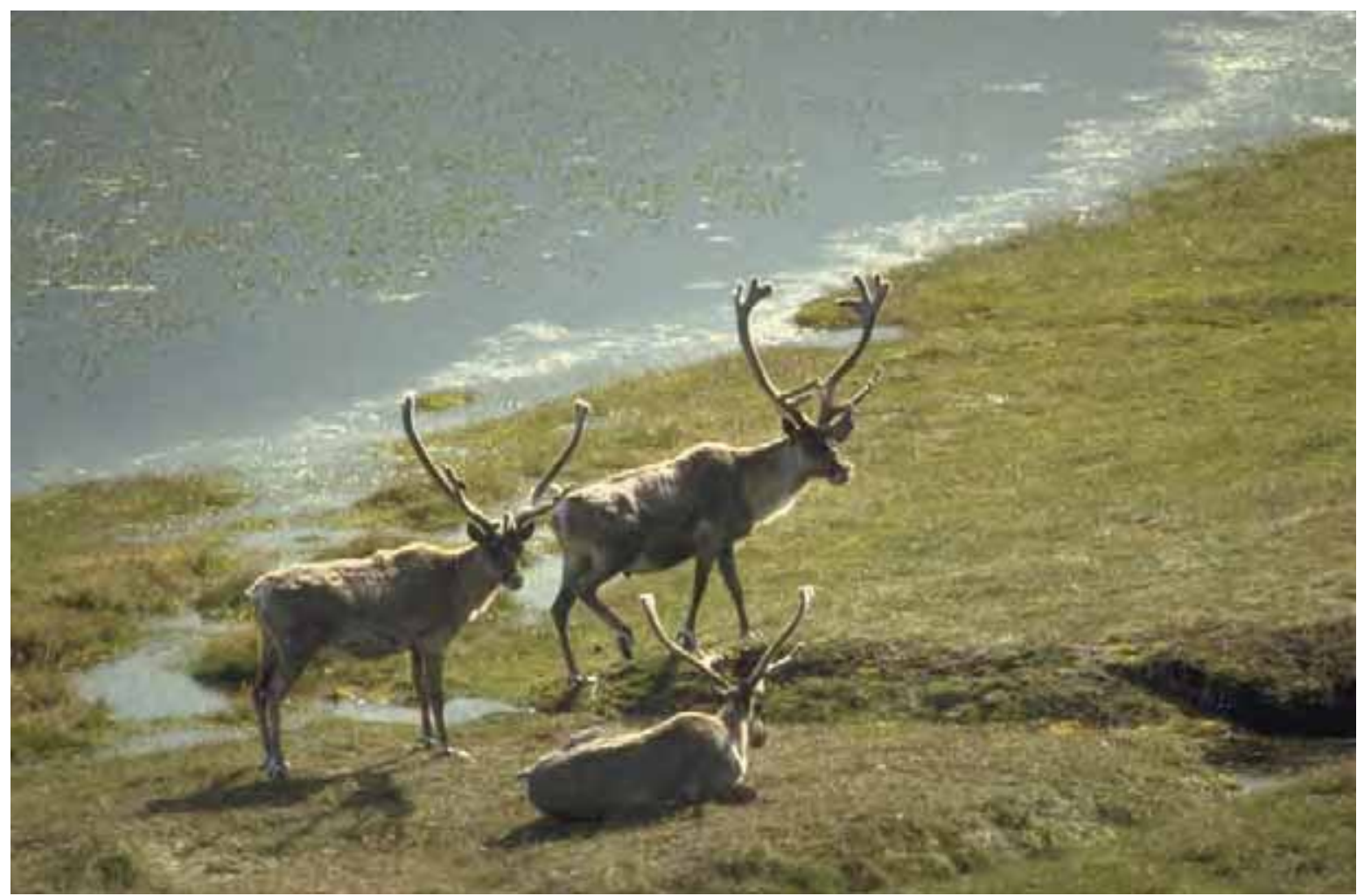

Fig. 8. A characteristic caribou habitat from the interior of the Sisimiut region. Caribou bulls with almost fully developed antlers photographed during summer. Photo: Henning Thing/Polar Photos.

\section{The interior}

Inland the annual distribution of game animals differs from the situation at the coast. Arctic fox (Alopex lagopus) and arctic hare (Lepus arcticus) are common throughout the year. Caribou (Rangifer tarandus groenlandicus) usually spend the summer far inland, with the does arriving at calving grounds close to the Inland Ice Cap at the end of May. Calving takes place from late May until late June, and peaks in mid June (Thing 1984). The caribou then gather in large postcalving aggregations and, in June and July, they disperse over a larger area (Meldgaard, M. 1983) (Fig. 8). During autumn, herds of does, calves, and young animals migrate towards the coast where they spend the winter in sheltered valleys foraging on lichens (Meldgaard, M. I983), especially the genus Cladina, which constitutes $30-60 \%$ of the winter food (Hansen 200I). Numerous prehistoric sites with caribou remains, stone fences and shooting-coverts, primarily of Neo-Eskimo origin, following the caribou migrations routes, indicate that seasonal migrations towards the interior in spring and towards the coastal areas during autumn seem to be applicable to prehistoric caribou populations (Meldgaard, M. I983, I986). It is, however, important to keep in mind that caribou behaviour changes with population size. During a population peak in the middle of the $19^{\text {th }}$ century caribou were reported to expand their range both northwards and towards the coast (see Meldgaard 1986); they even reached the off shore islands Tuttulik and Simiugaq near Attu in Kangaatsiaq District (Rink I852). During the same period, small groups of caribou were even seen near the houses of Sisimiut (Müller 1906). During population lows, the migration pattern nearly ceases and the caribou become stationary, even wintering in the interior parts of the region as recently reported by Strandgaard et al. (1983).

The only non-migratory bird species inland is the rock ptarmigan (Lagopus mutus rupestris) and, to some extent, the common raven (Corvus corax principalis). Small lakes and ponds, having a more lush vegetation than larger lakes (Riget and Böcher 200I), become ice-free relatively early and are favoured 


\section{Seasonal distribution of the game animals}

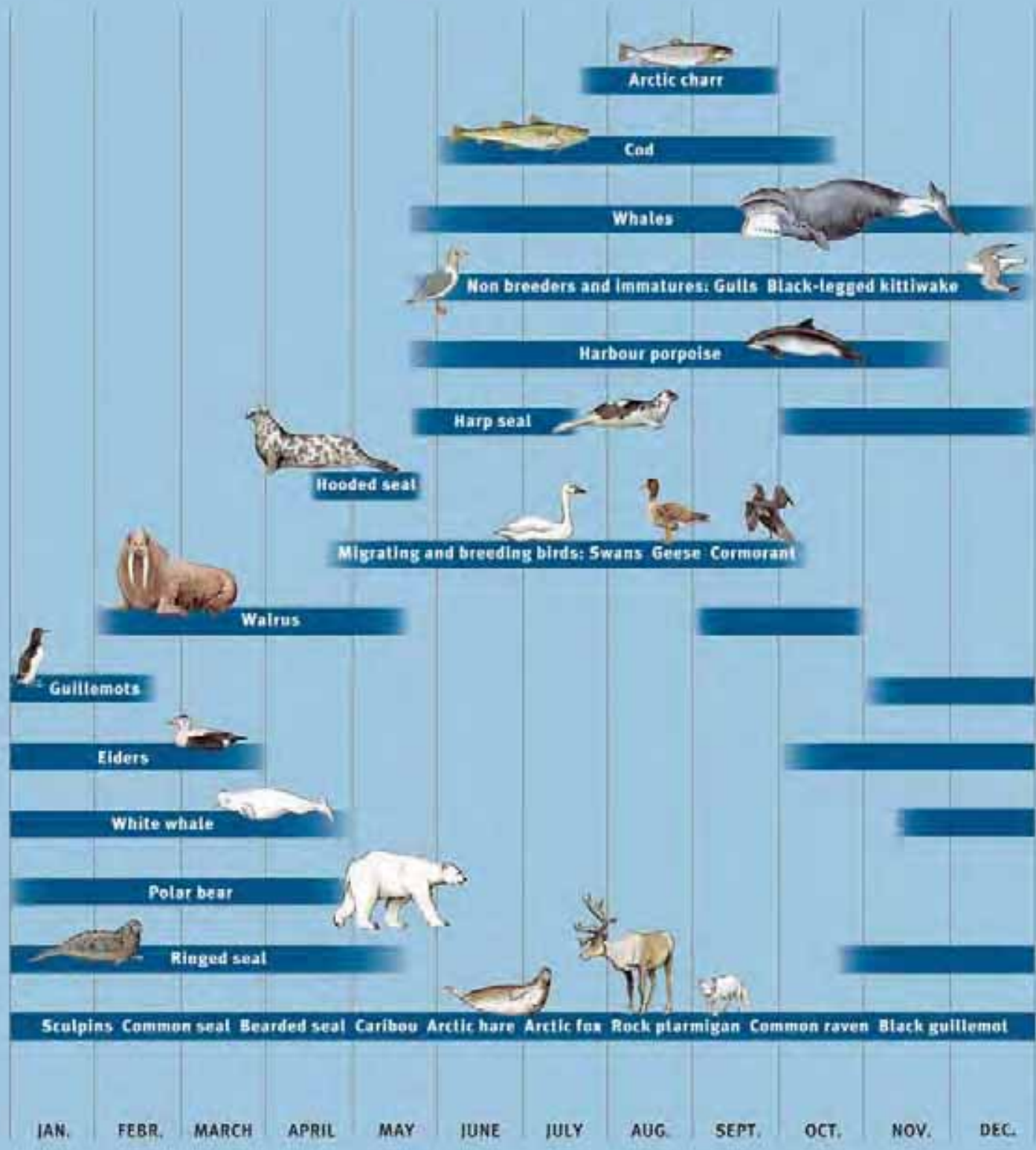

Fig. 9. The game animals represented at Nipisat and their present day seasonal distribution in the Sisimiut District. Small discrepancies from the seasonal occurrence of the species c. 3-4000 years ago cannot be totally ruled out. Drawing: Jørgen MürhmannLund.

breeding and foraging sites for Greenland white-fronted goose (Anser albifrons flavirostris), Greenland mallard (Anas platyrhynchos conboschas), long-tailed duck (Clangula hyemalis), and red-breasted merganser
(Mergus serrator). Red-throated diver (Gavia stellata) and great northern diver (Gavia immer) in particular prefer to nest at large lakes. In recent years the Canada goose (Branta canadensis) is also considered a breed- 
ing bird in the Sisimiut area (Boertmann 1994; Boertmann and Glahder 1999). Of less importance as game are the gyr falcon (Falco rusticolus) and the peregrine falcon (Falco peregrinus tundrius), which are both common breeders.

\section{Nipisat upon the arrival of humans}

As indicated by the presence of the common mussel (Mytilus edulis), which today is distributed in low arctic Greenland up to $72^{\circ} 77^{\prime} \mathrm{N}$ at the west coast and $66^{\circ} 30^{\prime}$ $\mathrm{N}$ at the east coast (Salomonsen I981a: 2I), warm subarctic water penetrated up along the West Greenland coast as early as $7000 \mathrm{BC}$ and c. 5500-3000 BC subarctic/boreal faunal elements, which are now absent from Greenland waters, were present (Kelly I980; Funder and Fredskild 1989). Low skerries and islets emerged after the retraction of the glaciers and a fairly rich fauna of gastropods and bivalves became established in the early Holocene (Funder and Fredskild 1989). Thus the feeding and nesting requirements of auks and other marine and coastal bird species existed in Greenland at least since arrival of the PalaeoEskimos and probably much earlier (Gotfredsen I999). But seals, whales and walrus must also have had good feeding opportunities. On the mainland, fairly rich vegetation was established soon after deglaciation (Funder and Fredskild 1989) and ponds and lakes may have existed both inland and near the coast. These habitats were suitable for swans, geese and other terrestrial and fresh water species. Before humans arrived, many nesting birds e.g. cormorant, eider, various kinds of gulls and auks may have nested on low skerries protected from arctic fox more commonly than seen today or even in historical times. Some species, which breed today on steep cliffs, may breed on low skerries, when protected from human interference, e.g. Iceland gull, glaucous gull (Boertmann 1994) and cormorant (Boertmann and Mosbech 1997:93, 99). The behaviour of various bird species may also have differed, for instance cormorants were reported to be extremely shy and left their nests when boats approached during the mid $20^{\text {th }}$ century (Salomonsen 1950, 1967) while they were still persecuted. With a low hunting pressure as today many adult cormorants remain on their nests or on the breeding ledges when approached by boats (Boertmann and Mosbech 1997).

When the Saqqaq people first arrived at Nipisat, it was a smaller island, probably surrounded by a broader sound than today due to isostatic factors (Fig. I96). Nipisat was part of a pristine archipelago with numerous breeding species of both mammals and birds, and with a good vantage point over the sound. Even though the postglacial climatic optimum had peaked when humans settled on Nipisat, the climate was milder than today (Fig. 2). In addition it has been suggested that there was a more pronounced seasonality 2500 years ago, with a greater June insolation (P. Mayewski pers. comm. 1999; O'Brien et al. 1995). These factors may, to some extent, have influenced the timing of arrival and departure of migrating species, in addition to the breeding period. Nevertheless, based on our knowledge of game animals from recent and historical times, the species found at Nipisat must, by and large, have had a seasonal occurrence in the Nipisat area as depicted in Fig. 9. 


\section{Chapter 3}

\section{The Nipisat site}

The site is situated on a small island $\mathrm{I} 5 \mathrm{~km}$ south of Sisimiut at $66^{\circ} 55^{\prime} \mathrm{N}$ and $53^{\circ} 28^{\prime} \mathrm{W}$ (Fig. 4) in the open water region (Fig. 5).

The settlement area lies $50 \mathrm{~m}$ from the present coast, on a series of raised beaches sloping to the southeast and at an elevation between 9 and $\mathrm{I} 3 \mathrm{~m}$ above sea level (i.e. above lowest tide level) (Fig. Io). The settlement area is covered by dense vegetation and nothing was therefore visible on the surface when the curator Finn Kramer, Sisimiut Museum, discovered the site in 1989. However, a test pit Io $\mathrm{cm}$ below recent sod revealed well preserved bones and stone artefact types of the Saqqaq Culture (Kramer 1994, 1996 a, b; Kramer and Jones 1992). The excellent preservation conditions and the fact that some of the stone artefacts were not previously known from the Saqqaq Culture, led to the excavation campaigns at the site from 1990

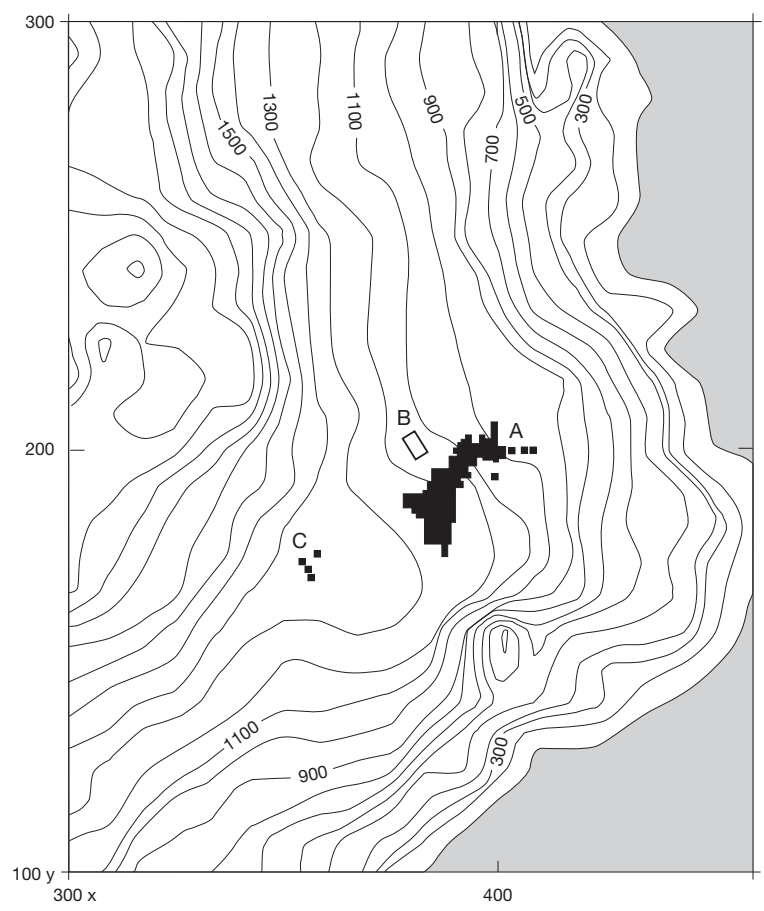

Fig. 10. Map showing the topography of Nipisat with the excavated area (A). B is an ionosphere station from 1950. C marks four graves from the middle of the 18th century. North is up and the scale is $100 \mathrm{~m}$ between $100 \mathrm{y}$ and $200 \mathrm{y}$. Drawing: Stig Grummesgaard-Nielsen. to 1994. Investigations showed no contamination from later occupation by Dorset or Thule in this part of the island (Fig. II).

The subsoil at the site consists of thick layers of crushed shells and sand, which indicate that the site lies on a raised sea-bed (Appendix 2). The deposits at Nipisat are outstanding in two ways. Firstly, thick deposits of crushed shells above and below the culture layer created excellent preservation conditions for bone, antler and ivory. Secondly, for the first time in the Sisimiut municipality, several distinct culture layers were documented at a Saqqaq site. The different culture layers were separated by lenses of crushed shell, mainly wind deposited. The investigation has shown that the site has both a horizontal and vertical stratigraphy and, as indicated by the ${ }^{\mathrm{I}} \mathrm{C}$ dates, the stratigraphy is highly complex.

\section{The excavation}

All the test pits from 1989 lie in the far northern part of the settlement area. In I990 the excavation concentrated on the same area, the test pits from 1989 were included and a total of $35 \mathrm{~m}^{2}$ was investigated. In 1990 it was only possible to detect one culture layer, often situated directly upon original cobble beach (Fig. I2).

The campaign in 1992 amounted to $44 \mathrm{~m}^{2}$ and revealed a much more complex stratigraphy than the previous excavation. Several culture layers were identified, separated by sterile lenses of crushed shells. For the first time a dwelling structure was found, although poorly defined, consisting of a box-hearth and several flat stones. Unfortunately it was not possible to connect the two areas stratigraphically due to rock outcrops (Fig. I3).

The purpose of the excavation in I993, where 50 $\mathrm{m}^{2}$ were excavated, was to elucidate the highly complex stratigraphy. To gain more control of the stratigraphy, all bones, flakes and tools were mapped three dimensionally in $7 \mathrm{~m}^{2}$ in the central part of the excavation. The central part was the only area where there were problems with permafrost. Elsewhere the soil 


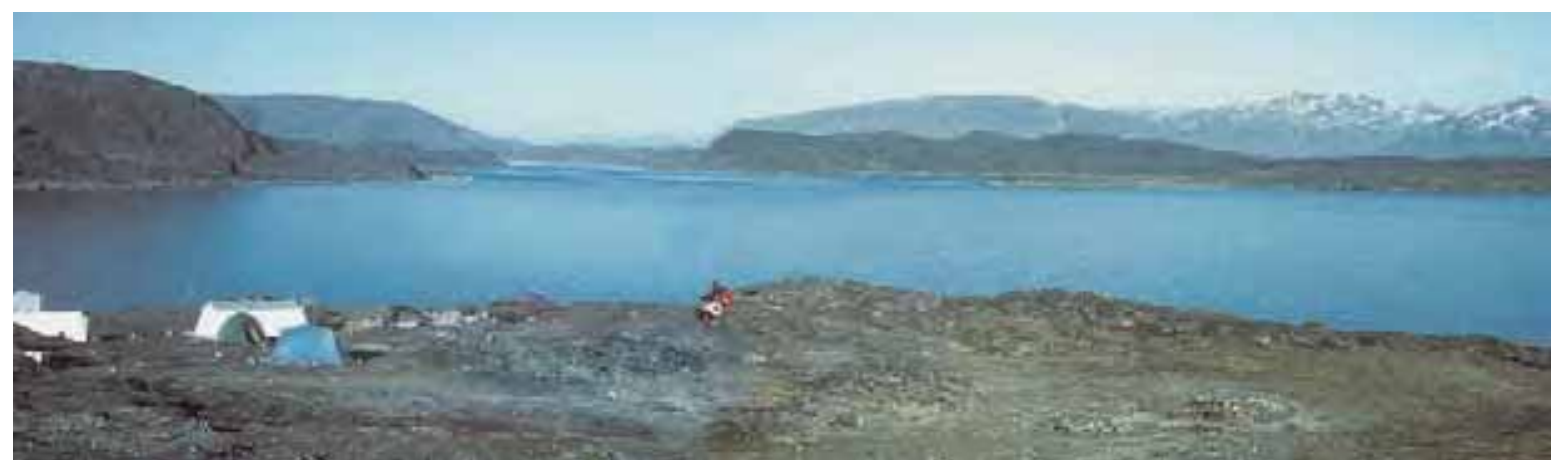

Fig. 11. From Nipisat there is a fine view across the straits where migrating seals and whales are often seen. To the right, the four European graves. Photo: Tinna Møbjerg.

was so well drained that no permafrost was registered. In addition to the area south of the excavation from 1992, a few $\mathrm{m}^{2}$ were excavated to the north and west of the former excavation in an attempt to connect the different culture layers. All of the sections at Nipisat reveal a similar stratigraphy, with two massive culture layers separated by sterile layers of crushed shell. In addition, poorly defined culture layers beneath these two were also registered, containing very few artefacts and unworked bones. Because of rock outcrops, lenses of crushed shell and cryoturbation, it was very difficult to follow the same layer continuously from south to north, especially in the case of the oldest layer.

One of the reasons for continuing the excavation in I994 was to clarify the connection between the hor-

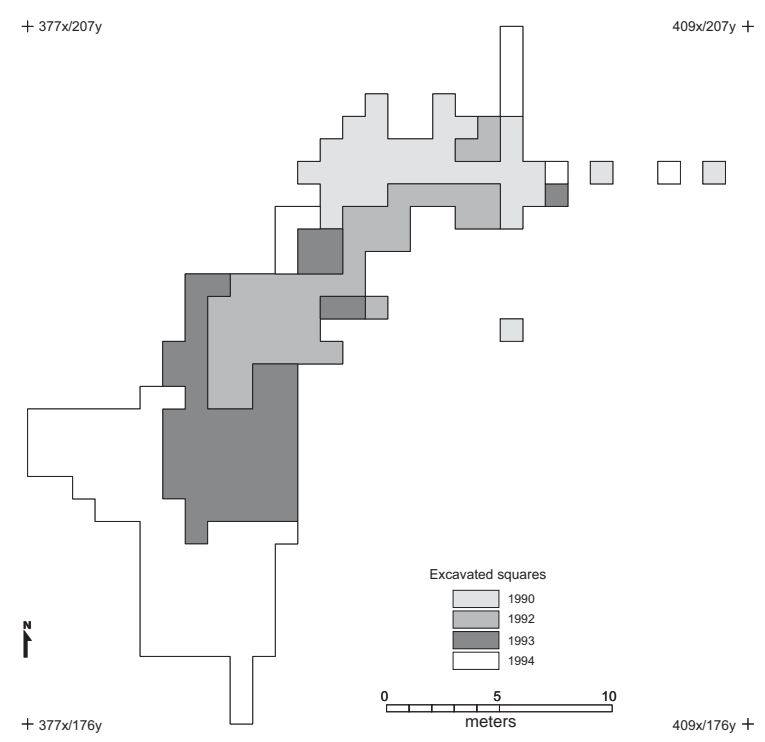

Fig. 12. The excavated area at Nipisat, 1990-1994. izontal and vertical stratigraphy of the different areas. Two I $m$ wide trenches were therefore excavated north and west of the 1990 excavation $\left(8 \mathrm{~m}^{2}\right)$. In addition, two $\mathrm{m}^{2}$ were excavated east of the previously excavated area. Furthermore, $67 \mathrm{~m}^{2}$ were excavated in the southern part of the settlement area, which means that a total of $206 \mathrm{~m}^{2}$ have now been excavated at Nipisat.

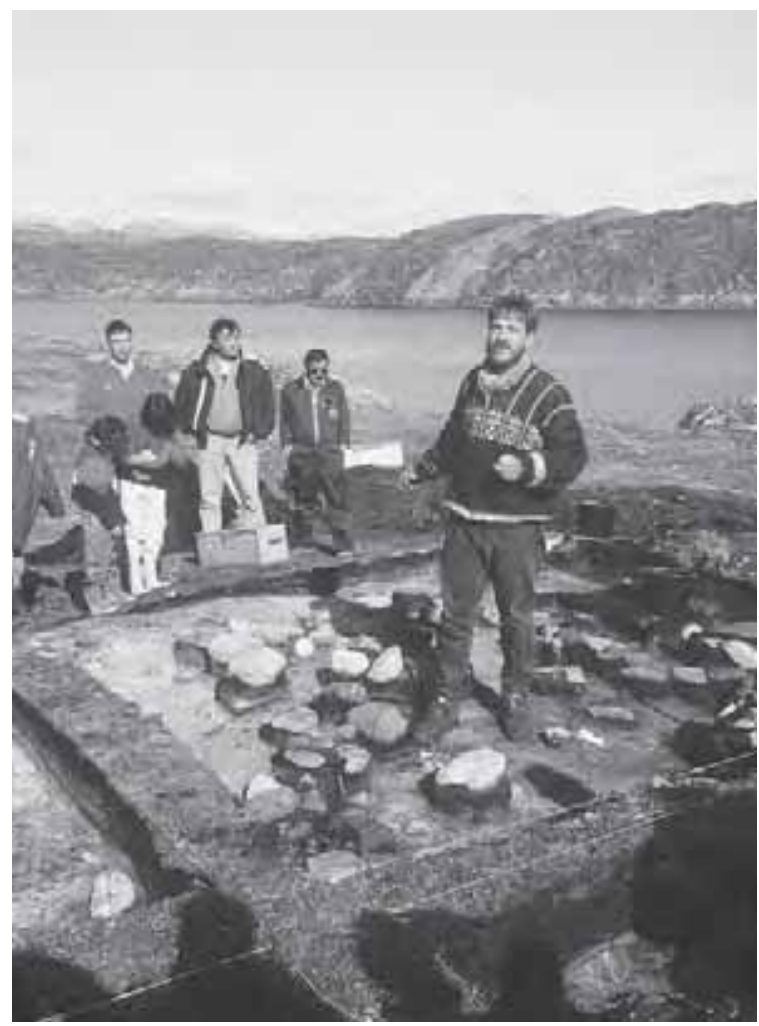

Fig. 13. The excavation in progress in 1992. Photo: Anne Birgitte Gotfredsen. 


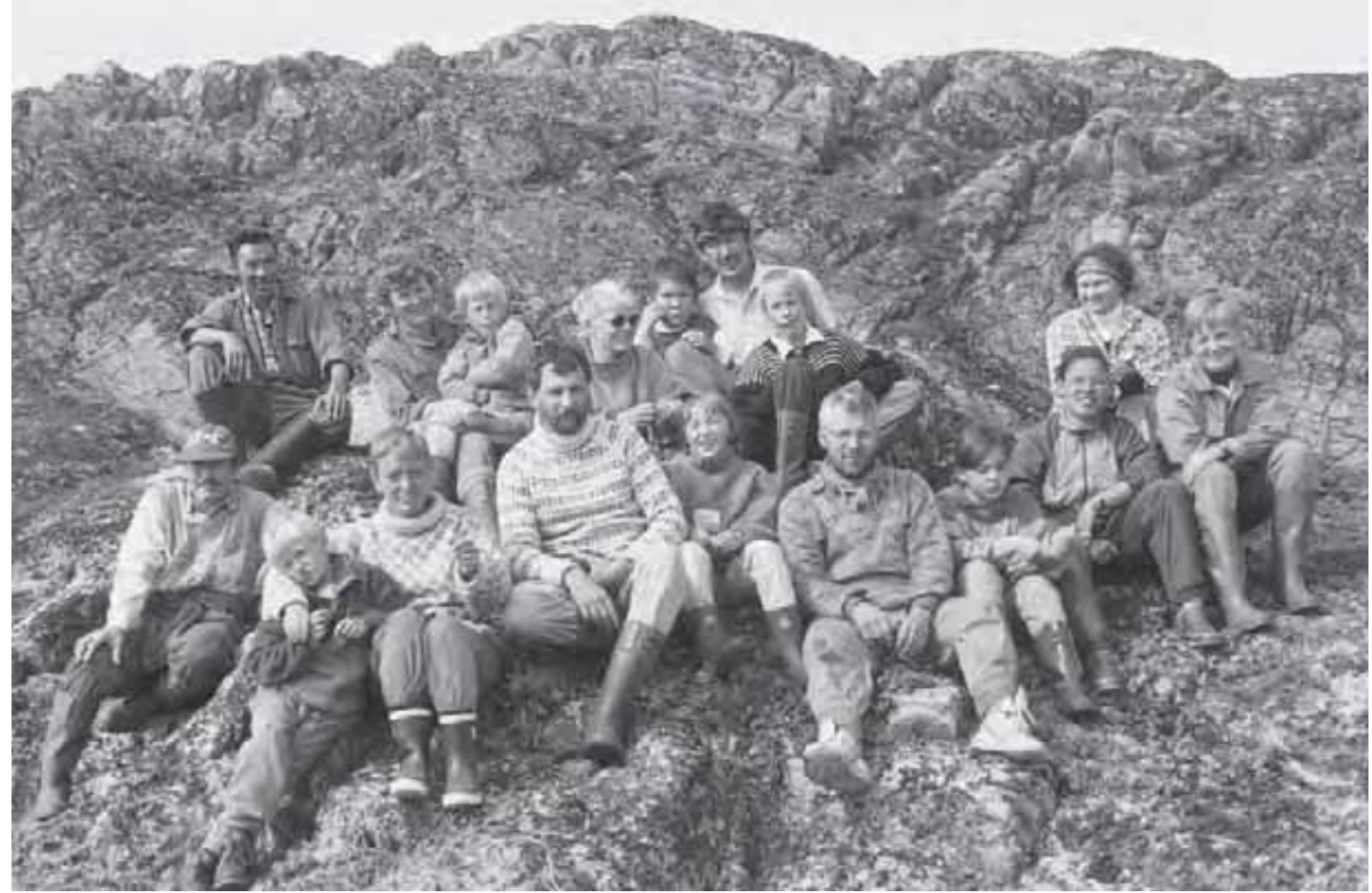

Fig. 14. The crew in 1994. Many volunteers from Sisimiut participated in the excavation together with students from Greenland and Denmark. Photo: John Pind.

The I994 excavation yielded one more box-hearth surrounded by a poorly defined stone circle.

From 1989 to 1994 more than 70,000 bone fragments, several thousand flakes, and c. I,ooo artefacts were recovered. Many different people participated in the field work at Nipisat (Fig. I4). From 1989 to 1993 curator Finn Kramer, Sisimiut Museum was in charge of the investigation (Kramer 1994, 1996 a, b; Kramer and Jones 1992) and the final field season in 1994 was led by Tinna Møbjerg (Møbjerg I995a, b, I997b, I998,

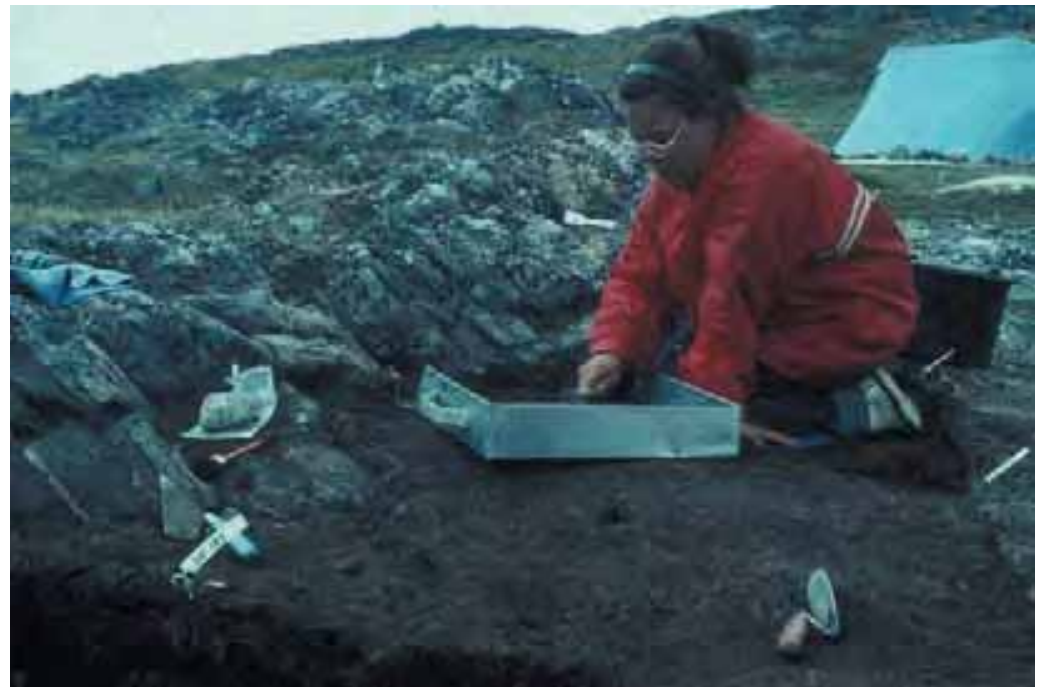

Fig. 15. Esther Jensen from Ilisimatusarfik, University of Greenland, excavating in the western part of the site. Nipisat 1994. Photo: Stig Grummesgaard-Nielsen. 
Fig. 16. The excavated area with the profile sections marked. Bedrock is marked with contour lines.

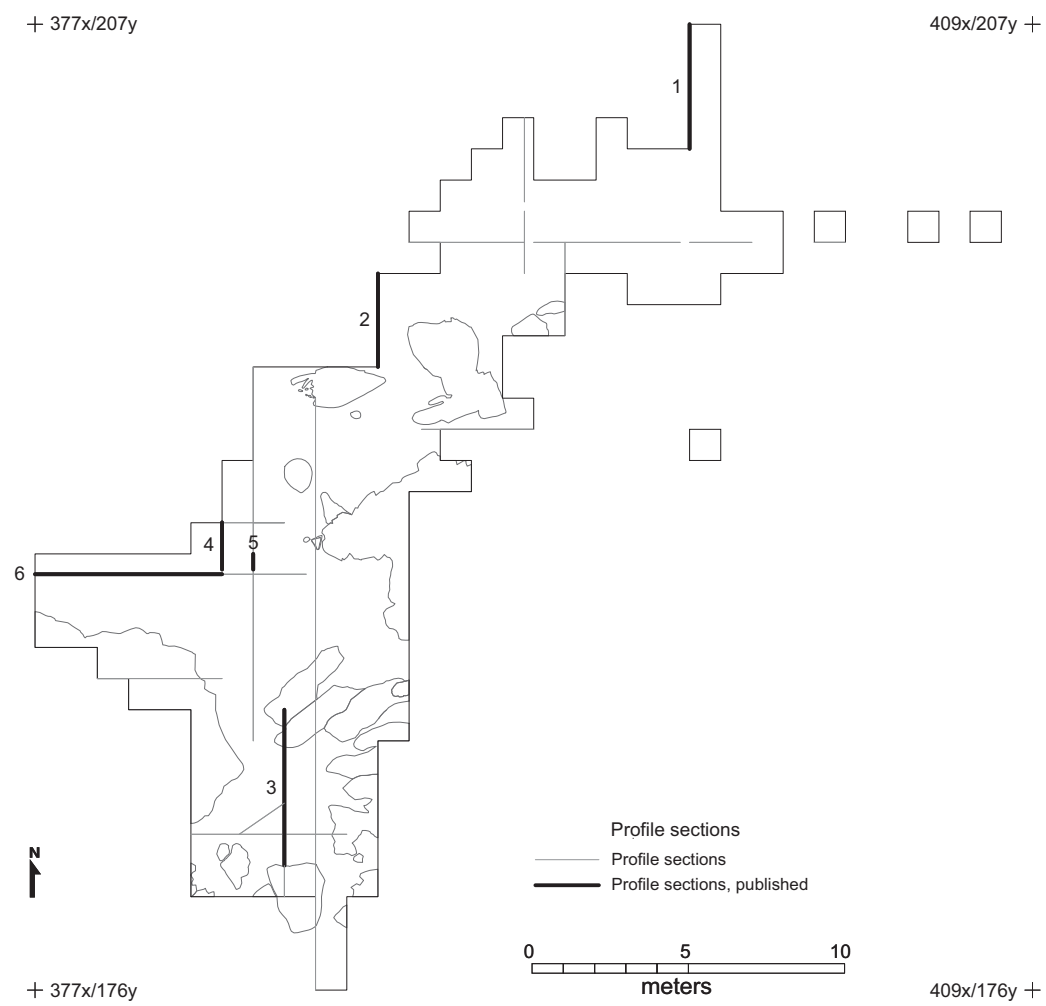

I999). Besides the archaeologists, zoologists and geologists also participated in the field work. During 1992 and 1993 Anne Birgitte Gotfredsen took part in the excavation and, in addition, she was responsible for all faunal analysis of the total faunal assemblages (Gotfredsen 1992, 1996, I997a, I998, 2002). In 1994 all organic material was taken care of in the field by museum conservator Lone Petersen. Because of the excellent preservation conditions at the site, only very few specimens needed conservation after retrieval.

All flakes and unworked bones were collected per $\mathrm{m}^{2}$. However, worked bones and artefacts were registered in three dimensions. In 1990, I992 and 1993 no sieving was carried out but the back dirt was checked through a second time on a wooden table. In 1994 a few $\mathrm{m}^{2}$ (383x/181y and 384x/181y) were chosen to be sieved through a $2 \times 2 \mathrm{~mm}$ grid. However, this method did not provide any additional results as the sandy nature of the soil made the recovery of artefacts and unworked bone easy (Fig. I5). Despite the lack of sieving, large amounts of tiny bone splinters, needle fragments and burin spalls were recovered and we therefore consider the excavation to have been carried out with sufficient care.

\section{Stratigraphy and ${ }^{14} \mathrm{C}$ dates}

Through the various field seasons, several sections were made in an attempt to ascertain the relationship between different areas and layers at the site (Fig. I6). In the following, the most important sections are reproduced. In I990 it was only possible to detect one culture layer (layer 2), but the excavation in 1992 showed a more complex picture. In the field the layers were named provisionally from o to 6 from the bottom up. These names were used more or less unchanged throughout the rest of the field seasons. Layer o is very thin (less than I cm) containing brown humic peat with very few artefacts. Below and above layer o, the deposits consist of sterile sand and crushed shell. Layer I and IB are also very thin layers consisting of humic peat, appearing as a thin vegetational zone with few bones and artefacts. Below and above these two layers was a crushed shell layer (IA). All of these culture layers were very difficult to identify while digging horizontally and were often not seen until the profile section was examined. Above IA there was a massive culture layer (layer $2 \mathrm{~K}$ ) containing a large amount of unworked bone and artefacts of stone, antler, bone 


\section{Section 1}

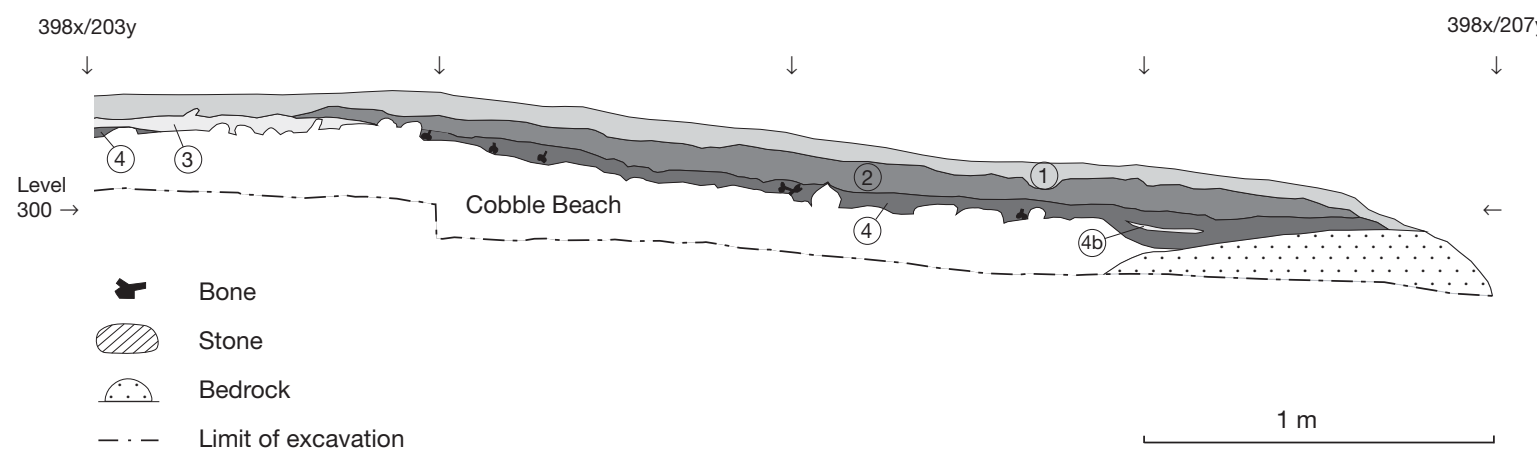

Fig. 17. Profile section 1 (south - north) seen from the east and showing the stratigraphy in the northernmost part of the settlement.

and ivory. The dwelling structures also belong to this layer. In several areas $2 \mathrm{~K}$ was separated into more layers $\left(2 \mathrm{KI}\right.$ and $\left.2 \mathrm{~K}_{3}\right)$ by thin lenses of crushed shell $(2 \mathrm{~K} 2)$. On top of $2 \mathrm{~K}$ is a relatively sterile layer (2s), mainly consisting of wind deposited sand and crushed shells. Above layer $2 \mathrm{~s}$ is the youngest culture layer (2) consisting of brownish peat, up to $30 \mathrm{~cm}$ thick, with large quantities of unworked bone, artefacts of bone, antler and ivory, flakes and stone tools. The uppermost layer 6 consists of recent turf with roots and few bones and artefacts. After the excavation, the sections were analysed and interpreted in the following way.

\section{Section I}

The section stretches from $398 \mathrm{x} / 203 \mathrm{y}$ to $398 \mathrm{x} / 207 \mathrm{y}$ at level 300 equivalent to $9.9 \mathrm{~m}$ above sea level (Fig. I7).

Description:

1. Recent turf with roots and few artefacts (layer 6)

2. Brownish, fairly homogeneous humic layer, with bones and artefacts (culture layer 2).

3. Light yellowish layer consisting of sand and crushed shells directly upon cobble beach (layer 2s)

4. Dark brown to black homogenous, humic layer with bones, artefacts and charcoal placed directly upon cobble beach (culture layer 2K)

4b. Light greyish sandy layer with crushed shell, sterile (2K2)

\section{Section 2}

$$
388 x / 196 y
$$

$$
\downarrow
$$

$\downarrow$ $\downarrow$

$388 x / 196 y$

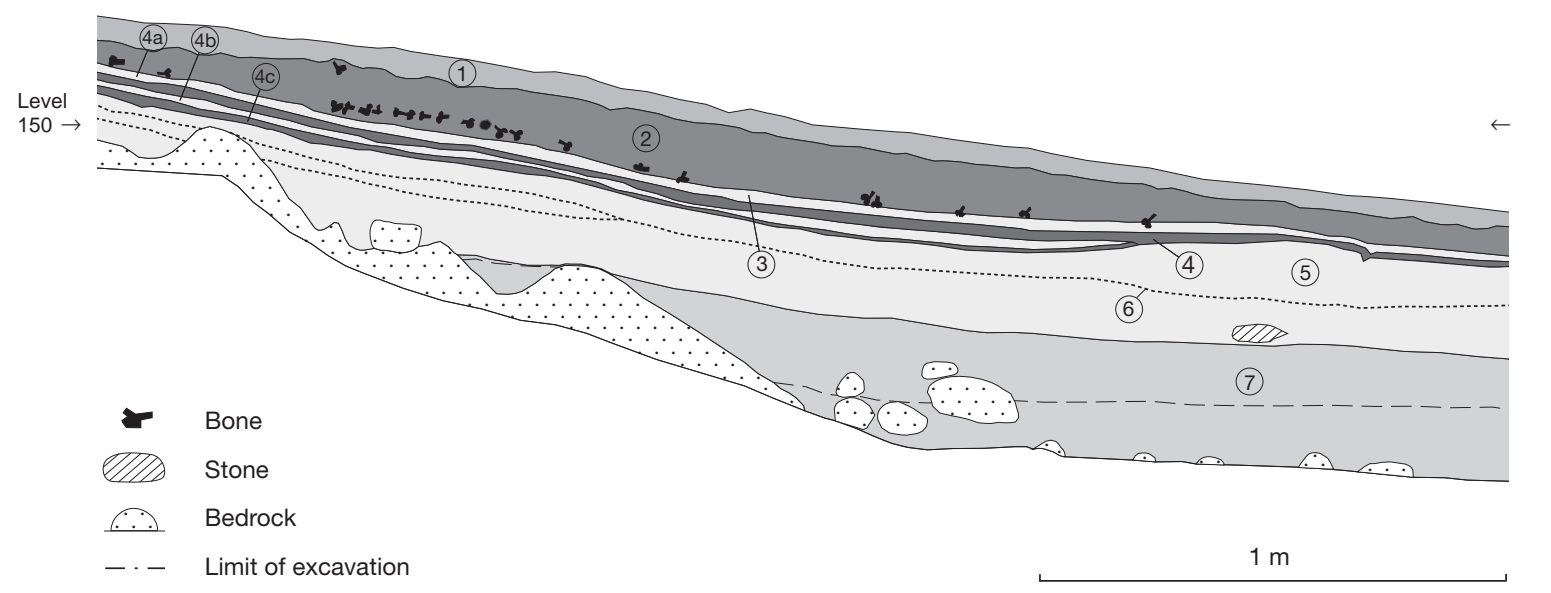

Fig. 18. Profile section 2 (south - north) seen from east and showing the stratigraphy in the western part of the settlement. 
Table $1 .{ }^{14} \mathrm{C}$ datings from Nipisat dated at the AMS Laboratory, Aarhus University (AAR), the ${ }^{14} \mathrm{C}$ laboratory, National Museum of Denmark, Copenhagen (K) and at the Archaeology Department, Simon Fraser University, Canada (CAMS). ${ }^{14} \mathrm{C}$ ages are given in conventional radiocarbon years BP (BP = before 1950) calibrated age and calibrated age \pm 1 standard deviation (Stuiver \& Pearson 1993).

\begin{tabular}{|c|c|c|c|c|c|c|c|c|}
\hline $\begin{array}{l}\text { Labora- } \\
\text { tory } \\
\text { no. }\end{array}$ & $\begin{array}{l}\text { x-co-or- } \\
\text { dinate }\end{array}$ & $\begin{array}{c}y \text {-co-or- } \\
\text { dinate }\end{array}$ & Layer & $\begin{array}{l}\text { Height } \\
\text { above } \\
\text { sea level } \\
\quad(\mathrm{m})\end{array}$ & $\begin{array}{c}{ }^{14} \mathrm{C} \\
\text { age BP }\end{array}$ & $\begin{array}{c}\text { Calibrated } \\
\text { age BC }\end{array}$ & $\begin{array}{c}\mathrm{Cal}+ \\
1 \mathrm{stdv} . \mathrm{BC}\end{array}$ & Sample type \\
\hline K-5584 & 399,00 & 200,00 & 2 & 9.89 & $2940 \pm 80$ & 1130 & $1260-1000$ & bone (Rangifer tarandus) \\
\hline K-5864 & 391,00 & 201,00 & 2 & 10.70 & $2860 \pm 80$ & 1000 & $1130-910$ & bone (Rangifer tarandus) \\
\hline K-6031 & 387,00 & 194,00 & $2 \mathrm{~K}$ & 11.63 & $3490 \pm 80$ & $1860-1790$ & $1890-1690$ & bone (Rangifer tarandus) \\
\hline K-6192 & 383,62 & 186,80 & 2 & 11.96 & $3670 \pm 90$ & 2030-1990 & 2180-1910 & bone (Rangifer tarandus) \\
\hline K-6193 & 385,70 & 188,35 & 2 & 11.78 & $2920 \pm 85$ & 1120 & $1260-950$ & bone (Rangifer tarandus) \\
\hline K-6194 & 384,02 & 187,13 & 2 & 11.82 & $2670 \pm 85$ & 810 & $900-790$ & bone (Rangifer tarandus) \\
\hline K-6195 & 384,74 & 191,98 & $2 \mathrm{~K}$ & 11.67 & $3310 \pm 85$ & $1600-1530$ & $1680-1470$ & bone (Rangifer tarandus) \\
\hline K-6196 & 384,50 & 191,72 & $1 \mathrm{~B}$ & 11.61 & $3300 \pm 85$ & 1530 & $1680-1460$ & bone (Rangifer tarandus) \\
\hline K-6198 & 386,50 & 192,50 & $2 \mathrm{~K}$ & 11.60 & $3180 \pm 125$ & 1430 & $1590-1310$ & charcoal (Salix sp. \& Betula n.) \\
\hline K-6459 & 383,00 & 189,80 & $2 \mathrm{~K}$ & 11.66 & $3010 \pm 95$ & $1260-1230$ & $1390-1080$ & bone (Rangifer tarandus) \\
\hline K-6460 & 388,00 & 196,50 & 2 & 11.45 & $2910 \pm 60$ & $1110-1060$ & $1200-1000$ & bone (Rangifer tarandus) \\
\hline AAR-3570 & 388,00 & 196,00 & $2 \mathrm{~K}$ & 11.30 & $3085 \pm 45$ & $1385-1325$ & $1405-1265$ & bone (Rangifer tarandus) \\
\hline AAR-3571 & 398,00 & 204,00 & 2 & 10.10 & $3040 \pm 50$ & $1290-1270$ & $1390-1210$ & bone (Rangifer tarandus) \\
\hline AAR-3572 & 405,00 & 200,00 & $2 \mathrm{~K}$ & 9.28 & $3065 \pm 40$ & $1370-1315$ & $1395-1265$ & bone (Rangifer tarandus) \\
\hline AAR-3573 & 385,08 & 188,16 & 2 & 11.70 & $2950 \pm 50$ & $1150-1130$ & $1260-1040$ & bone (Rangifer tarandus) \\
\hline AAR-3574 & 385,42 & 188,25 & 2 & 11.91 & $2455 \pm 50$ & 520 & $760-410$ & bone (Rangifer tarandus) \\
\hline AAR-3575 & 385,60 & 188,79 & 2 & 11.73 & $2815 \pm 45$ & $970-930$ & $1005-905$ & bone (Rangifer tarandus) \\
\hline AAR-3576 & 385,50 & 188,57 & $2 s$ & 11.66 & $3525 \pm 50$ & $1880-1790$ & $1910-1750$ & bone (Rangifer tarandus) \\
\hline AAR-3577 & 385,30 & 188,99 & $2 \mathrm{~K}$ & 11.64 & $3515 \pm 65$ & 1870-1705 & $1910-1740$ & bone (Rangifer tarandus) \\
\hline AAR-3578 & 385,38 & 188,84 & $2 \mathrm{~K}$ & 11.61 & $3480 \pm 50$ & 1760 & $1880-1700$ & bone (Rangifer tarandus) \\
\hline AAR-3580 & 384,00 & 189,00 & $2 \mathrm{~K}$ & 11.64 & $3445 \pm 50^{*}$ & 1740 & $1870-1680$ & shell (Littorina saxatilis) \\
\hline AAR-3581 & 384,00 & 189,00 & $2 \mathrm{~K}$ & 11.66 & $3490 \pm 50^{*}$ & $1860-1770$ & $1880-1740$ & shell (Hiatella arctica) \\
\hline AAR-3582 & 383,00 & 187,00 & 1 & 11.66 & $3570 \pm 60^{*}$ & 1890 & $1970-1780$ & shell (Mytilus edulis) \\
\hline AAR-3583 & 383,00 & 187,00 & 2 & 11.78 & $3020 \pm 50^{*}$ & 1260 & $1380-1140$ & shell (Mytilus edulis) \\
\hline AAR-3630 & 384,50 & 181,50 & $2 \mathrm{~K}$ & 12.60 & $3650 \pm 65$ & $2020-1980$ & 2130-1920 & charcoal (Salix sp.) \\
\hline AAR-4158 & 385,00 & 188,00 & 2 & 11.90 & $3060 \pm 45$ & 1310 & $1395-1230$ & bone (Rangifer tarandus) \\
\hline AAR-4159 & 385,59 & 188,42 & 2 & 11.88 & $2835 \pm 40$ & $990-950$ & $1015-920$ & bone (Rangifer tarandus) \\
\hline AAR-4160 & 398,00 & 204,00 & $2 \mathrm{~K}$ & 10.05 & $3025 \pm 40$ & 1265 & $1375-1210$ & bone (Rangifer tarandus) \\
\hline AAR-6698 & 380,00 & 189,00 & 2 & 12.10 & $3425 \pm 50$ & $1740-1695$ & $1855-1645$ & bone (Rangifer tarandus) \\
\hline AAR-6699 & 380,00 & 189,20 & $2 \mathrm{~K}$ & 12.05 & $3450 \pm 45$ & 1745 & $1875-1690$ & bone (Rangifer tarandus) \\
\hline AAR-6986 & 381,50 & 187,50 & $2 \mathrm{~K}$ & 12.00 & $3280 \pm 45$ & 1525 & $1620-1515$ & bone (Rangifer tarandus) \\
\hline AAR-6987 & 381,00 & 188,00 & 2 & 12.05 & $2975 \pm 45$ & $1255-1135$ & $1290-1125$ & bone (Rangifer tarandus) \\
\hline $\begin{array}{l}\text { CAMS- } \\
82924 \& 25\end{array}$ & 386,50 & 193,50 & 2 & 11.76 & $2935 \pm 25^{* *}$ & 1142 & $1207-1092$ & antler and bone (Rangifer \\
\hline
\end{tabular}

* The datings were corrected for the reservoir effect with 400 years.

** The age determination comes from the weighted average of the sample taken from a caribou skull with antler (Nelson and Møhl 2003).

Layer 2 is ${ }^{\mathrm{I}} \mathrm{C}$ dated to I290-I270 BC (cal) (AAR-357I) and layer $4(2 \mathrm{~K})$ is ${ }^{\mathrm{I}} \mathrm{C}$ dated to $\mathrm{I} 265 \mathrm{BC}$ (cal) (AAR4I60). To the east of this section a sample from layer 4 (2K) is dated to I370-I3I5 BC (cal) (AAR-3572). Layer 2 is dated by two more samples taken southwest of the profile section (Fig. 24). K-5584 is a sample of several caribou bones from test pits made in 1989 and dated to II30 BC (cal). K-5864 is one caribou bone dated to Iooo BC (cal) (Table I). Even though it was possible to detect internal stratigraphy in the profile section, it is 


\section{Section 3}

$385 x / 185 y$

$\downarrow$

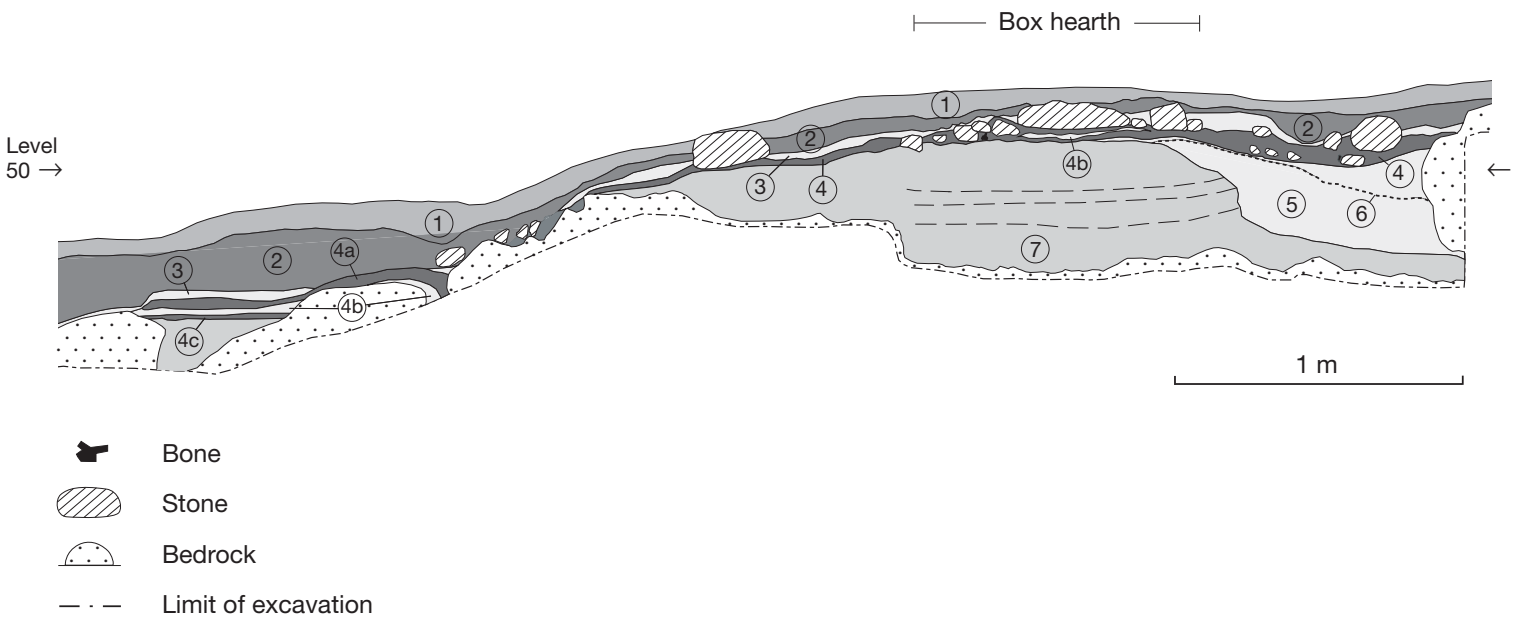

Fig. 19. Profile section 3 (north - south) seen from west and showing the southern part of the settlement with the hearth.

not possible to correlate these layers to different occupational phases, as the range between the ${ }^{\mathrm{I} 4} \mathrm{C}$ dates is so narrow. Therefore the interpretation made in the field in 1989-1990, that only one habitation period could be identified, proved to be correct.

\section{Section 2}

The section stretches from $388 \mathrm{x} / \mathrm{ig6y}$ to $388 \mathrm{x} / \mathrm{199y}$ at level I50 equivalent to II.4 $\mathrm{m}$ above sea level (Fig. I8).

\section{Description:}

1. Recent turf with roots and few artefacts (layer 6)

2. Brownish, fairly homogeneous, humic layer, with a large amount of bones and artefacts (culture layer 2)

3. Light yellowish layer consisting of sand and crushed shells with a little humus and few bones and artefacts (layer 2s)

4. Dark brown to black homogenous humic layer with bones, artefacts and charcoal (culture layer $2 \mathrm{~K}$ ) can be separated into:

a) Dark brown culture layer (2K1)

b) Light greyish sandy layer with crushed shell, sterile $(2 \mathrm{~K} 2)$

c) Dark brown culture layer (2K3)

5. Light greyish layer with crushed shell and sand, sterile and wind deposited (layer 1A)

6. Dark thin stripe consisting of humus and peat containing very few bones and artefacts (layer 1 and 1B)

7. Light greyish to yellow homogeneous gravel layer with a thin dark stripe of humus (layer 0 ). The gravel layer is sterile and lies directly on bedrock.
Layer 2 is ${ }^{\mathrm{I}} \mathrm{C}$ dated to IIIo-Io6o BC (cal) (K-6460) and layer $4(2 \mathrm{~K})$ is ${ }^{\mathrm{I}} \mathrm{C}$ dated to $\mathrm{I}_{3} 85-\mathrm{I} 325 \mathrm{BC}$ (cal) (AAR3570 ). To the south of this section a date from layer 6 (IB) gives I530 BC (cal) (K-6I96). Layer $4(2 \mathrm{~K})$ is dated by three dates south of the section - K-603I (I860-I790 BC (cal)), K-6I95 (I6oo-I530 BC (cal)) and K-6I98 (I430 BC (cal)). The last one is charcoal taken from a box-hearth.

Layer 2 is dated by one more sample of caribou bone and antler taken from the same cranium south of the profile section. The age determination thus comes from the weighted average which yields an age of II42 BC (cal). (CAMS-82924 and CAMS-82925) (Table I). This means that the youngest culture layer in this area is contemporary with the occupation phase in the northern part of the site.

\section{Section 3}

The section stretches from $385 \mathrm{X} / \mathrm{I} 85 \mathrm{y}$ to $385 \mathrm{x} / \mathrm{I} 8$ oy at level 50 equivalent to I2.4 m above sea level (Fig. I9).

\section{Description:}

1. Recent turf with roots and few artefacts (layer 6)

2. Brownish, fairly homogeneous and humic layer, with a large amount of bones and artefacts (culture layer 2)

3. Light yellowish layer consisting of sand and crushed shells with a little humus and few bones and artefacts (layer 2s) 
4. Dark brown to black homogenous humic layer with bones, artefacts, charcoal and stones from a box-hearth and dwelling structure (culture layer $2 \mathrm{~K}$ ) can be separated into:

a) Dark brown culture layer (2K1)

b) Light greyish sandy layer with crushed shell, sterile (2K2)

c) Dark brown culture layer (2K3)

5. Light greyish layer with crushed shell and sand, sterile and wind deposited (layer 1A)

6. Dark thin stripe consisting of humus and peat, containing very few bones and artefacts (layer 1 and 1B)

7. Light greyish to yellow homogeneous gravel layer with a thin dark stripe of humus (layer 0 , in this part no cultural remains). The gravel layer is sterile and lies directly on bedrock.

Layer $4(2 \mathrm{~K})$ is ${ }^{\mathrm{I}} \mathrm{C}$ dated to $2020-\mathrm{I} 980 \mathrm{BC}$ (cal) (AAR3630). The sample consists of charcoal from a boxhearth in a poorly defined dwelling structure and represents the oldest occupation phase at Nipisat (Table I).

\section{Section 4}

The section stretches from $383 \mathrm{x} / \mathrm{I} 89,5 \mathrm{y}$ to $383 \mathrm{x} / \mathrm{I} 9 \mathrm{Iy}$ at level Ioo equivalent to II.9 $\mathrm{m}$ above sea level (Fig. 20 and 2I).

\section{Description:}

1. Recent turf with roots and few artefacts (layer 6)

2. Brownish, fairly homogeneous, humic layer, with a large amount of bones and artefacts (culture layer 2)

3. Light yellowish layer consisting of sand and crushed shells with a little humus and few bones and artefacts (layer 2s)

4. Culture layer $2 \mathrm{~K}$ can be separated into:

a) Dark brown to black humic peat, (culture layer $2 \mathrm{~K} 1$ ) separated into two layers by a very high concentration of charcoal (d). In the northern part of the section cryoturbation has disturbed the layer.

b) Light greyish sandy lenses with crushed shells, disturbing the continuity of layer 4, sterile (2K2)

c) Dark brown culture layer with a large number of artefacts and bones (2K3)

d) Black humic layer with a high concentration of charcoal, interpreted as remains of a disturbed hearth.

\section{Section 4}

$383 x / 189,5 y$

$\downarrow$
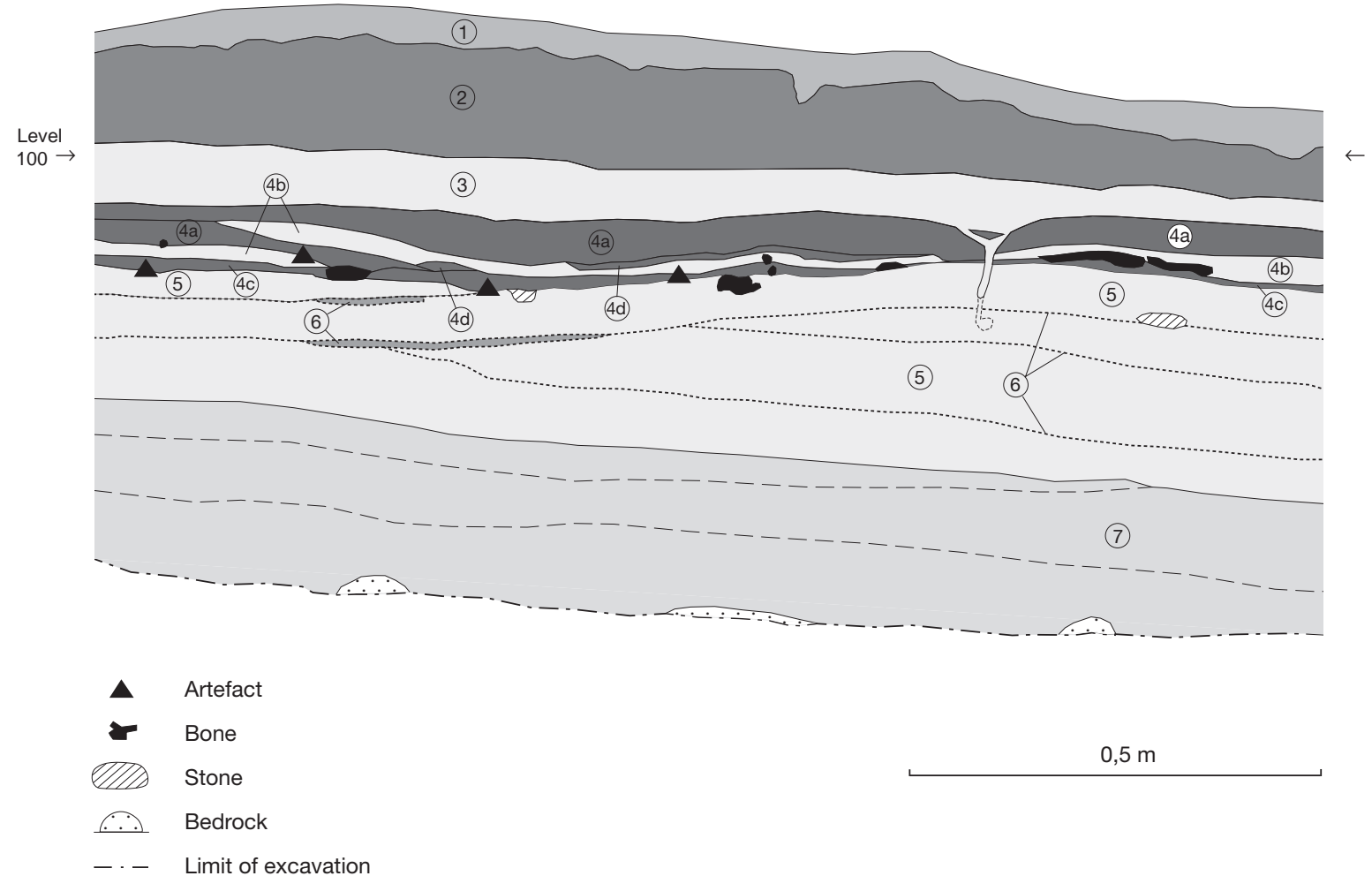

Fig. 20. Profile section 4 (south - north) seen from east and showing the stratigraphy in the central part of the settlement. 


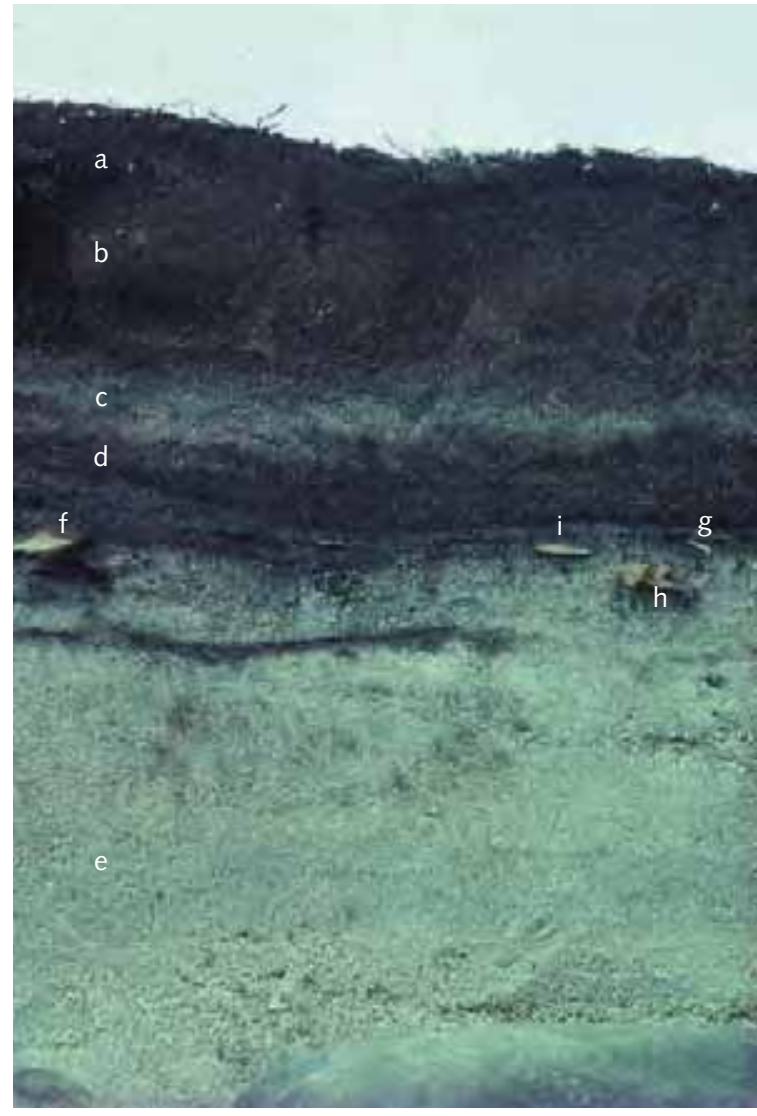

Fig. 21. Segment of section 4. From $383 x / 189,75 y$ to $383 x / 190,40 y$. a. turf layer formed after the site was abandoned. b. Late Saqqaq Culture. c. crushed shells. d. Early Saqqaq Culture e. crushed shells. f. caribou bone. g. bird bone. h. seal cranium. i. killiaq knife blade. Photo: Stig Grummesgaard-Nielsen.

5. Light greyish layer with crushed shell and sand, sterile and wind deposited (layer 1A)

6. Dark thin stripe consisting of humus and peat, containing very few bones and artefacts (layer 1 and 1B)

7. Light greyish to yellow homogeneous gravel layer with a thin dark stripe of humus (layer 0 , in this part no cultural remains). The gravel layer is sterile and lies directly on bedrock.

Layer $4 \mathrm{C}\left(2 \mathrm{~K}_{3}\right)$ is ${ }^{\mathrm{I}} \mathrm{C}$ dated to $\mathrm{I} 26 \mathrm{O}-\mathrm{I} 23 \mathrm{O} \mathrm{BC}$ (cal) (K6459). The dated caribou bone comes from the southern part of the section where layer $4 \mathrm{~b}$ disrupts the continuity of layer 4 . The date is too young to be from the oldest occupation phase in this area and is interpreted as contamination from a later phase. Finn Kramer mentioned in his field notes from this area, that the layers are "broken" south and north of I9oy (Kramer I993). Therefore, although there is no protruding bedrock, it has not been possible to correlate the oldest settlement phase $(2 \mathrm{~K})$ north and south of a line passing through I9oy (Fig. I6).

\section{Section 5}

The section stretches from $384 \mathrm{X} / \mathrm{I} 89,5 \mathrm{y}$ to $384 \mathrm{X} / \mathrm{I} 90 \mathrm{y}$ at level roo equivalent to II.9 $\mathrm{m}$ above sea level (Fig. 22).

\section{Description:}

1. Recent turf with roots and few artefacts (layer 6)

2. Brownish, fairly homogeneous and humic layer, with a large numbers of bones and artefacts (culture layer 2 ). The transition to layer 1 (6) is very uneven.

3. Light yellowish layer consisting of sand and crushed shells with a little humus, divided into three by a brown stripe in the middle (layer 2s)

4. Culture layer $2 \mathrm{~K}$ can be separated into:

a) Dark brown culture layers (2K1) separated into two layers by $4 b$

b) Light greyish sandy layer with crushed shell, sterile $(2 \mathrm{~K} 2)$, above and below the lowest part of $4 \mathrm{a}$, disrupting $4 \mathrm{a}$ into two different layers

c) Dark brown culture layer (2K3) with charcoal, flagstones and small stones from a hearth, many bones and artefacts.

5. Light greyish layer with crushed shell and sand, sterile and wind deposited (layer 1A)

6. Dark thin stripe consisting of humus and peat, containing very few bones and artefacts (layer 1 and 1B)

7. Light greyish to yellow homogeneous gravel layer with a thin dark stripe of humus (layer 0 ). The gravel layer is sterile.

From this section there are no ${ }^{14} \mathrm{C}$ dates. However, a few meters to the southeast in the central part of the site, I5 samples were dated, of which nine were from the same $\mathrm{m}^{2}$ (Table 2). All nine are from caribou bones taken in stratigraphic order from II.6I to II.9I $\mathrm{m}$ a.s.l. The oldest layer $(2 \mathrm{~K})$ is dated to $1870-1760 \mathrm{BC}$ (cal). The sandy shell layer (2s) between the two culture layers is approximately the same age: I880-I790 BC (cal). The youngest layer (2) is more than $30 \mathrm{~cm}$ thick and six samples date this occupations phase (Table 2). The earliest date (AAR-4I58) is I3IO BC (I395I230+ Istdv. BC). The youngest (AAR-3574) at 520 BC falls at a point on the calibration curve marked by many "oscillations" causing a plateau from 7604IO+Istdv. BC. It is therefore not possible to date the 
Fig. 22. Profile section 5 (south north) seen from east and showing the stratigraphy in the central part of the settlement.

\section{Section 5}

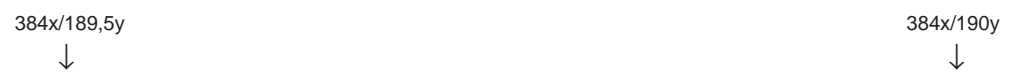

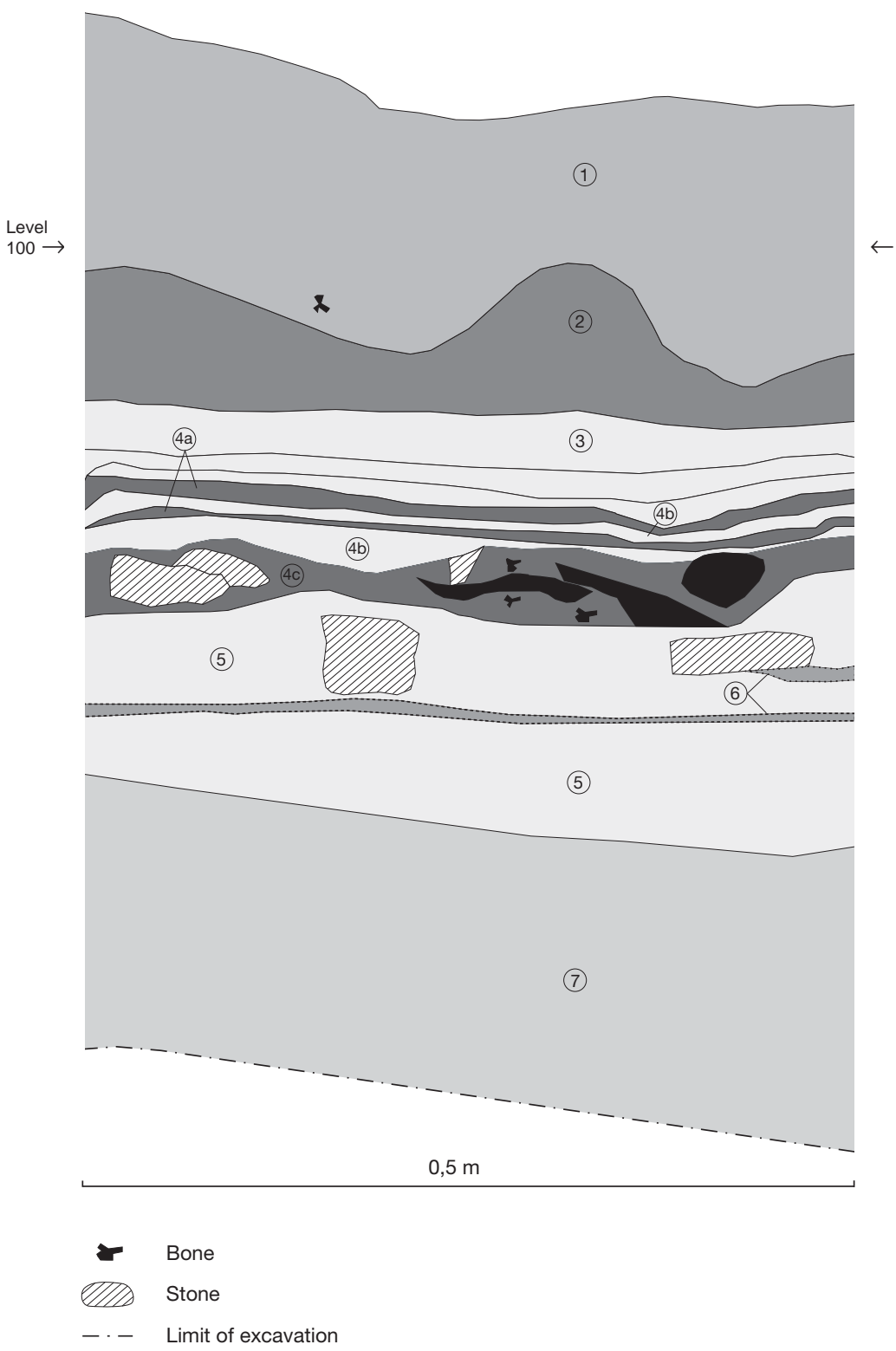

final phase of the Saqqaq Culture more precisely than to within this time period of c. 300 years (Table 3 ). Four shell samples support these dates and show that layer $\mathrm{I}, 2 \mathrm{~K}$ and $2 \mathrm{~s}$ are more or less contemporary, ranging from I89o to I740 BC (cal) (AAR-3576-3582).

Only one sample (K-6I92) falls outside the range expected for layer 2 and the caribou bone is interpreted as contamination from the oldest occupations phase as represented by AAR-3630 (Table I).

\section{Section 6}

The section stretches from $377 \mathrm{x} / \mathrm{I} 89,35 \mathrm{y}$ to $383 \mathrm{x} /$ I89,35y at level 80 equivalent to I2.I $\mathrm{m}$ above sea level (Fig. 23).

\section{Description:}

1. Recent turf with roots and very few artefacts (layer 6)

2. Brownish, fairly homogeneous and humic layer, with few artefacts and bones (poorly preserved) (culture layer 2). This layer is very thin and disappears towards the west. 
Table 2. ${ }^{14} \mathrm{C}$ datings taken in a stratigraphic context from $1 \mathrm{~m}^{2}(385 \mathrm{x} / 188 \mathrm{y})$.

\begin{tabular}{lccccccc}
\hline $\begin{array}{l}\text { Laboratory } \\
\text { no. }\end{array}$ & x-co-ordinate & $y$-co-ordinate & Layer & $\begin{array}{c}\text { Height above } \\
\text { sea level }(\mathrm{m})\end{array}$ & ${ }^{14}$ C age BP & Calibrated age BC & $\begin{array}{c}\text { Cal }+ \\
\text { stdv. BC }\end{array}$ \\
\hline AAR-3578 & 385,38 & 188,84 & $2 \mathrm{~K}$ & 11.61 & $3480 \pm 50$ & 1760 & $1880-1700$ \\
AAR-3577 & 385,30 & 188,99 & $2 \mathrm{~K}$ & 11.64 & $3515 \pm 65$ & $1870-1705$ & $1910-1740$ \\
AAR-3576 & 385,50 & 188,57 & $2 \mathrm{~s}$ & 11.66 & $3525 \pm 50$ & $1880-1790$ & $1910-1750$ \\
AAR-3573 & 385,08 & 188,16 & 2 & 11.70 & $2950 \pm 50$ & $1150-1130$ & $1260-1040$ \\
AAR-3575 & 385,60 & 188,79 & 2 & 11.73 & $2815 \pm 45$ & $970-930$ & $1005-905$ \\
K-6193 & 385,70 & 188,35 & 2 & 11.78 & $2920 \pm 85$ & 1120 & $1260-950$ \\
AAR-4159 & 385,59 & 188,42 & 2 & 11.88 & $2835 \pm 40$ & $990-950$ & $1015-920$ \\
AAR-4158 & 385,00 & 188,00 & 2 & 11.90 & $3060 \pm 45$ & 1310 & $1395-1230$ \\
AAR-3574 & 385,42 & 188,25 & 2 & 11.91 & $2455 \pm 50$ & 520 & $760-410$ \\
\hline
\end{tabular}

3. Light yellowish layer consisting of sand and crushed shells with a little humus and few bones and artefacts. In the eastern part of the section divided into three by a brown stripe in the middle (layer $2 \mathrm{~s}$ )

4. Culture layer $2 \mathrm{~K}$, in the eastern part of the section disturbed by cryoturbation. The layers are thin but can be separated into:

a) Dark brown culture layer (2K1)

b) Light greyish sandy layer with crushed shell, sterile $(2 \mathrm{~K} 2)$

c) Dark brown culture layer (2K3) only visible in the far eastern part of the section.

5. Light greyish layer with crushed shell and sand, sterile and wind deposited (layer 1A)

6. Dark thin stripe consisting of humus and peat (layer 1 and 1B)

7. Light greyish to yellow homogeneous gravel layer with a thin dark stripe of humus (layer 0 , in this part no culture remains). The gravel layer is sterile and lies directly on bedrock.

There are no ${ }^{14} \mathrm{C}$ dates from this section. Two caribou bone samples were collected less than one meter south of the section. AAR- 6699 is from layer $2 \mathrm{~K}$ and dated to I745 BC (cal). AAR-6698 is from layer 2 and dates to
I740-I695 BC (cal). However, it appears from the field notes that layer 2 and $2 \mathrm{k}$ were indistinguishable in this area, so both dates are interpreted as representing the oldest phase at the site. A little further south one more sample was collected from layer 2K (AAR-6986) dated to $1525 \mathrm{BC}(\mathrm{cal})$. In this $\mathrm{m}^{2}$ the presence of protruding bedrock can have caused contamination from a younger occupation phase. A caribou bone was collected one meter to the northwest in layer 2 (AAR6987) and dated to I255-II35 BC (cal). It is interpreted as representing the youngest occupation phase in the area (Table I and 4).

\section{Comments on the stratigraphy and dating}

Protruding bedrock disturbed the stratigraphy throughout the excavated area and with cryoturbation and several lenses of crushed shells interrupting the layers,

\section{Section 6}

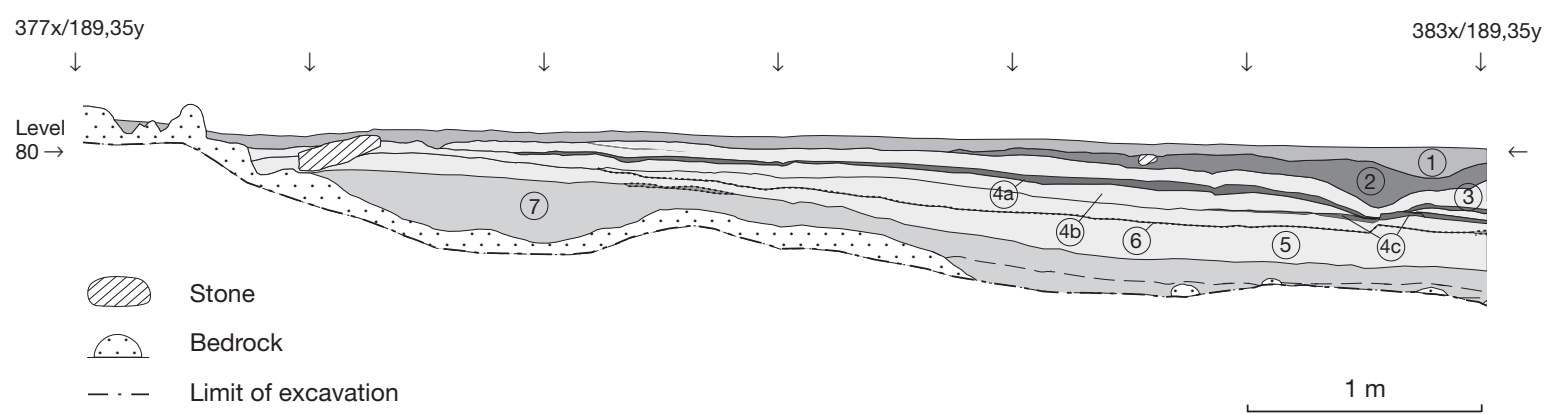

Fig. 23. Profile section 6 (west - east) seen from south and showing the stratigraphy in the western part of the settlement. 
Table 3. Calibration of the 29 datings from Nipisat. 13 of them are dating phase 1 and 2, 16 are dating phase 3 (see table 1 and 4). The datings are given after the laboratory number in conventional ${ }^{14} \mathrm{C}$ years $\mathrm{BP}$ (present $=$ 1950). To find the real age of the samples one has to convert (calibrate) the ${ }^{14} \mathrm{C}$ dates to calendar years using a calibration graph generated from ${ }^{14} \mathrm{C}$ datings of tree rings whose age is known from dendrochronology. For each sample, the figure illustrates the resultant probability distribution within the various time intervals on the year axis (Stuiver et al. 1998). Drawing by Martin Appelt.

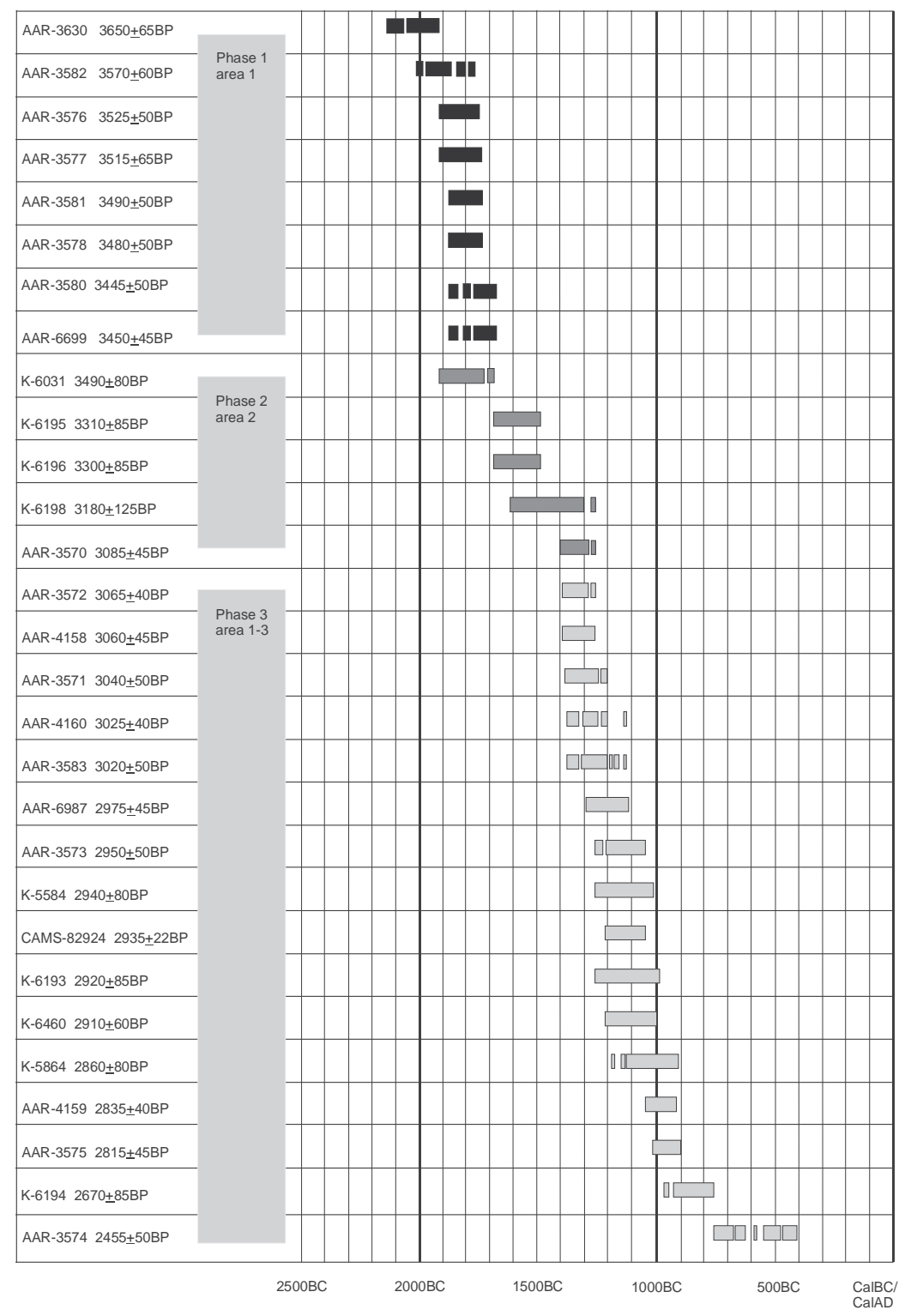

it has been difficult to correlate the oldest layer in the southern, central and northern parts of the site. Despite similarities in the appearance of the different layers in the profile sections, it is clear from the dates that there are great differences between $2 \mathrm{~K}$ in the northern and southern parts of the site. With 33 dates (Fig. 24), the site is one of the best dated in the Arctic and the dates show that Nipisat was occupied continuously for nearly I,500 years. Unfortunately, the youngest date from the site falls at the plateau on the calibration curve from 760 to 4 IO BC (Table 3 ). This means that it is not possible to ${ }^{\mathrm{I}} \mathrm{C}$ date the end of the Saqqaq Culture precisely.
The sample types mainly consisted of caribou bones with a very high collagen content (Fig. 25). In addition there was one sample of antler, four samples of shell and two of charcoal (locally grown species). There is great accordance between the dates obtained from these different sample types.

As shown in the previous description there were a few outliers in the series of ${ }^{\mathrm{I} 4} \mathrm{C}$ dates. In the interpretation of the different chronological phases, these outliers have been excluded. Although protruding bedrock disturbed the stratigraphy and several lenses of crushed shells interrupted the layers, three different chronological phases have been isolated (Table 4). The 


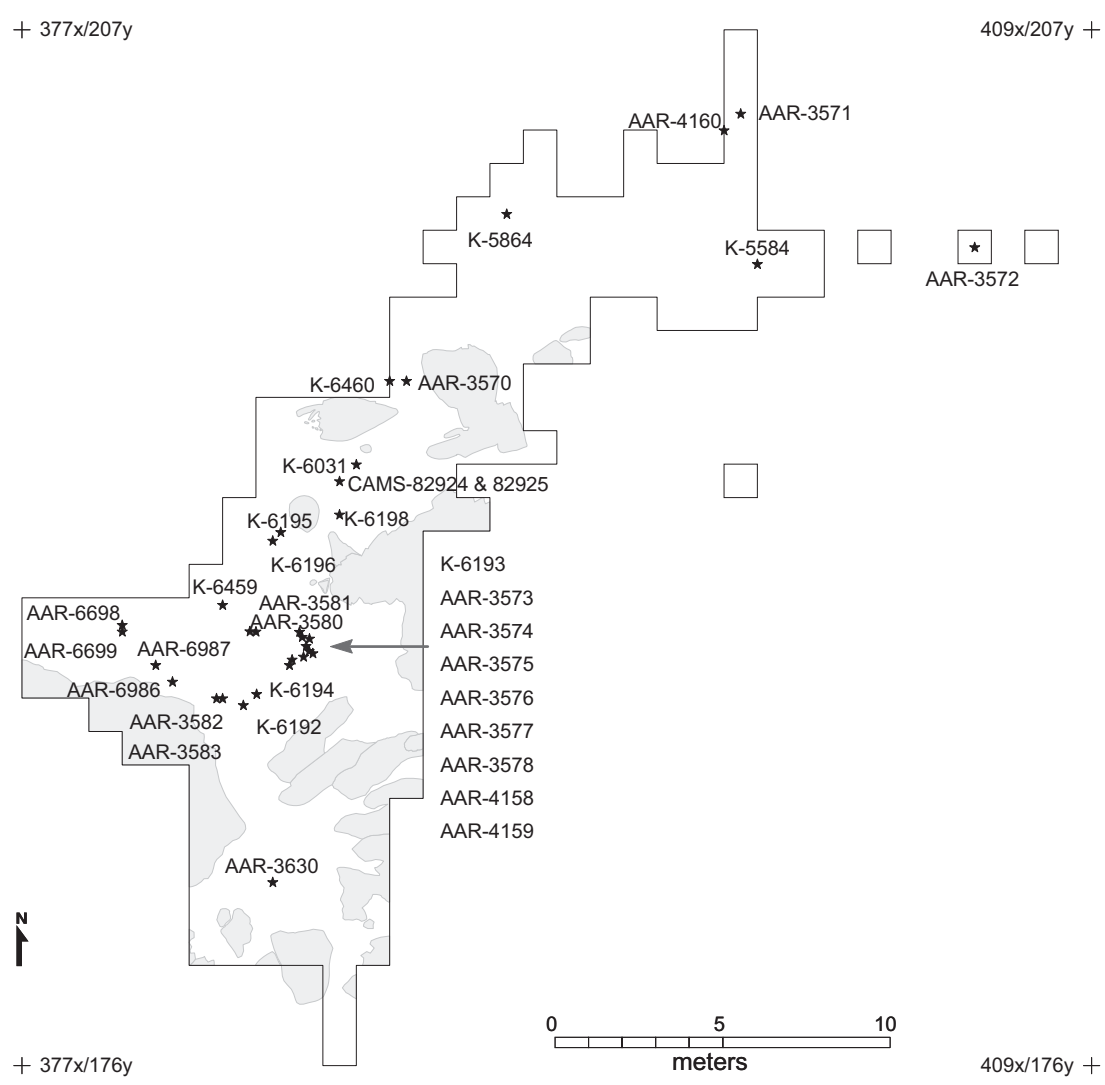

Fig. 24. Map of the excavated area at Nipisat with all the ${ }^{14} \mathrm{C}$ dates marked. The grey areas are protruding bedrock.

borders between the different phases (Fig. 26) were established in accordance with the stratigraphic interpretation and ${ }^{\mathrm{I}} \mathrm{C}$ dates, combined with the field notes concerning anomalies in the continuity of layer $2 \mathrm{~K}$.

Phase $\mathrm{I}$ is situated in the southern part of the site (area I). All artefacts and the faunal material from layers $o$, $\mathrm{I}, \mathrm{IB}, 2 \mathrm{~K}$ and $2 \mathrm{~S}$ are treated as one unit. Phase $\mathrm{I}$ has eight ${ }^{\mathrm{I} 4} \mathrm{C}$ dates ranging from 2020 to $\mathrm{I} 74 \mathrm{O} \mathrm{BC}$ (cal) (Fig. 26 and Table 4).

Phase 2 is situated in the central part of the site (area 2) and includes the layers $\mathrm{O}, \mathrm{I}, \mathrm{IB}, 2 \mathrm{~K}$ and $2 \mathrm{~s}$, the same

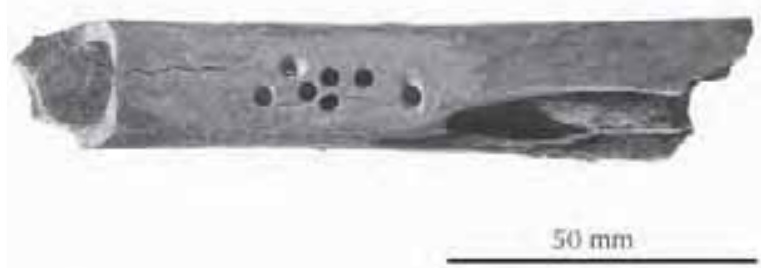

Fig. 25. Bone from caribou with high collagen content. The drilled holes are samples for AMS dates. Photo: Geert Brovad. as phase I. Phase 2 partly overlaps with, but is mainly younger than, phase I and has five ${ }^{\mathrm{I}} \mathrm{C}$ dates ranging between I860-1325 BC (cal) (Fig. 26 and Table 4).

Phase 3 is recorded in all excavated squares. In area I, phase 3 includes all artefacts and faunal material from layers 2 and 6. The phase 3 deposits are thickest and contain most finds here in area I. Nine ${ }^{\mathrm{I}} \mathrm{C}$ samples date phase 3 to I3Iо-8Iо BC (cal). The youngest date (520 BC (cal)) is problematic as mentioned above (Table 4). From area 2 the same layers are included in phase 3 as for area I, but here there are only two dates of II24 and Io6o BC (cal) (Table 4). In area 3, all layers fall within phase 3 because no chronological differences can be established between layers 2 and $2 \mathrm{~K}$. Phase 3 is here dated by five ${ }^{\mathrm{I}}{ }^{\mathrm{C}} \mathrm{C}$ samples ranging from I370 and Iooo BC (cal) (Fig. 26 and Table 4).

As can be seen from Table 3, there is no gap in occupation at Nipisat and the dates indicate a continuous use of the site from the oldest to the youngest phase, with transition from one phase to the next. It is remarkable that, even in phase 3 with its very young ${ }^{\mathrm{I}} \mathrm{C}$ date, there is continuity between the oldest and the 


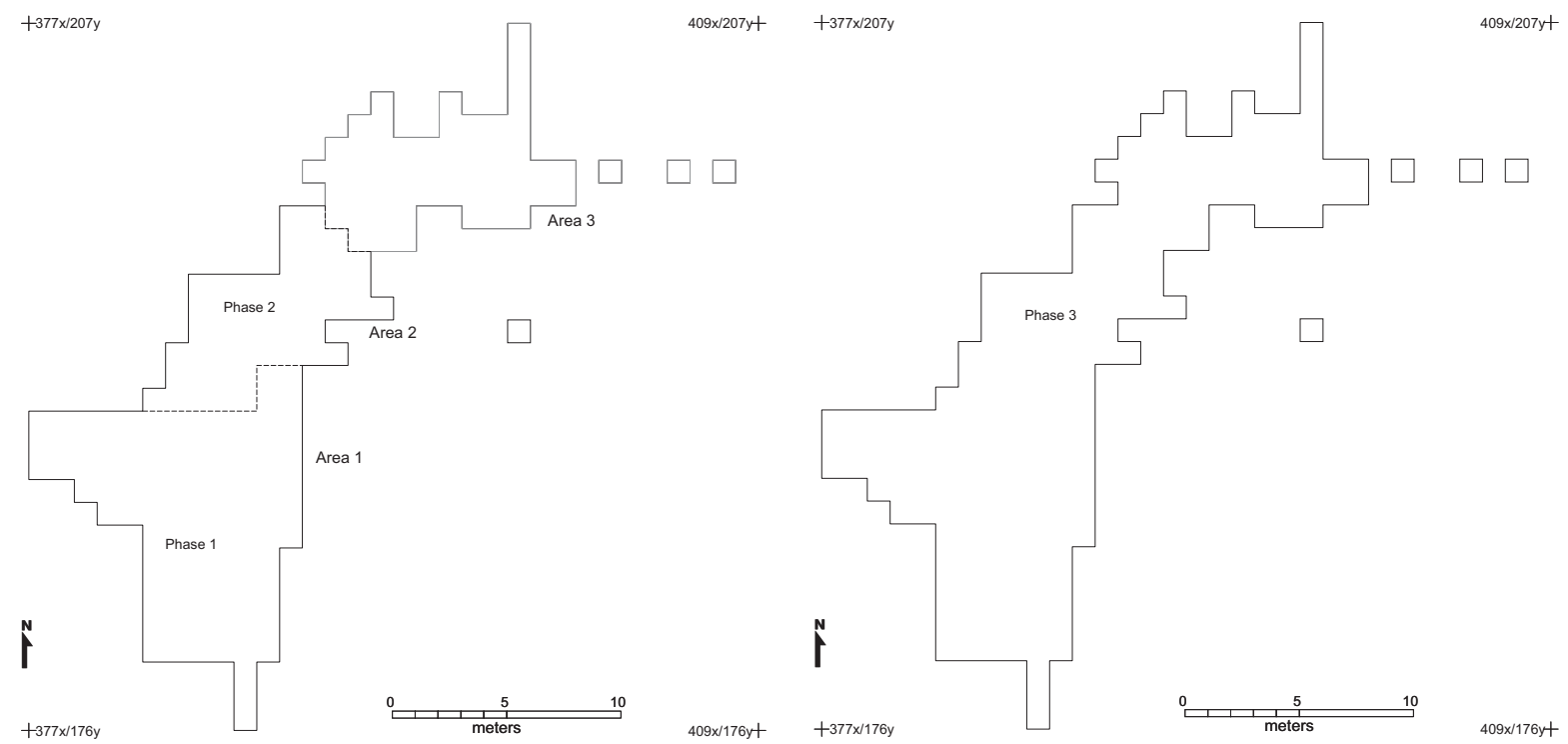

Fig. 26. Map showing the excavated area with phases 1 and 2 to the left and phase 3 to the right. In addition area 1-3 are indicated.

youngest dates. This does not mean that the site was used every year for nearly I,50o years, but indicates continuity in the use of the site. This aspect will be discussed later.

\section{Dwelling features}

Various features were recovered during the excavation, the majority belonging to phases I or 2 (Fig. 27). Only in the most northern part (area 3) are there some stone structures related to phase 3 (Fig. 28). The stones are scattered without any clearly recognisable pattern. Probably some of the stones derived from the cobble beach situated just beneath the culture layer. Traces of the culture layer were, however, found below all the stones depicted in Fig. 28. It is not possible to interpret the stones as part of dwelling structures, but the features might be part of a midden.

From phase 2 there is a well-defined box-hearth measuring $75 \mathrm{~cm}$ north-south and $60 \mathrm{~cm}$ west-east, and situated Ir.6o metres above sea level (Fig. 29) (Kramer 1996b:74-75). The hearth was not dug into the occupation surface, but was situated on top of a flat outcrop of bedrock covered by a 2-3 $\mathrm{cm}$ thick layer of crushed shells. The hearth was bounded by upright stones on three sides. On the fourth side the stones were missing. Perhaps the two stones just south and west of the hearth were moved by new settlers in phase 3. However, the large bedrock outcrop west of the hearth might also have been used in the construction. The hearth is filled with 40-45 small round stones (5-10 cm in diameter) (Fig. 30) mixed with bones and a small amount of charcoal. The lower layer of cookingstones is more fire-cracked than the top layer. The area around the hearth is enclosed on all sides by outcrops of bedrock, leaving relatively limited space for habitation, but east and northeast of the hearth, several flagstones were recorded and are interpreted as part of a platform. Even though some outline of a dwelling can be seen, this is definitely not a midpassage structure.

From phase I, two areas with features were recorded. Between 384x/186y, 384x/190y, 389x/190y and 389x/r86y (Fig. 27) a large number of fire-cracked rocks and several flagstones were seen, but without any recognisable pattern. Large quantities of charcoal, bones and artefacts were found in connection with the features. The stones probably represent more than one occupation episode and were reused several times (Fig. 3I). The distribution of stones and artefacts indicates a form of dwelling structure ( $4 \times 4 \mathrm{~m}$ ) situated in the central and eastern part of the before mentioned area. To the northwest, bordering area 2, a special activity area is located. The structure consists of at 
Table 4. ${ }^{14} \mathrm{C}$ datings from Nipisat distributed on phase 1-3. Outliers are excluded and the dates from phase 3 are separated into area 1, 2 and 3 (see Fig. 26 and Table 1).

\begin{tabular}{|c|c|c|c|c|c|c|c|}
\hline $\begin{array}{l}\text { Laboratory } \\
\text { no. }\end{array}$ & $\begin{array}{l}\text { x-co-or- } \\
\text { dinate }\end{array}$ & $\begin{array}{l}\text { y-co-or- Layer } \\
\text { dinate }\end{array}$ & $\begin{array}{l}\text { Height } \\
\text { above } \\
\text { sea level } \\
\quad(\mathrm{m})\end{array}$ & $\begin{array}{c}{ }^{14} \mathrm{C} \\
\text { age BP }\end{array}$ & $\begin{array}{l}\text { Calibrated } \\
\text { age BC }\end{array}$ & $\begin{array}{c}\text { Cal + } \\
1 \text { stdv. BC }\end{array}$ & Sample type \\
\hline
\end{tabular}

Phase 1 area 1

K-6192

AAR-3630

AAR-3582

AAR-3576

AAR-3577

AAR-3581

AAR-3578

AAR-3580

AAR-6699

AAR-6698

AAR-6986

Phase 2 area 2

K-6031

K-6195

K-6196

K-6198

AAR-3570

Phase 3 area 1

AAR-3583

K-6459

AAR-6987

AAR-3573

K-6193

AAR-4159

AAR-3575

K-6194

AAR-3574

Phase 3 area 2

CAMS-82924 \&25

K-6460

$383,62 \quad 186,80 \quad 2 \quad 11.96$

$384,50 \quad 181,50 \quad 2 \mathrm{~K} \quad 12.60$

$\begin{array}{llll}383,00 & 187,00 & 1 & 11.66\end{array}$

$385,50 \quad 188,57 \quad 2 s \quad 11.66$

$385,30 \quad 188,99 \quad 2 \mathrm{~K} \quad 11.64$

$384,00 \quad 189,00 \quad 2 K \quad 11.66$

$385,38 \quad 188,84 \quad 2 \mathrm{~K} \quad 11.61$

$384,00 \quad 189,00 \quad 2 \mathrm{~K} \quad 11.64$

$380,00 \quad 189,20 \quad 2 K \quad 12.05$

$\begin{array}{llll}380,00 & 189,00 & 2 & 12.10\end{array}$

381,50

$187,50 \quad 2 \mathrm{~K}$

387,00

384,74

$194,00 \quad 2 \mathrm{~K}$

$191,98 \quad 2 \mathrm{~K}$

11.63

384,50

191,72 1B

386,50

$192,50 \quad 2 \mathrm{~K}$

11.67

11.61

388,00

$196,00 \quad 2 \mathrm{~K}$

11.60

11.30

$3670 \pm 90$

2030-1990

$3650 \pm 65$

2020-1980

2180-1910 bone (Rangifer tarandus)

$3570 \pm 60 \quad 1890$

2130-1920

charcoal (Salix sp.)

$3525 \pm 50$

$3515 \pm 65$

1880-1790

1970-1780

shell (Mytilus edulis)

1870-1705

1910-1750 bone (Rangifer tarandus)

$3490 \pm 50$

1860-1770

1910-1740 bone (Rangifer tarandus)

$3480 \pm 50$

1760

$3445 \pm 50$

1740

$3450 \pm 45$

$3425 \pm 50$

1745

1740-1695

1880-1740 shell (Hiatella arctica)

1880-1700 bone (Rangifer tarandus)

1870-1680 shell (Littorina saxatilis)

1875-1690 bone (Rangifer tarandus)

1525

1855-1645

bone (Rangifer tarandus)

$3280 \pm 45$

1525

1620-1515 bone (Rangifer tarandus)

$3490 \pm 80$

$3310 \pm 85$

$3300 \pm 85$

1860-1790

1890-1690 bone (Rangifer tarandus)

1600-1530

1680-1470

bone (Rangifer tarandus)

1530

1680-1460 bone (Rangifer tarandus)

$3180 \pm 125 \quad 1430$

1590-1310

charcoal (Salix sp. \& Betula nana)

1385-1325

1405-1265 bone (Rangifer tarandus)

Phase 3 area 3

AAR-3572

AAR-3571

385,00

188,00

11.90

383,00

383,00

187,00

381,00

$189,80 \quad 2 \mathrm{~K}$

385,08

$188,00 \quad 2$

385,70

188,16

385,59

188,35

385,60

188,42

384,02

188,79

385,42

$187,13 \quad 2$

188,25

11.78

$3060 \pm 45$

1310

1395-1230 bone (Rangifer tarandus)

1260

1380-1140 shell (Mytilus edulis)

$11.663010 \pm 95$

1260-1230

1390-1080 bone (Rangifer tarandus)

12.05

11.70

$2975 \pm 45$

1255-1135

1290-1125 bone (Rangifer tarandus)

11.78

$2950 \pm 50$

1150-1130

1260-1040

bone (Rangifer tarandus)

1120

$1260-950$

bone (Rangifer tarandus)

$11.88 \quad 2835 \pm 40$

990-950

970-930

1015-920

bone (Rangifer tarandus)

$11.732815 \pm 45$

$11.82 \quad 2670 \pm 85$

810

1005-905

bone (Rangifer tarandus)

$900-790$

bone (Rangifer tarandus)

520

$760-410$

bone (Rangifer tarandus)

AAR-4160

K-5584

K-5864

$405,00 \quad 200,00 \quad 2 K$

$398,00 \quad 204,00 \quad 2$

$398,00 \quad 204,00 \quad 2 \mathrm{~K}$

$399,00 \quad 200,00 \quad 2$

$391,00 \quad 201,00 \quad 2$
$11.762935 \pm 22$

$11.452910 \pm 60$

1142

1207-1092 antler, bone (Rangifer tarandus)

$1110-1060$

1200-1000 bone (Rangifer tarandus)

395-1265 bone (Rangifer tarandus)

1390-1210 bone (Rangifer tarandus)

1375-1210 bone (Rangifer tarandus)

1260-1000 bone (Rangifer tarandus)

1130-910 bone (Rangifer tarandus) 


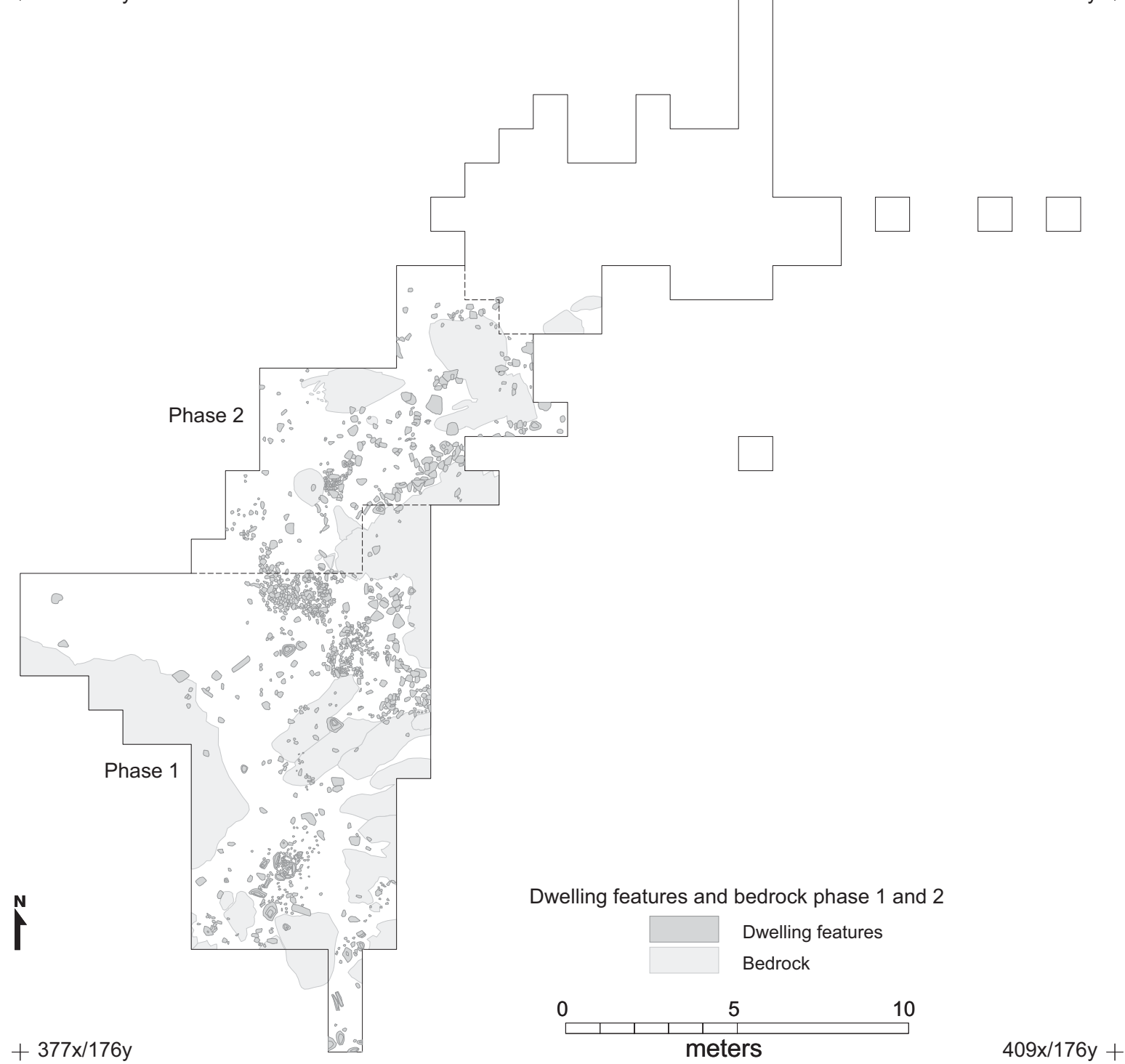

Fig. 27. Map with dwelling features from phase 1 and phase 2. Stone from dwelling structures is dark grey and protruding bedrock is marked in light grey.

least two features or hearths, the youngest has been dug into the occupation surface of the oldest, as mentioned in the field notes from square 384/189 (Kramer 1993). Some of the fire-cracked rocks were part of this hearth, while others might be part of a midden. However, these different features were only in use for a time period of less than 200 years, between I880-I740 BC (cal) (Table 4).

At the transition between phases I and 2, there were some difficulties in distinguishing the two phases from each other. The problem is that the squares on either side of this border were excavated through three different field seasons from 1992 to 1994 (Fig. I2), so the layers have been exposed to erosion and different excavation methods. The border between phase I (area I) and 2 (area 2) could therefore be more diffuse and not follow the excavation grid as shown on the map (Figs 26 and 27).

In the southernmost part of the excavation, a welldefined feature was recovered in 1994 at $12.50 \mathrm{~m}$ above sea level (Fig. 32). It consisted of a box-hearth measuring Ioo $\mathrm{cm}$ north - south (Fig. I9) and $75 \mathrm{~cm}$ east -west 

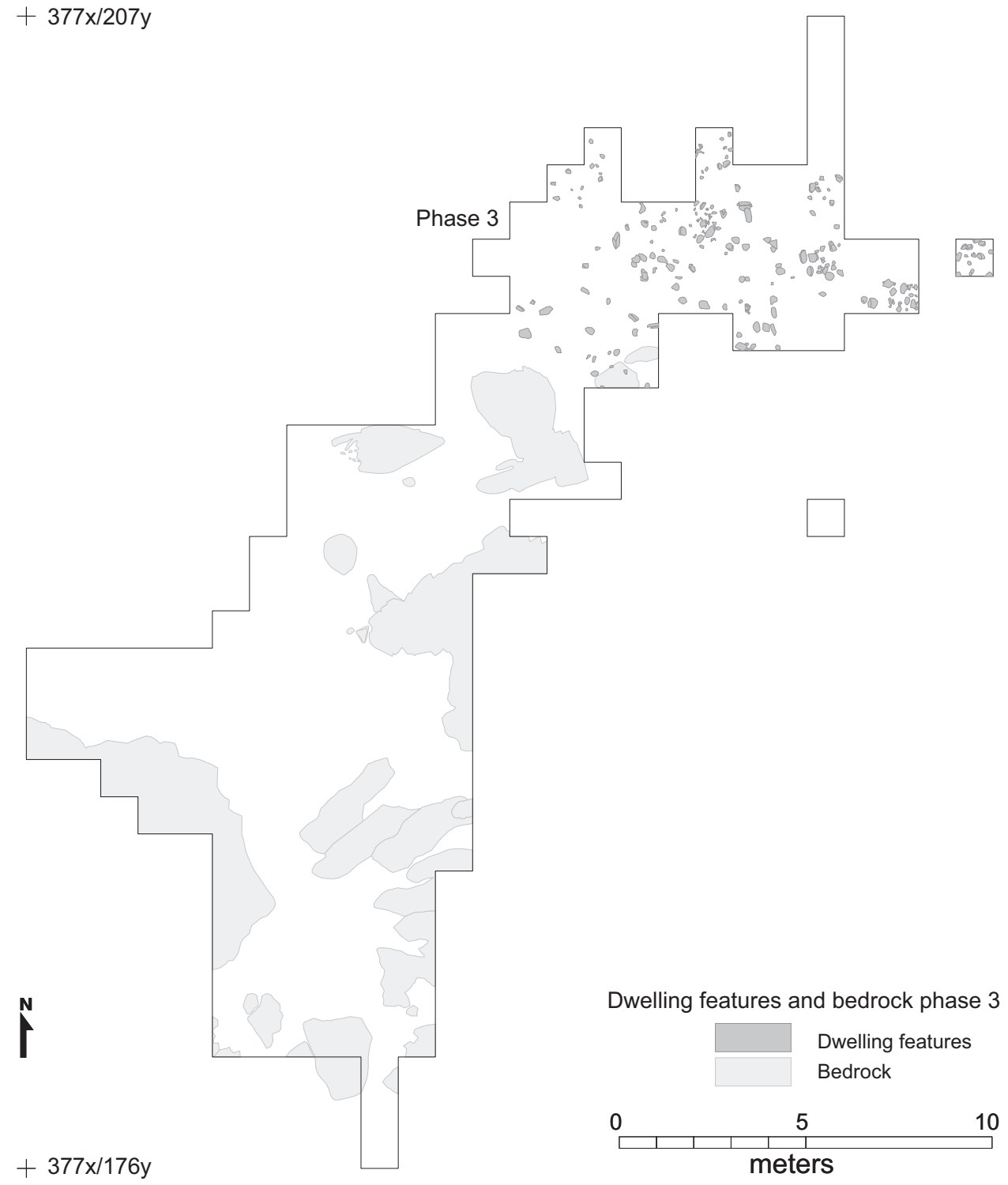

Fig. 28. Map with dwelling features from phase 3. Stone from dwelling features or midden is dark grey and protruding bedrock is marked in light grey.

(Fig. 33). On three sides the hearth was bounded by upright stones. On the fourth side the stones were missing due to later disturbances. The hearth was filled with 40-50 small stones (5-10 $\mathrm{cm}$ in diameter). Some of them were fire-cracked, but not to a high degree, and only small quantities of charcoal were present (Fig. 34). The small fire-cracked stones continued outside the hearth and, together with the upright stones, make up a kind of midpassage ending in two "wings". The hearth was not dug into the surface of the occupation layer (Fig. 35). This midpassage structure was surrounded by a ring (3-4 m) of flagstones (Fig. 27). Some of the flatter bedrock outcrops also appeared to have been incorporated in the construction. Although it was possible to collect a sample of charcoal from locally grown species for a ${ }^{\mathrm{I} 4} \mathrm{C}$ date, very little charcoal was found within the dwelling structure. The age of the structure is 2020-1980 BC (cal), which means that the oldest occupation at Nipisat is situated at the highest level above sea level (Table 4). 


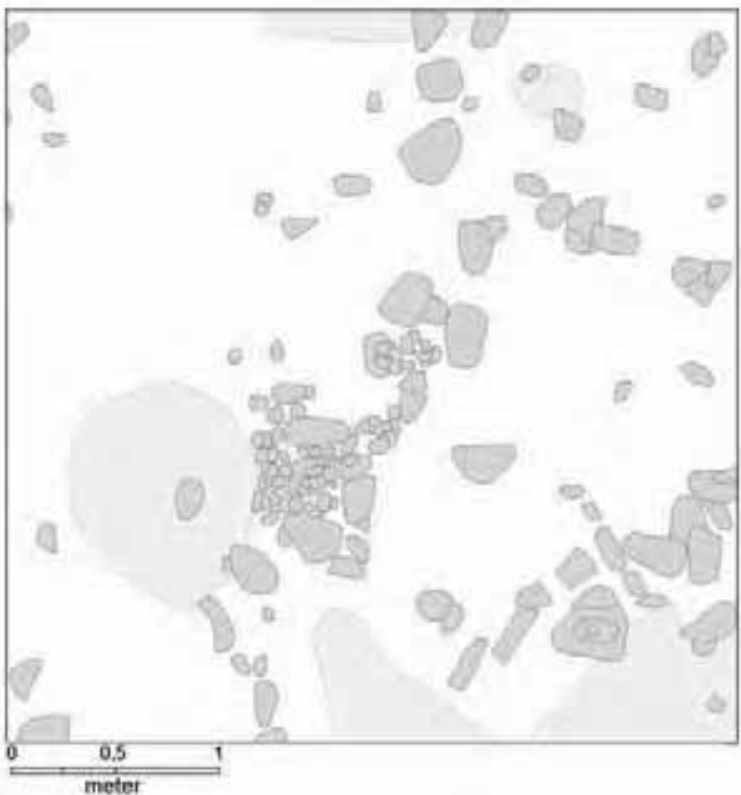

Fig. 29. Detailed map showing the box-hearth from phase 2 excavated in 1992.

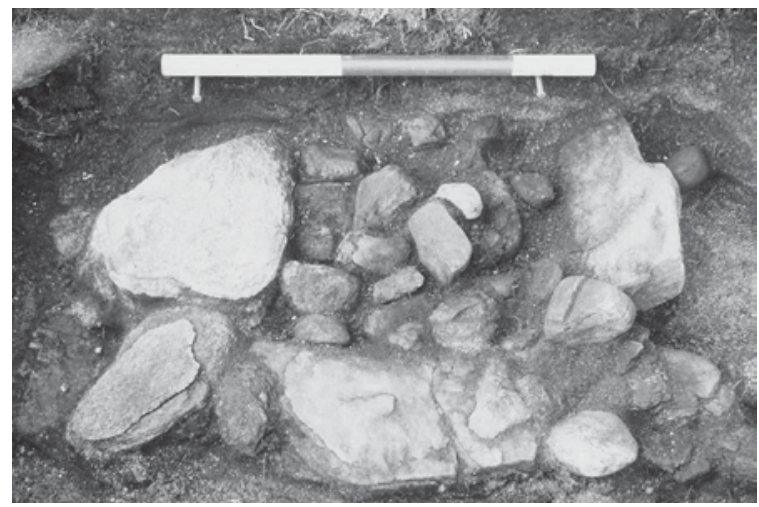

Fig. 30. The box-hearth from phase 2 after excavation. Photo: Sönke Hartz.

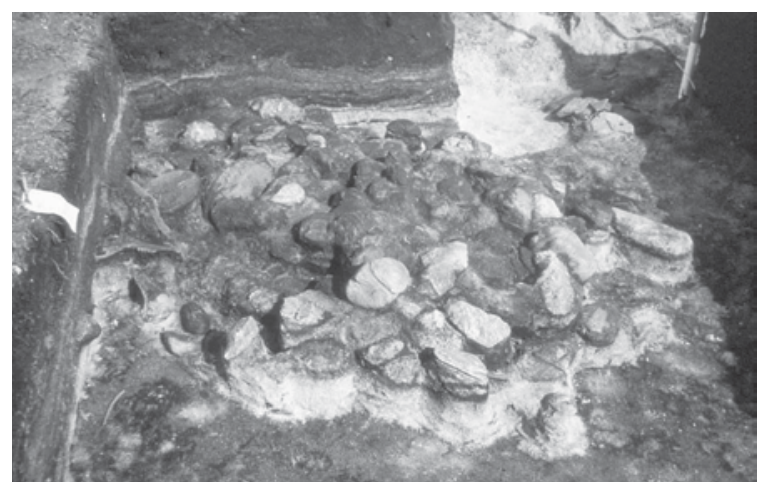

Fig. 31. Large quantities of fire-cracked rock were recovered in the northern part of area 1 (see Fig. 27) during the 1993 excavation. Photo: John Pind.
Fig. 32. The mid-passage dwelling structure seen from the south. Photo: Stig Grummesgaard-Nielsen.

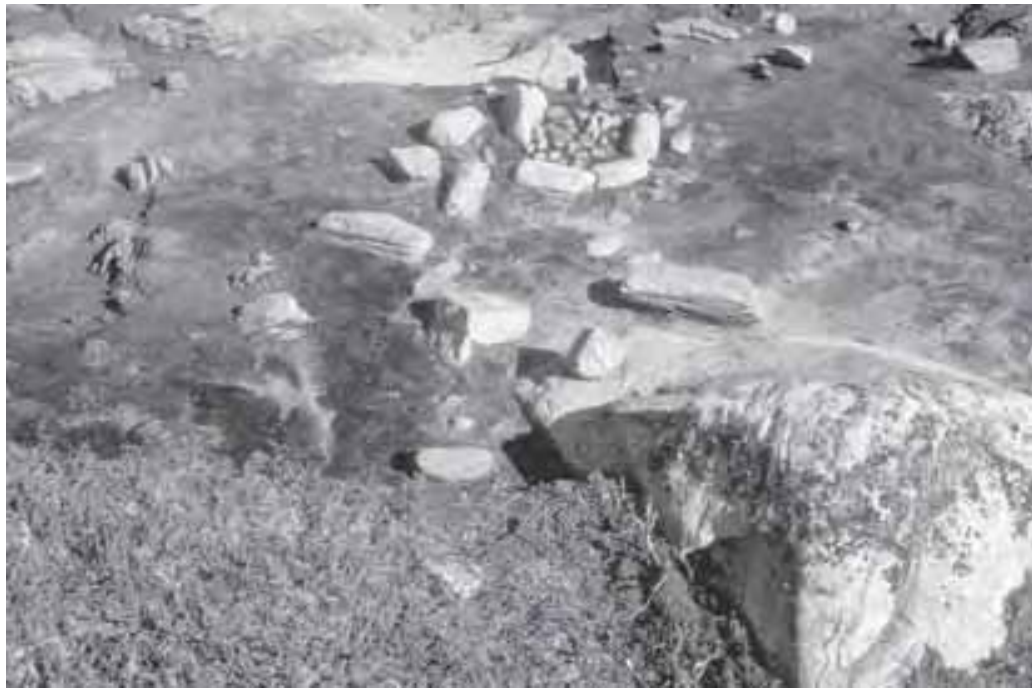



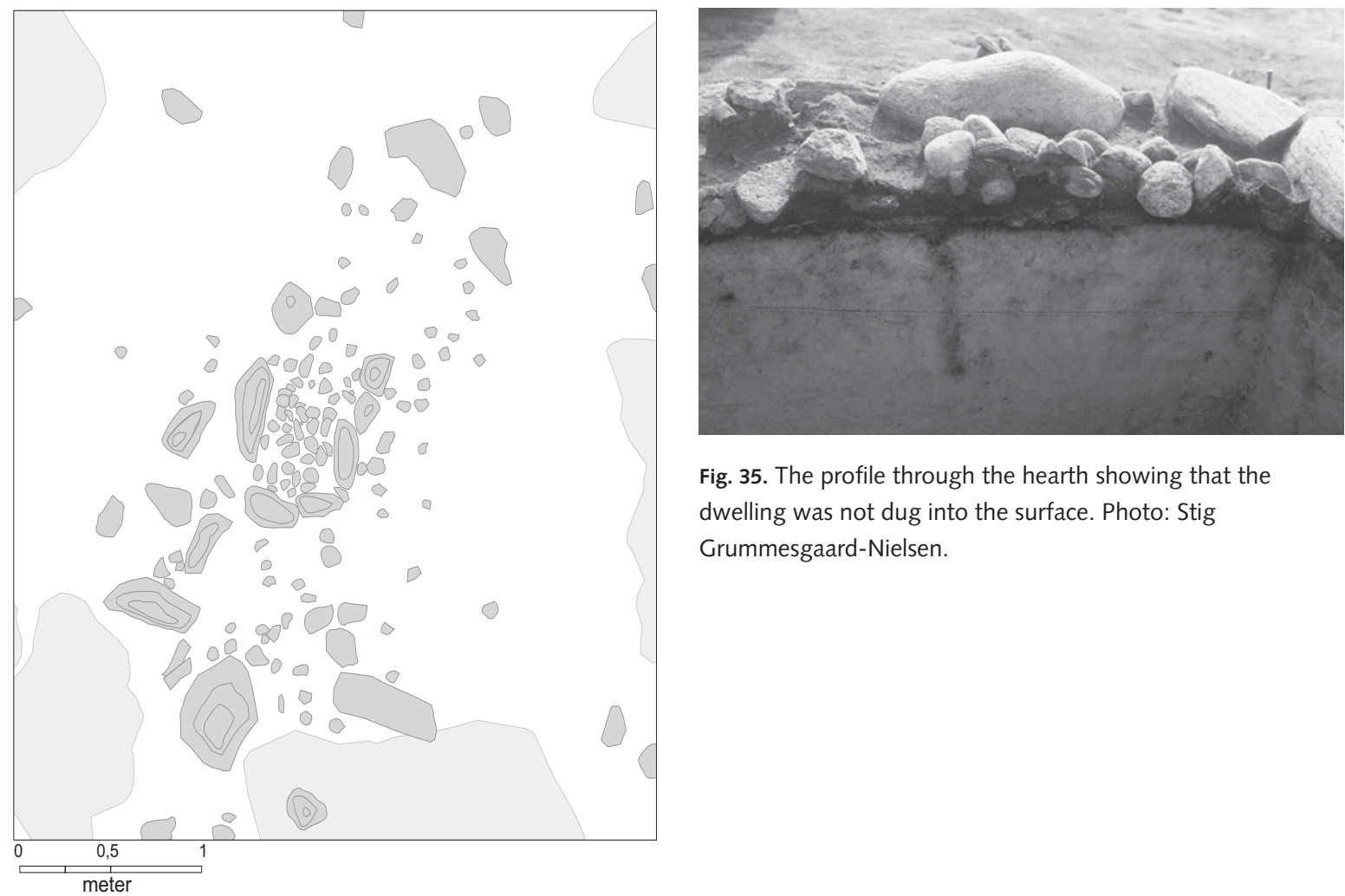

Fig. 35. The profile through the hearth showing that the dwelling was not dug into the surface. Photo: Stig Grummesgaard-Nielsen.

Fig. 33. Detailed map showing the mid-passage structures with a box-hearth excavated in 1994.

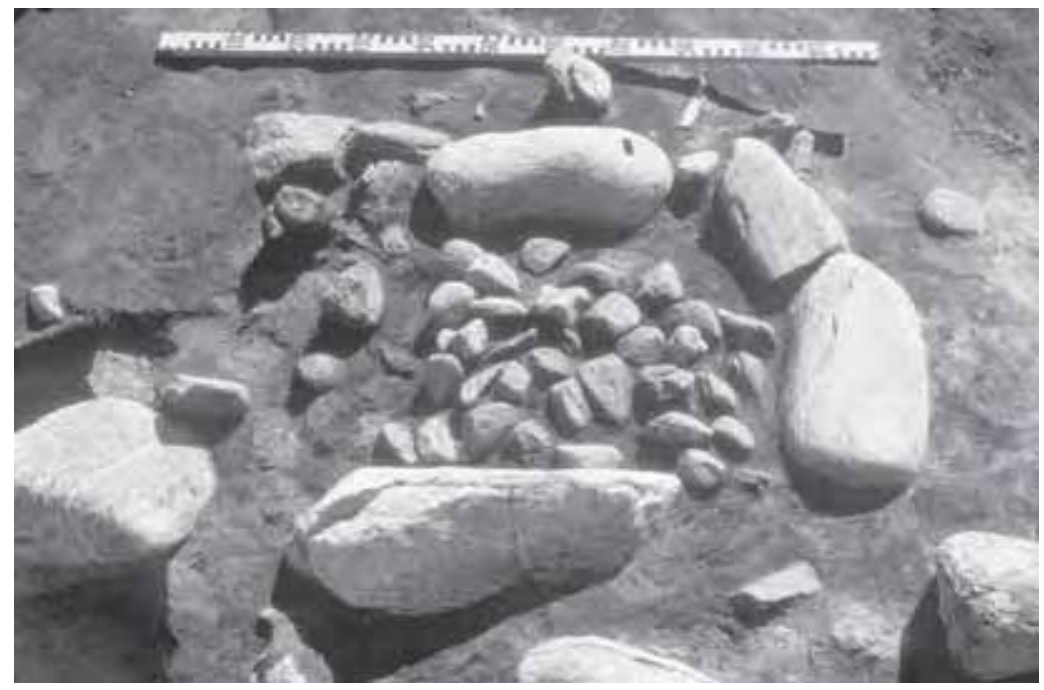

Anne Birgitte Gotfredsen \& Tinna Møbjerg:

$42 \mu$

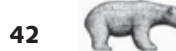

Nipisat - a Saqqaq culture site in Sisimiut, central West Greenland, 2004

eISBN 978-87-635-2626-5, Monographs on Greenland | Meddelelser om Grønland, vol. 331 (ISSN 0025-6676)

Man and Society, vol. 31 (ISSN 0106-1062), http://www.mtp.hum.ku.dk/details.asp?eln=201396 


\section{Chapter 4}

\section{Description of the tool inventory}

The Nipisat excavations resulted in the recovery of 3I4 tools (59 are unclassifiable fragments) and 37I waste products of bone, ivory or antler. In addition 7I7 tools made of flaked stone, pumice or soapstone were recovered together with 23,282 flakes (Table 5). All artefacts are identified by number: SIK 534XI, x2 etc. The three first letters indicate Sisimiut Museum and the next figures are the site number in the museum archives. The x-numbers relate to individual finds. All data were recorded in the database program Access with link to the GIS program MapInfo in such a way that it has been possible to make spreadsheets for the different tool types according to dwelling features and stratigraphy. There has been an ongoing discussion about whether to classify the bone material as artefacts or not. There are naturally no problems with tools, preforms and tool fragments. The problems arise when dealing with waste material. It was decided that objects which have burin grooves, adze marks or other working traces connected with tool produc- tion (and associated waste products) would be treated as artefacts. Objects with cut marks from skinning or butchering, marrow fractured bones and objects with other traces of consumption are described in the section concerning game animals. All organic specimens were, however, included in the faunal lists (Table I4, I7 and 35)

All artefacts are listed in Tables 5, 6 and 7. As can be seen, the numbers of artefacts from the three phases differ considerably. Phase 2 is very weakly represented compared to phase I (I:5) and phase 3 (I:Io). This pattern recurs when looking at the numbers of artefacts per excavated $\mathrm{m}^{2}$ (Fig. 36). Phase $\mathrm{I}$ has the highest proportion with 8I artefacts per $\mathrm{m}^{2}$, phase 2 only $3 \mathrm{I}$ and phase 3 has 74 artefacts per $\mathrm{m}^{2}$.

No attempt has been made to classify the artefacts into a formal typology. Instead, a more functional approach has been chosen. The combination of a functional and morphological classification has become a standard in description of Arctic Small Tool Tradition

Table 5. Frequency distribution of organic and lithic artefacts in phase 1-3. The distribution is shown for waste and tools of antler, bone and ivory together with flakes and tools of killiaq (silicified slate), agate, rock crystal and quartzite, soapstone, pumice etc.

\begin{tabular}{|c|c|c|c|c|c|c|c|}
\hline \multirow[b]{2}{*}{ Organic } & \multicolumn{2}{|c|}{ Phase 1} & \multicolumn{2}{|c|}{ Phase 2} & \multicolumn{2}{|c|}{ Phase 3} & \multirow[t]{2}{*}{ All phases } \\
\hline & waste & tools & waste & tools & waste & tools & \\
\hline Antler & 29 & 40 & 25 & 9 & 133 & 78 & 314 \\
\hline Bone & 9 & 62 & 2 & 11 & 23 & 90 & 197 \\
\hline Ivory & 3 & 4 & 5 & 3 & 142 & 17 & 174 \\
\hline Total & 41 & 106 & 32 & 23 & 298 & 185 & 685 \\
\hline Lithic & flakes & tools & flakes & tools & flakes & tools & \\
\hline Killiaq & 6811 & 111 & 1416 & 14 & 9845 & 382 & 18579 \\
\hline Agate & 699 & 13 & 2 & 4 & 720 & 36 & 1474 \\
\hline Quartz crystal & 24 & 8 & 9 & 2 & 102 & 21 & 166 \\
\hline Quartzite & 136 & 7 & 26 & 3 & 3492 & 29 & 3693 \\
\hline Soapstone & & 2 & & & & 26 & 28 \\
\hline Sandstone & & 9 & & & & 19 & 28 \\
\hline Pumice & & 7 & & & & 21 & 28 \\
\hline Other raw materials & & 1 & & & & 2 & 3 \\
\hline Total & 7670 & 158 & 1453 & 23 & 14159 & 536 & 23999 \\
\hline Total: organic+lithic & & & & & & & 24684 \\
\hline
\end{tabular}


Table 6. Frequency distribution of organic artefact types from Nipisat in phase 1, 2 and 3.

Phase 1 Phase 2 Phase 3 All phases

\section{Unclassifiable tools}

Waste products of antler,

$\begin{array}{lrrrr}\text { bone or ivory } & 41 & 32 & 298 & 371 \\ \text { Preforms } & 4 & 2 & 21 & 27 \\ \text { Fragments } & 10 & 2 & 20 & 32 \\ \text { Total } & 55 & 36 & 339 & 430\end{array}$

\section{Hand tools}

\begin{tabular}{lrrrr} 
Awls & 7 & 1 & 12 & 20 \\
Needles & 39 & 9 & 66 & 114 \\
Cutting boards & 1 & & & 1 \\
Engraving tools & 1 & & & 1 \\
Creasers & 1 & & & 1 \\
Scrapers & 1 & & & 1 \\
Unspecified handles & 8 & 1 & 3 & 12 \\
Handles for endblades & & & 2 & 2 \\
Handles with an eye & & & 2 & 2 \\
Shaft straighteners & 1 & & & 1 \\
Pressure flakers & 6 & 3 & 10 & 19 \\
Clubs & 1 & & & 1 \\
Wedges & 4 & 1 & 13 & 18 \\
Total & 70 & 15 & 108 & 193 \\
\hline
\end{tabular}

\section{Hunting and fishing}

Toggle harpoon heads

(female)
Tanged harpoon heads
(male)

Large tanged harpoon

or lance heads (male)

Foreshafts

Throwing boards

Barbed spears or leisters

Barbed spears with

slot for an endblade

Bows

Heads for arrow or

bird dart

Side prongs

Skinning knives

Dragging equipment, toggle

Fishhooks

Needles for making nets

Lures for fishing

Total

22

Household utensils

Art

1

1

Total number of

organic artefacts

147

55

483

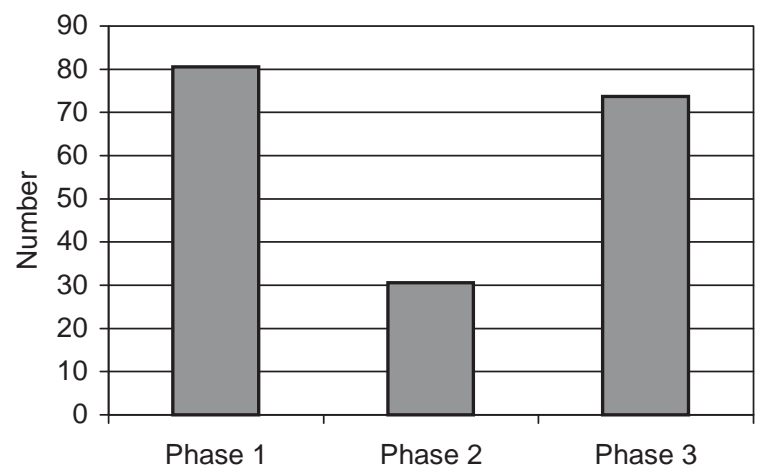

Fig. 36. The distribution of artefacts per square meter in phase 1-3.

artefacts (Grønnow I994:205; Kramer I996b:76; McGhee 1979:38). The identification of the tools of organic material has been very complicated, because several tool types had not been recognized in a Saqqaq context before. Many of the tools are very light and there is no obvious resemblance to the heavier tool inventory from historic Inuit times in Greenland (Grønnow I994:2I0). The closest parallel is seen in the material culture of the historic Inuit around Bering Strait (Nelson I899). This ethnographic material has been a basis for interpretation for several tools, but the material culture from the Northwest Coast Indians (Stewart 1977, 1996) has also been a great inspiration, especially concerning tools for fishing and net making.

In addition, several colleagues have seen the artefact material and contributed to the interpretation.

For the analysis, four main groups, each subdivided into organic or lithic materials, have been chosen: I. Unclassifiable tools. 2. Hand tools. 3. Tools for hunting and fishing. 4. Household utensils.

\section{Unclassifiable tools}

$\operatorname{Organic}(\mathrm{N}=430)$

Several pieces of worked bone, antler and ivory were recovered $(\mathrm{N}=37 \mathrm{I})$. Their distribution in terms of phase and type of raw material is seen in Tables 5 and 8. The waste products include nearly intact antlers with burin grooves such as xi2Io8 (Fig. 37) but antler tines with axe marks and burin grooves as shown on Fig. 38 were also found. Antler was the preferred raw material judging by the amount of waste products, especially in the two oldest phases. Several species are 
represented in the worked bone material, for example caribou, arctic fox, whale and different kind of birds (Table 8). Ivory was rare in the waste material from phase I (7.3\%) but becomes more important through phase 2 (I5.6\%) to phase 3 (47.7\%) (Fig. 39 and Figs I56-I57).

In addition to the waste material, there were several tool fragments and preforms $(\mathrm{N}=59)$ of unknown function (Fig. 67C).

\section{Lithic $(N=23,411)$}

A total of 23,282 flakes were recovered together with various preforms, fragments and retouched flakes $(\mathrm{N}=\mathrm{I} 29)$. The distribution through the different phases is shown in Table 7. In this presentation the raw material has been divided into four different categories: killiaq (Greenlandic word for silicified slate), agate (all kinds of flint-like material), quartz crystal (transparent) and quartzite (translucent). Soapstone, pumice and others are excluded. The distribution of different kinds of raw material per phase is seen in Table 5 and, for flakes, in Fig. 40 (number) and in Fig. 4I (percentage). As seen earlier in terms of the organic material, phase 2 is again underrepresented. Nevertheless, differences between the three phases can be seen. The use of killiaq dominates throughout all phases but the use of quartzite increases from $\mathrm{I} .8 \%$ in phase I to $24.7 \%$ in phase 3 . Agate and quartz crystal are less important although differences do exist. The use of agate decreases through time from 9.I\% in phase I to $5.8 \%$ in phase 3 .

Looking at the weight instead of numbers the picture is a bit different (Figs 42-43). The weight of agate flakes is more or less constant from phase I to 3 from 3.2 to $3.8 \%$, which means that a greater number of small flakes were used in phase I compared to phase 3. The weight of killiaq flakes decreases from 94.2 to $73.3 \%$ and quartzite increases from 2.I to $22.4 \%$. The differences between number and weight of the flakes are caused by the size of the individual flakes and the degree to which curation has taken place (se discussion below).

The spatial distribution of the flakes is not homogenous throughout the excavated area.

In phase $I$ there is a concentration in the southern and north eastern parts for all kinds of raw materials. As seen from Figs 44-5I, killiaq is the only raw material distributed all over the site except in the far west.
Table 7. Frequency distribution of lithic artefact types from Nipisat in phase 1, 2 and 3.

Phase 1 Phase 2 Phase 3 All phases

\begin{tabular}{|c|c|c|c|c|}
\hline \multicolumn{5}{|l|}{ Unclassifiable tools } \\
\hline Flakes & 7670 & 1453 & 14159 & 23282 \\
\hline Core reduction flakes & 4 & & 6 & 10 \\
\hline Preforms & 4 & & 14 & 18 \\
\hline Fragments & 12 & 1 & 71 & 84 \\
\hline Flakes with retouch & 10 & & 7 & 17 \\
\hline Total & 7700 & 1454 & 14257 & 23411 \\
\hline \multicolumn{5}{|l|}{ Hand tools } \\
\hline Knife blades & 9 & 3 & 35 & 47 \\
\hline \multicolumn{5}{|l|}{ Knife blades with } \\
\hline transversal edge & 1 & & & 1 \\
\hline Knife blades - bevelled & & & 4 & 4 \\
\hline Burins & 16 & 4 & 66 & 86 \\
\hline Burin spalls & 55 & 6 & 180 & 241 \\
\hline End scrapers & 1 & 1 & 11 & 13 \\
\hline Side scrapers & 6 & & 10 & 16 \\
\hline Scrapers - unspecified & 2 & & 2 & 4 \\
\hline Drills/gravers & 1 & 1 & & 2 \\
\hline Microcores & 2 & & 8 & 10 \\
\hline Microblades & 7 & 1 & 14 & 22 \\
\hline Adzes & & & 2 & 2 \\
\hline Chisels & & & 1 & 1 \\
\hline Hammerstones & 1 & & 1 & 2 \\
\hline Whetstones & 12 & & 29 & 41 \\
\hline Smoothing stones & & & 1 & 1 \\
\hline Total & 113 & 16 & 364 & 493 \\
\hline
\end{tabular}

Hunting and fishing

Harpoon blades -

Harpoon blades - bevelled

1

Projectile points -

stemmed 11

Projectile points - bevelled $\quad 8$

Projectile points -

$\begin{array}{lllll}\text { unspecified } & 7 & 6 & 24 & 37\end{array}$

Weights and sinkers

of soapstone $\quad 2 \quad 2$

$\begin{array}{lllll}\text { Total } & 9 & 6 & 36 & 51\end{array}$

Household utensils

$\begin{array}{llll}\text { Sherds of soapstone } & 1 & 23 & 24\end{array}$

"Strike a light"

Gaming pieces - soapstone $1 \quad 1 \quad 2$

Gaming pieces - sandstone $2 \quad 11 \quad 13$

Gaming pieces - pumice 2

$\begin{array}{llll}\text { Total } & 6 & 38 & 44\end{array}$

Total number of

lithic artefacts

7828

1476

1469523999 

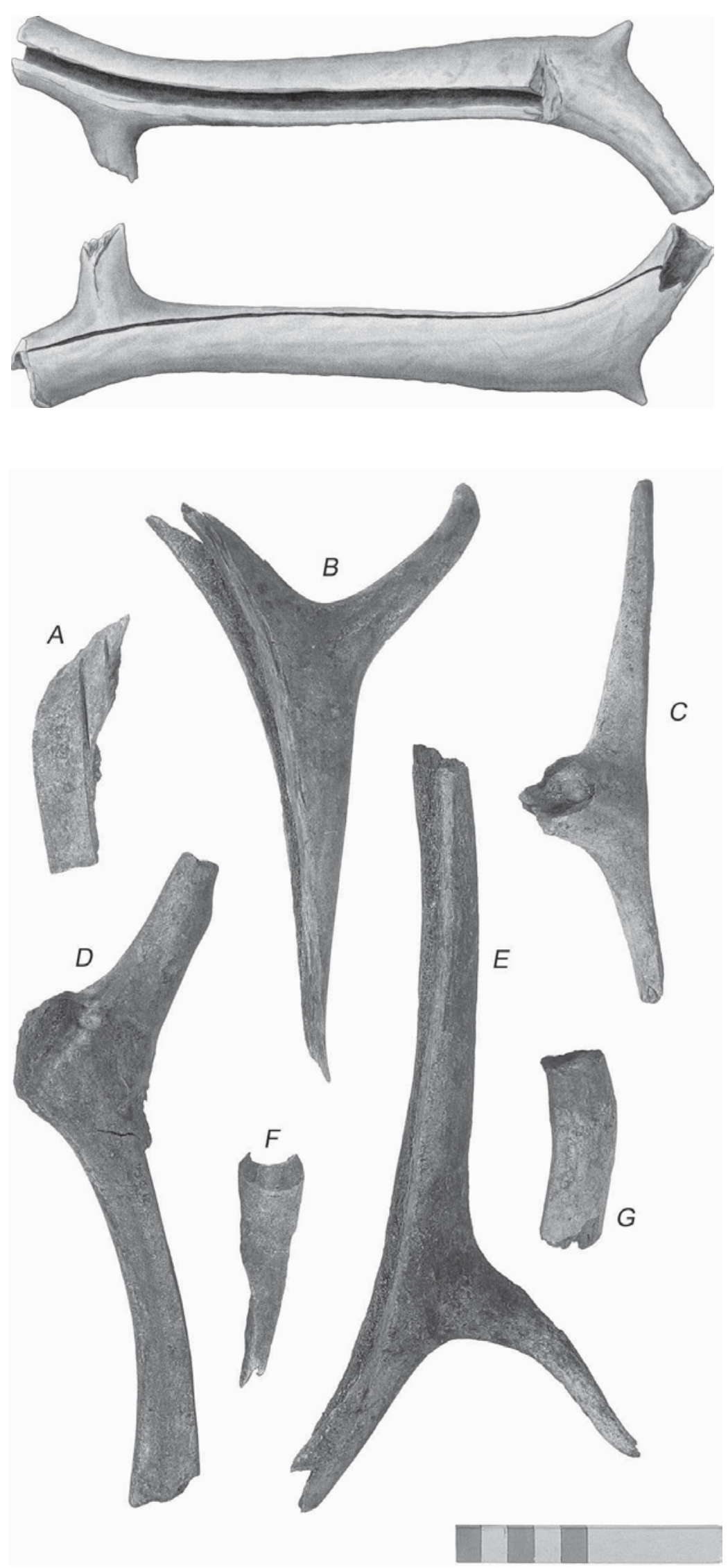

Fig. 37. Antler with a long groove (x12108) made with a burin on one side. On the other side a blank has been removed leaving burin grooves and chopping marks from an axe. Length $35 \mathrm{~cm}$.
Fig. 38. Selection of antler waste products exhibiting two kinds of working traces. A-E burin grooves and F-G chopping marks. D is a shed antler. Photo: Geert Brovad. 
Table 8. Raw material selected for tool production. A wide variety of species and materials were used by the Nipisat people, however antler was the preferred material.

\begin{tabular}{|c|c|c|c|c|}
\hline & Phase 1 & Phase 2 & Phase 3 & All phases \\
\hline \multicolumn{5}{|l|}{ Bird } \\
\hline Long bone (needles, fragment and preforms) & 39 & 9 & 66 & 114 \\
\hline Long bone (awls) & 1 & & 2 & 3 \\
\hline Long bone (preforms) & & & 2 & \\
\hline Long bone (burin grooves or other working traces) & & & 7 & 7 \\
\hline \multicolumn{5}{|l|}{ Goose } \\
\hline Humerus (burin grooves) & & & 1 & 1 \\
\hline \multicolumn{5}{|l|}{ Gull } \\
\hline Radius (awl) & 1 & & & 1 \\
\hline Humerus (burin grooves) & 1 & 1 & 2 & 4 \\
\hline \multicolumn{5}{|l|}{ Arctic fox } \\
\hline Tibia (burin grooves) & & & 1 & 1 \\
\hline \multicolumn{5}{|l|}{ Polar bear } \\
\hline Femur (awl) & & & 1 & 1 \\
\hline \multicolumn{5}{|l|}{ Walrus } \\
\hline Ivory (tools, fragments and preforms) & 4 & 3 & 17 & 24 \\
\hline Ivory (working traces) & 2 & 3 & 42 & 47 \\
\hline Ivory (debitage) & 1 & 2 & 100 & 103 \\
\hline Costa (tool) & & & 1 & 1 \\
\hline \multicolumn{5}{|l|}{ Caribou } \\
\hline Antler (tools, fragments and preforms) & 40 & 9 & 78 & 127 \\
\hline Antler (burin grooves or other working traces) & 29 & 25 & 133 & 187 \\
\hline Scapula (tool) & 1 & & & 1 \\
\hline Metatarsal and long bone (tools) & 4 & 1 & 8 & 13 \\
\hline Long bone (working traces) & 2 & & 4 & 6 \\
\hline \multicolumn{5}{|l|}{ Whale } \\
\hline Unspecified bone (tools, fragments and preforms) & 14 & 1 & 8 & 23 \\
\hline Unspecified bone (working traces) & 6 & & 5 & 11 \\
\hline \multicolumn{5}{|l|}{ Mammal } \\
\hline Unspecified bone (tools, fragments and preforms) & 2 & & 2 & 4 \\
\hline Unspecified bone (working traces ) & & 1 & 3 & 4 \\
\hline Total number of organic artefacts & 147 & 55 & 483 & 685 \\
\hline
\end{tabular}

In phase 2 there are also two concentrations, one in the south-western part of the area and one in the far northern area. Noteworthy is the lack of flakes around the hearth.

Phase 3 differs from the two previous phases in covering a larger area, and for analytical reasons, it has been divided into areas I-3 (see Fig. 26). It is noteworthy that horizontal stratigraphy can be seen in the distribution of flakes. The southern part of the excavated area, placed at the highest level, shows the low- est density of artefacts compared to phase I (Figs 445I). There are also clear differences in the density for the three areas, as can be seen in Fig. 52. There is a larger number of flakes from area $3(\mathrm{~N}=7037)$ than from areas I $(\mathrm{N}=424 \mathrm{I})$ and $2(\mathrm{~N}: 288 \mathrm{I})$. Killiaq decreases from $82.4 \%$ in area I to $6 \mathrm{I} .7$ in area 3 and quartzite increases from $14.9 \%$ to $30.7 \%$. Agate increases too, see Fig. 53. The difference between areas I, 2 and 3 is most clearly seen for agate (Fig. 49) and quartzite (Fig. 5I). Unfortunately it is not possible 


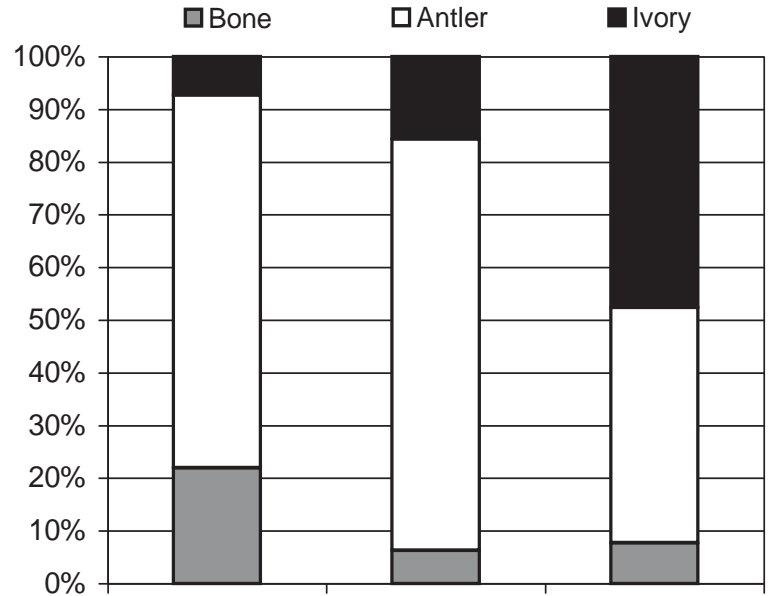

Phase $1 \mathrm{~N}=41$ Phase $2 \mathrm{~N}=32$ Phase $3 \mathrm{~N}=298$

Fig. 39. Distribution of waste products made of bone, antler and ivory.

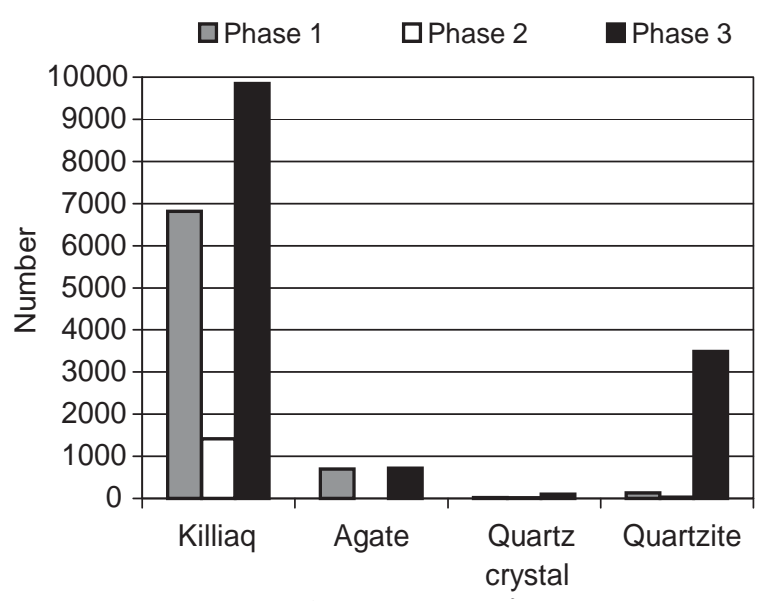

Fig. 40. Raw material preferences in the three phases at Nipisat (number of flakes).

to link these differences to chronological factors (Table 4). Variations in activities may however account for the disparities observed.

Five square meters (386x/180y, 387x/187y, 388x/ I94y, 391x/201y and 397x/201y) were chosen for an analysis of size distribution of flakes. It is significant that the majority of the flakes from these five units are less than $2 \mathrm{~cm}$ and several are less than $0.5 \mathrm{~cm}$ (in diameter). The largest flake (only $\mathrm{I}$ ) is $7 \mathrm{~cm}$ in diameter (Fig. 54-58). Besides several agate flakes from $387 \mathrm{x} / \mathrm{1} 87 \mathrm{y}$ with cortex preserved, (they are probably from the same piece of raw material), only very few primary flakes with cortex preserved were found. The $\square$ Killiaq $\square$ Agate $\quad$ Quartz crystal $\square$ Quartzite

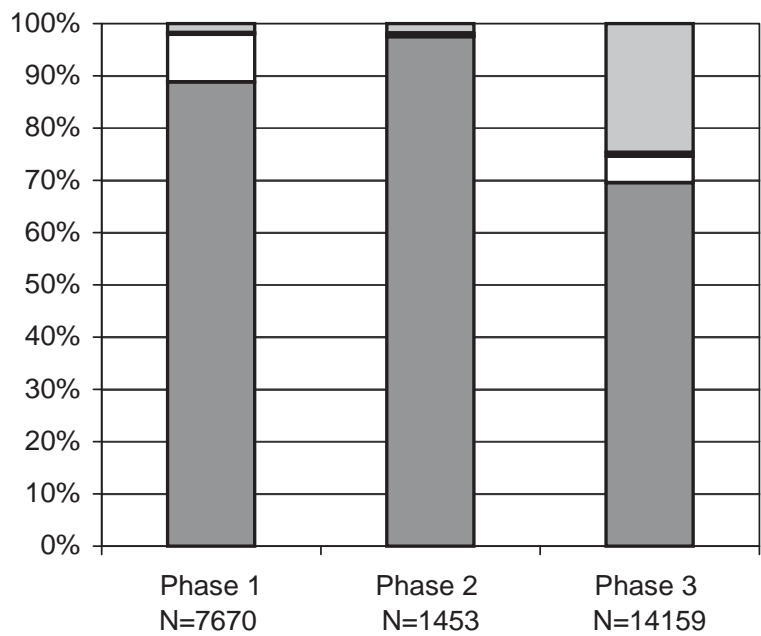

Fig. 41. Percentages of different raw materials (number of flakes).

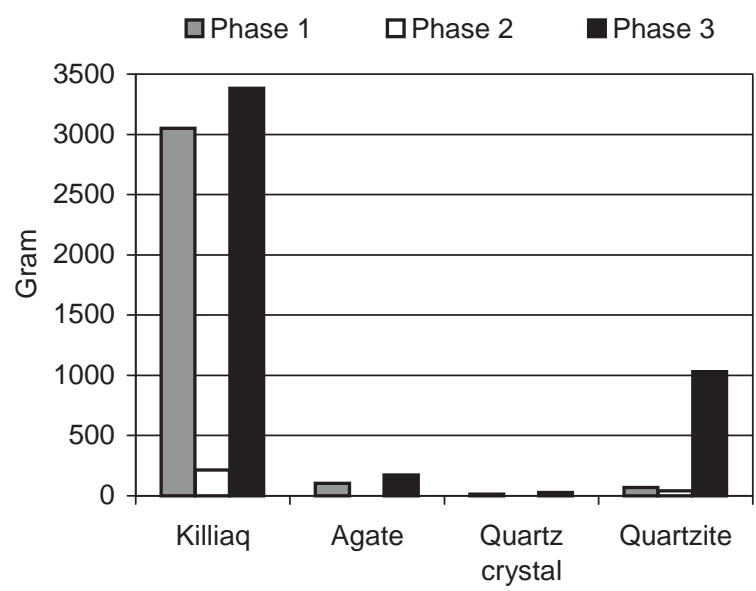

Fig. 42. Raw material preferences in the three phases at Nipisat (weight of flakes).

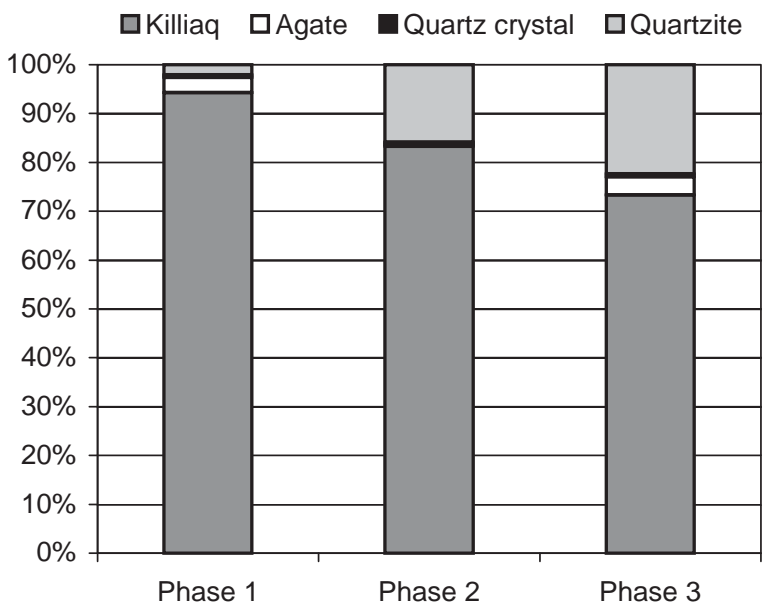

Fig. 43. Percentages of different raw materials (weight of flakes). 
Fig. 44. Horizontal distribution of flakes made from killiaq in phase 1 and 2 (number).

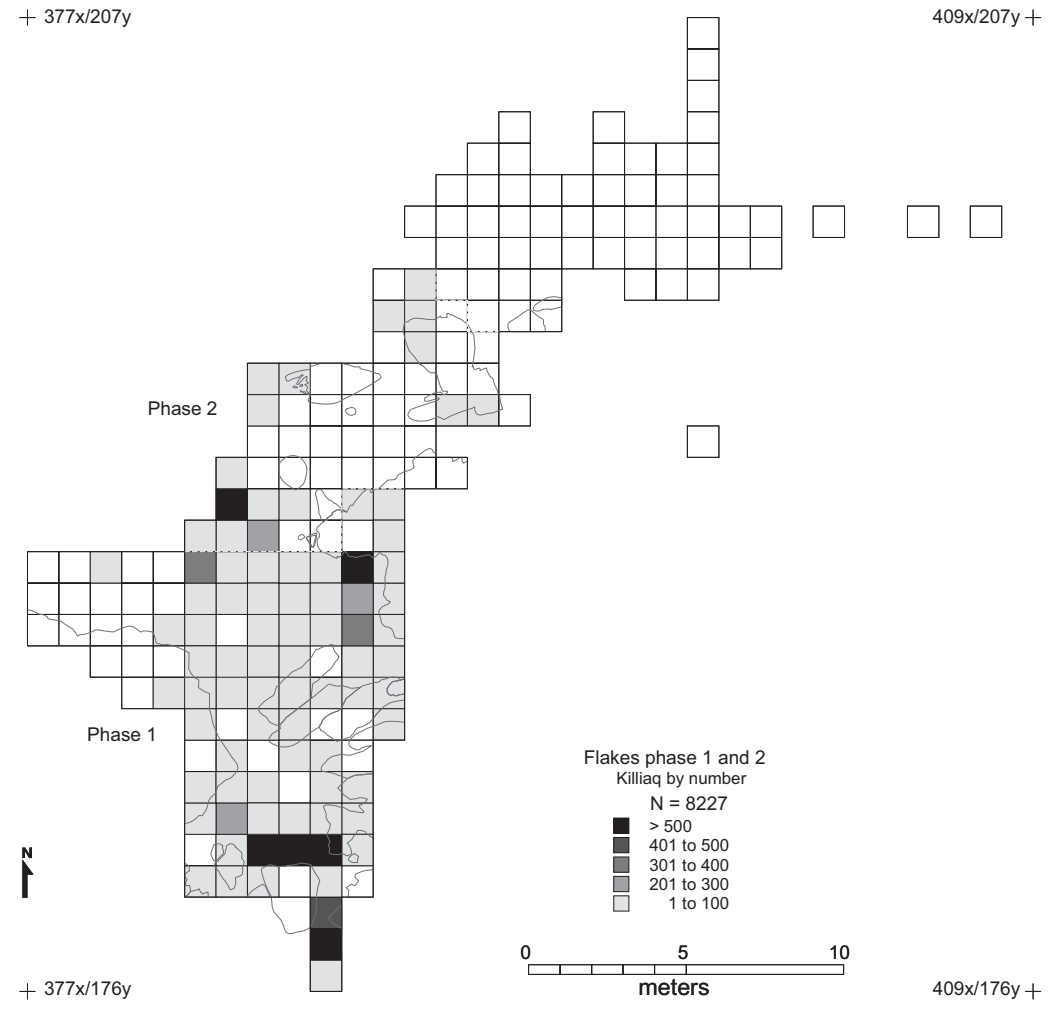

$+377 x / 207 y$

$409 x / 207 y+$
Fig. 45. Horizontal distribution of flakes made from killiaq in phase 1 and 2 (weight).

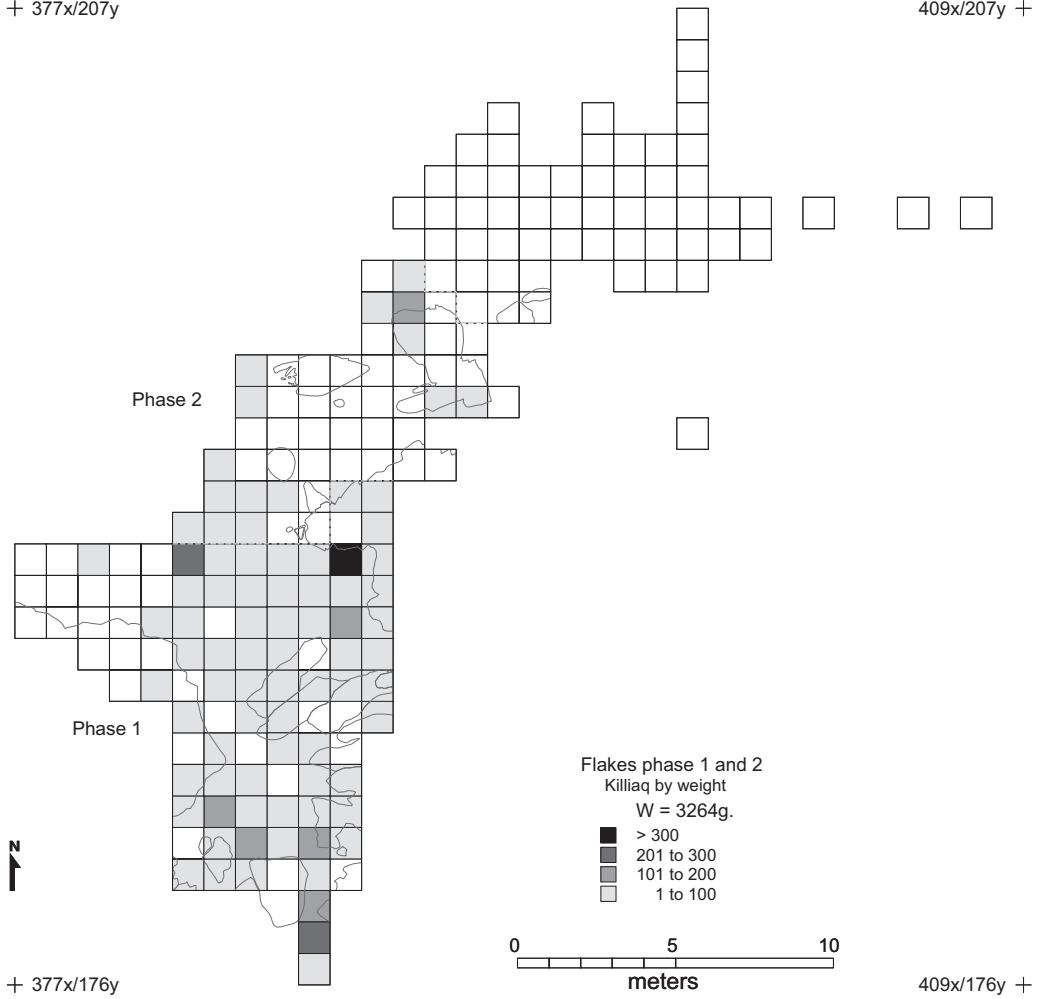

Anne Birgitte Gotfredsen \& Tinna Møbjerg:

Nipisat - a Saqqaq culture site in Sisimiut, central West Greenland, 2004 eISBN 978-87-635-2626-5, Monographs on Greenland | Meddelelser om Grønland, vol. 331 (ISSN 0025-6676) Man and Society, vol. 31 (ISSN 0106-1062), http://www.mtp.hum.ku.dk/details.asp?eln=201396 
$+377 x / 207$

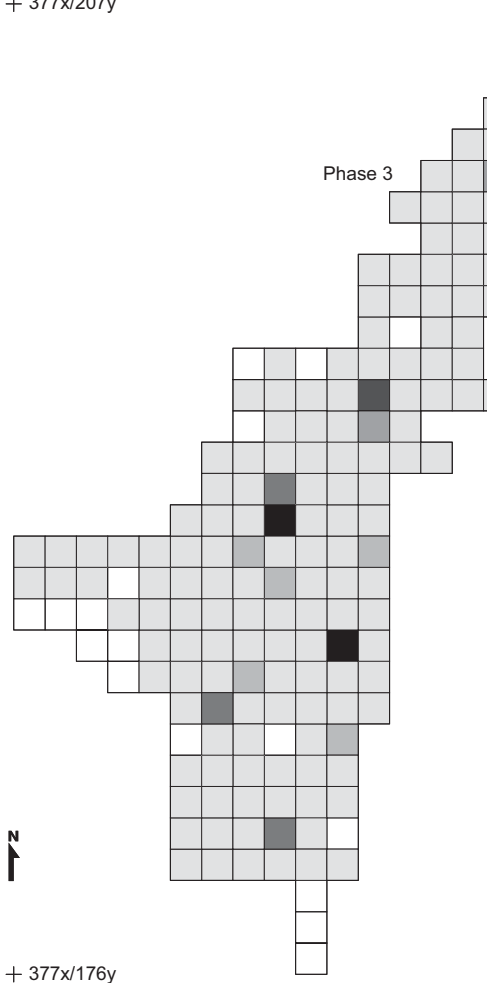

$+377 \mathrm{x} / 176 \mathrm{y}$

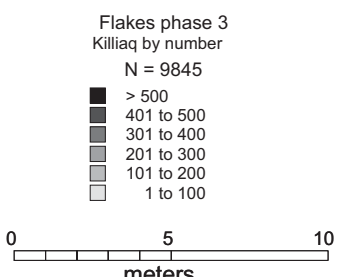

10

$+377 x / 207 y$

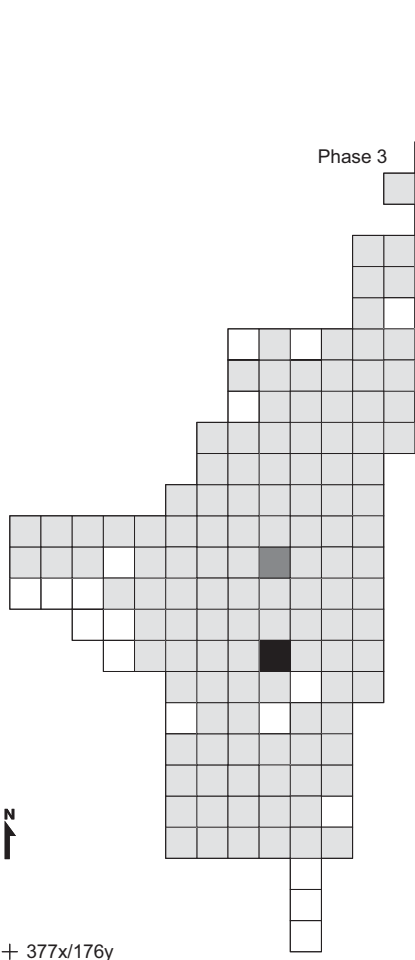

$+377 x / 176 y$

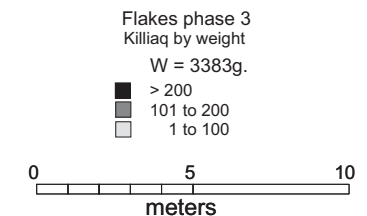

$409 x / 207 y+$

Fig. 46. Horizontal distribution of flakes made from killiaq in phase 3 (number).

$409 x / 176 y+$ 
Fig. 48. Horizontal distribution of flakes made from agate in phases 1 and 2 (number).

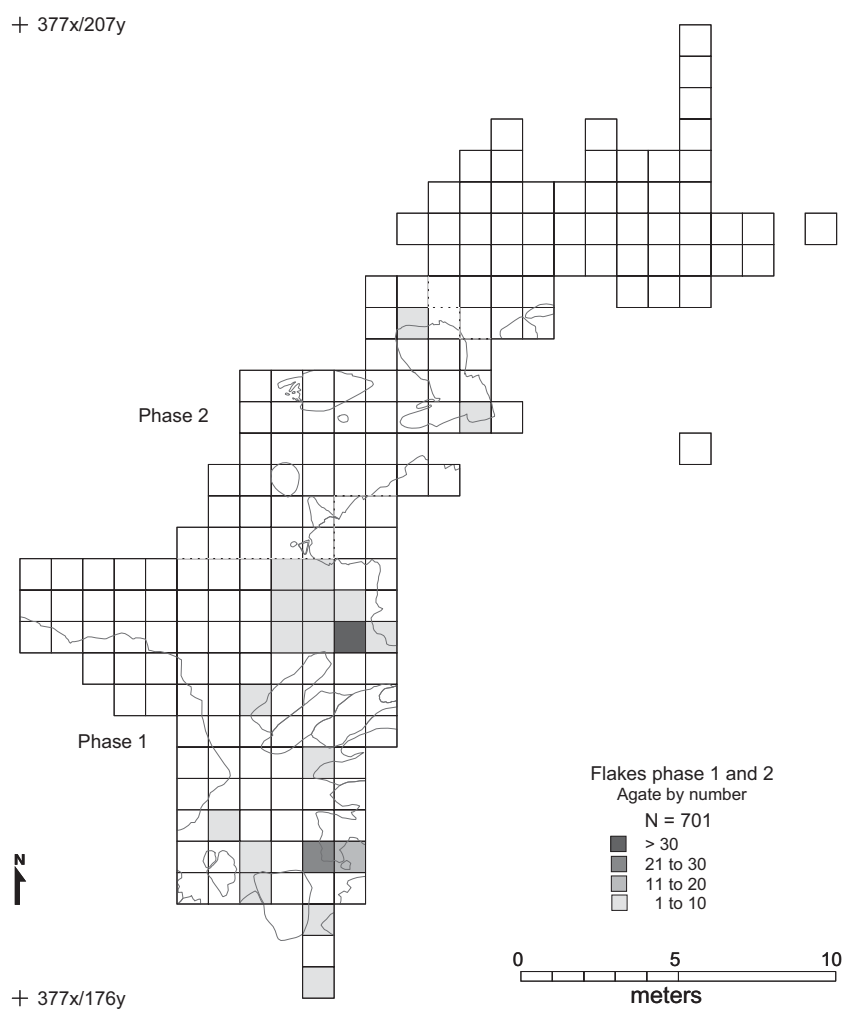

$409 x / 176 y+$

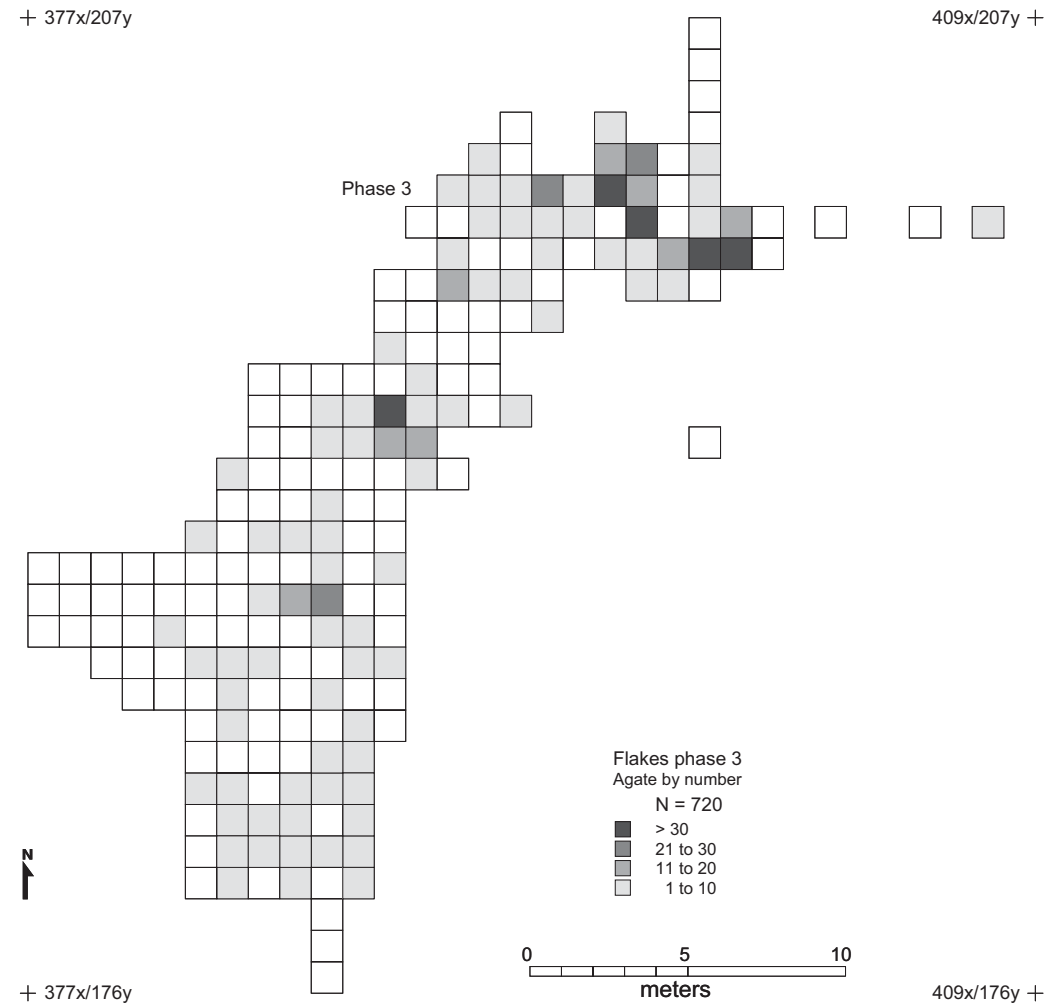

$+377 x / 176 y$
Fig. 49. Horizontal distribution of flakes made from agate in phase 3 (number). 
$+377 x / 207 y$

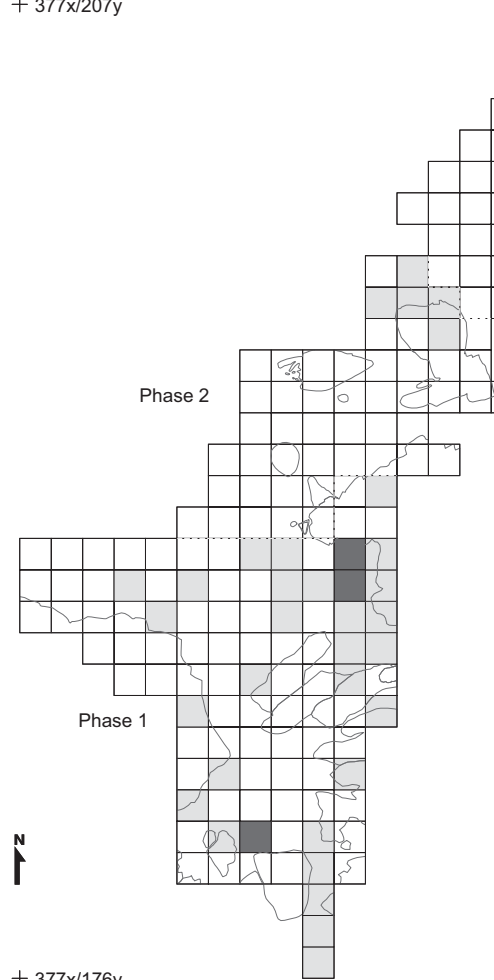

$+377 x / 176 y$

$+377 x / 207 y$

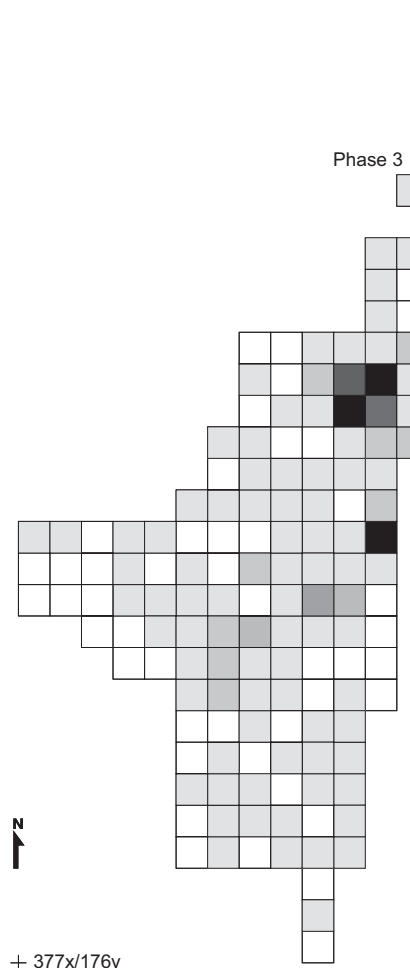

52

elSBN $978-8$
$409 x / 207 y+$

Fig. 50. Horizontal distribution of flakes made from quartzite in phases 1 and 2 (number).

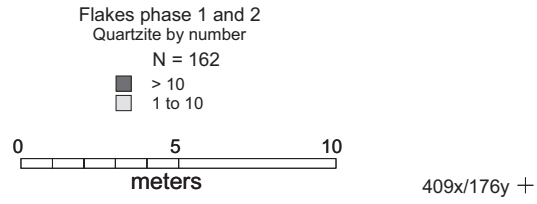

$409 x / 207 y+$

Fig. 51. Horizontal distribution of flakes made from quartzite in phase 3 (number). 
口Phase 3 area 1 Phase 3 area 2

Phase 3 area 3

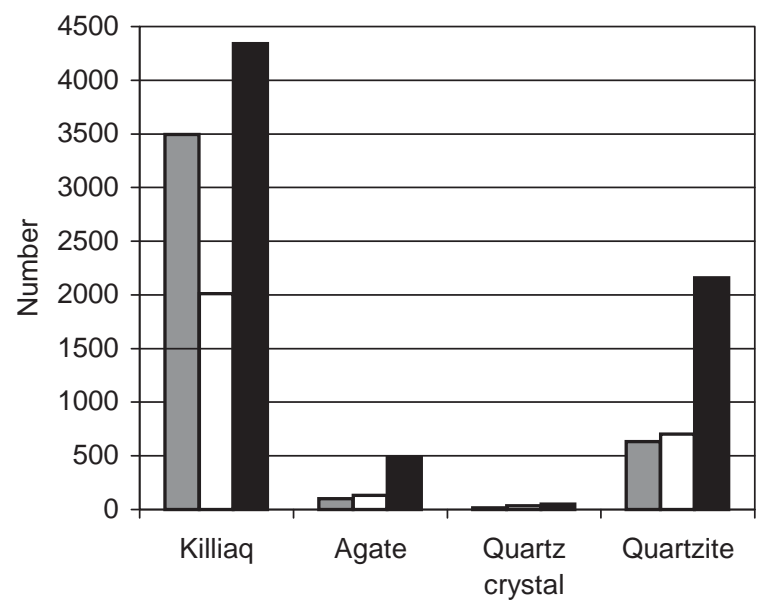

Fig. 52. Raw material preferences (number of flakes) in phase 3 from areas 1, 2 and 3 (see Fig. 26).

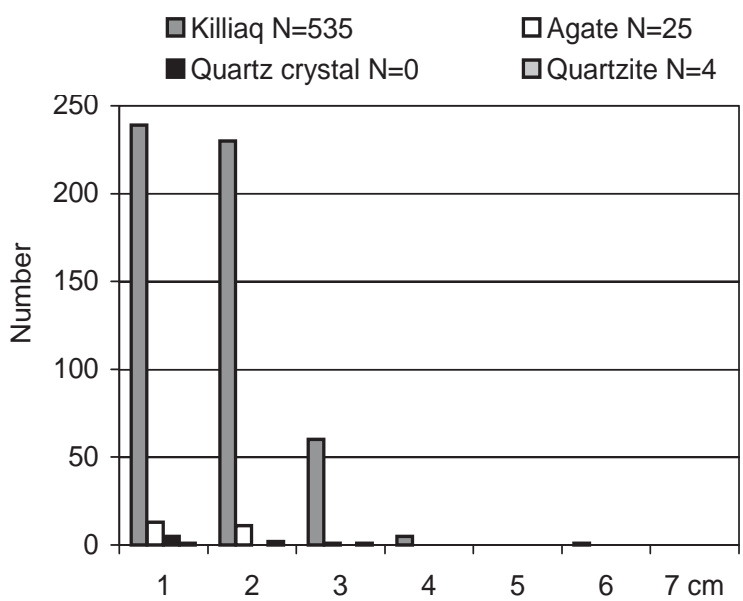

Fig. 54. The size distribution of flakes in square $386 x / 180 y$ (phase 1).

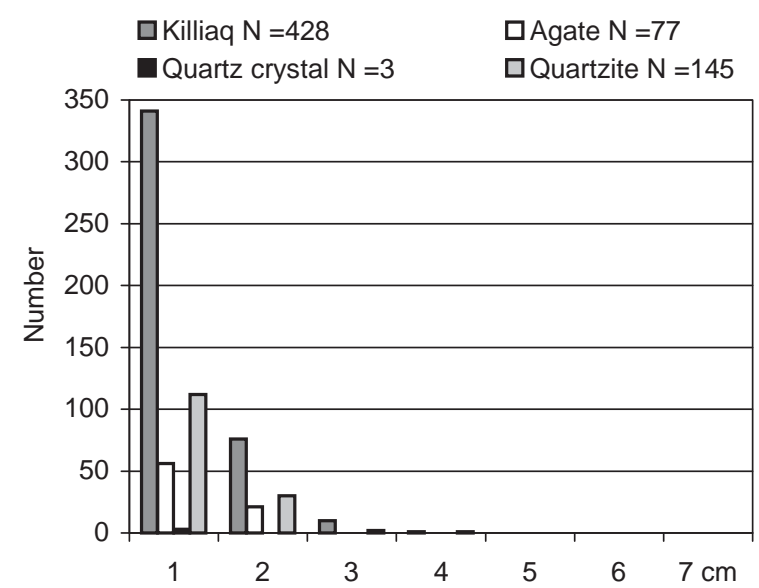

Fig. 56. The size distribution of flakes in square $388 x / 194 y$ (phase 3). $\square$ Killiaq $\square$ Agate $\square$ Quartz crystal $\square$ Quartzite

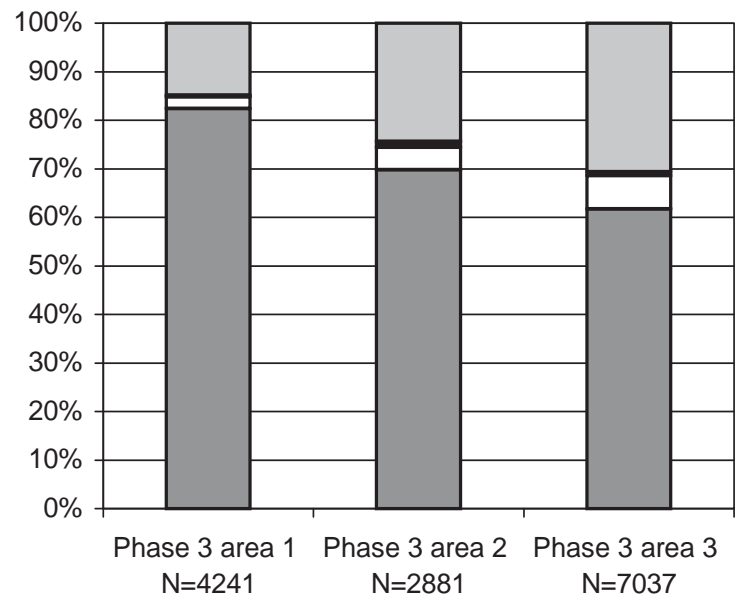

Fig. 53. Percentages of different raw materials (number of flakes) in phase 3 from areas 1, 2 and 3.

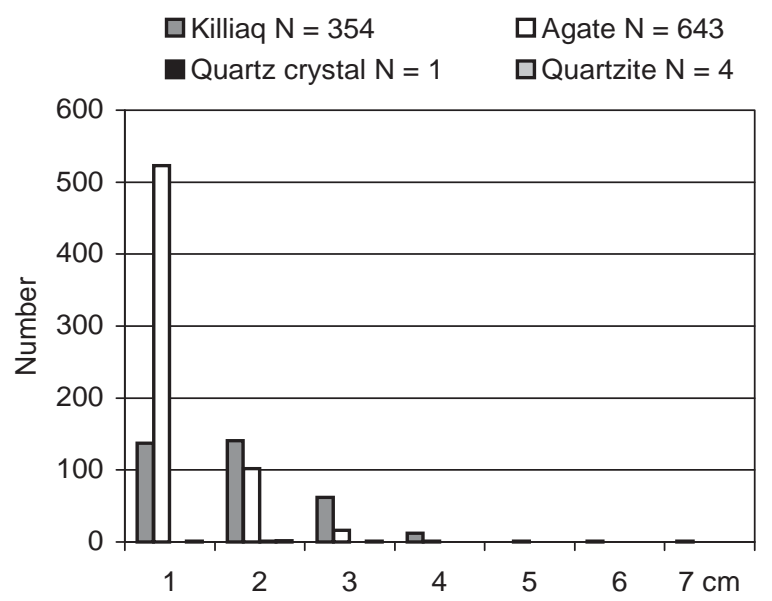

Fig. 55. The size distribution of flakes in square $387 x / 187 y$ (phase 1).

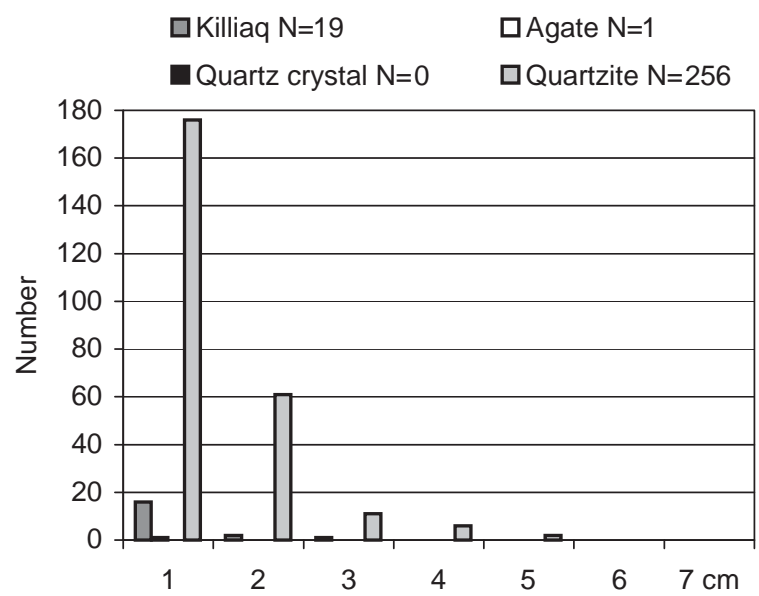

Fig. 57. The size distribution of flakes in square $391 x / 201 y$ (phase 3). 


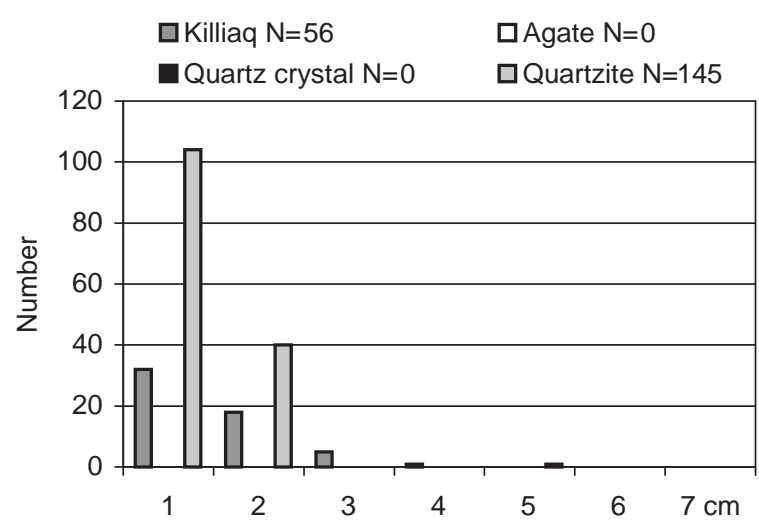

Fig. 58. The size distribution of flakes in square $391 x / 207 y$ (phase 3).

size distribution of flakes from these five square meters was found to be largely representative of the site as a whole, even though there are a few flakes more than $7 \mathrm{~cm}$ in diameter. No chronological differences or differences between the groups of raw material were found, although there are no flakes of agate or quartz crystal exceeding $5 \mathrm{~cm}$.

To understand the process of how the lithic waste products were created, it is necessary to analyse the reduction system from the moment a piece of raw

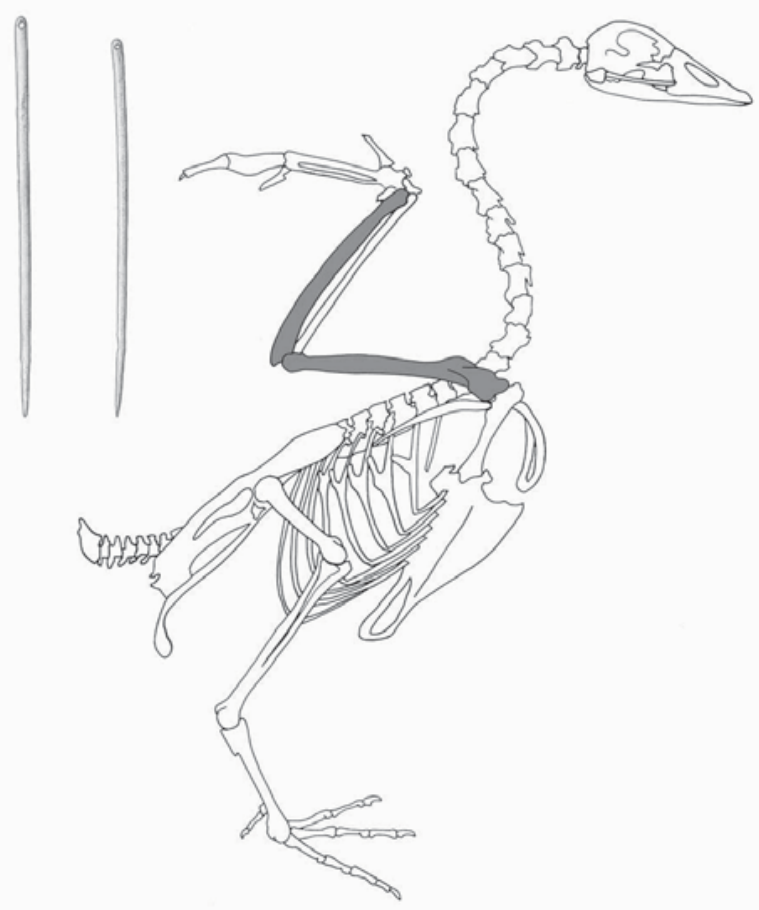

Fig. 59. The large wing bones, e.g. humerus and ulna of geese, might have served as a valued raw material for needles. material is picked up, to the point when a finished tool can be used and discarded. It is also important to understand the decisions of the flint knapper who chooses the raw material. That is the idea of the chaîne opératoire (see below) where the goal is to reconstruct the different stages of the process manifested in the excavated lithic material (Eriksen 2000:75-IOo).

\section{Hand tools}

The hand tools from Nipisat include a variety of types such as awls, needles, cutting boards, engraving tools, pressure flakers, different kinds of handles, wedges, hammers, knife blades, burins and burin spalls, endscrapers, sidescrapers, microblades and whetstones or grinding stones.

\section{Organic}

Awls $(N=20)$ and needles $(N=I I 4)$

Awls and needles are the most common tools at the site (see Table 6) and these types are well known from other sites with organic materials both in Greenland (Grønnow I996c:24; Knuth 1967) and Canada (Arnold I981:83; LeBlanc 1994:40-42; Taylor 1967:235)

Of the seven awls from phase $\mathrm{I}$, three are made of antler, two of bird bone, one of whalebone and one of caribou bone. From phase 2 only one awl of antler was recorded. One specimen (x650o) from phase 3 is made of a polar bear femur (see Fig. I55 and Kramer 1996 b:9o, pl.6.6 F). Two were made of bird bone, two of ivory, five of caribou bone (x6449 and 6457, Kramer I996 b:90, pl.6.6 D-E) and two of antler. The awls made of bird bone or ivory are very elegant and are circular in cross section. This is not the case for the awl made of polar bear femur (Fig. I55). The awls made of caribou bone are all smoothly polished

The needles are all made of bone. Geese (Fig. 59) and gulls were the preferred species. Bones of swans (see chapter 7) and even arctic fox may also have been used. There is one arctic fox tibia (xI7022) with burin grooves indicating that a preform for a needle had been removed (Fig. 6oC). From phase I there are three preforms, from phase 2 one and from phase 3 there are I3. More than half the needles are fragmentary in different ways. Some are broken across the eye, others are broken at the point and some lack both the point and the eye. This means that the real number of nee- 
dles will be a little lower than the counted number. The lengths of the intact needles ranged from $35 \mathrm{~mm}$ to $84 \mathrm{~mm}$. All needles have a finely drilled perfectly round eye (Fig. 6I and 62). The eye end is always rounded, never pointed as seen on needles from Independence II. In cross-section the needles are never completely circular or square but slightly flattened on one side. At the eye end the needles are always very flat so that the area where the thread passes through is as thin as possible. There is no apparent difference between needles from phases I, 2 and 3, so the observed differences in size might be due to different use or by the variable thickness of the skins worked.

\section{Peculiar tool types $(\mathrm{N}=4)$}

A group of more peculiar types of tools will be described together in the following; all of them are dated to phase I. A compact piece of whale bone formed into a kind of cutting or scraping board (Fig. 63).

A small engraving tool made of ivory (Fig. 64) with a tiny socket at the pointed end. The head is conical with a diameter of $7 \mathrm{~mm}$ and the shaft is $5 \mathrm{~mm}$ in diameter. The length is $43 \mathrm{~mm}$. The tool could have been used as shown in the drawing by Jens Rosing, where a small burin spall is inserted into the socket (Gynther and Meldgaard 1983:43).

xi6356 is made of antler ( $96 \mathrm{~mm}$ x $24 \mathrm{~mm}$ ). From the handle shaped proximal end, it tapers gradually to the point, which is slightly polished in the same way as the boot creasers known from historical times.

A kind of scraper made from a right caribou scapula. The cranial edge is preserved, but the cranioproximal part is worked, and the scapular spine is removed, thus reducing the original size (Fig. 65).

\section{Handles $(N=16)$}

From all three phases different kind of handles are found. Twelve are made of antler, the rest are made of whale bone. There is a great variation in size and form. Some of them are broken. Handles are well known from Qeqertasussuk, but due to permafrost, handles of driftwood are also preserved there giving a greater range of variation than at Nipisat (Grønnow I994:206-2I2).

From phase I there is a small handle xi6568 with cutting marks on the surface to give a better grip (Fig. 66). The handle xio769 is simple with cut marks at both

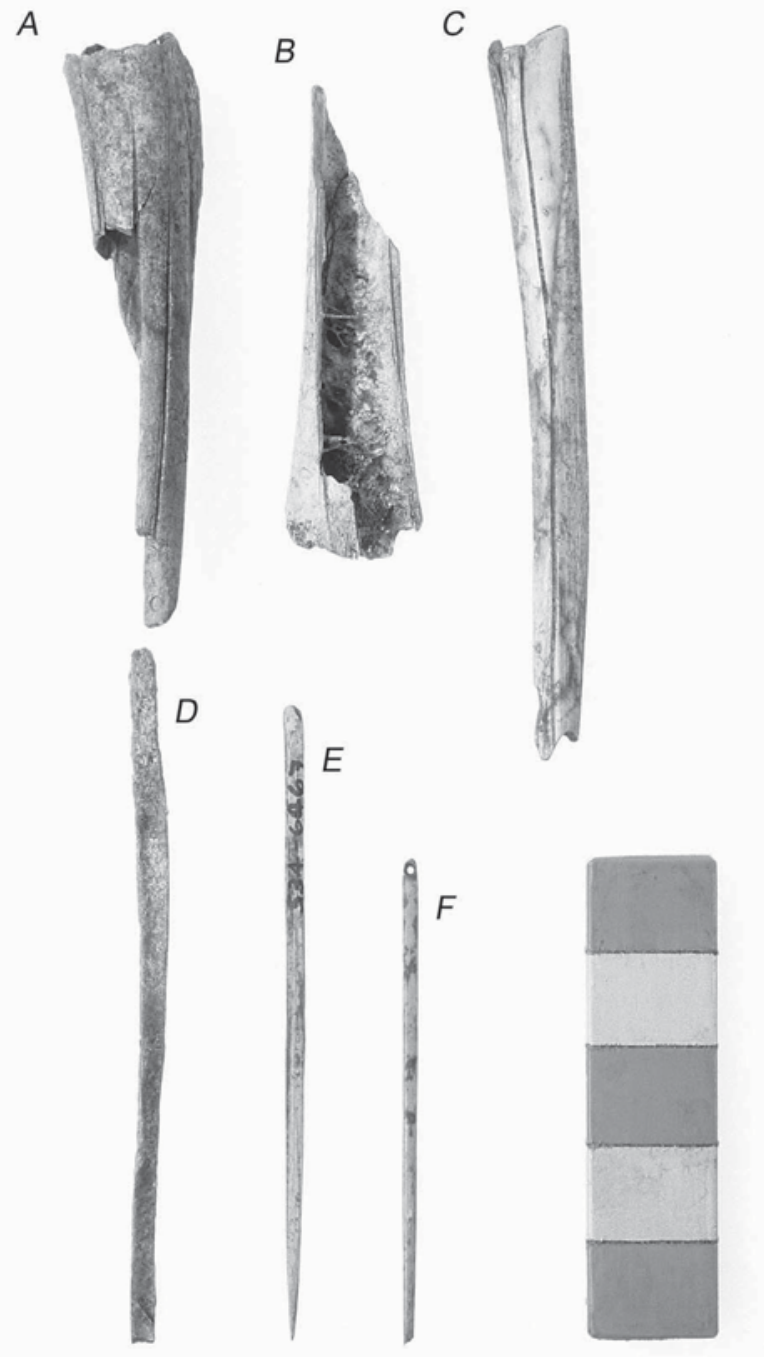

Fig. 60. Production waste with burin grooves, raw material and needles from Nipisat. A. proximal part of a goose humerus (x17125), B. distal part of a gull humerus (x16999), C. diaphysis of an arctic fox tibia (x17022), D. raw material, E preform of bird bone (x6467), and F. needle with a broken tip (x6472). Photo: Geert Brovad.

ends (Fig. 67A). The handle xio796 has shoulders on both sides and is thinned at the upper end. Marks at the shoulders are interpreted as traces of lashing (Fig. 68)

Four handles from phase 3 are noteworthy. The first is a shouldered handle x3198 with an elongated eye at the base (Fig. 92). The two others are handles for endblades (knives or burins) as seen from the size of the socket. $\mathrm{x} 6442$ has a marked socket and is worked at the end in the same way as xio769. The other has a vague socket and is split at the end (Fig. 69). The last 

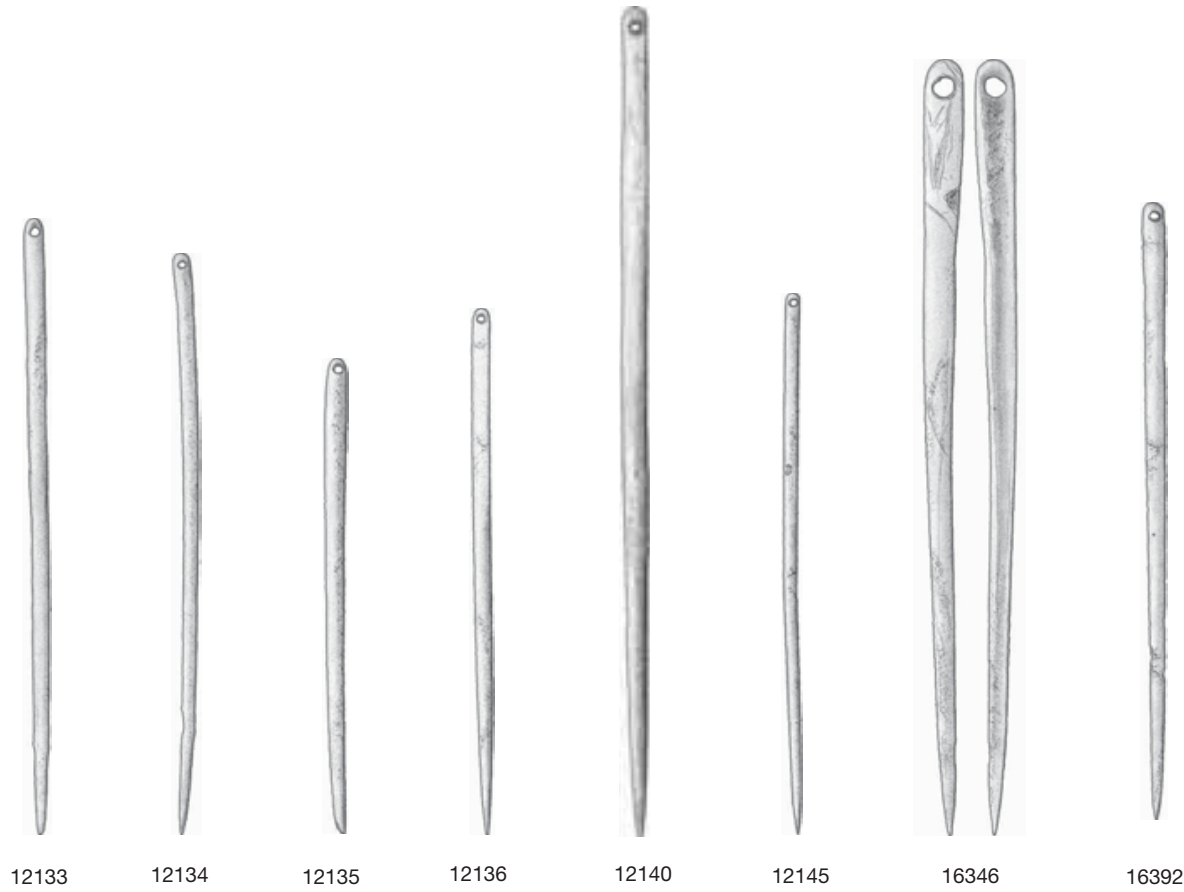

Fig. 61. Ten bone needles ranging in length from 53 to $84 \mathrm{~mm}$ from phase 1. Notice the perfectly drilled round eyes. 1:1.

one is a handle made of whale bone with a notch on one side (Kramer 1996b:93 pl. 6.IIE). This handle is only $63 \mathrm{~mm}$ long and has a diameter of II $\mathrm{mm}$.

\section{Shaft straightener $(N=1)$}

A $35 \mathrm{~mm}$ broad and $240 \mathrm{~mm}$ long tool made of antler XI2I8I has a curved incision at the base. Although now

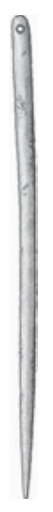

1218

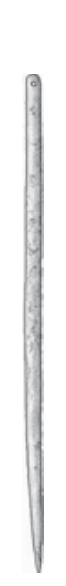

6478
6482

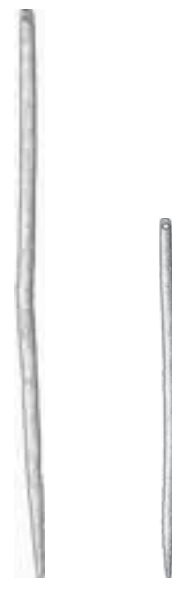

16279 broken, it originally had a circular eye. The tool is interpreted as a type of shaft straightener and dates to phase I (Fig. 70).

\section{Club or hammer $(\mathrm{N}=1)$}

From phase I a type of club or hammer (xIO75I) was found. It is made of a large rib from a minke whale or a large whale. It is $330 \mathrm{~mm}$ long and $56 \mathrm{~mm}$ in cross section.

\section{Pressure flakers ( $N=19)$}

Pressure flakers are a common type at the site. Nine are made of antler, and nine of caribou bone, the last one is made of whale or walrus bone. The type is known throughout the arctic (Grønnow 1996c:24; Knuth 1967; Taylor 1967:235).

There is great variation in form and size from 5-12 $\mathrm{mm}$ in width and 29-75 $\mathrm{mm}$ in length (Fig. 7I). The working edges are also highly variable from round (xI0757), rounded (xi65I5) to sharply pointed (xI2I6I). Nearly all of the pressure flakers have an oblique distal end and might have been lashed to some form of handle, except xI0757, which is circular in cross section, and xi646I, which is totally worn down. There appear to be no morphological differences 
Fig. 63. Cutting board made of compact whalebone from phase 1 (x12103). Size: $17 \times 85 \times 210 \mathrm{~mm}$.

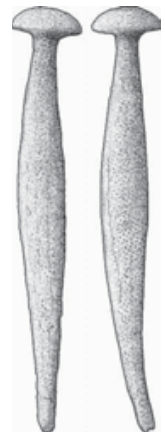

12165

Fig. 64. A small engraving tool made of ivory with a socket in the point from phase 1. (x12165). 1:1.

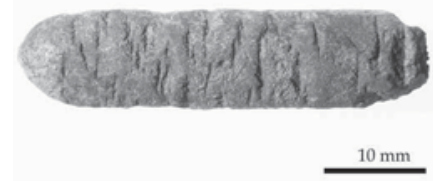

Fig. 66. Small handle with cutting marks on the surface made of antler (x16568) phase 1. Photo: Geert Brovad.
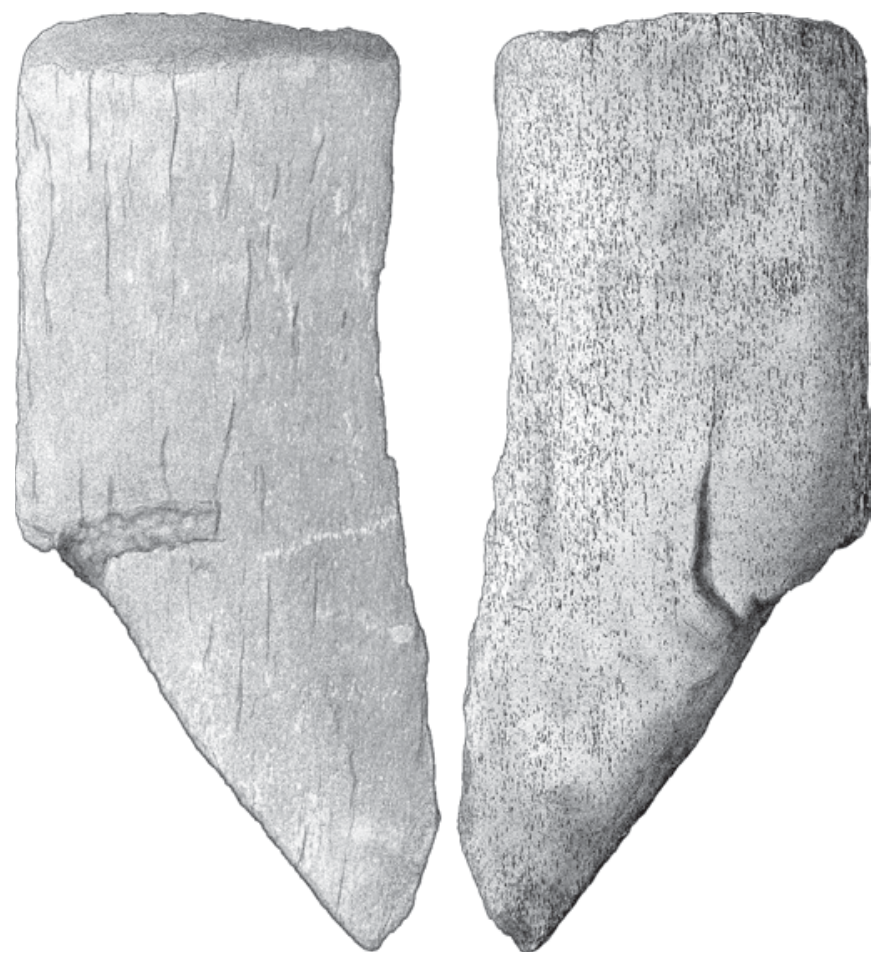

12103
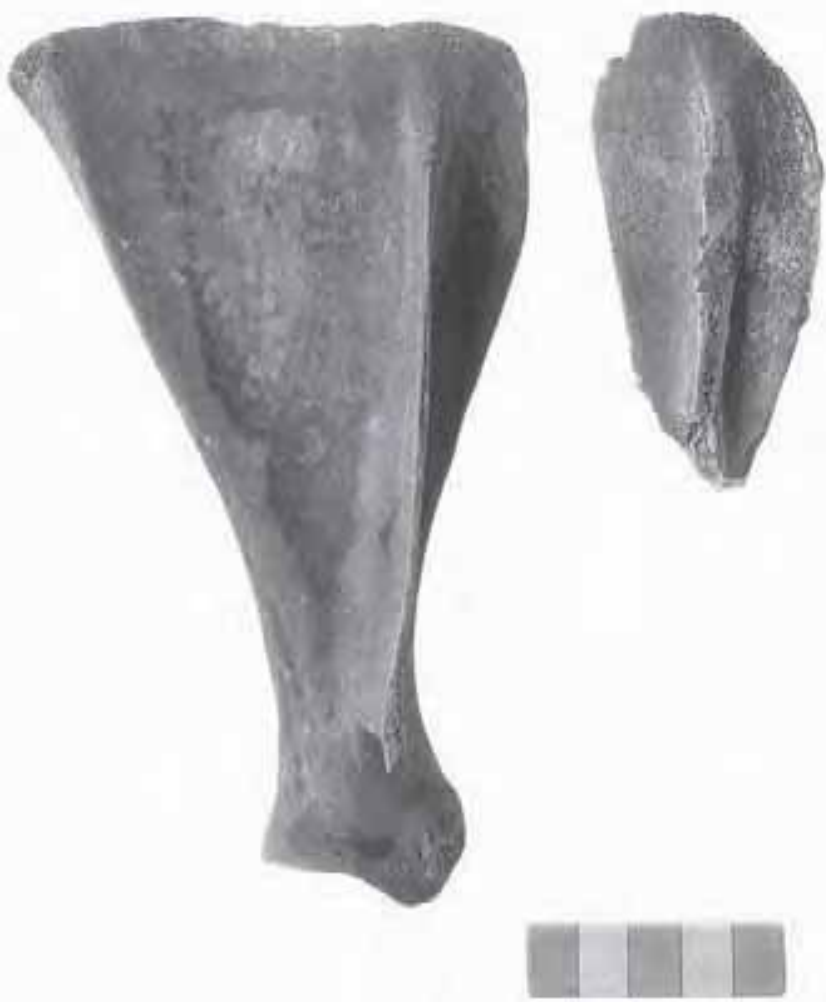

Fig. 65. A scraper (x10760) made of right scapula from caribou. The cranial edge is preserved but the cranioproximal part is worked and the scapular spine is removed. For comparison a right scapula is seen to the left. Photo: Geert Brovad. 
A

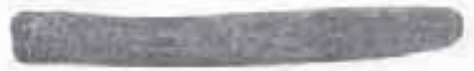

B

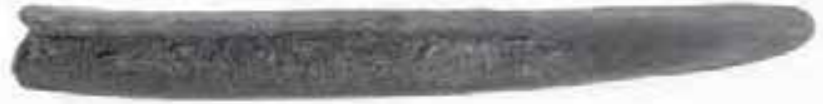

Fig. 67. Selection of tools made of antler. A. handle $\times 10769$, phase $1, \mathrm{~B}$. skinning knife $\times 10750$, phase $3, \mathrm{C}$. preform $\times 6497$, phase 3. Photo: Geert Brovad.

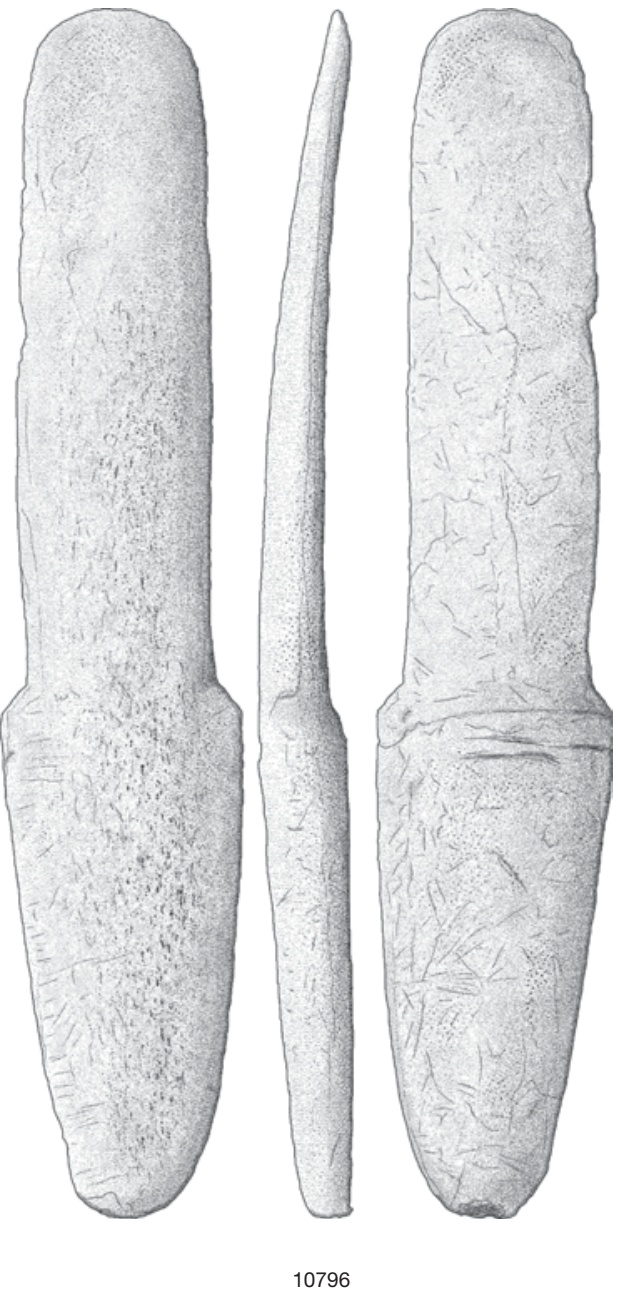

Fig. 68. Handle with distinct shoulders made of antler from phase 1 (x10796). 1:1. between phase $\mathrm{I}$ and 3 as seen from Fig. 7I. The differences observed might be due to the pressure flakers having been abandoned at different stages of use or that they were used for different tasks.

\section{Wedges $(N=18)$.}

Another common group of hand tools are the wedges, also known from Qeqertasussuk (Grønnow 1996a:84, I996c:24) and from the late Pre-Dorset Crane site too (LeBlanc 1994:38).

One is of ivory and the rest are made of antler. There is great variability in form and size, but three main groups can be seen. The first group is made of the compact base of a shed antler. The length varies between 166 and $240 \mathrm{~mm}$. At the base the tool has clearly been hammered and the other end is wedge shaped with numerous small transverse cuts, giving the wedge a better "bite" in the driftwood (Fig. 72). The second group is made of antler with part of a tine preserved (Fig. 73) and this end has traces of having been hammered. The opposite end is wedge shaped and has heavy use wear. Sometimes the wedge is split at the working edge due to heavy use. This group varies in length from IIo to I50 $\mathrm{mm}$. The third group is made of antler or ivory and vary in length from 66 to Ioo $\mathrm{mm}$ (Fig. 74). The wedges are thin and might have been hafted. There is no correlation between chronology and the observed morphological differences. Instead variations may be interpreted as reflecting different functions in splitting wood, bone, antler or ivory. 

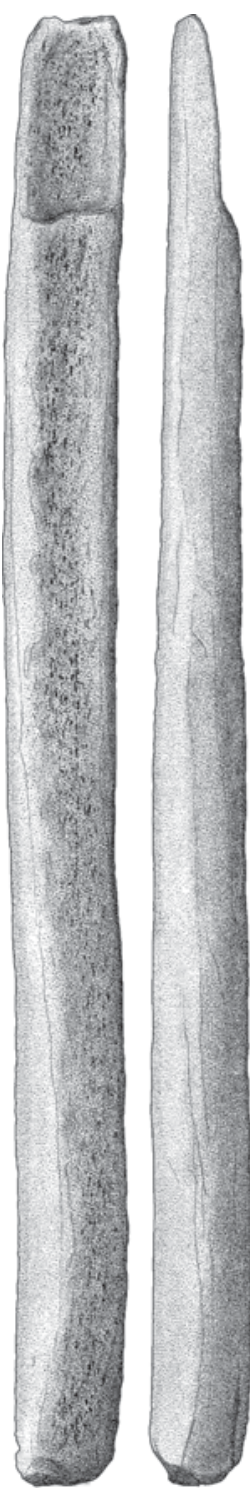

6442
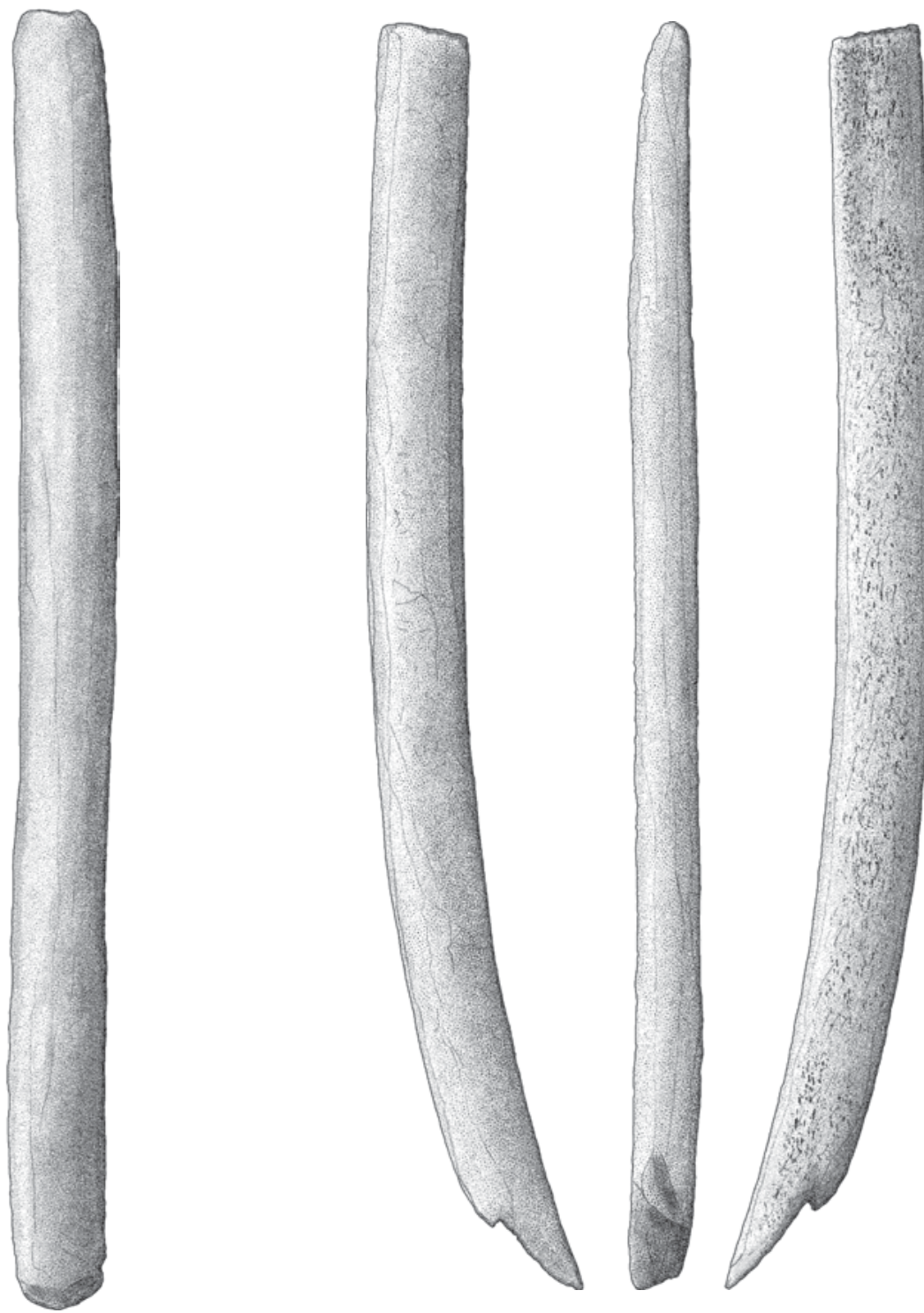

6444

Fig. 69. Handles for endblades. $x 6442$ has distinct socket for the blade. $x 6444$ has a more diffuse socket. Both are made of antler and dated to phase 3. 1:1.

\section{Lithic}

Knife blades $(\mathrm{N}=47)$

One of the dominant groups is knife blades with 9, 3 and 35 examples recovered from phases I, 2 and 3 respectively. The type is defined as being asymmetrical with a blunt point compared to projectile points and is well known from many sites in Greenland (Grønnow I994:206-209; Kramer 1996b:88; Larsen and Meldgaard I958:plate I.II-I3, 2.I5, 4.I-5; Meldgaard I96I:20).

From phase I seven are made of killiaq, one of agate and one of quartzite. Five of them are unifacial made on a flake, the rest are bifacial and made from a core (Fig. 75) One knife (xi623I) is larger than the others $(65 \mathrm{~mm})$ and is crescent shaped with heavy polishing on both sides.

From phase 2 all are of killiaq and bifacial (Fig. 75).

Phase 3 produced six knives of agate and the rest are of killiaq. Ten are unifacial and made from flakes and the rest are bifacial made from cores. The variation in size is large, as seen in Fig. 76. This is not due to 


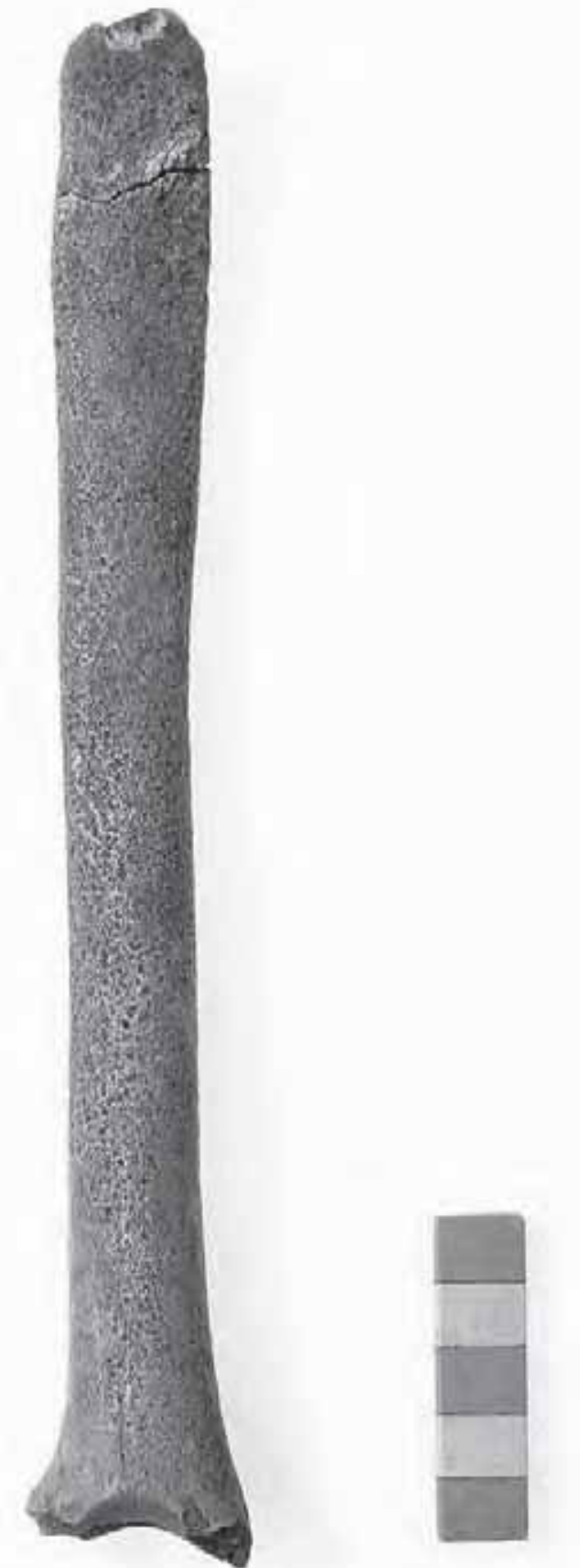

Fig. 70. Shaft straightener (x12181) of antler dated to phase 1. Photo: Geert Brovad.

chronological differences but might represent different stages in the resharpening sequence or that different types were used for different purposes. This can only be determined by use wear analysis. Unfortunately, use wear analysis on killiaq is highly problematic (Klaus Skriver pers. comm. 2002), so no results are available at present.

Two types of knife blade fragmentation have been recorded: I) the knife is broken off at the shaft and the proximal end is abandoned when the knife is reshafted or 2) the knife point breaks off during use, is abandoned and the knife is then resharpened.

One knife with a transverse edge (I7 X I4 mm) dates to phase I. The tool type is known from Akia (Kramer I996 b: 88 Pl. 6.I H) and Asummiut (SIK I73) (Møbjerg and Grummesgaard-Nielsen 1997b:252 Fig. 2I). In addition, the type is also well known from sites in Qeqertarsuup Tunua (Disko Bay). (Larsen and Meldgaard I958:56 and pl.4, 6-9; Mathiassen I958:2I and figs 7-8). Some researchers have interpreted the tool as a preform or unfinished burin (Mikkel Sørensen pers. comm. 2003). If this is correct it is noteworthy that the type is only represented in phase I and not in the younger phases, even though the burin frequency is the same.

Four bevelled or facetted knife blades, all of killiaq, date to phase 3 (Fig. II2). The complete tools are $38 \mathrm{~mm}$ long and between I5-I7 mm wide. Beneath the polishing it is seen that the knife blades have been bifacially flaked. This kind of tool had not been recorded on a Saqqaq site prior to excavations at Nipisat, but was only known through stray finds from the Qeqertarsuup Tunua area (Larsen and Larsen 1958: pl.5.2728; Mathiassen 1958:I9, fig. 7.I9-20). In addition there are finds from the southern part of Qeqertarsuup Tunua from Annertusuaqqaq Nuua (Jensen 1995, I998:68 and fig. 6). Recently the excavation at Asummiut (SIK 899) has also revealed three bevelled tools (Fig. 20I) (Møbjerg and Grummesgaard-Nielsen I997b:252).

\section{Burins $(N=86)$ and burin spalls $(N=241)$}

Burins and burin spalls are the most numerous types in the lithic assemblage. Burins are known from all sites belonging to the early part of the Arctic Small Tool Tradition, from Alaska in the west to Greenland in the east, although there are some local differences (for examples see Arnold 1981; Appelt and Pind 1996:I37; Giddings 1967:25; Grønnow 1996c:22, 25; Diklev 1992; Knuth 1967; Nagy 1997; McGhee 1979; Schledermann I990; Taylor 1968; Tuborg and Sandell 1999).

From phase $\mathrm{I}(\mathrm{N}=\mathrm{I} 6)$ three are made of agate, the rest are of killiaq. More than half of the burins are bifacially polished, irrespective of raw material. All of them are made on flakes and on some of them the bulb of percussion can be seen even though they are bifa- 


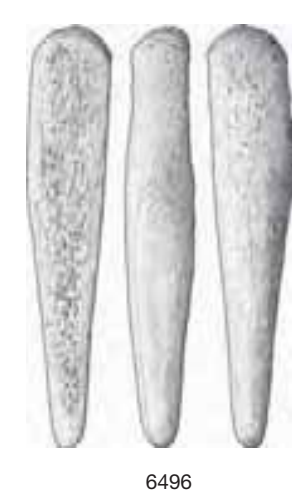

6496

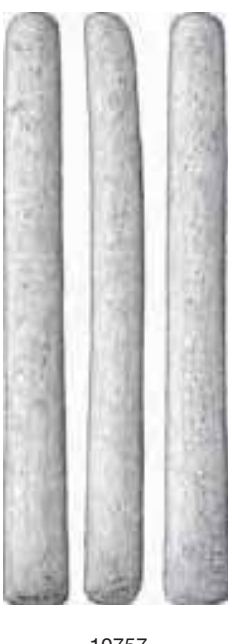

10757
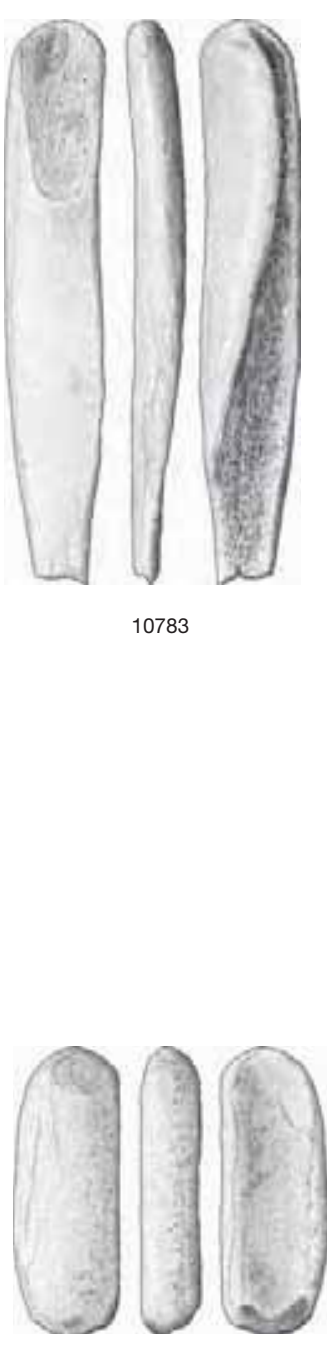

16461
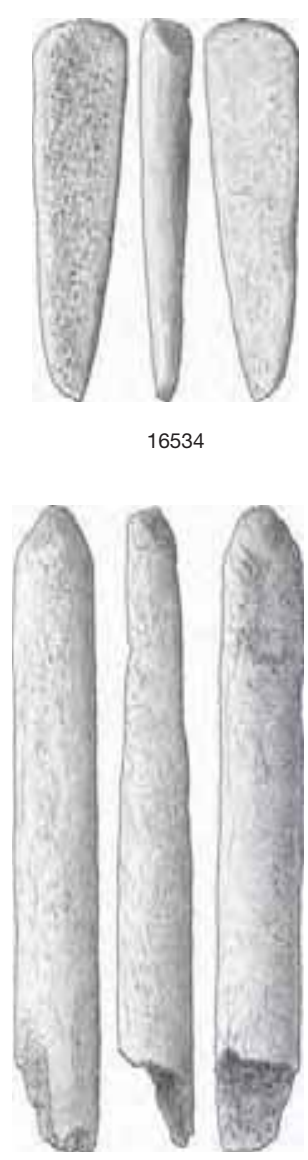

16771

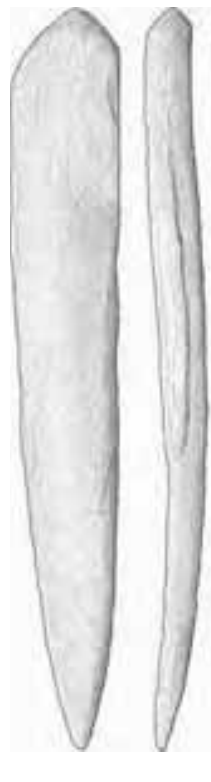

16348
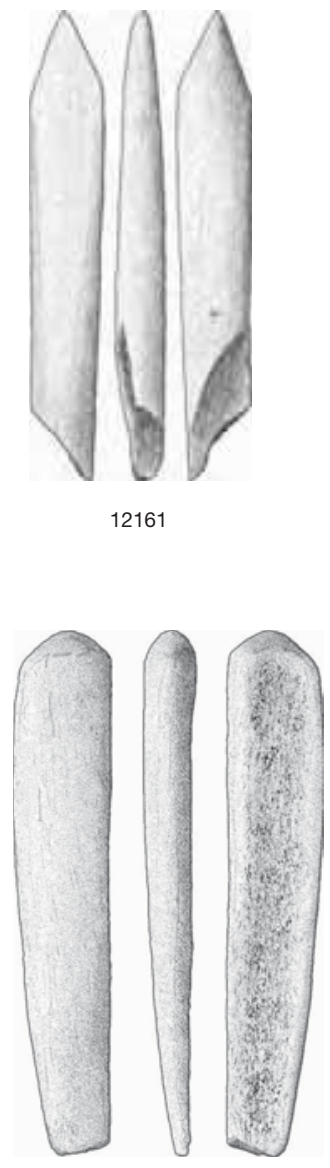

16417

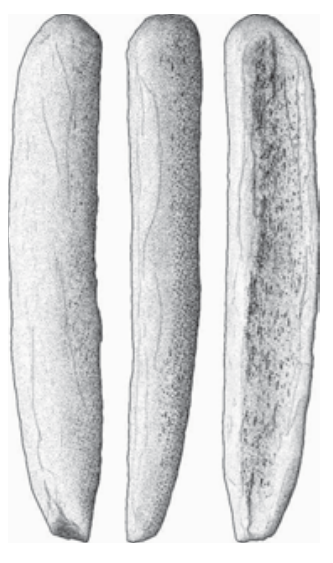

16515

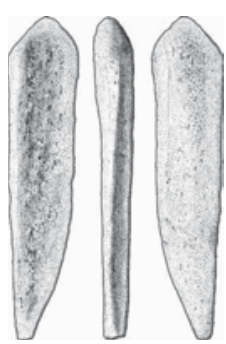

10795

Fig. 71. Pressure flakers made of caribou bone and antler. Lower row from phase 1, middle from phase 2 and upper row from phase 3. x6496, 10757, 12161 and 16771 are made of antler. $\times 10783,10795,16348,16417,16461,16515$ and 16534 are made of caribou bone. 1:1. 


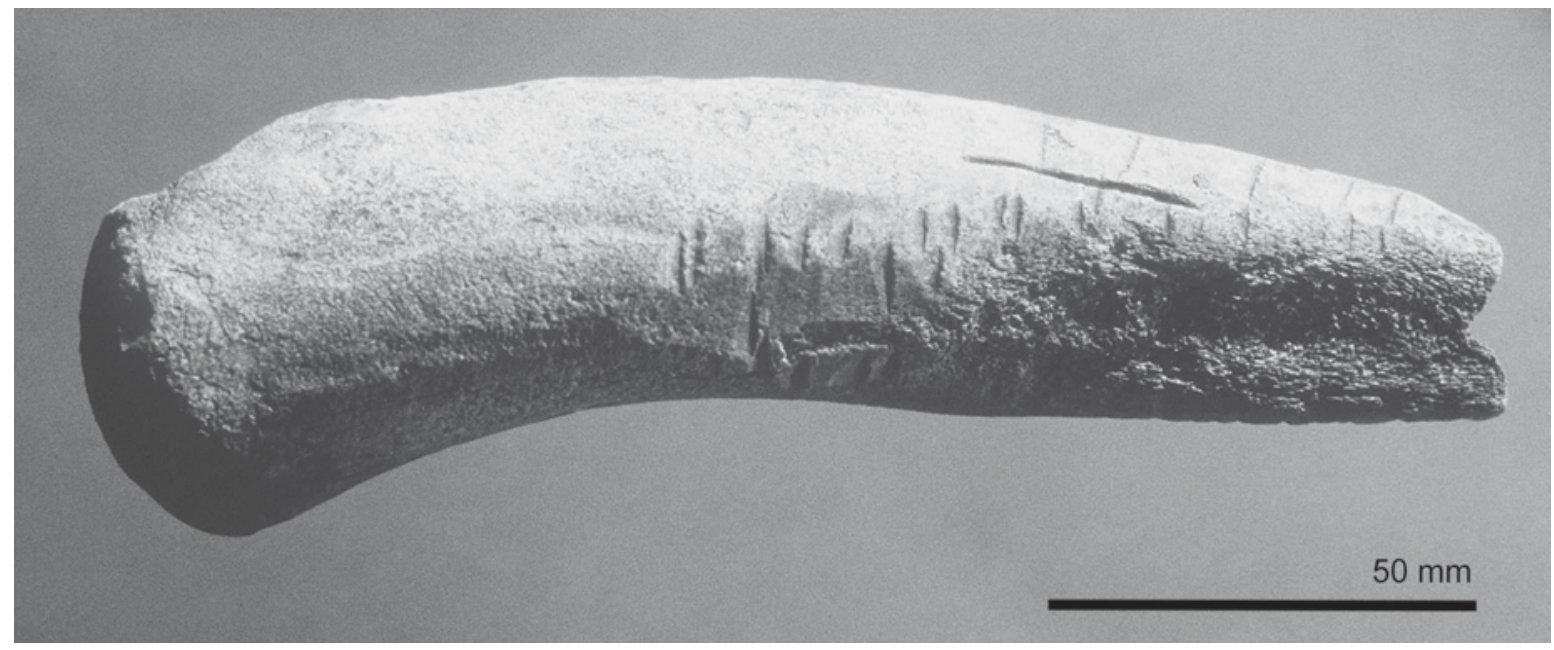

Fig. 72. The compact basis of a shed caribou antler was used to produce this wedge, $\times 16663$, phase 3. Photo: Preben Delholm.

cially flaked. In a few cases burin are made on a fragmented projectile point. From phase $2(\mathrm{~N}=4)$ all burins are made of killiaq and all are bifacially polished. From phase $3(\mathrm{~N}=66)$ all are made of killiaq except two made of quartz crystal. 43 are bifacially polished along the edges and one of them is totally bifacially polished (x4037). Some of the burins are the result of the reuse of other tool types such as projectile point or sidescrapers.

The burins vary greatly in both size and form (Figs 77-78). All burins with intact proximal ends were measured to see if any chronological trends could be observed, as suggested by Grønnow (Grønnow 1996c: 28-29; Kramer 1996b:83-85). A total of 83 burins was measured (Table 9). The conclusion is that no clear differences exist between the widths of the burins from the various phases. However, it seems that the range of variation within phase 3 is greater than in the older phases (Fig. 78).

Burin spalls are a very heterogeneous group in terms of size but not raw material as more than $95 \%$

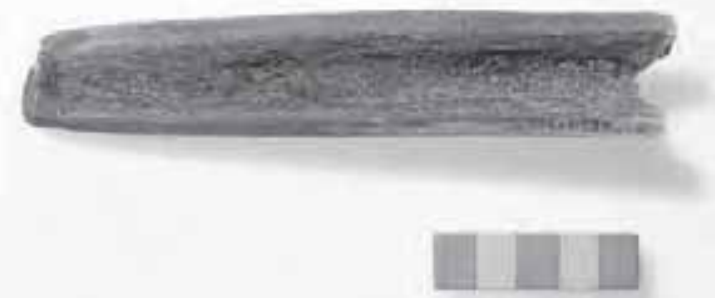

Fig. 73. Wedge made of antler, $\times 6539$, phase 3 . Notice the damage to the edge. Photo: Geert Brovad. are made of killiaq (as seen from Fig. 79). From phase I $(\mathrm{N}=55)$ I2 are primary spalls. Three spalls are made of agate and one of quartzite, the rest are made of killiaq. They range in length from $6-23 \mathrm{~mm}$ and in width
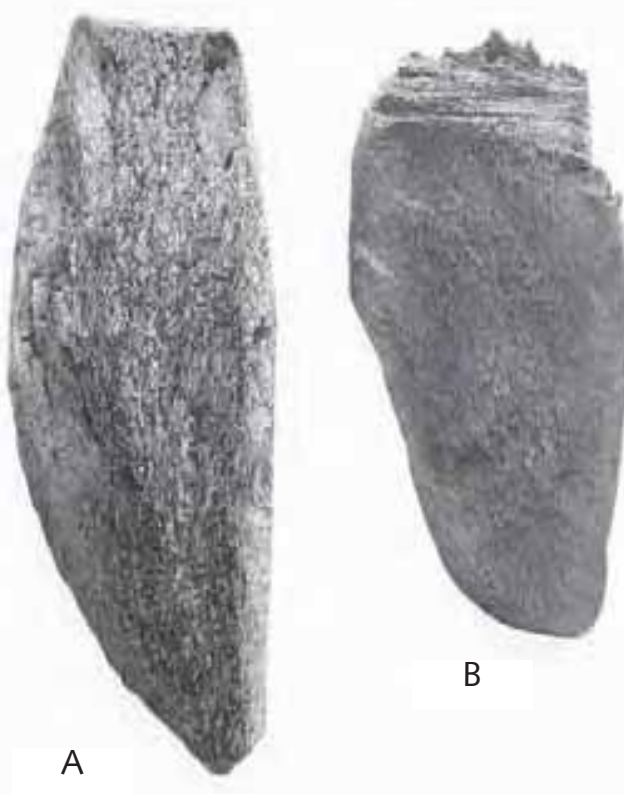

B

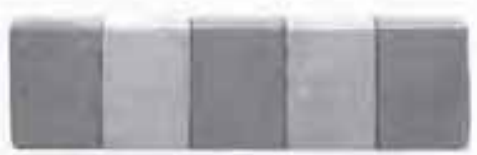

Fig. 74. Thin wedges made of antler. This type might have been hafted. A. x12175 and B. x10749. Photo: Geert Brovad. 
Fig. 75. Different kind of knife blades made of killiaq. $\times 16109,16231$ and 16364 from phase 1. $\times 16453$ from phase 2. 1:1.
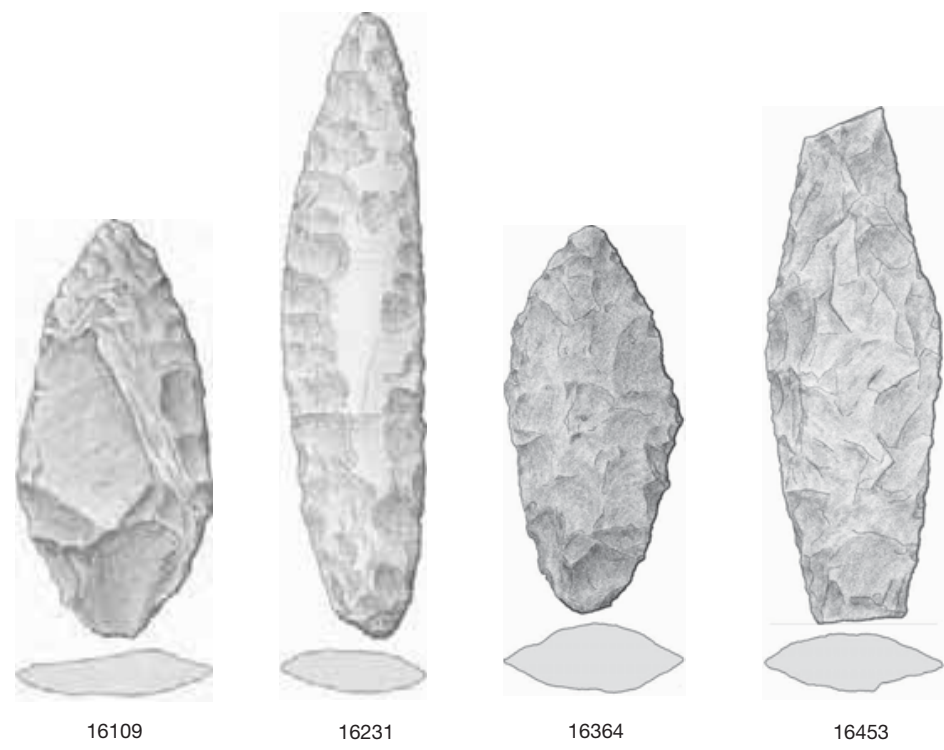

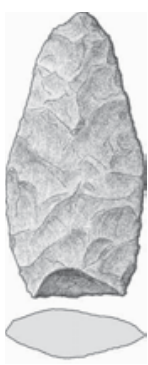

185

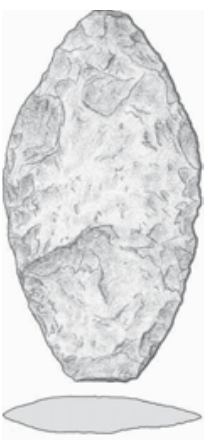

4842

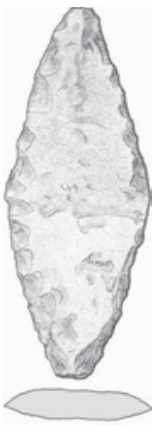

6302

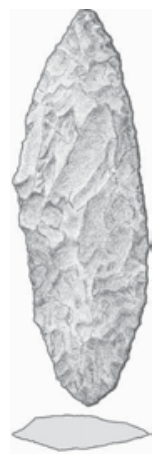

6363
Fig. 76. Different kind of knife blades made of killiaq, from phase 3. 1:1.
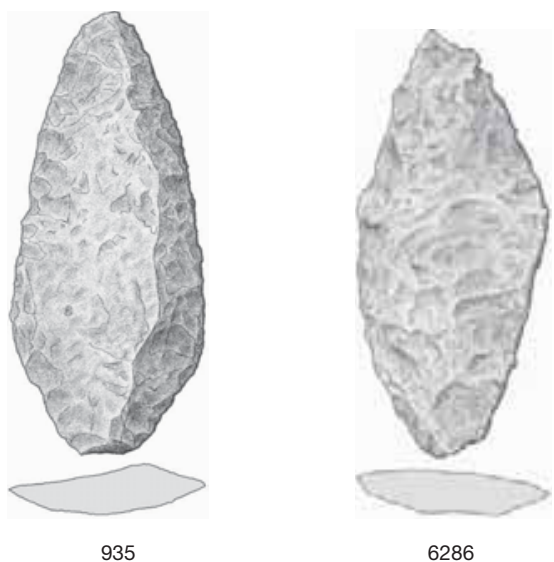

6286

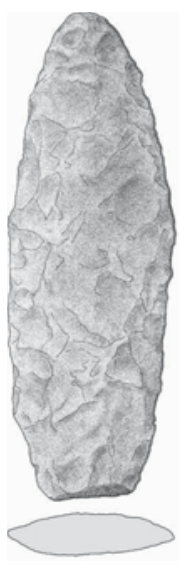

12297 

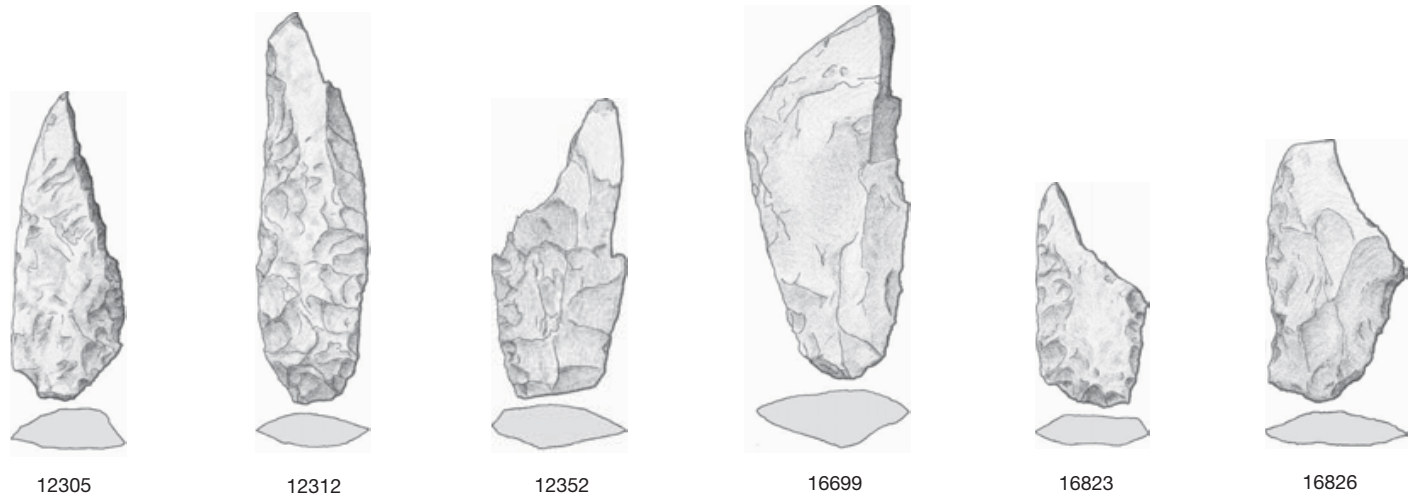

Fig. 77. Different kind of burins. $x 12305$ is made of agate, the rest are made of killiaq. $\times 12305,12312,12352$ and 16699 are from phase 1. $\times 16823$ and 16826 are from phase 2. 1:1.

from $2-5 \mathrm{~mm}$ (Fig. 79). From phase $2(\mathrm{~N}=6)$ one is made of agate and the rest are of killiaq. From phase 3 $(\mathrm{N}=\mathrm{I} 8 \mathrm{o})$ four are made of agate, one of quartz crystal, one of quartzite and the rest are killiaq. 23 are primary spalls. The length range is $4-27 \mathrm{~mm}$ and width $\mathrm{I}-5 \mathrm{~mm}$. Some of the burin spalls are retouched or have use wear at the distal end. None of the burin spalls recovered could be matched to the burins found at Nipisat. An explanation could be that the burins found at Nipisat are from the final stages of use only, whilst the entire range of spalls, from primary spalls to the final resharpening, are present in the archaeological record. In other words, the curation at the site was very high.

\section{Scrapers $(N=33)$}

Three different types of scrapers were found at the site: endscrapers, sidescrapers and unclassifiable scrapers. All three types are known from other Saqqaq sites (see Appelt and Pind 1996:137; Grønnow 1994:

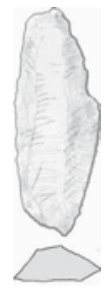

1837

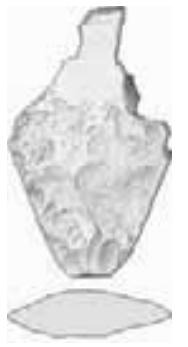

3166

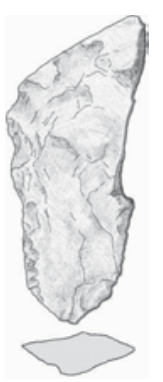

16221

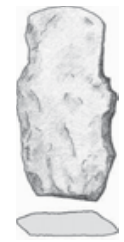

4037

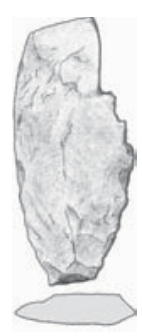

4975

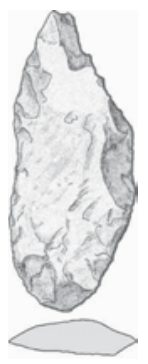

12194

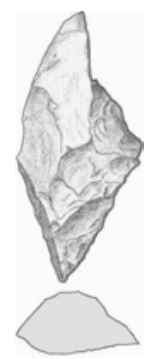

12293

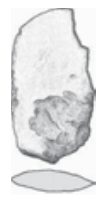

12321

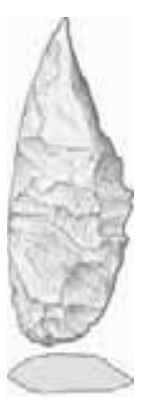

16561

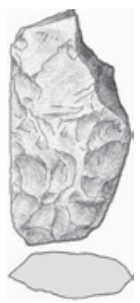

12340

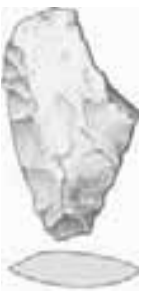

16724

Fig. 78. Different kind of burins from phase 3. $\times 1837$ is made of crystal quartz. The rest are made of killiaq. Note that $\times 16561$ is from phase 1 and made of agate. 1:1. 


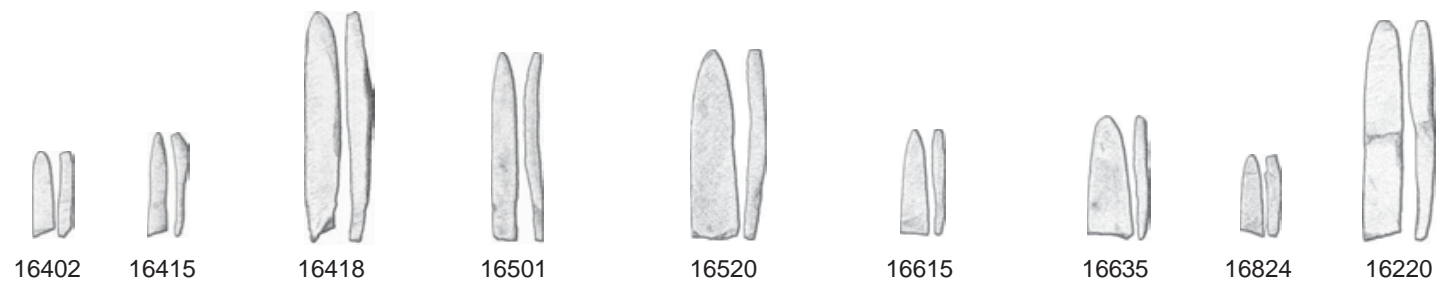

Fig. 79. Different kinds of burin spalls. $\times 16402,16415,16501,16520$ and 16615 are of killiaq, 16418 and 16635 of agate, all from phase 1. $\times 16824$ is of killiaq, from phase 2. x16220 is of agate, from phase 3. 1:1.

2II-2I2, I996c:23). All kinds of scrapers are made of flakes, and the bulb of percussion is clearly seen on the ventral side of endscrapers. On the sidescrapers traces of the bulb can be seen beneath the bifacial flaking.

I3 of them were triangular endscrapers. There is one from phase I made of killiaq and one from phase 2 made of agate (Fig. 80). From phase 3 there is a great variety in the choice of raw material. Three are made of agate, one of quartz crystal, four are made of killiaq and three are made of quartzite (Fig. 8I). The length of the scrapers varies between $19-44 \mathrm{~mm}$. However, the metric variation is not due to chronological differences but rather to the degree of use or to different tool functions (Grønnow I996c:29; McGhee 1980: 448).

I6 sidescrapers were found (six and ten from phases I and 3 respectively). From phase I, three are made of killiaq, the rest are made of agate (Fig. 82), two of them fit together so the true number is five instead of six as seen in Table 7. From phase 3 there are six agate sidescrapers (Fig. 82), one of them is a sshaped double scraper. One is of quartz crystal and very small (xi835), the rest are made of killiaq. The length varies between $30-43 \mathrm{~mm}$ in phase I and between $\mathrm{I} 8-37 \mathrm{~mm}$ in phase 3 .

Table 9. The burin base width measurements $(\mathrm{cm})$ from phase 1 to phase 3 .

\begin{tabular}{lccc}
\hline & Phase 1 & Phase 2 & Phase 3 \\
\hline Number & 15 & 4 & 64 \\
\hline Minimum width & 0.8 & 1 & 0.6 \\
Maximum width & 1.5 & 1.4 & 1.7 \\
Range & 0.7 & 0.4 & 1.1 \\
Mean & 1.15 & 1.17 & 1.13 \\
Variance & 0.03 & 0.02 & 0.03 \\
Standard Deviation & 0.199 & 0.147 & 0.196 \\
\hline
\end{tabular}

Four scrapers, two from phase I and two from phase 3, are unclassifiable. Scraper xI2I96 is from phase $\mathrm{I}$ and made of killiaq. It is $27 \mathrm{~mm}$ long and has a spatulate working edge, which is bifacially polished, the rest of the tool is bifacially flaked (Fig. 83). The other unclassifiable sidescraper from phase $\mathrm{I}$ is also made of killiaq and has a spatulated edge. One from phase 3 is of quartz crystal and the other is made of quartzite.

Seven scrapers were analysed for traces of use wear (x6368, I2196, I2197, I2353, I2354, I6316, I6395). All of them are made of killiaq, and all except one were too heavily patinated to permit use wear analysis. On xI2I96 (Fig. 83), however, traces of wood at the proximal end, probably from hafting, were observed (Claus Skriver pers. comm. 2003).

\section{Drills $(N=2)$}

The type is rare at Nipisat. One is from phase I with a crooked working edge. The other is from phase 2 and made on a flake. Both are made of killiaq.

\section{Microcores $(\mathrm{N}=10)$ and microblades $(\mathrm{N}=22)$}

Microcores and microblades are an irregular group of tools. Two cores are from phase I and eight from phase 3. Both of the phase I cores are irregular, with blades struck off from different directions. One is of green

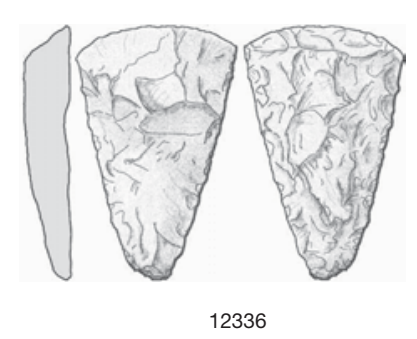

Fig. 80. Endscraper made of agate from phase 2. 1:1. 


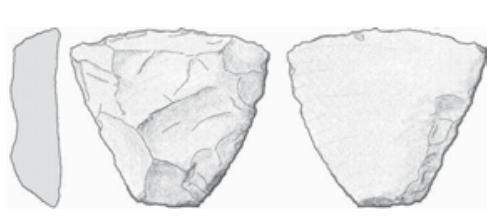

1237

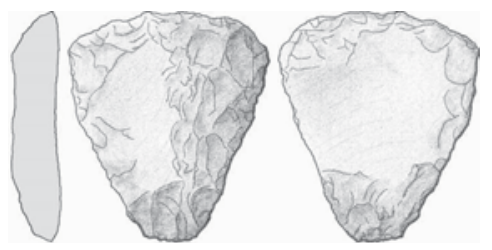

3773

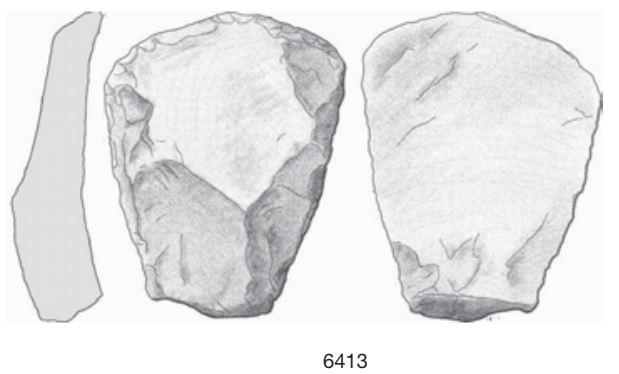

6413
Fig. 81. Different kinds of endscrapers from phase 3. $\times 1237$, 2021 and 3773 are made of agate. $x 6407,6413$ and 12354 are made of killiaq. 1:1.

2021

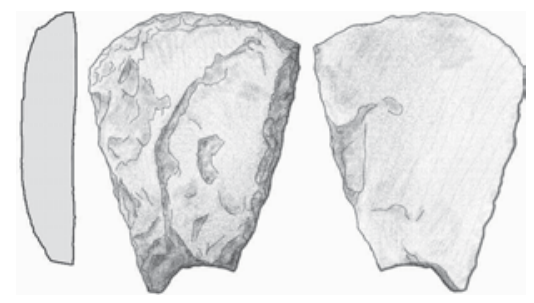

6407

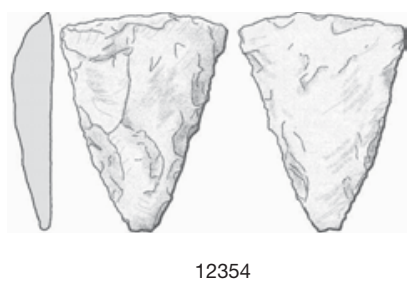

agate and the other of quartzite. From phase 3, four are made of quartz crystal, two of quartzite and two of killiaq, one of these is made of special red killiaq variant. Some of the cores are conical, some are much more irregular or fragmented.

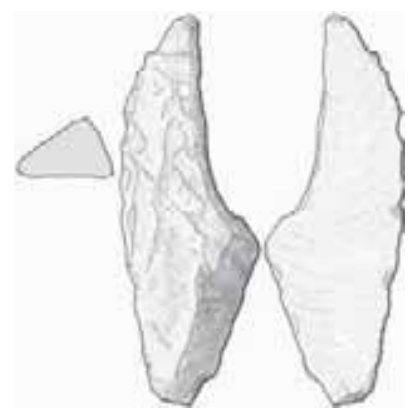

12300

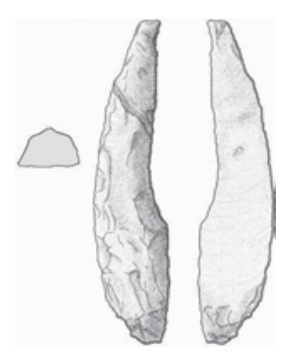

1833
From phase i seven microblades were registered, 2 of agate and the rest of quartz crystal. They generally have parallel sides and vary in length from $\mathrm{I} 6-23 \mathrm{~mm}$. From phase 2, one fragmented quartz crystal microblade was found. I4 microblades come from phase 3 .

Fig. 82. Different kinds of sidescrapers. $\times 12300$ is made of agate and from phase 1 . The rest are from phase $3 . \times 1833$ and 6285 are made of agate. $\times 1835$ is made of crystal quartz. 1:1. 
Three are made of agate, seven of quartz crystal, two of killiaq and two of quartzite. The length varies between I4-28 $\mathrm{mm}$.

\section{Adzes ( $N=2)$ and chisels $(N=1)$}

Adzes and chisels are rare at the site. All three are dated to phase 3 and are core tools. One of the adzes (x6295) is only 3I $\mathrm{mm}$ long and $32 \mathrm{~mm}$ wide at the edge, which is polished and bevelled (Kramer 1996b: 95 pl.6.I6B) The other xi6443 is a preform with a part of the cortex preserved. Both are made of killiaq. The type is also known from the oldest phase of the Saqqaq Culture as seen at Qeqertasussuk (Grønnow 1996a:84) and Ikaasap Ittiva (Møbjerg 1988a:85).

The chisel (x2003) is of quartzite and $58 \mathrm{~mm}$ long (Kramer i996b:95 pl.6.I6C).

\section{Hammerstones $(\mathrm{N}=2)$}

Two elongated cobbles were interpreted as hammerstones because of battering at the ends. The one from phase I is made of granite and measures $20 \times 22 \mathrm{~mm}$. The other, from phase 3 , is made of gneiss and has been battered at both ends. The size is $46 \mathrm{x} 60 \mathrm{~mm}$.

\section{Whetstones $(\mathrm{N}=41)$}

These are made of pumice or sandstone and are known from several Saqqaq sites (Grønnow I996a:85; Møbjerg and Grummesgaard-Nielsen I997b:253).

From phase I there are seven of sandstone and five of pumice. From phase 3 there are eight of sandstone and 2I of pumice. This tool type is modified in different ways. Some have a grip and a smooth surface on one side and might have been used for smoothing/polishing flat surfaces. Others have incisions or grooves cut into the surface and might have been used for fine polishing of needles, handles or shafts. Others are whetstones for sharpening knives, burins and bevelled points. The sandstone whetstones have a more finely grained, harder surface than those of pumice suggesting differential use. Sandstone might have been used for polishing lithic tools and pumice for organic material such as antler, ivory or bones.

\section{Smoothing stones $(N=1)$}

One granite cobble is interpreted as a smoothing stone for skin because of a very fine gloss all over the surface. It is dated to phase 3 and measures $27 \times 39 \mathrm{~mm}$.

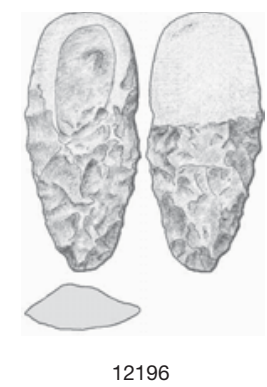

Fig. 83. A special kind of scraper with a polished working edge made of killiaq from phase 1. 1:1.

\section{Distribution of hand tools}

The distribution of all types was analysed on spreadsheets. The overall pattern of distribution is the same for all tool classes, (as for the flakes) so only selected spread-sheets are reproduced to show minor differences. On the spread-sheet showing tools from phase I and 2, both the bedrock and the dwelling structures are seen. The dwelling features from phase 3 in the northern part are so poorly defined that they are omitted from the spread-sheets. The same is the true for bedrock, because the main part has been covered by older deposits (layer $2 \mathrm{~K}$ and 2s, see p. 27) (Figs 8488).

Microblades are found hafted at Qeqertasussuk and could have been used as knives for skin working (Grønnow 1994:212 fig. I4; Grønnow and Meldgaard I99Ib:I20). Therefore their distribution is analysed on the same spreadsheet as other skin working hand tools (i.e. needles and awls) (Figs 84-85). The distribution of tools for skin working in relation to dwelling structures and other features in phases I and 2 is seen in Fig. 84. As can be seen, the distribution is highly patterned. There is a concentration around the dwelling structure in the southern part of the site. Another concentration is seen around the more disturbed dwelling features in the northern part of area I (see Fig. 26). This is very different from the distribution of artefacts in phase 2. No artefacts are found around the dwelling structure, but a few are seen in the northern part of the area. In phase 3 a more homogeneous distribution is seen throughout the excavated area, but there is a concentration in the central part of area 2 and in the northwestern part of area 3 (Fig. 85). In phases I and 2, 


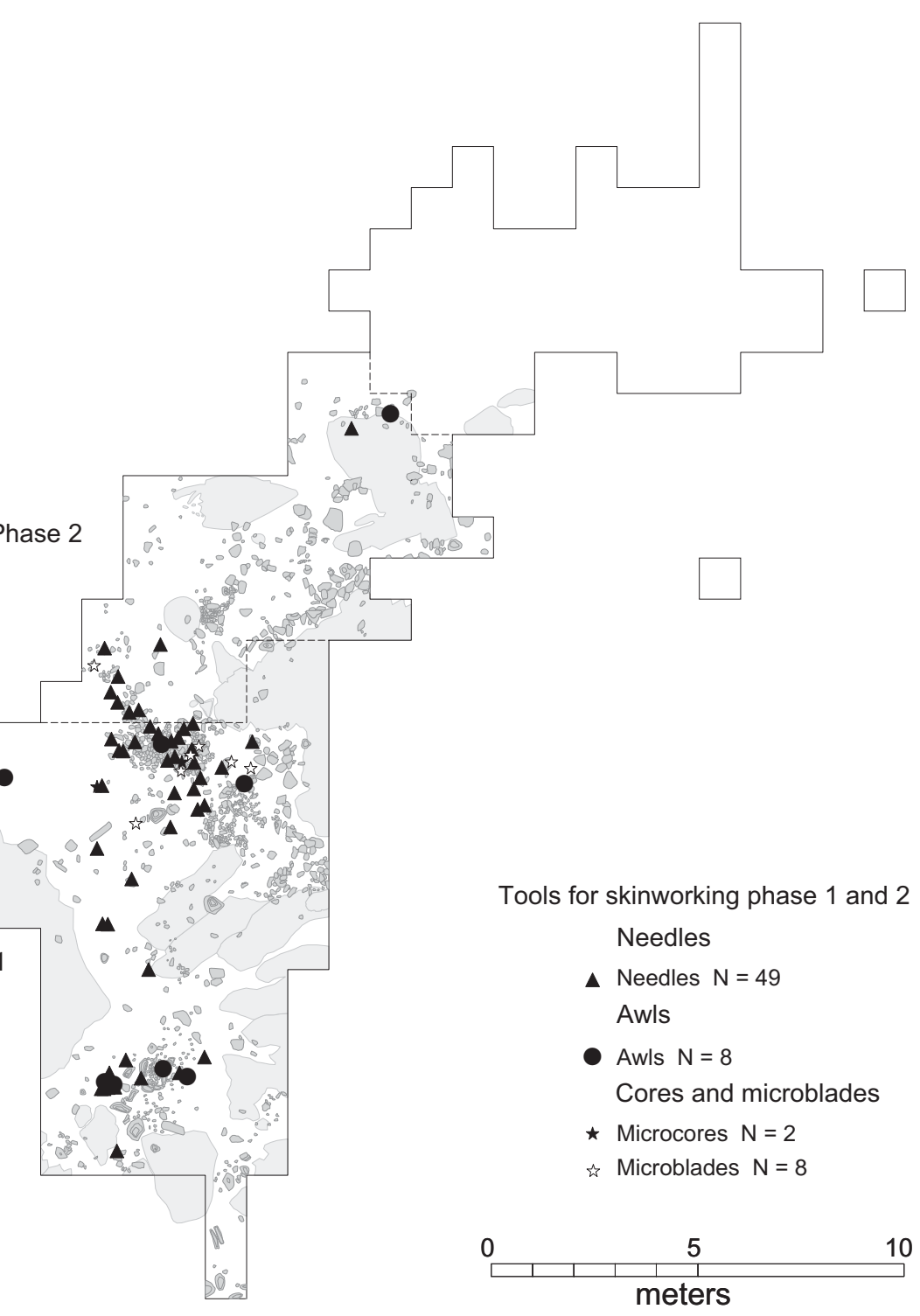

Fig. 84. The horizontal distribution of bone needles, awls, microcores and microblades in phases 1 and 2. One needle of antler (x10798) used for net making (from 385,48x/189,85y) should be omitted.

needles, awls and microblades tend to have identical distribution patterns, as if they were used together for the same purpose. In phase 3 , microblades are more diffusely distributed, especially in the north eastern part of area 3.

The distribution of killiaq burins and burin spalls is shown in Figs 86-87. From phase $\mathrm{I}$ it is obvious that there is an activity area southwest of the hearth and the burins and burin spalls have almost identical distribution patterns. Two further concentrations are seen, one in the central part of area I and one in con- nection with the feature in the northern part of area I. Interestingly, there is a total lack of tools around the hearth in area 2, phase 2. Looking at phase 3 there is a more even distribution for area I and a concentration in the central part of area 2. The density of both burins and spalls in the eastern part of area 3 is particularly noticeable (see Fig. 87).

From phasesi and 2, other hand tools such as knives and scrapers have nearly the same distribution as seen for burins and burin spalls (Fig. 88). Even though the number of artefacts is small, some activity areas can be 


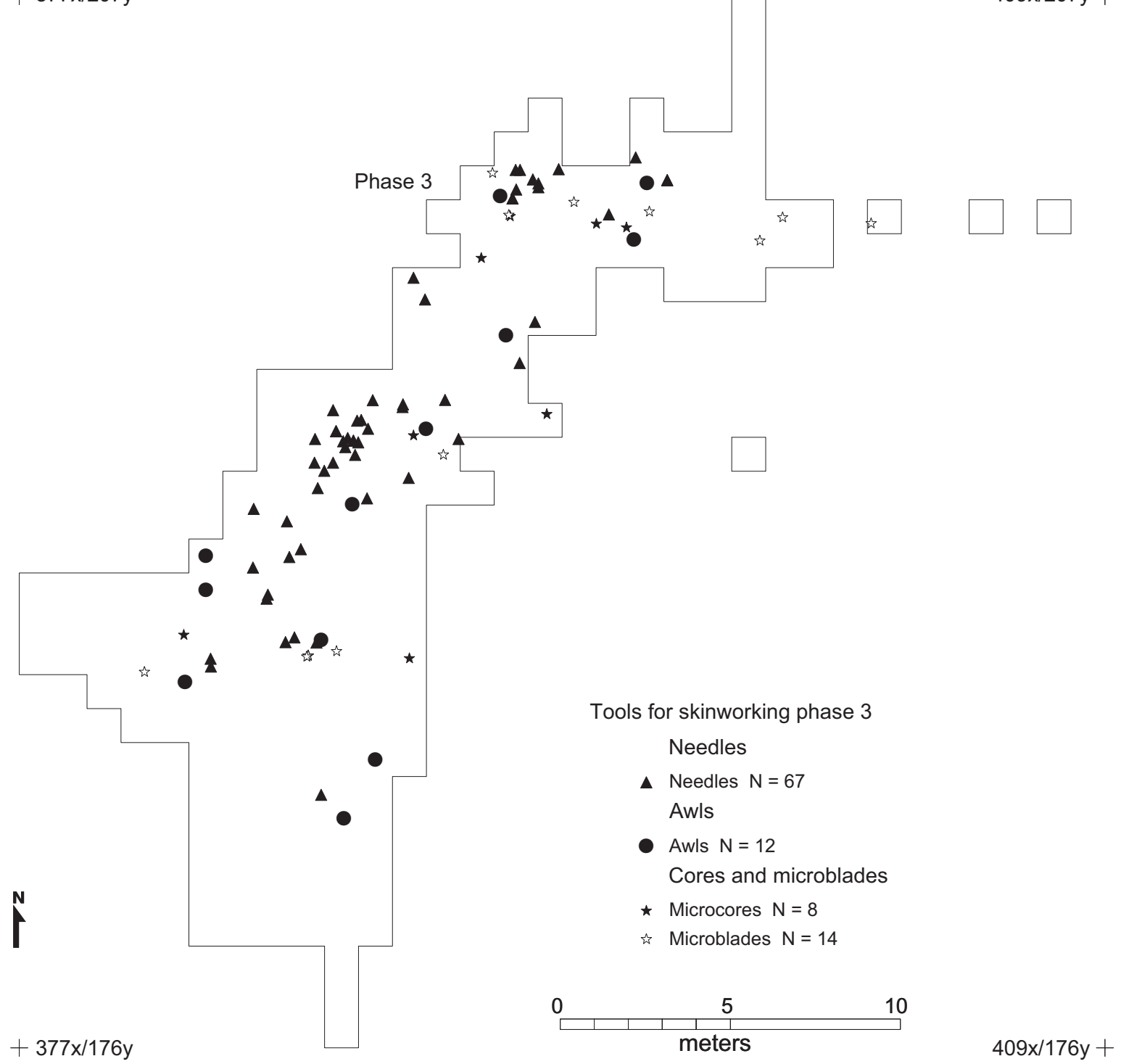

Fig. 85. The horizontal distribution of bone needles, awls, microcores and microblades in phase 3. One needle of antler (x6498) used for net making (from 388,48 x/192,80 y) should be omitted.

observed e.g. in the area just west of the hearth in area I. In phase 3 , the distribution for knives and scrapers are the same as for burins and burin spalls.

\section{Tools for hunting and fishing}

The finds from Nipisat reveal a wide variety of tool types used for hunting and fishing. Many of them are types unknown from previous excavations at Saqqaq sites. This is particularly true for phase 3 , where new types of harpoon heads, barbed spears, barbed leisters and bevelled harpoon blades were recovered.

\section{Organic}

Toggle harpoon heads (female) ( $N=2)$

Only two harpoon heads were found, both of them date to phase I and are made of antler. XIO793 (46 x 6 $\mathrm{mm}$ ) is a toggle harpoon with open socket (4 mm width) and one lateral spur, it is selfbladed and narrows at the socket. The elongated line hole is placed 2 $\mathrm{mm}$ above the socket and is parallel to the flat side of 


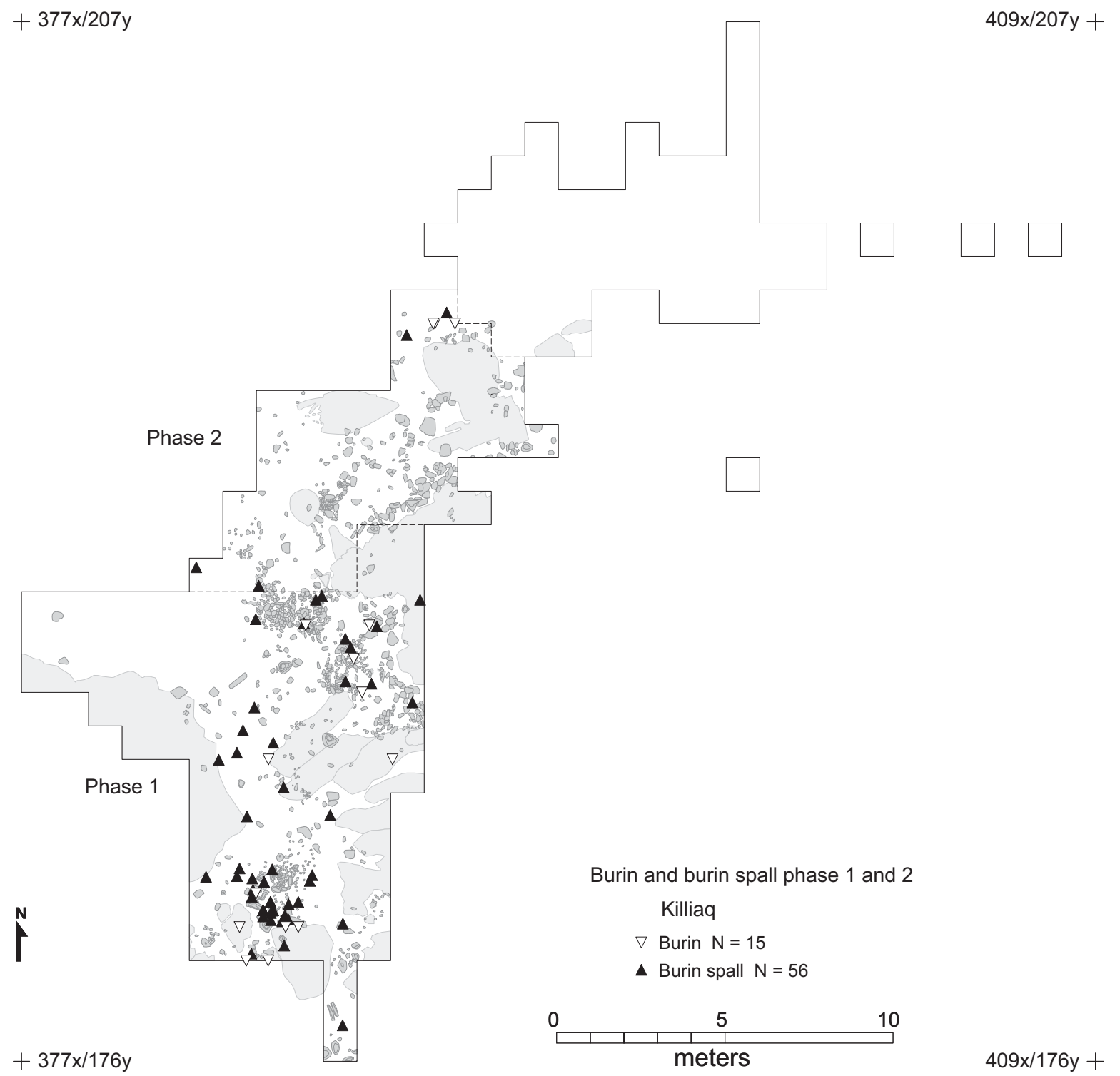

Fig. 86. The horizontal distribution of burins and burin spalls of killiaq in phase 1 and 2 .

head. xi6236 (37 x $4 \mathrm{~mm}$ ) is the same type, but smaller and very weathered (Fig. 89). Both harpoon heads are extremely small. Perhaps xio793 has been resharpened and xi6236 could be a child's plaything.

Parallels to this type are known from Qajaa (J. Meldgaard 1983:94), where a similar item was found in area $\mathrm{E}$ and here dated to $1975+85 \mathrm{BC}$ (cal). This type was not found at Qeqertasussuk (Grønnow I997:I25).

Tanged harpoon heads (male) $(N=1)$

$\mathrm{xI} 2 \mathrm{I} 66(47 \mathrm{x} 9 \mathrm{~mm})$ is a male harpoon head from phase
I with a tapering tang, scratched with very fine cutmarks. The line hole is asymmetrically placed through the broad side of the head. This harpoon was self-bladed but reworked into a kind of pressure flaker. It is therefore not possible to see whether the head was originally barbed (Fig. 89).

It is difficult to find parallels for this reworked harpoon head. Closest is type Qt-B from Qeqertasussuk (Grønnow I997:124-26 and fig. 3.9). The same type is known from Qajaa (J. Meldgaard 1983:94, I991:200), from Port Refuge, Upper Beach Feature 6 (McGhee 1979:70, pl.4s) and from Devon Island, 

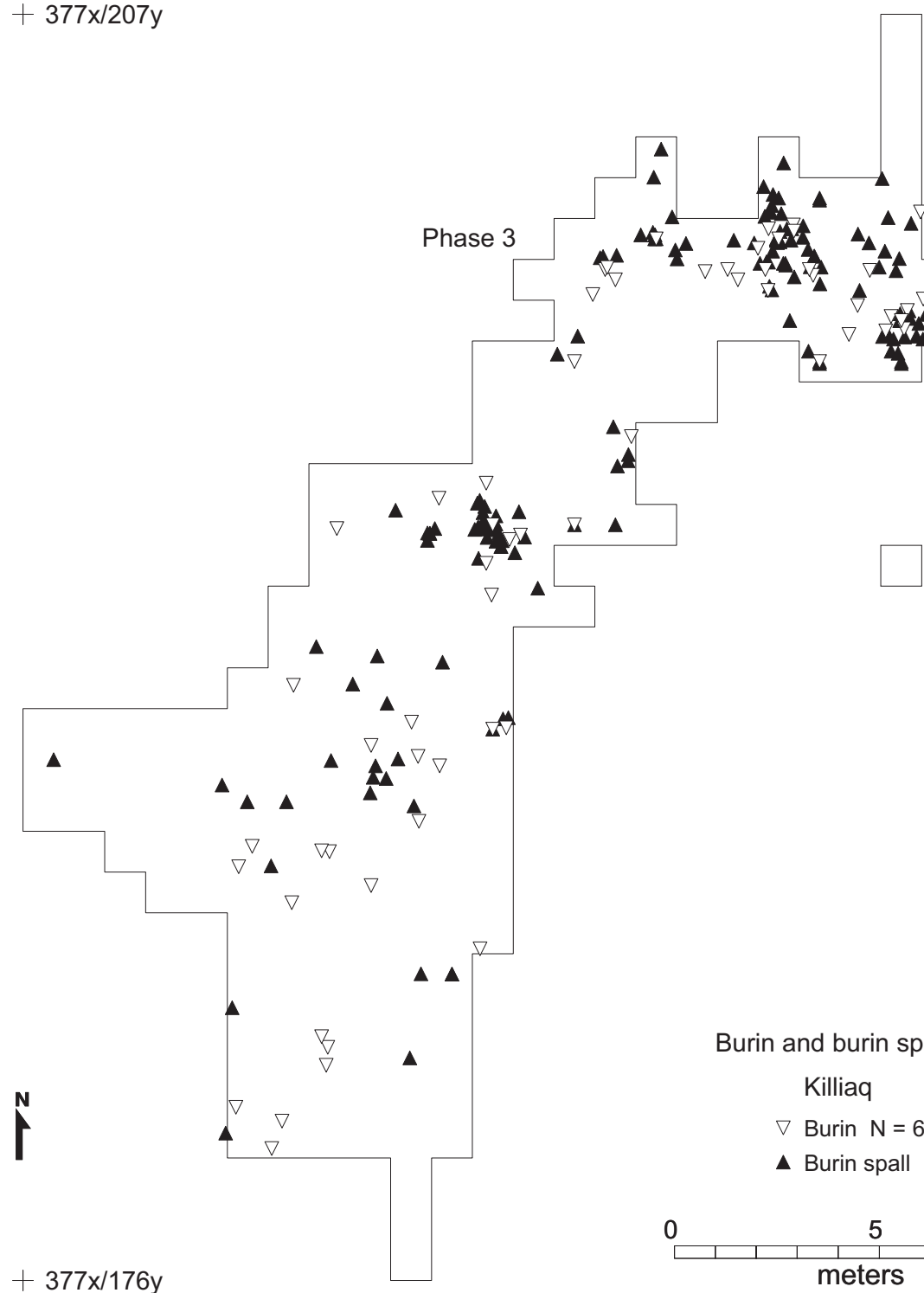

$409 x / 207 y+$

$+377 x / 176 y$

Fig. 87. The horizontal distribution of burins and burin spalls of killiaq in phase 3 .

Icebreaker Beach complex (Helmer 1991:305-308, fig. $8 \mathrm{a}-\mathrm{b})$. The harpoon heads from these sites all have relatively early dates around $2200 \mathrm{BC}$ (cal).

Large tanged harpoon or lance heads (male) $(\mathrm{N}=3)$

A new type of tanged harpoon or lance head was recovered at Nipisat (Fig. 90). All of them are made of antler, self-bladed and dated to phase 3. XI307 (I45 X $23 \mathrm{~mm}$ ) has a tapering tang with one shoulder and an elongated line hole centrally placed just above the shoulder. Io $\mathrm{mm}$ above the line hole there is a mark and from here the tool is cut at an oblique angle mak- ing a sharp point. $\mathrm{x} 6527$ ( $\mathrm{I} 37 \mathrm{x} 26 \mathrm{~mm}$ ) also has a tapering tang, two shoulders and an elongated line hole, asymmetrically placed to $\mathrm{mm}$ from the shoulders. The tool is made in the same way as XI307 with an oblique cut (Fig. 9I). x6535 (96 x $23 \mathrm{~mm}$ ) has a tapering tang, one shoulder and, at the same level, a centrally placed elongated line hole. The tool is reworked and had a square indentation on the ventral side (Fig. 92). For the time being there are no parallels from Saqqaq contexts in Greenland. The closest parallel is from Victoria Island, Ekalluk River region (Fig. I, no. II). Two items from the Early Dorset site at Ferguson Lake interpreted 


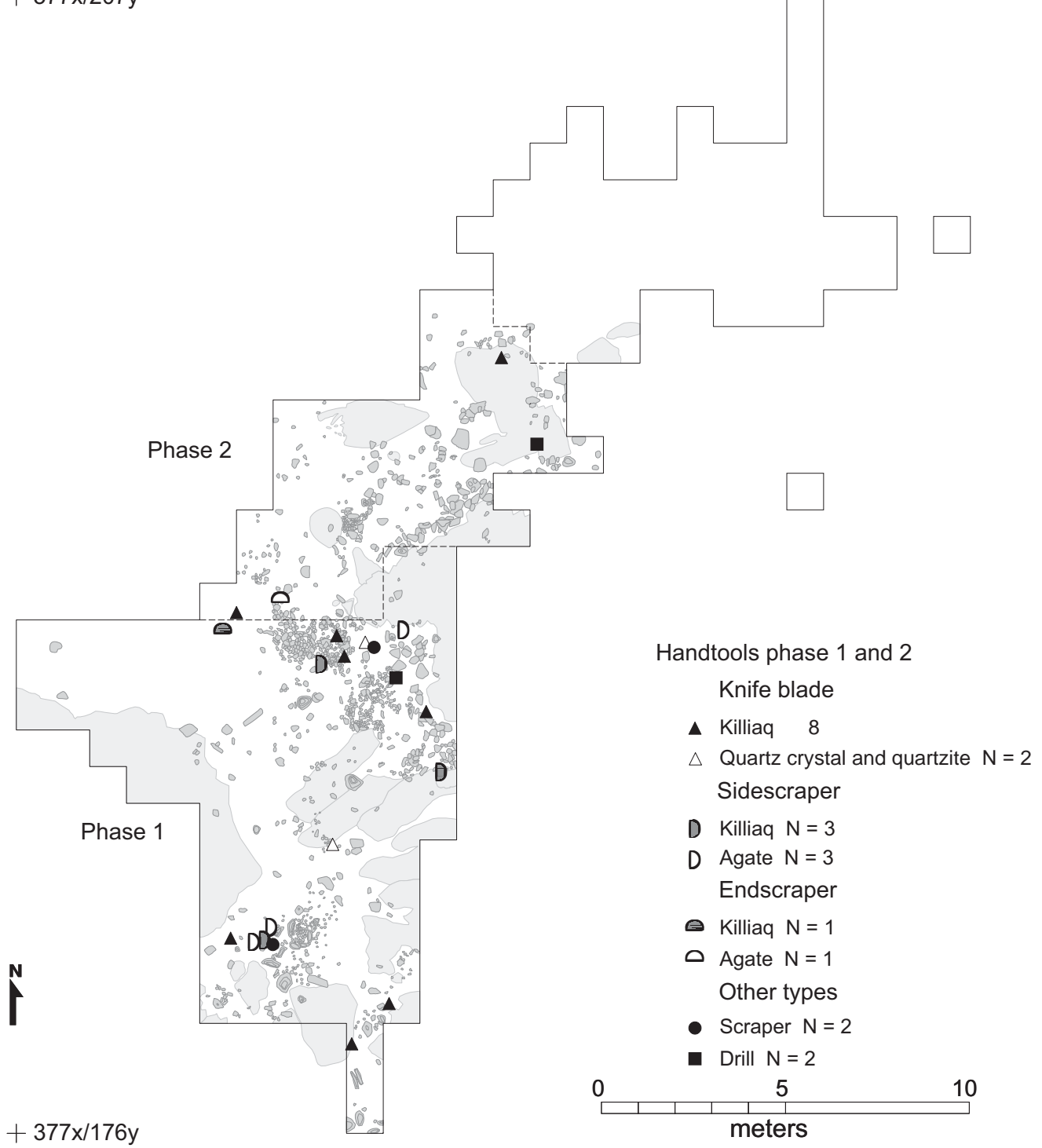

Fig. 88. The horizontal distribution of different kinds of hand tools in phases 1 and 2.

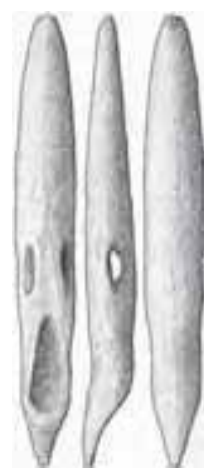

10793

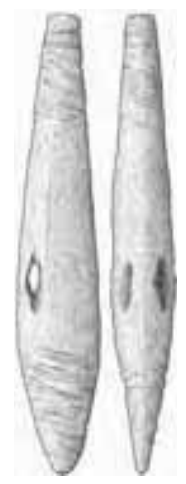

12166

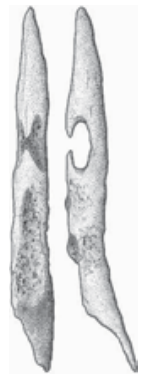

16236

as foreshafts have some similar traits (Taylor 1967:239, fig. 9 i-j). From the Pre-Dorset Buchanan and Menez sites there are several similar (but not identical) antler objects (Taylor 1967:235-36, fig. 5b, 6a). There are a few ethnographic parallels from the Makah Indians, where a similar composite tool is used for whaling (Stewart I996:I09-IIo; Waterman I920: plate 8 and

Fig. 89. Two toggle harpoon heads ( $x 10783$ and $\times 16236)$ and one tanged harpoon head ( $x 12166)$ The tanged harpoon head is reworked and used as a kind of pressure flaker. All are made of antler and from phase 1. 1:1. 
Fig. 90. Two heavy harpoon or lance heads of antler from phase 3 in area 3 square $388 \mathrm{x} / 194 \mathrm{y} . \mathrm{x} 6527$ to the right in situ and to the left $x 6535$ deriving from square $388 x / 193 y$. Photo: Sönke Hartz.

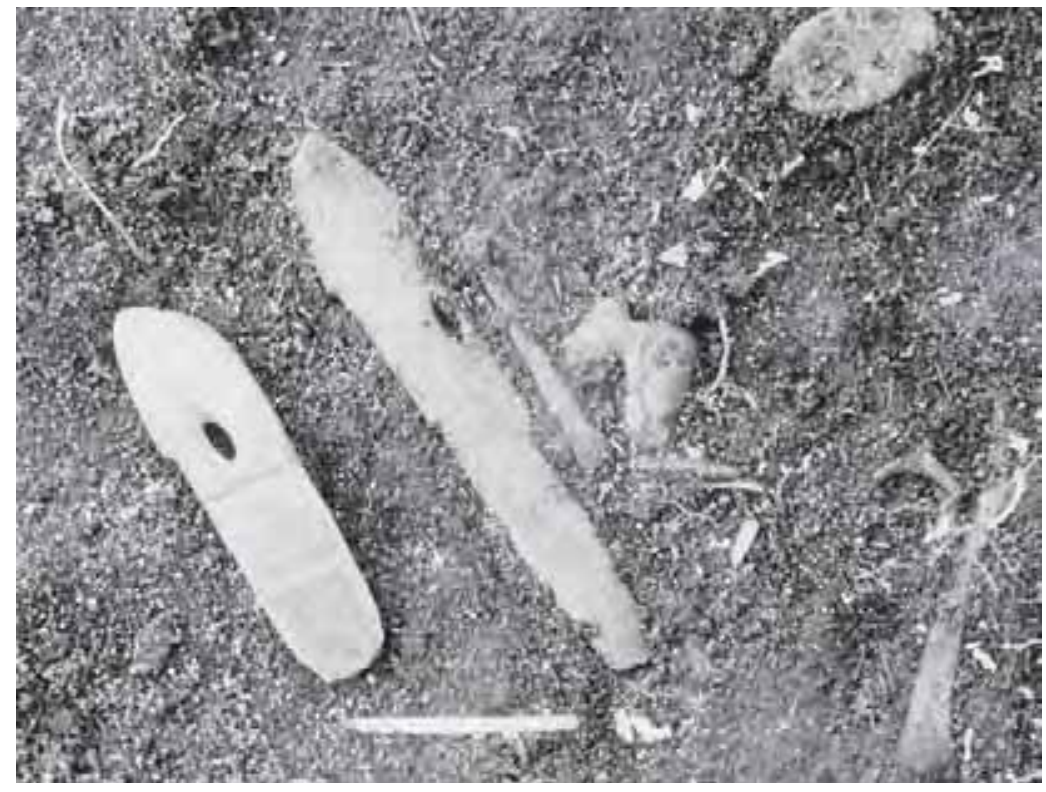

fig. I2). The ethnographic examples, combined with discussions with colleagues, provide the basis for these artefacts having been interpreted as weapons for hunting walrus or whales (R. McGhee pers. comm. I997; M. Meldgaard pers. comm. I995; P. Plumet pers. comm. 1996). This interpretation is also based on the sturdy appearance of the type and the fact that no other harpoon heads are recorded from phase 3.

\section{Foreshafts $(N=28)$}

The frequency of foreshafts is high, with Io, 2 and I6 examples occurring in phases $\mathrm{I}, 2$ and 3 respectively.

From phase I, four are made of whale bone, one is of ivory and the rest are of antler (Fig. 93). All are fragmented in such a way that only the oblique end used for lashing is preserved. The sole exception is xIo792 which is IIo $\mathrm{mm}$ long and $8 \mathrm{~mm}$ wide. This foreshaft is unique as it does not have an oblique base for lashing (Kramer 1994:22I).

Two foreshafts were recorded from phase 2, both made of antler and both fragmented.

From phase 3, three ivory and two whale bone foreshafts were recovered. x6545 is considerably longer (400 mm) than the others (Kramer 1996b:94 pl.6.I3). The rest are made of antler. Two of these are complete and measure 160 and $140 \mathrm{~mm}$ in length respectively (Fig. 94). These two could have been used as arrowheads rather than foreshafts. $\mathrm{x} 6502$ is a small fragment ( $35 \times 5 \mathrm{~mm})$ and has a slot in the basal end
(Kramer I996b:93 pl. 6.12E). xi6994 has a groove for lashing and XI7040 has a lateral groove.

It was possible to measure the width of 24 foreshafts (Table Io). As can be seen, the mean and the variance are greatest for phase $\mathrm{I}$ and the range is greatest in phase 3. The histogram in Fig. 95 shows the numbers for phase $\mathrm{I}$ and 3 (phase 2 is excluded because of the small sample size). The width of the foreshafts from phase I lie between 5-I5 $\mathrm{mm}$ with one exception ( $18 \mathrm{~mm}$ ), compared to phase 3 where the range is 5-Io $\mathrm{mm}$ with one exception ( $19 \mathrm{~mm}$ ). In spite of the small number of foreshafts, this hints at chronological differences in the material.

In addition to foreshafts made of bone and antler, several foreshafts from Qeqertasussuk were made of driftwood (Grønnow 1988b:30, I996a:87, I997:I28),

Table 10. Metric analysis of foreshaft diameter $(\mathrm{cm})$ from phase 1 to phase 3 .

\begin{tabular}{lccc}
\hline & Phase 1 & Phase 2 & Phase 3 \\
\hline Number & 10 & 2 & 12 \\
\hline Minimum width & 0.6 & 0.8 & 0.5 \\
Maximum width & 1.8 & 1 & 1.9 \\
Range & 1.2 & 0.2 & 1.4 \\
Mean & 1.1 & 0.9 & 0.75 \\
Variance & 0.16 & 0.01 & 0.13 \\
Standard Deviation & 0.4 & 0.1 & 0.37 \\
\hline
\end{tabular}




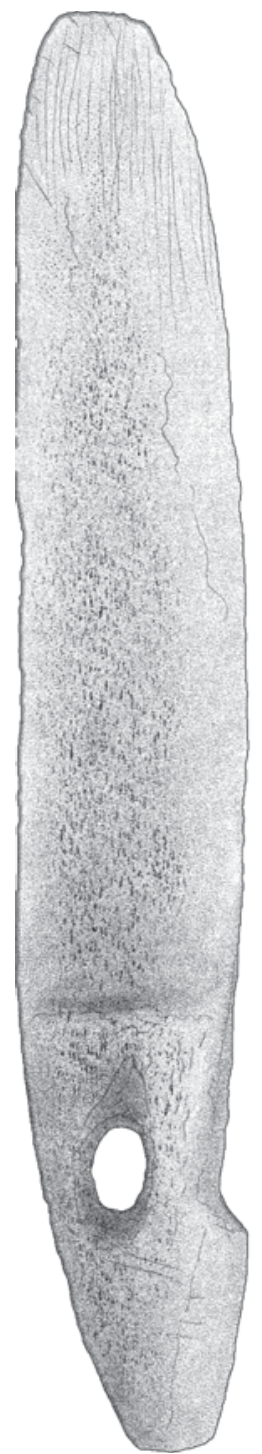

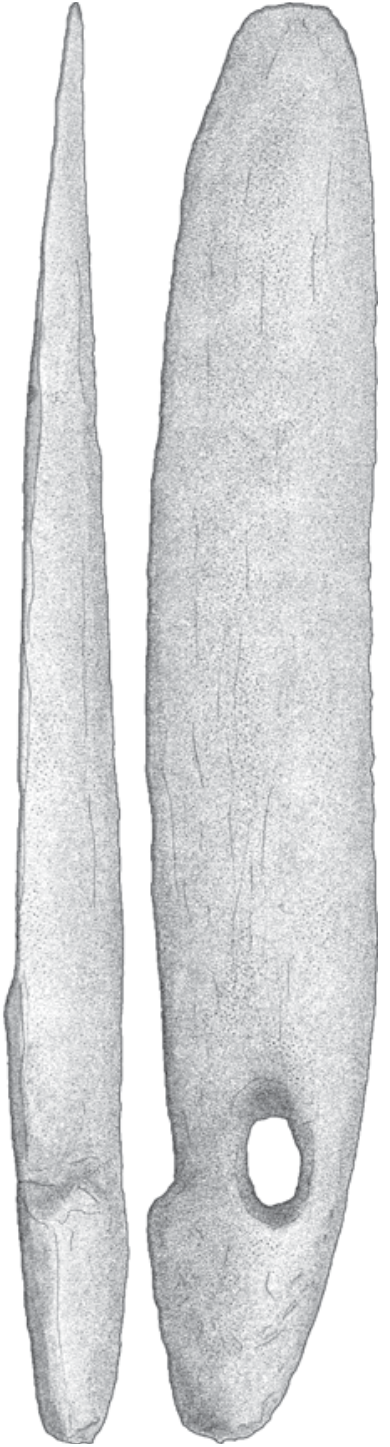

1307
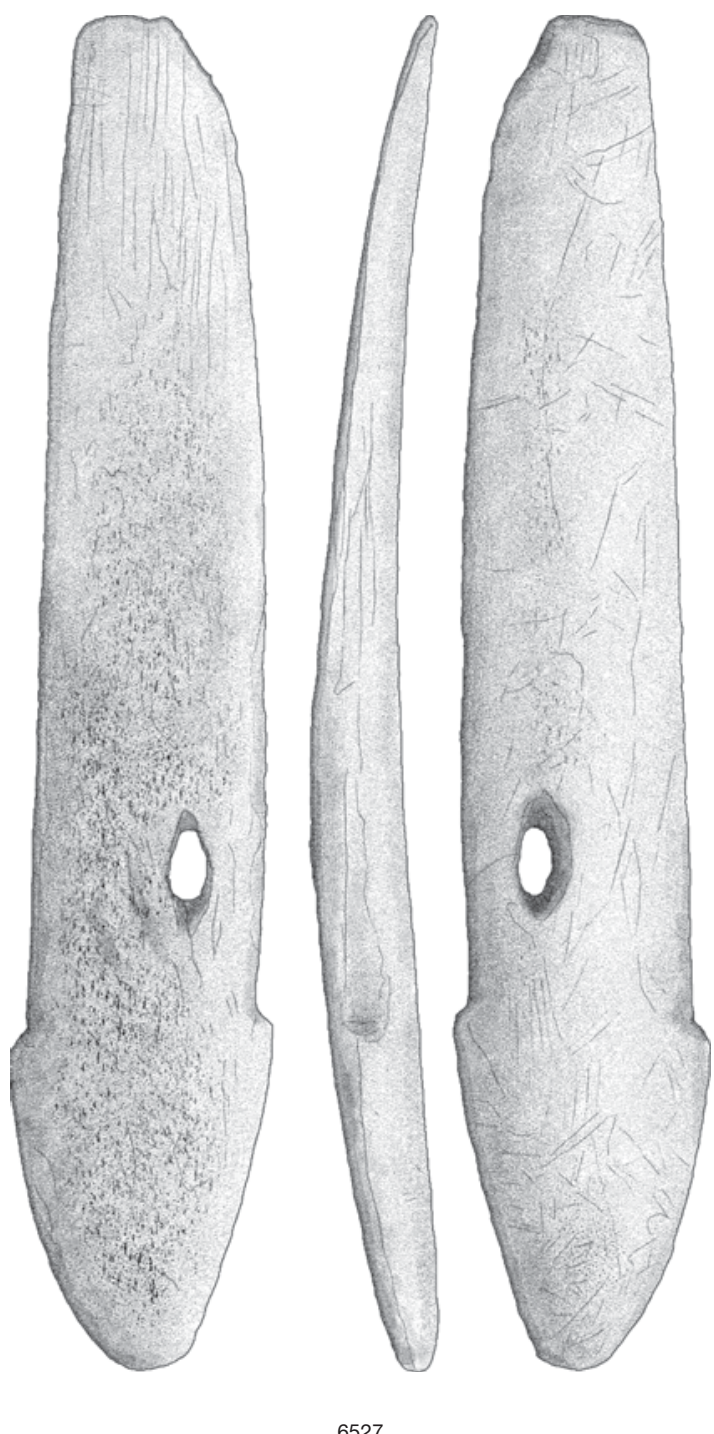

6527

Fig. 91. Heavy tanged harpoon or lance heads made of antler from phase 3. 1:1.

Table 11. Metric analysis of length $(\mathrm{cm})$ of projectile point from phase 1 to phase 3.

\begin{tabular}{lccc}
\hline & Phase 1 & Phase 2 & Phase 3 \\
\hline Number & 7 & 5 & 20 \\
\hline Minimum length & 2.2 & 2.1 & 1.7 \\
Maximum length & 5.2 & 3.9 & 3.6 \\
Range & 3 & 1.8 & 1.9 \\
Mean & 3.3 & 2.86 & 2.67 \\
Variance & 0.771 & 0.554 & 0.404 \\
Standard Deviation & 0.878 & 0.745 & 0.636 \\
\hline
\end{tabular}

which makes the comparison with Nipisat more complex.

\section{Throwing boards ( $N=1)$}

Only one example from phase $\mathrm{I}$ is registered (Fig. 96). It is fragmented and only the distal end is preserved. It is made of whale bone with a little hook $(25 \mathrm{~mm})$ for the harpoon shaft made of antler. The preserved section of the throwing board is only $55 \mathrm{~mm}$ long and 2 $\mathrm{mm}$ wide. The groove for the harpoon shaft is $9 \mathrm{~mm}$ in diameter. Like the harpoon heads, the throwing board 

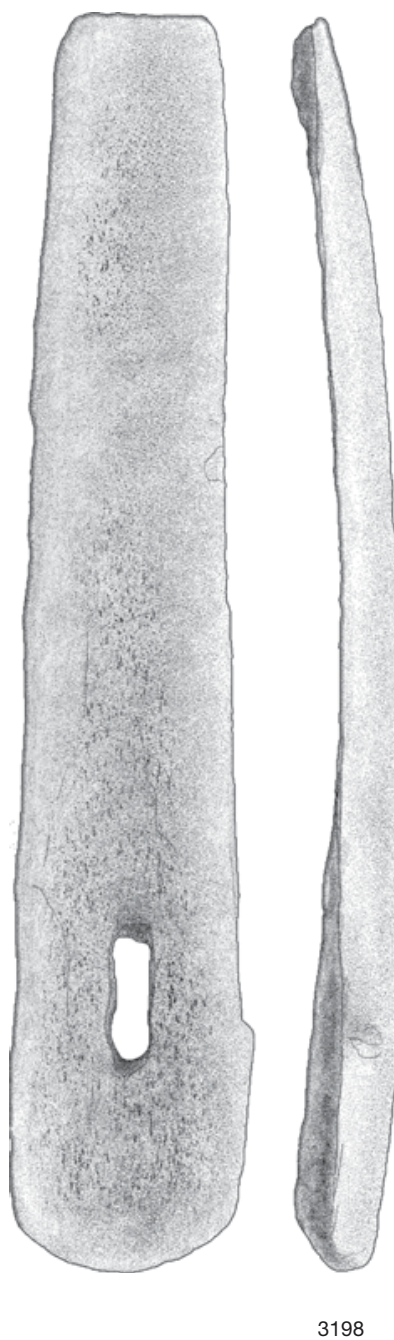

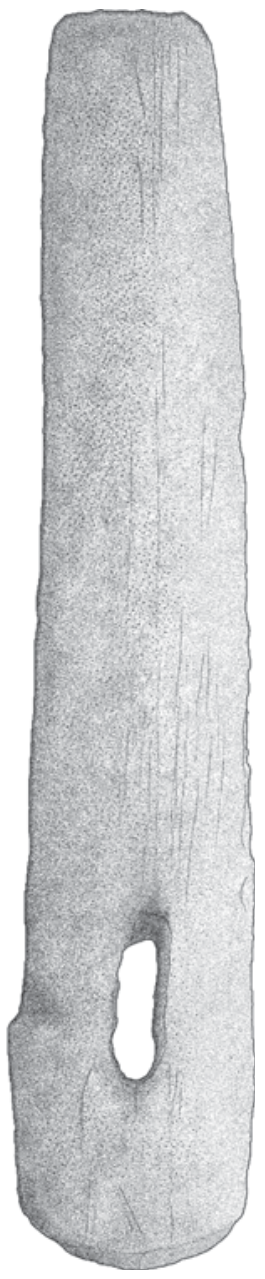

3198
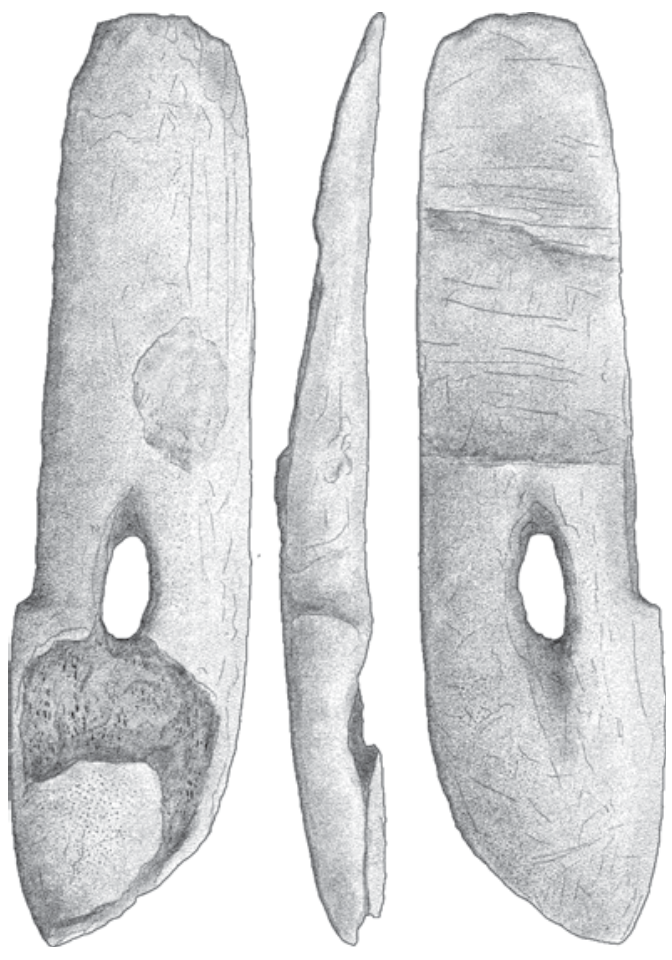

6535

Fig. 92. $\times 3198$ is a handle with an eye and a slightly marked shoulder. $\times 6535$ is a tanged harpoon or lance head, the blade is reworked. Both artefacts are made of antler and are from phase 3. 1:1.

is very light. This is in accordance with the foreshafts found from phase I (see Fig. 93), but also corresponds well with the few fragments of throwing boards found on other early sites in Greenland and Canada, one from Qajaa (Meldgaard, J. 1983:94, I99I:200) and one from Devon Island, Icebreaker Beach complex (Helmer 1991:306, fig. 8h).

\section{Barbed spears or leisters $(N=5)$}

This group is heterogeneous, but all date to phase 3 . XI2I9 is made of ivory and measures I6o $\mathrm{mm} \mathrm{X} \mathrm{II} \mathrm{mm}$. It has three barbs along one side. The leister or spear could have had more barbs as the tip is missing. Below the last barb there is an incision, which resembles a bird footprint. It would originally have been bi-point- ed and was not designed for lashing onto a shaft (Figs 97-98). x60o is similar to that previously mentioned, but has four barbs and is broken at both ends just

Table 12. Metric analysis of width $(\mathrm{cm})$ of projectile point from phase 1 to phase 3 .

\begin{tabular}{lccc}
\hline & Phase 1 & Phase 2 & Phase 3 \\
\hline Number & 7 & 5 & 20 \\
\hline Minimum width & 1.1 & 0.4 & 0.5 \\
Maximum width & 2 & 2.7 & 2.1 \\
Range & 0.9 & 2.3 & 1.6 \\
Mean & 1.5 & 1.48 & 1.4 \\
Variance & 0.126 & 0.533 & 0.077 \\
Standard Deviation & 0.355 & 0.73 & 0.277 \\
\hline
\end{tabular}




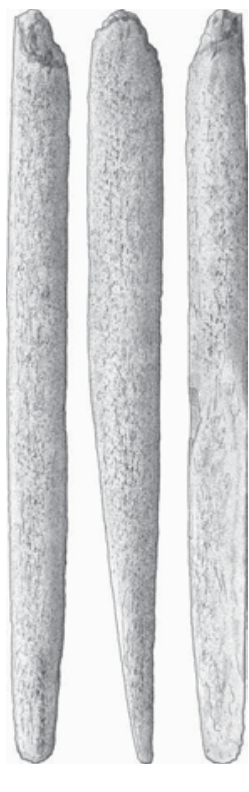

10748

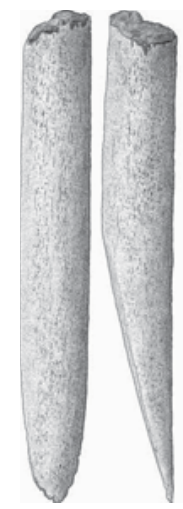

10752

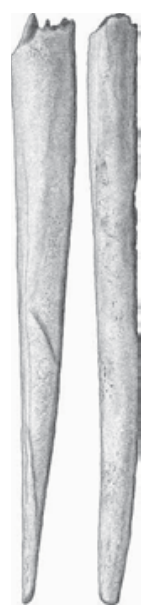

10754

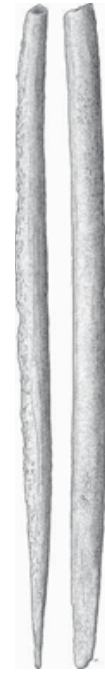

10788

Fig. 93. Heavy and light foreshafts from phase 1. x10748 and 10752 are made of whale bone. $\times 10754$ and 10788 are made of antler. 1:2.

above and below the barbs (Fig. 99). It is therefore not possible to see if there were any incisions. Similar tools are known from Qeqertasussuk, although they are made of whale bone and are more curved (Grønnow I994:223).

XIO759 is made of antler and is broken at the distal end just below a barb or spur. At the opposite end it is obliquely cut to facilitate lashing (Fig. 99). This tool has been reworked in some way, as can be seen from the groove running from the barb and into the obliquely cut end. There are also several cut marks along and on the barb.

XI2I62 is made of antler and only the mid section of the tool is preserved. It has one barb formed as a caribou hoof. There is a groove running along one side of the tool from the hoof (Figs IOo-IOI). This tool is unique from a Saqqaq context but the caribou hoof is reminiscent of a small pendant dated to Independence II found at Eigil Knuth site (Fig. I, no. 33) (Andreasen I997:28, fig. 4, I998:205). There is also some resemblance to the small Late Dorset pendants from the Bache Peninsula region (Fig. I, no. 25) (Schledermann I98I:589) and the Igloolik area (Fig. I, no. I3) (Taylor and Swinton 1967: fig 15).

x6535 is made of antler and, although broken, is the only one where the size could be measured ( $80 \times 5$
mm)(Kramer 1996b:9o, pl.6.5A). The tool has been classified as a leister or spear but could instead be a kind of harpoon head because of the lateral spur and the open shaft socket with a small Io mm long Yformed groove running away from the socket. No parallels are known except one Pre-Dorset fragment from Igloolik (Maxwell I985:83, fig.52E).

\section{Barbed spears with socket for a blade $(N=1)$}

Only one example of this type was registered. It is made of ivory and is $200 \times 25 \mathrm{~mm}$ (Fig. IO2). It has a slot ending in a groove and at the opposite end is an oblique cut for lashing. Originally there was a barb on one side, now fragmented. No parallels are known from the arctic area.

\section{Bows ( $N=1)$}

XI2II4 is a I2O $\mathrm{mm}$ long and $24 \mathrm{~mm}$ wide fragment made of whale bone dated to phase I (Fig. IO3). On the flat dorsal side there is a longitudinal groove intended for sinew backing. The ventral side is more convex. Because of resemblance to ethnographically known bows, this fragment is interpreted to be the mid section of a bow. The rest could have been made of driftwood as seen at Qeqertasussuk (Grønnow 1988b:32 and fig. 9). 


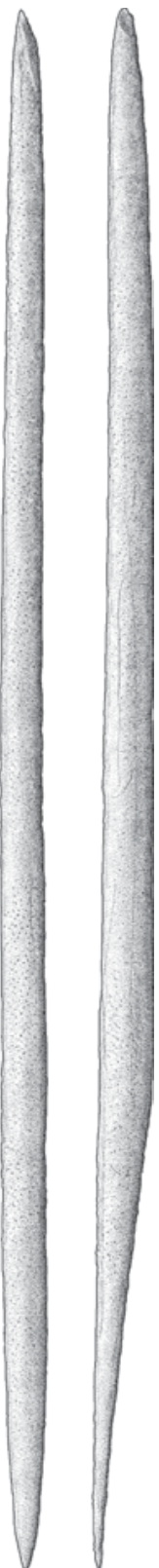

6509

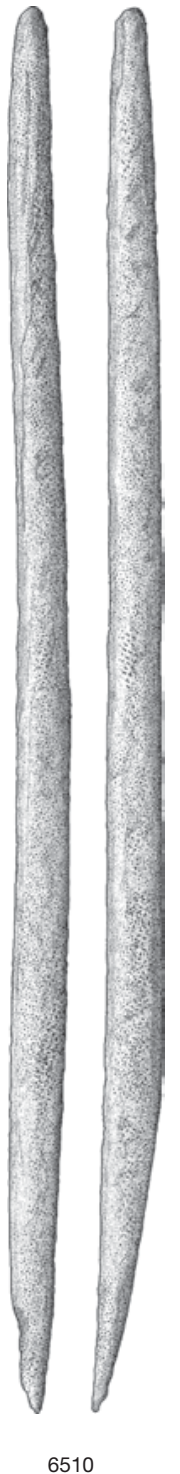

Fig. 94. Light foreshafts from phase 3, both made of antler. $1: 1$.

\section{Heads for arrows or bird darts $(N=10)$}

The group is rather heterogeneous and some may perhaps have been used as foreshafts or awls (Kramer I996b:89, pl.6.4D). Six are dated to phase I and four to phase 3. All are made of antler and are self-bladed. Most of the items have an oblique base (for lashing) and grooves running along the sides. xI6296 is from phase I and is II6 mm long and $6 \mathrm{~mm}$ wide with a groove on one side (Fig. I04).

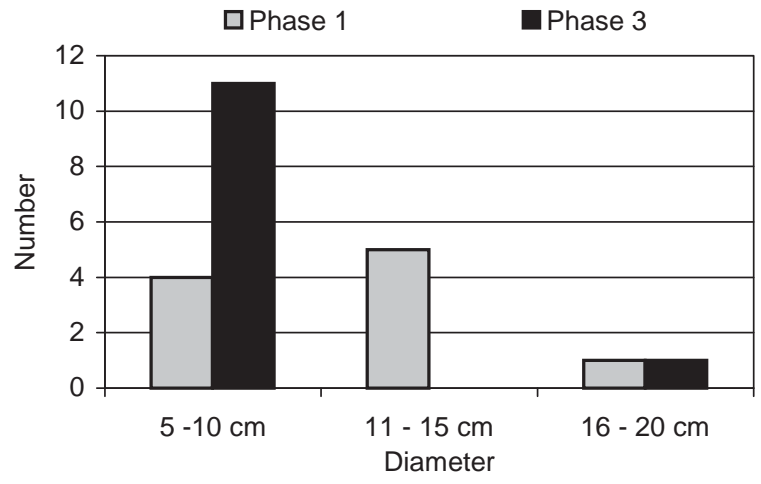

Fig. 95. Metric analysis of foreshaft diameter in phases 1 and 3.

xı0780 also has an oblique base to facilitate lashing and a blunt head (Ioo x $9 \mathrm{~mm}$ ). It is interpreted as having been used for bird hunting (Fig. I05).

The width of the heads varies between 5-9 mm for phase I specimens and between 4-7 $\mathrm{mm}$ for those from phase 3 (Fig. I06). Because of the low number it is not possible to determine if this difference is due to chronological or functional factors.

\section{Side prongs $(\mathrm{N}=1)$}

Only one specimen is interpreted as a side prong. It is from phase 3 , made from a walrus rib and measures I50 $\mathrm{x}$ Io $\mathrm{mm}$. It has a base for lashing (Kramer I996b:93 pl. 6.I2G).

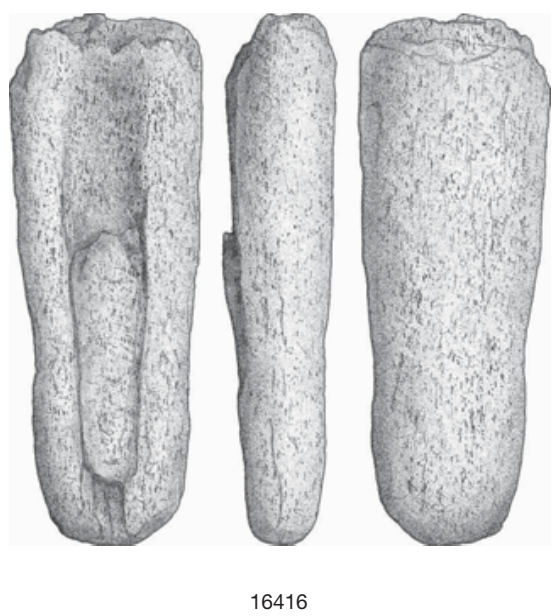

Fig. 96. Throwing board. Only the bone mounting made of whale bone is preserved. The little hook is made of antler. The diameter of shafts for this throwing board might not exceed $17 \mathrm{~mm}$. 1:1. 


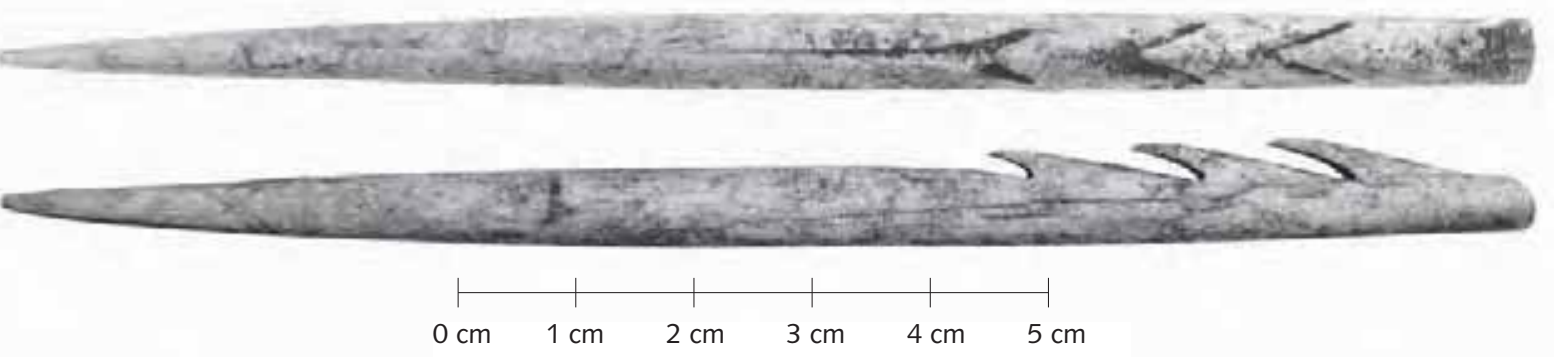

Fig. 97. Barbed leister or spear x1219 made of ivory. Notice the incision shaped as a footprint from bird below the last barb. Phase 3. Photo: Geert Brovad.

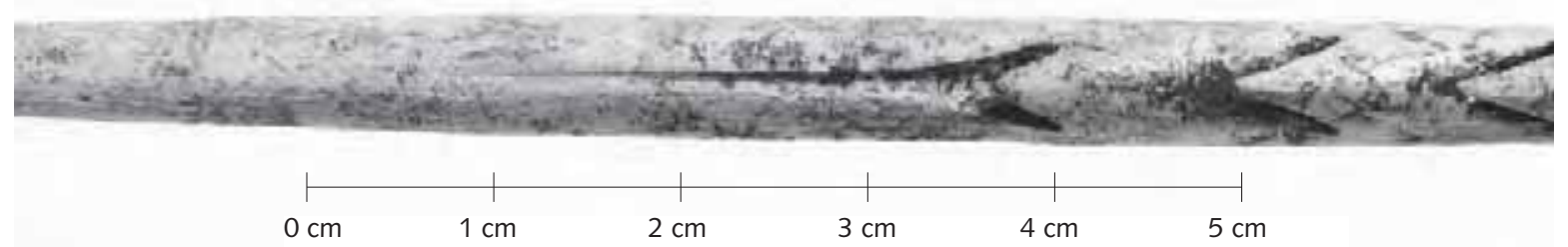

Fig. 98. Close up of the footprint. Photo: Geert Brovad.
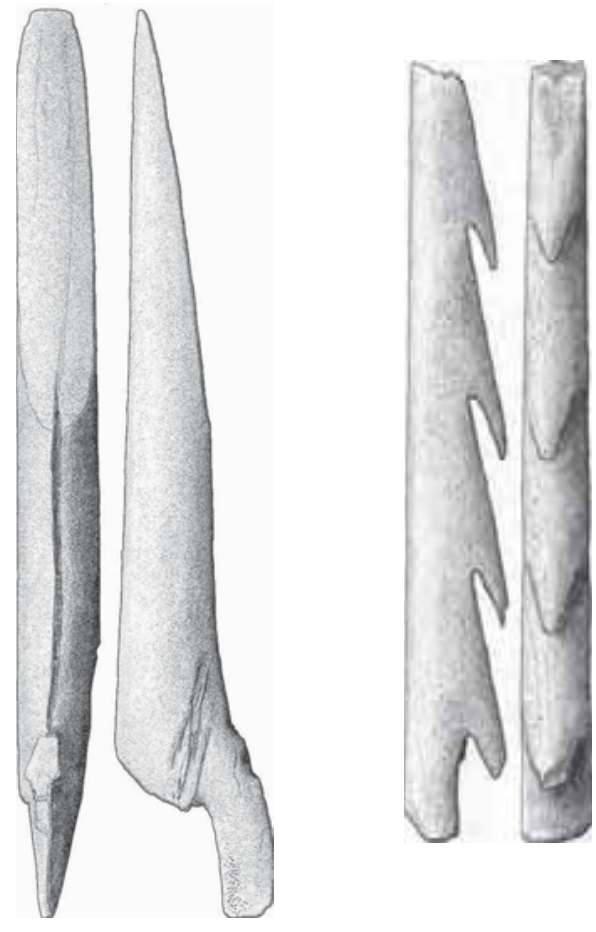

Fig. 99. Barbed leisters or spears from phase 3. $\times 10579$ is made of antler. It might be a part of a composite tool given the lashing at the upper end. $x 600$ is fragmented and made of ivory. 1:1.

\section{Skinning knives ( $N=2$ )}

Although uncertain, the classification of this group seems plausible due to the presence of neatly polished edges. xIO750 is made from an antler blank with burin grooves along the sides. The knife (240 mm x $30 \mathrm{~mm}$ ) tapers gradually towards the distal end, which is smoothly polished at the edge (Fig. 67B.). xI2IO4 is made on the basis of a shed antler and has an oblique cutting edge, which is polished. The size of this knife is $240 \times 39 \mathrm{~mm}$. Both antler knives are dated to phase 3 .

\section{Dragging equipment, toggle $(N=1)$}

XI2I60 is a $55 \mathrm{~mm}$ long and $8 \mathrm{~mm}$ wide, elongated symmetrical slightly curved tool. It is made of whale bone and interpreted as a kind of toggle used as part of dragging equipment. It is dated to phase 3 .

\section{Fishhooks ( $N=1$ )}

x6507 is $88 \mathrm{~mm} \times 5 \mathrm{~mm}$ with a base for lashing and tapers gradually to the pointed distal end. It is interpreted as part of a composite fishhook, which would have been lashed on to another piece at an oblique angle as seen in Fig. I07 (Stewart 1977). The fishhook is made of antler and dated to phase 3 .

Needles for making nets ( $N=3$ )

All three are made of antler with elongated eyes. 


\section{.}
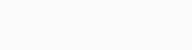

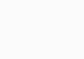

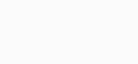
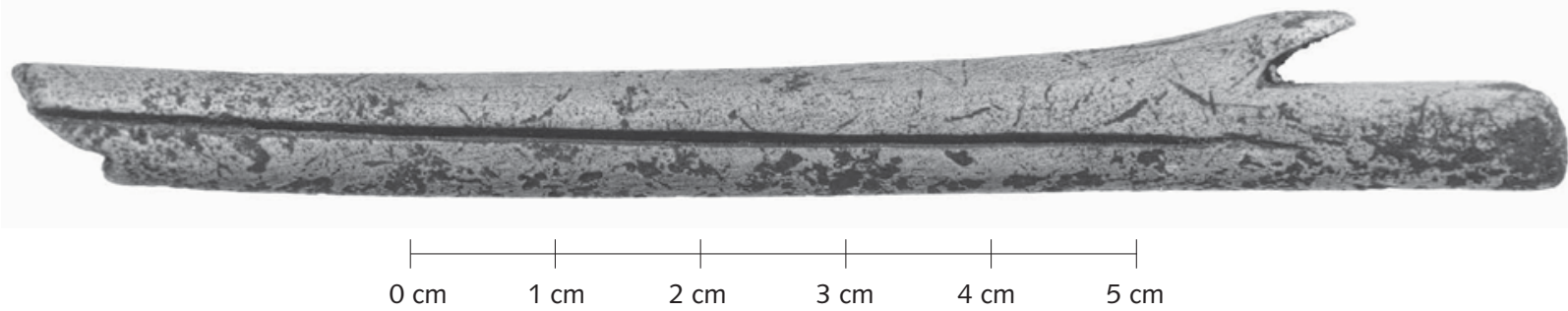

Fig. 100. Barbed leister or spear $\times 12162$ made of antler. Notice the incised line and the barb shaped as a caribou hoof. Phase 3. Photo: Geert Brovad.

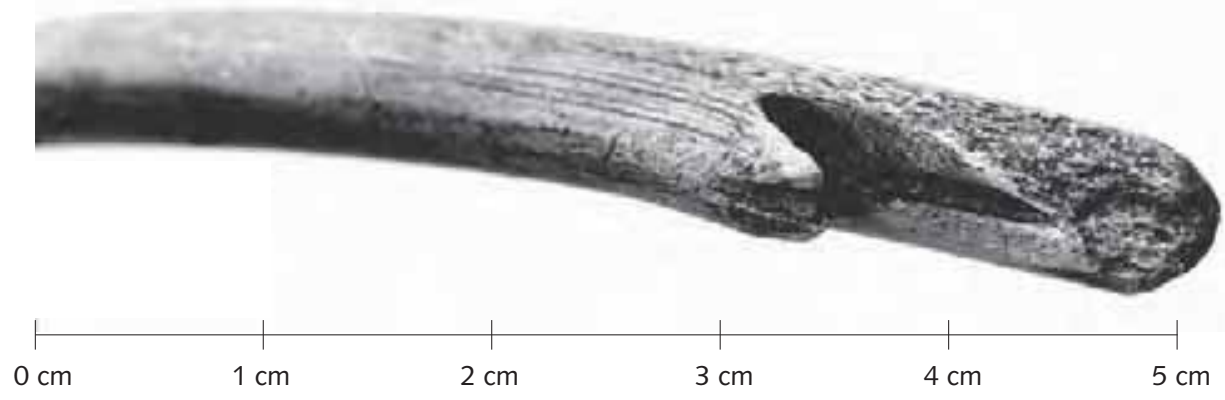

Fig. 101. Close up of the caribou hoof. Photo: Geert Brovad.
XIO798 is from phase $\mathrm{I}$ and is $70 \mathrm{x}$ IO $\mathrm{mm}$. The point is curved at a right angle to the body of the needle (Fig. I08). XI7I4I is dated to phase 2 and is straighter. The size is $168 \times 9 \mathrm{~mm}$ (Fig. I09). The last one, dated to phase 3, is broken at the eye (Kramer 1996b:93, pl.6.IIA). Based on ethnographic parallels and discussions with colleagues, these needles are interpreted as having been used for making nets (Nelson 1897; McGhee pers. comm. 1997; Plumet pers. comm. I996). There is no baleen preserved at Nipisat, but baleen knots were found at both Qeqertasussuk and Sermermiut. From Qeqertasussuk several pieces of net structures with complicated knots were recovered all dating to the Saqqaq Culture (Grønnow 1996c:27 and
Fig. 102. Barbed spear $\times 10797$ with a socket for blade, made of ivory, phase 3. Photo: Geert Brovad.

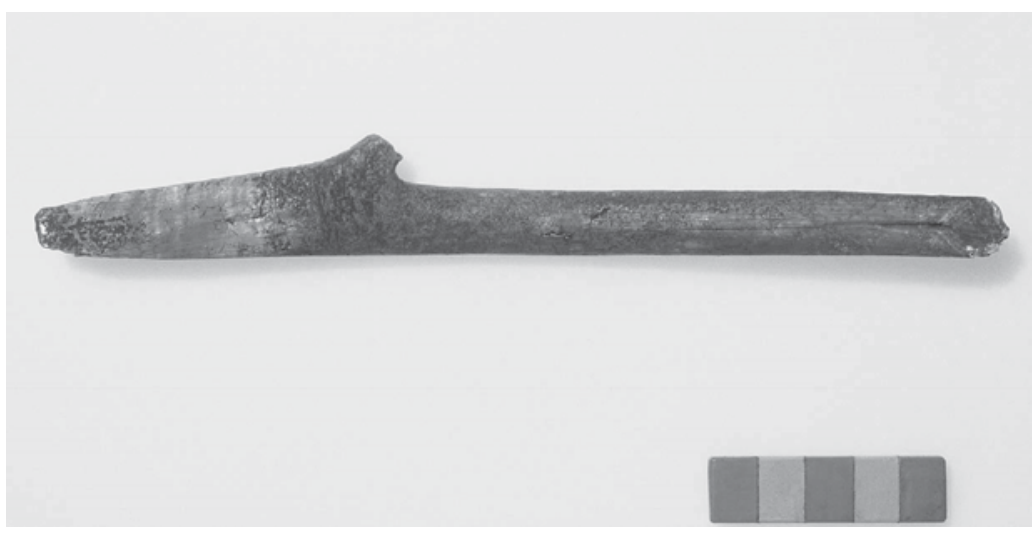




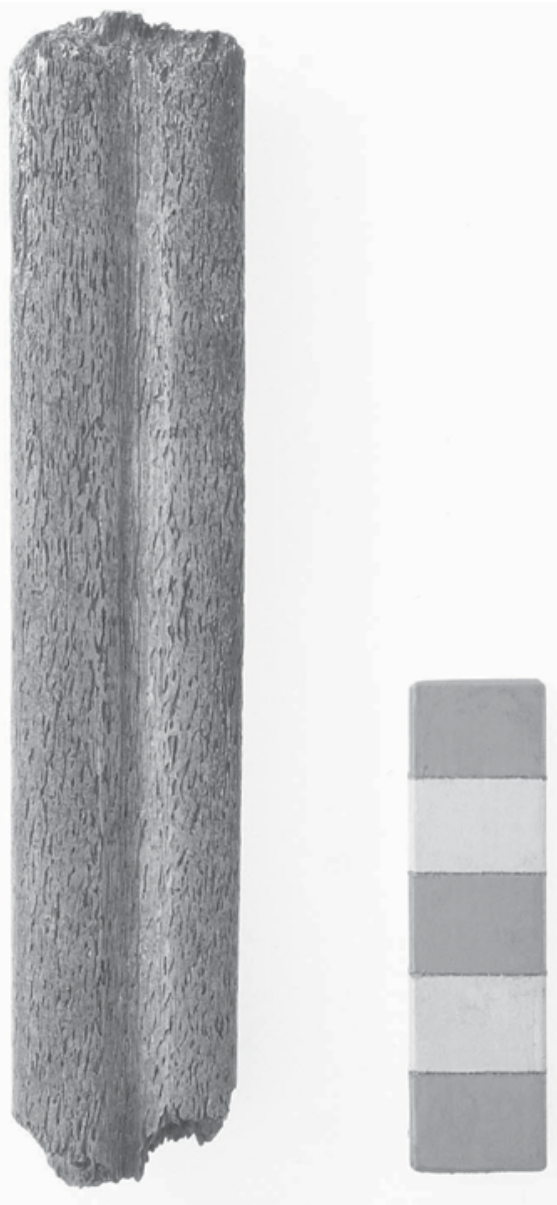

Fig. 103. Fragment of bow $\times 12114$. Only the mid-section made of whale bone is preserved. Notice the groove in the middle for the sinew backing. Photo: Geert Brovad.

fig. 3.I2). From Sermermiut there are pieces of baleen from a Saqqaq context and a real knot from the Dorset Culture (K-3769:405 BC (cal)) (Møbjerg I986b:29, 49 and fig. 7). It is not possible to establish whether the nets were used for fishing or trapping.

\section{Lures for fishing $(N=1)$}

xI6359, made of antler, is $120 \times 24 \mathrm{~mm}$. It is elongated with slots at the proximal end and interpreted as a kind of lure (Stewart 1977). The slot would have made it possible to fasten the lure onto a line. The distal end is slightly tapering with a very light polish (Fig. IIo). It is dated to phase 3 .

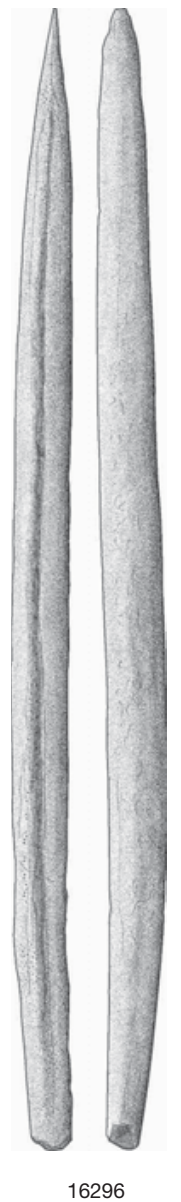

Fig. 104. Self-bladed arrow head $\times 16296$ made of antler, notice the incised line at the side. Phase 1. 1:1.

\section{Lithic}

Harpoon blades - triangular $(N=1)$

This small killiaq blade measures I4 x 7 x $2 \mathrm{~mm}$ and dates from phase I. The outer tip is broken so the tool might have been 2-3 mm longer. It was original bifacially flaked and then polished (Fig. III). The base is thinned so it could fit into a harpoon head with blade sockets (although no such finds were recorded at Nipisat). The type is well known from all Early Saqqaq sites (see Grønnow 1996c:23) and it is noteworthy that only one is recorded from Nipisat.

\section{Harpoon blades - bevelled $(\mathrm{N}=2)$}

X257 (2I x 2I mm) and XI6I5I (2I x I3 mm) are both classified as harpoon blades (Fig. II2). They are sturdy compared to the previous type and the matching harpoon heads have not yet been recorded from Nipisat or 


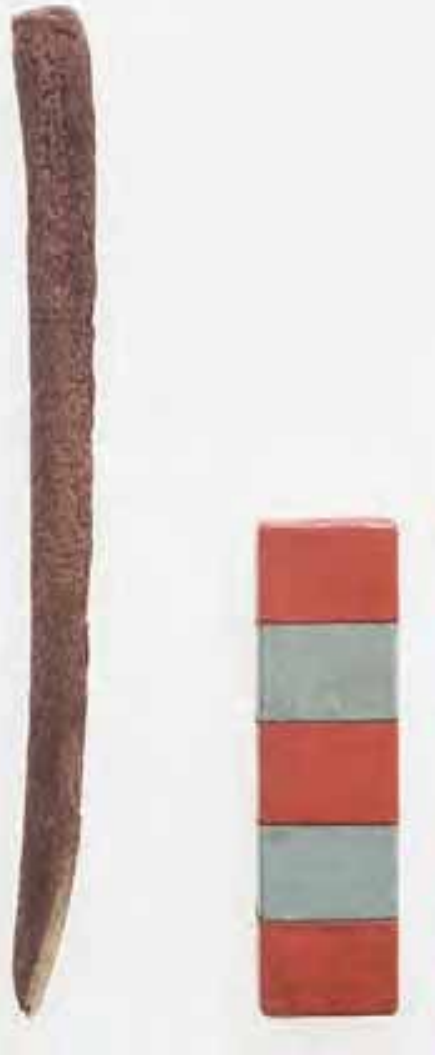

Fig. 105. Arrow head $\times 10780$ made of antler. The point is blunt and it is interpreted as used for bird hunting. Dated to phase 1. Photo: Geert Brovad.

other sites. Both are made of killiaq and, beneath the polishing, it can be seen that the harpoon blades were bifacially flaked. They date to phase 3 .

\section{Projectile points - stemmed $(N=1)$}

XI704I is a stemmed projectile point measuring 3I X II $\mathrm{mm}$. It is made of killiaq and bifacially flaked without

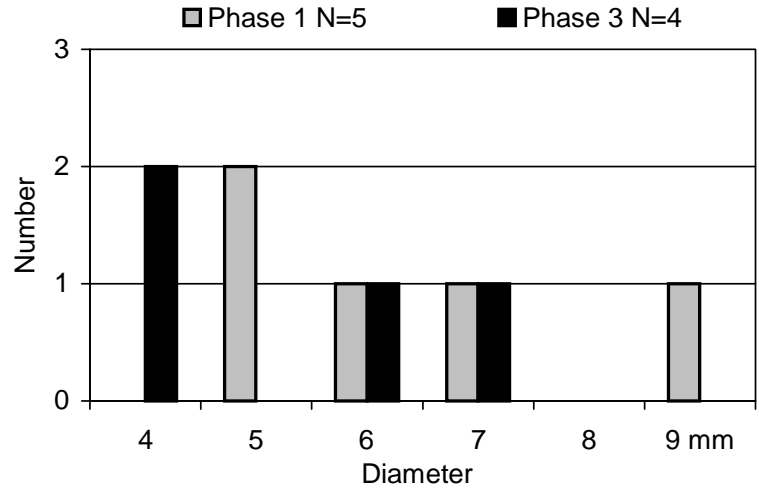

Fig. 106. Arrow heads from phases 1 and 3 according to size.

polishing. It dates to phase I and resembles stemmed points found at Akia (Kramer I996 b:88, plate 6.2F) and Sermermiut (Larsen and Meldgaard I958:plate 4).

\section{Projectile points - bevelled $(\mathrm{N}=8)$}

This type is symmetrical, pointed and fairly large (more than $30 \mathrm{~mm}$ long), except xi6360, which has been reworked, so the bevelling or faceting has been removed (Fig. II4). All are made of killiaq and dated to phase 3. (Fig. II2).

\section{Projectile points - unspecified $(N=37)$}

This group varies greatly in terms of size, form and raw material. Seven are dated to phase I, and of these five are of killiaq, one of quartz crystal and one of quartzite. All are bifacial with limited polishing (Fig. II3). Of the six from phase 2, one is made of killiaq, one of agate, one of quartz crystal and 3 are made of quartzite. XI2296 is very slender with a triangular cross section. It might be a kind of preform instead of a projectile point (Fig. II3). 24 date to phase 3 and the
Fig. 107. Reconstruction of fishing with line and using a composite hook and a weight of soapstone used for cod and salmon (partly after Stewart 1977:41). Drawing: Jørgen Mürhmann-Lund.

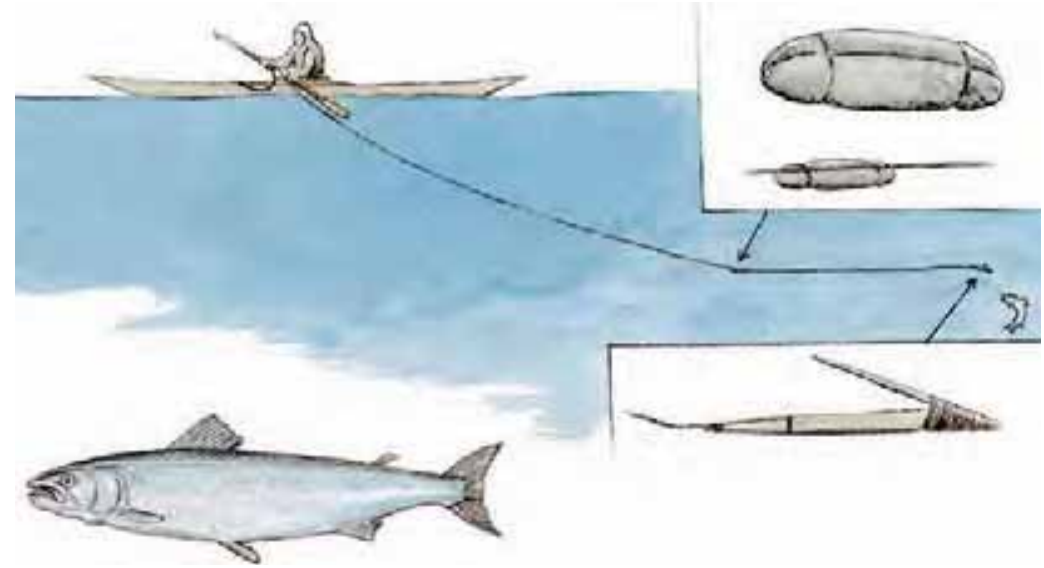

Anne Birgitte Gotfredsen \& Tinna Møbjerg: 


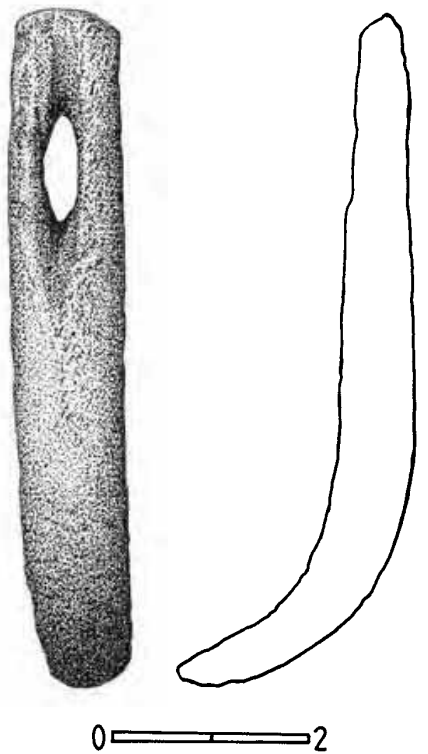

Fig. 108. Needle $\times 10798$ made of antler. Notice the elongated form of the carved eye and the curved point. Probably for net making, dated to phase 1. 1:1.

greatest variation is seen here (Fig. II4). I4 are made of killiaq, three are made of agate and seven are made of quartzite. Polishing is rare and all of them are bifacially flaked.

There is no clear correlation between the width of projectile points (Fig. II5) and the width of foreshafts (as seen from Fig. 95 and Table ro). Nevertheless, the variation in the width of projectile points implies that different "calibres" were used for hunting different species at Nipisat as known from Qeqertasussuk (Grønnow I994:212 and fig.22, 1996c:26).

Weights or sinkers of soapstone $(N=2)$

x63Io is a conical piece with grooves (Fig. II6) used for suspending on a fishing line (Fig. I07) or as a weight (weight 50 grams) for fishing nets. x6366 is a rectangular piece with a central hole drilled from both sides (Fig. II7). It is also interpreted as used for fishing. Both are from phase 3. No parallels are known from Greenland. Two are known from the site Philips Garden East at Port au Choix (Fig. I, no. 2I) (Renouf 1994:I78, fig. Io). Both of them have distinct grooves.

\section{Distribution of tools for hunting and fishing}

In phase I the same pattern as seen for hand tools, with a concentration around the hearth, is registered

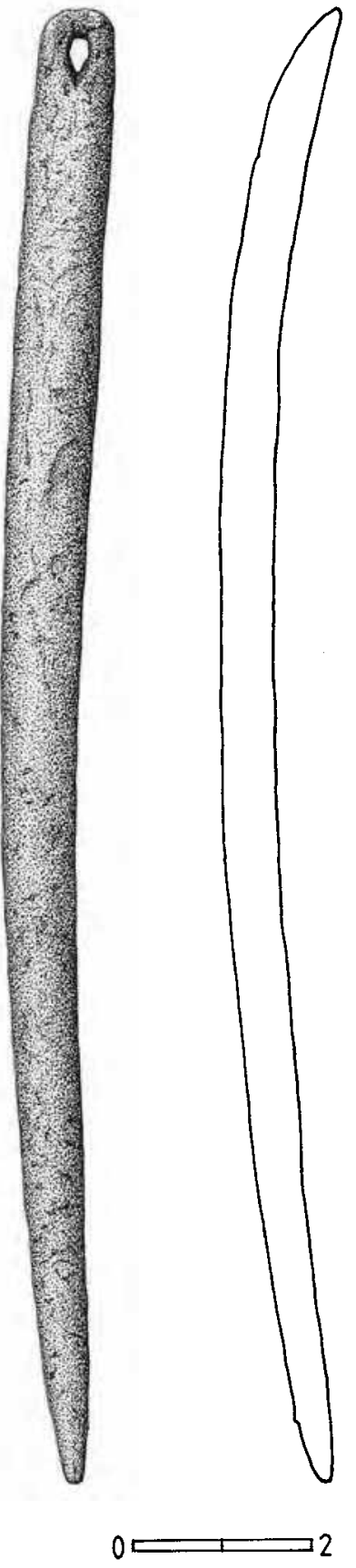

Fig. 109. Needle $\times 17141$ made of antler. Notice the elongated form of the carved eye. Probably for net making, dated to phase 2. 1:1.

and there is also a concentration in the northernmost part of area I. The pattern is similar to the distribution seen for hand tools in phase 2. In phase 3 the distribution is clustered around the centre of area 2 and in area 3. This is particularly true for the bevelled tools, where 9 out of I2 were found in area 3 (Fig. II8). 
Fig. 110. Lure for fishing $\times 16359$ made of antler and dated to phase 3.

Computer graphic by N. Levinsen, 1997.

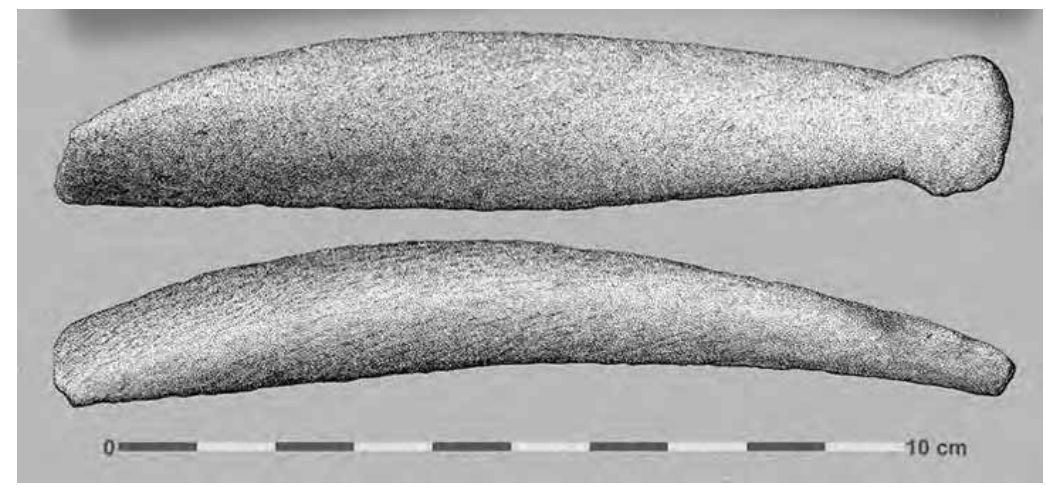

\section{Household utensils}

Due to the preservation conditions at Nipisat, no household utensils of skin, baleen or wood are preserved. The excavation, therefore, provides only a fragmentary picture consisting of a little piece of artwork, soapstone sherds and small worked pieces of pumice and sandstone.

Fig. 111. A small triangular harpoon blade made of killiaq, fragmented. Phase 1. 1:1.

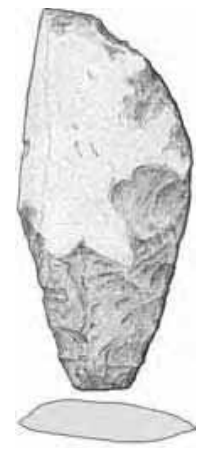

183

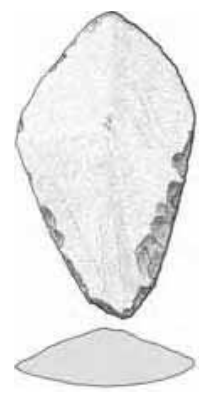

12404

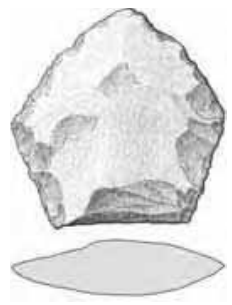

257

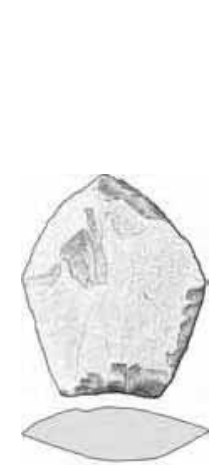

16151

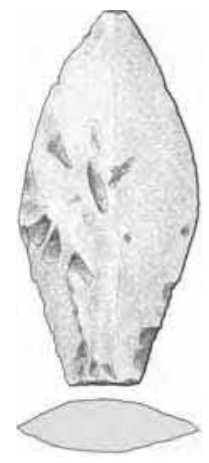

2018

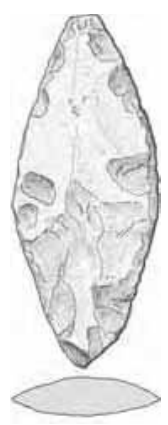

12294
Fig. 112. Different kinds of bevelled and polished tools made of killiaq. x257 and 16151 are harpoon blades. $\times 2018,12294$ and 12404 are projectile points. $x 183$ and 16513 are knife blades. Phase 3. 1:1.

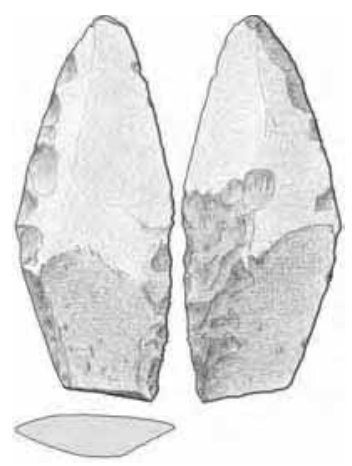

16513 


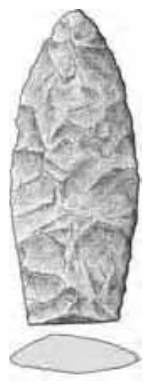

12192

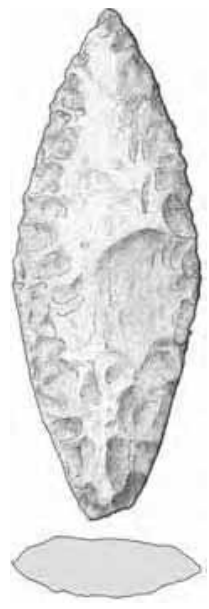

12311

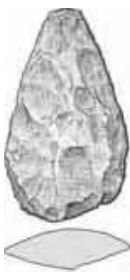

16487

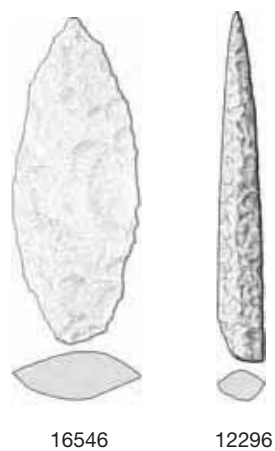

Fig. 113. Different kinds of projectile points. $\times 12192,12311$ and 16487 are of killiaq. $x 16546$ is of quartzite. $\times 12296$ is of killiaq and from phase 2 . The rest are from phase 1. 1:1.

\section{Organic}

$\operatorname{Art}(N=1)$

A small rectangular object (XI2I54) made of antler has no clear function, but with cross-hatched ornamentation on two sides. This piece of art is dated to phase I (Fig. I20).

\section{Lithic}

Soapstone $(N=24)$

All lamps or vessels are fragmented and the size of the sherds varies between 83 x $64 \mathrm{~mm}$ and $4 \times 4 \mathrm{~mm}$. They are all dated to phase 3 , except one small piece (I5 $\mathrm{X}$ II $\mathrm{mm}$ ) from phase $\mathrm{I}$ found in the southern part of the site.

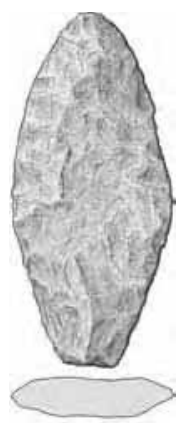

184

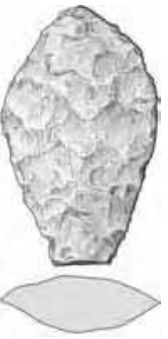

6299

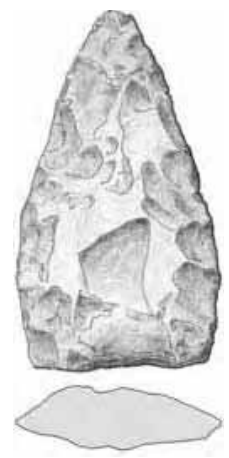

1310

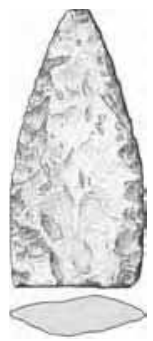

1316

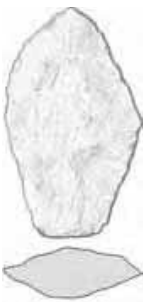

2172

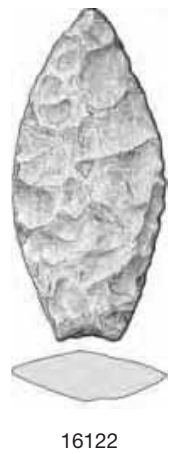

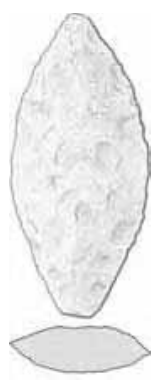

2291

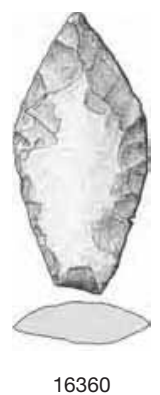

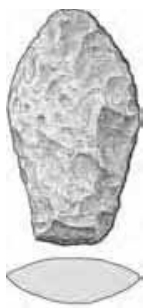

4022

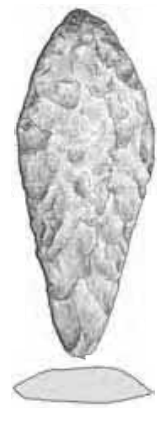

16262

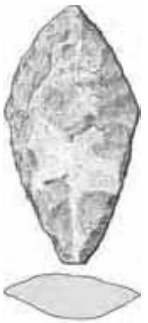

4042

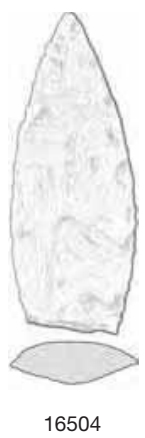

Fig. 114. Different kinds of projectile points from phase 3. $\times 184,1310,1316,4022,4042,12295,16122,16262$ and 16360 (bevelled) are made of killiaq. x2172, 2291, 6358 and 16504 are of quartzite. x6299 and 6300 are of agate. 1:1. 
Fig. 115. The relation between length and width of complete projectile points from phase 1 to phase 3 .
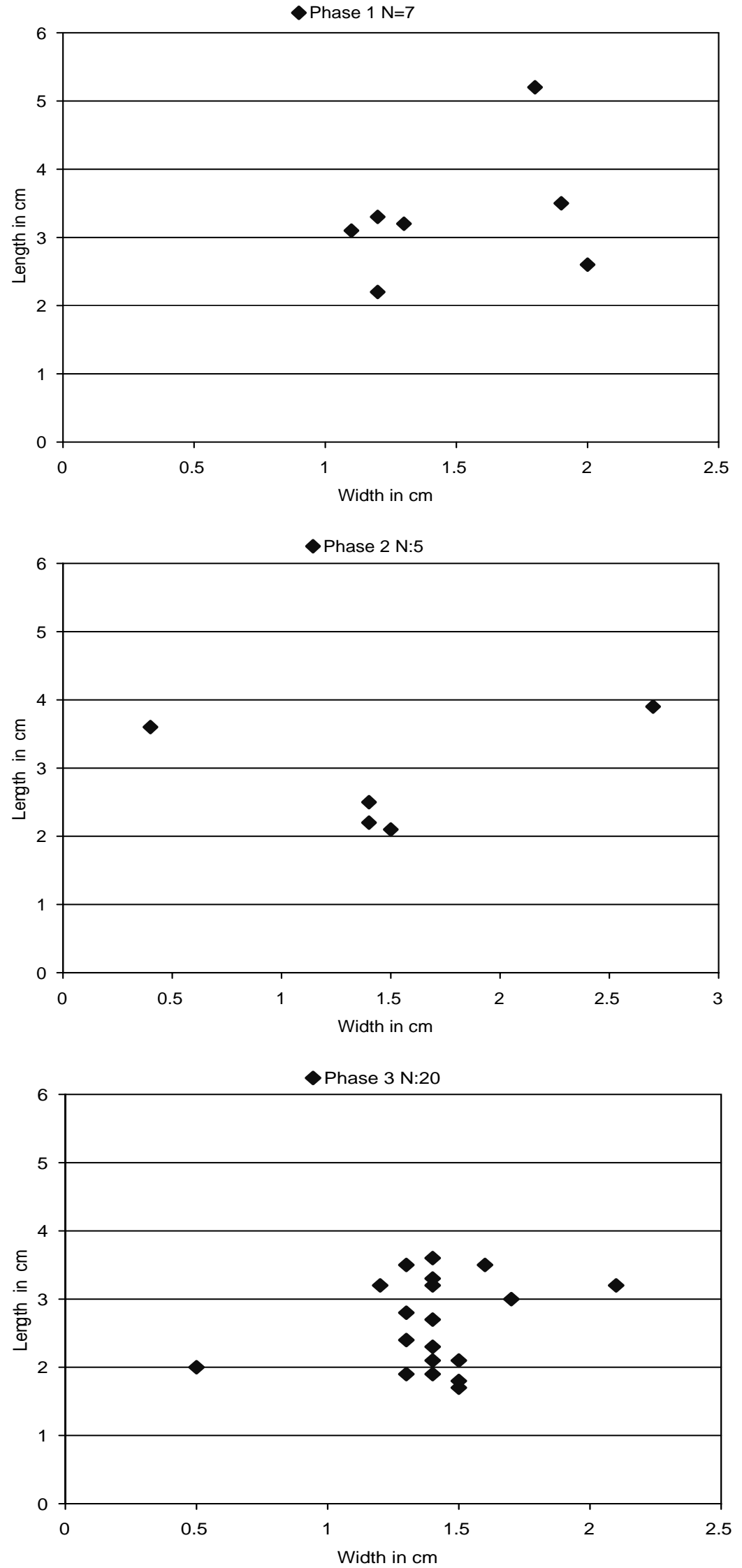

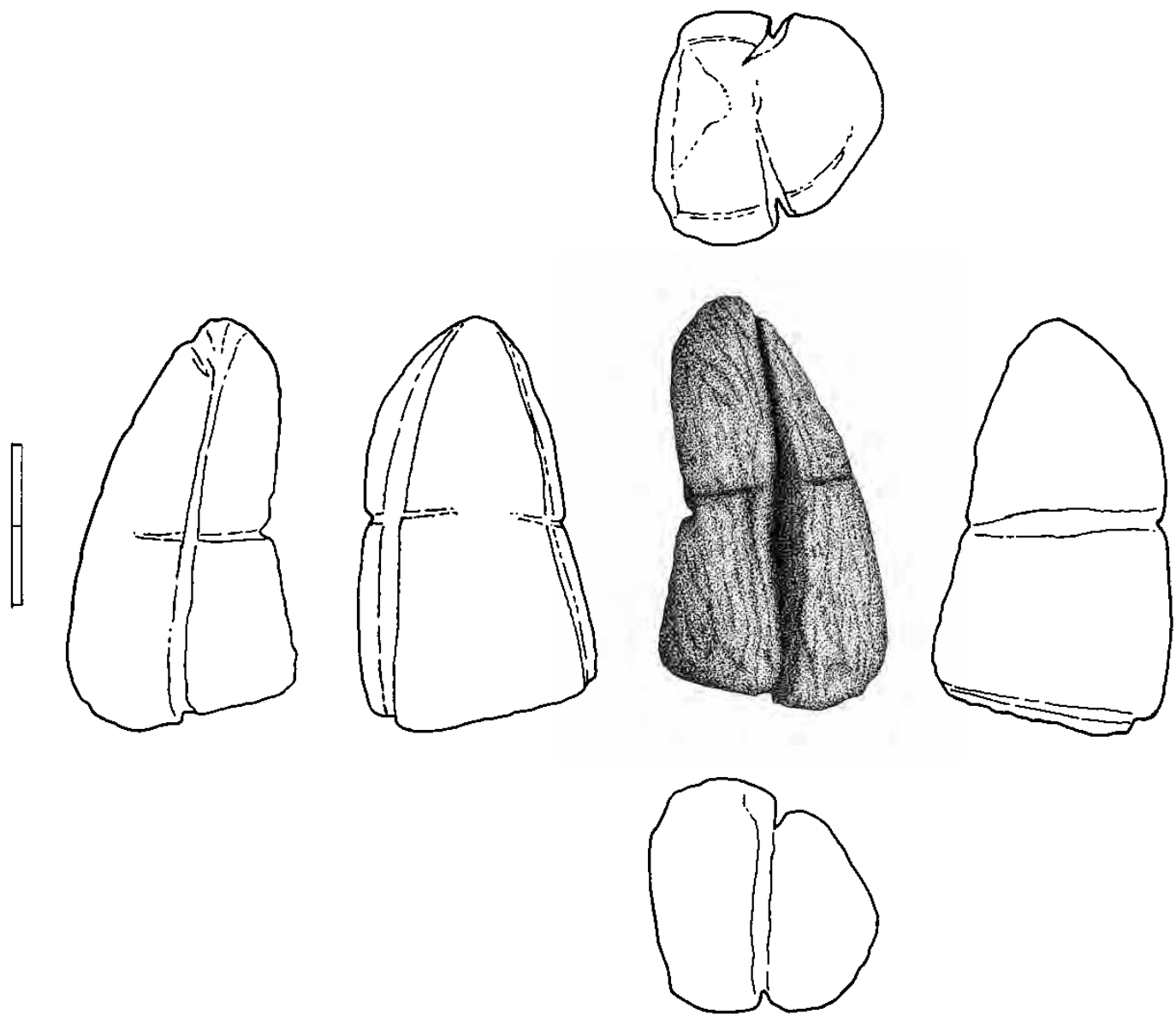

Fig. 116. Piece of soapstone $x 6310$ with incised grooves, interpreted as a weight for fishing (see Fig. 107). Phase 3. 1:1.

This is interpreted as an intrusion from the younger layer and is therefore regarded as originating from phase 3. Approximately half of the sherds have thin walls and represent small lamps or vessels similar to the types known from Itinnera (Meldgaard 1961:18) and

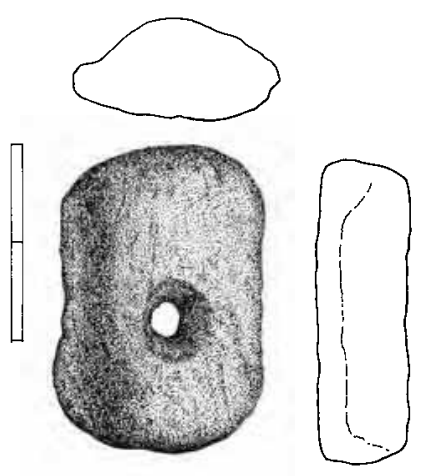

Fig. 117. Piece of soapstone $\times 6366$ with a double conical perforation, interpreted as a weight for fishing. Phase 3. 1:1.
Nunnguaq (Appelt and Pind 1996:I39-I4I, and fig. Io.6, Io.7.I, Io.8.2-5). The rest are thick walled and represent large vessels or lamps as known from Nunnguaq (Appelt and Pind 1996:I40-I4I and fig. I0.7.2, fig. Io.8.I). One sherd has a depression drilled close to the edge as if an attempt at repair had been made. Other sherds have been reworked and polished, but their function is unknown (Kramer 1996b:96 pl.6.I7 A-H).

\section{"Strike-a-light" ( $N=3)$}

All are made of killiaq and dated to phase 3. X2296 was originally a microcore $(50 \times 34 \mathrm{~mm})$ but reused as a strike-a-light (Kramer 1996b:95 pl.6.I6D). All three show heavy use marks on one or both ends.

\section{Gaming pieces - soapstone ( $N=2)$}

Both are conical with flat bases (Fig. I2I). XI5553 is dated to phase 3 and xi23I3 is dated to phase $\mathrm{I}$, but was found only $3 \mathrm{~cm}$ lower and only $90 \mathrm{~cm}$ north of XI5553. 
Fig. 118. The horizontal distribution of bevelled knife blades and projectile points of killiaq in phase 3 .

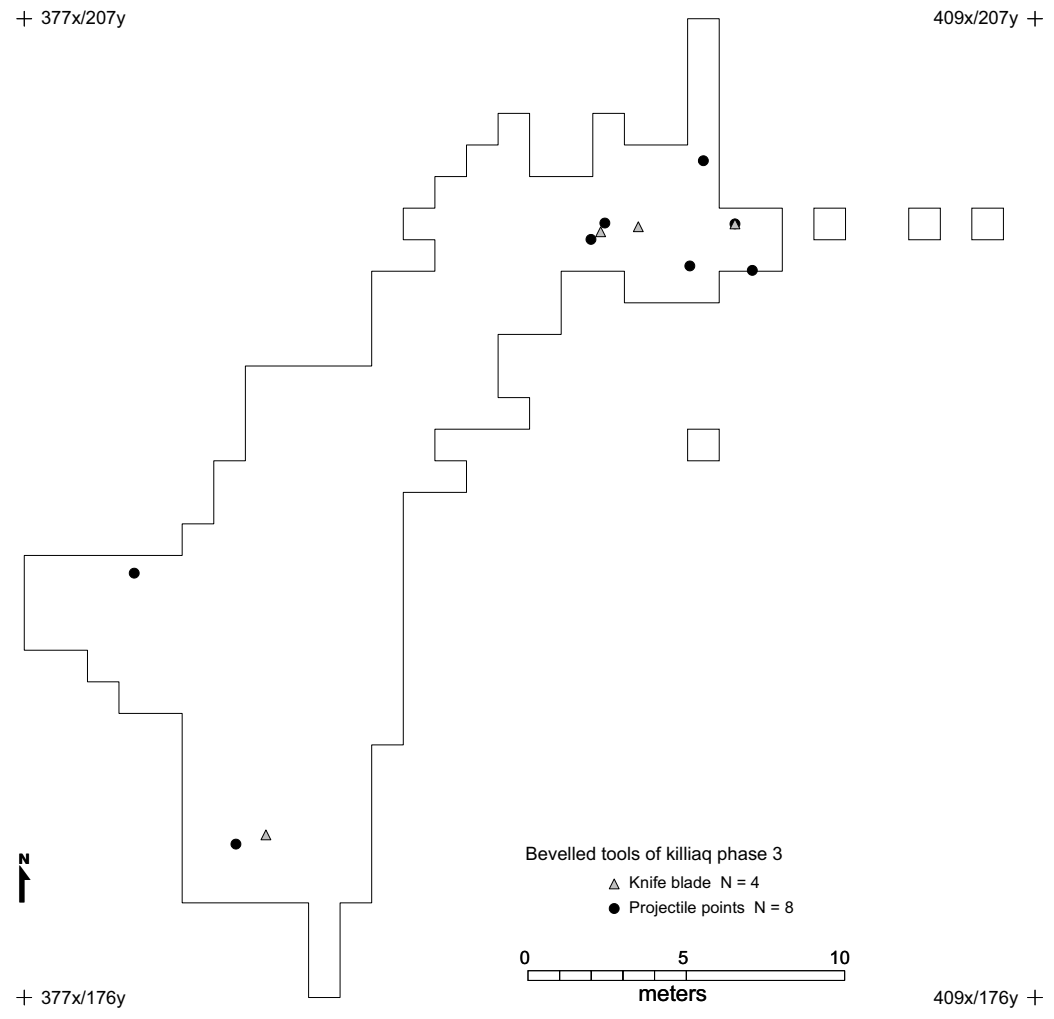

XI23I3 is so small (I3 X $5 \mathrm{~mm}$ ) that solifluction may have caused disturbance between the two different layers. Both gaming pieces are therefore regarded as belonging to phase 3 . These small objects have often been interpreted as used for supporting a type of circular wick in small circular lamps (Gynther and Meldgaard 1983:40-4I). The lack of traces of burning or heating on these objects from Nipisat does not support this theory, however, and they have therefore been interpreted as gaming pieces.

\section{Gaming pieces - sandstone $(N=13)$}

This group is very heterogeneous, some are conical (the two made of soapstone), others are hemispherical, and some are kidney or pear shaped. Some would have been simply collected and probably used as they were, whilst others are worked. XI5529 (I8 X I8 mm) closely resembles one made of soapstone (Kramer I994:224, NI-93-384X/I90y). Two are dated to phase I and II to phase 3 .

\section{Gaming pieces - pumice $(N=2)$}

XI5534 is formed like a marble and XI5537 is hemispherical. They date to phase I.

\section{Distribution of household utensils}

This group of artefacts is very limited and only the soapstone artefacts reveal any distribution patterning (Fig. II9). There is a concentration of sherds and sinkers in the north-eastern part of area 2 and of sherds in the northern part of area 3.

\section{Comments on formation processes, activity areas and tool inventory}

The preservation conditions at Nipisat have been outstanding and the question is whether the spatial patterning of dwelling structures and artefacts reflects the spatial patterning of the Saqqaq peoples activities on the site. When looking at the artefact distribution it is necessary to decide if it is primary refuse - material discarded at the location of use or secondary refuse where the material is discarded at another location (Schiffer 1972). To understand the activities going on at Nipisat it is necessary to understand the processes leading to the archaeological record from procurement, manufacture, use, maintenance and discard of the artefacts. Looking at the lithic material it is possi- 


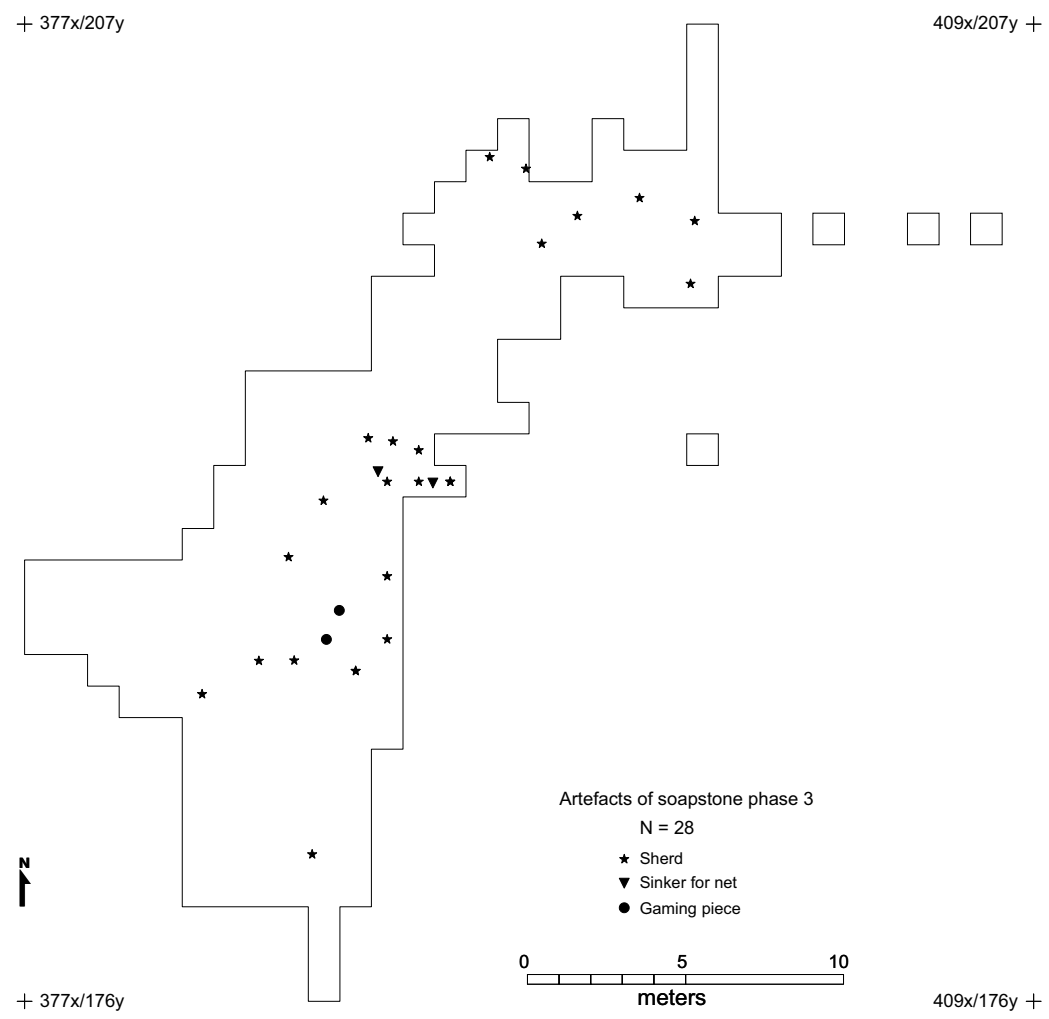

Fig. 119. The horizontal distribution of sherds and different artefacts made of soapstone. All are from phase 3 except a small sherd $(386,12 x / 180,68 y)$ and a gaming piece $(386,98 x / 188,40 y)$.

ble to interpret some of the stages of the chaîne opératoire. There is no real core preserved in the material but large flakes from them indicate that they were brought to the site. The cores were used as a basis for axes and large bifacial blades (knives, lances etc), or smaller flakes were removed from the core and used for burins, scrapers and small bifacial blades such as

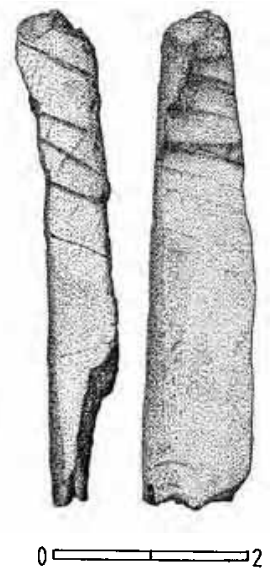

Fig. 120. A piece of antler $\times 12154$ with incised cross hatching one side and more diffuse incision on the other side is interpreted as a piece of art, phase 2. 1:1. arrow points and harpoon blades. In the production of both groups of tools, several small flakes (debitage) were created and discarded. Thus all stages of tool manufacturing are recorded at Nipisat. The high number of small flakes (see Figs 54-58) shows that the raw material really was exhausted. All tool classes show a similarly high degree of curation, i.e. they were discarded at the final stage of the chaine opératoire (Figs 75-78). Tools of organic material show the same degree of fragmentation. However, as a rule people do not leave well functioning tools behind, only broken or worn-out tools (Møbjerg and Robert-Lamblin I990: 240).

From ethnoarchaeological studies it is known that a dwelling area sometimes reveals a snapshot (primary refuse) of the last season of occupation, whereas the midden contains refuse of several seasons (secondary refuse) (Møbjerg and Robert-Lamblin I990: 258). The picture becomes highly complex, however, when the site has been used again and again over a period of nearly I500 years. At Nipisat the area around the hearth dated to phase i seems as if it was respected by later occupants, so the spatial distribution around the hearth is seen as primary refuse and interpreted as 
an activity area represented by flakes, tools and bones. North of the hearth, there is also a form of dwelling structure, but the deposits seem much more random and this has been interpreted as a midden. This interpretation is confirmed by the great thickness of the layers and, in addition, the majority of bones with cut marks are found in this area too (Appendix I). Looking at phase 2 it is remarkable that almost no artefacts (nor bones) are found around the hearth, but there is a type of midden north of it. (Figs 44, 48, 50, 86, 88). Phase 3 is slightly different and it is difficult to separate primary refuse from secondary refuse because there is no dwelling structure. It is therefore not easy to define any activity areas but only to define concentrations of artefacts. There is, however, a higher concentration of bones and artefacts in the most northern part of area 3.

The Saqqaq hunter at Nipisat had a wide range of tools, hunting equipment and household utensils. In phases I and 2 the tool inventory at Nipisat resembles that known from other large sites such as Qeqertasussuk and Qajaa. Tools such as needles (Fig. 6I), awls and small microblades show that skin working must have been an important activity at the site. The large numbers of burins (Fig. 77) and the numerous pieces of antler with traces of having been worked (Figs 37-38) indicate that bone and antler were used as raw materials for tool production at Nipisat. Although no driftwood is preserved, the presence of wedges, axes and chisels testify that this resource was exploited. The large numbers of pressure flakers (Fig. 7I) indicate that flint knapping was done at the site. Finally knives (Fig. 75), side- and endscrapers (Figs 80, 82, 83) together with pumice or sandstone whetstones, show the high level of craftsmanship obtained by the inhabitants of Nipisat.

There are no dramatic changes in the tool inventory between phases I-2 and phase 3 . The most notable difference is the introduction of the bevelled and polished knife blades (Fig. II2).

Although objects of wood, baleen or skin are not preserved at Nipisat, the finds recovered provide a good picture of the hunting equipment in phases I-2, as represented by both the toggle and tanged harpoon heads (Fig. 89), slender foreshafts (Fig. 93) for lashing onto a shaft and the associated throwing boards (Fig. 96). Noteworthy is the very low number of harpoon blades and harpoon heads compared to the number of

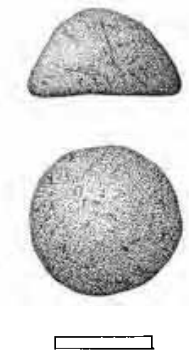

Fig. 121. Conical shaped artefact $\times 15533$ of soapstone interpreted as a gaming piece. 1:1.

other tool classes. In addition to the light items of hunting equipment, some heavier foreshafts made of whale bone are also found (Fig. 93). Small triangular killiaq blades (Fig. III) indicate that the harpoon heads were tipped. One fragment of a bow made of whale bone (Fig. I03) had a slot for sinew backing to help achieve the required flexibility. A wide variety of arrowheads were recovered, some are self-bladed (Fig. I04) whilst others had killiaq or agate points (Fig. II3). One arrowhead with a blunt point (Fig. I05) is interpreted as having been used for bird hunting. Furthermore several large antler needles (Figs Io8I09) were probably used for manufacturing nets etc. The vast majority of cod caught at Nipisat (Chapter 6) were so large, however, that they must have been caught using hooks.

Phase 3 brings with it an entirely new tool type not previously seen in the arctic: heavy antler harpoon or lance heads (Figs 90-92). These have carved elongated line holes but no associated foreshafts have been found. Simultaneously, bevelled and polished harpoons and arrowheads are introduced. This tool inventory is interpreted as having been used for walrus hunting which perhaps intensified at this time due to the increased need for blubber. During phase 3, the use of bows and arrows was abandoned in favour of a wide range of spears or lances. Barbed leisters or spears also appear with much greater variety than had previously been seen in Greenland (Figs 97-IO2). This late phase is also marked by the introduction of a range of soapstone items, several of which have been interpreted as being associated with fishing (Figs I07, II6).

Due to the preservation conditions at Nipisat, only a small percentage of the household items have been preserved. This is particularly striking when making 


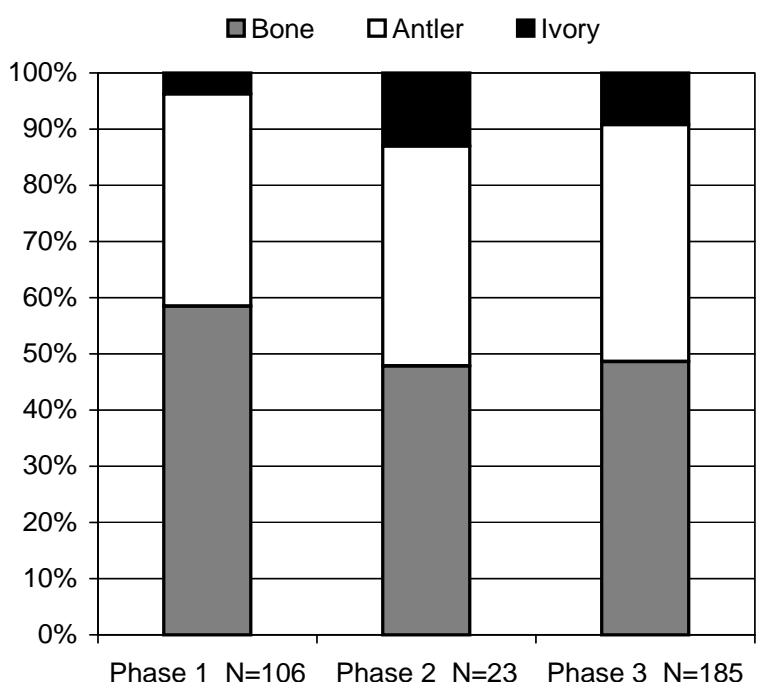

Fig. 122. Frequency distribution of tools made of bone, antler and ivory from phases 1, 2 and 3.

comparisons with Qeqertasussuk where ladles, spoons and bowls have been found. It is remarkable, however, that a number of these spoons and ladles are actually made of ivory or antler (Grønnow I988a:35). Not until phase 3 are lamps and vessels found at Nipisat, all made of soapstone.

From phase I to 3 a change in both organic and lithic raw material choice takes place. The use of bone and antler dominates at the expense of ivory in all three phases when looking at frequencies for tools alone (Fig. I22). If frequencies for both tools and waste products are included, however, a large increase in the

\section{$\square$ Killiaq $\square$ Agate $\square$ Quartz crystal $\square$ Quartzite}

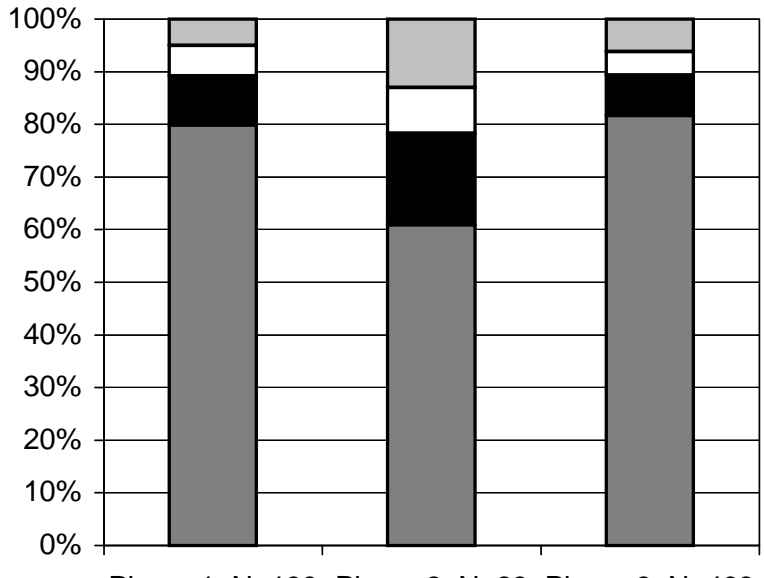

Phase $1 \mathrm{~N}=139$ Phase $2 \mathrm{~N}=23$ Phase $3 \mathrm{~N}=468$

Fig. 124. Frequency distribution for raw material (inorganic) used for tools in the three phases at Nipisat.

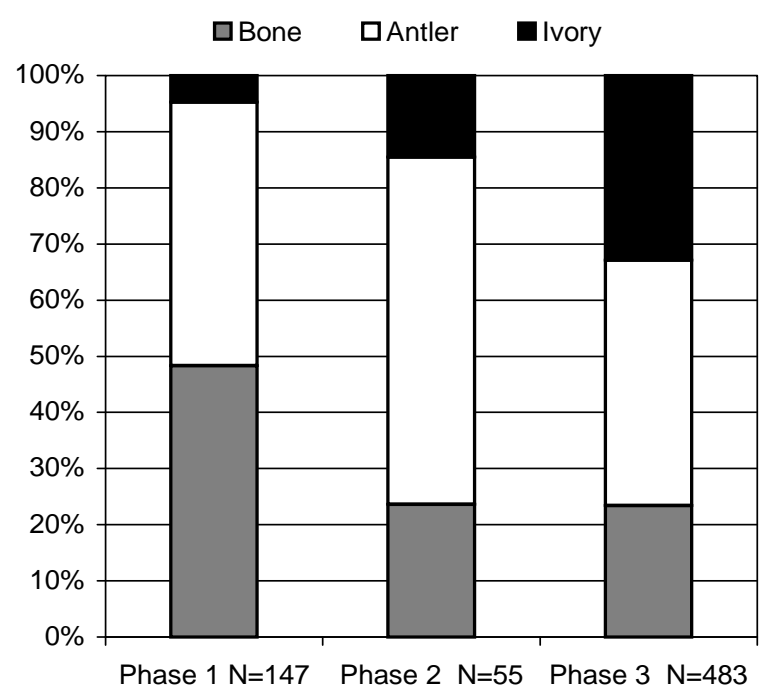

Fig. 123. Frequency distribution of tools and waste made of bone, antler and ivory from phases 1, 2 and 3.

use of ivory can be seen in phase 3. This can be interpreted in two ways: either that ivory is of much greater importance in phase 3 , or that there is a greater emphasis on working ivory at Nipisat than previously (Fig. I23). Lithic raw material choice exhibits clear chronological differences. In terms of flakes alone, killiaq accounts for $90 \%$ in phase $\mathrm{I}$, agate $9 \%$ and the rest is quartzite and quartz crystal. In phase $2,97.5 \%$ of flakes are killiaq and agate is reduced to $0.1 \%$, which corresponds well to the situation at Qeqertasussuk (Grønnow I994:225-26). In phase 3 killiaq has fallen to ca. $70 \%$, agate has risen again to $5 \%$ and quartzite now accounts for nearly $25 \%$. The figures are slightly different if frequencies are worked out in terms of weight rather than number (Fig. 4I, 43). The frequencies of the various lithic raw materials used for tool production differs from that seen for flakes. The frequencies of tools made of agate and quartz crystal is notably higher than for flakes and lower for quartzite (Fig. I24).

More than 40 different species of fish, birds and mammals (see chapters 6-8) were brought to the site of Nipisat where processing of food (both for immediate consumption and storage), clothing and tools was carried out. It is noteworthy that tools for hunting and fishing are less dominant than tools for food processing and tool making. Artefacts associated with flint knapping, skin, antler and bone working are particularly numerous compared to harpoon blades, harpoon heads, bows and arrows. 


\section{Chapter 5}

\section{The faunal assemblage}

In the following chapters, the faunal assemblage covers all specimens of bone, antler and ivory (worked as well as unworked) representing fish (Pisces), birds (Aves) and mammals (Mammalia). In order to examine the arthropod fauna (Class Insecta and Arachnida) at Nipisat, sampling for this purpose was carried out during the 1994 excavation campaign. The soil samples from Nipisat seem to be devoid of insect remains (Jens Böcher pers. comm. 1996). However, samples from Saqqaq layers at Asummiut yielded remnants of insects and oribatid mites (Oribatida) and documented the extant rove beetle Euaestethus laeviusculus for the first time at a prehistoric site (Böcher 1997:262, I998:I34). The apparent lack of insects in the Nipisat deposits seem surprising and contrasts with the results from Qeqertasussuk, where the sediments contained abundant and well preserved fragments of insects and other arthropods (Böcher and Fredskild 1993). When organic matter accumulates, e.g. at a site, it strongly improves the living conditions for various kinds of arthropods (Böcher 1997:260). The absence of arthropod remains at Nipisat may partly be ascribed to the fact that only few samples were examined and only from a restricted part of the excavation area. However, the nature of the layers with many wind deposited lenses (see chapter 3) together with the fact that the site was primarily a seasonal, only briefly visited locality, may also explain the scarcity. During the bone analysis, very few fly puparia were observed, supporting the results obtained by Jens Böcher. Molluscs (Mollusca) are dealt with in further detail by Petersen and Hoch (Appendix 2).

\section{Sampling methods}

The sampling strategy may have affected the recovery of small-boned taxa and, in addition, excavation conducted by trowels alone is strongly influenced by the skill of the excavator. Still, presence of little auk (Alle alle) and sandpiper (Calidris spp.) bones, and a substantial number of tiny needles and needle fragments, indicates an overall thorough excavation. In the 1994 excavation season, sieving was carried out in two squares (383x/18ry and 384x/181y, area I) on $2 \mathrm{~mm}$ mesh through all layers. This test sieving did not contribute additional bones. According to data in McGovern (1985), the identified proportion of 5 sieved ( 3 and I mm mesh) Norse bone assemblages varied between $26-48 \%$. The identified proportion of the Nipisat sample was $42 \%$. The unidentified proportion of a sub-sample of the Nipisat assemblage accounted only for $14 \%$ of the total weight of the bones (Gotfredsen 1996:98), which further indicates that the recovery of bone fragments at the site was quite good (Fig. 125).

\section{Preservation of the bones}

The Nipisat site is located in the low arctic climate zone and the island is presently situated in the zone of discontinuous permafrost (Heide-Jørgensen and Johansen 1997). Traces of permafrost were seen in the central part of the excavation (area I), particularly in square $386 \mathrm{x} / \mathrm{I} 85 \mathrm{y}$ and $386 \mathrm{x} / \mathrm{I} 86 \mathrm{y}$ in association with rocks (Kramer 1993), and in some parts of the excavation solifluction and cryoturbation had occurred (see Figs 2I and 23). Numerous lenses of very fine-grained crushed mollusc shells primarily of aeolian origin (see Appendix 2) inhibited to a large extent decalcification of the bones, and in general the bones are very well preserved with a high content of collagen (see Fig. 25). After abandonment, the entire site was covered by vegetation and the peat sealed the deposits until discovery of the locality in the summer of 1989. This special situation on Nipisat created optimal preservation conditions for bone, antler and ivory, although, due to the near absence of permafrost, no wood, baleen, fur, feathers or horn material has survived. In area 2, a few exceptions to these observations were a seal claw (39IX/I94y), phase 3, and a lower shaft of a feather (39I,20X/197,I2y), phase 3, even though no permafrost was detected in that part of the excavation.

The very large proportion of bird bones and particularly juvenile bird bones in the Nipisat assemblage 


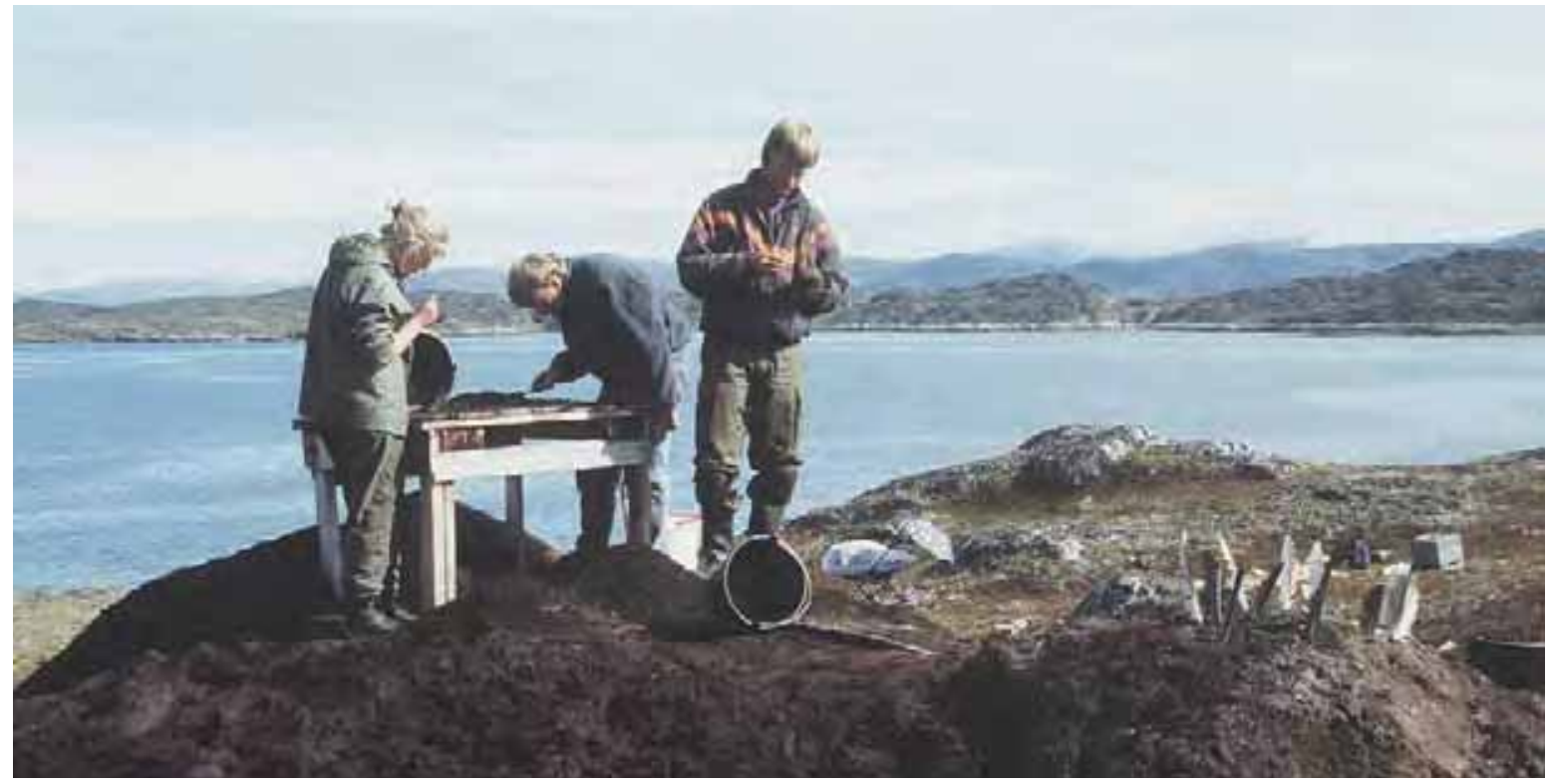

Fig. 125. Instead of systematic sieving, the back dirt of the excavation was examined carefully on a wooden table during the excavation campaigns of 1990, 1992 and 1993. From the left Anne Mette Olsvig, zoologist Carl Christian Kinze and archaeologist Sönke Hartz in 1993. Photo: Anne Birgitte Gotfredsen.

is indicative of the excellent preservation conditions. Although the preservation conditions in general are good, a large proportion of the bones show surface erosion of varying degrees, primarily due to exposure prior to covering by sediments. Post-depositional damage has also occurred, e.g. etching by roots. In the top layer (Layer 6) in particular, some bones were decalcified and exfoliation of the bone surface had commenced. The lowermost layers (Layer $2 \mathrm{~K}, 2 \mathrm{~S}$, I and o) had the best preservation conditions, while the preservation conditions in layer 2 varied to a larger degree. Even though preservation stages were not recorded for each bone fragment during the faunal analysis, qualitative comments were recorded for bones with a poor state of preservation. The degrading of the bone surface may to some extent have made observation of bone alterations such as cut marks more difficult to assess.

\section{Articulation of the bone elements}

Occurrence of articulated bone elements, i.e. bones found in a correct anatomical position, was only rarely noted in the field, although in a few instances they were registered in three dimensions. During subse- quent analysis in the laboratory, it was possible to rearticulate joints or portions of the backbone thus increasing the number of articulated parts at the site. In most cases it was possible to rearticulate skeletal elements within the same excavation unit i.e. within one square metre, however in rare cases it was possible to rearticulate bone elements of neighbouring excavation units. Refitting of broken bones was done in the same way. Examining the bone assemblage of each taxon separately would have increased the number of rearticulated joints and portions further and possibly also the number of refitted bones to some degree. The size of the bone collection, however, made it impossible to mark every single bone fragment. The described method still provided useful information on the portions of articulated limbs and other anatomical parts most frequently thrown onto the Nipisat midden. The type and description of rearticulated joints are listed under the species in question.

\section{The bone analysis}

All squares yielding faunal remains (bone, antler and/or ivory) were analysed. In the 1993 campaign seven square meters (384x/I87y; 385x/187y; 385x/I88y; 
$385 x / 189 y ; 386 x / 187 y ; 386 x / 188 y$ and 386x/I89y) of area I were very meticulously excavated, through registration of nearly every bone or small concentrations of bones in three dimensions, and stored in separately tagged bags. This recording method makes bone analysis very time consuming and hence only three squares (385x/387y; 385x/188y and 385x/189y) were thoroughly examined while the remaining four squares (384x/I87y; 386x/I87y; 386x/I88y and 386x/ I89y) were more extensively analysed and looked through in order to detect new species and extract mandibles and limb bones for aging and measuring respectively. Therefore, these four squares in the scatter plots, describing the spatial distribution of the fauna exhibit either no or a low number of fragments.

The bone material was analysed using the comparative collections of the Zoological Museum, University of Copenhagen (ZMUC). The bone material apart from artefacts and preforms is kept at the Zoological Museum. Each fragment was identified to taxon, bone element, and part of the bone. All identifiable bone fragments were recorded without a lower size limit. For each bone, a code for fragment type was applied, e.g. for long bones counting proximal and distal ends, proximal and distal ends including more than $50 \%$ of the diaphysis, diaphyses lacking the articular ends, fragments, and loose epiphyses.

In the case of small seals (Phoca spp.) post cranial skeletal elements are difficult to identify due to a large degree of both intra and inter specific variability. Therefore species-level identification was made on selected bone elements only (auditory bulla, mandibula, humerus, ulna and femur) having diagnostic features separating the phocid species. Fortunately auditory bullae, mandibles, and e.g. distal humeri are some of the densest and easily preserved elements of the phocid skeleton (Lyman 1996) and are often the elements used for MNI (Minimum Number of Individuals) for seals.

All physical damage to the bone e.g. gnawing, burning, cut marks, digestion of the bone surface and pathology was registered. Cut marks were sighted by the naked eye but checked under microscope. For taxa identified to species, side of the bone element was recorded. The ontogenetic age of bird and mammal bones was determined by classification into four age categories: pullus (small undifferentiated bones with a porous surface and unfused epiphyses); juvenilis (bones with unfused epiphyses and a rough surface); subadultus (bones of an adult size but with epiphyses not completely fused); and adultus (bones with completely fused epiphyses).

Walrus dentine is deposited in two distinct layers, with an outer homogenous and an inner mottled or marbled layer that builds up in the pulp cavity (MacGregor 1985:18). Walrus ivory is therefore easily distinguished from other ivory because of its marbled appearance (e.g. LeMoine and Darwent 1998). All ivory tools and ivory debitage at Nipisat were classed as walrus ivory.

The bone material resulting from four excavation campaigns during 1990 to 1994 including the test pits from 1989 was analysed over a considerable time span, however, by the same analyst, and was therefore identified in a standardized manner. The bone data was entered into a database (Paradox 4.5). The nomenclature of mammals follows Mitchell-Jones et al. (1999), which, however, does not include the arctic hare (Lepus arcticus) and Greenland caribou (Rangifer tarandus groenlandicus). For the sperm whale (Physeter macrocephalus) Holthuis (1987) was applied. The nomenclature of the bird species followed Boertmann (I994) and the fish species European Commission (1998). Definitions of measurements and ageing criteria are referred to under the species in question.

\section{Quantification}

The quantification units primarily used in the present study are NISP (Number of Identified Specimens) per taxon, MNE (Minimum Number of Elements) and MAU (Minimum Animal Unit). How to quantify faunal assemblages and estimate taxonomical abundance has been a matter of extensive discussion (e.g. Grayson 1984; Lyman 1994, I996; Marshall and Pilgrim 1993). In the present study, the term NISP is used whenever referring to taxonomic abundance. NISP counts are generally more easily applicable to small collections, so they represent a useful level for inter assemblage comparisons (Grayson 1984; Amorosi et al. 1996). Furthermore NISP counts are considered more useful when quantifying accretional deposits such as middens where portions of carcasses enter the archaeological record over extended periods, as extensively subdivided or transported butchered units, and reworked 
Table 13. Description of the faunal assemblage at the Nipisat site by class and phases.

\begin{tabular}{lcccccccc}
\hline & \multicolumn{2}{c}{ Phase 1 } & \multicolumn{2}{c}{ Phase 2 } & \multicolumn{2}{c}{ Phase 3 } & \multicolumn{2}{c}{ Total } \\
& NISP & \%NISP & NISP & \%NISP & NISP & \%NISP & NISP & \% NISP \\
\hline Fish ident. & 339 & - & 40 & - & 279 & - & 658 & - \\
Fish indet. & 476 & - & 98 & - & 323 & - & 897 & - \\
Total fish & 815 & 4.62 & 138 & 1.93 & 602 & 1.38 & 1555 & 2.27 \\
Birds ident. & 3524 & - & 1771 & - & 7936 & - & 13231 & - \\
Birds indet. & 5172 & - & 2028 & - & 11469 & - & 18669 & - \\
Total birds & 8696 & 49.33 & 3799 & 53.21 & 19405 & 44.38 & 31900 & 46.58 \\
Mammals ident. & 3568 & - & 1488 & - & 9878 & - & 14934 & - \\
Mammals indet. & 4552 & - & 1715 & - & 13835 & - & 20102 & - \\
Total mammals & 8120 & 46.05 & 3203 & 44.86 & 23713 & 54.24 & 35036 & 51.15 \\
\hline Total & 17631 & 100.00 & 7140 & 100.00 & 43720 & 100.00 & 68491 & 100.00 \\
\hline
\end{tabular}

refuse deposits (Woollett et al. 2000). MNI (Minimum Number of Individuals) counts have only to a limited extent been used because this is a derived measure of NISP and therefore not independent. MNI is too greatly influenced by the effects of aggregation to be a good measure of taxonomic abundance (Grayson 1984:9) In addition, MNI counts have been calculated by a variety of means, which makes comparison of published data difficult. In the present study MNI was calculated by taking non-overlapping portions of the most numerous bone element and the most numerous side. In a few cases, when side was not assessed, all specimens of e.g. a paired bone element were summed up and divided by two. Age was not taken into consideration, which may of course have deflated the MNI values. The MNE was calculated by summing up non-overlapping portions of each bone element.

Comparisons of NISP and MNE e.g. the NISP:MNE ratio illustrates the degree of fragmentation of the bone elements, while MAU accounts not only for the degree of fragmentation but also for the fact that skeletal elements are differently represented in a complete skeleton of the various taxa.

\section{Seasonal indicators}

There are various osteological indicators for the hunting season: I) Presence of migrating species occurring only seasonally, as for instance staging birds during spring or autumn migrations, or nesting birds during summer. II) Presence of juvenile bones which is a stronger tool for birds than for mammals because the ontogenetic development of the bones progresses faster with fusion of epiphyses occurring within months, as the ability to fly demands a strong rigid skeleton with fused epiphyses. In addition, mammalian juvenile mandibles showing tooth eruptions (where the deciduous teeth are replaced by the permanent dentition) of known sequence and timing are usable for determining seasonal occupation. III) Presence of medullary bone in bird bones. Medullary bone is a non-structural secondary bone, which forms as a calcium reserve in the marrow cavity of female birds during the breeding period. It builds up in a period of I-2 weeks before egg laying, is present throughout the egg-laying period and then gradually is absorbed after the last egg has been laid (Simkiss 1967; Taylor 1970). It is normally best observed in the femur, but tibiotarsus, scapula, coracoid, radius and ulna may also contain medullary bone. Besides giving a rather narrow indication of season, medullary bone also provides information on the sex ratio of the hunted birds. IV) Caribou frontal bones with shed, still attached, or deliberately broken off antlers can provide seasonal information. Does and bulls shed antlers at different times of the year, thus sexing of the calvarium is necessary.

In arctic regions, the growth of both birds and mammals is retarded during winter. The breeding and rapid growth of young takes place in spring and summer and the development of dentition in mammalian young also occur during the productive season (see p. I74). Since the migrating species only occur during 
summer osteological seasonal indicators are in effect synonymous with osteological summer indicators, and winter presence is very difficult to establish. Examination of growth layers in teeth may demonstrate possible winter occupation. This method was, however, not applied in the present study. The potentials and drawbacks of the various seasonal indicators are discussed under the specific taxon in question.

\section{Characteristics of the faunal assemblage}

The fauna is described according to chronological phases as defined in the section concerning stratigraphy and ${ }^{14} \mathrm{C}$ dates, in order to detect any changes over time. Due to a relatively smaller sample size in phase 2, however, material from this phase was omitted in some analyses.

From Table I3 it is seen that the relative proportions of the three classes (fish, birds and mammals) vary only marginally through all phases. The identified proportion of the bone material is also rather constant, comprising 42, 46 and $42 \%$ for phases I, 2 and 3 respectively. The large number of unidentified fragments is explained by a high degree of fragmentation, due to marrow fracturing and a large proportion of juvenile bones. These are more prone to fragmentation and, in addition, make identification of especially unfused bird bones difficult. Each major group of game animals (fish, birds and mammals) are dealt with separately in the following three chapters. 


\section{Chapter 6}

\section{Fish}

In total I555 fish remains were recovered from Nipisat, comprising about $2 \%$ of the entire faunal assemblage (Table I3). The relative proportion of fish bones seems to decrease through the occupation period, comprising 4.6, I.9 and I.4\% for phases I, 2 and 3 respectively. The species list is short with a maximum of four taxa represented and with gadids as the overwhelmingly dominant group, accounting for c. $98 \%$ of the species identified fish bones (Table I4). Of all fish bones $42.2 \%$ are identifiable to taxon and bone element. The remaining unidentified fish bones consist primarily of fin rays and flakes of gadid bone. The fish bones are generally well preserved, but have a tendency to disintegrate into flakes (see Fig. I26). The fact that more fish remains were recovered from phase I may be due to the generally better preservation potential in the lower strata. It may, however, also reflect the increased importance of cod fishing during the early occupation phase.

\section{Factors affecting the species composition}

The small number of fish species and relative frequen- cies of small and large sized species was obviously influenced by the lack of sieving. At the Norse site 'the Farm Beneath the Sand' (GUS), Nuuk District, capelin (Mallotus villosus) remains were recovered partly by wet sieving on mesh sizes down to I mm, partly from sediment attached to the bone material (Enghoff 2003). This illustrates how tiny the bones of capelin are and how easily they can be overlooked. Sieving samples at Qeqertasussuk increased the relative proportion of small sized fish species as, e.g. polar cod (Boreogadus saida) and capelin considerably (Meldgaard 2004:IOo). Therefore, we cannot expect the fish assemblage to reveal all aspects of fishing at Nipisat. It may also be suspected that some of the fish carcasses never ended up in the sediments at the site but were discarded on the beach or fed to the dogs (Gotfredsen I996, I998).

\section{Cod}

Cod (Gadus morhua) comprise c. 66, 58 and 68\% of the species identified fish bones in phases I, 2 and 3 respectively. By including the fish remains classified as Gadidae, the proportion increases to c. 98, 93 and 99\%

Table 14. The number of identified specimens (NISP) of fish (Pisces) at Nipisat and their relative frequencies and distribution according to chronological phase.

\begin{tabular}{|c|c|c|c|c|c|c|c|c|}
\hline & \multicolumn{2}{|c|}{ Phase 1} & \multicolumn{2}{|c|}{ Phase 2} & \multicolumn{2}{|c|}{ Phase 3} & \multicolumn{2}{|c|}{ Total } \\
\hline & NISP & $\%$ NISP & NISP & $\%$ NISP & NISP & $\%$ NISP & NISP & $\%$ NISP \\
\hline \multicolumn{9}{|c|}{ Atlantic salmon/arctic charr } \\
\hline \multicolumn{9}{|l|}{ (Salmo salar/Salvelinus } \\
\hline alpinus) & - & 0.00 & - & 0.00 & 1 & 0.36 & 1 & 0.15 \\
\hline \multicolumn{9}{|l|}{ Arctic charr } \\
\hline (Salvelinus alpinus) & 5 & 1.47 & 1 & 2.50 & - & 0.00 & 6 & 0.91 \\
\hline Gadids total & 333 & 98.23 & 37 & 92.50 & 277 & 99.28 & 647 & 98.33 \\
\hline Gadids (Gadidae) & 111 & 32.74 & 14 & 35.00 & 88 & 31.54 & 213 & 32.37 \\
\hline Cod (Gadus morhua) & 222 & 65.49 & 23 & 57.50 & 189 & 67.74 & 434 & 65.96 \\
\hline Sculpins (Cottidae) & 1 & 0.29 & 2 & 5.00 & 1 & 0.36 & 4 & 0.61 \\
\hline Total identified fish & 339 & 100.00 & 40 & 100.00 & 279 & 100.00 & 658 & 100.00 \\
\hline Fish indet. (Pisces spp.) & 476 & & 98 & & 323 & & 897 & \\
\hline Total fish & 815 & & 138 & & 602 & & 1555 & \\
\hline
\end{tabular}




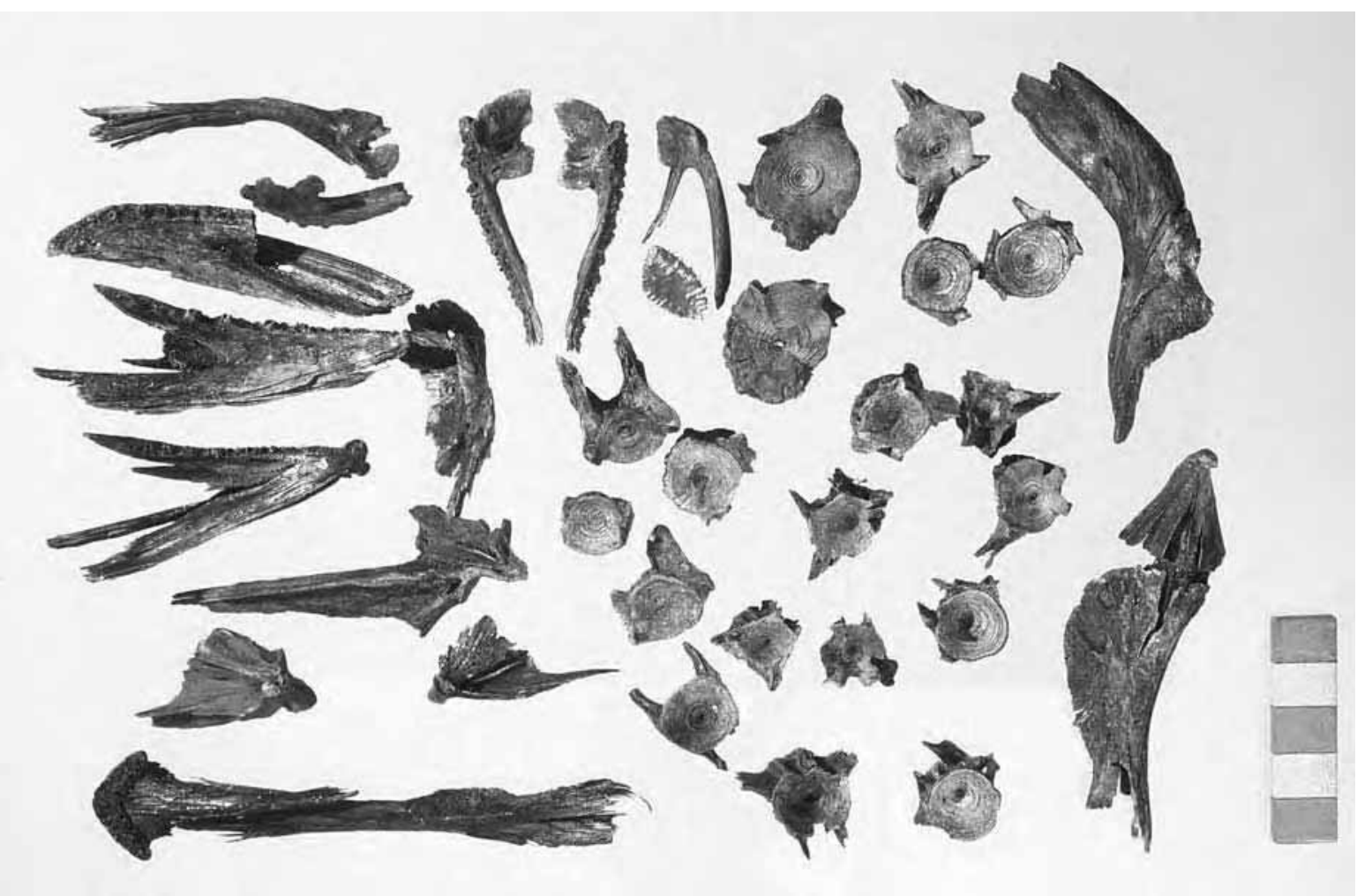

Fig. 126. A selection of fairly large gadid bones at Nipisat comprising bones from Gadus morhua and Gadidae. Note flaking of some of the bones. Foto: Geert Brovad.

respectively, and in the following all gadid bones have been treated together as a single group. It cannot be entirely excluded that some unspecified gadid bones derive from the uvak (Gadus ogac). However most of the gadid bones were too large to be from that species since uvaks only reach lengths of $65 \mathrm{~cm}$ (Muus I98г:70).

\section{Horizontal distribution and skeletal element distribution of cod}

From Table 15, presenting the entire sample of gadid bone elements, it can be seen that whole fish were brought up to the site. Bones of the head, the shoulder girdle and vertebrae, both precaudal $(\mathrm{N}=\mathrm{I} 22)$ and caudal $(\mathrm{N}=40)$, were found through all layers. The cod remains account for at least 7 individuals in phase I $(\mathrm{N}=333), 2$ individuals in phase $2(\mathrm{~N}=37)$ and 6 individuals in phase $3(\mathrm{~N}=277)$. The horizontal distribution of gadid bones demonstrates that cod bones were scattered over several squares both in phase I and 2 and in phase 3 (Figs 127 and 128). Some concentrations were seen in the northern and central part of area I, phase I, especially on top of the protruding bedrock and close to the hearth in the southern part of area I, phase I (Fig. 127). In phase 3, the scattering of cod remains (Fig. I28), although with a few concentrations, also implies that cod was caught more than occasionally.

Some of the concentrations of cod bones shown in Fig. 127 represent articulated body parts, for instance most of a head in square $386 \mathrm{x} / \mathrm{I} 85 \mathrm{y}$, phase I and part of a backbone in square $387 \mathrm{X} / \mathrm{I} 91 \mathrm{y}$, phase I. In phase 3 , square $387 \mathrm{x} / \mathrm{I} 87 \mathrm{y}$ yielded a smashed neurocranium representing many bones but only one individual.

\section{Size of the cod}

The total length of the cod at Nipisat was calculated from measurements of largest width of the posterior face of first and second vertebrae. Definitions of measurements were taken according to Casteel (1976) and regression equations after Enghoff (I994:appendix 2). To increase sample size measurements of the posterior face of vertebra no 3 and 4 were also included and for those vertebrae estimates of total length were made 
Table 15. Census of gadid bones at Nipisat including Gadus morhua and Gadidae by skeletal element and phases. Sin=left. sym=bones in the median plane and bones not assigned to side. Dex=right.

\begin{tabular}{|c|c|c|c|c|c|c|c|c|c|c|c|c|}
\hline & \multicolumn{4}{|c|}{ Phase 1} & \multicolumn{4}{|c|}{ Phase 2} & \multicolumn{4}{|c|}{ Phase 3} \\
\hline & $\operatorname{Sin}$ & -sym & Dex & Total & $\operatorname{Sin}$ & -sym & Dex & Total & $\operatorname{Sin}$ & -sym & Dex & Total \\
\hline \multicolumn{13}{|l|}{ Head } \\
\hline Neurocranium unspecified & & 18 & & 18 & & 5 & & 5 & & 17 & & 17 \\
\hline Parasphenoid & & 7 & & 7 & & 2 & & 2 & & 9 & & 9 \\
\hline Vomer & & 3 & & 3 & 1 & & 2 & 3 & 1 & 3 & 1 & 5 \\
\hline Nasale & & 1 & & 1 & & & & & & & & \\
\hline Frontale & & 18 & & 18 & & 2 & & 2 & 4 & 4 & 3 & 11 \\
\hline Pteroticum & 1 & & & 1 & & & & & & & & \\
\hline Basioccipitale & & 1 & & 1 & & 1 & & 1 & & 11 & & 11 \\
\hline Ophistoticum & 1 & & 1 & 2 & & & & & & & & \\
\hline Otolith & 1 & & 3 & 4 & & & & & 2 & & 1 & 3 \\
\hline Premaxillare & 7 & & 4 & 11 & 3 & & 1 & 4 & 4 & & 4 & 8 \\
\hline Maxillare & 2 & & 2 & 4 & & & 1 & 1 & 3 & & 6 & 9 \\
\hline Dentale & 7 & & 4 & 11 & & & & & 7 & & 5 & 12 \\
\hline Articulare & 3 & 2 & 4 & 9 & & & 1 & 1 & 3 & & 2 & 5 \\
\hline Angulare & & & 1 & 1 & & & & & & & & \\
\hline Quadratum & 2 & & 3 & 5 & & & & & 5 & & 3 & 8 \\
\hline Palatinum & 5 & & 3 & 8 & & & 1 & 1 & 2 & & 2 & 4 \\
\hline Pterygoid & & & 3 & 3 & & & 1 & 1 & & & 1 & 1 \\
\hline Preoperculum & 3 & & 2 & 5 & & & 1 & 1 & 3 & & & 3 \\
\hline Suboperculum & & & & & 1 & & & 1 & 1 & & & 1 \\
\hline Operculum & 1 & & 3 & 4 & & & & & 2 & 13 & 1 & 16 \\
\hline Symplecticum & 1 & & 4 & 5 & & & & & 1 & & & 1 \\
\hline Hyomandibulare & 1 & & 1 & 2 & 2 & & & 2 & 3 & 1 & 1 & 5 \\
\hline Epihyale & 1 & & 3 & 4 & & & & & 1 & 1 & & 2 \\
\hline Ceratohyale & & 4 & & 4 & & & 1 & 1 & 2 & 1 & & 3 \\
\hline Hypobranchialis & & 6 & & 6 & & & & & & 2 & & 2 \\
\hline Epibranchialis & & 2 & & 2 & & & & & & 5 & & 5 \\
\hline Ceratobranchialis & & 9 & & 9 & & & & & & 12 & & 12 \\
\hline Pharyngium inferius & 1 & 1 & & 2 & & 1 & & 1 & & 4 & & 4 \\
\hline \multicolumn{13}{|l|}{ Shoulder girdle } \\
\hline Posttemporale & 2 & & 5 & 7 & 1 & & 1 & 2 & 1 & & 1 & 2 \\
\hline Supracleithrum & 4 & & 2 & 6 & & & & & 3 & & 3 & 6 \\
\hline Cleithrum & 3 & & 5 & 8 & 1 & & & 1 & 1 & & 1 & 2 \\
\hline Postcleithrum & 1 & & 1 & 2 & & & & & 1 & & 1 & 2 \\
\hline Radialia & & 2 & & 2 & & & & & & 4 & & 4 \\
\hline \multicolumn{13}{|l|}{ Vertebrae } \\
\hline Vertebrae total & & 156 & & 156 & & 7 & & 7 & & 100 & & 100 \\
\hline V. precaudal & & 63 & & 63 & & 3 & & 3 & & 56 & & 56 \\
\hline V. caudal & & 22 & & 22 & & & & & & 18 & & 18 \\
\hline V. unspecified & & 71 & & 71 & & 4 & & 4 & & 26 & & 26 \\
\hline Others & & 2 & & 2 & & & & & & 4 & & 4 \\
\hline Total & & & & 333 & & & & 37 & & & & 277 \\
\hline
\end{tabular}

graphically (Enghoff unpublished data) (see Table I6). The size-frequency diagram thus reflects the size distribution and not necessarily the number of individuals, because one individual may be represented by more than one vertebra. It can be seen that most of the cod from the entire site had a total length between 70 and $100 \mathrm{~cm}$, few being under $50 \mathrm{~cm}$ or over $100 \mathrm{~cm}$ (Fig. 129). 
Fig. 127. Horizontal distribution of gadid bones in phases 1 and 2 including bones assigned to both Gadus morhua and Gadidae.
Fig. 128. Horizontal distribution of gadid bones in phase 3 including bones assigned to both Gadus morhua and Gadidae.

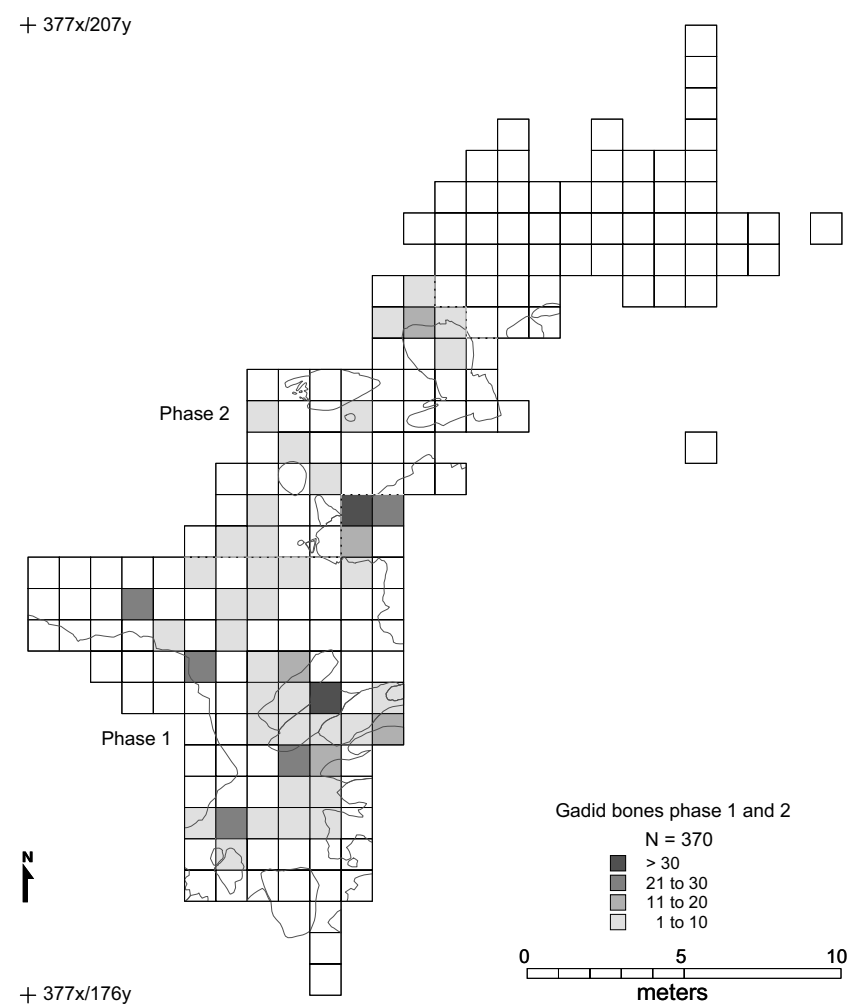

$409 x / 207 y+$

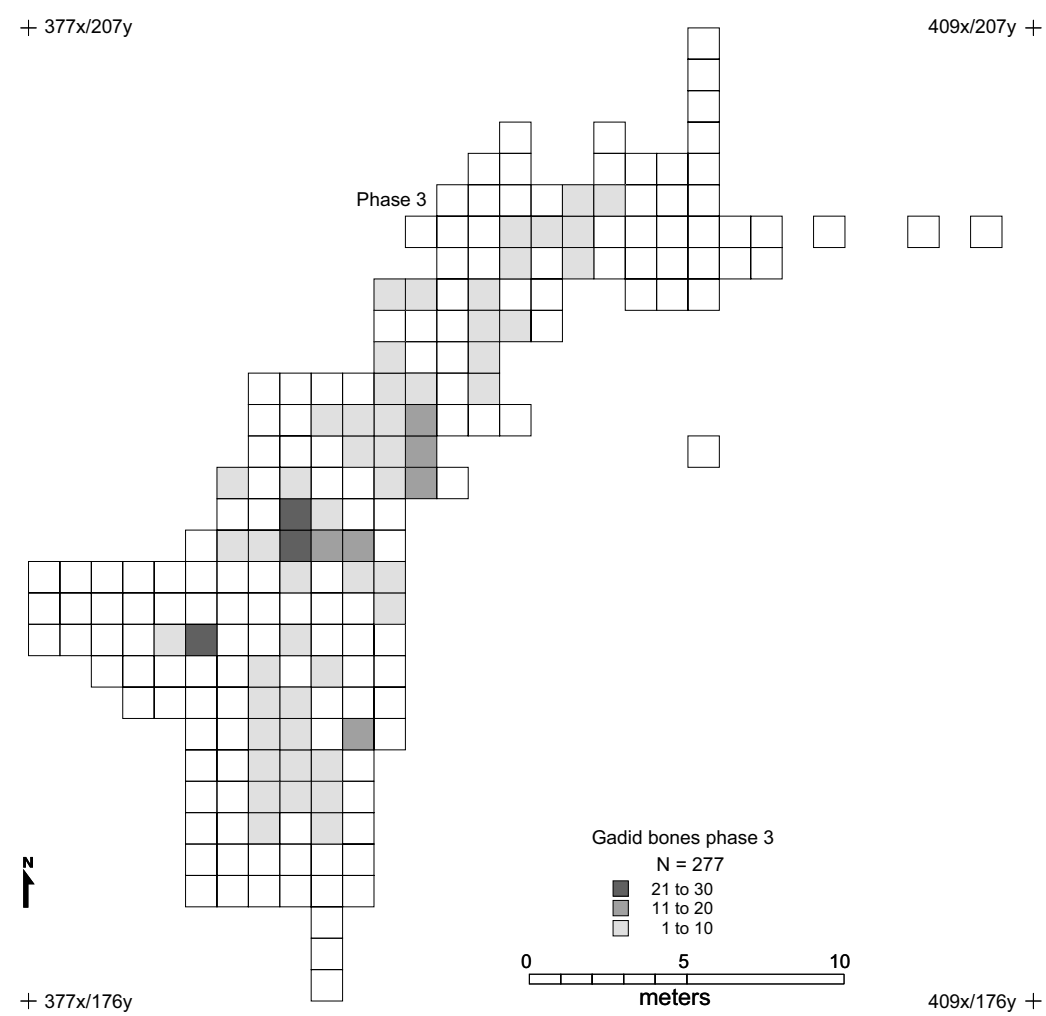

Anne Birgitte Gotfredsen \& Tinna Møbjerg:

Nipisat - a Saqqaq culture site in Sisimiut, central West Greenland, 2004

eISBN 978-87-635-2626-5, Monographs on Greenland | Meddelelser om Grønland, vol. 331 (ISSN 0025-6676)

Man and Society, vol. 31 (ISSN 0106-1062), http://www.mtp.hum.ku.dk/details.asp?eln=201396 
Table 16. Total length (T. L.) of cod (Gadus morhua) at Nipisat estimated from posterior width (P.W.) of vertebrae no. 1 to 4 . Definition of posterior width was according to Casteel (1976). Total length calculated for vertebra no 1 and 2 was after regression equations from Enghoff (1994). For vertebra no. 3 and 4 the total length was graphically estimated (Enghoff pers. comm.).

\begin{tabular}{|c|c|c|c|}
\hline & Phase & P.W. in $\mathrm{mm}$ & T. L. in $\mathrm{cm}$ \\
\hline \multicolumn{4}{|l|}{ Vertebra no 1} \\
\hline 382x/186y K:117 & 1 & 14.20 & 78 \\
\hline 387x/193y 2:541 & 3 & 14.60 & 80 \\
\hline $388 x / 196 y 2: 384$ & 3 & $15.54 *$ & 84 \\
\hline \multicolumn{4}{|l|}{ Vertebra no 2} \\
\hline 382x/186y K:118 & 1 & $15.3^{*}$ & 80 \\
\hline 385x/183y K:307 & 1 & 15.85 & 82 \\
\hline $385,29 x / 189,90 y$ S:1 & 1 & 18.72 & 94 \\
\hline 387x/189y SB:19 & 1 & 15.98 & 83 \\
\hline 387x/190y SB:101 & 1 & $19.43^{*}$ & 97 \\
\hline 386x/183y K:234 & 1 & 7.57 & 45 \\
\hline $385 x / 190 y 2: 851$ & 3 & 15.24 & 80 \\
\hline $385 x / 191 y 2: 461$ & 3 & 14.43 & 76 \\
\hline $388 x / 196 y 2: 385$ & 3 & 15.24 & 80 \\
\hline $391 x / 197 y 2: 766$ & 3 & 23.2 & 112 \\
\hline \multicolumn{4}{|l|}{ Vertebra no 3} \\
\hline 385x/183y K:308 & 1 & 16.39 & 83 \\
\hline $385,29 x / 189,90 y$ S:2 & 1 & 19.10 & 99 \\
\hline 387x/189y SB:20 & 1 & 18.22 & 93 \\
\hline 387x/190y S:101A & 1 & $20^{*}$ & 102 \\
\hline 388x/185y S:141 & 1 & 24.91 & 120 \\
\hline $385 x / 191$ y $2: 461$ & 3 & 17.40 & 90 \\
\hline $386 x / 191 y$ 2:534 & 3 & 18.14 & 95 \\
\hline $388 x / 196 y 2: 386$ & 3 & 16.35 & 83 \\
\hline \multicolumn{4}{|l|}{ Vertebra no 4} \\
\hline 386x/183y K:235 & 1 & 8.19 & 46 \\
\hline 386x/185y K:578 & 1 & 16.63 & 89 \\
\hline 387x/190y 1:176 & 1 & 18.57 & 99 \\
\hline 388x/184y K:429 & 1 & 26.33 & 134 \\
\hline 388x/191y K:240 & 1 & 13.11 & 71 \\
\hline $383 x / 190 y 2: 126$ & 3 & 13.20 & 72 \\
\hline $385 x / 191$ y $2: 462$ & 3 & $16.64^{*}$ & 84 \\
\hline $386 x / 191 y 2: 525$ & 3 & $18.07^{*}$ & 95 \\
\hline $388 x / 196 y$ 2:387 & 3 & 15.80 & 84 \\
\hline
\end{tabular}

* Indicates that the measure was estimated due to a slight damage of the bone.

\section{Season and method of cod fishing}

In Greenland, cod occurs along the west coast north to Uummannaq District and is found in fjords as well as on the fishing banks (Muus I98I). They prefer depths of 5-600 $\mathrm{m}$ and water temperatures of 2-IO ${ }^{\circ} \mathrm{C}$. Most often they are found near the bottom but may also occur in the free water column (Muus and Nielsen 1998). The cod at Nipisat could be from local stocks of cod breeding in the fjords or migrating bank cod. Bank cod may rise periodically from the bottom, thus being in its pelagic phase, and stay in warmer surface water when the banks are flooded by cold water from the East Greenland Current, often during June and July (Muus 198I). Glahn (I77I:I25) states that cod were caught at the mouth of Amerloq, in the fjord itself and at Sydbay during autumn. At the beginning of the $2 \mathrm{O}^{\text {th }}$ century, a large part of the Inuit population gathered at Qeqertalik and Avaleq, the southern branch of Ikertooq fjord, to catch cod as soon as the fast ice broke up in spring (Bendixen I92I). The cod consumed at other Saqqaq sites were also reported to have been of a considerable size of up to I m (Grønnow I994), as for instance at Qeqertasussuk most cod were 60-120 cm long (Grønnow and Meldgaard I988). Today, individuals of a total length of 70-I0o $\mathrm{cm}$ weigh $3-8 \mathrm{~kg}$ and cod of more than $\mathrm{I} 5 \mathrm{O} \mathrm{cm}$ long are very rare (Muus and Nielsen 1998).

Comparisons of Scandinavian Mesolithic fish assemblages have shown that Danish sites situated at coasts with shallow waters showed a large species diversity and produced fish of a small body size while contemporary Swedish and Norwegian sites typically at rocky shores provided large sized gadids (Enghoff I994:84-85). This was interpreted by Enghoff (I994) to reflect two different methods of fishing viz. stationary fish traps and hooks on lines, respectively. The cod caught by the Nipisat inhabitants were most likely taken with hooks during the summer half of the year or they could have been taken with leister when approaching the surface. Stationary fish traps and nets would have resulted in individuals of smaller size and possibly also in catches of uvak occurring in fjords and near the coast (Muus 198I). The topographical conditions near Nipisat were not suitable for fishing in shallow water. Setting up fish traps would require sandy beaches or other soft substrate and relatively calm waters. 
Fig. 129. Size-frequency diagram of total length of cod (Gadus morhua) based on the posterior width of vertebrae no 1 to 4 . Total length calculated for vertebra no 1 (W1) and 2 (W2) was after regression equations from Enghoff (1994). For vertebra no 3 (W3) and 4 (W4) total length was graphically estimated (Enghoff pers. comm.). (Data from Table 16).

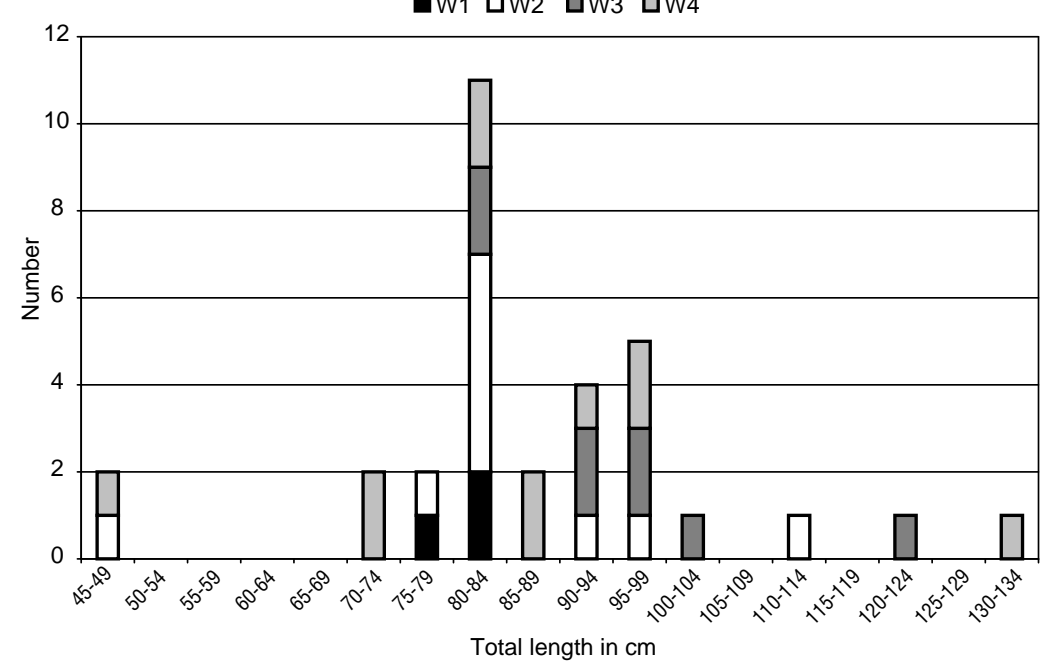

\section{Other fish species}

\section{Salmonids}

Bones identified to arctic charr occurred in phase I and 2 only. Phase I yielded one right oral part of an articulare and one right dentale (385x/193y) and three vertebrae $(384 \mathrm{X} / \mathrm{I} 84 \mathrm{y})$. Phase 2 provided one oral part of a left articulare (384x/190). In phase 3 , one vertebra (385x/193y) could not be identified more specifically than to Atlantic salmon/arctic charr. There may be a taphonomical bias against bones of salmonids because they are poorly ossified (see Casteel 1976:88). Furthermore, salmonids are fatty fish, a factor speeding up bone decay. Thus salmonids would be expected to have a poorer survival in the soil, as opposed to the stronger bones of the cod family, which often survive well in archaeological deposits (Wheeler and Jones I989).

Some populations of arctic charr spend their entire life in fresh water while others migrate annually to fjords and coastal waters spending 2-4 months in salty water feeding, before they return to fresh water from July to September to spawn and winter (Muus I98I). Arctic charr were probably caught in the rivers up the fjords by leister or nets. Besides being fat and delicious during late summer, ascending arctic charr are easily obtainable due to their tendency to congregate at river mouths.

\section{Sculpins}

Bones of sculpins occur through all phases, albeit scarcely. Phase I produced one parasphenoid (383X/
I85y), phase 2 yielded two fragments of a preoperculum (387x/193y) while phase 3 yielded one fragment of a preoperculum (396x/20ry).

According to Rink (1857:232) the Greenlanders considered sculpins and Uuvak to be an important extra resource during winter when other resources were scarce. Sculpins occurred in the surrounding waters year round, however, during the summer they probably did not play a large role in the economy of the Nipisat inhabitants.

\section{The importance of fishing at Nipisat}

For the above-mentioned reasons, it is very difficult to estimate how much fishing contributed to the site economy. From other lines of evidence, e.g. breeding birds, we know that the site was inhabited in early summer (June) when schools of capelin came close to the coast to spawn. In the mid $18^{\text {th }}$ century, the fattest and best capelin was caught at Amerloq and was found in abundance especially in the fjords, through the entire summer (Glahn I77I:II3-II4). It is believed that the inhabitants at Nipisat took advantage of this opportunity for obtaining an easily accessible resource, probably for drying and storing. However, we have not found any evidence of such practice at the site. Fishing cod, especially selective fishing for large individuals, was of some importance and could be carried out during the whole summer and even spring. Arctic charr and sculpins seem to have been of minor importance, although this is difficult to assess. 


\section{Chapter 7}

\section{Birds}

There were a total of 31,900 (46.6\%) avian bone fragments comprising $49.3 \%, 53.2 \%$ and $44.4 \%$ of the bone assemblage for phases I, 2 and 3 respectively (Table I3). At least 24 bird species are documented on the site, representing a number of marine, coastal, freshwater and terrestrial species (Table I7). The most important taxa were gulls (Laridae) and ducks (Anatinae), with eider ducks (Somateria spp.) as the dominating group. Geese (Anserinae) and auks (Alcidae) were also represented, but less frequently. The four dominating groups accounted for between $93-96 \%$ of the identified bird remains, while the remaining 4-7\% of the bird assemblage primarily consisted of divers (Gaviidae), fulmars and shearwaters (Procellariidae) great cormorant (Phalacrocorax carbo), swans (Cygnus spp.), and rock ptarmigan (Lagopus mutus) (Table I7 and Fig. I30). Birds associated with coastal waters dominate the bird assemblages, with gulls and eiders ranking as first and second through all layers. Nevertheless, the Nipisat people also hunted birds associated with fresh water and terrestrial habitats (Table I8). Bird species or taxonomic groups are described below according to their preferred habitat, as listed in Table I9.

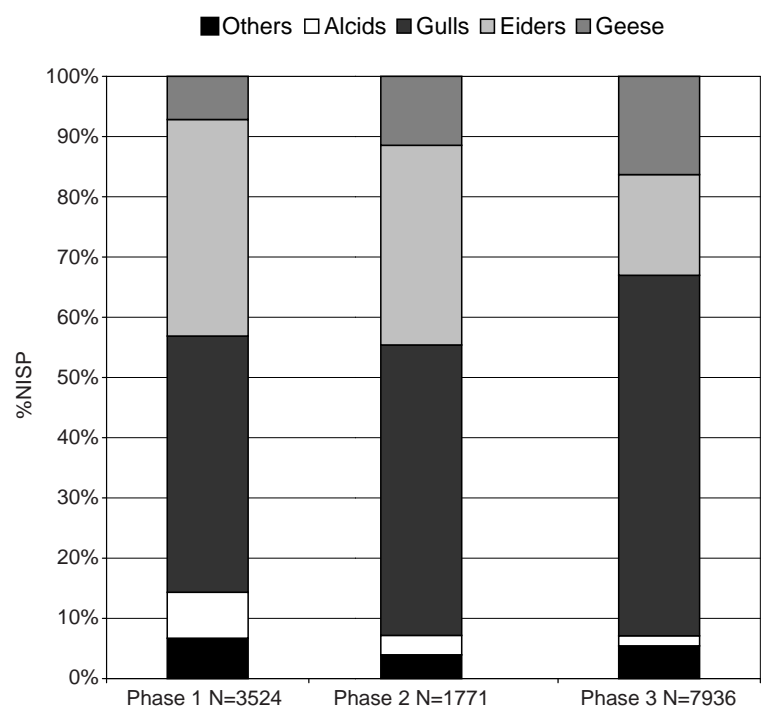

Fig. 130. The dominating bird taxa at Nipisat through all phases were gulls and eiders, but geese and auks also played a role in the site economy. (Data extracted from Table 17).

\section{Hunting in coastal waters}

\section{Fulmars and shearwaters}

For this group identification to genus is quite easy and, for nearly all post-cranial elements, several reliable distinguishing features at the generic level (Fulmarus from Puffinus) exist (e.g. Lepiksar 1958). Only a few fragmented bones lacking morphological features had to be classified as fulmar or great shearwater.

Fulmars comprise less than $\mathrm{I} \%$ of the avian remains at Nipisat, varying from I.4, 0.7 and $0.5 \%$ in phases I, 2 and 3 respectively (Table I7). Only six bones were from juveniles. In phase $\mathrm{I}$, a left proximal tarsometatarsus (384x/181y), a right complete tarsometatarsus (384x/I84y) and a left complete tibiotarsus (386x/I83y) were from subadults. In phase 3 , distal parts of two coracoids (38Ix/I87y) and a proximal part of a right ulna (387x/19oy) could be assigned to subadults. Remains of great shearwater also occurred in small numbers, comprising 0.I, 0.7 and $0.8 \%$ of the bird bones in phases I, 2 and 3 respectively (Table I7). All these bones were from adults.

Remains of both species were scattered all over the site and only in some instances could bone elements be rearticulated. Often, the pectoral girdle i.e. a cranial fragment of sternum, the furcula, right and left scapula and coracoid were left articulated. Nearly all body parts of both procellarid species occurred in the bone assemblage, however costae and vertebrae were absent (Tables 20-22). Two fulmar bones exhibited cut marks. One right femur (385x/185y), phase I, showed sub-parallel faint $3 \mathrm{~mm}$ long cut marks on the middle of the diaphysis at an oblique angle to the long axis placed on the cranial face. One left humerus (394X/ 2ory), phase 3 , exhibited several long, fine scratch marks along the entire length of the shaft, but most pronounced on the lateral face. One right femur (395x/20ry), phase 3, of great shearwater revealed several c. $3 \mathrm{~mm}$ long transverse sub-parallel scrape marks in particular on the mid part of the diaphysis on the lateral face. These few cut marks have been interpreted as filleting marks inflicted when meat and sinews were removed. A large proportion of the long 
Table 17. The number of identified specimens (NISP) of birds (Aves) at Nipisat and their relative frequencies and distribution according to chronological phase.

\begin{tabular}{|c|c|c|c|c|c|c|c|c|}
\hline & \multicolumn{2}{|c|}{ Phase 1} & \multicolumn{2}{|c|}{ Phase 2} & \multicolumn{2}{|c|}{ Phase 3} & \multicolumn{2}{|c|}{ Total } \\
\hline & NISP & $\%$ NISP & NISP & $\%$ NISP & NISP & $\%$ NISP & NISP & $\%$ NISP \\
\hline Red-throated diver (Gavia stellata) & 43 & 1.22 & 14 & 0.79 & 15 & 0.19 & 72 & 0.54 \\
\hline Great northern diver (Gavia immer) & 24 & 0.68 & 6 & 0.34 & 5 & 0.06 & 35 & 0.26 \\
\hline \multicolumn{9}{|l|}{ Fulmar/great shearwater } \\
\hline (Fulmarus glacialis/Puffinus gravis) & 3 & 0.09 & 1 & 0.06 & 8 & 0.10 & 12 & 0.09 \\
\hline Fulmar (Fulmarus glacialis) & 50 & 1.42 & 12 & 0.68 & 42 & 0.53 & 104 & 0.79 \\
\hline Great shearwater (Puffinus gravis) & 4 & 0.11 & 13 & 0.73 & 65 & 0.82 & 82 & 0.62 \\
\hline Great cormorant (Phalacrocorax carbo) & 18 & 0.51 & 6 & 0.34 & 100 & 1.26 & 124 & 0.94 \\
\hline \multicolumn{9}{|l|}{ Whooper/tundra swan } \\
\hline (Cygnus cygnus/colombianus) & 2 & 0.06 & 2 & 0.11 & 56 & 0.71 & 60 & 0.45 \\
\hline Geese (Branta spp.) & 253 & 7.18 & 203 & 11.46 & 1301 & 16.39 & 1757 & 13.28 \\
\hline Ducks (Anas spp./Somateria spp.) & 27 & 0.77 & 3 & 0.17 & 27 & 0.34 & 57 & 0.43 \\
\hline Mallard (Anas platyrhynchos) & 19 & 0.54 & - & 0.00 & 6 & 0.08 & 25 & 0.19 \\
\hline Eiders (Somateria spp.) & 1267 & 35.95 & 587 & 33.15 & 1323 & 16.67 & 3177 & 24.01 \\
\hline Long-tailed duck (Clangula hyemalis) & 2 & 0.06 & - & 0.00 & 2 & 0.03 & 4 & 0.03 \\
\hline Gyrfalcon (Falco rusticolus) & - & 0.00 & - & 0.00 & 1 & 0.01 & 1 & 0.01 \\
\hline Rock ptarmigan (Lagopus mutus) & 40 & 1.14 & 13 & 0.73 & 50 & 0.63 & 103 & 0.78 \\
\hline Sandpipers (Calidris spp.) & 3 & 0.09 & & 0.00 & 2 & 0.03 & 5 & 0.04 \\
\hline Arctic skua (Stercorarius parasiticus) & - & 0.00 & - & 0.00 & 3 & 0.04 & 3 & 0.02 \\
\hline Gulls total & 1499 & 42.54 & 854 & 48.22 & 4754 & 59.90 & 7107 & 53.71 \\
\hline Gulls (Larus spp.) & 917 & 26.02 & 611 & 34.50 & 3131 & 39.45 & 4659 & 35.21 \\
\hline Iceland gull (Larus glaucoides) & 79 & 2.24 & 55 & 3.11 & 491 & 6.19 & 625 & 4.72 \\
\hline \multicolumn{9}{|l|}{ Glaucous gull/great black-backed gull } \\
\hline (Larus hyperboreus/Larus marinus) & 440 & 12.49 & 156 & 8.81 & 786 & 9.90 & 1382 & 10.45 \\
\hline Black-legged kittiwake (Rissa tridactyla) & 63 & 1.79 & 32 & 1.81 & 346 & 4.36 & 441 & 3.33 \\
\hline Alcids total & 269 & 7.64 & 57 & 3.22 & 133 & 1.68 & 459 & 3.47 \\
\hline Guillemots/razorbill (Uria spp./Alca torda) & 2) 37 & 1.05 & 2 & 0.11 & 40 & 0.50 & 79 & 0.60 \\
\hline Brünnich's guillemot (Uria lomvia) & 42 & 1.19 & 12 & 0.68 & 10 & 0.13 & 64 & 0.48 \\
\hline Razorbill (Alca torda) & 5 & 0.14 & - & 0.00 & 4 & 0.05 & 9 & 0.07 \\
\hline Black guillemot (Cepphus grylle) & 125 & 3.55 & 43 & 2.43 & 69 & 0.87 & 237 & 1.79 \\
\hline Little auk (Alle alle) & 12 & 0.34 & - & 0.00 & 8 & 0.10 & 20 & 0.15 \\
\hline Great auk (Pinguinus impennis) & 48 & 1.36 & - & 0.00 & 2 & 0.03 & 50 & 0.38 \\
\hline Snowy owl (Nyctea scandiaca) & - & 0.00 & - & 0.00 & 4 & 0.05 & 4 & 0.03 \\
\hline Common raven (Corvus corax) & 1 & 0.03 & - & 0.00 & 39 & 0.49 & 40 & 0.30 \\
\hline Total identified birds & 3524 & 100.00 & 1771 & 100.00 & 7936 & 100.00 & 13231 & 100.00 \\
\hline Birds indet. (Aves spp.) & 5172 & & 2028 & & 11469 & & 18669 & \\
\hline Total birds & 8696 & & 3799 & & 19405 & & 31900 & \\
\hline
\end{tabular}

bones lacked both articular ends. Most of the adult wing and leg long bones (humerus, radius, ulna, femur and tibiotarsus) lacked articular ends (69.7\% $(\mathrm{N}=46))$ while $30.3 \%(\mathrm{~N}=20)$ were complete. This pattern of breaking off the ends was observed for most bird bones at Qeqertasussuk (Grønnow and Meldgaard I988) and the Thule Culture site Orkrusset ${ }^{\mathrm{I}}$ for both gull and fulmar bones (see Gotfredsen r997a).

I. The geologist K. J. V. Steenstrup collected bones from Eskimo middens during his $2^{\mathrm{I}} / 2$ years of fieldwork at the Nuussuaq peninsula in the I870's. According to handwritten notes (on file at Zoological Museum) Steenstrup claimed that a sample of bird bones was collected in 1872 at a locality by the name of Orkrusset near Nuussaq. However, no such locality exists and Steenstrup presumably misspelled an Eskimo place name (H.C. Gulløv pers. comm. 1999). The localities examined by Steenstrup at Nuussuaq were assigned to Thule Culture (H.C. Gulløv pers. comm. 1999). 
Table 18. The most abundant bird taxa and their preferred habitat for the three phases. The rank is according to NISP (data from Table 17).

Phase 1 Phase 2 Phase 3 All phases NISP NISP NISP NISP

\section{Marine}

Fulmars and petrels

$\begin{array}{cllll}\text { (Procellariidae) } & 6 & 5 & 5 & 5 \\ \text { Alcids (Alcidae) } & 3 & 4 & 4 & 4\end{array}$

Coastal

Great cormorant

\begin{tabular}{|c|c|c|c|c|}
\hline (Phalacrocorax carbo) & 9 & 8 & 6 & 6 \\
\hline Ducks (Anatinae) & 7 & 9 & 10 & 9 \\
\hline Eiders (Somateria spp.) & 2 & 2 & 2 & 2 \\
\hline Gulls (Laridae) & 1 & 1 & 1 & 1 \\
\hline \multicolumn{5}{|l|}{ Freshwater } \\
\hline Divers (Gaviidae) & 5 & 6 & - & 7 \\
\hline Swans (Cygnus spp.) & - & 10 & 7 & 10 \\
\hline Geese (Branta spp.) & 4 & 3 & 3 & 3 \\
\hline \multicolumn{5}{|l|}{ Long-tailed duck } \\
\hline (Clangula hyemalis) & - & - & - & - \\
\hline \multicolumn{5}{|l|}{ Sandpipers } \\
\hline (Calidris spp.) & 10 & - & - & - \\
\hline \multicolumn{5}{|l|}{ Terrestrial } \\
\hline \multicolumn{5}{|l|}{ Rock ptarmigan } \\
\hline (Lagopus mutus) & 8 & 7 & 8 & 8 \\
\hline \multicolumn{5}{|l|}{ Common raven } \\
\hline (Corvus corax) & - & - & 9 & - \\
\hline
\end{tabular}

The scattered deposition and fragmentary nature of the bones strongly suggests that fulmar and great shearwater remains were leftovers from food preparation. The relative scarcity of fulmar and great shearwater bones in the Nipisat assemblage may indicate that they were only hunted occasionally.

\section{Hunting season and method}

Various special devices for fulmar hunting were developed by the Thule people, especially in the northern districts along the West Greenland coast (see Bertelsen I92Ib) where the collection of fulmar eggs was also of great importance. In the southern districts, the Inuit hunted fulmars with bird darts from kayaks (Helms I926). The Nipisat people may have hunted fulmar and great shearwater, probably using similar methods. The great shearwater is a widespread low arctic summer and autumn visitor, breeding in the southern Atlantic and abundant in July-September (occasionally -October) (Boertmann 1994:I2). This provides a rather narrow seasonal indicator. In historical times this species was considered even more abundant than the fulmar along the islands of the southwest Greenland coast (Helms I92I:I3I). Great shearwaters were hunted in large numbers from kayaks during August when the flightless moulting birds came close to the coast (Holbøll I843; Müller 1906). Because the birds were so extremely fat, (Holbøll I843; Oldendow 1933:63), the Inuit made use only of the oil and meat, not their skins (Helms I92I:I3I).

\section{Former breeding occurrence of fulmar in the Sisimiut District?}

The subadult bones at Nipisat deriving from fledglings most likely represent young having left breeding colonies of the Qeqertarsuup Tunua (Disko Bugt) further north, taking place during September to October (Salomonsen I98Ib: 173). The large Saqqaq site of Qeqertasussuk (Fig. I, no. 43) produced numerous fulmar bones comprising $25 \%$ of the avian remains, ranking this species as the second most important bird at the site (Table 34). The relative proportion of fulmars in bird bone assemblages from sites situated in the Qeqertarsuup Tunua was generally larger than at sites south of this area, indicating the existence of breeding colonies through millennia in Qeqertarsuup Tunua (Gotfredsen 1999). At Tingit in Aqulleq Fjord (Fig. I93, SIKo92), fulmar remains were retrieved from a small seasonal site (Gotfredsen I997b, I999). Presence of fulmar at the head of large fjords is rare, but reportedly occurred several summers in a row near Sarfannguaq (e.g. Müller 1906:79). Presence of fulmar bones at Tingit and subadult fulmar bones at Nipisat may indicate the existence of former small breeding colonies in the Sisimiut District. Until recently, the southernmost known breeding colonies on the West coast were situated in Qeqertarsuup Tunua (Holbøll I843; Bertelsen 1921a, 1932); around I945, however, breeding colonies of fulmar became established at Ydre Kitsissut off the south coast (Salomonsen I979; Kampp and Falk 1994).

\section{Great cormorant}

For the entire site, nearly $\mathrm{I} \%$ of the bird bones derived from great cormorants, comprising 0.5, 0.3 and I.3\% for phases I, 2 and 3, respectively (Table 17). The proportion of juvenile bones (comprising both chicks and 
Table 19. The presence or absence of bird taxa according to phase and preferred habitat.

\begin{tabular}{|c|c|c|c|c|}
\hline & Phase 1 & Phase 2 & Phase 3 & All phases \\
\hline \multicolumn{5}{|l|}{ Marine } \\
\hline Fulmar (Fulmarus glacialis) & $x$ & $x$ & $x$ & $x$ \\
\hline Great shearwater (Puffinus gravis) & $x$ & $x$ & $x$ & $x$ \\
\hline Brünnich's guillemot (Uria lomvia) & $\mathrm{x}$ & $x$ & $x$ & $x$ \\
\hline Razorbill (Alca torda) & $x$ & & $x$ & $x$ \\
\hline Black guillemot (Cepphus grylle) & $x$ & $x$ & $x$ & $x$ \\
\hline Little auk (Alle alle) & $x$ & & $x$ & $x$ \\
\hline Great auk (Pinguinus impennis) & $x^{a}$ & & & $x$ \\
\hline \multicolumn{5}{|l|}{ Coastal } \\
\hline Great cormorant (Phalacrocorax carbo) & $x$ & $x$ & $x$ & $x$ \\
\hline Eiders (Somateria spp.) & $x$ & $x$ & $x$ & $x$ \\
\hline Sandpipers (Calidris spp.) & $\mathrm{x}$ & & $x$ & $x$ \\
\hline Arctic skua (Stercorarius parasiticus) & & & $x$ & $x$ \\
\hline Iceland gull (Larus glaucoides) & $x$ & $x$ & $x$ & $x$ \\
\hline \multicolumn{5}{|l|}{ Glaucous gull/black-backed gull } \\
\hline (Larus hyperboreus/Larus marinus) & $\mathrm{x}$ & $x$ & $x$ & $x$ \\
\hline Black-legged kittiwake (Rissa tridactyla) & $x$ & $x$ & $x$ & $x$ \\
\hline \multicolumn{5}{|l|}{ Freshwater } \\
\hline Red-throated diver (Gavia stellata) & $x$ & $x$ & $x$ & $x$ \\
\hline Great northern diver (Gavia immer) & $x$ & $x$ & $x$ & $x$ \\
\hline Swan (Cygnus spp.) & $x$ & $x$ & $x$ & $x$ \\
\hline Geese (Branta spp.) & $x$ & $x$ & $x$ & $x$ \\
\hline Mallard (Anas platyrhynchos) & $x$ & & $x$ & $x$ \\
\hline Long-tailed duck (Clangula hyemalis) & $x$ & & $x$ & $x$ \\
\hline \multicolumn{5}{|l|}{ Terrestrial } \\
\hline Gyrfalcon (Falco rusticolus) & & & $x$ & $x$ \\
\hline Rock ptarmigan (Lagopus mutus) & $x$ & $x$ & $x$ & $x$ \\
\hline Snowy owl (Nyctea scandiaca) & & & $x$ & $x$ \\
\hline Common raven (Corvus corax) & $x$ & & $x$ & $x$ \\
\hline
\end{tabular}

a Two bones deriving from phase 3 were considered to derive from phase 1 (see text for explanation).

subadults) varied from $67 \%$ (phase 2 and 3 ) to $74 \%$ (phase I) (Tables 23-25, Figs I3I-I33).

The bones were scattered all over the site and only in few instances could they be rearticulated. This implies that cormorant hunting was not merely an occasional pastime. Bone elements of the wings and the legs were quite well represented compared to bones of the pectoral girdle and to some extent vertebrae and head bones, especially in phases I and 2 (Tables 20-22). This may to some extent be explained taphonomically, because the furcula of cormorants is rather fragile and in juvenile birds the sternum is only weakly developed. The limb bones are more robust, even in the young birds (Fig. I34). This relative underrepresentation of sterna and a few other bone elements was also seen in juvenile gulls (Gotfredsen
I997a:280). However, the apparent lack of coracoids and scapulae cannot be explained entirely by the dominance of juvenile cormorant bones. The bones left at the site were from both fleshy parts e.g. the legs (femur and tibiotarsus) and from parts with less meat e.g. the wings (humerus, ulna and radius). One right proximal part of a humerus (385x/I85y), phase I exhibited two distinct $3 \mathrm{~mm}$ long cut marks on caput humerus placed cranially. These are most likely dismemberment traces, inflicted when the wing was removed from the trunk. No bones exhibited evidence of gnawing.

\section{Hunting season and method}

In Greenland, the cormorant is a strictly coastal bird associated with the neritic zone where it dives for fish, 


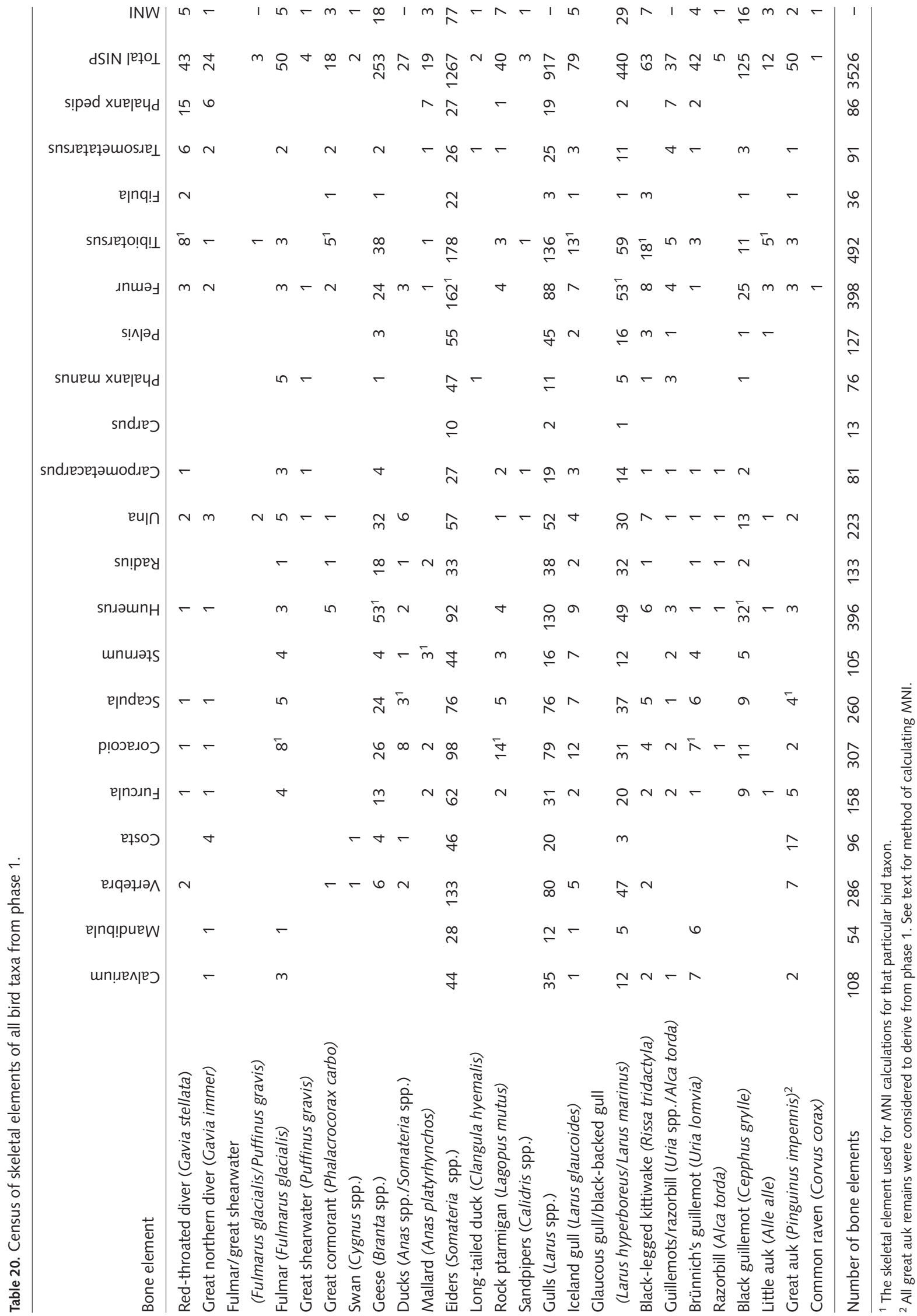


Fig. 131. The relative proportions of juvenile and adult bones in the avian assemblage, phase 1. Pullus comprise bones from hatchlings, while juvenile comprise bones from both juvenile and subadult birds. (Data from Table 23).

Fig. 132. The relative proportions of juvenile and adult bones in the avian assemblage, phase 2 . Pullus comprise bones from hatchlings while juvenile comprise bones from both juvenile and subadult birds. (Data from Table 24).

Fig. 133. The relative proportions of juvenile and adult bones in the avian assemblage, phase 3. Pullus comprise bones from hatchlings while juvenile comprise bones from both juvenile and subadult bones. (Data from Table 25).

口Adult $\square$ Juvenile $\square$ Pullus

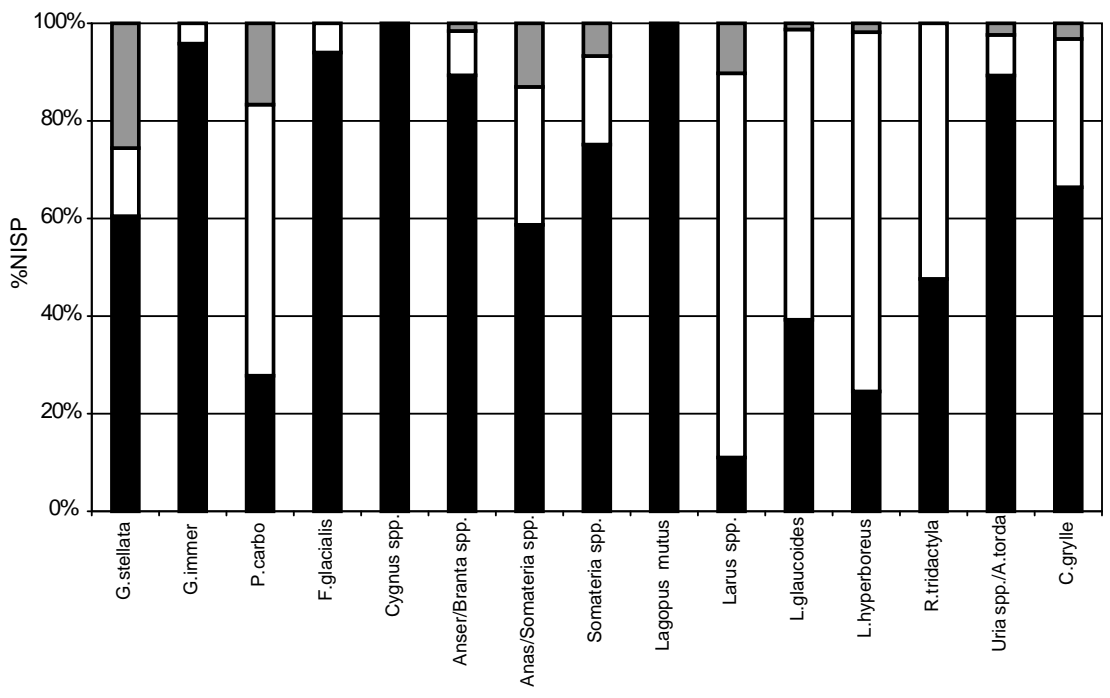

口Adult $\square$ Juvenile $\square$ Pullus

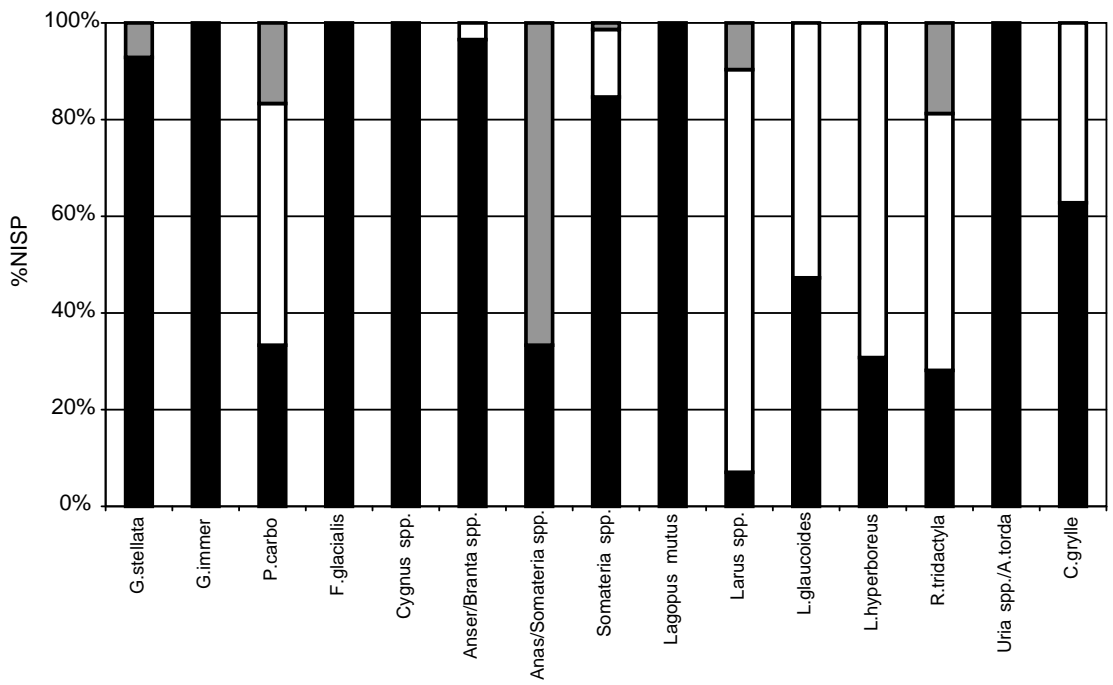

口Adult $\square$ Juvenile $\square$ Pullus

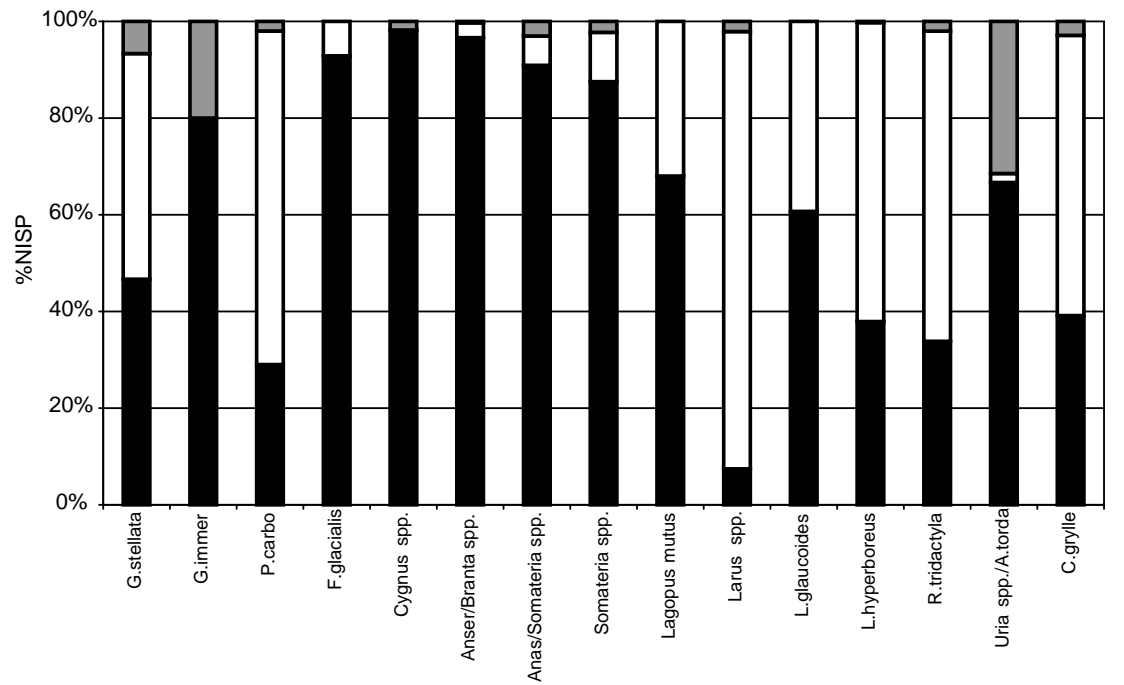

Anne Birgitte Gotfredsen \& Tinna Møbjerg: 


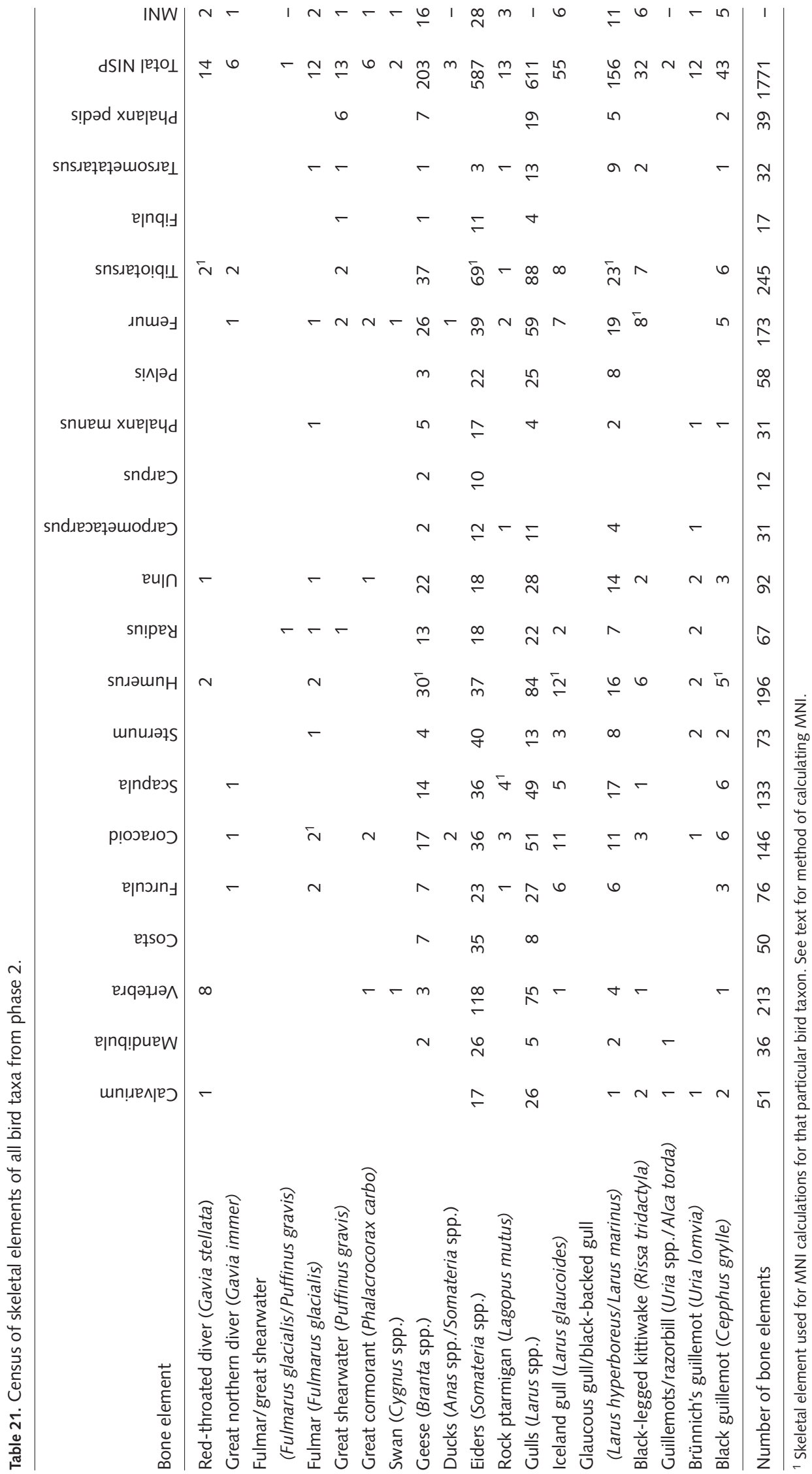




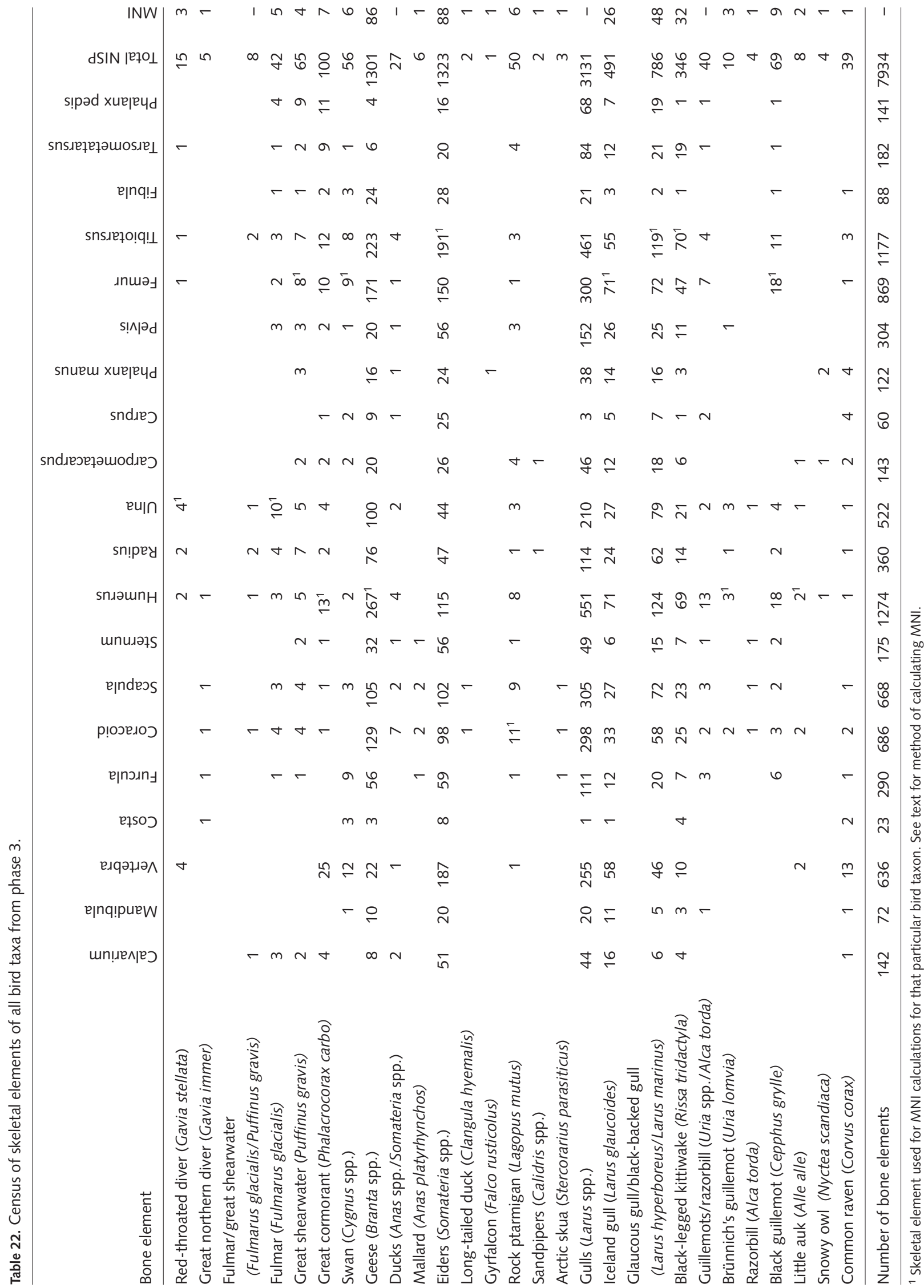


Table 23. Number and relative frequencies of bird bones by age, phase 1 .

\begin{tabular}{|c|c|c|c|c|c|c|c|}
\hline & \multicolumn{2}{|c|}{ Pullus } & \multicolumn{2}{|c|}{ Juvenile } & \multicolumn{2}{|c|}{ Adult } & \multirow[b]{2}{*}{ NISPTotal } \\
\hline & NISP & $\%$ & NISP & $\%$ & NISP & $\%$ & \\
\hline Gavia stellata & 11 & 25.58 & 6 & 13.95 & 26 & 60.47 & 43 \\
\hline Gavia immer & 0 & 0.00 & 1 & 4.17 & 23 & 95.83 & 24 \\
\hline Phalacrocorax carbo & 3 & 16.67 & 10 & 55.56 & 5 & 27.78 & 18 \\
\hline Fulmarus glacialis & 0 & 0.00 & 3 & 6.00 & 47 & 94.00 & 50 \\
\hline Cygnus spp. & 0 & 0.00 & 0 & 0.00 & 2 & 100 & 2 \\
\hline Anser/Branta spp. & 4 & 1.58 & 23 & 9.09 & 226 & 89.33 & 253 \\
\hline Anas/Somateria spp. ${ }^{1}$ & 6 & 13.04 & 13 & 28.26 & 27 & 58.70 & 46 \\
\hline Somateria spp. & 85 & 6.71 & 230 & 18.15 & 952 & 75.14 & 1267 \\
\hline Lagopus mutus & 0 & 0.00 & 0 & 0.00 & 40 & 100 & 40 \\
\hline Laridae spp. & 94 & 10.25 & 722 & 78.74 & 101 & 11.01 & 917 \\
\hline Larus glaucoides & 1 & 1.27 & 47 & 59.49 & 31 & 39.24 & 79 \\
\hline Larus hyperboreus & 8 & 1.82 & 324 & 73.64 & 108 & 24.55 & 440 \\
\hline Rissa tridactyla & 0 & 0.00 & 33 & 52.38 & 30 & 47.62 & 63 \\
\hline Uria spp./Alca torda ${ }^{2}$ & 2 & 2.38 & 7 & 8.33 & 75 & 89.29 & 84 \\
\hline Cepphus grylle & 4 & 3.20 & 38 & 30.40 & 83 & 66.4 & 125 \\
\hline
\end{tabular}

\footnotetext{
1 includes species identified Anas platyrhynchos.

2 includes species identified Uria lomvia and Alca torda.
}

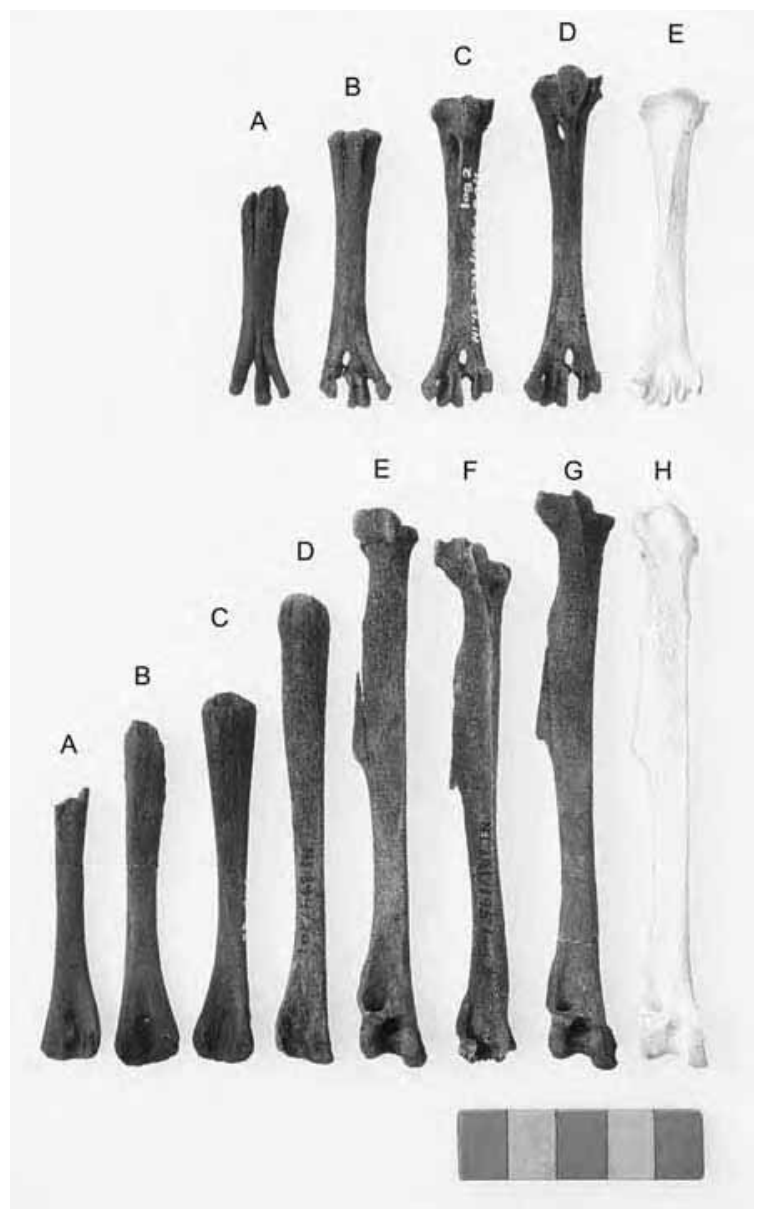

sculpins in particular, in water depths of ro-20 m (Salomonsen 1950, 1974). Their colonies are situated on steep cliffs, occasionally on low islands along exposed coasts but also in fjords and inshore waters (Boertmann and Mosbech 1997). The need for roosting sites and night roosts, however, makes the species vulnerable. In historical times the Inuit took advantage of the predictability of the birds and hunting took place at these roosting places (e.g. Fabricius I8I8:25I; Rink 1857:I83). Flightless young were also sought out and brought down to waiting kayaks by having towing bladders thrown at them from above (Müller I906:I2I; Oldendow 1935:I2I). The age composition at Nipisat shows that juvenile individuals were the focus of cormorant hunting. The great cormorant may have nested in close proximity to the site, as indicated by the many juvenile bones. The species does not breed near

Fig. 134. Juvenile and subadult leg bones of great cormorant (Phalacrocorax corax) at Nipisat. Above, tarsometatarsals from unfledged young (A-B), fledged young (C-D) and a $C$. one year old individual (E) (ZMUC Phalacrocorax carbo A 579), killed $24^{\text {th }}$ of July. Below, tibiotarsi from unfledged young (A-D), fledged young (E-G) and a $C$. one year old individual $(\mathrm{H})$ (ZMUC Phalacrocorax carbo A 579), killed $24^{\text {th }}$ of July. Photo: Geert Brovad. 
Table 24. Number and relative frequencies of bird bones by age, phase 2 .

\begin{tabular}{|c|c|c|c|c|c|c|c|}
\hline & \multicolumn{2}{|c|}{ Pullus } & \multicolumn{2}{|c|}{ Juvenile } & \multicolumn{2}{|c|}{ Adult } & \multirow[b]{2}{*}{ NISPTotal } \\
\hline & NISP & $\%$ & NISP & $\%$ & NISP & $\%$ & \\
\hline Gavia stellata & 1 & 7.14 & 0 & 0.00 & 13 & 92.86 & 14 \\
\hline Gavia immer & 0 & 0.00 & 0 & 0.00 & 6 & 100 & 6 \\
\hline Phalacrocorax carbo & 1 & 16.67 & 3 & 50.00 & 2 & 33.33 & 6 \\
\hline Fulmarus glacialis & 0 & 0.00 & 0 & 0.00 & 12 & 100 & 12 \\
\hline Cygnus spp. & 0 & 0.00 & 0 & 0.00 & 2 & 100 & 2 \\
\hline Anser/Branta spp. & 0 & 0.00 & 7 & 3.45 & 196 & 96.55 & 203 \\
\hline Anas/Somateria spp. & 2 & 66.67 & 0 & 0.00 & 1 & 33.33 & 3 \\
\hline Somateria spp. & 8 & 1.36 & 82 & 13.97 & 497 & 84.67 & 587 \\
\hline Lagopus mutus & 0 & 0.00 & 0 & 0.00 & 13 & 100 & 13 \\
\hline Laridae spp. & 59 & 9.66 & 509 & 83.30 & 43 & 7.04 & 611 \\
\hline Larus glaucoides & 0 & 0.00 & 29 & 52.73 & 26 & 47.27 & 55 \\
\hline Larus hyperboreus & 0 & 0.00 & 108 & 69.23 & 48 & 30.77 & 156 \\
\hline Rissa tridactyla & 6 & 18.75 & 17 & 53.13 & 9 & 28.12 & 32 \\
\hline Uria spp./Alca torda ${ }^{1}$ & 0 & 0.00 & 0 & 0.00 & 14 & 100 & 14 \\
\hline Cepphus grylle & 0 & 0.00 & 16 & 37.21 & 27 & 62.79 & 43 \\
\hline
\end{tabular}

${ }^{1}$ includes species identified Uria lomvia.

the site today, but during the $19^{\text {th }}$ century it was recorded at three localities between the towns of Sisimiut and Itilleq and many old night roosting places were known in the Sisimiut District (Müller 1906:I20). Cormorants are also known to have nested at Oqaatsorsuit at the western side of Qeqertarsua in Qeqertalik Fjord (Bendixen I92I:23). Hatching takes place from mid July to mid August (Salomonsen 1967), however, may take place in late May in early breeding years (Boertmann and Mosbech 1997:98). The nesting sites are normally deserted by the end of September (Salomonsen 1967). The flightless young and inexperienced fledged subadults at Nipisat were hunted, at least from August and onwards when the young had

Table 25. Number and relative frequencies of bird bones by age, phase 3.

\begin{tabular}{|c|c|c|c|c|c|c|c|}
\hline & \multicolumn{2}{|c|}{ Pullus } & \multicolumn{2}{|c|}{ Juvenile } & \multicolumn{2}{|c|}{ Adult } & \multirow[b]{2}{*}{ NISPTotal } \\
\hline & NISP & $\%$ & NISP & $\%$ & NISP & $\%$ & \\
\hline Gavia stellata & 1 & 6.67 & 7 & 46.67 & 7 & 46.67 & 15 \\
\hline Gavia immer & 1 & 20.00 & 0 & 0.00 & 4 & 80.00 & 5 \\
\hline Phalacrocorax carbo & 2 & 2.00 & 69 & 69.00 & 29 & 29.00 & 100 \\
\hline Fulmarus glacialis & 0 & 0.00 & 3 & 7.14 & 39 & 92.86 & 42 \\
\hline Cygnus spp. & 1 & 1.79 & 0 & 0.00 & 55 & 98.21 & 56 \\
\hline Anser/Branta spp. & 4 & 0.31 & 40 & 3.07 & 1257 & 96.62 & 1301 \\
\hline Anas/Somateria spp. ${ }^{1}$ & 1 & 3.03 & 2 & 6.06 & 30 & 90.90 & 33 \\
\hline Somateria spp. & 30 & 2.27 & 135 & 10.20 & 1158 & 87.53 & 1323 \\
\hline Lagopus mutus & 0 & 0.00 & 16 & 32.00 & 34 & 68.00 & 50 \\
\hline Laridae spp. & 66 & 2.11 & 2832 & 90.45 & 233 & 7.44 & 3131 \\
\hline Larus glaucoides & 0 & 0.00 & 193 & 39.31 & 298 & 60.69 & 491 \\
\hline Larus hyperboreus & 2 & 0.26 & 486 & 61.83 & 298 & 37.91 & 786 \\
\hline Rissa tridactyla & 7 & 2.02 & 222 & 64.16 & 117 & 33.82 & 346 \\
\hline Uria spp./Alca torda ${ }^{2}$ & 17 & 31.48 & 1 & 1.85 & 36 & 66.67 & 54 \\
\hline Cepphus grylle & 2 & 2.90 & 40 & 57.97 & 27 & 39.13 & 69 \\
\hline
\end{tabular}

1 includes species identified Anas platyrhynchos.

2 includes species identified Uria lomvia and Alca torda. 


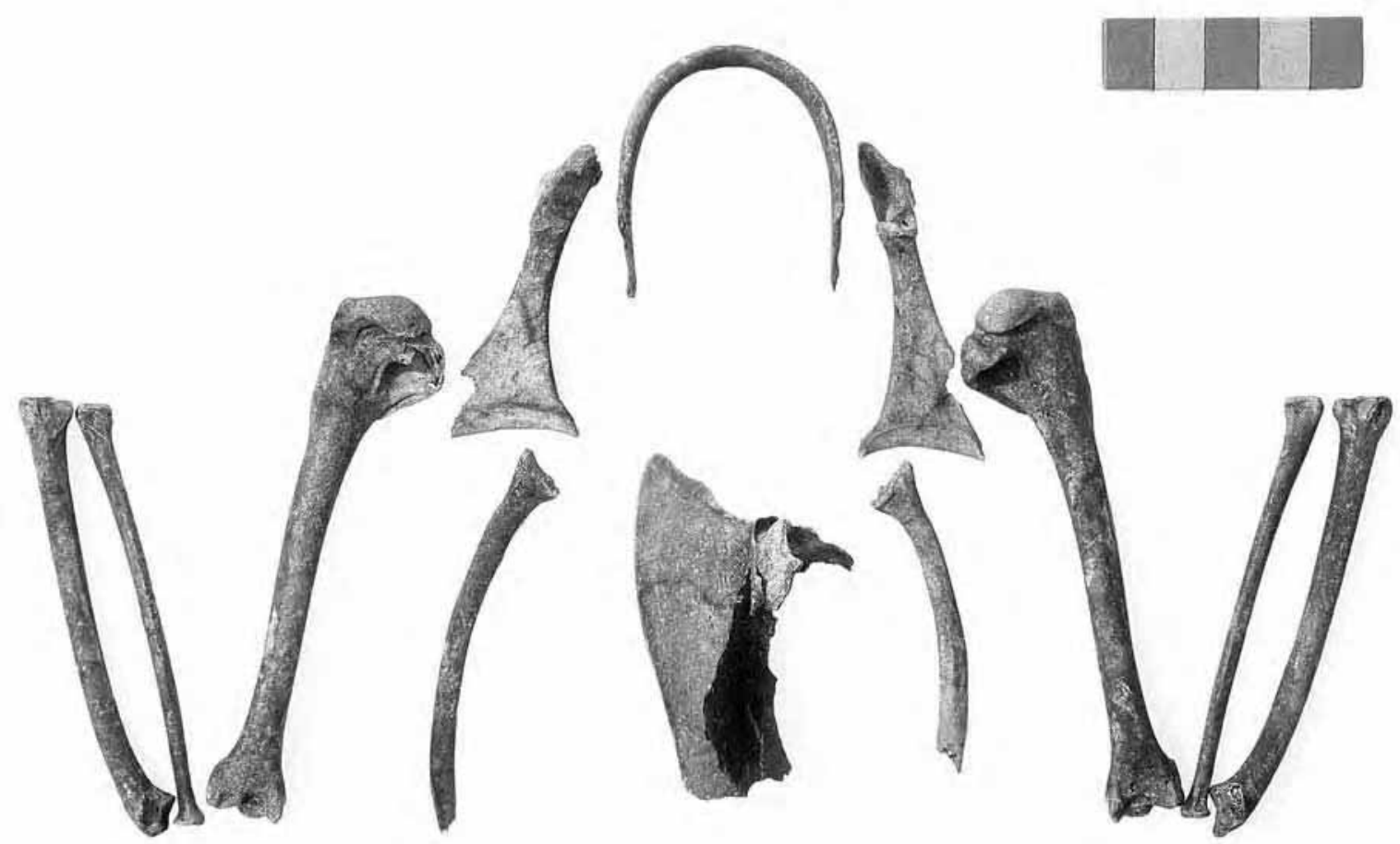

Fig. 135. Many bird carcasses were found in a partially articulated state. This anterior part of an eider skeleton (Somateria spp.) was found in association (386,50x/194,20y, phase 2 ) and derived from a single individual. The bones exhibited no butchering marks but the right humerus had tiny punctures, most likely from fox teeth. Photo: Geert Brovad.

reached a certain size (see Fig. 134). During winter, cormorants stayed in the Open Water Area and the population increased because breeding birds arrived from North Greenland (Salomonsen 1974). In historical times, most cormorants were hunted during autumn and winter and the majority were shot within their first year of life (Salomonsen I967).

Cormorants provided meat (meat from young birds was considered a particular delicacy) (Müller I906:I2I), excellent skins, eggs claimed to be the best of all eggs by Glahn (I77I:II2) and, in addition, a soft elastic oesophagus used by historic Inuit for bladders of bladder darts (Helms I92I:I33). The large contingent of juvenile cormorants in the Nipisat assemblage may be due to unintentional selective hunting, because they were easier to catch, or the young birds may have been deliberately sought after for their tasty meat.

\section{Eiders}

Comprising nearly a fourth (24\%) of the avian remains (Table 17) eider ducks rank as second most frequent after gulls (Table I8). Their relative proportion seems to decrease through time, comprising c. 36, 33 and I7\% in phases I, 2 and 3, respectively (Table I7, Fig. I30). All phases produced juvenile bones, although their relative frequencies varied from $25 \%$ in phase I to $15 \%$ and I3\% in phases 2 and 3 (Tables 23-25, Figs I3I-I33).

There are no morphological features to separate the common eider (Somateria mollissima) from the king eider (Somateria spectabilis), but size can be used as a general guideline. In the Nipisat sample, a few adult eider bones $(\mathrm{N}=65)$ were comparable to king eider in size. Both eider species therefore may have been present in the Nipisat assemblage. Today king eiders breed in the High Arctic, but post breeding males and non-breeders occur in West Greenland during summer, in particular north of Asiaat. During winter they are numerous in the Open Water Area (Boertmann 1994:20). The juvenile bones from unfledged young are presumed to derive from common eider while subadult bones may derive from either species.

All eider bones were classified as Somateria spp., although the common eider is considered absolutely the most frequent eider species at the site. In the following, the eider remains are treated collectively. 
Bone element representation and treatment of the bones Eider bones were distributed over the entire site and occurred in all three areas, with a distribution similar to that of the gull remains (see Figs I39 and I40).

In several instances it was possible to rearticulate bones of eider. Most frequently the synsacrum, some ribs and vertebrae were found in association, but also part of the backbone, wings e.g. an entire left wing in square $38 \mathrm{Ix} / \mathrm{I} 87 \mathrm{y}$, phase 3 , or parts of the pectoral girdle were recovered. Anterior parts of two individuals were retrieved from square 386,50x/194,20y, phase 2. In Fig. I35 the most complete carcass of the two including some of the wing bones is shown. All skeletal elements of eider were present at the site (Tables 20-22). Leg bones (femur and tibiotarsus) have the highest \%MAU values, but also bones of the pectoral girdle and the humerus are well represented (Table 26 and Fig. I36). Ulna and radius are less well represented than the humerus and head bones, vertebrae, ribs, wing and leg extremities are predictably underrepresented.
In total 23 eider bones exhibit cut marks (Appendix I). The majority of cut marks are interpreted as deriving from the filleting process. A total of 35 bones exhibit clear tooth or gnawing marks. The proportion of intact adult eider long bones (i.e. humerus, ulna, radius, femur and tibiotarsus) is $44.5 \%(\mathrm{~N}=254)$ compared to $55.5 \%(\mathrm{~N}=3 \mathrm{I} 7)$ lacking both articular ends.

\section{Season and methods of eider hunting}

Fragments containing medullary bone amount to II specimens, all deriving from phase 3. Medullary bone was detected in one cranial part of a sternum, one scapula, four coracoids, one humerus and four femora. The number of eider bones containing medullary bone is probably underrepresentative, because they were not systematically assessed as, e.g. the goose bones. However, it is assumed that the proportion of eider bones containing medullary bone is small and that eider remains largely represent males, non-breeding females and females presumably taken after the breeding period.

Table 26. The distribution of eider bones by skeletal element and phase. Numbers in parenthesis designate the number of that particular element in a complete eider skeleton.

\begin{tabular}{|c|c|c|c|c|c|c|c|c|c|c|c|c|}
\hline & \multicolumn{4}{|c|}{ Phase 1} & \multicolumn{4}{|c|}{ Phase 2} & \multicolumn{4}{|c|}{ Phase 3} \\
\hline & NISP & MNE & MAU & $\% M A U$ & NISP & MNE & MAU & $\% M A U$ & NISP & MNE & MAU & $\% M A U$ \\
\hline Calvarium (1) & 44 & 10 & 10 & 13 & 17 & 4 & 4 & 14 & 51 & 7 & 7 & 8.1 \\
\hline Mandibula (2) & 28 & 21 & 10.5 & 13.6 & 26 & 16 & 8 & 28.1 & 20 & 12 & 6 & 6.9 \\
\hline Vertebra (24) & 133 & 132 & 5.5 & 7.1 & 118 & 118 & 4.9 & 17.2 & 187 & 175 & 7.3 & 8.4 \\
\hline Costa $(28)^{1}$ & 46 & 37 & 1.3 & 1.7 & 35 & 11 & 0.4 & 1.4 & 8 & 5 & 0.2 & 0.2 \\
\hline Furcula (1) & 62 & 20 & 20 & 26 & 23 & 18 & 18 & 63.2 & 59 & 34 & 34 & 39.1 \\
\hline Coracoid (2) & 98 & 97 & 48.5 & 63 & 36 & 36 & 18 & 63.2 & 98 & 87 & 43.5 & 50 \\
\hline Scapula (2) & 76 & 70 & 35 & 45.5 & 36 & 35 & 17.5 & 61.4 & 102 & 100 & 50 & 57.5 \\
\hline Sternum (1) & 44 & 22 & 22 & 28.6 & 40 & 18 & 18 & 63.2 & 55 & 30 & 30 & 34.5 \\
\hline Humerus (2) & 92 & 75 & 37.5 & 48.7 & 37 & 34 & 17 & 59.7 & 116 & 89 & 44.5 & 51.1 \\
\hline Radius (2) & 33 & 31 & 15.5 & 20.1 & 18 & 18 & 9 & 31.6 & 47 & 41 & 20.5 & 23.6 \\
\hline Ulna (2) & 57 & 52 & 26 & 33.8 & 18 & 18 & 9 & 31.6 & 44 & 39 & 19.5 & 22.4 \\
\hline Carpometac. (2) & 27 & 26 & 13 & 16.9 & 12 & 12 & 6 & 21.1 & 26 & 24 & 12 & 13.8 \\
\hline Carpus (4) & 10 & 10 & 2.5 & 3.3 & 10 & 10 & 2.5 & 8.8 & 25 & 25 & 3.3 & 3.8 \\
\hline First phalanx II (2) & 30 & 29 & 14.5 & 18.8 & 8 & 8 & 4 & 14 & 15 & 14 & 7 & 8.1 \\
\hline Synsacrum (1) & 18 & 16 & 16 & 20.8 & 13 & 9 & 9 & 31.6 & 30 & 26 & 26 & 29.9 \\
\hline Femur (2) & 162 & 154 & 77 & 100 & 39 & 39 & 19.5 & 68.4 & 152 & 137 & 68.5 & 78.7 \\
\hline Tibiotarsus (2) & 178 & 154 & 77 & 100 & 69 & 57 & 28.5 & 100 & 191 & 174 & 87 & 100 \\
\hline Fibula (2) & 22 & 22 & 11 & 14.3 & 11 & 11 & 5.5 & 19.3 & 28 & 28 & 14 & 16.1 \\
\hline Tarsometat. (2) & 26 & 26 & 13 & 16.9 & 3 & 3 & 1.5 & 5.3 & 21 & 17 & 8.5 & 9.8 \\
\hline Phalanx pedis (14) & 27 & 27 & 1.9 & 2.5 & - & - & - & - & 16 & 14 & 1 & 1.1 \\
\hline Total & 1213 & & & & 569 & & & & 1292 & & & \\
\hline
\end{tabular}

\footnotetext{
${ }^{1}$ the number of costae is not representative because most costae were left unidentified.
} 


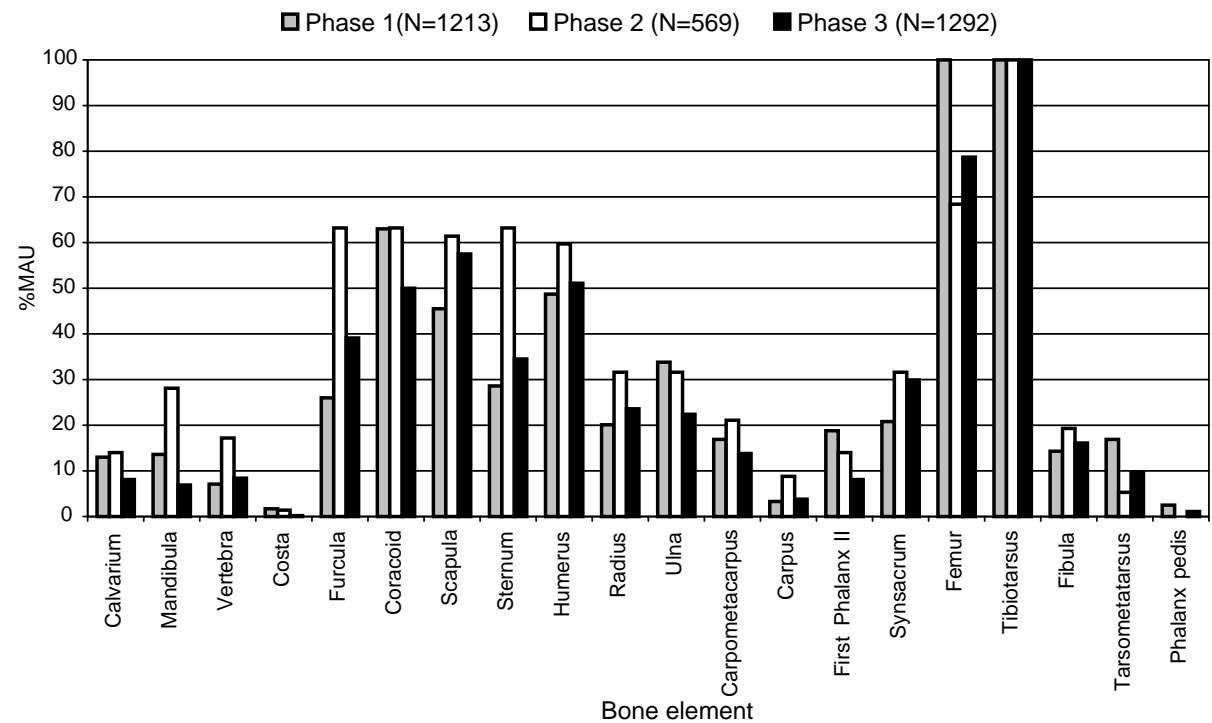

Fig. 136. The \%MAU distribution of eider bones showing very similar patterns for the three phases. (Data were from Table 26).

Arrival at the nesting sites takes place during April and egg laying commences in late May to early June (Salomonsen 1967). Downy young are able to swim from the first day after hatching by the end of June to early July. $2^{\mathrm{I}} / 2$ months later, they are able to fly (Salomonsen 198Ib). The small number of chicks (pulli), together with the low number of bones with medullary bone, points to site occupancy during the egg laying

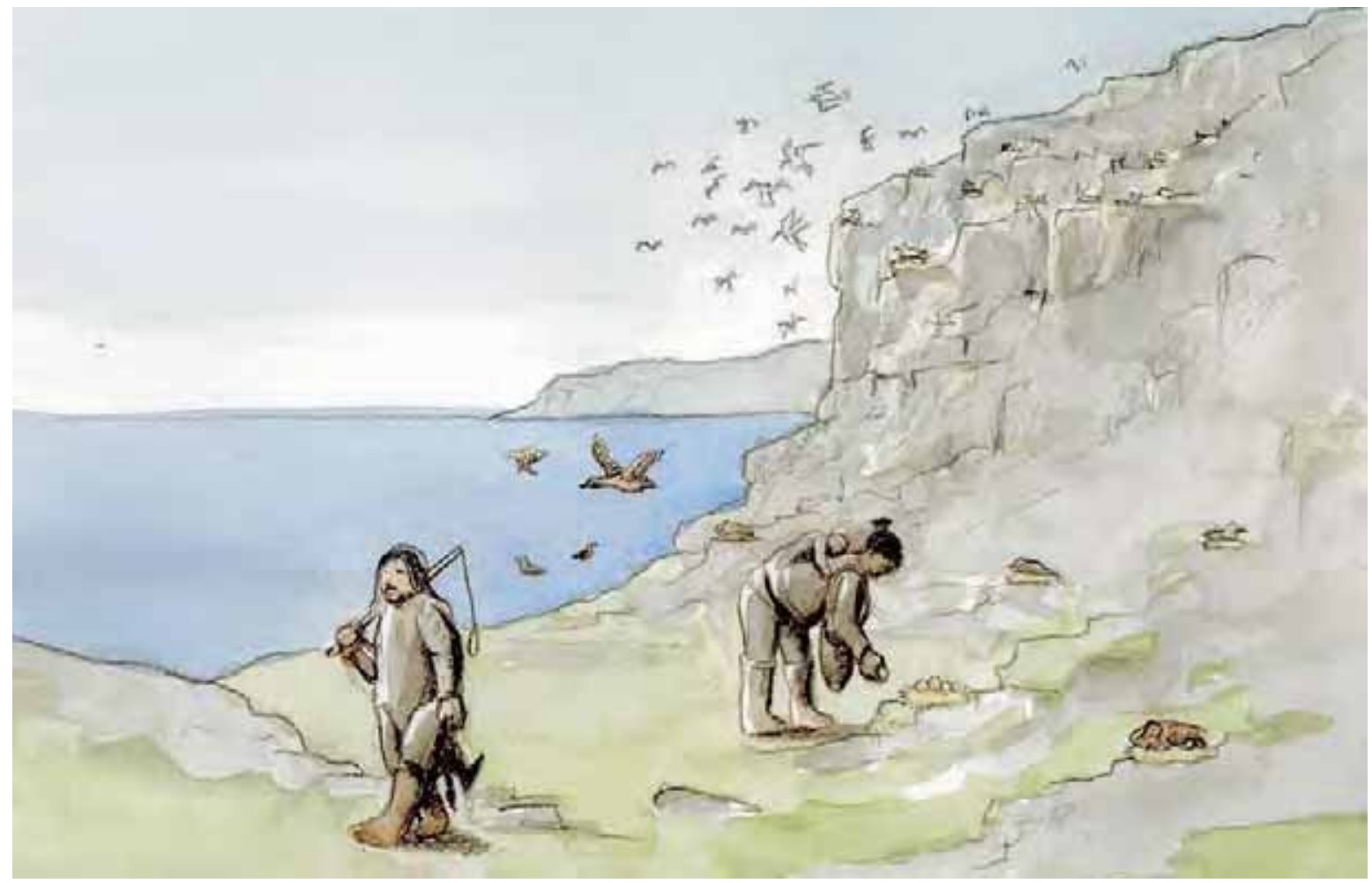

Fig. 137. The Nipisat site was occupied during spring and early summer as documented by the presence of bones from neonatals and newly hatched chicks of eiders, various auk and gull species and of bones containing medullary bone from adult nesting females, geese in particular. Thus indicating that egg collecting was of some importance to the inhabitants. Drawing: Jørgen Mürhmann-Lund. 
and brooding period. At the beginning of the $19^{\text {th }}$ century, Giesecke saw several boats loaded with thousands of eggs coming from south of Sisimiut on the 20$2 \mathrm{I}^{\text {st }}$ of June (Johnstrup I878:I05). No doubt the Nipisat inhabitants did collect eider eggs in huge numbers for immediate consumption and for storage (Fig. 137). The tiny bones from eider chicks may represent stomach contents of gulls (Gotfredsen I997a) and/or neonatals from the collected eggs. The majority of the juvenile eider bones, however, derive from juveniles and subadults (Figs I3I-I33) taken weeks after hatching.

The main focus of eider hunting was still adult birds. They may have been taken year round and the archipelago surrounding Nipisat was well suited for nesting common eider. The Sisimiut District is a major breeding area even today (Salomonsen 1974) and the shallow banks off Sisimiut provide optimal foraging opportunities (Fig. 6). According to Fabricius (I8I8), the rather timid birds were difficult to hunt and they were preferably taken during the moulting period from the end of July to the beginning of August, either in a drive hunt or more likely in exhaustion hunt using bird darts (the flightless bird tries to escape the hunter by repeated dives and eventually gets caught). Traditionally the most widespread eider hunting method was the use of bird darts (Fabricius I8I8:246; Rink I857:183). Drive hunting requires the participation of several people, in contrast to the bird dart method that can be carried out by a single hunter. The moult in eiders is complete and all flight feathers are lost simultaneously. This occurs after feathers of the head, neck, chest, and rest of the body have moulted (Cramp and Simmons 1977). The pelts are therefore in fine condition during the moult of the flight feathers and it is likely that the majority of adult eiders were caught during this flightless moulting period. The juvenile birds at Nipisat were probably a by-catch during this period (Fig. I38). We cannot exclude the possibility that some eiders were caught at other times of year. The low incidence of guillemot bones, however, indicates that winter hunting probably did not take place (see Gotfredsen I997a:277 and section medium sized alcids).

\section{The importance of eider hunting}

According to several $18^{\text {th }}$ and $19^{\text {th }}$ authors (e.g. Egede, H. I74I; Crantz I770; Glahn I77I; Holbøll I843; Rink I857), eiders were of immense importance to the Inuit. Holbøll (I843), probably referring to the Nuuk area,

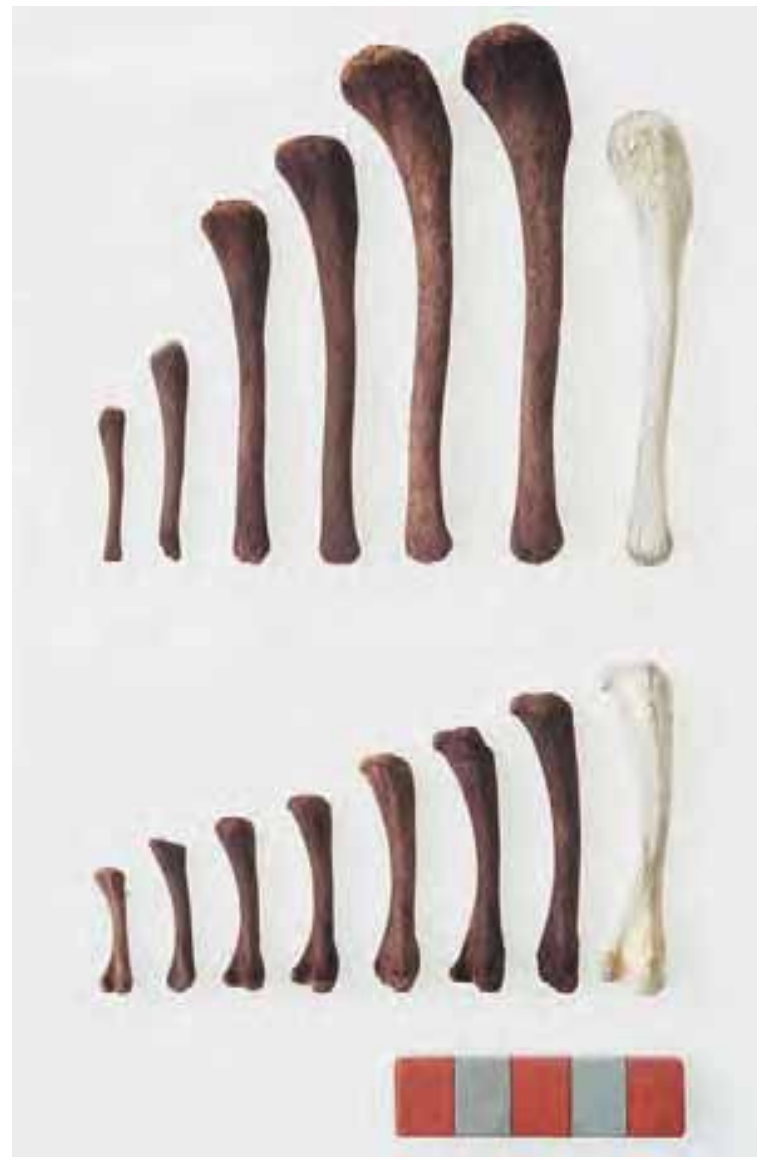

Fig. 138. A selection of juvenile eider (Somateria spp.) humeri (above) and femora (below) showing a continuum of size and age classes. The eider chicks were killed from the time of hatching in late June until at least mid autumn. Right: recent young of common eider (ZMUC Somateria mollissima A 601) killed on the $23^{\text {rd }}$ of August. Photo: Geert Brovad.

stated that eiders were caught in huge numbers year round. At several places along the Southwest coast the species was the main source of meat for the Inuit population during February and March (Holbøll I843:382, 444; Müller 1906:I0o). According to Müller (1906:93), no bird was more useful to the Greenlanders than the eider, providing meat, fat, good quality skins for clothing and eggs, which were particularly well suited for winter storage, compared to eggs of other species (Rink 1857:185; Oldendow 1935:93).

To the inhabitants at Nipisat the eider was the second most important bird species. The spatial distribution of the eider remains at the site and skeletal element frequencies indicate that the birds were brought whole to the site. Here they were processed and eaten 
and/or stored for later consumption as evidenced by the cut marks, primarily reflecting filleting, the gnawing marks and the broken off ends of long bones. Most of the partly articulated carcasses or limbs were most likely raw when they were thrown onto the midden still kept together by sinews and ligaments. This assumption is supported by the fact that most of the rearticulated bones were complete, except for ribs, some furcula and sterna, and did not exhibit gnawing or cut marks.

\section{Sandpipers and snipes}

A total of five bones assigned to the family Scolopacidae were recovered (Table 17). Phase I produced one right ulna, proximal part $(385,69 \mathrm{x} / \mathrm{I} 89$, ory), one left carpometacarpus $(384,09 x / 189,13 y)$ and one left tibiotarsus, distal part $(385,46 \mathrm{x} / \mathrm{I} 89,44 \mathrm{y})$ and phase 3 , area 2, one left radius (387x/19oy) and a left carpometacarpus (386x/19ry). All were from adult birds and none exhibited cut marks.

The bones conformed to bones of purple sandpiper (Calidris maritima) in size, however the possibility that other sandpipers are represented cannot be excluded. Sandpipers are small shore birds, feeding in the intertidal zone. Depending on the species, they are either summer visitors (if high arctic breeders) or they may stay in the Open Water Area during winter (as for instance the purple sandpiper (Calidris maritima)) (Boertmann 1994). Fabricius (I8I8:253; Helms I92I:I5I) described how the purple sandpipers and other 'snipes' were caught with snares while they were foraging and that only boys went snipe hunting. At Nipisat, sandpipers were almost certainly actively hunted using e.g. snares or bolas on the shore. Perhaps it was an opportunity for the boys to practice. We cannot, however, exclude the possibility that the birds were left at the site by birds of prey or foxes.

\section{Arctic skua}

A total of three arctic skua bones were recovered from phase 3. One left scapula, a fragment of furcula and one left coracoid were retrieved from square $387 \mathrm{x} /$ I93y, area 2. The bones were articulated and from an adult bird. No juvenile skua bones were recognised, although the possibility of confusing juvenile skua bones with juvenile gull bones should be kept in mind. Adult bones of skuas and gulls are distinguishable, however, for most skeletal elements, and therefore skua hunting at Nipisat is considered to have been negligible. No other low arctic Greenland localities have yielded arctic skua remains (Gotfredsen 1999). In the High Arctic, a few fragments of the species were reported from Umingmak together with remnants from long-tailed skua (Stercorarius longicaudus) and pomarine skua (Stercorarius pomarinus) (Münzel 1987a).

Today the arctic skua is a common breeder from the northern part of the Qaqortoq District continuously up to Kangerlussuaq, Sisimiut District, although absent as a breeding bird for the next $250 \mathrm{~km}$ northwards (Salomonsen 1967:204). Müller (1906:78), however, knew it as a breeding bird on islands at the outer coast. They are summer visitors arriving in late May to early June and departure takes place in late August to September (Salomonsen I98Ib). Their preferred nesting places are on archipelagos and low coasts (Boertmann 1994).

Holbøll (1843:427), referring to the Nuuk area, reported that the Inuit caught skuas in snares set up for black-legged kittiwakes. There may be several reasons for the scarcity of skuas in the Nipisat assemblage. They may have been rare as breeding birds on the coast north of the mouth of Kangerlussuaq. The fact that arctic skuas often steal prey from other gull species, snapping it from them in the air instead of foraging at the sea surface, could have lowered the chance of being caught by e.g. snares or other devices on the sea surface or land. Furthermore, subadults leave the breeding area together with the adult birds immediately after fledging (Salomonsen 1967:205), instead of staying in the area with other immature gulls.

\section{Gulls}

Gulls, comprising at least three species, i.e. glaucous gull, possibly great black-backed gull, Iceland gull and black-legged kittiwake, constitute the absolute dominant group at Nipisat comprising c. $54 \%$ of the bird remains (Table 17 ). The relative proportion of gulls increased over time from c. $43 \%$ in phase I to $48 \%$ and $60 \%$ in phases 2 and 3 (Table I7, Fig. I30) although gulls rank as number one in each individual phase (Table I8). Most of the gull remains originate from juvenile birds comprising 82,85 and $80 \%$ of the total number of gull bones from phases I, 2 and 3 respectively (see details for species identified gulls and unspecified Laridae in Tables 23-25 and Figs I3I-I33). 
Fig. 139. Horizontal distribution of gull $\quad+377 \times / 207 y$

bones in phases 1 and 2. The gull bones comprise both the larger gulls Larus hyperboreus/marinus and Larus glaucoides and the smaller gull Rissa tridactyla.

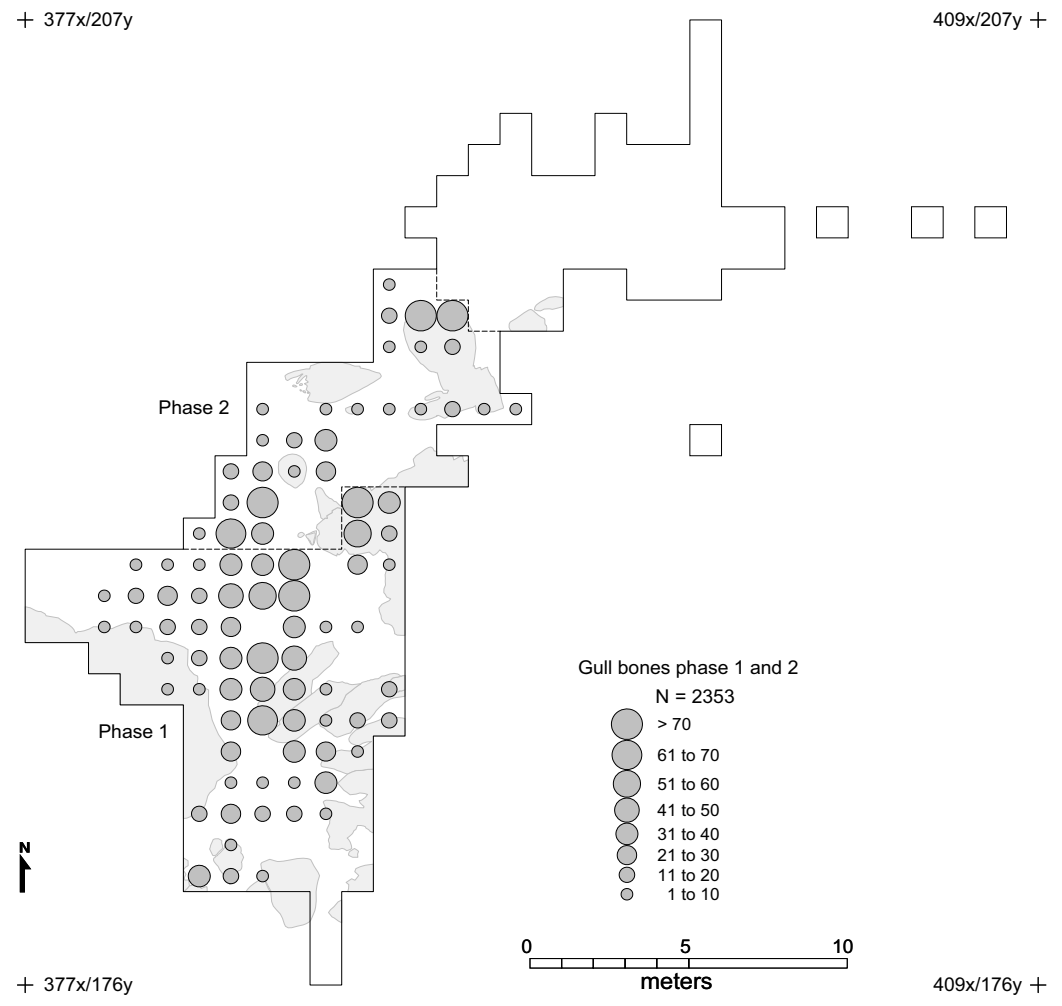

\section{Identification of gulls}

Gull bones can easily be identified to family. Osteological features distinguishing one gull species from another (Larus spp.) are almost non-existent, but size is normally used as a guideline. Still for some species there are considerable size overlaps, in e.g. wing length of glaucous gull and great black-backed gull (Olsen 1967:138), which presumably is reflected in length measurements of the wing bones (Gotfredsen I999). The majority of the Nipisat gull bones derived from juveniles. Only i $6 \%$ of the adult long bones were intact and therefore biometric studies were not carried out. Nevertheless, the gull bones were categorised into three size groups: small (comprising black-legged kittiwake), medium (comprising Iceland gull) and large (comprising glaucous gull and great blackbacked gull). The bones classified to Larus spp. comprised the large and medium sized gulls.

Today, the great black-backed gull is a widespread low artic breeder, breeding most abundantly in the archipelagos of Nuuk, Maniitsoq and Sisimiut Districts (Boertmann 1994:39). The species was known as a member of the Greenland avifauna to Crantz (I770:II4) and Glahn (I77I:IO5). Bendixen (I92I:22) reported it breeding on the outer islands in the Sisimiut area. It bred very often as single breeding pairs or few pairs together, and was considered extremely shy and rarely shot (Müller 1906:77). In the $18^{\text {th }}$ century, Fabricius wrote that great black-backed gulls occurred less frequently than glaucous gull, but the young birds of both species occurred together in the fjords (Helms I92I:I44I45). It may be suspected that some of the gull remains classed as large sized gulls derive from great blackbacked gull, however the proportion is not quantifiable.

\section{Spatial distribution and bone element representation} Gull bones were scattered all over the site with frequencies of more than 70 bones/square in some squares (Figs I39 and I40). In phase I, the central part of area I with the thickest culture layers revealed large numbers of gull bones. In phase 2, gull remains were also very numerous close to the protruding bedrock in square $389 x /$ I97y $(\mathrm{N}=307)$ and 390x/197y $(\mathrm{N}=\mathrm{I62})$ furthermore, some concentration occurred in the southern part of area 2 (Fig. I39). There seemed to be no particular concentrations of gull bones around the two hearths in areas I and 2. In phase 3, gull bones were recovered from 143 squares, although in varying numbers (Fig. I40). 


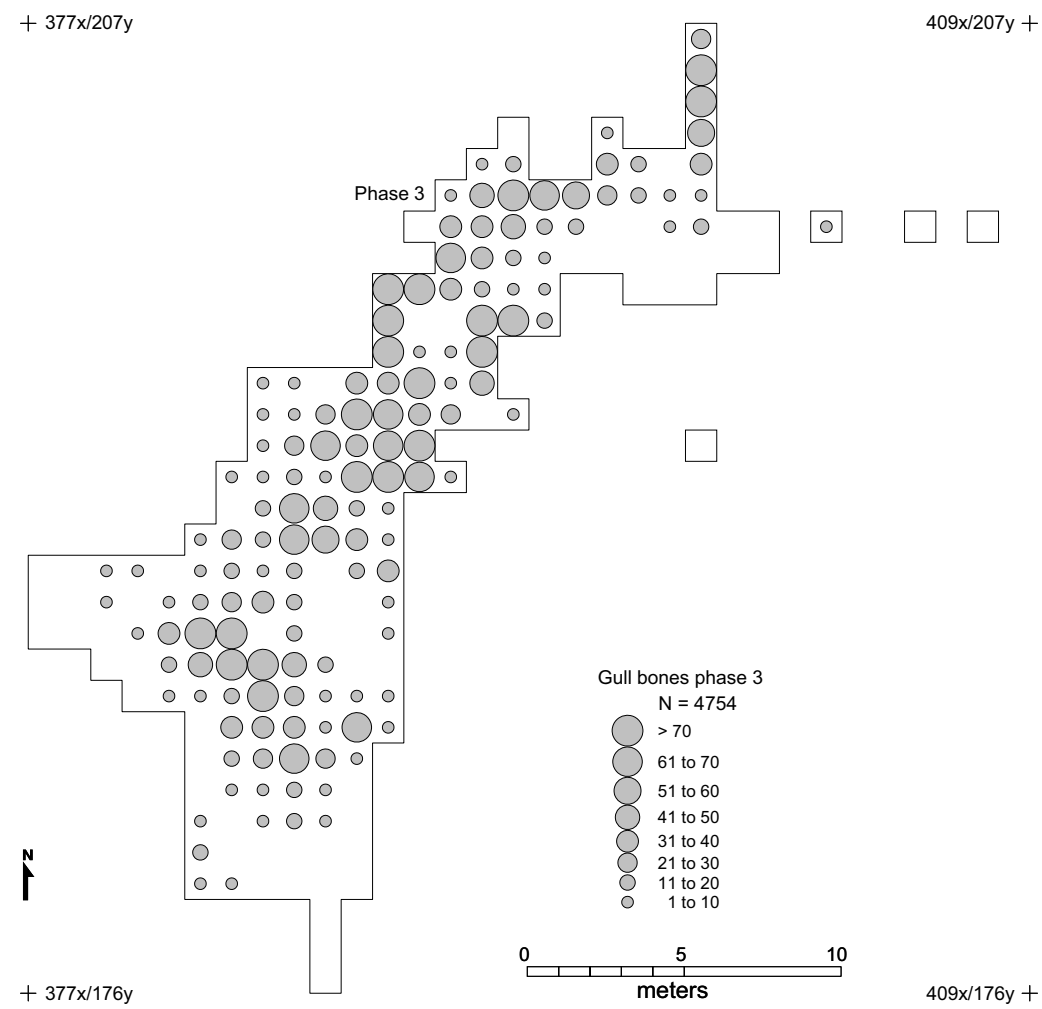

Fig. 140. Horizontal distribution of gull bones in phase 3. The gull bones comprise both the larger gulls Larus hyperboreus/marinus and Larus glaucoides and the smaller gulls Rissa tridactyla.

All body parts of the gull species are represented at the site (Tables 20-22). The relative frequencies of skeletal elements were calculated on a subsample $(\mathrm{N}=586)$ of the adult Larus spp. bone elements (Gotfredsen I997a:table 3b, fig. J) showing a distribution very similar to that of eider bones (Fig. 136). Calculations on juvenile gull bones ( $\mathrm{N}=$ I9I5) (Gotfredsen I997a:table 3b, fig. $3 \mathrm{~K}$ ) however, showed a different relative representation with cranial bones, sternum, vertebrae, synsacrum and especially carpometacarpals being less frequent than the corresponding adult bone elements. The differential distribution is most likely caused by the fragility and unfused state of the juvenile bones affecting both survival and identification of the elements (see Gotfredsen 1997a: 280). The horizontal distribution and the representation of gull bones indicate that gull hunting was indeed an important activity through all phases.

In total II bones exhibited cut marks (Appendix I). The adult gull bones (including black-legged kittiwakes) of wings and legs (i.e. humerus, ulna, radius, femur and tibiotarsus) were rarely intact $\mathrm{I} 6 \%(\mathrm{~N}=54)$ while $84 \%(\mathrm{~N}=283)$ lacked both articular ends. The situation differed among the juvenile gulls (excluding bones of pulli) with a proportion of $46 \%(\mathrm{~N}=638)$ intact bones and 54\% (N=74I) lacking articular ends. Unequivocal gnawing marks were found on 2I bones deriving from both juvenile and adult gulls.

\section{Season and methods of gull hunting}

In contrast to the goose and eider hunting, gull hunting focused on immature birds. The proportion of juvenile bones varies between 80 and $85 \%$, however this may be an underestimation because the vast majority of unidentified bird bones classified to Aves spp. derive from juvenile birds, in most instances probably gulls. A few bones contained medullary bone, documenting some gull hunting at the beginning of the nesting period. Collecting gull eggs may have been important too. However most gulls (regarding all gull species as a whole) were taken as juvenile unfledged young (c. 68\%) including hatchlings and fledglings (c. I3\%) probably from July till mid or late autumn.

All the gull species present at Nipisat are known from the Sisimiut area today (Boertmann 1994) and from historical times (e.g. Müller 1906; Bendixen I92I). Suitable cliffs for nesting sites exist in the surroundings of Nipisat for e.g. kittiwakes and Iceland gull preferring steep sea facing cliffs (Boertmann 1994:38, 40). Kittiwakes used to be numerous during 
Fig. 141. The great auk (Pinguinus impennis) in summer coat (left) compared to its half sized smaller relative the razorbill (Alca torda) (right). Bones of both species were retrieved from the Nipisat site. Photo: Geert Brovad.

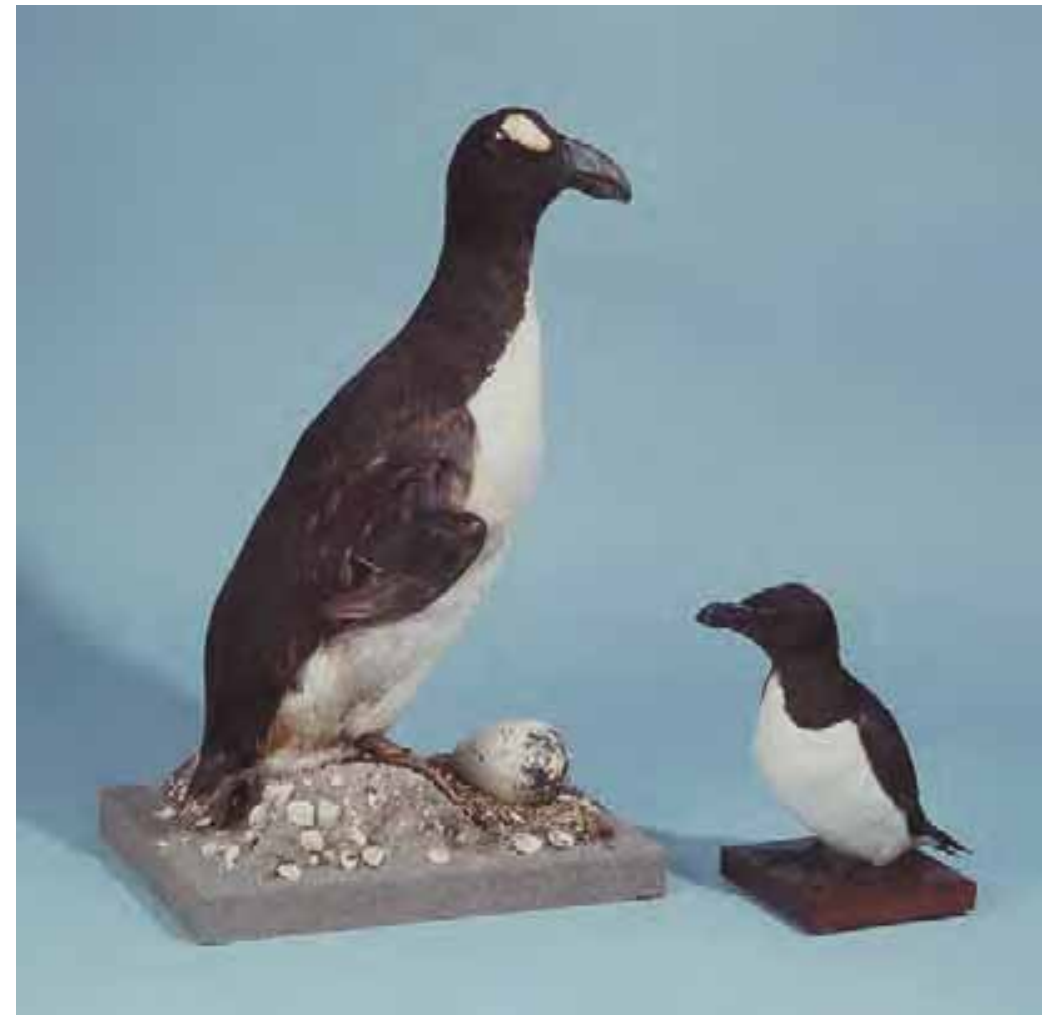

summer in Ikertooq Fjord (Müller 1906:70). Glahn (I77I:II5, II6) pointed out the importance of capelin to the breeding birds and, especially at Sarfannguaq in Amerloq, large numbers of capelin attracted numerous flocks of kittiwakes (Jensen I885:4I).

During the end of August, the young leave their parents and gather in huge flocks along the coast and in the fjords (Salomonsen 1974). At that time of year the immature gulls are easy to catch and in addition the Inuit considered their meat very tasty (Glahn I77I:IO5; Fabricius (Helms I92I:I43); Müller 1906:77).

The Saqqaq people at Nipisat may have caught gulls in several ways. We know from ethnographic sources that the Inuit hunted large gulls mainly with gull hooks or snares and, in rare instances, with throwing darts (Helms I92I:I43). The unfledged young could have been taken with bare hands or snared on the beach. We need not think of people climbing steep cliffs to get the immature young. All the abovementioned gull species, including kittiwakes, may to a larger extent than seen today, have used low islands for nesting prior to the arrival of humans. At present, undisturbed populations of great blackbacked gull, glaucous gull and even kittiwakes are known to nest on low skerries in archipelagos or fjords (Boertmann 1994). Gull hooks, if they were used, could only be used for catching fledglings and adult birds because they consist of bait and hook concealed below the sea surface and take advantage of the way the gulls forage. Bird darts may also have been used.

\section{Auks}

Alcids comprise $3.5 \%$ of the entire bird assemblage. Their relative proportion seemingly decreased over time from c. $8 \%$ in phase I to c. $3 \%$ and $2 \%$ in phases 2 and 3 respectively (Table I7). Extant auk species occurring in Greenland waters except for the Atlantic puffin (Fratercula arctica) and possibly Atlantic guillemot (Uria aalge) were retrieved. The most abundant species was the black guillemot (I.8\%) followed by Brünnich's guillemot (o.5\%). Guillemots could have comprised as much as c. I\%, however, provided that most of the bones from the group guillemots/razorbill are in fact from guillemots. Remains of razorbill and little auk occurred in small numbers and were confined to phases I and 3 only. Remains of the large extinct great auk were recovered (Fig. I4I) from phases I and 3 (see p. I22). 
Species within the alcidae can easily be distinguished from other groups. However, it is difficult to distinguish between the medium sized auks, Brünnich's guillemot, Atlantic guillemot (Uria aalge) and to some extent razorbill using post-cranial bones (e.g. Olsen 1967). Criteria for separating guillemots from razorbill were listed and discussed in Gotfredsen (1999). No further attempt to distinguish the two guillemot species was made. Among the maxillary and mandibular bones only Brünnich's guillemot was identified, and the chance that remains of Atlantic guillemot occurred in the Nipisat bone assemblage is considered negligible.

\section{Medium sized alcid}

Brünnich's guillemot is infrequent (0.48\%) in the Nipisat assemblages even when remains classified as guillemots/razorbill are included (I.I\%). The bones were retrieved from all phases and primarily from area I. In several instances, wings or parts of the carcass could be rearticulated, e.g. one right wing (humerus, ulna, radius, carpometacarpus) square $382 \mathrm{x} / \mathrm{I} 79 \mathrm{y}$ and an anterior part (sternum, left and right coracoid and left and right scapula) square 383x/I8ry, all from phase I. In square $389 \mathrm{X} / \mathrm{I} 97 \mathrm{y}$, phase 2 , an anterior part of a skeleton was found comprising the sternum, right coracoid, left and right humerus, left and right ulna, left and right radius, left carpometacarpus and left first phalanx II. No bones exhibit cut marks or clear gnawing marks and all derive from adults. The rather high incidence of rearticulated bones found in association indicates that guillemot hunting occurred rarely.

The razorbill occurred in small numbers in phase I $(\mathrm{N}=5)$ and phase $3(\mathrm{~N}=4)$ (Table I7). In phase I one left wing (humerus, ulna radius) could be rearticulated $(384,93 \mathrm{x} / \mathrm{I} 84,94 \mathrm{y})$ and a left carpometacarpus from square $384 \mathrm{X} / \mathrm{I} 84 \mathrm{y}$ presumably derived from the same wing. One additional left coracoid was retrieved from square $385 \mathrm{x} / \mathrm{i} 8 \mathrm{ry}$. In phase 3 , square $385,57 \mathrm{x} /$ I88,36y, a sternum, left scapula and left coracoid were rearticulated and one additional right ulna was retrieved from square 386,60x/188, I5y. No bones exhibit cut marks or gnawing marks and all derive from adults. Of all medium sized auk remains, I9 wing and leg bones (humerus, radius, ulna, femur and tibiotarsus) are intact while I7 lack both articular ends.
Juvenile guillemots and razorbills. Medium sized auk bones were classified as guillemots/razorbill when lacking diagnostic features, when those features were not visible, or when the bones derived from juveniles. For the three phases respectively juvenile bones accounted for II, o and 33\% of all medium-sized auk remains including species identified fragments (Tables 23-25, Figs I3I-I33). The presence of quite young chicks indicated hunting during summer and that either razorbill, or Brünnich's guillemot, or both species bred not far from the site. Chicks of Brünnich's guillemot leave the colony, when partially grown accompanied by the male parent (Kampp and Falk 1994). Chicks were probably taken while swimming and not necessarily from the nests. About Ioo pairs of Razorbills reportedly bred around the turn of the $20^{\text {th }}$ century on low skerries off Sisimiut (Müller 1906:I40) and in many small colonies in Ikertooq Fjord and in larger numbers than Brünnich's guillemot (Müller I906:I4I; Bendixen I92I:23). According to Brummerstedt (Winge I898:225) Brünnich's guillemot bred in the Sisimiut District, especially in Ikertooq Fjord, and the species wintered in huge numbers in the area (Bendixen I92I:22).

The species may have been hunted year round in the vicinity of Nipisat but probably occurred most abundantly during autumn and winter. At present guillemots usually stay well offshore during early autumn, but in late autumn and winter they are in coastal waters and in the archipelagos along the coast (Falk and Durinck 199I). Today winter hunting starts in mid October and peaks during the first half of November in central West Greenland (Falk and Durinck 1992). The very low frequency of guillemot remains may be an indication that Nipisat was rarely used during late autumn or winter. Judging by the relative scarcity of both juvenile and adult bones, it is concluded that medium sized auks were of little importance to the Nipisat inhabitants and any breeding colonies in the area were probably small. In contrast, guillemots ranked first at Qeqertasussuk and second at Qajaa (Table 34). Absence of juvenile bird bones and other lines of evidence indicated occupation at Qeqertasussuk primarily during the winter half of the year (Grønnow and Meldgaard I99Ib). At Itinnera, guillemots were also the most abundant taxon (Table 34). However, at this caribou hunting station, 
the adult bones probably derived from breeders or non-breeders taken in late summer and early autumn (Gotfredsen 1999).

\section{Black guillemot}

The frequency of black guillemot remains was 3.6, 2.4 and $0.9 \%$ (Table I7) and juvenile bones comprised c. 34,37 and $61 \%$ in phases I, 2 and 3 respectively (Tables 23-25, Figs I3I-133). Body parts representing the pectoral girdle, wings, and hind limbs were well represented, while the rest of the skeleton was underrepresented (Tables 20-22). This underrepresentation is most likely explained by the small bone size of the birds and, to some extent, by the relatively high proportion of juvenile bones. Black guillemot remains were distributed evenly throughout the whole excavated area, although area 3 yielded only few fragments.

A total of four adult bones deriving from phase I exhibit cut marks. One left coracoid (385,80x/189,51y) shows two short distinct and one faint cut marks distally on the medial face, one right humerus (383x/ I88y) had a pronounced $8 \mathrm{~mm}$ long transverse cut mark distally on the medial face and square $185 \mathrm{X} / \mathrm{I} 86 \mathrm{y}$ yielded one right humerus showing a $2 \mathrm{~mm}$ long transverse cut mark placed mid shaft on the medial face, and a left humerus with several $2 \mathrm{~mm}$ long sub-parallel transverse cut marks on the ventral face. No unequivocal gnawing marks were observed. The long bones of wings and legs (i.e. humerus, radius, ulna, femur and tibiotarsus) showed little breakage, as 38 were intact and only eight lacked both articular ends.

Hunting season and method. In Greenland the black guillemot is a widespread breeder, nesting in pairs or small colonies in cracks and holes. They remain in the Open Water Area during winter (Salomonsen I967, I974; Boertmann 1994) and are especially attracted by current openings (Crantz I770:II3). Müller (I906) stated that the species never occurred in such abundance as e.g. guillemots and that hunting of black guillemots was occasional when encountered on hunting expeditions for e.g. gulls, eider and guillemots.

Bones of unfledged young and subadults indicate that black guillemots were caught from the end of July (when the one or two eggs hatched) through August and possibly further until mid autumn when subadults reach skeletal maturity. During the last half of August, the fledglings are abandoned and occur alone or in pairs, but are still not shy and are thus vulnerable (Müller 1906:136; Salomonsen 1974:103). The mean age of fledglings is $33-36$ days (Gaston and Jones 1998:I77) and they are already capable of flying which implies that skeletal maturity has been reached by the end of August or beginning of September. By this time the fledglings have a body weight almost the same as adult birds (60-IOI\% often 85 -IоI\% of the adult weight) (Gaston and Jones 1998:I76). It would thus make good sense to catch immature black guillemots being of nearly adult weight and much easier to catch. Many suitable nesting sites existed in the surroundings of Nipisat and the black guillemots were probably often brought back to the site when the hunter returned from hunting trips for other game in the neighbourhood. Adult birds may have been caught all year but since they are fast and excellent divers, changing direction during their dive, great hunting skills were required. They may have been taken with bird darts or nesting birds may have been snared. Historic Inuit exploited meat, eggs and skins even the red feet were used as bait and the birds were normally taken with bird darts or snares at the nest (Helms I92I:136-37). Often the large unfledged young were taken directly from the nests, or the birds were taken in open leads during winter (Müller 1906:136-38).

\section{Little auk}

Remains of little auk were recovered from phases I and 3 with NISP counts of $\mathrm{I} 2$ and 8 respectively (Table I7). The bones were scattered over several squares in area I (phases I and 3) and area 2 (phase 3). No cut or gnawing marks were found on the bones. Müller (I906:I39) received eggs of little auks from both the Ikertooq and the Nordre Isortoq fjords, which indicates that they may have bred in the Sisimiut District at the turn of $19^{\text {th }}$ century. At present little auks are numerous in the Open Water Area from October (Boertmann 1994:42) and the primary hunting period for this species in the Sisimiut area would be similar to that of other auks. Accordingly, the small auks were easy to hunt either with bird darts or with paddles when approached by kayaks (Helms I92I:I29; Müller 1906:I39).

Because the sediments were not systematically sieved, the relative abundance within the site compared to other auks with larger body size could not be estimated. Sieving at Qeqertasussuk increased the rel- 
Table 27. The distribution of 50 great auk bones by skeletal element in phase 1. Numbers in parenthesis designate the number of that particular element in a complete great auk skeleton (after Owen 1865).

\begin{tabular}{lcccr}
\hline & NISP & MNE & MAU & $\%$ MAU \\
\hline Calvarium (1) & 1 & 1 & 1 & 50 \\
Maxillare (1) & 1 & 1 & 1 & 50 \\
V. cervicalis (13) & 6 & 6 & 0.5 & 25 \\
V. thoracica (9) & 11 & 1 & 0.1 & 5 \\
Costa (34) & 17 & 17 & 0.5 & 25 \\
Scapula (2) & 4 & 4 & 2 & 100 \\
Furcula (1) & $5^{2}$ & 2 & 2 & 100 \\
Coracoideus (2) & 2 & 2 & 1 & 50 \\
Humerus (2) & 3 & 3 & 1.5 & 75 \\
Ulna (2) & 2 & 2 & 1 & 50 \\
Femur (2) & 3 & 3 & 1.5 & 75 \\
Tibiotarsus (2) & 3 & 2 & 1 & 50 \\
Fibula (2) & 1 & 1 & 0.5 & 25 \\
Tarsometatarsus (2) & 1 & 1 & 0.5 & 25 \\
\hline Total & 50 & 46 & & \\
\hline
\end{tabular}

1 one $v$. thoracica derived from phase 3 (see text for explanation).

2 one fragment of furcula derived from phase 3 (see text for explanation). ative proportion of little auk bones dramatically (Meldgaard 2004:table 8.2) and with corrected numbers, the species ranked third (Table 34) at that site. Despite the lack of sieving at Nipisat, this small sized auk was probably not important to the economy, considering that other larger auks also played a minor role.

\section{Great auk}

In total $50(0.4 \%)$ fragments (reassembled to 46$)$ great auk bones were retrieved (Table 17). All bones were confined to area I and all but two fragments derived from phase I. However, one fragment of furcula (384x/184y), phase 3, could be reassembled with a furcula from square $385 \mathrm{x} / \mathrm{I} 84 \mathrm{y}$, phase I. Solifluction or other agents of mixing of the strata may have occurred and it is suspected that a vertebra thoracica, (382x/187y) phase 3, also derives from phase I (see Fig. I42). In the following all great auk remains are considered to derive from phase $\mathrm{I}$.

Bone element representation and horizontal distribution. Almost all body parts of great auk were represented except for the mandibula, sternum, wing

Table 28. Archaeological localities of low arctic Greenland with great auk remains. The localities are either dated archaeologically or by ${ }^{14}$ C. Datings shown with an arrow (e.g., 2020 $\rightarrow 1740$ BC) indicate that bones occur throughout the time interval. Datings shown with a hyphen (e.g., 1000-1400 AD) indicate that bones date somewhere within the time interval. N designates the number of great auk bones at the sites. Data obtained from Meldgaard (1988) and Gotfredsen (1999). All localities are shown in Fig. 144 .

\begin{tabular}{|c|c|c|c|c|c|c|}
\hline & Position & Dating & Culture & $\mathrm{N}$ & \%NISP (Aves) & Reference \\
\hline 1.Qeqertasussuk & $68^{\circ} 35^{\prime} \mathrm{N} 51^{\circ} 04^{\prime} \mathrm{W}$ & $2400 \rightarrow 1400$ BC & Saqqaq & 3 & - & Meldgaard 1988 \\
\hline 2. Nipisat I & $66^{\circ} 49^{\prime} \mathrm{N} 53^{\circ} 30^{\prime} \mathrm{W}$ & $2020 \rightarrow 1740$ BC & Saqqaq & 50 & 0.4 & Gotfredsen 1999 \\
\hline 3. Illutalik & $65^{\circ} 52^{\prime} \mathrm{N} 53^{\circ} 22^{\prime} \mathrm{W}$ & $1500-1650 \mathrm{AD}$ & Thule & 4 & 2.2 & $\begin{array}{l}\text { Meldgaard } 1988 \\
\text { Gotfredsen } 1999\end{array}$ \\
\hline 4. Uummannat & $65^{\circ} 52^{\prime} \mathrm{N} 53^{\circ} 23^{\prime} \mathrm{W}$ & $1700-1750 \mathrm{AD}$ & Thule & 3 & 3.4 & Meldgaard 1988 \\
\hline 5. Utorqaat & $65^{\circ} 52^{\prime} \mathrm{N} 53^{\circ} 14^{\prime} \mathrm{W}$ & $1350-1500 \mathrm{AD}$ & Thule & 9 & 2.6 & $\begin{array}{l}\text { Meldgaard } 1988 \\
\text { Gotfredsen } 1999\end{array}$ \\
\hline 6. Itissalik & $64^{\circ} 07^{\prime} \mathrm{N} 52^{\circ} 06^{\prime} \mathrm{W}$ & $1700-1800 \mathrm{AD}$ & Thule & 20 & 1.4 & Meldgaard 1988 \\
\hline 7. Håbets koloni & $64^{\circ} 08^{\prime} \mathrm{N} 52^{\circ} 05^{\prime} \mathrm{W}$ & $1721-1728$ AD & Colonial & 4 & 1.7 & Meldgaard 1988 \\
\hline 8. Itinnera & $64^{\circ} 23^{\prime} \mathrm{N} 50^{\circ} 24^{\prime} \mathrm{W}$ & c. $1500 \mathrm{BC}$ & Saqqaq & 7 & 0.9 & $\begin{array}{l}\text { Meldgaard } 1988 \\
\text { Gotfredsen } 1999\end{array}$ \\
\hline 9. Illorpaat & $64^{\circ} 07^{\prime} \mathrm{N} 52^{\circ} 06^{\prime} \mathrm{W}$ & $1475 \rightarrow 1800$ AD & Thule & 98 & 0.2 & $\begin{array}{l}\text { Meldgaard } 1988 \\
\text { Gotfredsen } 1999\end{array}$ \\
\hline 10. Kangeq & $64^{\circ} 06^{\prime} \mathrm{N} 52^{\circ} 03^{\prime} \mathrm{W}$ & $1375 \rightarrow 1970$ & Thule & 13 & 0.8 & $\begin{array}{l}\text { Meldgaard } 1988 \\
\text { Gotfredsen } 1999\end{array}$ \\
\hline 11. Gammel Frederikshåb & $62^{\circ} 01^{\prime} \mathrm{N} 49^{\circ} 45^{\prime} \mathrm{W}$ & $1400-1800 \mathrm{AD}$ & Thule & 1 & - & Meldgaard 1988 \\
\hline 12. Unartoq & $60^{\circ} 31^{\prime} \mathrm{N} 45^{\circ} 20^{\prime} \mathrm{W}$ & $1700-1800 \mathrm{AD}$ & Thule & 1 & 4.2 & Meldgaard 1988 \\
\hline
\end{tabular}


Fig. 142. Horizontal distribution of great auk (Pinguinus impennis) bones in phase 1. Two great auk fragments from phase 3 were included in the plot because they were argued to derive from the carcasses found in phase 1 (see text for explanation).

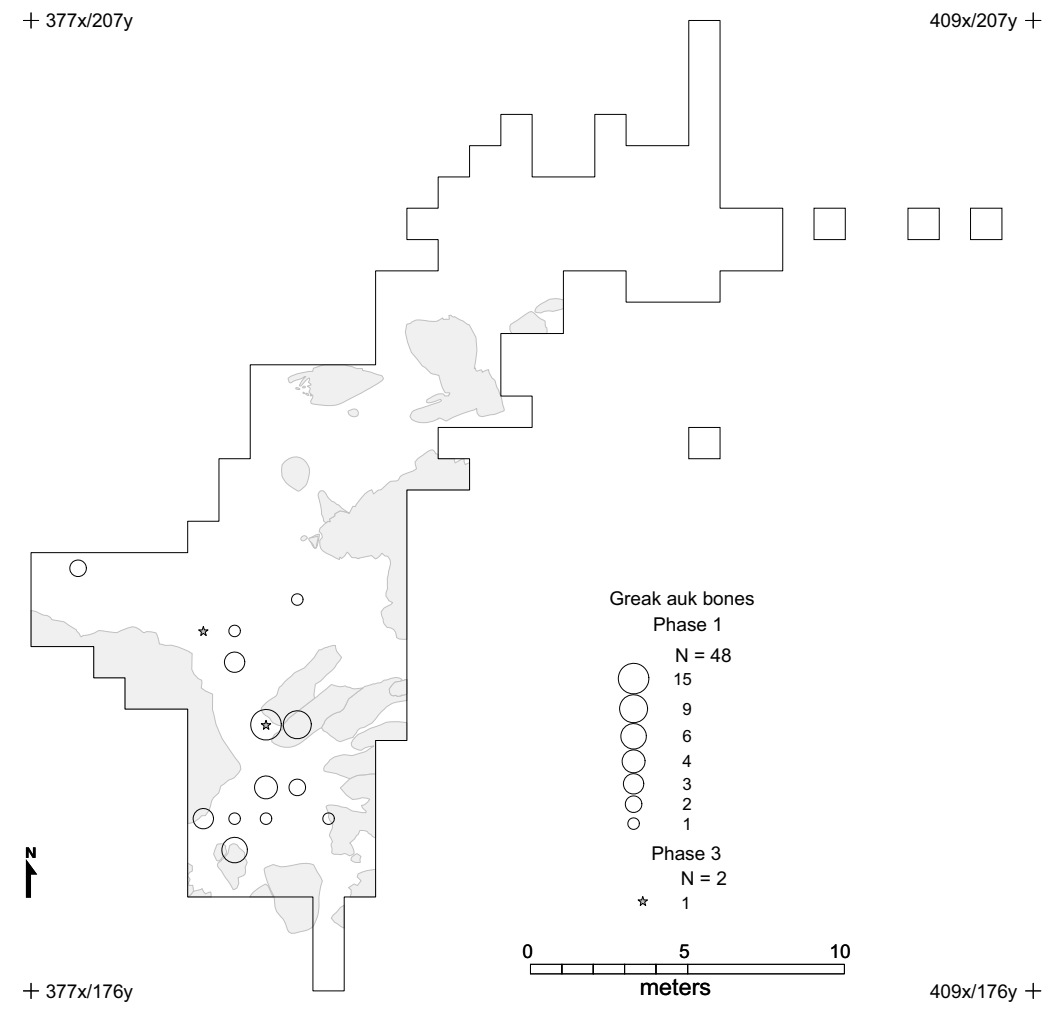

extremities and the phalanges (Table 20). The relative representation of most of the recovered bone elements is surprisingly even (Table 27). Although \%MAU varied between 5-Ioo, most values varied between 25 and Ioo, even costae, identified from great auk for the first time in Greenland assemblages (Gotfredsen I999), and v. cervicales had \%MAU values of 25 . Some skeletal elements could be rearticulated, e.g. one axis and four v. cervicales (383x/180y) south of the hearth, while the ribs were recovered from three squares $384 \mathrm{x} / \mathrm{r} 84 \mathrm{y}$ ( 5 sin, 4 dex), 385x/r84y ( 2 sin, 2 dex) and $384 \mathrm{x} / \mathrm{I} 82 \mathrm{y}(4 \mathrm{sin})$ north of the hearth. For each skeletal element, the MNI was I or 2 when side was taken into consideration, which supports the notion that the great auk remains may represent just two individuals.

Cut marks were found on three bones. A left rib (384x/I82y) had two clusters of sub-parallel $3 \mathrm{~mm}$ long cut marks placed on the lateral face. A left humerus (384X/I84y) had one deep distinct and three faint cut marks placed transversely on the ventral face at the middle of the diaphysis (Fig. I43A), and one right femur (384X/I84y) had several $3 \mathrm{~mm}$ long subparallel cut marks placed in an oblique angle to the long axis ventral to the caput femoris on the mediocra- nial face. Cut marks at the rib and humerus may best be interpreted as filleting or skinning traces. Although the traces on humerus are deep and distinct, conforming to the description of dismembering marks (see Noe-Nygaard I989:482), the position at the middle of the shaft does not indicate dismembering. Marks on the femur were inflicted during primary butchering when the femur was dismembered from the acetabulum. These observations agreed with an examination of I48 Greenland great auk bones documenting cut marks on $\mathrm{I} 3.5 \%$ of the bones and interpreted as reflecting initial skinning and subsequent dismembering of the carcass (Meldgaaard I988:I66). The majority of the cut marks are parallel c. $3 \mathrm{~mm}$ long grooves placed transversely on the long bones. More than half of the long bones (one humerus, two ulnae, two femora and the tarsometatarsus) at Nipisat had their ends broken off.

The two complete humeri with GL of I02.2 and IOI. $6 \mathrm{~mm}$ and the femur with GL of $70 \mathrm{~mm}$ (Gotfredsen 1999) were within the size range of other Greenland great auks ranging from Ioo to $109 \mathrm{~mm}$ $(\mathrm{N}=\mathrm{I4})$ and 67 to $7 \mathrm{I} \mathrm{mm}(\mathrm{N}=2)$, respectively (Meldgaard I988:164). 

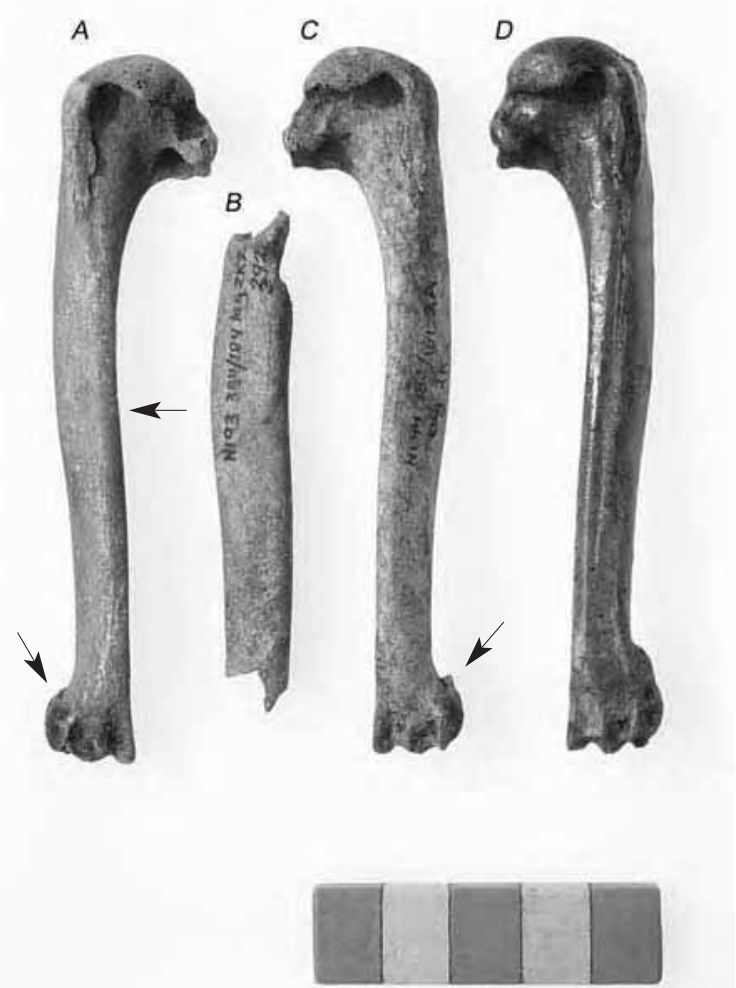

Fig. 143. Two intact (A and C) and one diaphysis (B) of great auk (Pinguinus impennis) humeri recovered from Nipisat. Note cut mark and the weakly developed tuberculum pronator brevis indicated with arrows. (D) right humerus from an adult great auk from the Thule Culture site Illorpaat, Nuuk District. Photo: Geert Brovad.

Hunting season and method. Several bones were obviously from juveniles: an unfused nasal process of the premaxillare, two tibiotarsi a left and right with unfused distal epiphyses, a mid piece of a tarsometatarsus and two humeri a left and a right (with a weakly developed tuberculum pronator brevis) (Gotfredsen I999) (Fig. I43A and C). All skeletal elements have a rough and porous surface and are from subadults of approximately the same ontogenetic age. They are slightly smaller and more slender than corresponding adult bones. The great auk remains probably derive from as few as two subadult birds and thus originate from a single event. However the bones were scattered over several squares in area I (Fig. I42) and may reflect several hunting events. In that case the similar ontogenetic age of the bones thus indicates that the birds were taken during the same season.
Great auk remains from Itinnera $(\mathrm{N}=7)$ and possibly Qeqertasussuk $(\mathrm{N}=3)$ were believed to be either breeding birds or non-breeding summering subadults killed during summer (Meldgaard I988:I6I). The bones from these sites did not, however, exhibit juvenile characteristics. We do not know how long it took great auks to reach skeletal maturity, but Meldgaard (1988:I52) suggests at least five months. The birds at Nipisat had not reached skeletal maturity, but were presumably several months old. Based on Fabricius' (I808) observations of great auks off Southwest Greenland from September to January, Brown (1985) suggests that the West Greenland great auks represented a post breeding dispersal from Icelandic colonies. However, based on Glahn's (I77I:Ioo) statement that great auks bred on the outer skerries in Sisimiut District and Fabricius' (1808) observation of downy young near Paamiut, Meldgaard (I988:I68) concludes that great auk bred in small numbers during the $18^{\text {th }}$ century. Suitable breeding conditions for this large auk most likely existed while Nipisat was inhabited, but from the ontogenetic age of the Nipisat birds, it cannot be determined whether they were in fact local birds or represented post-breeding dispersals from foreign breeding colonies, as suggested by Brown (1985) and Lyngs (1994). If great auks bred near Nipisat, they would probably have been caught in larger numbers and at a younger age, as is the case for the other auk species. The presence of great auks which were probably caught during late autumn or winter, however, supports Meldgaard's (1988:I62) proposal that the winter range was probably pushed further north during Saqqaq times than was known during the period c. I500-I800 AD (see Fig. I44).

The scattering of great auk remains, the cut marks and the long bones with broken off ends demonstrate that these large flightless birds were butchered and eaten, and presumably their oil and skin was valued as well. According to Fabricius (I808), nearly all parts of great auks were used, even the intestines were eaten and the black skin of the feet used for decorative purposes. Great auks were excellent divers (Holm I887; Lyngs 1994) and probably difficult to hunt while they were at sea. Historic Inuit primarily hunted great auks communally with bird darts from kayaks (Fabricius I808, I8I8), often during August-September (Møhl 1997a). 
Fig. 144. Prehistoric localities with great auk bones (Pinguinus impennis) along the West Greenland coast. During Saqqaq times the distribution of great auk seemed to have been extended northwards. Numbers refer to numbers in Table 28 (Data from Meldgaard 1988 and Gotfredsen 1999).

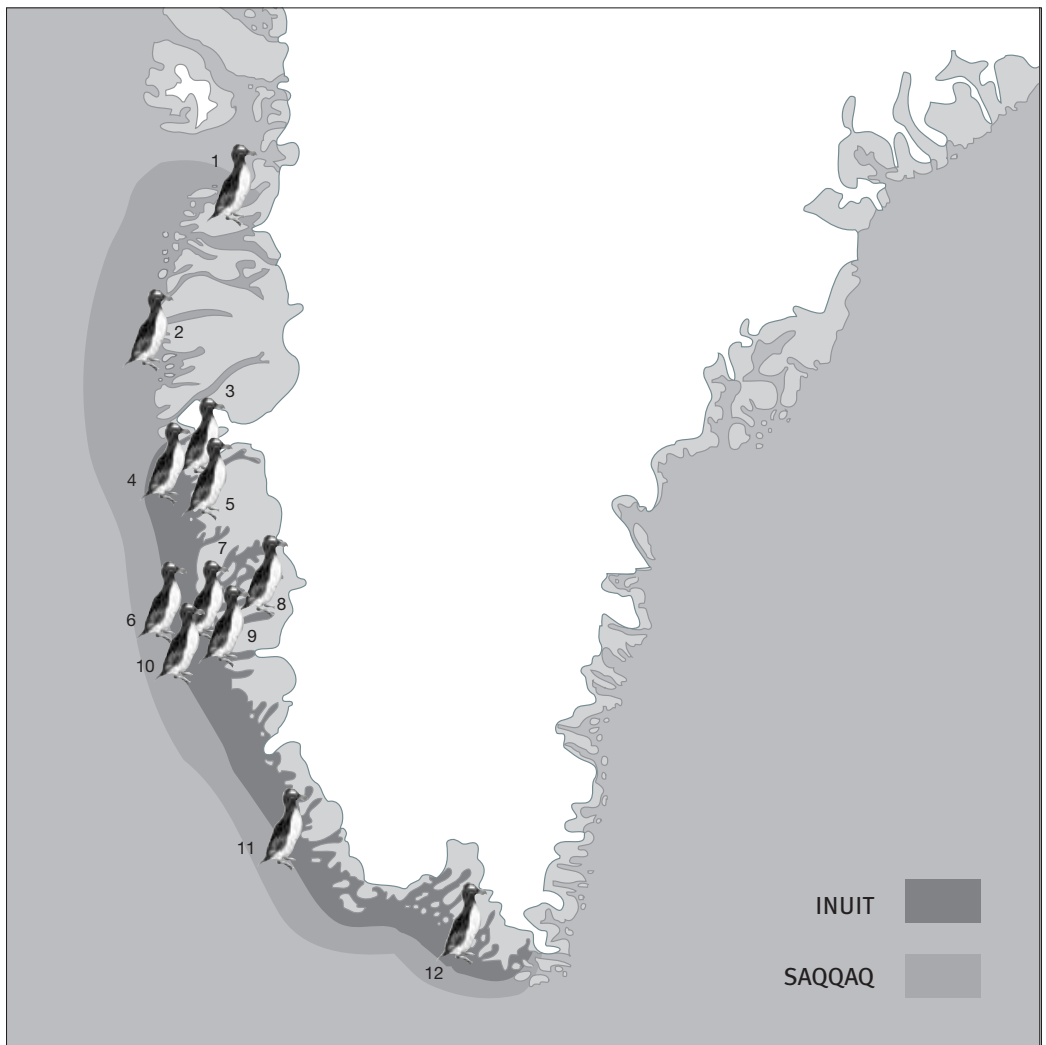

\section{Hunting in terrestrial and fresh water habitats}

\section{Divers}

Bones of divers occur through all phases with the redthroated diver being most numerous, comprising I.2, 0.8 and $0.2 \%$, and great northern diver comprising $0.7,0.3$ and $0.1 \%$ in phases $\mathrm{I}, 2$ and 3 respectively (Table I7). All phases produced juvenile bones of redthroated diver, while juvenile bones of great northern diver were retrieved from phases I and 3 only (Tables 23-25, Figs I3I-I33). One right femur (384x/188y) (phase I), from a red-throated diver, has a $3 \mathrm{~mm}$ long cut mark placed transversely on the cranial face of the diaphysis. This is interpreted as a filleting mark. One right coracoid (385x/I85y), phase I, of great northern diver, has three distinct c. $2 \mathrm{~mm}$ long cut marks placed distally on the medial face. These marks resulted most likely from dismemberment. In total, seven adult diver long bones (i.e. humerus, radius, ulna, femur and tibotarsus) were intact, while six bones had both ends broken off. No obvious gnawing marks were observed on the bones.
The diver remains were almost solely confined to the central and southern part of the excavation (area I and 2), with one exception. Bones of red-throated diver included the head, wings, pectoral girdle, vertebrae and the legs including phalanges (Tables 20-22). In phase I it was possible to rearticulate several body parts e.g. one right leg (femur, tibiotarsus and tarsometatarsus) square $384 \mathrm{X} / \mathrm{I} 88 \mathrm{y}$, one left leg (femur, tibiotarsus, fibula) square $383 \mathrm{x} / \mathrm{r} 88 \mathrm{y}$ and one left foot (one tarsometatarsus and Io phalanges) square $386 \mathrm{x} / \mathrm{I} 85 \mathrm{y}$. Phase 2 produced a part of the backbone (one v. thoracica and seven v. cervicales) square $384 \mathrm{X} /$ I9oy and phase 3 part of the backbone (four v. thoracicae) square $385 \mathrm{x} /$ I95y and part of a left wing (ulna, radius) square $386 \mathrm{x} / \mathrm{I} 82 \mathrm{y}$. In some instances bone elements of great northern diver were also found in close association. One left foot (one tarsometatarsus and 6 phalanges) square $388 \mathrm{x} / \mathrm{I} 84 \mathrm{y}$, phase I and a cranial part of furcula, a left coracoid and left scapula (385,53x/187,61y), phase 3, were presumably thrown onto the midden while the bones were still articulated. 


\section{Hunting method and season}

The great northern diver normally prefers larger lakes for nesting than the red-throated diver does, and they are therefore more common in the hinterland (Salomonsen 1967). However, Müller (I906:I2I) reported it to breed on large islands in Sisimiut District. Great northern divers were reported by Glahn to occur every year in June in Amerloq Fjord (Ostermann I92I:204) and the species was considered numerous in Ikertooq Fjord (see Winge I898:I37). The red-throated diver breeds in small ponds and often in coastal areas (Boertmann 1994). Both species leave Greenland during autumn (August to September), although a few great northern divers may winter in the Open Water Area (Salomonsen I967; Boertmann 1994). Some of the unfledged young were caught during July most likely at the breeding sites. Adult birds especially red-throated diver occurring along the coast during summer (Boertmann I994:Io) may have been hunted in the vicinity of Nipisat.

Both diver species are excellent and strong divers and in historical time they were most often hunted with bird darts (Fabricius I8I8; Müller I906:I2I). Snares, especially for the young, may also have been used. Both species, especially the larger northern diver, provided fine pelts for inner furs and decorative purposes (e.g. Rink ı857; Müller ı906; Ostermann I92I; Oldendow I933). Although bones with butchering marks were scarce, it is presumed that divers were occasionally hunted during the summer period but contributed only little to the economy.

\section{Geese}

Geese comprised c. I3\% of the species identified birds for the entire site: 7 , II and I6\%, in phases I, 2 and 3 respectively (Table I7). Geese ranked as number 4 in phase $\mathrm{I}$ and as number 3 in phases 2 and 3 (Table I8), and the relative proportions appear to have increased through time (Fig. I30).

At Greenland low arctic sites, both inland and coastal, goose bones generally occur in low numbers (Gotfredsen 2002:table I) and comprise but a few percent of the avian remains. However, at the caribou hunting site Aasivissuit, situated far inland (Fig. 3), $48 \%$ of the bird remains were from Greenland whitefronted goose (Anser albifrons flavirostris) (Meldgaard, M. I983). This is not surprising because today the species is known to breed inland near marshes and plains (Salomonsen I98Ib, Fox and Stroud I988).
In the High Arctic, dominance of geese in bird bone assemblages occurs more frequently. This would be expected because most Greenland breeding goose species are high arctic breeders today. At most Greenland high arctic Independence I sites in Jørgen Brønlund Fjord, Peary Land, geese consisting largely of brent geese (Branta bernicla) or brent/barnacle geese (Branta bernicla/leucopsis) were the most numerous group of species identified bird bones (Darwent 20oI). Also at Umingmak, Banks Island, (Fig. I, Io) geese comprised $56 \%$ of the bird bones (Münzel i987a). In general, with a few exceptions, birds contributed little to the economy as a whole in the High Arctic (see Münzel I987a; Le Blanc I994; Nagy I997; Darwent 200I).

\section{Identification of the Nipisat geese}

Osteological identification of post-cranial goose remains is considered notoriously difficult (e.g. Bacher I967; Alison I985) even distinction between the genera Anser and Branta poses problems. However, there are a few diagnostic features on the calvarium e.g. the pars nasale of the os frontale (Münzel I987a:I67). None of the few identified calvaria fragments at Nipisat (Tables 20-22) yielded a positive identification while the mandibular fragments, although not intact, conformed to size and morphology of mandibles of barnacle goose (Branta laucopsis).

Selected post-cranial bones, the coracoid, humerus and the femur, of the Nipisat geese were compared with bones of the extant goose species of Greenland (Gotfredsen 2002). The variance in the subfossil geese did not differ from modern goose species, which indicates that only one goose species was present at Nipisat (Gotfredsen 2002). The furcula proved to be the best post-cranial element to distinguish the genus Anser from Branta being mostly pneumatised in the former genus and unpneumatised in the latter (Bacher 1967). At Nipisat 23 of 24 geese furcula (four complete and twenty left branches) were unpneumatised whilst one specimen had inconspicuous pneumatic foramina (Gotfredsen 2002). On the basis of this morphological and biometric evidence Gotfredsen (2002) concluded that the Nipisat geese belonged to the genus Branta and were of a size significantly smaller than white-fronted geese $(\mathrm{p}<0.05)$ and of comparable size to barnacle geese.

If the Nipisat geese were in fact barnacle geese 
Fig. 145. The $\%$ MAU distribution of goose (Branta spp) bones showing similar patterns for the three phases. (Data were from Table 30).

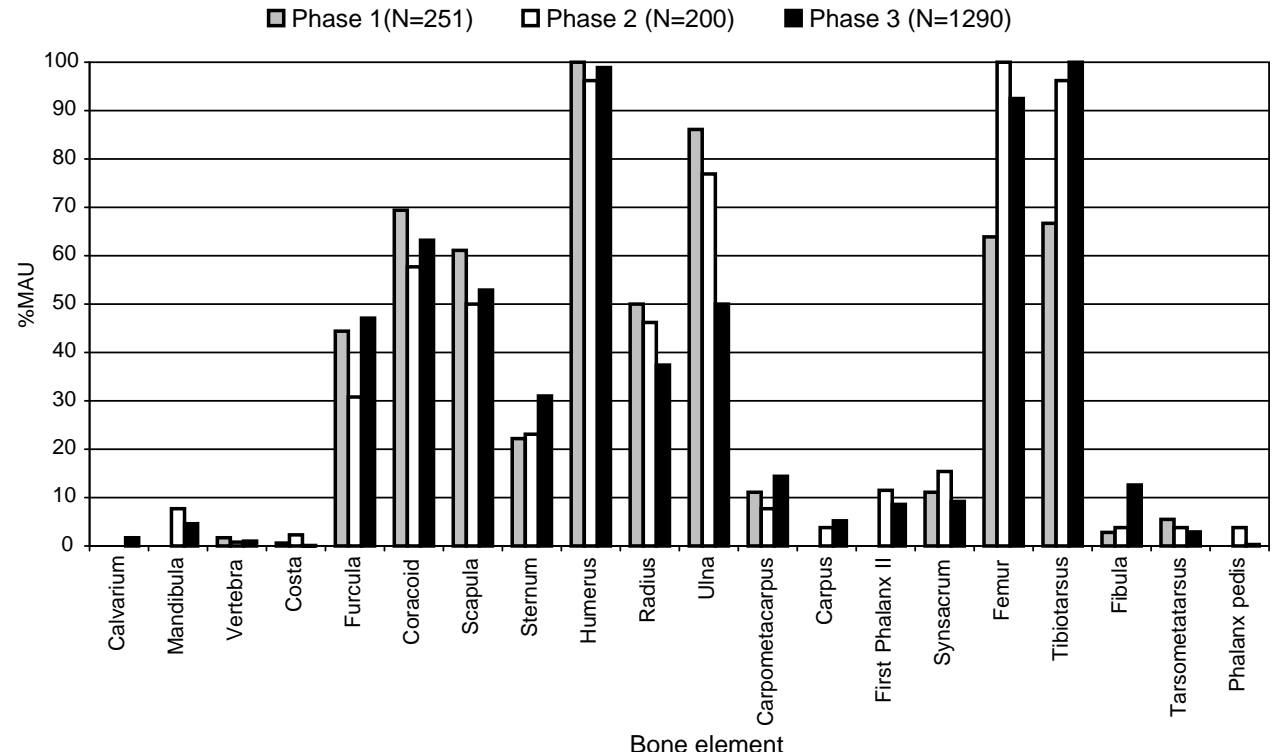

this implies that the breeding distribution of barnacle geese has changed dramatically since Saqqaq times. Today the Greenland population of barnacle geese breeds in high arctic Northeast Greenland between c. $70^{\circ} \mathrm{N}$ and $79^{\circ} \mathrm{N}$ (Ogilvie et al. 1999). In historical times, on the West Greenland coast, barnacle geese have only been sighted a few times (Boertmann I994:I6) and stragglers are known from the Canadian east coast (Godfrey I986). Another possibility is that the Branta spp. at Nipisat is a small subspecies of Canada goose (Branta canadensis) (Gotfredsen 2002). Recently the Canada goose has expanded its breeding range and numbers in West Greenland (Boertmann I994:I6; Fox et al. I996; Glahder et al. I996). In some areas, e.g., Qeqertarsuaq (Disko Island), Canada geese even outnumber the white-fronted geese (Bennike I990).
Spatial distribution and treatment of bone element. The goose remains were scattered over the entire site. In phase 3, I35 squares yielded goose bones varying between I and 6o (388x/I97y) fragments per square, with a few concentrations occurring in areas I and 3 . In area 2, concentrations were observed especially in the squares from $388 \mathrm{x} / \mathrm{I} 92 \mathrm{y}$ to $388 \mathrm{x} / \mathrm{I} 98 \mathrm{y}$, 389x/I92y, 389x/I93, 389x/I95y and 389x/I98y. Those squares also yielded many gull bones (see Fig. I40) and is a reflection of thick midden-like deposits. In phase 2, only I6 squares produced goose bones with most squares yielding fewer than Io bones. Square 389x/ I97y, however, close to protruding bedrock produced 97 goose bones. In phase I, 75 squares produced goose remains varying between I and 2r bones per square. No particular concentrations occurred in association with the two hearths.

Table 29. Occurrence of medullary bone in femora of adult geese (Branta spp.). - designates absence and,+++ and +++ various degrees of presence.

\begin{tabular}{|c|c|c|c|c|c|c|c|c|}
\hline & \multicolumn{2}{|c|}{ Phase 1} & \multicolumn{2}{|c|}{ Phase 2} & \multicolumn{2}{|c|}{ Phase 3} & \multicolumn{2}{|c|}{ Total } \\
\hline & $\mathrm{N}$ & $\%$ & $\mathrm{~N}$ & $\%$ & $\mathrm{~N}$ & $\%$ & $N$ & $\%$ \\
\hline+ & 1 & 5.9 & 0 & 0.0 & 9 & 5.6 & 10 & 4.9 \\
\hline++ & 2 & 11.8 & 2 & 8.3 & 5 & 3.1 & 9 & 4.5 \\
\hline+++ & 2 & 11.8 & 14 & 58.3 & 89 & 55.3 & 105 & 52.0 \\
\hline Subtotal & 5 & 29.4 & 16 & 66.7 & 103 & 64.0 & 124 & 61.4 \\
\hline- & 12 & 70.6 & 8 & 33.3 & 58 & 36.0 & 78 & 38.6 \\
\hline Total & 17 & 100 & 24 & 100 & 161 & 100 & 202 & 100 \\
\hline
\end{tabular}


Table 30. The distribution of goose bones by skeletal element and phase. Numbers in parenthesis designate the number of that particular element in a complete goose skeleton.

\begin{tabular}{|c|c|c|c|c|c|c|c|c|c|c|c|c|}
\hline & \multicolumn{4}{|c|}{ Phase 1} & \multicolumn{4}{|c|}{ Phase 2} & \multicolumn{4}{|c|}{ Phase 3} \\
\hline & NISP & MNE & MAU & $\% M A U$ & NISP & MNE & MAU & $\% M A U$ & NISP & MNE & MAU & $\% M A U$ \\
\hline Calvarium (1) & - & - & - & - & - & - & - & & 8 & 1.5 & 1.5 & 1.7 \\
\hline Mandibula (2) & - & - & - & - & 2 & 2 & 1 & 7.7 & 10 & 8 & 4.0 & 4.6 \\
\hline Vertebra (24) & 6 & 6 & 0.3 & 1.7 & 3 & 3 & 0.1 & 0.8 & 22 & 22 & 0.9 & 1.0 \\
\hline Costa $(28)^{1}$ & 4 & 4 & 0.1 & 0.6 & 7 & 7 & 0.3 & 2.3 & 3 & 2 & 0.1 & 0.1 \\
\hline Furcula (1) & 13 & 8 & 8 & 44.4 & 7 & 4 & 4 & 30.8 & 56 & 41 & 41.0 & 47.1 \\
\hline Coracoid (2) & 26 & 25 & 12.5 & 69.4 & 17 & 15 & 7.5 & 57.7 & 129 & 110 & 55.0 & 63.2 \\
\hline Scapula (2) & 24 & 22 & 11 & 61.1 & 14 & 13 & 6.5 & 50 & 105 & 92 & 46.0 & 52.9 \\
\hline Sternum (1) & 4 & 4 & 4 & 22.2 & 4 & 3 & 3 & 23.1 & 32 & 27 & 27.0 & 31.0 \\
\hline Humerus (2) & 53 & 36 & 18 & 100 & 30 & 25 & 12.5 & 96.2 & 267 & 172 & 86.0 & 98.9 \\
\hline Radius (2) & 18 & 18 & 9 & 50 & 13 & 12 & 6 & 46.2 & 76 & 65 & 32.5 & 37.4 \\
\hline Ulna (2) & 32 & 31 & 15.5 & 86.1 & 22 & 20 & 10 & 76.9 & 100 & 87 & 43.5 & 50.0 \\
\hline Carpometac. (2) & 4 & 4 & 2 & 11.1 & 2 & 2 & 1 & 7.7 & 20 & 15 & 12.5 & 14.4 \\
\hline Carpus (4) & - & - & - & - & 2 & 2 & 0.5 & 3.8 & 9 & 9 & 4.5 & 5.2 \\
\hline First phalanx II (2) & - & - & - & - & 3 & 3 & 1.5 & 11.5 & 16 & 15 & 7.5 & 8.6 \\
\hline Synsacrum (1) & 2 & 2 & 2 & 11.1 & 2 & 2 & 2 & 15.4 & 9 & 8 & 8.0 & 9.2 \\
\hline Femur (2) & 24 & 23 & 11.5 & 63.9 & 26 & 26 & 13 & 100 & 171 & 161 & 80.5 & 92.5 \\
\hline Tibiotarsus (2) & 38 & 24 & 12 & 66.7 & 37 & 25 & 12.5 & 96.2 & 223 & 174 & 87.0 & 100.0 \\
\hline Fibula (2) & 1 & 1 & 0.5 & 2.8 & 1 & 1 & 0.5 & 3.8 & 24 & 22 & 11.0 & 12.6 \\
\hline Tarsometat. (2) & 2 & 2 & 1 & 5.5 & 1 & 1 & 0.5 & 3.8 & 6 & 5 & 2.5 & 2.9 \\
\hline Phalanx pedis (14) & - & - & - & - & 7 & 7 & 0.5 & 3.8 & 4 & 4 & 0.3 & 0.3 \\
\hline Total & 251 & & & & 200 & & & & 1290 & & & \\
\hline
\end{tabular}

${ }^{1}$ the number of costae is not representative because most costae were left unidentified.

Only in a few instances was it possible to rearticulate the goose bones recovered. All body parts are represented (Tables 20-22) but the head, vertebrae, ribs, wing extremities, synsacrum and lower legs are strongly underrepresented (Table 30, Fig. I45). The meatiest parts of the birds are well represented e.g. the pectoral girdle although the sternum only has \%MAU values of 20-25 and the upper leg bones but also less fleshy parts such as the wings are very well represented. This pattern holds true for all phases. The skeletal element distribution differs to some extent from that of eider (Table 26, Fig. I36), which has a better relative representation of head, vertebrae and especially synsacrum. There may be several reasons for the discrepancy between those two species of nearly the same size (mean weight of East Greenland male eider is $2000 \mathrm{~g}$, for barnacle geese it is zoro $\mathrm{g}$ (Cramp and Simmons 1977)). Firstly, diving ducks like eiders have more robust bones, often containing marrow, while geese have pneumaticed bones, making them more prone to breakage and destruction. Taphono- mical bias against goose remains may explain some of the discrepancies. Secondly, the carcasses of the two species may also have been treated differently. This issue will be discussed in more detail in the section concerning storage.

In total 62 bones exhibited cut marks (Appendix I). Most of the long bones (i.e. humerus, radius, ulna, femur and tibiotarsus) from adult geese had both articular ends broken off comprising $69 \%(\mathrm{~N}=426)$ while $31 \%(\mathrm{~N}=192)$ were intact. A total of 39 bones had gnawing marks.

The scattered nature of the goose remains and the fact that only few bones could be rearticulated, indicates that goose hunting took place relatively frequently. The bones had a high incidence of cut marks compared with other bird species at the site and many long bones were broken or chewed. Almost all the cut marks were found on bones with muscles attached and are considered to derive primarily from the filleting process (Appendix I). 


\section{Hunting season}

Medullary bone was observed in femur, tibiotarsus, radius, ulna and furcula, however, was most pronounced in femur. All goose femora were assessed and scored with,,,-++++++ , designating absence, trace amount, half or completely filled with medullary bone, respectively (Table 29). In broken bones, the state could easily be detected, and radiographs facilitated an assessment of intact bones. In total $61 \%$ of the adult goose femora contained medullary bone and it occurred through all phases albeit in varying frequencies (Table 29). This would indicate that more than half of the adult goose bones derive from breeding females. This apparent preponderance of bones with medullary bone may be explained taphonomically. Bones filled with granular calcium tissue are expected to have a better preservation potential than hollow bones (Gotfredsen 2002). Hollow bones do not necessarily represent males but may derive from non-breeding females or females hunted before or after the breeding period. The sex ratio in the living population on the breeding grounds is expected to be I:I as geese pair for life (Ogilvie 1978; Owen 1980; Madsen 1989) and they arrive at the breeding ground in pairs, staying together during the entire breeding period (Owen et al. 1978), even though some populations with a surplus of male non-breeders are known (Owen et al. I978).

Goose species breeding in the Arctic have developed various strategies to build up sufficient nutrient reserves for reproduction. Most species build up stores on the wintering grounds but also have to feed at one

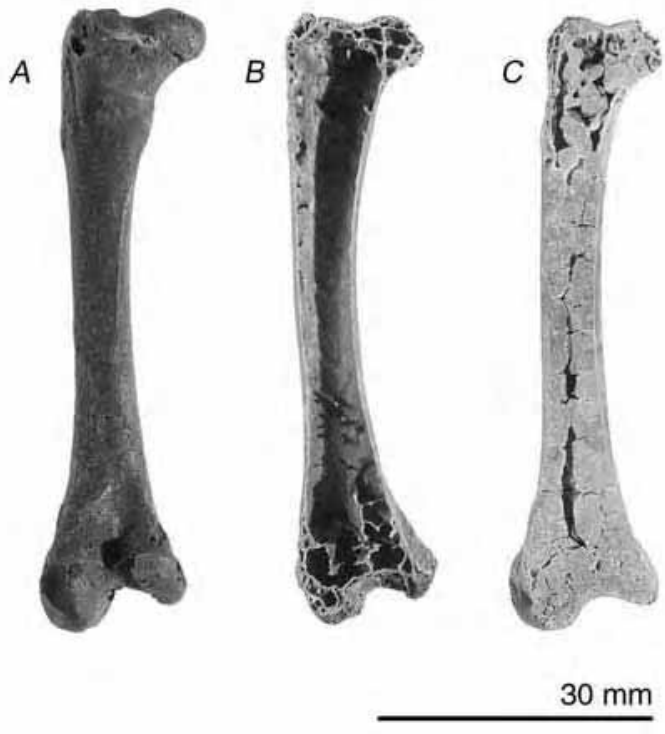

Fig. 146. Goose femora at Nipisat. Intact femur (A) and longitudinally sectioned femora, showing one hollow (B) and one completely filled with medullary bone (C). Photo: Geert Brovad.

or more spring staging areas before reaching the breeding grounds (see e.g. Ebbinge and Spaans 1995), some species may even feed on the breeding grounds prior to incubation (Choinière and Gauthier 1995). The various contents of medullary bone in the goose femora at Nipisat indicated that the geese were hunted during spring on special spring staging areas, or on the breeding grounds when medullary bone was accumulating, or during egg-laying and incubation or both

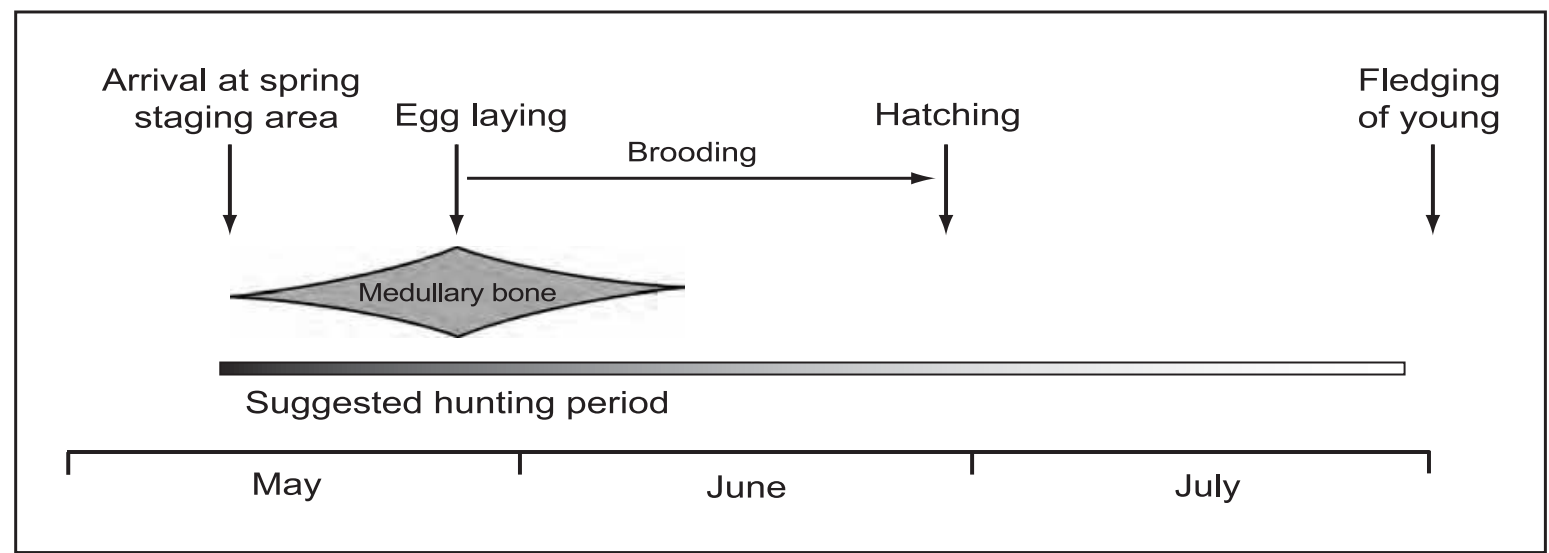

Fig. 147. The primary goose-hunting season at Nipisat. Most of the goose remains derived from adult breeding and staging geese captured in the spring and early summer. Drawing: Poul Nygaard Andersen. 


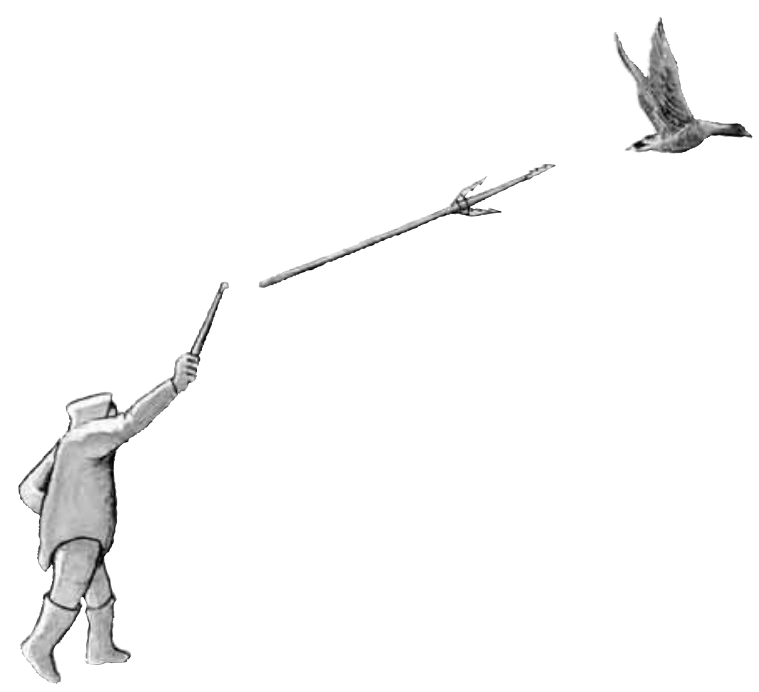

Fig. 148. The Nipisat geese were primarily hunted before moulting took place while they were still able to fly. Drawing: Jørgen Mürhmann-Lund.

periods. Most of the bones containing medullary bone were completely filled with tissue (Table 29 and Fig. I46, C). This may even narrow down the main hunting period to around the time of egg-laying (Fig. I47). In arctic breeding goose species the laying period is shortened to a minimum by producing one egg per day (Ogilvie 1978:I25).

Most of the goose bones derived from adults (95.5\%) with a proportion varying from c. $89 \%$ in phase I to $97 \%$ in phase 2 and 3 . The remaining bones (4.5\%) were from juveniles including both newly hatched goslings and near fledglings (Tables 23-25, Figs I3I-I33). Due to both taphonomic issues and identification problems of juvenile bones, the proportion of goslings could be underrepresented. Still, the preponderance of adult bones and the fact that more than half of the adults were breeding females, documents that the Nipisat people focused on breeding geese, primarily females, close to the time of egg-laying. At that time of year, geese are still able to fly, as moulting does not take place until after the young hatch later during the summer. The exact timing of moulting, with a flightless period varying from 3-4 weeks (Ogilvie 1978:308), depends on the species in question.

\section{Hunting methods}

How can we interpret the fact that staging and breeding geese still able to fly were preferred to more easily accessible moulting geese later in summer? Numerous accounts refer to the habit of catching moulting geese. Flightless geese have been likened to 'aquatic sheep' (Ogilvie 1978) because of their acquiescence to being guided over water. In historical times, and until recently, Greenlanders used to round up flightless geese in July during the moulting period (Kampp et al. 1988). Did the Saqqaq people take the brooding females, reluctant to leave their eggs, by hand or perhaps with light throwing spears or bird darts (Fig. I48)? We do not know, but either method required great skill.

Marine birds use fat as insulation to a higher degree than do terrestrial and freshwater birds that use their feathers as insulation. Geese, although not fat birds, were at an optimal stage of nutritional condition at the beginning of their breeding period, after having eaten all the fresh sprouts at their spring staging area. At the time of egg-laying, the geese are well nourished after having fed on the over-wintering below ground parts of Eriophorum (Fox et al. 1996) and fresh sprouts of grasses Poa spp. and sedges Carex spp. with very high nutritional contents. Geese may increase their weight by 30-40\% during spring staging (Madsen 1989). Are we dealing with a stress situation? Geese and other migrants arrive in spring, which was in many ways the worst time of the year, when storage was short and accessibility to fresh meat was difficult. According to Owen (1980:I86), all native people in all regions where geese bred collected eggs in spring and geese were highly prized since they were the first arrivals in northern areas. A smaller contingent of geese was most likely caught during the moult, the unfledged goslings being a by-catch of that practice.

\section{Existence of goose breeding grounds close to} the coast?

The relative frequency and spatial distribution of goose bones at the site indicate that goose hunting was more than just an occasional practice. The geese were presumably hunted on the mainland but not necessarily far inland. Müller (1906:8I), referring to the whitefronted goose, stated that no regular hunting was carried out, although spring migrants were occasionally shot. However, breeding occurrences of white-fronted geese on small islands in a coastal environment in the Aasiaat District during the 1940's (Salomonsen 1974: 59 ) indicate that geese may have nested closer to the coast if they were not too disturbed. Barnacle geese are colonial breeders, often preferring islets and cliffs 
Table 31. Archaeological localities of low arctic Greenland with swan remains. The localities are either dated archaeologically or by ${ }^{14} \mathrm{C}$. Dating shown with an arrow (e.g., 2030 $\rightarrow 810 \mathrm{BC}$ ) indicates that bones occur throughout the time interval. Dating shown with a hyphen (e.g., 1000-1400 AD) indicates that bones date somewhere within the time interval. NISP designates the number of swan bones at the sites. All localities are shown in Fig. 149.

\begin{tabular}{|c|c|c|c|c|c|c|}
\hline & Position & Dating & Culture & NISP & $\begin{array}{l}\% \text { NISP } \\
\text { (Aves) }\end{array}$ & Reference \\
\hline 1. Nipisat & $66^{\circ} 49^{\prime} \mathrm{N} 53^{\circ} 30^{\prime} \mathrm{W}$ & $2030 \rightarrow 810$ BC & Saqqaq & 60 & 0.5 & Gotfredsen 1998, 1999 \\
\hline 2. Malmquist Site & $66^{\circ} 49^{\prime} \mathrm{N} 51^{\circ} 31^{\prime} \mathrm{W}$ & c. $450 \mathrm{BC}$ & Early Dorset & 4 & 12.5 & Kramer 1996 \\
\hline 3. V 59 Eqaluit & $64^{\circ} 09^{\prime} \mathrm{N} 50^{\circ} 28^{\prime} \mathrm{W}$ & $1000-1400 \mathrm{AD}$ & Norse & 4 & 2.0 & $\begin{array}{l}\text { Meldgaard unpubl.; } \\
\text { McGovern 1979; } \\
\text { Møhl } 1982\end{array}$ \\
\hline 4. V 51 Sandnes & $64^{\circ} 15^{\prime} \mathrm{N} 50^{\circ} 12^{\prime} \mathrm{W}$ & $1025 \rightarrow 1325$ AD & Norse & 12 & 2.4 & $\begin{array}{l}\text { Degerbøl 1936; } \\
\text { McGovern 1979; } \\
\text { McGovern et al. } 1996\end{array}$ \\
\hline 5. GUS & $64^{\circ} 05^{\prime} \mathrm{N} 50^{\circ} 04^{\prime} \mathrm{W}$ & 1000 - c. 1400 AD & Norse & 8 & 1.4 & Enghoff 2003 \\
\hline 6. Ø 29 & $61^{\circ} 09^{\prime} \mathrm{N} 45^{\circ} 32^{\prime} \mathrm{W}$ & - & Norse & 1 & 50.0 & Krogh 1965 \\
\hline 7. $\varnothing 17 a$ & $60^{\circ} 55^{\prime} \mathrm{N} 46^{\circ} 03^{\prime} \mathrm{W}$ & $1000-1500 \mathrm{AD}$ & Norse & 4 & 13.8 & $\begin{array}{l}\text { McGovern 1979; } \\
\text { McGovern et al. } 1993\end{array}$ \\
\hline 8. Utorqaat & $55^{\circ} 62^{\prime} \mathrm{N} 53^{\circ} 14^{\prime} \mathrm{W}$ & $1350-1750 A D$ & Thule & 1 & 0.2 & Degerbøl et al. 1931 \\
\hline
\end{tabular}

(Ogilvie 1978) and the nesting sites are situated in places inaccessible to arctic foxes (Ogilvie et al. 1999). Small-sized Canada geese breed dispersed on the mainland or islets (Ogilvie 1978). The Nipisat geese presumably staged and nested close to the coast in the Sisimiut District, given that their breeding grounds were not too disturbed.

\section{Ducks}

Only two species of ducks besides eider were recognized, namely the mallard and the long-tailed duck, albeit in small numbers (Table 17). Bones of longtailed duck were easy to distinguish from the larger mallard, however some damaged bones lacking morphological diagnostic features were classified as Anas spp./Somateria spp. Those bones were comparable to mallard and common eider bones in size and robustness and it was not suspected that other species belonging to the genus Anas were present.

\section{Mallard}

A total of 25 mallard remains with I9 fragments in phase I $(\mathrm{MNI}=3)$ (Table 20) and six fragments in phase $3(\mathrm{MNI}=\mathrm{I})$ (Table 22) were recovered. Skeletal elements representing most body parts were present, although elements of the pectoral girdle dominated. All mallard bones in phase 3, area 2 square $385 x / 190 y$ articulated (cranial part of a sternum, left and right scapula, left and right coracoid, and one intact furcula). In phase i square $385,82 \mathrm{x} / \mathrm{I} 89,63 \mathrm{y}$ one right foot of a subadult individual (distal part of tibiotarsus, tarsometatarsus and seven phalanges) was found in articulation. The tibiotarsus exhibited cut marks on the craniolateral face. Square $386 \mathrm{x} / \mathrm{I} 85 \mathrm{y}$ yielded three cranial parts of sterna, one of them articulated with furcula and left and right coracoid.

According to Müller (1906:83) mallards were numerous in inner fjord areas e.g. at Itivnek and Ikertooq during summer and autumn and they bred on islands in the fjord and near the Ice Cap. Out of 20 prehistoric localities yielding mallard bones, only two were coastal sites (i.e. Nipisat and Qeqertasussuk) (Gotfredsen 1999). The scarcity of mallard bones at Nipisat is a further indication that this species did not occur in great abundance near the outer coast during Saqqaq times and that the prehistoric distribution of mallard resembles that known from historical times and the present. Mallard hunting occurred on rare occasions, presumably when hunters went inland. The subadult individual documented that at least some duck hunting took place during late summer or early autumn.

\section{Long-tailed duck}

A total of four bones derived from long-tailed duck. Phase I produced two bones found in adjacent squares, namely one complete right tarsometatarsus 


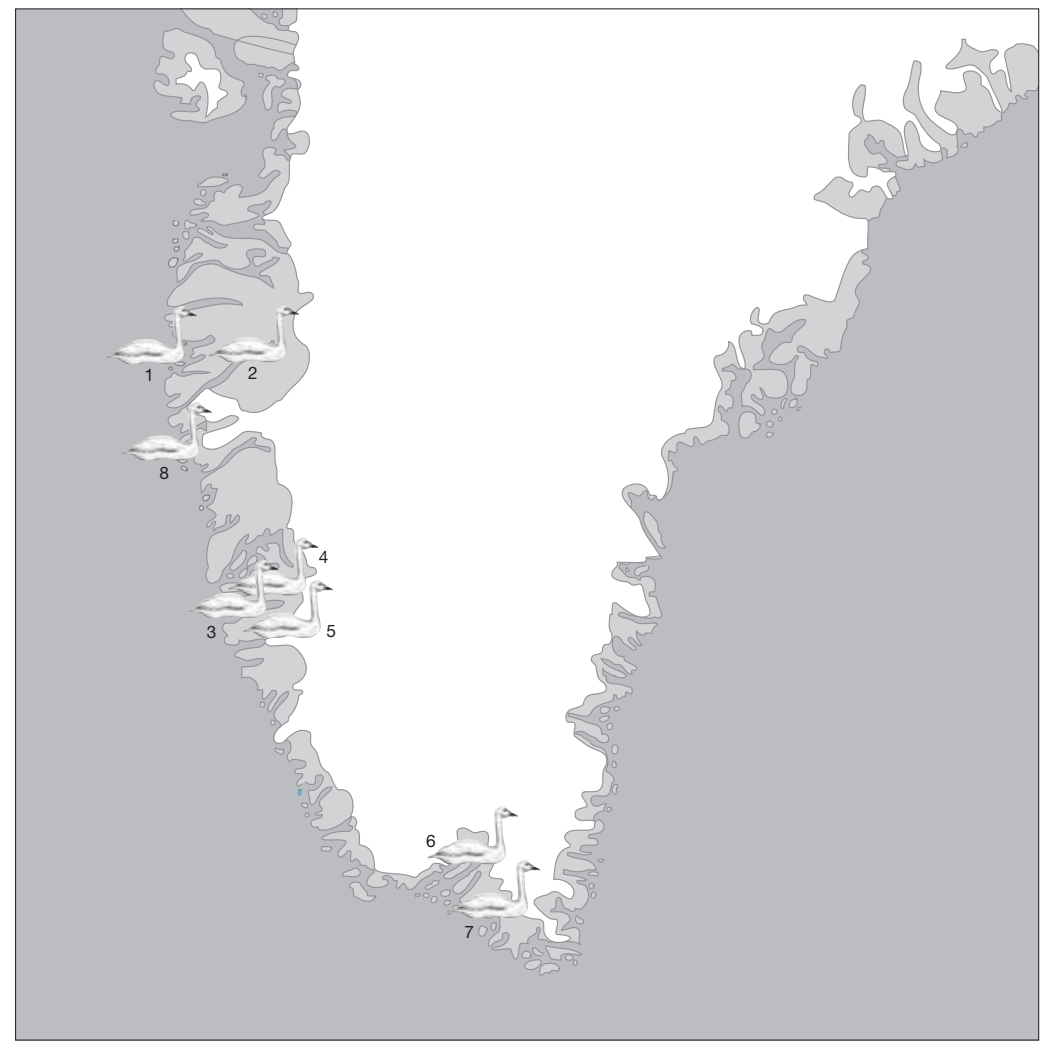

Fig. 149. Prehistoric localities with swan (Cygnus spp.) bones on the West Greenland coast. Most swan bones derive from inland sites. Numbers refer to numbers in Table 31 (Data from Table 31).

(385,I4X/187,I5y) and one first phalanx II from the wing $(385,78 \mathrm{x} / \mathrm{I} 88,40 y)$. In phase 3 , area $\mathrm{I}$, one left coracoid and one left scapula (388x/185y) probably derived from the same individual. All bones derived from adults.

Long-tailed ducks were seen year round in the Sisimiut District (Winge I898:88), nesting regularly on the outer skerries and were particularly numerous near the Ice Cap (Müller 1906:86-87). However, it was considered rather shy and extremely difficult to hunt (Fabricius I8I8:249) and Müller (I906:86, 88) stated that no regular hunting was carried out. During moult males of long-tailed duck gather in protected bays and at that time of year they were presumably easier to capture (D. Boertmann pers. comm. 2003). The scarcity of long-tailed duck remains, however, indicates that the species did not occur in great numbers in the vicinity of Nipisat when the site was inhabited. The bones are quite robust and their scarcity is probably not due to taphonomic biases.

\section{Swans}

A total of 60 swan bones comprising less than $\mathrm{I} \%$ of the species identified bird remains were retrieved from the Nipisat assemblage, however, most of the bones derived from phase 3 (Table 17). This find is the most numerous from any archaeological site in Greenland (Table 3I) and the northernmost in the low arctic region (Fig. I49). In phase 3 , five non-overlapping left femora from adults and one right juvenile femur (from an individual just a few weeks old) accounted for a MNI of six (Table 22). The juvenile swan femur at Nipisat is the earliest evidence of breeding swans in Greenland (Gotfredsen 1999). Localities 2, 5 and 8 (Fig. I49) also produced juvenile swan bones (Gotfredsen 1999).

\section{Identification of swans}

Bones from northern swan species are difficult to identify to species except for mute swan (Cygnus olor), that can be distinguished from other palearctic swan species (Bacher 1967). The whooper swan (Cygnus cygnus) and the Bewick's swan (Cygnus columbianus bewickii) can be distinguished from each other by size only (Bacher 1967). The fragmentary nature of the swan remains at Nipisat complicate species identification. Measurements could be obtained from one intact right femur (383x/186y), phase 3, with GL of IOI.oI 
mm, Lm: 92.3I mm, Bp: 28.99, Dp: I7.3I mm; SC: II.49 $\mathrm{mm}$ Bd: $26,97 \mathrm{~mm}$ and Dd: $19.40 \mathrm{~mm}$ and compared to measurements of extant whooper swan skeletons kept at the Zoological Museum, Copenhagen ( $\mathrm{N}=\mathrm{I5})$. The measurements were according to Driesch (1976). All measurements except Dd fall within the range of whooper swan, although at the lower end (Gotfredsen 1999). GL also falls within the range of nearctic tundra swan (Cygnus columbianus columbianus) of 99-III mm $(\mathrm{N}=4)$ (Gilbert et al. 1996). Other non-measurable swan bones at Nipisat also seem small. Swan remains from other localities in southwest Greenland (Fig. 149) conformed to size measurements of whooper swan (Gotfredsen 1999).

Whooper swans of the Greenland population were reported to be smaller and the Iceland whooper swans somewhat intermediate compared to nominate race (Cramp and Simmons 1977; Madge and Burn 1988). The few measurements of bill length of tundra swan obtained from the literature (Madge and Burn I988) showed size overlap with whooper swan. All historical observations including skins sent to the Zoological Museum, Copenhagen, were palearctic whooper swans (Helms 1926:227; Salomonsen 1950, 1967). The swans at Nipisat were presumably whooper swans, occurring as occasional breeding birds or perhaps occurring continuously through the occupation period. Recently, breeding nearctic tundra swan on the
Greenland West coast have been recorded, due to an increase in the eastern Canadian population (see Boertmann 1994:I4). The possibility that the swans at Nipisat were tundra swans cannot be entirely ruled out (Gotfredsen I999).

\section{Spatial distribution of swan remains}

In phase 3 the swan fragments $(\mathrm{N}=56)$ lie scattered within two main concentrations one in the northern part of the site, mainly in area 3 and to some extent in area 2, and one in the central part of area I (Fig. I50). Both concentrations comprise elements representing the leg (femur, tibiotarsus and fibula), the vertebral column, the pectoral girdle (scapula and furcula) and the wing (humerus, carpometacarpus and carpus). The horizontal distribution of swan bones indicates that the swans were caught on several occasions and not during a single event.

Phase 2 yielded two swan bones, a vertebra and a femur, and phase I yielded two bones, a costa and a vertebra (Table 32). In area 2 one v. cervicalis (389x/ 197y), phase 2, was situated in close proximity to a v. cervicalis (390x/198y), phase 3 . In the central part of area I one v. cervicalis (385x/I85y), phase I, and four v. cervicales $(384 \mathrm{x} / \mathrm{I} 84 \mathrm{y})$, phase 3 also occurred in squares of close proximity. The vertebrae were, however, too poorly preserved to assess whether they could articulate. The swan remains of the two oldest

Table 32. The distribution of 60 swan bones by skeletal element and phase. A number in parenthesis is the number of that particular element in a complete swan skeleton.

\begin{tabular}{|c|c|c|c|c|c|c|c|c|}
\hline & \multicolumn{2}{|c|}{ Phase 1} & \multicolumn{2}{|c|}{ Phase 2} & \multicolumn{4}{|c|}{ Phase 3} \\
\hline & NISP & MNE & NISP & MNE & NISP & MNE & MAU & $\% M A U$ \\
\hline Mandibula (2) & - & - & - & - & 1 & 1 & 0.5 & 12.5 \\
\hline V. cervicalis (23) & 1 & 1 & 1 & 1 & 12 & 12 & 0.5 & 12.5 \\
\hline Costa (48) & 1 & 1 & - & - & 3 & 3 & 0.1 & 2.5 \\
\hline Scapula (2) & - & - & - & - & 3 & 3 & 1.5 & 37.5 \\
\hline Furcula (1) & - & - & - & - & 9 & 3 & 3 & 75 \\
\hline Humerus (2) & - & - & - & - & 2 & 1 & 0.5 & 12.5 \\
\hline Carpometacarpus (2) & - & - & - & - & 2 & 2 & 1 & 25 \\
\hline Carpus (4) & - & - & - & - & 2 & 2 & 0.5 & 12.5 \\
\hline Pelvis (2) & - & - & - & - & 1 & 1 & 0.5 & 12.5 \\
\hline Femur (2) & - & - & 1 & 1 & 9 & 8 & 4 & 100 \\
\hline Tibiotarsus (2) & - & - & - & - & 8 & 3 & 1.5 & 37.5 \\
\hline Fibula (2) & - & - & - & - & 3 & 3 & 1.5 & 37.5 \\
\hline Tarsometatarsus (2) & - & - & - & - & 1 & 1 & 0.5 & 12.5 \\
\hline Total & 2 & 2 & 2 & 2 & 56 & 43 & & \\
\hline
\end{tabular}




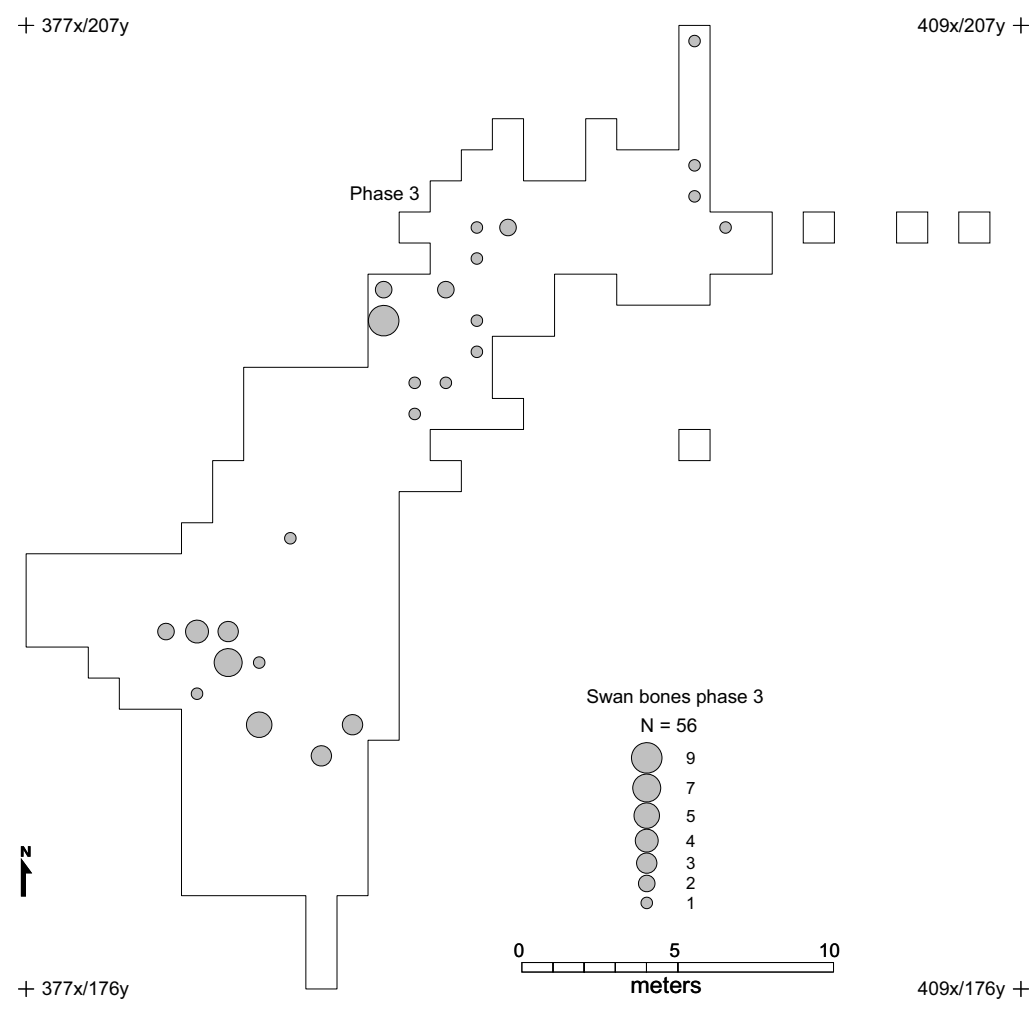

Fig. 150. Horizontal distribution of swan (Cygnus spp.) bones in phase 3. Four swan fragments attributed to phase 1 and 2 (see Table 32) are not shown. phases may represent intrusions from the overlying phase 3 or they might belong to phases I and 2 respectively and document swan hunting during the earliest occupation periods.

\section{Bone element representation and treatment of} the swan bones

The relative frequencies of swan skeletal elements in phase 3 showed a large variation (Table 32). Compared to femur, all other elements were underrepresented. This underrepresentation would have been even more pronounced had $\mathrm{MNI}=6$ been applied to femur, however, MAU was calculated in the standardized way (see section Methods). Besides the fleshy femur, tibiotarsus and fibula with \%MAU of Ioo, 37.5 and 35.5 , respectively furcula and scapula were well represented with \%MAU of 75 and 37.5 respectively (Table 32, Fig. I5I). The representation of vertebrae, ribs and extremities were expectedly low. The virtual absence of wing bones, however, is noteworthy and quite different from the relative frequencies observed in, for instance, goose and eider (Figs I36 and 145). Swan wing bones are very large and robust and the low representation indicates differential treatment of swans compared to other members of the Anatidae.
The wings, still with feathers attached, may have been used for decorative purposes or brooms, or the long strait bones could have provided raw material for awls and needles (see p. 54, Hand tools). The complete absence of the meat bearing part of sternum and coracoid is difficult to explain, because both scapula and furcula are well represented. Were those parts stored and removed from the site as provisions? Another explanation may be that swans were not hunted in the vicinity of the site but further inland and that the bone elements represented at the site reflect differential transport, in addition to differential survival of the bones.

\section{Bone alterations on swan bones}

The swan bones were heavily fragmented with only seven limb bones (four femora and three scapulae) and the vertebrae being intact. The bones exhibited a high degree of surface erosion, which prevented recognition of unequivocal gnawing marks. One diaphysis (390x/I95y), phase 3, and one fragment (389x/ I94y), phase 3 could be reassembled to one left carpometacarpus. One diaphysis of a left femur (383x/ I86y) and a proximal fragment (382x/I87y), both in phase 3 , derived from the same bone. Two tibiotarsi 
and one tarsometatarsus had their ends deliberately broken off, one proximal tibiotarsus was broken in the middle of the shaft, and the furculae were broken into pieces.

A total of six swan bones (Iо\%) exhibited cut marks. One furcula (383x/187y), phase 3, has several transverse $2 \mathrm{~mm}$ long parallel cut marks on the ventral face. One proximal fragment of a right humerus (383x/I86y), phase 3, has dorsally on caput humeri one c. $6 \mathrm{~mm}$ long cut mark. One proximal fragment of a left tibiotarsus (38Ix/I87y), phase 3, has two $2 \mathrm{~mm}$ long transverse cut marks on the cranial face. One left diaphysis of tibiotarsus (398x/202y), phase 3 , has several long fine marks parallel to the long axis of the bone placed on the caudal face (Gotfredsen 1996: Fig. 7.3). Two v. cervicalis (388x/197y), phase 3, and (389x/I97y), phase 2, has few I mm long cut marks dorsally at an oblique angle to the long axis. The long parallel scrape marks on the tibiotarsus are interpreted as scrape marks to remove meat for consumption and perhaps to clean the bone of e.g. sinews to prepare the diaphysis for later use. The remaining cut marks on the swan remains are interpreted as butchering marks related to filleting or removal of meat from the bones according to definitions by Binford (198I) and Noe-Nygaard (1989). The marks on the proximal humerus and the proximal tibiotarsus may be traces from dismemberment of the wing and disarticulation of the joint between femur and tibiotarsus.

The bone element distribution, fragmentation pattern and the presence of butchering marks indicate that the swans must have been highly valued birds providing meat, feathers, soft skin, and presumably also bones for e.g. needle cases, awls and needles. Gilbert et al. (1996:4) mentions examples of Eskimo use of swan products e.g. humeri of whistling swans for needle 'keep-safes' by the Mackenzie Delta Eskimo people and another example of carrying bags sewn from six swans' feet.

\section{Swan hunting}

None of the adult swan bones contained medullary bone indicating that they derived from either males or females caught before or after the egg-laying season. The small size of the femora may indicate that most of the bones were from females. In Iceland, egg-laying occurs in late April and incubation lasts approximately 35 days (Cramp and Simmons 1977). The juvenile

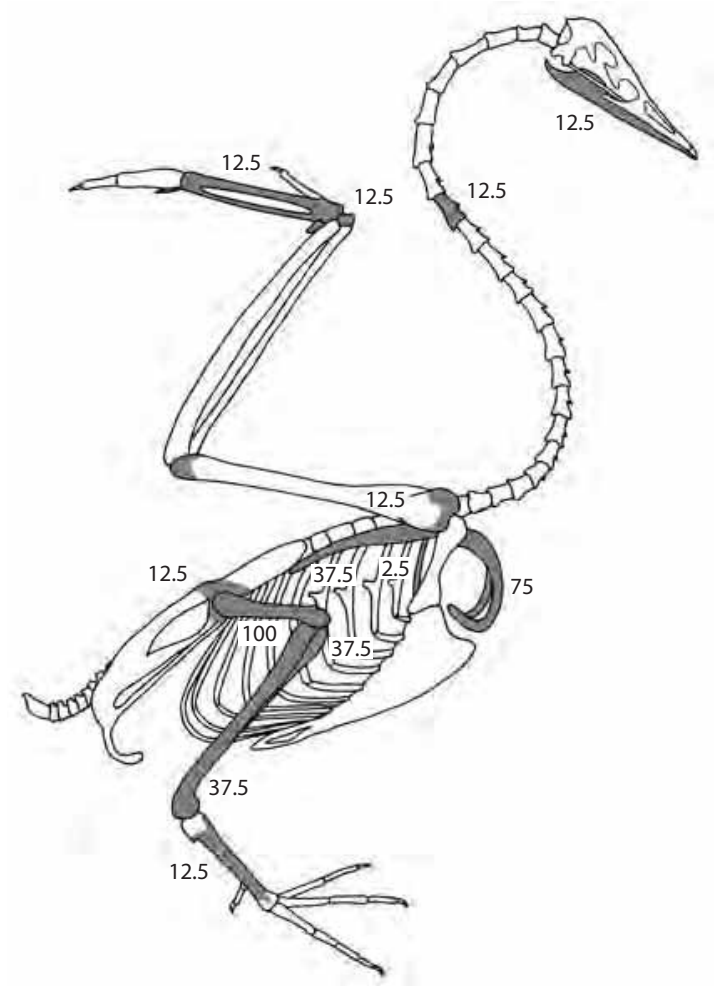

Fig. 151. Relative frequencies of swan (Cygnus spp.) bones at Nipisat. Frequencies are based on \%MAU values from Table 32. Note the clear under representation of large wing bones e.g. humerus, which may have served as a valued raw material for needles.

femur from an individual just a few weeks old suggests hunting in June-July, presumably at the breeding site. For whooper swan, the moult is complete and the birds are flightless for 5-6 weeks within the period June to late August (Cramp and Simmons 1977). In referring to old legends told by the Greenlanders, Holbøll (I843:432) wrote that swans used to nest on a certain stretch of land called Qussuq in Nuup Kangerlua (Nuuk Fjord) and that they were hunted to extinction during their flightless moulting period by the Inuit. Such large birds would indeed have been easier to catch with harpoons or light spears during the moulting period. But also non-breeders or stragglers of the Iceland population visiting the West Greenland coasts from April to September may have been caught. One juvenile bone found at the Malmquist site c. 450 BC (Table 3I, Fig. I49) documents breeding in the interior of the Sisimiut District.

Whooper swans require shallow lakes with lush 
vegetation but also open tundra can be used for nesting and, outside the breeding period, they prefer large lakes and shallow coasts (Salomonsen 1967). In Greenland, swans have been observed at inland lakes and marshes in recent times (Boertmann 1994). The swans may have bred closer to the coast if not disturbed and if suitable breeding habitats existed while Nipisat was inhabited. However, the amount of bones and the relative frequency of bone elements suggest that swans were only hunted occasionally and perhaps at some distance from the site.

\section{Rock ptarmigan}

Ptarmigan remains occur through all layers, although in low numbers, and comprise I.I, 0.7 and $0.6 \%$ of the bird bones in phases I, 2 and 3 respectively (Table I7). Bones of juvenile rock ptarmigan were recovered from phase 3 only comprising 32\% (Tables 23-25, Figs I3II33). With a few exceptions, all ptarmigan bones were retrieved from the central and southern part of the site (area I and 2). The ptarmigan remains were scattered over several squares, indicating several instances of ptarmigan hunting. Square 383x/186y, phase 3, produced 28 bones, representing at least four individuals. The spatial distribution within the square was not registered but the bones may derive from one hunting bag.

Most of the long bones of wing and leg (i.e. humerus, radius, ulna, femur and tibiotarsus) $(\mathrm{N}=2 \mathrm{O})$ had one or both articular ends broken off while eight were intact. One right diaphysis of humerus (385,32x/ I87,31y), phase I, exhibited cut marks proximally on the lateral face presumably representing filleting marks. One right diaphysis of a humerus (383x/186y), phase 3, had tooth marks distally. Skeletal elements of rock ptarmigan were not equally represented (see Tables 20-22). Bones of the pectoral girdle (furcula, coracoid and scapula) and to some extent wing bones and bones of the leg were more numerous than bones of e.g. head, neck and the rib cage, which were almost lacking. Both in phases I and 3, the coracoid was the most numerous bone element indicating that the rock ptarmigan bones primarily derived from the meatiest parts of the bird. Ptarmigans with a mean body weight of $449 \mathrm{~g}$ (Cramp and Simmons 1980:415) are rather lean compared to the marine and coastal bird species and handling for food preparation may have differed from other birds of comparable size e.g. the black guillemot with a mean body weight of $427 \mathrm{~g}$ (Gaston and Jones 1998:169), which showed dominance of wing bone elements and femora (Tables 20-22). The differential representation may also to some extent be due to differential survival of ptarmigan and alcid bones. The auk bones are more robust and contain marrow while ptarmigan bones are thin walled and pneumatised.

\section{Ptarmigan hunting}

Rock ptarmigans occur and breed in a broad spectre of habitats (e.g. Holbøll I843:402; Boertmann 1994) and the species may have been hunted year round at the island of Nipisat or on hunting trips to the mainland. Traditionally, ptarmigan hunting was of no particular interest to Greenlanders and it was considered a prey item for boys practicing hunting techniques (Rink I857:I78; Oldendow I933:56), probably because of the low amount of calories. Nevertheless, many special devices for ptarmigan hunting were developed, varying from region to region, and most Greenland prehistoric Neo-Eskimo and Palaeo-Eskimo bird bone assemblages yield rock ptarmigan remains (Gotfredsen 1999). At Qeqertasussuk, ptarmigan accounted for quite a large amount of the bird bones, ranking fifth in terms of abundance of avian remains (Table 34). No doubt the species may have played a role during winter in times of depletion of other game. Due to their apparent lack of shyness and a tendency to stay on the ground and run for some distance when disturbed, the most widespread way to catch ptarmigan was by slings (Crantz I770:I02; Rink 1857:I79) (Fig. I52) or various kinds of snares (Helms 1921:I60; Holm I887:83), sometimes in combination with decoy whistles (e.g. Thalbitzer 1914:467-70). For the people at Nipisat, ptarmigan hunting may have occurred year round, however, the juvenile bone deriving from phase 3 , indicates that some ptarmigan hunting took place during summer.

\section{Common raven}

Raven remains comprised less than $\mathrm{I} \%(\mathrm{NISP}=4 \mathrm{O})$ of the avian bone assemblage (Table I7). One complete left femur (388x/19ry) derived from phase I. The remaining bones were from phase 3 . A total of 33 raven bones were found in close association in square 387,80x/193,30y (Fig. I53). A right wing (humerus, ulna, radius, two carpalia, carpometacarpus, first digit of metacarpale II and first digit of metacarpale I) was 
Fig. 152. Some of the smaller bird species may have been hunted with bolas. Drawing: Jørgen MürhmannLund.

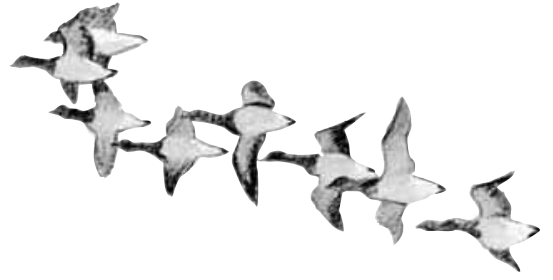

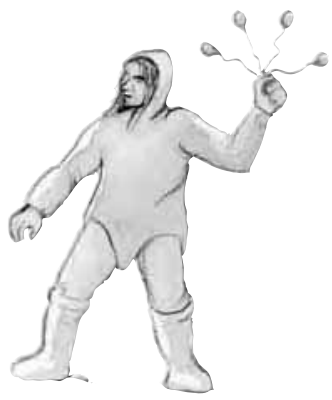

found in correct anatomical order associated with a right coracoid and a right scapula. Additionally parts of a left wing (carpometacarpus, carpale and a first digit of metacarpale I), one furcula, I2 vertebrae cervicales, two ribs, one left mandibula, one left os quadratum, two fragments of a right tibiotarsus and a few bone rings of the pharynx were retrieved. All bones derived from one adult individual. Adjacent squares produced one left coracoid (386x/r9oy), one left tibiotarsus (388x/192y), one vertebra, one left fibula, one left first digit of metacarpale II and one left first digit of metacarpale I (388x/193y) (see Table 22). The raven remains of the adjacent squares may also derive from the articulated individual. No cut marks or obvious gnawing marks were observed. However, several of the long bones i.e. the two tibiotarsi and the right femur, had both ends broken off. The humerus and ulna also had their ends broken off even though they were lying in correct anatomical order. The damage may have been post depositional or resulting from breakage of the joint while the bones were still attached by ligaments. Both carpometacarpals were damaged distally, perhaps also as a result of breakage of the joint. Although the raven carcass was thrown on the midden in partially articulated condition, meat and probably the skin, claws and beak may have been used. It is worth noticing that the tarsometatarsals and phalanges were not retrieved nor were the skull and upper beak.

In historical times, according to Fabricius (Helms I92I:I06) and Oldendow (1933), the Greenlanders used ravens for culinary purposes but also the skin, considered excellent for inner furs, beaks and claws were used (Helms I92I:I06). Several authors (e.g. H.
Egede I74I:35; Crantz I770:I05; Helms I92I:I05) noticed the raven's habit of gathering around houses and human refuse dumps. In historical times, the species was considered common year round near the

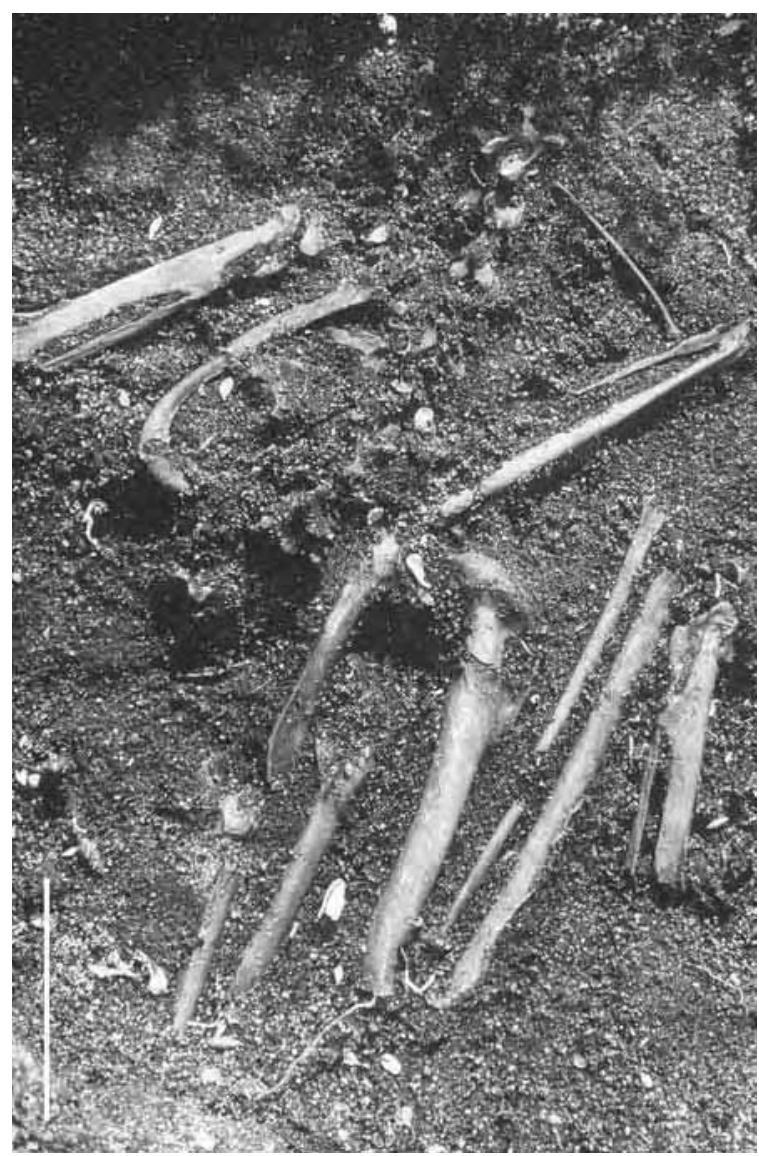

Fig. 153. A nearly complete carcass of a common raven (Corvus corax) was found in situ with the wings and the backbone in correct anatomical order in square 387,80x/193,30y phase 3, area 2. Scale $50 \mathrm{~mm}$. Photo: Sönke Hartz. 
town of Sisimiut (see Winge 1898:27I) and Müller (1906:33) reported it to breed near the coast and up the fjords, but rarely inland. The presumably brief seasonal visits at Nipisat probably did not attract ravens in any greater number, especially during summer and fall where the birds had other foraging possibilities. Catching ravens at Nipisat was a rare event. In comparison, the Saqqaq site of Qajaa (Fig. I, no. 44) produced raven bones in larger relative abundance comprising $2.5 \%$ of the avian remains (see Table 34 ).

\section{Owls}

Phase 3 yielded four fragments of snowy owl (Tables I7 and 22) accounting for at least one adult individual. In area 2 a left mid-piece of a humerus (388x/I9ry) and an articulated tip of a right wing (distal part of carpometacarpus, digit I and II of metacarpale II) (383x/ I92y) were recovered. The bones were well preserved and only the humerus showed a little surface degrading. None exhibited clear butchering or gnawing marks. However, the humerus had both ends broken off while the carpometacarpus had a hole on the caudal surface of the diaphysis and the metacarpale III was broken off.

At the beginning of the $20^{\text {th }}$ century snowy owls were considered breeding birds along the entire West Greenland coast (Bertelsen 1932; Oldendow 1933), they were sighted all year round and bred in the Sisimiut District, although, eggs were rarely seen (Winge 1898:265). Snowy owls are considered dependent on collared lemming (Dicrostonyx groenlandicus) during the breeding time (D. Boertmann pers. comm. 2003), and did probably not breed in the Sisimiut District. The owls may have been hunted on occasion either inland or near the coast at any season. Since no unequivocal butchering traces were found on the bones, the possibility that the snowy owl remains were left by scavengers e.g. arctic fox or raven still exists.

\section{Gyrfalcon}

One left first digit of metacarpale II of an adult gyrfalcon was retrieved from square $383 \mathrm{x} / \mathrm{I} 88 \mathrm{y}$, phase 3 , area 2 (Tables 17 and 22). The bone is fairly large and presumably derived from a female bird. The bone at Nipisat is the oldest and northernmost record of gyrfalcon in Greenland (Gotfredsen 1999). Today gyrfalcons are recognized as widespread but sparse breeders nesting both inland and near the coast. The low arctic population is stationary or partially migratory (Boertmann 1994:24). Gyrfalcons may in fact have been hunted year round.

\section{Food preparation, consumption and storage of birds}

The nearly complete absence of burned bones at the site indicates that meat, in most cases if not exclusively, was boiled and not roasted. There were cut marks on the bird bones albeit few. The most frequently occurring traces were faint sub-parallel cut marks in one or sometimes a few groups placed transversely or at an oblique angle to the long axis of the bone, presumably inflicted when meat was scraped off or, in some cases, during skinning (see Appendix I and Table 33). Cut marks interpreted as resulting from dismemberment occurred less frequently and were situated near the articular ends, e.g. close to or on the caput femoris or on the caput humeri. These interpretations were in accordance with observations from the extensive bone material of Anseriformes from two Italian Upper Palaeolithic sites (Tagliacozzo and Gala 2002). A few exceptions may be a swan tibiotarsus (398x/ 202y), phase 3, fulmar humerus (394x/201y), phase 3 , and a goose humerus (392x/197y), phase 3 showing several traces placed parallel to the long axis of the shaft which may represent cleaning of the bone surface in order to prepare it for tool production. Skinning and dismemberment traces were inflicted before boiling, while the scrape marks for removing meat were made after boiling, when boiled, or during the filleting process when producing dried meat for storage.

All but a few bird species could be hunted in the vicinity of the site. The skeletal representation of eider and goose bone elements differed with goose being even more underrepresented with respect to head, neck and feet than the eider. A possible explanation might be that the goose remains represent provisions brought to the site and that geese were hunted at some distance from the site, in contrast to eiders that nested in the surroundings of Nipisat together with other breeding birds. However, geese ranked third at the site, which does indicate that they were hunted in the vicinity.

Many long bones (including both wing and legs) 
Table 33. Summary of alterations on bird bones retrieved from the Nipisat site (NISP=13,231).

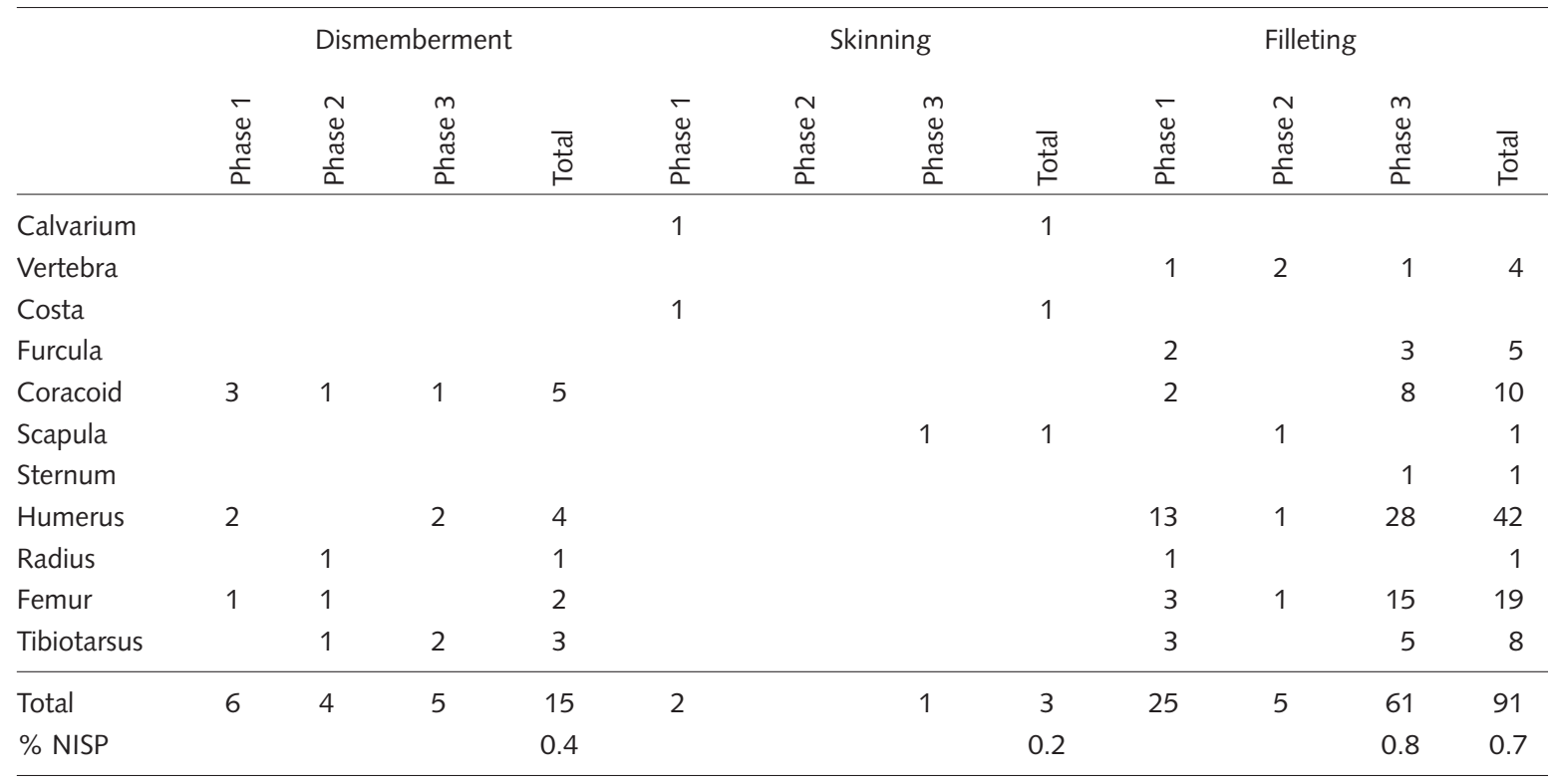

most likely had their articular ends gnawed and chewed by humans even though unequivocal tooth marks were rare. In several instances, although not quantified, pitting of the bone surface was observed near the missing articular ends indicating that they were in fact bitten off. This pattern of absent articular ends of long bones was most pronounced in gulls, frequently occurring within procellarids and geese but least frequent in e.g. eiders. The habit of damaging the articular ends was not only observed in species containing marrow as a means of marrow extraction, as suggested by Grønnow and Meldgaard (I988, I99Ib) but also in geese, which have pneumaticed humeri and ulnae and to a large extent medullary bone in femora and tibiotarsi.

Many bird carcasses were discarded in a partially articulated state, although it was difficult to quantify the extent to which this practice occurred. The most frequently observed parts were the pectoral girdle or shoulder girdle but also the synsacrum with a part of the backbone as well as tips of wings, parts of legs and feet occurred in an articulated state. According to Schäfer (I972:46) wing bones tend to stay together in correct anatomical order longer when naturally deposited than do leg bones, due to the small amounts of meat and stronger ligaments. Some wings may have been disposed of in an articulated state with meat on, however the cut marks and gnawing occurred even more frequently on wing bones than on leg bones (Table 33), demonstrating that bird wings were indeed used for food.

Traditionally important storage products were dried capelin, dried meat (e.g. seals, walrus, whale, and caribou), birds and eggs (Meldgaard 1995). The overwhelming quantities of bird remains at Nipisat reflect various activities such as skinning, boiling and immediate consumption but probably also production of storage products. From the seasonal osteological indicators (Fig. 192), we know the site was visited during the main bird breeding period and it must be assumed that large amounts of eggs were collected and possibly stored.

\section{Change in the bird composition over time}

Fowling played an important role during all three phases. There seem to be no general temporal trends in the importance of bird hunting, although the proportion of bird remains of the total bone material varies from $49 \%$ (phase I), to $53 \%$ (phase 2) to $44 \%$ (phase 3). In total 2I, I4 and 23 bird species are represented in phases I, 2 and 3 respectively (Table I9). The apparent decrease in number of species in phase 2 could be ascribed to the smaller sample size because 
Table 34. Relative frequencies of avian taxa at large West Greenland Saqqaq sites. Numbers in parentheses indicate taxon rank and bold values highlight the first and second ranked taxon.

\begin{tabular}{|c|c|c|c|c|}
\hline & Qeqertasussuk $^{1}$ & Qajaa $^{2}$ & Nipisat & Itinnera ${ }^{3}$ \\
\hline Red-throated diver & + & 0.05 & 0.54 & - \\
\hline Great northern diver & $0.02(10)$ & - & 0.26 & - \\
\hline Fulmar/great shearwater & - & - & 0.09 & - \\
\hline Fulmar & $25.2(2)$ & $6.12(4)$ & $0.79(8)$ & - \\
\hline Great shearwater & 0.01 & - & $0.62(10)$ & - \\
\hline Great cormorant & - & - & $0.94(7)$ & $0.25(7)$ \\
\hline Swan & - & - & 0.45 & - \\
\hline Geese & 0.01 & 0.05 & $13.28(3)$ & $0.13(8)$ \\
\hline Ducks & $0.8(7)^{4}$ & $0.1(10)$ & 0.43 & $9.27(4)$ \\
\hline Mallard & + & - & 0.19 & $0.13(8)$ \\
\hline Common eider & + & $7.36(3)$ & $24.01(2)$ & $15.50(2)$ \\
\hline King eider & + & 0.05 & - & - \\
\hline Long-tailed duck & - & - & 0.03 & - \\
\hline Red-brested merganser & + & - & - & - \\
\hline Gyr falcon & - & - & 0.01 & - \\
\hline Rock ptarmigan & $9.77(5)$ & $4.08(5)$ & $0.78(9)$ & - \\
\hline Sandpipers & - & - & 0.04 & - \\
\hline Glaucous/Iceland gull & $9.94(4)$ & $54.95(1)$ & $50.38(1)$ & $1.27(5)$ \\
\hline Black-legged kittiwake & $0.05(9)$ & $0.30(9)$ & $3.33(4)$ & - \\
\hline Guillemots & $37.36(1)$ & $20.0(2)$ & $1.08(6)$ & $72.5(1)$ \\
\hline Razorbill & - & - & 0.07 & - \\
\hline Great auk & + & - & 0.38 & $0.89(6)$ \\
\hline Black guillemot & $2.82(6)$ & $2.29(7)$ & $1.79(5)$ & - \\
\hline Little auk & $13.45(3)$ & $2.19(8)$ & 0.15 & - \\
\hline Snowy owl & - & & 0.03 & - \\
\hline Common raven & $0.54(8)$ & $2.49(6)$ & 0.30 & - \\
\hline Sample size & 11766 & 2011 & 13231 & 787 \\
\hline $\mathrm{N}$ taxa & $12[18]^{5}$ & 13 & 24 & 8 \\
\hline
\end{tabular}

+ The taxon is present at the site, although not included in the quantified sample of 4 square meters that had corrected NISP values obtained from sieving results.

1 Data compiled from Meldgaard (2004:tables 9.1 and 9.2), sieved.

2 Data compiled from Gotfredsen (1999), unsieved

3 Data compiled from Møhl (1972) and Gotfredsen (1999), unsieved.

4 Comprises common eider, king eider and mallard.

5 The number of identified taxa at the entire site.

faunal assemblage richness is tightly correlated with the size of the retrieved sample (Grayson 1984:32). However, some changes over time in relative frequencies of the most important taxa seem to have occurred, with marine auks and coastal eiders decreasing and coastal gulls and the geese increasing (Fig. 130). Today geese (white-fronted geese) in West Greenland are considered inland birds, however, as argued above, the Nipisat geese may have staged and bred closer to the coast during Saqqaq times. The skeletal element distribution, however, may indicate that geese were brought to the site from some distance. The evidence from geese was thus inconclusive with respect to catchments area.

The most obvious change in bird exploitation was the increase of gulls and decrease of eider. Assuming that the species abundance in the Nipisat assemblage reflects abundance in the ancient environment, changes in the environment may have affected gull species and eiders differentially. In present day conservation regulations, it is of vital importance that birds are protected during breeding. It is considered unlike- 
ly that the exploitation of breeding birds would have affected the populations considerably, even though they were disturbed on the breeding grounds. We must assume that the island was not used continuously, but only in periods then left for a while, perhaps decades, because other hunting fields were more attractive. This might be due to local depletion of the game animals at Nipisat and surrounding skerries, in combination with short-term climatic fluctuation influencing the breeding populations of the area. However, the impact on the breeding populations may not have been detrimental, as we are presumably dealing with very small family groups moving around in the landscape. While visiting the Nuuk District during the last part of the $18^{\text {th }}$ century, Thorhallesen (Bobé 19I4) noticed that the breeding population of eider did not suffer until the Greenlanders became stationary and gave up their seasonal rounds. The increase in geese and gulls at Nipisat may have resulted from a slight shift in the seasonal round with more visits in spring (May) and early autumn (August-September) and fewer visits during mid summer (July-August) when the eiders were easier to catch during moult.

Despite these changes in relative distributions of major taxa, the bird material at Nipisat shows a noticeable constancy in species diversity and relative importance of species. This overall constancy through time of species exploited is also reflected in the selected age groups (Figs I3I-I33) and the representation of e.g. skeletal elements for important game species (Figs I36 and I45). 


\section{Chapter 8}

\section{Mammals}

There were a total of 35036 (5I.2\%) mammal remains comprising 46.I, 44.9 and $54.2 \%$ of the faunal assemblage for phase $\mathrm{I}, 2$ and 3 respectively (Table I3). At least I4 taxa are documented with a number of marine and terrestrial species represented (Table 35). Marine mammals comprised c. $48 \%$ of the entire assemblage with common seal (Phoca vitulina) as the most frequent species, while the terrestrial caribou (Rangifer tarandus) comprised a surprisingly large proportion of $51 \%$ on a coastal site. Other terrestrial game played a negligible role. The proportions of the various groups changed through time with marine mammals being relatively better represented in phases I and 2 while caribou dominate in phase 3 (Fig. I54). These differences were, however, not significant.

\section{Marine mammals}

\section{Polar bear}

A total of four polar bear bones, all confined to phase 3, were retrieved (Table 35). The few bones represent the skull, trunk and the limbs consisting of one frag-

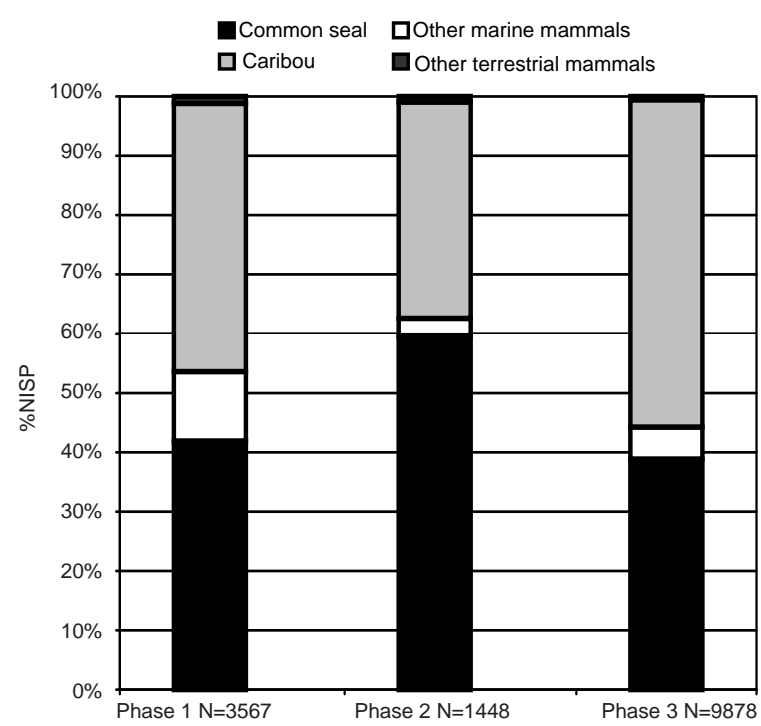

Fig. 154. The dominating mammalian taxa at Nipisat through all phases were caribou and common seals. (Data extracted from Table 35). ment of os temporale (dex) (394x/200y), an upper first molar $\left(\mathrm{M}^{\mathrm{I}}\right)$ ( $\left.\sin \right)$ (394X/199y), a complete rib (dex) (392x/194y) and a worked caudal fragment of femur (sin) (388x/194y) (x650o) (Fig. I55). The fragments were scattered in the northern part of the excavation and may all derive from one animal. Remnants of polar bear in Saqqaq context are sparse, although a small Saqqaq site, Niivertussannguaq in Disko Bay (Fig. I, no. 4I), yielded one first phalanx of bear (Andreasen, T. N. 1998). Polar bear remains have not been found on other low arctic Palaeo-Eskimo sites. In the high arctic region, however, polar bear remains occur at most Palaeo-Eskimo localities, although not in large numbers (see Darwent 200I). The high arctic Eigil Knuth Site, dated to Independence II (Fig. I, 33), produced several worked fragments of polar bear long bone with burin grooves, demonstrating that bear bones were used for tool manufacturing (Gotfredsen unpublished). This may be expected in a high arctic environment with limited access to good raw materials for tool production such as ivory from walrus or narwhal (Monodon monoceros) and long bones from terrestrial game such as musk ox (Ovibos moschatus) and occasionally caribou, also providing antler. It is thus noteworthy that the Nipisat people used the thick walled polar bear femur for the manufacture of a
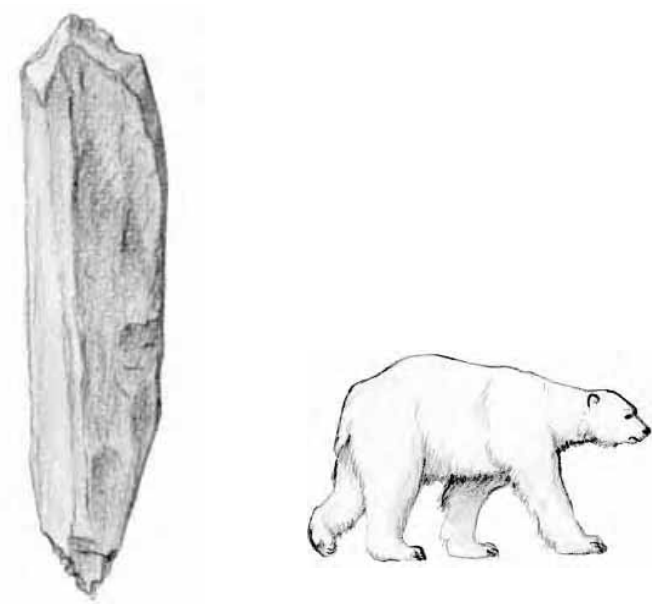

Fig. 155. The thick compact bone wall of a polar bear femur served as tool material for this wedge shaped awl (x6500) from phase 3. Drawing: Jørgen Mürhmann-Lund. 
Table 35. The number of identified specimens (NISP) of mammals (Mammalia) at Nipisat and their relative frequencies and distribution according to chronological phase.

\begin{tabular}{|c|c|c|c|c|c|c|c|c|}
\hline & \multicolumn{2}{|c|}{ Phase 1} & \multicolumn{2}{|c|}{ Phase 2} & \multicolumn{2}{|c|}{ Phase 3} & \multicolumn{2}{|c|}{ Total } \\
\hline & NISP & $\%$ NISP & NISP & $\%$ NISP & NISP & $\%$ NISP & NISP & $\%$ NISP \\
\hline Arctic hare (Lepus arcticus) & 10 & 0.28 & 6 & 0.40 & 19 & 0.19 & 35 & 0.23 \\
\hline Domestic dog (Canis familiaris) & - & 0.00 & - & 0.00 & 17 & 0.17 & 17 & 0.11 \\
\hline Arctic fox (Alopex lagopus) & 33 & 0.92 & 8 & 0.54 & 19 & 0.19 & 60 & 0.40 \\
\hline Polar bear (Ursus maritimus) & - & 0.00 & - & 0.00 & 4 & 0.04 & 4 & 0.03 \\
\hline Walrus (Odobenus rosmarus) & 29 & 0.81 & 14 & 0.94 & 220 & 2.23 & 263 & 1.76 \\
\hline Seals total & 1679 & 47.06 & 889 & 59.74 & 4083 & 41.33 & 6651 & 44.54 \\
\hline Seals (Phoca spp.) & 1447 & 40.55 & 803 & 53.97 & 3628 & 36.73 & 5878 & 39.36 \\
\hline Common seal (Phoca vitulina) & 202 & 5.66 & 85 & 5.71 & 422 & 4.27 & 709 & 4.75 \\
\hline Ringed seal (Phoca hispida) & 1 & 0.03 & - & 0.00 & - & 0.00 & 1 & 0.01 \\
\hline Harp seal (Phoca groenlandica) & 25 & 0.70 & - & 0.00 & 26 & 0.26 & 51 & 0.34 \\
\hline Bearded seal (Erignathus barbatus) & 4 & 0.11 & - & 0.00 & 6 & 0.06 & 10 & 0.07 \\
\hline Hooded seal (Cystophora cristata) & - & 0.00 & 1 & 0.07 & 1 & 0.01 & 2 & 0.01 \\
\hline Caribou (Rangifer tarandus) & 1612 & 45.18 & 543 & 36.49 & 5450 & 55.17 & 7605 & 50.92 \\
\hline Whales indet. (Cetacea) & 32 & 0.90 & 2 & 0.13 & 20 & 0.20 & 54 & 0.36 \\
\hline White whale (Delphinapterus leucas) & - & 0.00 & - & 0.00 & 2 & 0.02 & 2 & 0.01 \\
\hline Harbour porpoise (Phocoena phocoena) & 173 & 4.85 & 26 & 1.75 & 44 & 0.44 & 243 & 1.63 \\
\hline Total identified mammals & 3568 & 100.00 & 1488 & 100.00 & 9878 & 100.00 & 14934 & 100.00 \\
\hline Mammals indet. (Mammalia spp.) & 4552 & & 1715 & & 13835 & & 20102 & \\
\hline Total mammals & 8120 & & 3203 & & 23713 & & 35036 & \\
\hline
\end{tabular}

wedge shaped awl (Fig. I55) despite the apparently easy access to antler and ivory. Did the Nipisat people still remember the old tradition for using polar bear bones in tool manufacturing used by their high arctic ancestors?

\section{Polar bear hunting}

Taking into account that all main body parts of the bear were represented at Nipisat, it is assumed that hunting of polar bears took place in the vicinity of the site. Today the polar bear is not a frequent visitor in the Sisimiut District. However, it may occur in most seasons both in winter, spring and even in summer, e.g. one individual was shot in July 1986 7-8 km north of Nipisat (F. E. Kramer pers. comm. I99I). Müller (I906:269) reported at the end of the $19^{\text {th }}$ century that polar bear tracks were seen every winter near Sisimiut. The polar bears arrived with the drift ice transported by the East Greenland Current (Vibe 198I) presumably in early spring or they may have been stray bears coming from the West Ice after having crossed Baffin Bay. In his diary of March 1738 Poul Egede wrote that quite a number of white bears were killed that winter and that they arrived to Disko Island from the American side (Egede P. I74I:59). Judging by the few scattered bear remains, polar bear hunting was indeed a rare event at Nipisat. They were probably hunted with light spears or lances, and a couple of dogs may have assisted the Saqqaq hunter.

\section{Walrus}

Pinnipeds comprised $46.3 \%$ of the identified mammal bones found at Nipisat. Walrus remains comprised $3.8 \%$ of the total NISP of pinnipeds, if all walrus fragments are included. However, this frequency is reduced to only I.4\%, if ivory tools and ivory debitage are excluded.

\section{Age distribution}

The permanent maxillary canines erupting at an age of four months are made of dentine covered by a small cap of enamel, which is worn away in about two years (King I983). Phase 2 produced an aboral fragment of a tusk (dex), 389x/197y, from a subadult individual older than 2 years and an ulna (sin) deriving from a subadult individual of approximately 2-3 years. Those two specimens may derive from the same individual. Considering side and ontogenetic age of eight intact or 
A

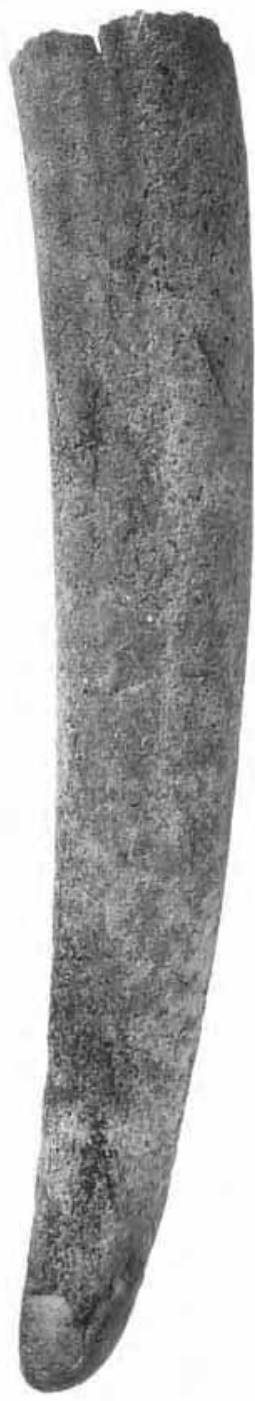

B

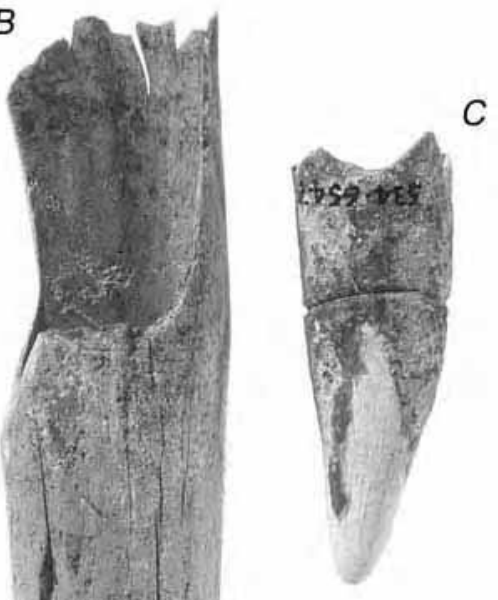

$B$

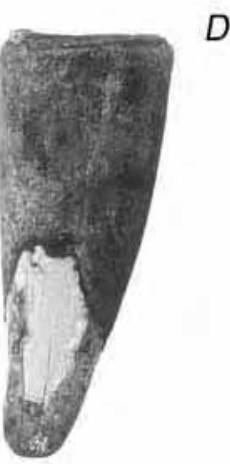

Fig. 156. Tusk from young walruses from phase 3. $\times 6538$ (A) and $\times 16762$ (B), worked orally, from subadults. Worked tusks from juveniles. $x 6547$ (C) with an incision and $x 6546$ (D) cut off orally. Scale $50 \mathrm{~mm}$. Photo: Geert Brovad. distal fragments of tusk from phase 3, at least 6 individuals are represented: two calves, two subadult and two adult animals. A $35 \mathrm{~mm}$ long tusk (sin), 389x/ I98y, with nearly unworn enamel derived from a few months old calf. A $46 \mathrm{~mm}$ long tusk (dex), 389x/ I93y, with some retained enamel at the apex is from a slightly older calf (Fig. I56, C). An intact $140 \mathrm{~mm}$ long juvenile tusk (dex), 388x/192y, still retaining some enamel at the apex is from an approximately $\mathrm{I}-\mathrm{I}^{\mathrm{I}} / 2$ year old individual (Fig. I56, A). The distal part of a worked tusk (dex), 388,07x/197,66y (Fig.I56, B) and the distal part of a tusk (sin), 391x/195y (Fig. I56, D) both with traces of enamel at the apex derive from individuals $\mathrm{c}$. two years old. In theory these two may derive from the same individual. Two left tusks account for at least two adult animals (Fig. I57, A and C).
The abovementioned age classes are reflected among the post-cranial bones. The frequencies of unfused skeletal elements are 10о\% $(\mathrm{N}=8), 67 \%$ $(\mathrm{N}=4)$ and $28 \%(\mathrm{~N}=\mathrm{I} 2)$ for phases $\mathrm{I}, 2$ and 3 respectively. The lower representation of unfused bones in phase 3 is probably due to an overrepresentation of rib fragments classified to be from adults even though fusion stages could not be properly assessed.

According to Müller (I906), walrus typically gave birth in March-April on the pack ice. He pointed out, however, that time of birth was variable and newborn calves were also seen during the autumn. A humerus (dex), phase 3, was of comparable size and ontogenetic age to a humerus of a modern calf killed in September (ZMUC Odobenus rosmarus CN 252) (Fig. I58) and supposedly derived from a calf younger than six 
Fig. 157. A collection of tusks and ivory debitage from tool production at Nipisat. $x 12184(A), \times 16709(B)$, note the groove marks, and $\times 12185(\mathrm{C})$ with natural wear of the apex. Photo: Geert Brovad.
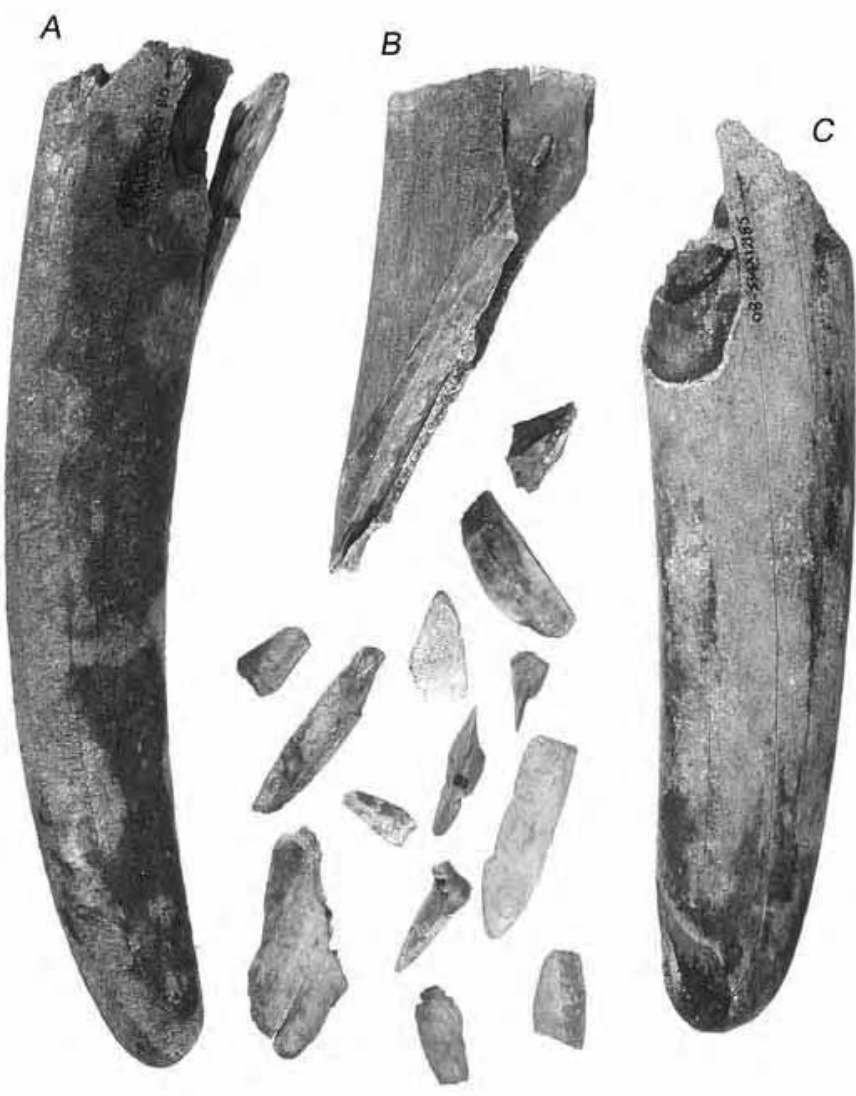

months most likely caught during autumn. One femur (dex), phase 3 was slightly larger than, and of an ontogenetic age comparable to, a modern calf c. one year old (ZMUC Odobenus rosmarus CN Ioor). Intact tusks of adult walruses may be strongly underrepresented in the assemblage because they were used for tool production. However, both tusks and post-cranial bones indicate a rather large proportion of juvenile and subadult individuals.

Bone element representation and horizontal distribution. Walrus bones and ivory debitage were present through all phases; although more abundantly in phase 3 (see Tables 35 and 36). The walrus remains were considered too scarce to calculate MNE and MAU. Bone elements representing the head, trunk (ribs), backbone, fore and hind limbs and extremities were retrieved (Table 36). Phalanges derived from both front and hind flippers. Maxillary bones consisted of small fragments of maxillare and premaxillare produced during extraction of the tusks. The relative frequencies of skeletal elements do not suggest a practice of bringing only the heads to the site. Nevertheless, bones of the backbone are clearly underrepresented, and primary butchering of the adult and subadults is presumed to have taken place at the kill site, while the calves may have been brought to the site as whole carcasses. At the Pita site (Fig. I, no. I7), for example, \%MAU indicated that head and limbs were the only walrus parts brought back to the camp (Nagy 1997). At Nipisat, cut marks were found on one fragment of the hyoid bone, phase I and dorsally at the phalanx of a front flipper in phase 3. These few traces were interpreted as filleting and skinning marks. This is consistent with observations made by LeMoine and Darwent (1998) at Late Dorset sites, Little Cornwallis Island, Canadian Central High Arctic. They interpreted cut marks on the bones to be primarily filleting marks rather than traces of dismembering.

The bone elements and whole tusks were scat- 


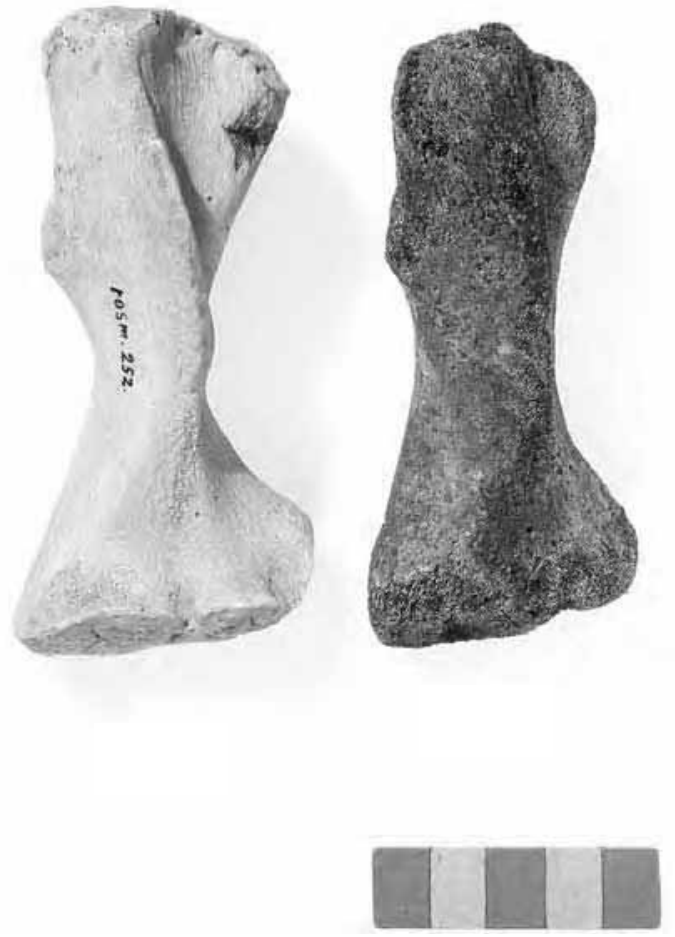

Fig. 158. The humerus of a walrus calf (right) from Nipisat, phase 3 and a walrus calf killed in September (left) (cranial view). Photo: Geert Brovad. tered all over the site (Fig. I59) and no particular areas of tusk extraction could be identified. The horizontal scattering of walrus remains indicates that walrus hunting took place on several occasions. In phase 3 , five concentrations of ivory debitage were evident in the northern part of the site especially in area 2 (Fig. I60). According to LeMoine and Darwent (I998:76) most ivory debitage was associated with warm-season features, and ivory working seems to be primarily a warm-season activity. It was suggested that walrus hunting took place in spring and summer and the ivory was used for tool production while still fresh and supposedly easier to handle (ibid.).

According to the relatively large number of both tusks and bones from young walruses, it is argued that the need for ivory may not have been the sole purpose for hunting walruses. Meat, blubber and hide were as important. Traditionally, the skins of foetuses or newborn calves were considered particularly well suited for making thongs (Born et al. 1994:22). The easy access to antler, which is a better tool material, may have reduced the need for ivory. However, the Nipisat inhabitants used tusk of all age classes for various purposes (Figs I56 and I57).

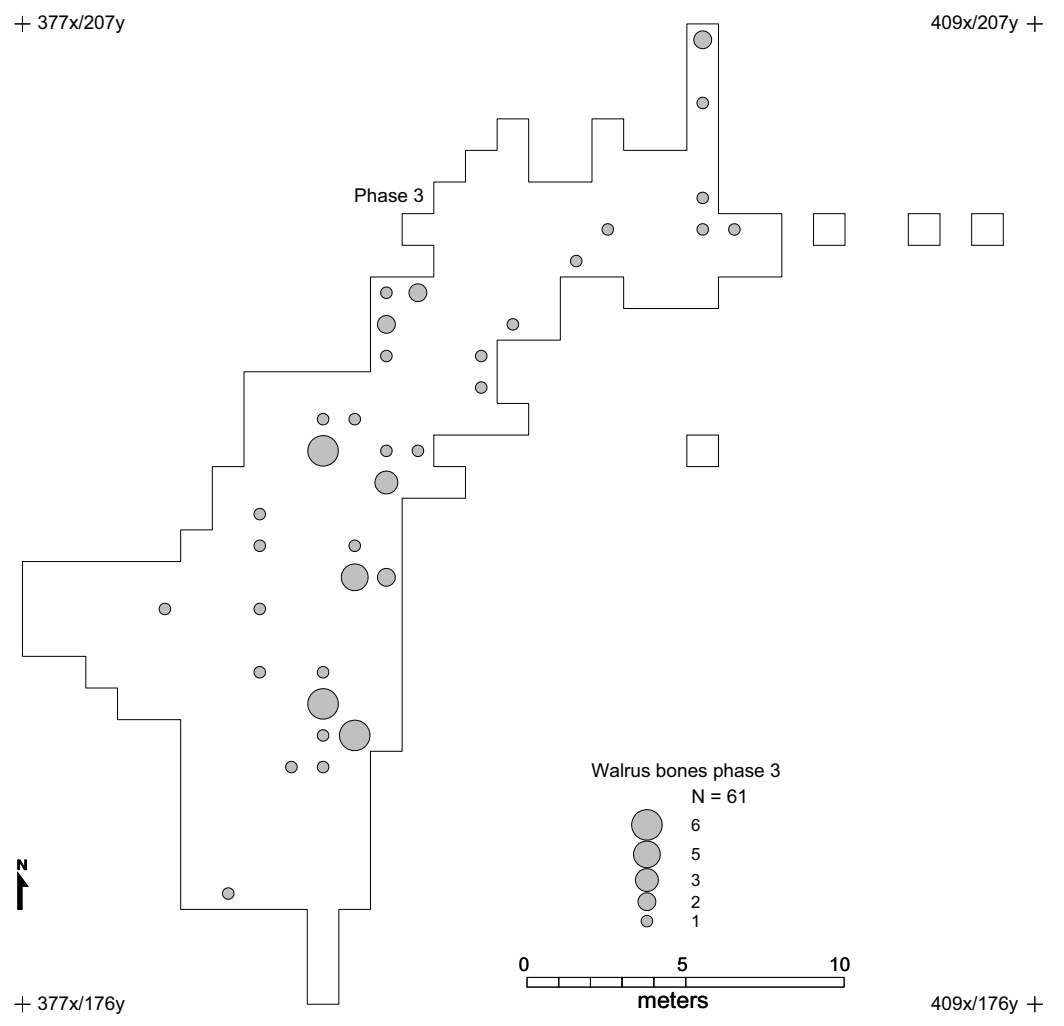

Fig. 159. Horizontal distribution of walrus bone elements in phase 3. (Data from Table 36). 
Table 36. Bones and teeth of walrus (Odobenus rosmarus) and their distribution by skeletal element and phase. Numbers in parentheses include ivory tools and ivory debitage (not included in relative frequencies).

\begin{tabular}{|c|c|c|c|c|c|c|c|c|}
\hline & \multicolumn{2}{|c|}{ Phase 1} & \multicolumn{2}{|c|}{ Phase 2} & \multicolumn{2}{|c|}{ Phase 3} & \multicolumn{2}{|c|}{ Total } \\
\hline & NISP & $\%$ & NISP & $\%$ & NISP & $\%$ & NISP & $\%$ \\
\hline Calvarium & - & - & - & - & 6 & 8.9 & 6 & 6.1 \\
\hline Maxillare & 13 & 59.1 & - & - & 6 & 8.9 & 19 & 19.4 \\
\hline Mandibula & - & - & - & - & 1 & 1.4 & 1 & 1.0 \\
\hline Os hyoideum & 1 & 4.6 & - & - & - & - & 1 & 1.0 \\
\hline Postcaninus & - & - & - & - & 4 & 5.8 & 4 & 4.1 \\
\hline Tusk & - & - & 1 & 14.3 & 8 & 11.6 & 9 & 9.2 \\
\hline Tusk unsp. & $7 *$ & - & $7^{*}$ & - & $151^{*}$ & - & $165^{*}$ & - \\
\hline V. cervicalis & - & - & 1 & 14.3 & - & - & 1 & 1.0 \\
\hline V. thoracica & - & - & 1 & 14.3 & 2 & 2.9 & 3 & 3.1 \\
\hline V. lumbalis & - & - & - & - & 2 & 2.9 & 2 & 2.0 \\
\hline V. unsp. & - & - & - & - & 3 & 4.3 & 3 & 3.1 \\
\hline Costa & 1 & 4.6 & 1 & 14.3 & 14 & 20.3 & 16 & 16.3 \\
\hline Humerus & - & - & - & - & 1 & 1.4 & 1 & 1.0 \\
\hline Radius & - & - & - & - & 1 & 1.4 & 1 & 1.0 \\
\hline Ulna & - & - & 1 & 14.3 & - & - & 1 & 1.0 \\
\hline Metacarpale & - & - & 1 & 14.3 & 3 & 4.3 & 4 & 4.1 \\
\hline Carpus & - & - & - & - & 1 & 1.4 & 1 & 1.0 \\
\hline Femur & - & - & - & - & 1 & 1.4 & 1 & 1.0 \\
\hline Phalanges & 7 & 31.8 & 1 & 14.3 & 16 & 23.2 & 24 & 24.5 \\
\hline Total & $22(29)$ & 100 & $7(14)$ & 100 & $69(220)$ & 100 & $98(263)$ & 100 \\
\hline
\end{tabular}

* Ivory tools and ivory debitage.

Fig. 160. Horizontal distribution of walrus ivory in phase 3. Ivory fragments comprise tools and ivory debitage while specimens of intact or nearly intact tusk could be identified to side and in some instances aged. (Data from Table 36).

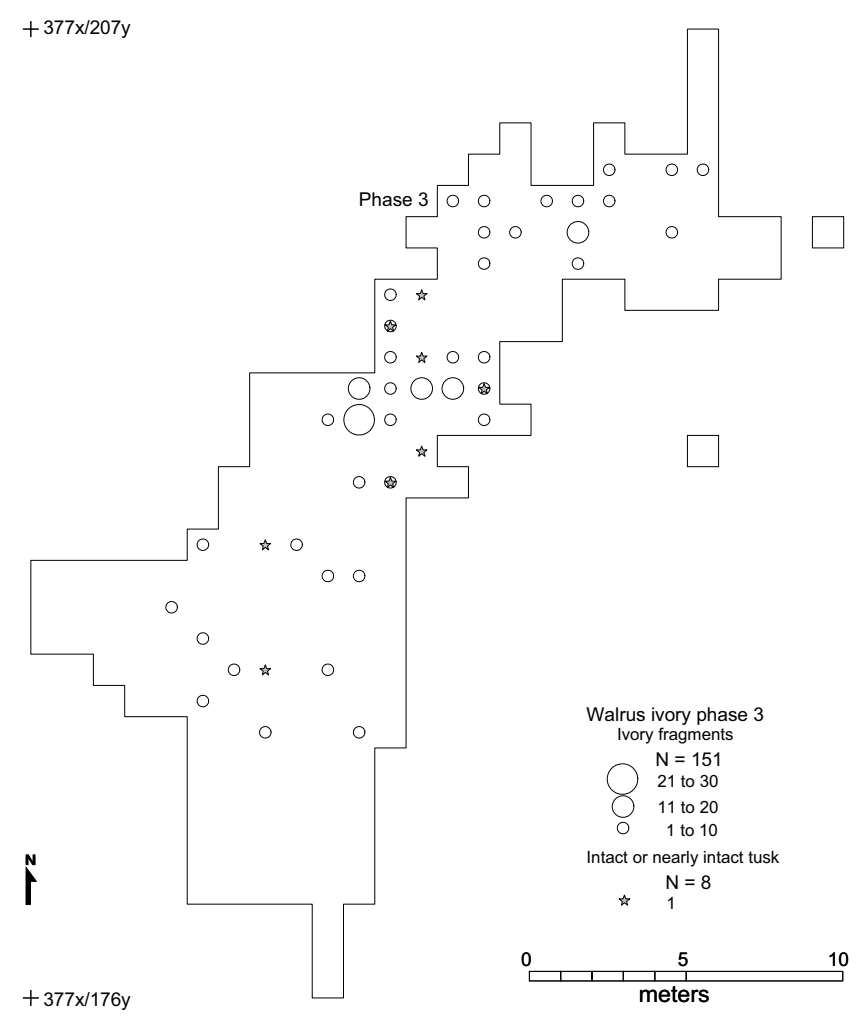

$409 x / 207 y+$ 
Seasonal occurrence of walruses in the Sisimiut District. Walruses are among the most gregarious of sea mammals and tend to travel in small groups and haul out on land in large herds of up to several thousand (Fay 198I). The calf stays with its mother for at least two years and is defended with vigour. After separation from the mother, the subadults, especially the young females, tend to stay with groups of adult females (Fay I98I).

At the shallow banks along the coast of Central West Greenland, between approximately $66^{\circ} \mathrm{N}$ and $70^{\circ} 45^{\prime} \mathrm{N}$, walruses have long been known to occur mainly in winter and spring (e.g. Müller 1906; Freuchen I92I; Vibe 1956) (Fig. 6). Because of their diet walruses are attached to coasts with extensive areas of even sea bottom of depths less than $80 \mathrm{~m}$ (Vibe 1956:82). Around the end of the $19^{\text {th }}$ century, walruses reportedly hauled out at several places between c. $67^{\circ} 25^{\prime} \mathrm{N}$ and $67^{\circ} 47^{\prime} \mathrm{N}$ from October to April-May (Müller 1906). At the entrance of Nassuttooq, kept ice-free during winter by strong tidal currents (Freuchen and Salomonsen I96I), walruses were known to occur in large numbers especially at Illorsuit, Simiuttat and Taseralik (Fig. 3) (see Born et al. 1994). All age groups of both sexes were present at haul outs at that time of year (Müller 1906). North of Sisimiut at the entrance of Kangerluarsuk Ungalleq (Nordre Bredebugt) and Kangerluarsuk Tulleq (Søndre Bredebugt) walruses occurred on islands mainly as mixed herds of adult females with subadults and calves during spring (Müller 1906). The walruses retreated from the coastal areas in April to stay in the pack ice of the West Ice off shore during summer (Müller 1906). The arrival of walruses in Central West Greenland is dependent on the timing of build up of pack ice in the West Ice. At the beginning of the $2 \mathrm{O}^{\text {th }}$ century, arrival and departure in Central West Greenland was August and June respectively. After the increase of sea temperatures in the 1920's (e.g. Vibe 1967), the arrival occurred later in the autumn about October-November and departure was earlier in the spring, about May (Born et al. 1994). This change in seasonal arrival and departure of walruses in Central West Greenland was supposedly caused by climatic changes (Born et al. I994). The migration pattern of walrus was probably similar when Nipisat was inhabited, although the exact timing of arrival and departure may have varied.
Walrus hunting season and methods. In historical times, the Greenlanders were known to gather in autumn, usually in October, to participate in communal hunting at haul-outs near the entrance of Nassuttooq. Due to adverse weather conditions prevailing during autumn, the catches varied in size because of limited access to the haul-outs and failure in retrieving the shot animals (Müller 1906). In modern times walrus hunting in the Nuuk - Aasiaat area takes place from March to May with maximum catches in April (Born et al. 1994:fig. I3 A). In April, reproductive females were selectively hunted because they occurred closer to the coast while the males occurred further offshore (Born et al. 1994:22). Furthermore the female were considered economically more valuable because they yielded relatively more blubber and their tusks were better suited for tool making, as they had fewer cracks (Born et al. 1994:25). Hunters in the Aasiaat District were said to prefer females, because the ivory of female tusks is softer and tougher than male tusks (C. Andreasen pers. comm. 2003).

In a sample of 26 walruses (Io males and I6 females), caught in March-April in the I980's between Sisimiut and Attu, 2 (8\%) were subadults of 3-4 years while 24 (92\%) were adults more than eight years old (Born et al. 1994:fig. 14). The age distribution at Nipisat (Fig. 16I) differed markedly from the age distribution in modern catches. This may to some extent be a result of unintentional selective hunting. The inexperienced juveniles were easier to hunt, however females with their calves would still demand very skilled hunters.

In conclusion the age distribution and the relative distribution of skeletal elements reflected local hunting. Good feeding opportunities for walruses existed in the surroundings of Nipisat and, with suitable undisturbed islands where currents keep the water open during winter; walruses may have hauled out on land very close to Nipisat from mid autumn to April-May. At the beginning of the $2 \mathrm{O}^{\text {th }}$ century, walrus hunting still took place near Maniitsorsuaq north of Nipisat in April-May (Born et al. 1994:7). Müller (1906) reported that communal hunting from kayaks, especially for females and young, was more common than hunting on land or ice. At Nipisat walruses, adults, females with their calves and inexperienced subadults were hunted either in the surrounding waters or when haul- 
Fig. 161. The age distribution of walrus tusks at Nipisat showed a preponderance of juvenile individuals.

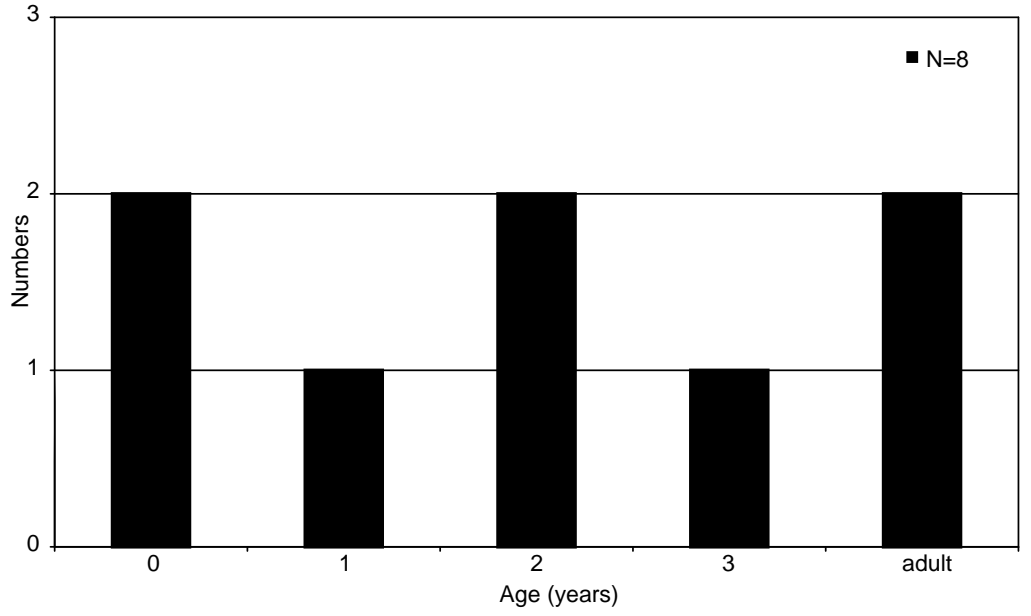

ing out on skerries or islands in the vicinity. The distribution of walrus bones and tusks at the site, both stratigrafically through all occupation phases and horizontally in phase 3 , indicates that walrus hunting took place from time to time throughout the occupation of the island. The difficulty in estimating the exact age of the retrieved juvenile tusks and the variable birth time complicates the assessment of the hunting season. Spring is suggested as the primary hunting season because of the calmer weather conditions and a greater need for fresh meat and blubber at that time of year. Autumn hunting cannot, however, be excluded.

\section{Seals}

In total 69I4 pinniped fragments were retrieved from the Nipisat site of which 6639 (96\%) derived from small seals Phoca spp. Next to caribou, seals comprising c. $45 \%$ of the mammals (Table 35 ) were important for the Nipisat people, contributing meat, blubber, blood and hide. All the Greenland seal species were present at Nipisat, although in very different numbers. The key species was common seal (Phoca vitulina) followed by harp seal (Phoca groenlandica). Bones of ringed seal (Phoca hispida), bearded seal (Erignathus barbatus) and hooded seal (Cystophora cristata) are scarce in the assemblage (Tables 35 and 40).

\section{The common seal}

Ageing of seals based on fusion data. The age distribution of seals was based on fusion patterns of seal femora. The femur was chosen for several reasons: i) fusion data for this element is available, ii) reliable measurements can be taken on the femur and iii) it is well rep- resented in the Nipisat assemblage (Table 37). Fusion data was obtained for Baltic common seals (Phoca vitulina vitulina) (Storå 20or). Although the fusion data were obtained for another subspecies of common seal than the common seal occurring in Greenland waters, it was considered safe to apply the relatively crude fusion pattern. According to Storå (200I), the earliest and latest fusion time of the proximal femoral epiphyses is 2.25-4 years and of the distal femoral epiphysis it is 4-6 years. All intact or nearly intact femora of the Nipisat seals assigned to species or to Phoca spp. were examined. From Fig. I62 it is seen that 93\% (N=I03) of the seals from the whole site were younger than approximately 4 years, which is the latest date of epifyseal fusion of the proximal femur. Comparisons of the morphology of the unfused seal femora and extant comparative skeletons of ringed seal, harp seal, and common seal confirmed the relative distribution of seals obtained from easily identifiable skeletal elements (see p. 92). Only one juvenile unfused harp seal femur was identified (see Fig. I65) while the remaining femora conformed to the morphology of the common seal.

The depth and breadth of the diaphysis of all unfused seal femora were measured according to the guidelines of Rowley-Conwy and Storå (1997) and plotted for each phase (Figs I63-I65). It is assumed that the size clusters reflect age classes of juvenile seals. The largest group consists of new born to pups a few months old while the subsequent clusters comprise yearlings, two year old juveniles, and three year old subadults caught before fusion of the epiphyses had started (Fig. I66). Some individuals from the last 
口Unfused Prox fused

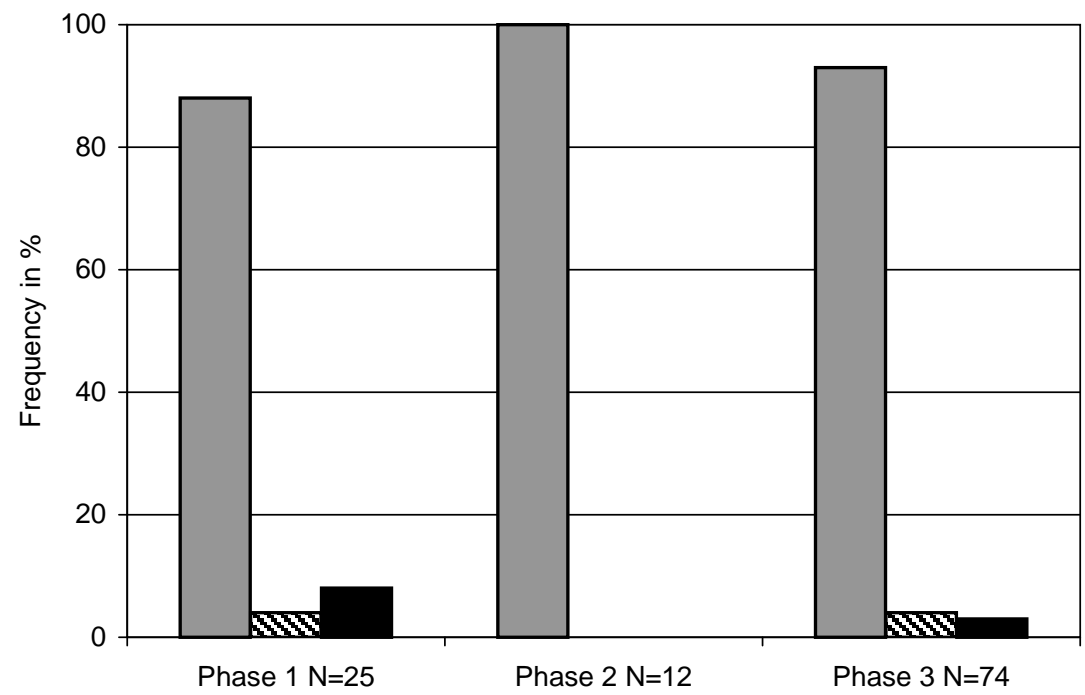

Fig. 162. Age distribution of seals at Nipisat. The unfused portion comprises newborn and juvenile seals up to an age of four years. The portion with the proximal epiphysis fused comprises subadults three to six years old. Femora with both ends fused comprise adult seals at least four years old. Overlapping ages categories are due to earliest and latest fusion dates of proximal and distal epiphyses (see text for explanation). age class may already have had fused proximal epiphyses and were therefore not measured. The largest group representing neonatals and pups a few months old exhibits the largest size variation both in terms of depth and breadth of the femoral diaphysis, while the successive groups show less variation (see Figs 163I65). This pattern clearly reflects a postnatal growth characterized by a rapid increase in body size and weight recorded for all seal species, while later in life growth continues in progressively slower rates (e.g.
Bryden I972; Härkönen and Heide-Jørgensen 1990). The segregation between groups is not clear, which may be explained by a size overlap between age groups and/or seals hunted outside the primary hunting season. However, the first option is in accordance with observations of Baltic seal populations where there is a considerable overlap in body size between skeletal age groups (Storå 200I). This pattern is most clearly seen in phase 3 (Fig. 165) but the same tendency is also visible in phases I and 2 (Figs I63 and I64).

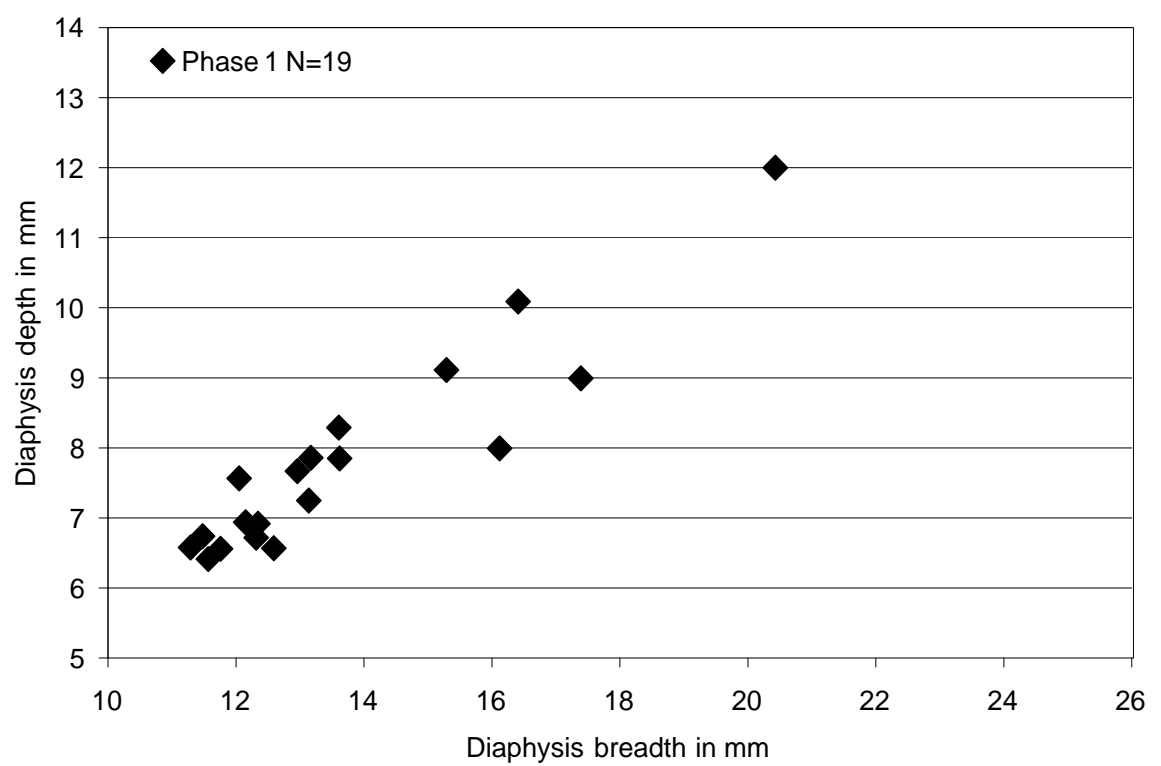

Fig. 163. Size distribution of juvenile phocid femora with unfused epiphyses from phase 1. Based on diaphysis depth and breadth. 
Fig. 164. Size distribution of juvenile phocid femora with unfused epiphyses from phase 2. Based on diaphysis depth and breadth.

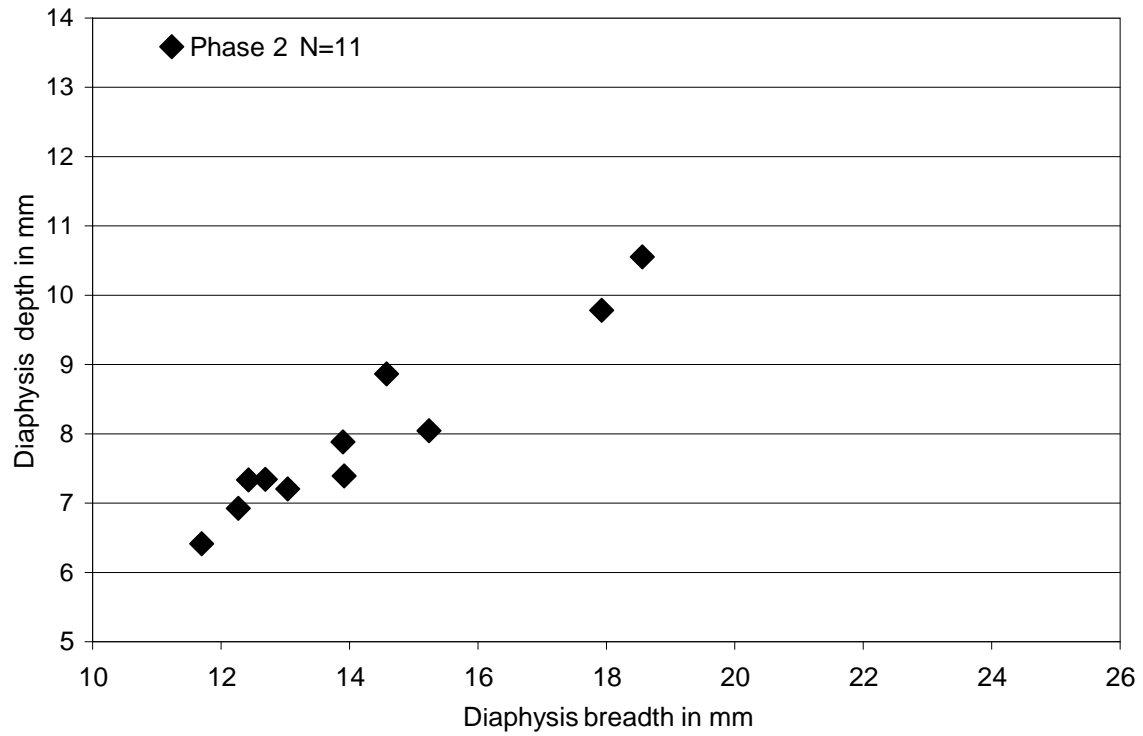

For many skeletal elements, the assignment to the correct age category is problematic because proper age determination of certain bone elements is difficult (e.g. Nagy 1997). For the entire seal skeletal assemblage, this would result in an overrepresentation of bones assigned to the adult age group. This trend is most clearly seen when the relative frequency of NISP values of adult seal bones (42\%) and the sum of NISP values of bones of neonatals, juveniles, and subadults (58\%) are compared with the results based on femoral fusion data (Fig. I62). However, the distribution of age classes extracted from femur fusion data is expected to be representative for the age distribution for other skeletal elements of the Nipisat seals.

Bone element representation of seals. The phocids (common seal, ringed seal, harp seal and Phoca spp.) are treated together in the following paragraph. The most frequent anatomical groups for all seals based on NISP are cranial bones, loose teeth, vertebrae, ribs, and pha-
Fig. 165. Size distribution of juvenile phocid femora with unfused epiphyses from phase 3. Based on diaphysis depth and breadth. The arrow indicates the femur of a harp seal (Phoca groenlandica).

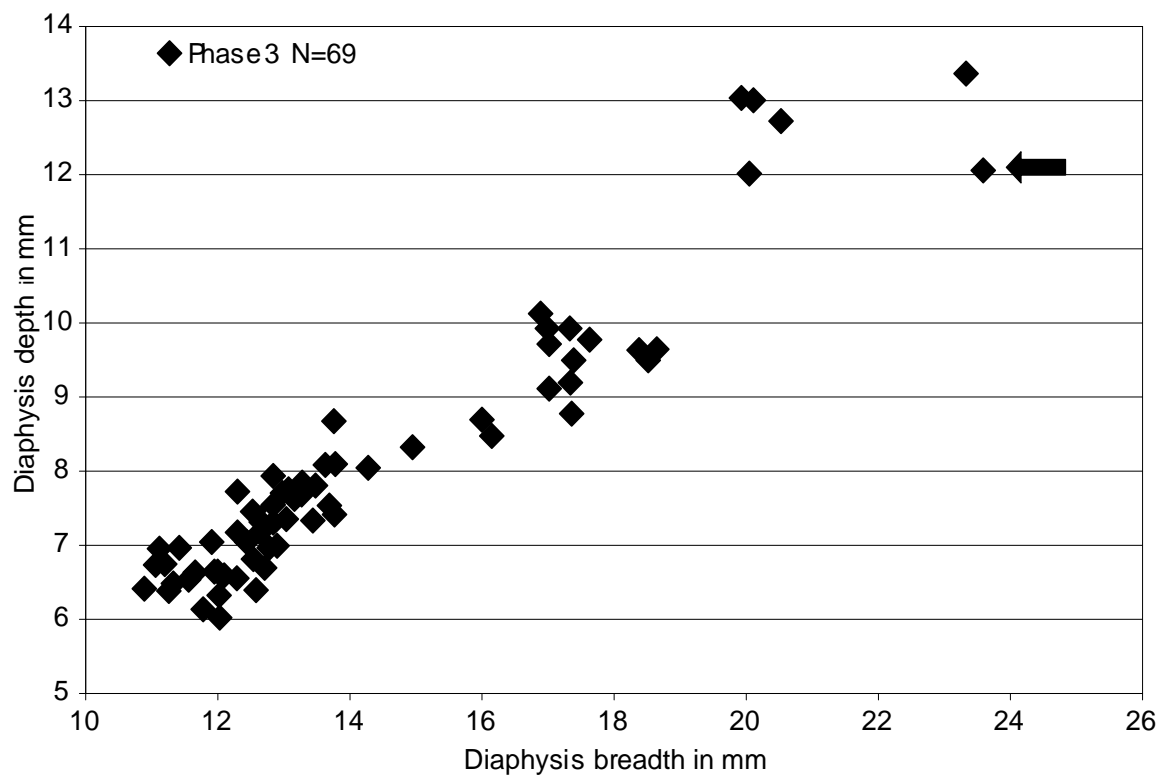


Museum Tusculanum Press - University of Copenhagen :: www.mtp.dk :: info@mtp.dk

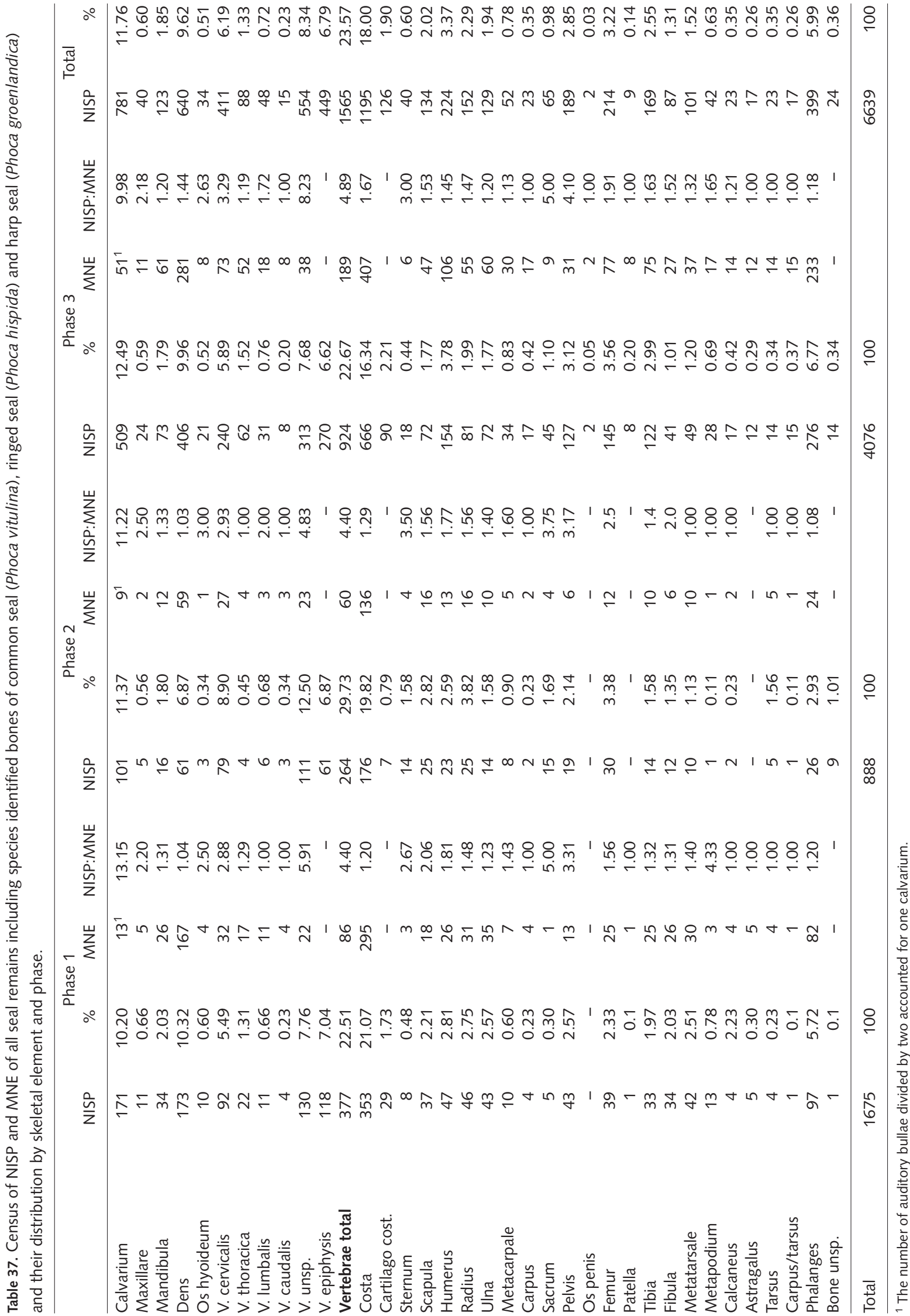


Table 38. MAU and \%MAU of all small seals Phoca spp. MAU is based on MNE values from Table 37.

\begin{tabular}{|c|c|c|c|c|c|c|}
\hline & \multicolumn{2}{|c|}{ Phase 1} & \multicolumn{2}{|c|}{ Phase 2} & \multicolumn{2}{|c|}{ Phase 3} \\
\hline & MAU & $\% M A U$ & MAU & $\% M A U$ & MAU & $\% M A U$ \\
\hline Calvarium $(1)^{1}$ & 13 & 74.3 & 9 & 100 & 51 & 96.2 \\
\hline Mandibula (2) & 13 & 74.3 & 6 & 66.7 & 30.5 & 57.5 \\
\hline V. cervicalis (7) & 4.6 & 26.3 & 3.9 & 43.3 & 10.4 & 19.6 \\
\hline V. thoracica (15) & 1.1 & 6.3 & 0.3 & 3.3 & 3.5 & 6.6 \\
\hline V. lumbalis (5) & 2.2 & 12.6 & 0.6 & 6.7 & 3.6 & 6.8 \\
\hline V. caudalis (11) & 0.4 & 2.3 & 0.3 & 3.3 & 0.7 & 1.3 \\
\hline Costa (30) & 9.8 & 56 & 4.5 & 50 & 13.6 & 25.7 \\
\hline Sternum (8) & 3 & 17.1 & 4 & 44.4 & 6 & 11.3 \\
\hline Scapula (2) & 9 & 51.4 & 8 & 88.9 & 23.5 & 44.3 \\
\hline Humerus (2) & 13 & 74.3 & 6.5 & 72.2 & 53 & 100 \\
\hline Radius (2) & 15.5 & 88.6 & 8 & 88.9 & 27.5 & 51.9 \\
\hline Ulna (2) & 17.5 & 100 & 5 & 55.6 & 30 & 56.6 \\
\hline Metacarpale (10) & 0.7 & 4 & 0.5 & 5.6 & 3 & 5.7 \\
\hline Carpus (14) & 0.3 & 1.7 & 0.1 & 1.1 & 1.2 & 2.3 \\
\hline Sacrum (1) & 1 & 5.7 & 4 & 44.4 & 9 & 17 \\
\hline Pelvis (2) & 6.5 & 37.1 & 3 & 33.3 & 15.5 & 29.2 \\
\hline Femur (2) & 12.5 & 71.4 & 6 & 66.7 & 38.5 & 72.6 \\
\hline Patella (2) & 0.5 & 2.9 & - & - & 4 & 7.5 \\
\hline Tibia (2) & 12.5 & 71.4 & 5 & 55.6 & 37.5 & 70.8 \\
\hline Fibula (2) & 13 & 74.3 & 3 & 33.3 & 13.5 & 25.5 \\
\hline Metatarsale (10) & 3 & 17.1 & 1 & 11.1 & 3.7 & 7 \\
\hline Calcaneus (2) & 2 & 11.4 & 1 & 11.1 & 7 & 13.2 \\
\hline Astragalus (2) & 2.5 & 14.3 & - & - & 6 & 11.3 \\
\hline Tarsus (10) & 0.4 & 2.3 & 0.5 & 5.6 & 1.4 & 2.6 \\
\hline Phalanges (56) & 1.5 & 8.6 & 0.4 & 4.4 & 4.2 & 7.9 \\
\hline
\end{tabular}

${ }^{1}$ designates the number of that particular skeletal element in a complete phocid skeleton.

langes (Tables 37 and 38). Applying MNE and MAU according to the definitions of Diab (I998) to the seal bone assemblage compensated to some degree for fragmentation and the large number of juvenile unfused bones (expressed by the NISP:MNE ratio) (Table 37). All body parts of seals were represented in
Fig. 166. Size classes of juvenile common seals at Nipisat. Femora of a newborn $(A)$, one year old (B), two years old $(C)$, and a three to six years old individual (D), where fusion of the proximal epiphysis have started (caudal view). Sizes of the femora A-D correspond with the four size clusters in Figs 163-165, respectively. Note cut marks proximally below the caput femoris (B). Photo: Geert Brovad.

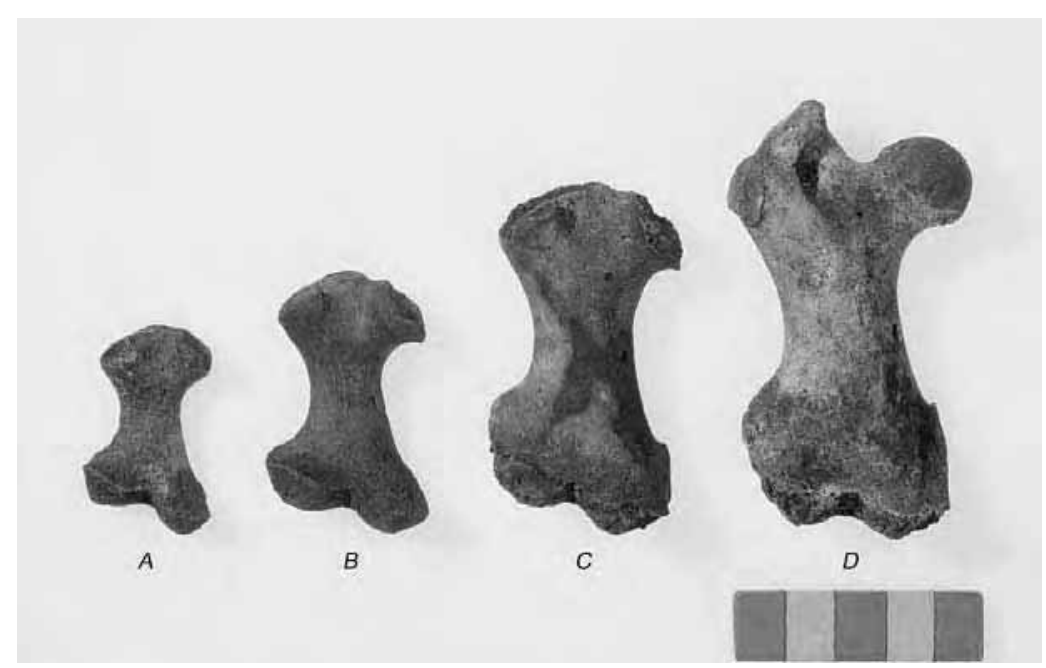




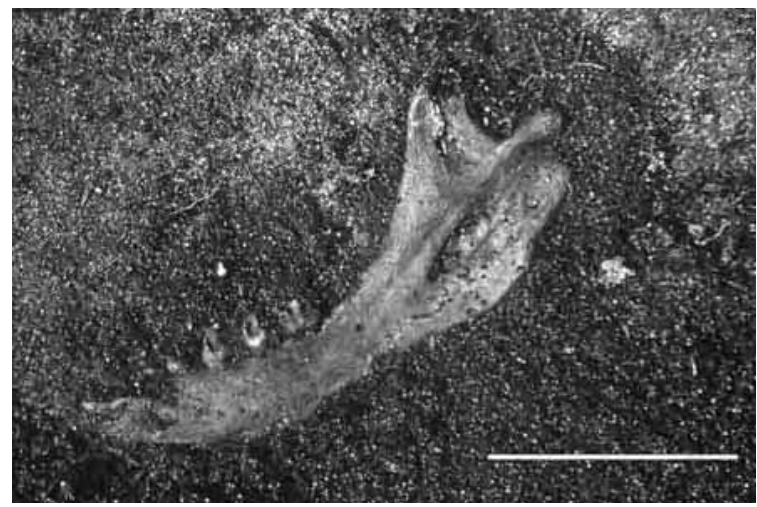

Fig. 167. Most seal bones were intact or unintentionally broken. Here a complete right mandible of a common seal (Phoca vitulina) in situ. Scale 50 mm. Photo: Sönke Hartz.

the deposits. Calvarium, mandibula (Fig. 167) and most of the appendicular limb bones e.g. the humerus, radius, ulna, femur, tibia, fibula, and the scapula were almost equally represented while the backbone, metapodials and the phalanges were underrepresented (Table 38 and Fig. I68). The reason why the backbone is underrepresented compared to ribs and pelvis is to some extent due to the many unfused vertebrae, which may have deflated the MNE count. To account for that tendency, Diab (1998:8) suggested that agespecific \%MUI (meat utility indices) would be useful for isolating specific body part treatment of smaller and larger seals otherwise differences in culling and transport would be masked. Body part preference may also be influenced by other factors than meat weight, for instance type of processing (roasting, boiling, drying, raw or pickled) and taste preference (Diab 1998:I2). The Nipisat seal sample was not broken down into age classes for the purpose of calculating MAU because the assemblage was completely dominated by young seals.

There seems to be little variation between the three phases, each showing roughly the same pattern (Table 38 and Fig. I68). The slightly better representa-

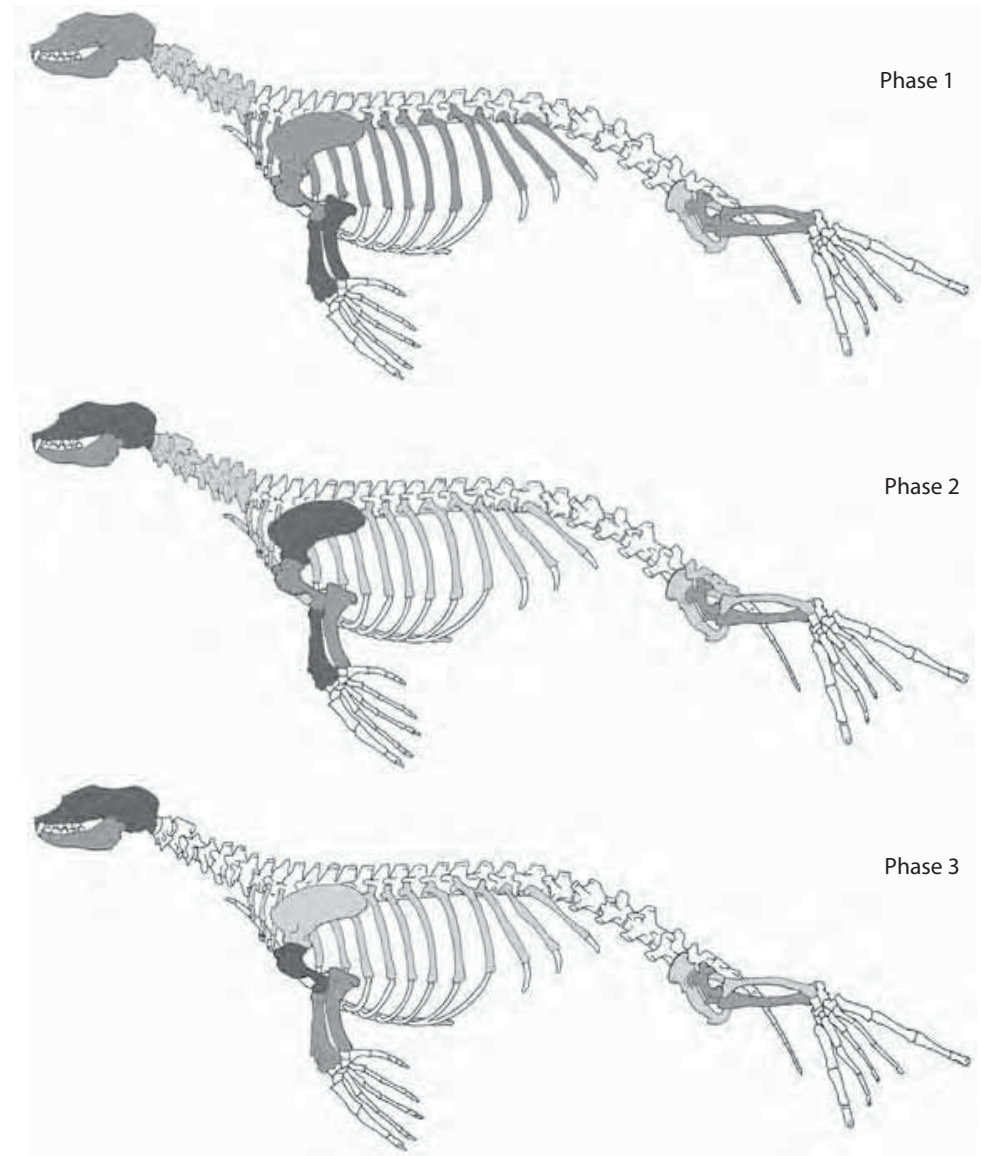

$0-25 \%$ $26-50 \%$ $51-75 \%$
Fig. 168. Relative frequencies of seal bone elements at Nipisat. All phocids bones were pooled. The frequencies are \%MAU from Table 38. 
Table 39. Summary of alterations of bones from all small seal species retrieved from the Nipisat site (NISP=6639).

\begin{tabular}{|c|c|c|c|c|c|c|c|c|}
\hline & \multicolumn{4}{|c|}{ Gnawing } & \multicolumn{4}{|c|}{ Cut marks } \\
\hline & Phase 1 & Phase 2 & Phase 3 & Total & Phase 1 & Phase 2 & Phase 3 & Total \\
\hline Calvarium & & & & & 2 & 1 & & 3 \\
\hline Mandibula & & & & & & & 1 & 1 \\
\hline V. unsp. & 6 & & 3 & 9 & & & & \\
\hline V. thoracica & 1 & & 1 & 2 & & & & \\
\hline V. lumbalis & 1 & & & 1 & & & & \\
\hline Costa & 9 & 1 & 13 & 23 & 3 & 1 & 2 & 6 \\
\hline Scapula & & 1 & 1 & 2 & & & & \\
\hline Humerus & 4 & 3 & 8 & 15 & & & 1 & 1 \\
\hline Radius & 3 & 1 & & 4 & & & & \\
\hline Ulna & 5 & & 3 & 8 & & & & \\
\hline Metacarpale & & & & & & & 1 & 1 \\
\hline Pelvis & & & 1 & 1 & & & & \\
\hline Femur & 1 & 1 & 1 & 3 & 3 & 2 & 7 & 12 \\
\hline Tibia & 1 & 1 & 4 & 6 & & & & \\
\hline Fibula & 1 & & & 1 & & & & \\
\hline Metatarsale & & 1 & & 1 & & & & \\
\hline Phalanx & & & 1 & 1 & & & & \\
\hline Total & 32 & 9 & 36 & 77 & 8 & 4 & 12 & 24 \\
\hline$\%$ NISP & 1.9 & 1.0 & 0.9 & 1.2 & 0.5 & 0.5 & 0.3 & 0.4 \\
\hline
\end{tabular}

tion of ribs in phase I may be due to chance or the fact that preservation conditions were generally better in the lower layers. The rib cage, neck, and lumbar pelvic region of ringed seals account for a large proportion (47-57\%) of the total amount of flesh of a seal (Diab I998:8). Despite some morphological differences in the musculature and anatomy, particularly in the forelimb of ringed and harp seals, the distribution of flesh is similar for the two species (Diab I998:Io). This distribution of flesh is assumed to be valid for the common seal too. The neck vertebrae (v. cervicales), ribs and the pelvis are relatively well represented, in most cases $26-50 \%$ (Fig. I68) and for ribs $5 \mathrm{I}-75 \%$ in phase I (Fig. 168). This indicates that seals were brought to the site whole and were butchered and probably eaten on site. This would be expected because pups dominate the seal assemblage. The common seal pup has a mean body weight of $28 \mathrm{~kg}$ at the time of weaning, compared to an adult female of about $70 \mathrm{~kg}$ (Born 200I). Intrasite and interhousehold transport may have more influence on the movement of carcass parts, especially for small to medium sized animals, which would have arrived at the site intact. Larger animals would have been butchered at the kill site and selected parts only would have been transported home (Marshall and
Pilgrim I99I). When the Saqqaq people first settled on Nipisat, the site was situated close to the sea level (Fig. I96) and killed seals could easily be dragged to the camp from the kayaks.

Underrepresentation of certain bone elements in the assemblages can partly be explained by size and density of the bone in question. Density mediated attrition would lead to an overrepresentation of appendicular elements because they are denser than, e.g. elements from the axial skeleton (Diab 1998). At Nipisat, dogs or humans may have chewed or swallowed small bones, e.g. of flippers. In total I.2\% (Table 39) of the seal bones had gnawing marks, demonstrating a low frequency of carnivore attrition. This low incidence of damage, presumably by carnivores, is in accordance with observations from Canadian PalaeoEskimo sites at Ivujivik with carnivore damage varying between 0.17 and 1.04\% (Nagy 1997). Some of the meat rich portions of the seals may have been removed as provisions when moving on to another camp, thus accounting for the under-representation of certain bone elements.

Only two seal bacula (os penis) were retrieved from the site (Table 37). Seal bacula consist of a tough and compact material and were often used for tool 

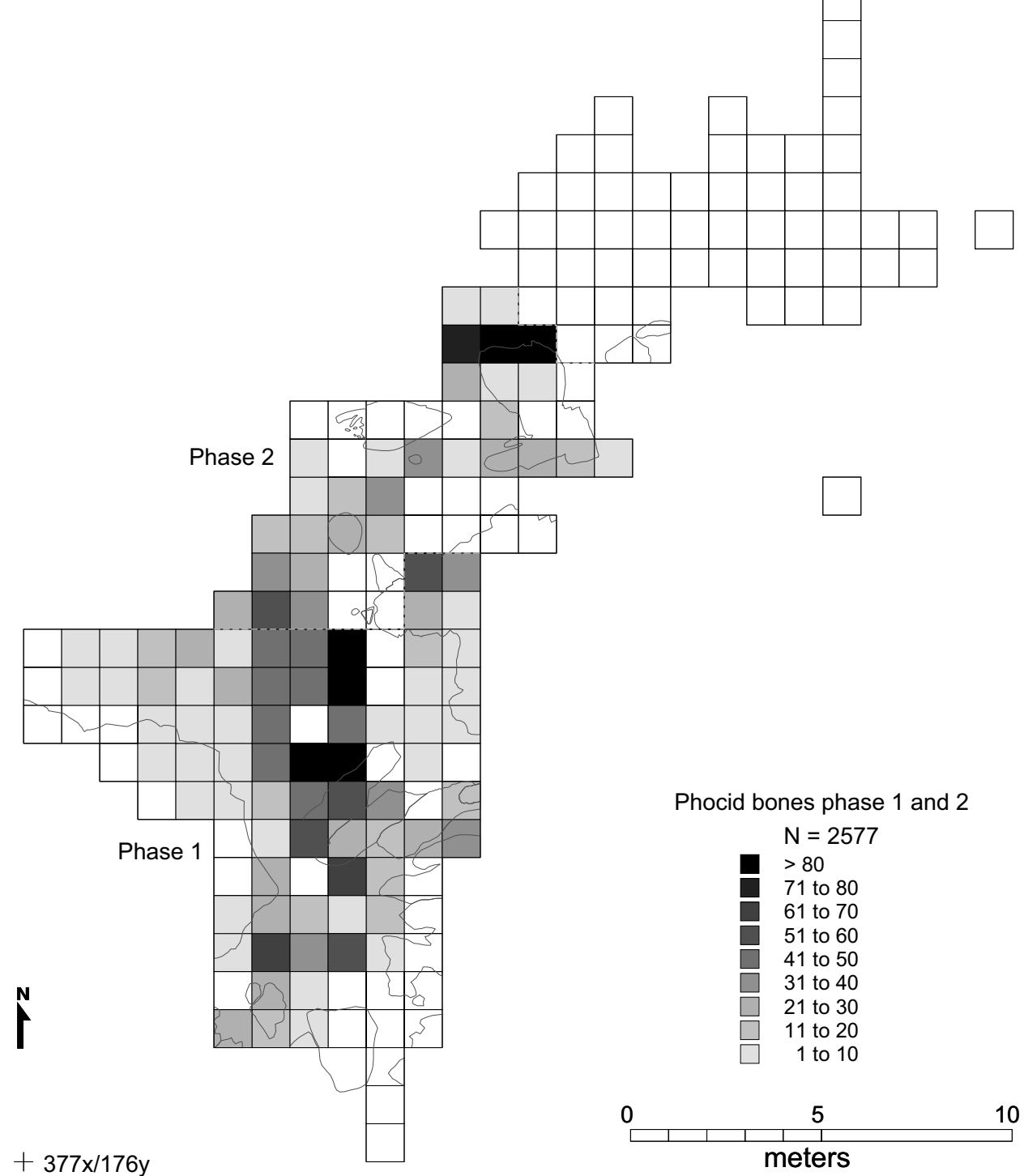

Fig. 169. Horizontal distribution of phocid bones (Phoca spp.) comprising all bone fragments and teeth of small seals in phase 1 and 2 .

production by Neo-Eskimos. The scarcity of bacula is not accounted for in the collection of artefacts and debitage of tool manufacturing of the Nipisat assemblage. A low incidence of bacula was also noted at a Dorset dwelling, Newfoundland (Murray 1992) and at several Pre-Dorset/Dorset Transitional sites consisting almost exclusively of ringed seal remains (Nagy 1997). The notion put forward by Nagy (I997) that relative lack of bacula should be due to the practice of removing the baculum of male seals prior to transporting seems unlikely in explaining the scarcity of bacula at Nipisat.
Horizontal seal bone distribution on the site. The seal bones were scattered all over the site, however some concentrations could be identified both in the early phases (Fig. 169) and the late phase (Fig. I70). The distribution of individual body parts (e.g. bones of head, trunk, front and hind limbs) present the same pattern as observed for seal bones as a whole. In the southern part of the site in phase I (area I), there seems to be some concentration of bones close to the hearth (Fig. I69). In the central part of the site, area I, there were several squares with high frequency of bones, which to some degree reflects the thickness of the deposits. No 


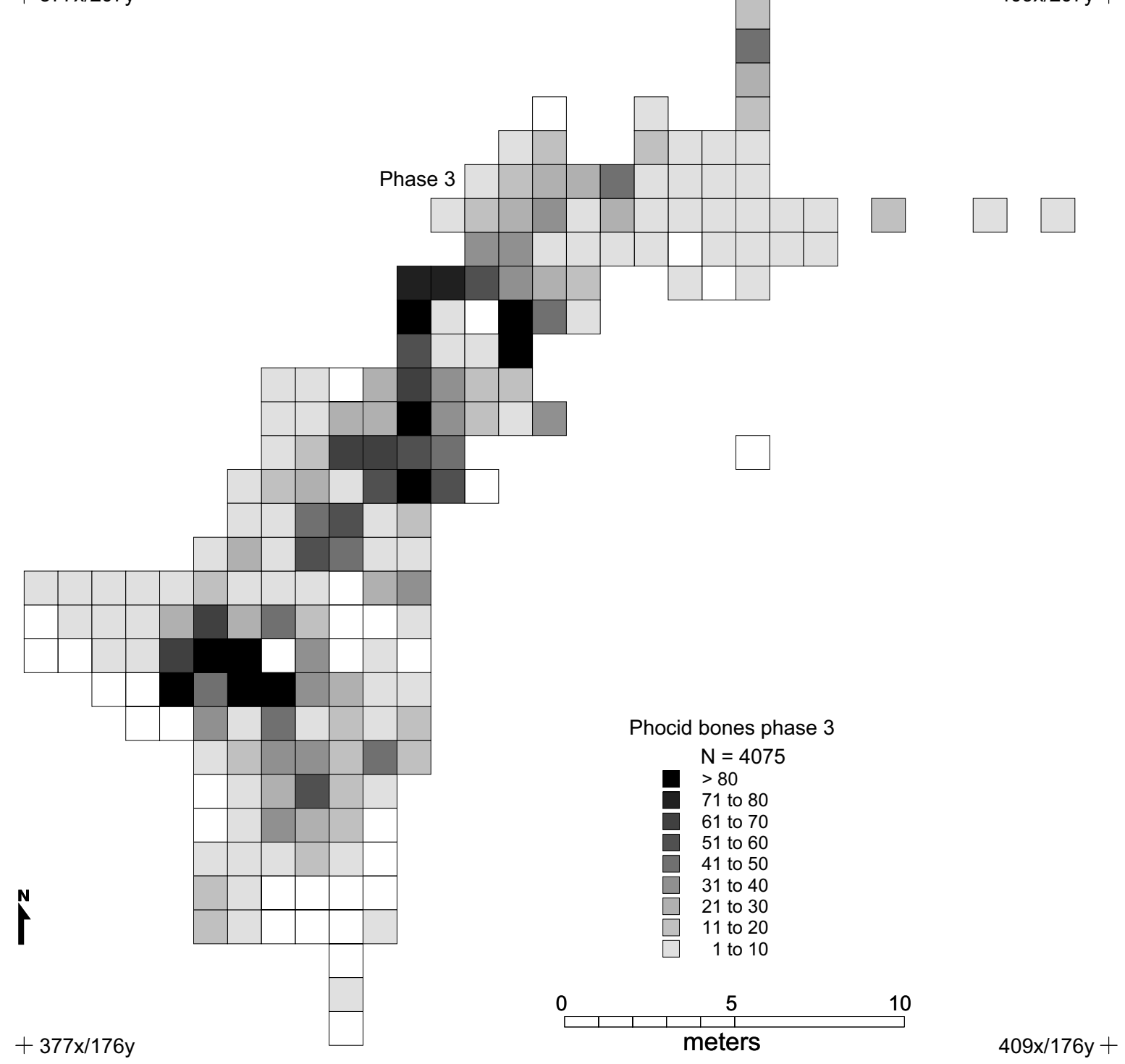

Fig. 170. Horizontal distribution of phocid bones (Phoca spp.) comprising all bone fragments and teeth of small seals in phase 3 .

particular concentration associated with the hearth in phase 2 (area 2) could be detected. The scattering of bones over the entire site with no particular patterning of individual body parts would be expected because the bones accumulated over such a long period of time.

Bone alterations. Only one seal bone (a rib $(385,78 \mathrm{x}$ / I87,46y)), phase I, was charred. Similar low incidences of burnt bones were reported from Ivujivik, which had 0.3 to I.96\% burnt seal bone (Nagy 1997). The near absence of charred bones at Nipisat is a strong indication that the meat was boiled and not roasted at the site and/or smoked and dried and subsequently removed from the site as provisions and for storage. Cut marks were found on $0.4 \%$ of the bones (Table 39). Scarcity of cut marks was also recorded from the Ivujivik sites, with frequencies of bones exhibiting cut marks varying between 0.17 to $0.3 \%$ (Nagy 1997). The reason for a slightly higher frequency of bones exhibiting cut marks in phases $\mathrm{I}$ and 2 compared to phase 3 may be ascribed to the generally better preservation conditions in the two early phases. 
Specialization on young common seals. The very high frequency of newborn and juvenile common seals indicates that the Nipisat people specialised on immature seals, and the near absence of bacula suggests a low number of mature males. Pups grow fast during lactation which, for common seal, lasts for about 2-3 weeks (Winge 1902; Vibe 198I) or c. 30 days (according to Born (20or)), and about the time of weaning weighing c. $28 \mathrm{~kg}$ (Born 200I) they are ideal game. In the Sisimiut District, birth took place in late May or the beginning of June (Winge I902; Müller I906; Degerbøl I936).

Besides the amount of blubber, the soft skin with or without fur might also have served for underwear or summer clothing in the same way as the Inuit used skins of caribou calves (Stefànsson 19I4:I49). The prenatal fur is lost before birth and the short grey, spotted fur looks like the fur of adults (Müller 1906). The high blubber contents of the pups would compensate hunters for the leanness of the adult females from May to October. Especially during moulting (from July through August (Vibe 197I)) feeding and fur condition of the adults deteriorates (Teilmann and Dietz 1994). Saqqaq people may have caught seal pups in the water as the common seal is able to swim and follow its mother shortly after birth (King I983:8I) or, more likely, basking seals may have been captured on land. The surplus of juvenile animals compared to adults could partly be explained by unintended selective hunting. The pups and juveniles would be easier to stalk and club as juveniles are not timid and therefore more easily killed than the more experienced and alert adult seals. In historical times at Sassat (Fig. 3) at the end of June the Greenlanders had such easy access to the common seals that they reportedly captured fat pups by hand or with bird darts (Müller 1906:223). Recent catches of common seal show a peak in June-August (Teilmann and Dietz 1994:fig. 4). Not only newborn pups but also yearlings and 2 years old juveniles were hunted. This would require more skilfulness of the hunter because the yearlings had already learned from adults and were more alert (Müller I906).

In conclusion, the species composition of seals at Nipisat differs in several respects from other known sites of the region. The Saqqaq people at the site had specialised in young common seals primarily hunted during summer and autumn. Both the age distribution and the skeletal element representation seem to indicate that the seal hunting strategy at Nipisat did not change during the occupation of the site: young common seals, in particular newborns, were hunted most likely on the surrounding skerries (Fig. I7I) or up the fjords and brought back to the camp site as whole carcasses.

\section{The ringed seal}

Only one bone, an auditory bulla, phase I, derived from ringed seal (Table 40), which indicates that only very few bones of this species are to be expected in the group of unspecified seal bones (Phoca spp.).

The ringed seal is the most ice-adapted of the Greenland seal species and much of its life cycle revolves around ice. Fast ice in fjords and bays is a primary winter habitat of the species but drift ice is also used to a small degree (King 1983). After the ice broke up, ringed seals occurred commonly in the fjords and coastal waters at least until July, but were observed less frequently during summer until September (Müller 1906:I7I). The ringed seal is considered of profound importance to modern Inuit because it is the most widely dispersed marine mammal in the circumpolar region, contributing valued food products such as meat, blubber, blood and hide (Wein et al. 1996). It is the cornerstone of Inuit winter subsistence for the Baffin Island and Labrador areas (Woollett et al. 200o) and the most important seal species for Palaeo-Eskimo hunters in the High Arctic (e.g. Darwent 20oI). Prehistoric Inuit in Greenland were to a large extent dependent on this seal species for millennia, as shown by the large proportion of ringed seal remains in many Neo- and Palaeo-Eskimo assemblages, e.g. it ranked second after harp seal at the two large sites, Saqqaq, Qeqertasussuk and Qajaa, in Qeqertarsuup Tunua (Table 54). Traditionally, the primary hunting season was winter and early spring where the seals were hunted from the ice. The ringed seals at Nipisat may have been hunted all year, but the near absence of this species may indicate that the site was not used during the winter months. It is also possible that, during the Saqqaq-period with a slightly milder climate than today, the ice conditions in the Open Water Area may have been less favourable to this ice adapted seal species. From the Atlantic warming episode in the 


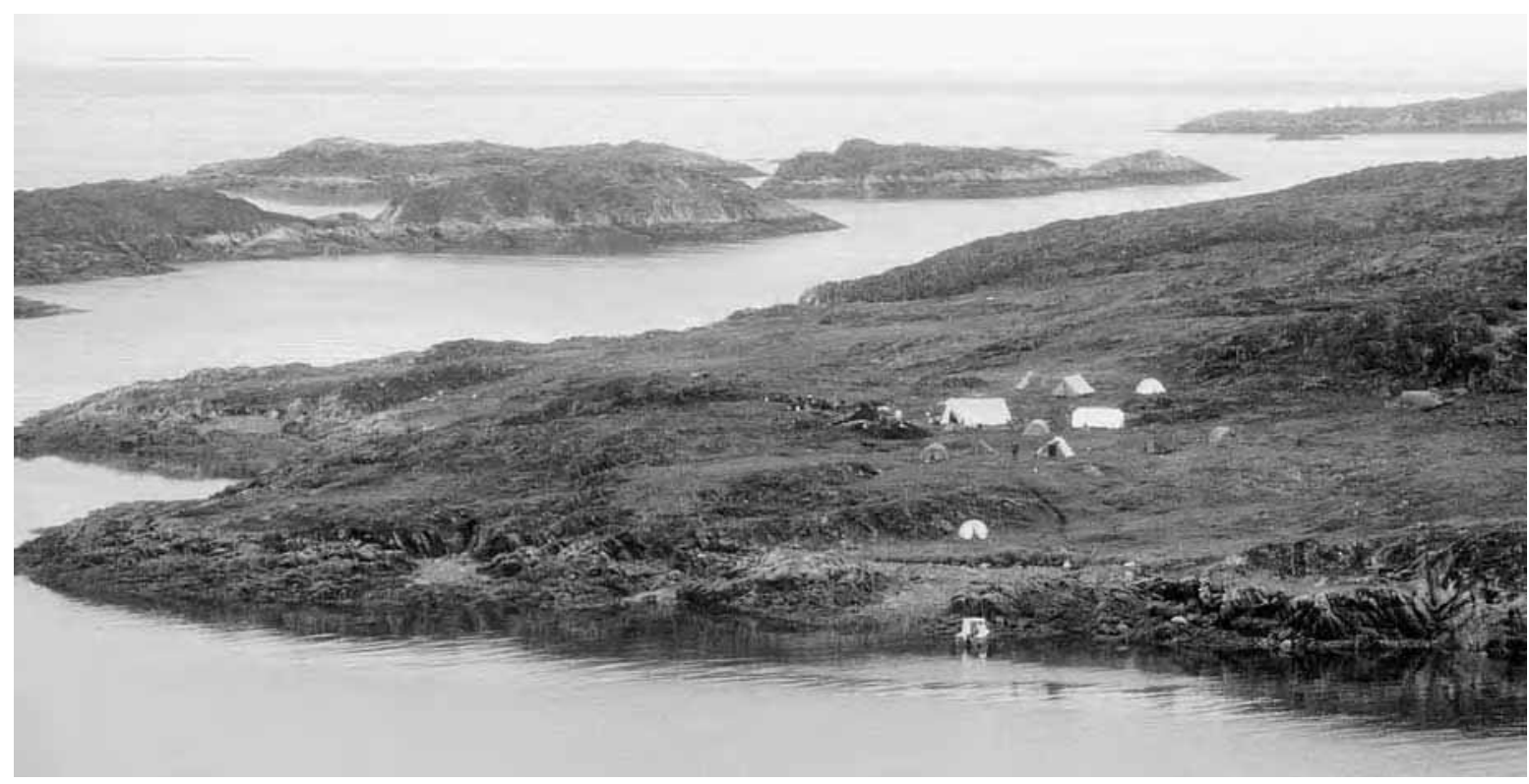

Fig. 171. The archipelago surrounding Nipisat offered excellent breeding grounds for numerous bird species, especially common eider and various gulls. Common seals and walruses were possibly also attracted. The view is facing westwards. In the centre are the archaeologist's camp and the excavation. Photo: John Pind.

I930s it was seen that boreal sea mammal species e.g. the harp seal, expanded northwards, while arctic species e.g. the ringed seal retreated northwards (Meldgaard I995:fig. 8).
The harp seal

A total of $5 \mathrm{I}$ harp seal remains (0.34\%) were retrieved from the site with $26(0.7 \%)$ and $25(0.26 \%)$ in phases I and 3 respectively (Tables 35 and 40). No harp seal bones were retrieved from phase 2, which may be

Table 40. NISP distribution of species identified seal species by skeletal element and phase.

\begin{tabular}{|c|c|c|c|c|c|c|c|c|c|c|}
\hline & \multicolumn{4}{|c|}{ Phase 1} & \multicolumn{2}{|c|}{ Phase 2} & \multicolumn{4}{|c|}{ Phase 3} \\
\hline & $\begin{array}{c}\text { Common } \\
\text { seal }\end{array}$ & $\begin{array}{c}\text { Ringed } \\
\text { seal }\end{array}$ & $\begin{array}{l}\text { Harp } \\
\text { seal }\end{array}$ & $\begin{array}{c}\text { Bearded } \\
\text { seal }\end{array}$ & $\begin{array}{c}\text { Common } \\
\text { seal }\end{array}$ & $\begin{array}{c}\text { Hooded } \\
\text { seal }\end{array}$ & $\begin{array}{c}\text { Common } \\
\text { seal }\end{array}$ & $\begin{array}{l}\text { Harp } \\
\text { seal }\end{array}$ & $\begin{array}{c}\text { Bearded } \\
\text { seal }\end{array}$ & $\begin{array}{c}\text { Hooded } \\
\text { seal }\end{array}$ \\
\hline Calvarium & 14 & - & - & - & 6 & - & 23 & 1 & 1 & - \\
\hline Bulla & 22 & 1 & 2 & - & 17 & - & 92 & 11 & - & - \\
\hline Mandibula & 26 & - & 6 & - & 16 & - & 62 & 4 & 1 & - \\
\hline Dens & 129 & - & 17 & - & 44 & - & 209 & 1 & - & 1 \\
\hline Costa & - & - & - & 1 & - & 1 & - & - & 1 & - \\
\hline Scapula & 2 & - & - & - & - & - & 2 & 1 & - & - \\
\hline Radius & - & - & - & 1 & & - & - & - & - & - \\
\hline Humerus & 2 & - & - & - & - & - & 15 & 3 & - & - \\
\hline Ulna & 3 & - & - & - & 1 & - & 8 & 1 & 1 & - \\
\hline Pelvis & - & - & - & 1 & & - & - & - & - & - \\
\hline Femur & 4 & - & - & - & 1 & - & 11 & 4 & - & - \\
\hline Tibia & - & - & - & 1 & & - & - & - & - & - \\
\hline Metacarpale & - & - & - & - & - & - & - & - & 1 & - \\
\hline Phalanx & - & - & - & - & - & - & - & - & 1 & - \\
\hline Total & 202 & 1 & 25 & 4 & 85 & 1 & 422 & 26 & 6 & 1 \\
\hline
\end{tabular}


ascribed to sample size. The anatomical representation for the common seal and the harp seal is similar with a dominance of head bones (Table 40). The age distribution of harp seal and common seal differs, however, in that harp seal do not contribute with neonatal and very young pups, but with subadults (e.g. Fig. 165) and adults only.

The seals may have been hunted on their northwards spring migration or southwards autumn migration route or during both seasons (see Fig. 9). Only analyses of dental annuli may narrow down the main hunting period. The autumn migrating harp seals would be in prime condition and have better skins and more meat and blubber than the more lean spring migrating harp seals. The autumn seals would thus more readily have provided food for storage during winter. With respect to bones identified to harp seal, there is a clear dominance of mandibles and auditory bullae (Table 40) representing at least 4 and 2 individuals, respectively (phase I) and 4 and 5 individuals respectively (phase 3) compared to very few limb bones. This may be due to some portions of the seals having been removed from the site as provisions.

\section{Large seals}

The bones of large seals were identified for all bone elements and only few if any bones of large seals are hidden in the assemblage assigned to Phoca spp. The bearded seal was represented with four fragments in phase I and six fragments in phase 3 (Table 35). The Io bone elements represented all body parts (Table 40) and were scattered over the entire site. Bone deriving from both adults and juveniles were retrieved from phase I and phase 3 respectively. Like common seals, bearded seals occurred in the Sisimiut District throughout the year (Müller 1906) and they were hunted on occasion most likely in the surrounding waters close to the site.

Only two hooded seal bones were found at Nipisat: one rib in phase 2 and one tooth in phase 3 (Tables 35 and 40). Both elements derived from adults. This seal species was obviously of little importance to the inhabitants while they stayed at the site. Hooded seals were presumably hunted during spring (see Fig. 9) or later in summer (July to August). However, according to Bendixen (192I:24) very few hooded seals reached the waters of the Sisimiut area. The recovered frag- ments may have derived from provisions (the rib) and raw material (the tooth) brought to the site.

\section{Whales}

\section{The harbour porpoise}

In total 243 fragments were retrieved, comprising I.6\% of the total number of identified mammal bones. The fragments were not evenly distributed stratigraphically and the species was more abundant both in terms of absolute numbers and in relative frequencies in the oldest layers, constituting 4.9, I.8 and $0.4 \%$ of the mammal bones for phase I, 2 and 3, respectively (Table 35 ).

Fusion of bone elements. The frequency of unfused bones was $43.5,53.8$ and $20.5 \%$ for the phase I, 2 and 3 respectively. Assessment of the age distribution of porpoises is complicated by the fact that fused and unfused vertebrae may derive from the same individual. The fusion pattern of a large sample of Danish harbour porpoises showed that fusion starts in the cervical region and proceeds from both ends terminating in the thoracic region, and physical maturity, i.e. complete fusion of all vertebrae is achieved very late in an individuals life (Galatius and Kinze 2003).

In phase I, two specimens of completely fused atlases derived from adults. In the Danish population of porpoises all cervical vertebrae are fused in age group 6-7 years (females) and age group Io-13 years (males) (Galatius and Kinze 2003). A subadult, not yet sexually matured individual, was documented with a $63 \mathrm{~mm}$ long pelvic bone. Pelvic bones below $75 \mathrm{~mm}$ (males) and $85 \mathrm{~mm}$ (females) are from sexually immature individuals (Andersen et al. 1992). The Greenland population of harbour porpoises reach sexually maturity at an age of 3.6 years (females) and 2.5 years (males) (Lockyer et al. 20oI). In phase 2, both fused and unfused vertebrae may in theory derive from the same animal. And in phase 3, fused thoracic vertebrae document adult individuals and unfused lumbar vertebrae represent younger adult individuals.

The age distribution indicates that several fully matured individuals were hunted together with some subadult not yet sexually mature animals. No newborn individuals were detected in the bone material. Extant adult harbour porpoises have a mean body length of I $43 \mathrm{~cm}$ and $\mathrm{I} 54 \mathrm{~cm}$ for males and females respectively (Lockyer et al. 200I) and a body weight varying 
Table 41. Bones and teeth of harbour porpoise (Phocoena phocoena) and their distribution by skeletal element and phase.

\begin{tabular}{|c|c|c|c|c|c|c|c|c|}
\hline & \multicolumn{2}{|c|}{ Phase 1} & \multicolumn{2}{|c|}{ Phase 2} & \multicolumn{2}{|c|}{ Phase 3} & \multicolumn{2}{|c|}{ Total } \\
\hline & NISP & $\%$ & NISP & $\%$ & NISP & $\%$ & NISP & $\%$ \\
\hline Calvarium & 33 & 19.1 & - & - & 8 & 18.2 & 41 & 16.9 \\
\hline Maxillare & 3 & 1.7 & - & - & 1 & 2.3 & 4 & 1.6 \\
\hline Dens & 1 & 0.6 & - & - & 1 & 2.3 & 2 & 0.8 \\
\hline Os hyoideum & 1 & 0.6 & - & - & - & - & 1 & 0.4 \\
\hline V. cervicalis & 4 & 2.3 & - & - & 2 & 4.5 & 6 & 2.5 \\
\hline V. thoracica & 11 & 6.4 & 3 & 11.5 & 4 & 9.1 & 18 & 7.4 \\
\hline V. lumbalis & 24 & 13.9 & 2 & 7.7 & 3 & 6.8 & 29 & 11.9 \\
\hline V. caudalis & - & - & 6 & 23.1 & - & - & 6 & 2.5 \\
\hline V. unsp. & 6 & 3.5 & 6 & 23.1 & 1 & 2.3 & 13 & 5.3 \\
\hline V. epiphysis & 45 & 26.0 & 2 & 7.7 & 4 & 9.1 & 51 & 21.0 \\
\hline Sternum & 2 & 1.1 & - & - & 2 & 4.5 & 4 & 1.6 \\
\hline Costa & 27 & 15.6 & 6 & 23.1 & 13 & 29.6 & 46 & 18.9 \\
\hline Cartilago cost. & 12 & 6.9 & 1 & 3.8 & 3 & 6.8 & 16 & 6.6 \\
\hline Scapula & 2 & 1.1 & - & - & - & - & 2 & 0.8 \\
\hline Humerus & 1 & 0.6 & - & - & 2 & 4.5 & 3 & 1.2 \\
\hline Pelvis & 1 & 0.6 & - & - & - & - & 1 & 0.4 \\
\hline Total & 173 & 100 & 26 & 100 & 44 & 100 & 243 & 100 \\
\hline
\end{tabular}

between 70-90 kg (Kinze 1994). One animal would have provided the Saqqaq people with a substantial amount of meat and blubber. The latter known to have a very high oil content as already stated by Fabricius (Helms 1921:90).

Skeletal element representation and horizontal distribution. Table 4I shows the distribution of skeletal elements for the three phases. Because whales have no fixed number of vertebrae and ribs (Kinze 1994) MAU counts were not calculated. In phase I three maxillary bones account for two animals. Including the ontogenetic age of porpoise bones in phase I at least three individuals are accounted for. In phase 2, only one individual is represented and in phase 3 two fused sterna from adults account for at least two individuals.

In general, bones of the head were quite well represented. The calvaria were heavily fragmented and represent but a few individuals. All parts of the backbone, e.g. cervical, thoracic, lumbar and caudal vertebrae, are represented. However, the backbone is underrepresented compared to head bones, maxillary bones and the sternum, when considering that a harbour porpoise skeleton has 59-69 vertebrae (Kinze 1994). Ribs, which were fragmented, are also underrepresented in the assemblage with the number of ribs in a skeleton varying between 24-28 (Kinze 1994). Appendicular bone elements of e.g. the flippers are strongly underrepresented.

In the two oldest phases, skull fragments, the backbone, ribs and sternal fragments were scattered primarily in the central part of the site (area I and 2) (Fig. I72). The largest concentrations of bones were in phase I, area I, square $386 \mathrm{x} / \mathrm{I} 85 \mathrm{y}$ comprising a congregation of vertebrae, while the squares $387 \mathrm{x} / \mathrm{I} 84 \mathrm{y}$ and $388 \mathrm{x} / \mathrm{r} 84 \mathrm{y}$ comprised skull fragments of at least two individuals and in addition vertebrae and ribs. In phase 3 , the various porpoise remains occurred in area I and 2 only and in no major concentrations (Fig. I73).

Bone alterations. In phase I, gnawing marks were found on three (I.7\%) bones, two sternal ribs and one rib exhibited cut marks and one pelvic bone had chop marks. One sternum was longitudinally cleaved. In phase 2, a lumbar vertebra was longitudinally cleaved. Phase 3 yielded two (4.5\%) gnawed fragments and one sternal rib with cut marks $(2.3 \%)$. The butchering marks are interpreted as primary butchering marks. The piles of bones comprising trunk elements and bones of the skull suggest that at least some of the porpoises were dragged to the campsite and butchered on the site. 


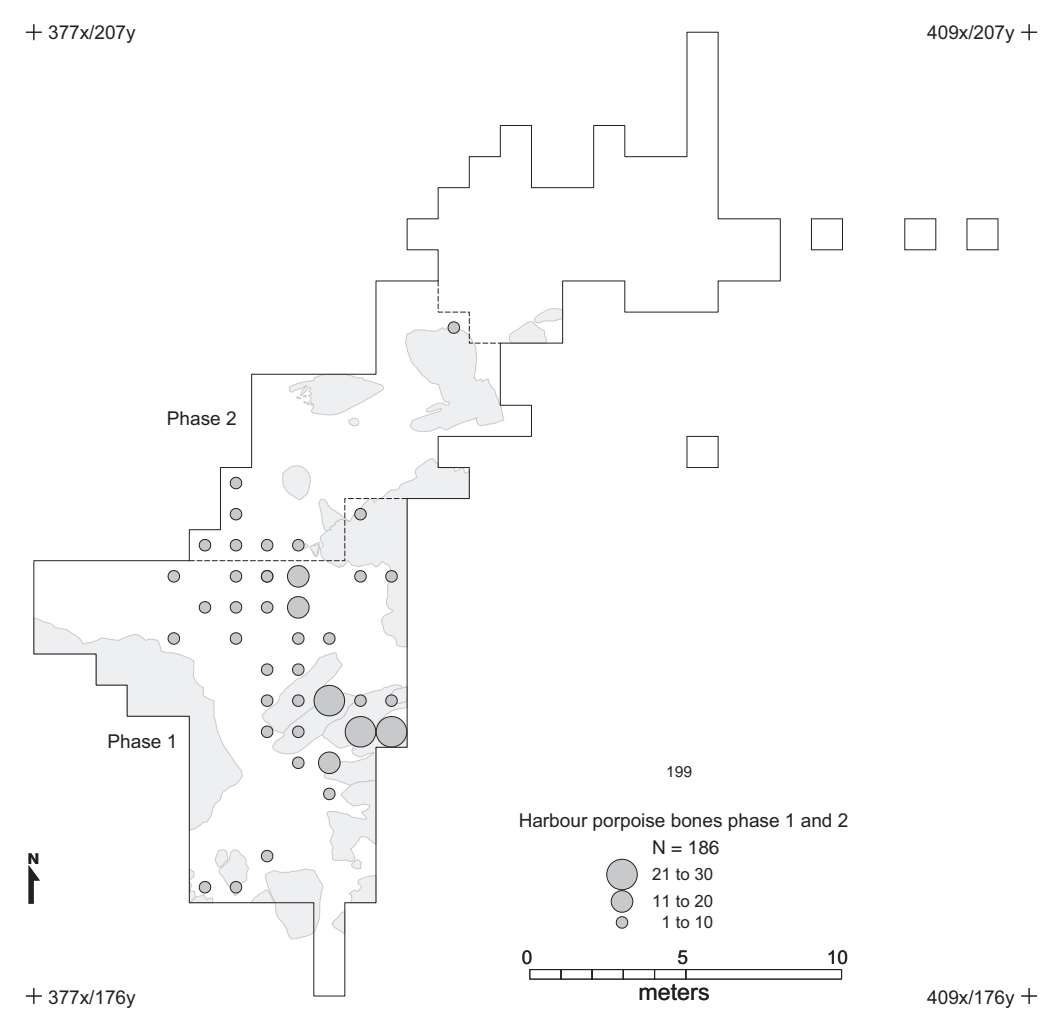

Fig. 172. Horizontal distribution of harbour porpoise bones and teeth at Nipisat in phase 1 and 2.

Hunting method and season. A drive catch would require manpower, large boats and very special topographical conditions (a narrow strait in combination with a catch site, e.g. inlets with shallow waters where the animals could be stabbed). In historical drive catches in Gamborg fjord, Northern Lillebælt, Denmark, at least 30 persons participated (Kinze 1995). The use of nets also requires calm, shallow waters (C. C. Kinze pers. comm. 2002). Strong currents and tidal factors would further complicate the abovementioned methods as the normal difference between high and low tide at Nipisat is $4 \mathrm{~m}$, (spring tide $6 \mathrm{~m}$ ) (T. Møbjerg pers. comm. 2003). The relative scarcity and distribution of porpoise remains, both horizontally (Figs I72 and I73) and vertically, also suggests that harbour porpoise hunting occurred only occasionally and was not organised. The harbour porpoises presumably occurred in the waters surrounding Nipisat from spring to late autumn (see Fig. 9) and were presumably harpooned from kayaks. Porpoise swim fast and surface only briefly to breathe. It would have required skill and patience to wait for a porpoise to surface for a short instance before it dived again. A foraging animal, however, will stay in one area and surface every 3 minutes (C. C Kinze pers. comm. 2002).
According to Bendixen (I92I:24), harbour porpoises were primarily caught from July to November and they were hunted in the same manner as seals with harpoons from kayaks. Today, primary catches are from the Nuuk-Maniitsoq Districts and modern catches from the I96os and I970s showed a peak in the summer months of July and August (Kapel I977:fig. 6). The fact that no newborns were found at Nipisat meant that no further indication concerning seasonality could be provided, and the retrieval of only two teeth offered no opportunity for thin sections. The hunting season could therefore not be narrowed down further than between spring and late autumn.

\section{White whale}

Two teeth retrieved from square $386 \mathrm{x} / \mathrm{i} 93 \mathrm{y}$, area 2, document the presence of white whale in the youngest occupation phase (Table 35). One is an intact premaxillary and the other is a slightly worn mandibulary tooth with open pulp cavities, indicating a younger animal. Both teeth derived from the most anterior portion of the tooth row and are presumably from the same individual. 
Fig. 173. Horizontal distribution of har- $\quad+377 x / 207 y$

bour porpoise bones and teeth at Nipisat in phase 3.

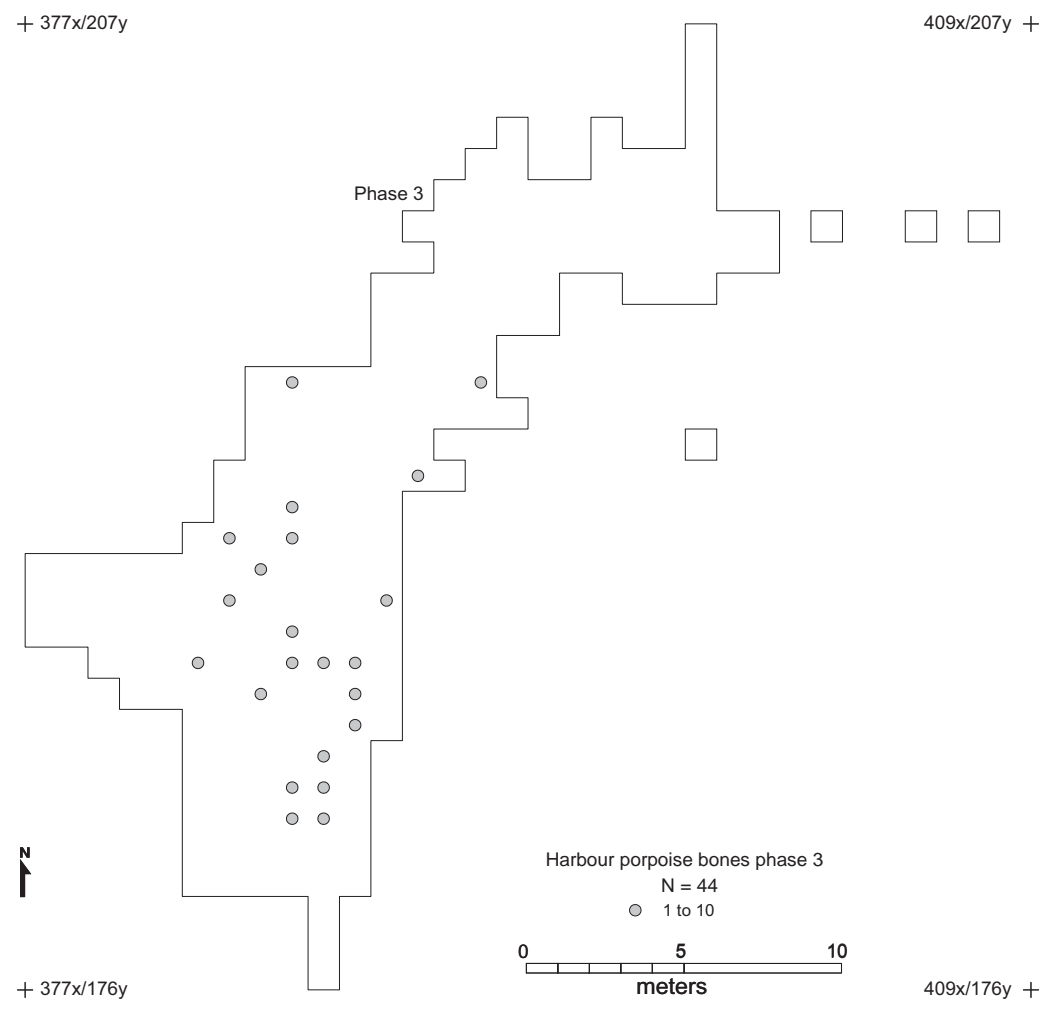

Were they hunted? Because these teeth are the only trace of white whale in the assemblage, it is not known whether the species was hunted and consumed during the occupation period or whether the teeth were brought in from another campsite as pearls or amulets. Moreover, the teeth could derive from a stranded carcass. There seems to be a general paucity of white whale and narwhal remains in Palaeo-Eskimo sites in the eastern Canadian Arctic, supposedly due to lack of a sophisticated whale hunting technology (Savelle 1994). These species are also extremely rare in Greenland Palaeo-Eskimo contexts. The large Saqqaq sites in the Qeqertarsuup Tunua (Disko Bay) area, Qeqertasussuk and Qajaa, produced but a very few fragments (Table 54). At Qajaa, two rib fragments could be identified to narwhal/white whale. The specimens at Qeqertasussuk were two proximal tusk fragments from narwhal (Meldgaard 2004:table 9.Io). The eastern Canadian Arctic Neo-Eskimo sites have produced more remains, although the two whale species never occur in abundance (Savelle 1994). From ethnographical evidence, it is known that the Thule people of Northwest Greenland used the same large harpoons for hunting all large sea mammals (i.e. walrus and small whales) (J. Møhl pers. comm. 2002). The Nipisat people hunted walrus of all age classes and may have been capable of hunting white whale too. Aspects of transport and processing, may explain the scarcity of white whale bone in Palaeo-Eskimo contexts, as it should be kept in mind that the Saqqaq people probably did not have sledges for transportation.

The most likely hunting season. White whales were previously present, at least seasonally, in large numbers in Southwest and South Greenland (south of $65^{\circ} \mathrm{N}$ ) (Heide-Jørgensen 1994:I47). Winge (1902:506) considered white whale the commonest whale species along the West Greenland coast. At the end of the $19^{\text {th }}$ century they migrated southwards during autumn passing Qeqertarsuaq in October and reaching Nuuk in December (Winge 1902). Bearing in mind the slightly higher temperatures (Fig. 2) during the occupation of Nipisat, migration times may have been slightly different, suggesting a plausible presence of white whales in the Sisimiut area from late autumn to mid spring (see Fig. 9). However, if the Nipisat people actively hunted white whales, this would probably have taken place during winter and early spring. This would indicate seasonal visits at Nipisat during spring or late autumn. 


\section{Large whales}

Fifty-four fragments were classified as being unspecified whale (Cetacea) (Table 35). The whale remains derived from large whales, either baleen whales (Mysticeti), sperm whale (Physeter macrochephalus) or killer whale (Orcinus orca). They comprised both artefacts and fragments with working traces $(\mathrm{N}=34)$. The unworked proportion $(\mathrm{N}=2 \mathrm{O})$ probably constitutes waste from tool fabrication. Only one fragment (xIo748, phase I) could be identified to element, namely a rib from a whale of the size of either killer whale or minke whale. The remaining fragments were too small or too worked to be identified to skeletal part. Thirty-two fragments derived from phase I and were widely scattered, except for one aggregation of nine small fragments in square $384 \mathrm{x} / \mathrm{I} 80 \mathrm{y}$. Phase 2 only yielded two fragments. Phase 3 produced twenty fragments of whale bones scattered over area I, 2 and 3 with no particular aggregations observed.

At Qeqertasussuk, large whales e.g. bowhead or northern right whale (Balena mysticetus/glacialis), minke whale or sei whale (Balaenoptera acutorostrata/borealis) and sperm whale were retrieved (Grønnow I994; Meldgaard 2004) and these species no doubt also passed through the Nipisat Sound, which historically was known as a good place for whale hunting (see Chapter 2).

It can thus be stated that whale bone, in addition to antler and ivory, was a valued resource for tool production through all phases. The importance of whale meat, blubber and baleen is, however, impossible to estimate. It is presumed that baleen was exploited for strings, snares, slings etc. At Qeqertasussuk, baleen knots were preserved in the frozen midden layers (Grønnow I994). We do not, however, have any such evidence at Nipisat, due to lack of optimal preservation conditions for baleen. Whale products could have been obtained from stranded carcasses as well as hunted whales.

\section{Terrestrial mammals}

\section{Arctic hare}

A total of 35 arctic hare bones comprise $0.23 \%$ of the total identified mammal bones (Table 35). The relative proportion of arctic hare remains in all three phases constitute less than I\% (see Table 35) and the ten, six, and nineteen arctic hare fragments from phases I, 2

Table 42. NISP distribution of the small land mammals, arctic hare (Lepus arcticus), arctic fox (Alopex lagopus) and the dog (Canis familiaris) by skeletal element and phases.

\begin{tabular}{|c|c|c|c|c|c|c|c|}
\hline & \multicolumn{2}{|c|}{ Phase 1} & \multicolumn{2}{|c|}{ Phase 2} & \multicolumn{2}{|c|}{ Phase 3} & \multirow[b]{2}{*}{ Dog } \\
\hline & Arctic hare & Arctic fox & Arctic hare & Arctic fox & Arctic hare & Arctic fox & \\
\hline Calvarium & - & 3 & - & - & 2 & 1 & - \\
\hline Maxillare & - & 2 & - & - & - & - & - \\
\hline Mandibula & - & 2 & - & 1 & - & 3 & 2 \\
\hline Dens & - & 1 & - & 2 & - & 6 & 7 \\
\hline V. cervicalis & - & 1 & - & - & - & - & 2 \\
\hline V. lumbalis & 3 & - & - & - & - & - & - \\
\hline Costa & 4 & 9 & 3 & - & 6 & 2 & - \\
\hline Scapula & 1 & 1 & 1 & 1 & 2 & - & - \\
\hline Humerus & - & 2 & 1 & - & 3 & - & 2 \\
\hline Radius & - & 2 & - & - & 2 & 2 & - \\
\hline Ulna & - & - & 1 & 1 & 1 & - & 1 \\
\hline Pelvis & - & - & - & - & 1 & - & - \\
\hline Femur & - & 2 & - & - & 1 & - & - \\
\hline Tibia & - & 4 & - & - & 1 & 4 & 2 \\
\hline Fibula & - & 1 & - & - & - & - & 1 \\
\hline Calcaneus & 1 & - & - & - & - & - & - \\
\hline Metatarsale & 1 & 1 & - & 3 & - & 1 & - \\
\hline Phalanx & - & 2 & - & - & - & - & - \\
\hline Total & 10 & 33 & 6 & 8 & 19 & 19 & 17 \\
\hline
\end{tabular}




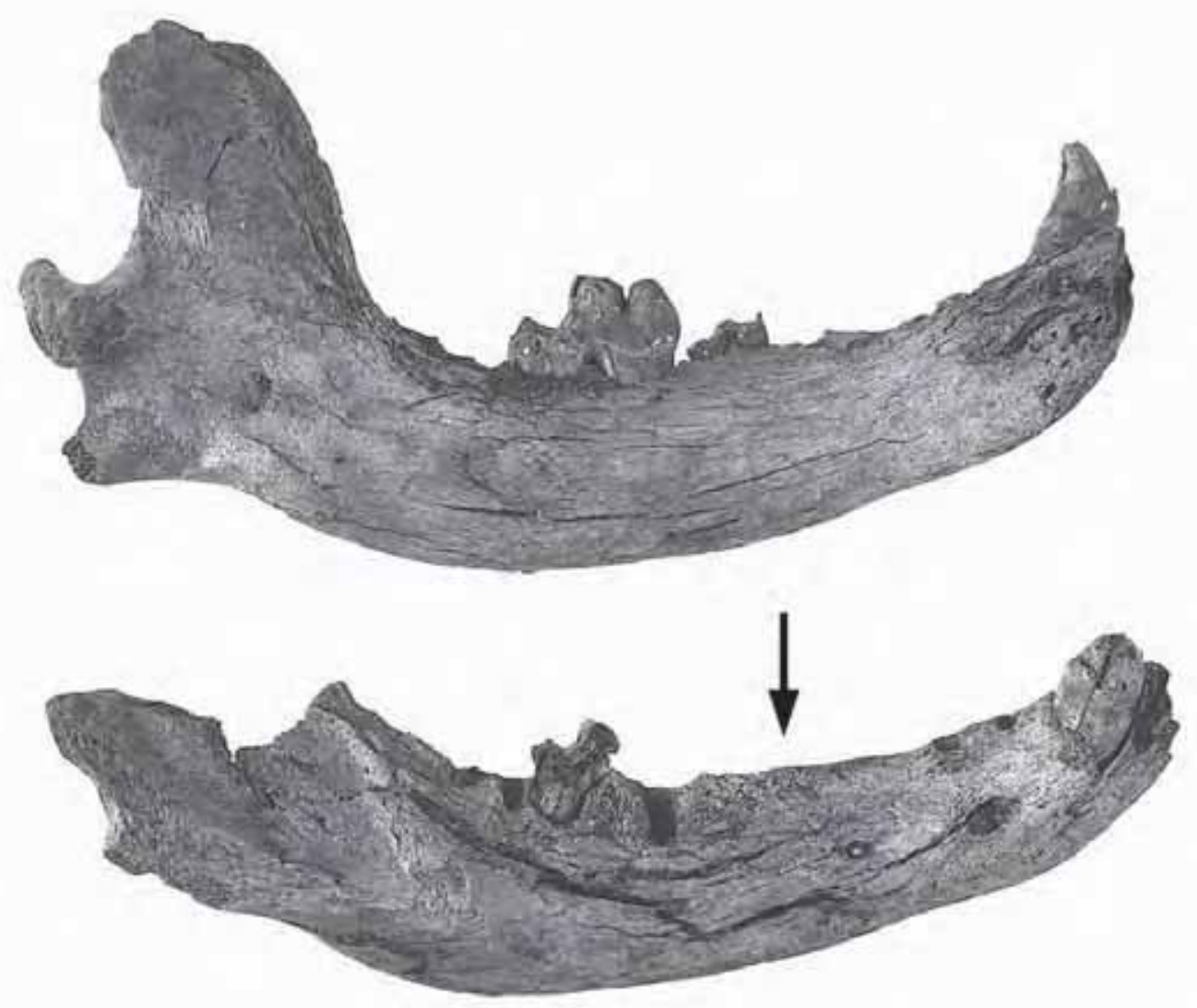

$50 \mathrm{~mm}$

Fig. 174. Dog mandibles from Nipisat, phase 3. Above a left and below a right mandible presumably deriving from the same individual. Note that the alveoli of premolars P3 and P4 are obliterated (indicated by arrow). Photo: Geert Brovad.

and 3 account for at least one, one, and two individuals respectively. Bone elements of arctic hare derive from the head, trunk, and limbs (Table 42). None of the bones are gnawed or exhibit cut marks. Three lumbar vertebrae (phase I) could be rearticulated and one of them is longitudinally cleaved. As opposed to fox bones, almost all arctic hare bones were from adult individuals. One ulna (dex) (phase 2) and three lumbar vertebrae (phase I) were from subadults. The few subadult bones indicate autumn hunting, and, as is the case for arctic fox, hares played a negligible role in the economy of the Nipisat people.

\section{Dog}

The dog is represented by $\mathrm{I} 7$ bones and teeth (Table 42) reassembled from 25 fragments (see Gotfredsen 1998; Morey and Aaris-Sørensen 2002). The dog remains were confined to phase 3 with a relative fre- quency of $0.17 \%$ of the total number of identified mammal bones (Table 35).

Based on one right mandible with the canine in situ and two loose right lower canines, a minimum of three individuals can be accounted for. The most spectacular dog remains in the Nipisat assemblage were two complete mandibles, a left and a right, presumably deriving from one individual (Fig. I74). These are the only dog mandibles so far known from the Saqqaq Culture in Greenland. The post-cranial bone elements consist of two axis fragments (a complete and a cranial fragment), two humeri (a complete bone and a distal part), an ulna (proximal part), two tibiae (a diaphysis and a distal part), and a diaphysis of fibula (for a detailed list see Morey and Aaris-Sørensen 2002:table I). The distal tibia and humeri have fused epiphyses and hence derive from adult individuals, while the ulna is unfused proximally originating from an indi- 


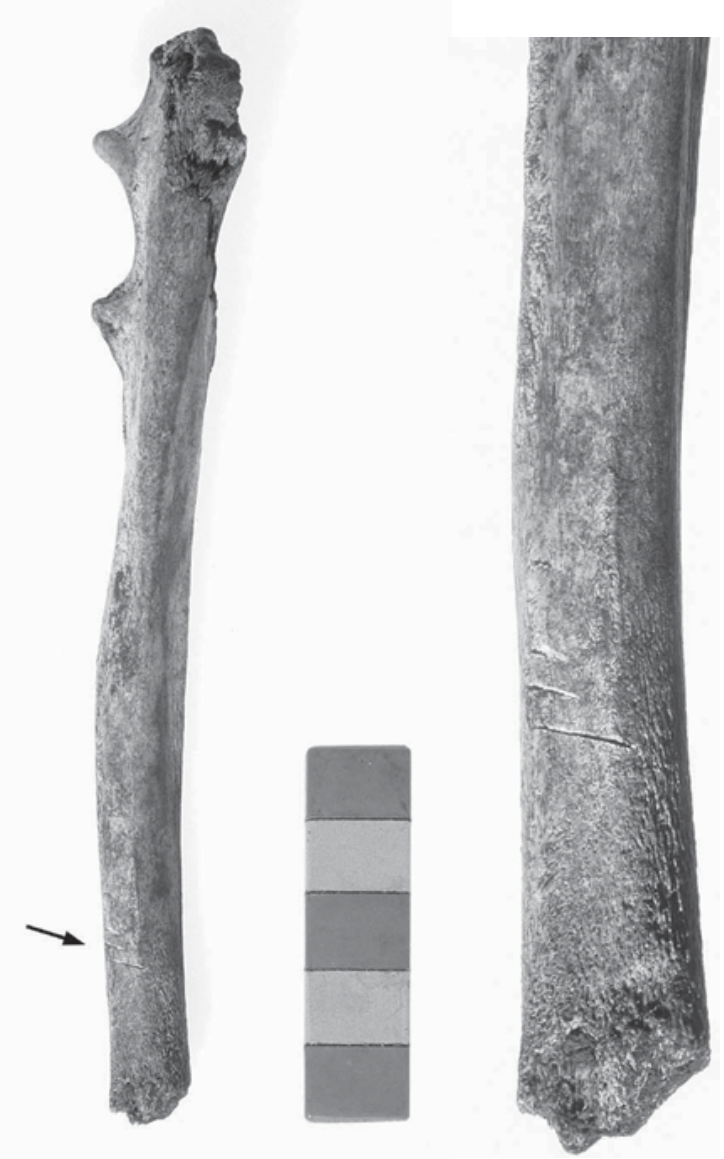

Fig. 175. Left ulna from a young dog with gnawing marks proximally and cut marks distally, phase 3, (caudal view). Inset shows close up of cut marks. Photo: Geert Brovad.

vidual less than I5 months old according to information from Habermehl (I975:167).

Alterations on the bones. In total three dog bones were gnawed: a distal humerus fragment distally on the condyles, a tibia both distally and proximally, and the subadult ulna proximally (Fig. I75). The right mandible had closed alveoli of the third $\left(\mathrm{P}_{3}\right)$ and fourth $\left(\mathrm{P}_{4}\right)$ premolar (Fig. I74). This could be attributed to a deliberate action by man, but was more likely due to natural causes (Gotfredsen 1996). The ulna exhibited cut marks (Fig. 175) consisting of three parallel 2-5 mm long scores angled sharply downwards, orientated perpendicularly to the long axis and situated distally on the lateral face of the diaphysis (Fig. I75).

Horizontal distribution of dog bones at the site. Dog bones were primarily scattered over the northern half of the site (area 2 and 3) while only two fragments square $383 \mathrm{x} / \mathrm{I} 82 \mathrm{y}$ and $388 \mathrm{x} / \mathrm{I} 89 \mathrm{y}$ were retrieved from the southern part of the excavation (area I). The horizontal distribution and the fragmentary nature of the dog bones indicate that the dog remains were deposited gradually and not during one single event. No articulated bones were found, although two mandibles were found in close proximity (400x/200y) and a left distal tibia and left broken fibula (392x/202y) may derive from one hind limb.

Evidence of dogs in the early phases? All dog remains were confined to phase 3 . The majority were found in the northern part of the site dated to II42-1060 BC (area 2) and I370-Iooo BC (area 3) with only two fragments found in area I, dated to I310-8Iо BC (see Table I and p. 36). Even though dog bones were not documented from phase 2 and phase I, carnivore gnawed bones were retrieved from both strata. Damage caused by dogs is difficult to distinguish from that caused by foxes or wolves (Noe-Nygaard 1989). However, the scores and tooth marks on several of the damaged bones seem to be too large for arctic fox and point to either dog or wolf (see Fig. I89). Dogs seem to be the more plausible large carnivores at Nipisat. Although wolves cannot be excluded, they are rare in the archaeological record of West Greenland and also today only occur sporadically (Vibe 1967; Dawes et al. 1986). In Qeqertarsuup Tunua (Disko Bay) at Qeqertasussuk, dogs accompanied humans when they first settled on the island at c. 2400 BC (see Morey and Aaris-Sørensen 2002). Likewise, at Qajaa, dated to c. I8Io-945 BC (Meldgaard, J. 1983:95), dog remains were confined to the earliest occupation levels (Møhl 1986). It is therefore quite plausible that the dog arrived with the first settlers of Nipisat c. 2030 BC. In the High Arctic evidence of dog is virtually non-existent. A survey of a large number of high arctic localities failed to yield unequivocal dog bones (Darwent 1999, 200I). For further evaluation of Eastern Arctic large canid finds see Morey and Aaris-Sørensen (2002).

Size of the Nipisat dogs. Measurements of the dog bones are shown in Table 43 and discussed in Gotfredsen (1996) and Morey and Aaris-Sørensen (2002). The size of the left mandible falls within the size range of modern sled dogs as well as dogs of the Thule 
Table 43. Measurements of the dog mandibles and measurable long bones from phase 3. All measurements were taken according to Driesch (1976) and in $\mathrm{mm}$.

\begin{tabular}{|c|c|c|}
\hline Measurement of mandibula in $\mathrm{mm}$ & Sin, $400 x / 200 y$ & Dex, 400x/200y \\
\hline 4. Length: the condyle process to aboral border of the canine alveolus & 132.25 & - \\
\hline $\begin{array}{l}\text { 5. Length: indentation between the condyle process and angular process - } \\
\text { aboral border of the canine alveolus }\end{array}$ & 126.18 & - \\
\hline 6. Length: the angular process - aboral border of the canine alveolus & 131.03 & - \\
\hline $\begin{array}{l}\text { 7. Length: the aboral border of the alveolus of } \mathrm{M}_{3}-\text { aboral border of } \\
\text { the canine alveolus }\end{array}$ & 83.02 & 84.64 \\
\hline 8. Length of the cheek tooth row $\mathrm{P}_{1}-\mathrm{M}_{3}$ & 79.27 & 81.94 \\
\hline 9. Length of the cheek tooth row $\mathrm{P}_{2}-\mathrm{M}_{3}$ & 73.87 & 75.61 \\
\hline 10. Length of the molar row & 39.62 & 39.74 \\
\hline 11. Length of the premolar row $\mathrm{P}_{1}-\mathrm{P}_{4}$ & 43.12 & 44.42 \\
\hline 12. Lenght of the premolar row $\mathrm{P}_{2}-\mathrm{P}_{4}$ & 36.72 & 37.40 \\
\hline 13 a. Length of the carnassial & 23.44 & - \\
\hline $13 \mathrm{~b}$. Breadth of the carnassial & 9.62 & - \\
\hline 14. Length of the carnassial aveolus & 23.49 & 23.57 \\
\hline 18. Height of the vertical ramus & 62.78 & - \\
\hline 19. Height of the mandible behind $M_{1}$ & 26.62 & 24.11 \\
\hline 20. Height of the mandible between $P_{2}$ and $P_{3}$ & 20.88 & 21.11 \\
\hline Measurement of long bones in $\mathrm{mm}$ & $\begin{array}{l}\text { Humerus, dex } \\
386 x / 193 y\end{array}$ & $\begin{array}{l}\text { Tibia, sin, } \\
392 x / 202 y\end{array}$ \\
\hline GLC Greatest length from caput & 157.42 & - \\
\hline Dp Depth of the proximal end & 45.64 & - \\
\hline SD Smallest breadth of diaphysis & 13.41 & 14.00 \\
\hline Bd Breadth of the distal end & 38.62 & 26.44 \\
\hline
\end{tabular}

Culture (Gotfredsen 1996:fig. 7.6) and is markedly smaller than extant Greenland wolves (Morey and Aaris-Sørensen 2002). The intact humerus at Nipisat also lies within the range of Neo-Eskimo sled dogs and contemporary Palaeo-Eskimo dogs and below the size of modern Greenland wolves (Morey and Aaris-Sørensen 2002, fig. 3, B). Dimensions of Saqqaq dogs, including the Nipisat specimens, lay in the upper end of the size range of Thule Culture dogs (see Morey and Aaris-Sørensen 2002). A larger, stouter dog type would, however, be expected for animals used for pulling or carrying a burden than for sled dogs, exposed to selective pressures for traits other than size and strength alone (ibid.).

The use of the Nipisat dogs. The most important function of the Saqqaq dogs was supposedly to serve as individual pack animals (Fig. 209) and to assist during hunting activities (Grønnow and Meldgaard I988, Gotfredsen 1996). At Qajaa, one vertebra lumbalis exhibited a pathological deformation of the processus spinosus indicating that the individual had carried a burden (Morey and Aaris-Sørensen 2002). The Nipisat people occasionally hunted polar bears and dogs may have assisted during bear hunting or in the pursuing of other game on land. Besides the general scarcity of dog bones in Saqqaq contexts, the lack of any artefacts connected to dog sledging from Palaeo-Eskimo sites further points towards the use of Saqqaq dogs as pack animals and hunting dogs. The ulna exhibited cut marks similar to those found on dog bones from other West Greenland Saqqaq sites, where limb bones, pelvis, ribs, and vertebrae from Qeqertasussuk and limb bones at Qajaa showed cut marks (Morey and Aaris-Sørensen 2002). The nature and position of the cut marks on the Saqqaq specimens primarily suggested processing for food rather than skinning (Morey and Aaris-Sørensen 2002). The cut marks on the Nipisat dog ulna are situated approximately 7-8 cm from the joint articulating with the carpals and may therefore be attributed to filleting activities as described by Binford (198I) and Noe-Nygaard (1989), rather than dismemberment and skinning. Obviously humans consumed Saqqaq dogs and their skins were 
used for clothing and other purposes. However, the scarcity of dog remains in the Saqqaq assemblages, as pointed out by Morey and Aaris-Sørensen (2002), indicates that they were not a major food source. The Saqqaq dogs probably served as food only during periods of famine or when individuals died of natural causes.

In conclusion, dogs at Nipisat were probably rather infrequent. One or a few dogs accompanied the Saqqaq family group to the island and served as pack animals and probably assisted during hunting expeditions. Taken into account that the site was primarily a seasonal site visited during the summer half of the year, one would not expect many dog remains. However, shortages of provisions may still have occurred and at least one subadult individual was eaten.

\section{Arctic fox}

A total of 60 arctic fox bones, comprising $0.4 \%$ of the identified mammal bones (Table 35), were recovered. In all three phases the relative proportion of arctic fox was below I\% (Table 35) and the 33, 8, and I9 fox remains account for at least three, one and four individuals from phases I, 2 and 3 respectively. In phase 3 , fox remains were scattered in all parts of the excavation i.e. areas I, 2 and 3. Almost all body parts of the fox were represented, at least in phase I and 3 (Table 42). A large proportion of the bones with unfused epiphyses and mandibles with deciduous teeth in situ derived from juvenile foxes $44 \%, 88 \%$, and $47 \%$ for phase I, 2, and 3 respectively. Two nearly intact fox mandibles (dex, sin) $(385,80 \mathrm{ox} / \mathrm{I} 89,75 \mathrm{y})$, phase I, with deciduous teeth and $\mathrm{M}_{\mathrm{I}}$ not yet erupted, derived from a juvenile only a few months old, and a mandible (dex) (382x/I9oy), phase 2, with $\mathrm{M}_{\mathrm{I}}$ erupting is from a slightly older cub. Phase 3 yielded one mid piece of a mandible ( $\sin )(385,2 \mathrm{IX} / \mathrm{I} 89,59 \mathrm{y})$ with deciduous premolars in situ and one caudal part of a mandible (dex) (385,33/189,51y) with dp3 and dp4 in situ probably deriving from the same individual. With a whelping period corresponding to the present one around mid to late May (Müller I906; Vibe I98I), most of the foxes were killed in late summer and autumn. No cut marks or signs of gnawing were observed on the fox bones, however one lateral part of a left tibia diaphysis, xI7022 had burin grooves (Fig. 6o, C). Three unfused metatarsals, metatarsale II, III and IV (384x/19ry), phase I could be rearticulated.
Fox hunting and the use of foxes. The skeletal element distribution (Table 42) showing that all parts of the body were represented, although with different frequencies, indicates that whole carcasses were brought to the site. The relatively low number of fox remains indicates that fox hunting was of minor economic importance. No butchering marks were found on the bones that could give an indication of the use of arctic fox at the site, however it is assumed that both meat and pelts were exploited. While foxes live alone most of the year, mothers and their young live together during the breeding season. The dominance of young foxes is most likely the result of unintentional selective hunting. The inexperienced juveniles and subadults were probably easiest to catch in early autumn after having left their mothers. A similar age distribution and hunting season for arctic fox was seen at the Palaeo-Eskimo site of Umingmak (Fig. I, no. Io) (Münzel 1987b:IoI). Here, fox bones exhibited only few butchering marks, however the presence of skinning marks and filleting traces indicated that foxes were used both for consumption and for the sake of their fur (Münzel r987b:10o).

The Nipisat fox assemblages, however, produced a diaphysis of a fox tibia exhibiting burin grooves. The bone wall of a fox long bone is slightly thicker than that of a medium sized bird e.g. a goose or a gull. At Nipisat fox bones may also have served as raw material for needles and fine awls as was the case for bird bones (Fig. 6o, C). The arctic fox played a larger role in the economy at Qeqertasussuk (Table 54) where tooth sections on canines documented winter hunting (Grønnow and Meldgaard 1988, I99Ib). The pelts have the best quality during winter and the different pattern in fox exploitation may indeed be caused by the season of occupation of the sites.

In conclusion, arctic foxes were hunted only occasionally, most likely on the island of Nipisat. The inexperienced subadults caught in early autumn dominate and the foxes presumably provided both meat and pelts. Burin grooves on a fox tibia documents the use of fox bones for tool production.

\section{Caribou}

Caribou remains constituted c. 45,37 and $55 \%$ of the species identified mammal bones at the site (Table 35 and Fig. I54) and this terrestrial herbivore was the absolute most important game in terms of meat yield. 
Table 44. Tooth eruption patterns and age in recent caribou (after Miller 1974) with age distribution of caribou mandibles at Nipisat distributed by phases.

\begin{tabular}{|c|c|c|c|c|c|}
\hline & \multicolumn{5}{|c|}{ Number of mandibles } \\
\hline & Ages & Phase 1 & Phase 2 & Phase 3 & Total \\
\hline M1 absent & $0-2$ months & - & - & 1 & 1 \\
\hline M1 erupting & $3-5$ months & 3 & - & 4 & 7 \\
\hline \multicolumn{6}{|l|}{ Tooth wear and general } \\
\hline ontogenetic development & $6-9$ months & - & - & - & - \\
\hline M2 erupting & $10-15$ months & 1 & 1 & 4 & 6 \\
\hline \multicolumn{6}{|l|}{ Tooth wear and general } \\
\hline ontogenetic development & $16-21$ months & 1 & - & 1 & 2 \\
\hline Premolars erupting & $22-29$ months & 5 & 2 & 6 & 13 \\
\hline Total & & 10 & 3 & 16 & 29 \\
\hline
\end{tabular}

The very large proportion of caribou at a coastal site is quite outstanding, and to understand the role of this game animal at Nipisat, age structure, sex distribution and skeletal element frequencies, along with treatment of the carcass are examined in some detail in the following sections.

Age determination of caribou mandibles. The age determination of caribou mandibles from Nipisat is based on tooth eruption patterns for animals younger than 29 months old and tooth wear for animals older than 29 months. All mandibles with teeth in situ were included in the study and only loose teeth that could be refitted into mandibles were taken into account. Both left and right mandibles were included, although for paired mandibles deriving from the same individual, one side was omitted. The chance that one individual was counted twice was thus minimal. Due to large numbers of highly fragmentary mandibles resulting in many loose teeth (Table 49), the number of aged mandibles was clearly under-representative.

Tooth eruption and tooth wear were compared to data from Canadian caribou Miller (1974). Comparing Greenland caribou populations with Canadian popu-

Table 45. Tooth wear stages and age in recent caribou (after Miller 1974 and Spiess 1979 (Meldgaard 1983)) with age distribution of the caribou mandibles at Nipisat distributed by phases.

\begin{tabular}{|c|c|c|c|c|c|}
\hline & \multicolumn{3}{|c|}{ Number of mandibles } & \multirow[b]{2}{*}{ Phase 3} & \multirow[b]{2}{*}{ Total } \\
\hline & Ages & Phase 1 & Phase 2 & & \\
\hline \multicolumn{6}{|c|}{$\begin{array}{l}\text { Wear on the premolars advances to the point where dentin exposed } \\
\text { on each cusp is wider than each bordering piece of enamel, } \\
\text { while the molars still retain sharp lingual cusps that are noticeably }\end{array}$} \\
\hline higher than the buccal cusps. & $2,3-5$ years & 8 & - & 20 & 28 \\
\hline \multicolumn{6}{|c|}{$\begin{array}{l}\text { The high lingual points on premolars are worn and blunted, and } \\
\text { all the molars have buccal and lingual cusps worn to even } \\
\text { height. The exposed dentin on each molar has widened to a } \\
\text { broad quarter or halfmoon. There is still some up and down }\end{array}$} \\
\hline wave-form going from front to back along each tooth. & $6-9$ years & 2 & 1 & 10 & 13 \\
\hline \multirow{2}{*}{\multicolumn{6}{|c|}{$\begin{array}{l}\text { The occlusal surfaces are flat buccolingually and anterior- } \\
\text { posteriorly. The white cementum layer that originally separated } \\
\text { the buccal from the lingual cusps has been worn to a small oval } \\
\text { circle. In very old caribou M1 may be worn down to its roots and }\end{array}$}} \\
\hline & & & & & \\
\hline Total & & 10 & 1 & 31 & 42 \\
\hline
\end{tabular}




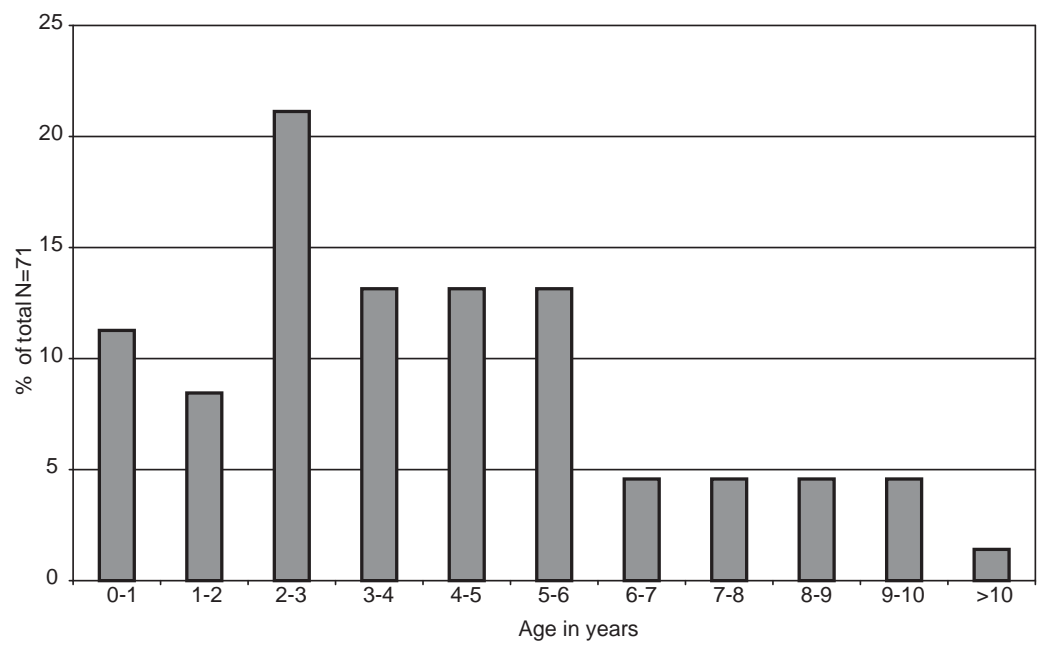

Fig. 176. Age distribution of caribou mandibles at Nipisat all phases compiled ( $\mathrm{N}=71$ ). Data from Tables 44 and 45.

lations may be problematic. Miller (I974) concluded, however, that tooth eruption dates for Canadian, Scandinavian and Russian caribou are comparable. It was therefore considered safe to use Canadian data on the Nipisat sample. Comparing tooth wear patterns between geographically separated populations poses even larger difficulties because factors such as soil conditions and silica contents in various grasses may differ from region to region, strongly affecting tooth wear. The broad age categories (see Table 45) nevertheless give a fairly good impression of the relative age distribution of the adult caribou population in the Nipisat sample. For two series (males and females) of recent caribou mandibles of known age from the Kangerlussuaq area, the tooth wear pattern agreed with the broader categories defined by Miller (I974) and Spiess (I979). The age of the recent caribou mandibles were determined by thin sections (M. Meldgaard pers. comm. 200I). Caribou mandibles from the Thule Culture site Aasivissuit were aged using data from Miller (1974) (Meldgaard, M. I983) and the age distributions of the Neo-Eskimo and the PalaeoEskimo site are thus directly comparable. Criteria for ageing and results are shown in Tables 44 and 45. The age distribution for each occupation phase did not seem to differ markedly and therefore the data was treated collectively (see Fig. I76).

Age determination using fusion data of caribou post cranial bones. The use of fusion data for age determination is generally considered cruder than the use of tooth eruption and tooth wear. However, due to the excellent preservation conditions at Nipisat, and the careful excavation methods, a large number of juvenile bones including small bones and tiny loose epiphyses were recovered. Therefore it was considered worth examining the fusion data in order to provide additional information on age structure in the caribou death assemblage. The age structure obtained from the mandibles may differ from that obtained from the post-cranial skeleton. The preference for large antlers for tool production may result in an overrepresentation of adults among the head bones. Information drawn from epiphyseal fusion data may give additional information of the group of young adults in the age category 2,3-5 years.

The sequence of fusion and approximate fusion dates of Scandinavian mountain reindeer (Rangifer tarandus tarandus L.) killed at Hardangervidda (Hufthammer 1995) was applied to the Nipisat sample. The sequence of fusions proposed by Hufthammer (I995) differs slightly from the general sequence documented for domestic ungulates by Silver (I969) e.g. fusion of proximal ulna and olcranon is placed in the category of late fusing instead of middle fusing epiphyses, and fusing of the tuber calcaneum is placed in the middle fusing instead of late fusing group (see Tables 46-48). The discrepancies may be due to the relatively small sample size (I9 males and I6 females) of recent reindeer used by Hufthammer (I995) or real differences. The process of ossification may be different in the two sexes e.g. Habermehl (I96I) demonstrated that ossification was faster in male roe deer than in females. Food quality may also influence the epiphyseal fusion intervals, although the relatively broad fusion intervals given by Hufthammer (I995) can provide a broad 
Table 46. Fusion data for Caribou at Nipisat phase 1. The data are arranged in early, middle and late fusing elements. Fusing epiphyses are considered unfused. The sequence and age of fusion are according to Hufthammer (1995:41). $p=$ proximal, $d=$ distal.

\begin{tabular}{|c|c|c|c|c|c|c|}
\hline & Age in months & No. unfused & No. fusing & No. fused & Total & $\%$ unfused \\
\hline \multicolumn{7}{|l|}{ Early fusing } \\
\hline Tuber scapulae & $2-6$ & 5 & & 12 & 17 & 29.4 \\
\hline Radius $p$ & $4-10$ & 4 & & 11 & 15 & 26.6 \\
\hline Humerus d & $6-15$ & 4 & & 6 & 10 & 40.0 \\
\hline Phalanx I p & $6-18$ & - & & 11 & 11 & 0 \\
\hline Phalanx II p & $6-18$ & - & & 9 & 9 & 0 \\
\hline Total & & 13 & & 49 & 62 & 21.0 \\
\hline \multicolumn{7}{|l|}{ Middle fusing } \\
\hline Tibia d & $18-30$ & 8 & & 4 & 12 & 66.6 \\
\hline Metacarpus d & $18-30$ & 1 & & 4 & 5 & 20 \\
\hline Metatarsus d & $18-30$ & 3 & & 14 & 17 & 17.6 \\
\hline Calcaneus & $18-42$ & 4 & & 8 & 12 & 33.3 \\
\hline Total & & 16 & & 30 & 46 & 34.8 \\
\hline \multicolumn{7}{|l|}{ Late fusing } \\
\hline Radius d & $36-48$ & 4 & & 5 & 9 & 44.4 \\
\hline Femur $p$ & $36-48$ & 4 & & 2 & 6 & 66.6 \\
\hline Femur d & $36-48$ & 3 & 1 & 1 & 5 & 80 \\
\hline Tibia $p$ & $36-48$ & 3 & & 4 & 7 & 42.8 \\
\hline Ulna $p$ & $42-48$ & 2 & & 4 & 6 & 33.3 \\
\hline Humerus $p$ & $42-54$ & 3 & & - & 3 & 100 \\
\hline Total & & 19 & 1 & 16 & 36 & 55.6 \\
\hline All groups & & 48 & 1 & 95 & 144 & 33.3 \\
\hline
\end{tabular}

indication of the age profile of the dead caribou up to adulthood e.g. when all epiphyses have fused to the diaphyses at about the age of $4^{\mathrm{T}} / 2$. For the fusion analyses, the long bones of the fore and the hind limbs, calcaneus and phalanges were chosen. Fusion data from the three phases are listed in Tables 46-48. The age profiles of phase I and phase 3 are almost identical while that of phase 2 has a smaller proportion of fused bones within all three fusing categories (Fig. I77). The discrepancy is possibly due to the small sample size $(\mathrm{N}=44)$ while the sample sizes of phases I $(\mathrm{N}=\mathrm{I} 44)$ and $3(\mathrm{~N}=475)$ are more reliable. The data from phase 2 may thus be ignored. Few deaths (up to c. $20 \%$ ) occurred during the early fusing period, which covers the first I8 months (Fig. I77). This pattern corresponds to the information obtained from the mandibular tooth eruption patterns (Fig. 176). Here about $20 \%$ were killed before reaching the age of $\mathrm{I}^{\mathrm{T}} / 2$ year. More deaths occurred during the middle end late fusing stages, however about $40-45 \%$ of the animals survived until after all bones were fused that is about the age of $4-4^{\mathrm{T}} / 2$ (Fig. 177). Epiphysial fusion of vertebra in the assemblage might have provided further information, as those epiphyses are usually the last to close. They were nevertheless excluded from the present examination because no fusion data for caribou exist. The fusion data and tooth wear analysis both show that at least $60 \%$ of the caribou were older than c. $2^{\mathrm{I}} / 2$ (Table 45 ).

Two lines of evidence thus demonstrate that up to c. $40 \%$ of the caribou killed by the Nipisat inhabitants were juveniles younger than $2^{\mathrm{I}} / 2$ years and that up to $40 \%$ of the hunted caribou were mature animals with all bones in the skeleton fused i.e. older than $4-4^{\mathrm{T}} / 2$ years old. The age profile seen at Nipisat differs in some aspects from the age composition demonstrated at the Thule culture caribou-hunting site of Aasivissuit (Meldgaard, M. 1983). Here nearly $70 \%$ of the hunted animals were younger than $2^{\mathrm{I}} / 2$ years old and this was interpreted as a result of either unintentional or inten- 
Table 47. Fusion data for caribou at Nipisat phase 2. The data are arranged in early, middle and late fusing elements. Fusing epiphyses are considered unfused. The sequence and age of fusion are according to Hufthammer (1995:41). $p=$ proximal, $d=$ distal.

\begin{tabular}{|c|c|c|c|c|c|c|}
\hline & Age in months & No. unfused & No. fusing & No. fused & Total & $\%$ unfused \\
\hline \multicolumn{7}{|l|}{ Early fusing } \\
\hline Tuber scapulae & $2-6$ & 2 & - & 3 & 5 & 40 \\
\hline Radius $p$ & $4-10$ & - & - & 5 & 5 & 0 \\
\hline Humerus d & $6-15$ & 2 & - & 1 & 3 & 66.7 \\
\hline Phalanx I p & $6-18$ & - & - & - & - & - \\
\hline Phalanx II p & $6-18$ & - & - & - & - & - \\
\hline Total & & 4 & - & 9 & 13 & 30.8 \\
\hline \multicolumn{7}{|l|}{ Middle fusing } \\
\hline Tibia d & $18-30$ & 1 & - & 3 & 4 & 25 \\
\hline Metacarpus d & $18-30$ & 1 & - & - & 1 & 100 \\
\hline Metatarsus d & $18-30$ & 5 & - & 2 & 7 & 71.4 \\
\hline Calcaneus & $18-42$ & - & - & 3 & 3 & 0 \\
\hline Total & & 7 & - & 8 & 15 & 46.7 \\
\hline \multicolumn{7}{|l|}{ Late fusing } \\
\hline Radius d & $36-48$ & 1 & - & - & 1 & 100 \\
\hline Femur $\mathrm{p}$ & $36-48$ & 5 & - & - & 5 & 100 \\
\hline Femur d & $36-48$ & 2 & - & - & 2 & 100 \\
\hline Tibia $p$ & $36-48$ & 1 & - & 2 & 3 & 33.3 \\
\hline Ulna $p$ & $42-48$ & - & - & 1 & 1 & 0 \\
\hline Humerus $p$ & $42-54$ & 4 & - & - & 4 & 100 \\
\hline Total & & 13 & - & 3 & 16 & 81.3 \\
\hline All groups & & 24 & - & 20 & 44 & 53.3 \\
\hline
\end{tabular}

tional selective hunting (Meldgaard, M. 1983). Unintentional selective hunting may indeed have resulted in a comparatively large contingent of yearlings (Meldgaard, M. 1983:table 4) because yearlings would not normally be a preferred age group. Yearlings have a less fine hide than calves and they have not yet gained as much body weight and fat or as large antlers as adults. From the age profile at Nipisat, it seems that calves were hunted probably because of their fine hides and that subadults, having the body size of

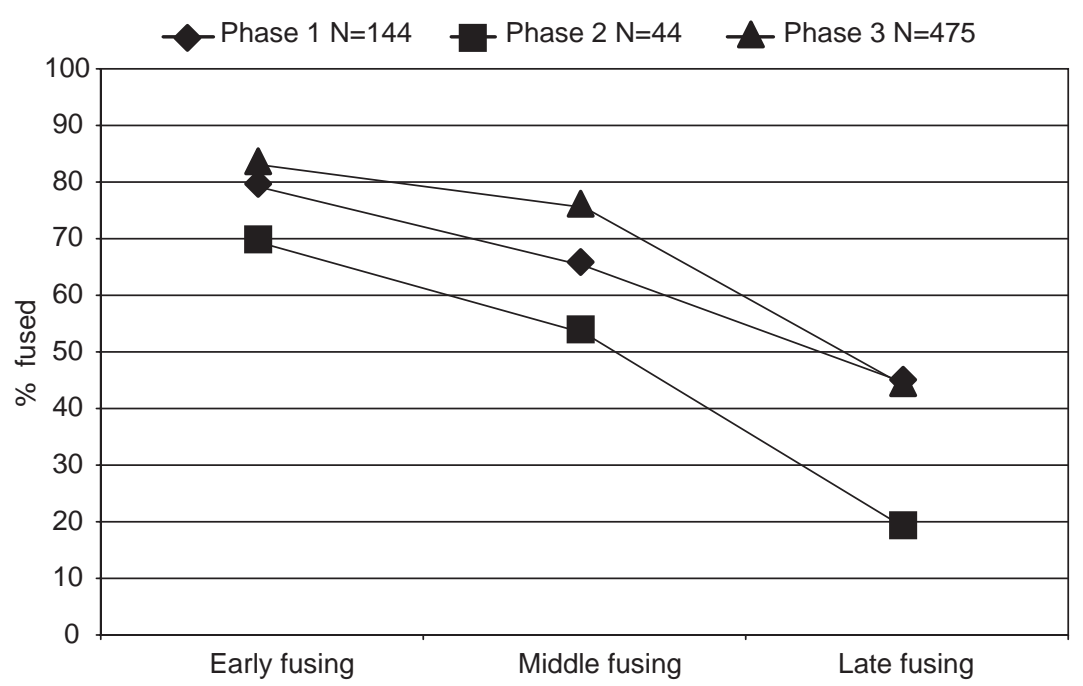

Fig. 177. The proportion of early, middle, and late fusing caribou bones of the Nipisat assemblage and their distribution by phase. (Data compiled from Tables 46-48). 
Table 48. Fusion data for caribou at Nipisat phase 3. The data are arranged in early, middle and late fusing elements. Fusing epiphyses are considered unfused. The sequence and age of fusion are according to Hufthammer (1995:41). $p=$ proximal, $d=$ distal.

\begin{tabular}{|c|c|c|c|c|c|c|}
\hline & Age in months & No. unfused & No. fusing & No. fused & Total & $\%$ unfused \\
\hline \multicolumn{7}{|l|}{ Early fusing } \\
\hline Tuber scapulae & $2-6$ & 6 & 3 & 18 & 27 & 33.3 \\
\hline Radius $p$ & $4-10$ & 4 & 2 & 26 & 32 & 18.8 \\
\hline Humerus d & $6-15$ & 4 & 2 & 14 & 20 & 30 \\
\hline Phalanx I p & $6-18$ & 8 & & 57 & 65 & 12.3 \\
\hline Phalanx II p & $6-18$ & 2 & & 36 & 38 & 5.3 \\
\hline Total & & 24 & 7 & 151 & 182 & 17.0 \\
\hline \multicolumn{7}{|l|}{ Middle fusing } \\
\hline Tibia d & $18-30$ & 10 & 1 & 33 & 44 & 25 \\
\hline Metacarpus d & $18-30$ & 6 & & 26 & 32 & 18.8 \\
\hline Metatarsus d & $18-30$ & 10 & & 38 & 48 & 20.8 \\
\hline Calcaneus & $18-42$ & 13 & & 26 & 39 & 33.3 \\
\hline Total & & 39 & 1 & 123 & 163 & 24.5 \\
\hline \multicolumn{7}{|l|}{ Late fusing } \\
\hline Radius d & $36-48$ & 7 & 1 & 12 & 20 & 40 \\
\hline Femur $p$ & $36-48$ & 20 & & 10 & 30 & 66.7 \\
\hline Femur d & $36-48$ & 10 & & 4 & 14 & 71.4 \\
\hline Tibia $p$ & $36-48$ & 20 & & 7 & 27 & 74.1 \\
\hline Ulna $p$ & $42-48$ & 8 & 1 & 18 & 27 & 33.3 \\
\hline Humerus $p$ & $42-54$ & 6 & & 6 & 12 & 50.0 \\
\hline Total & & 71 & 2 & 57 & 130 & 56.2 \\
\hline All groups & & 134 & 10 & 331 & 475 & 30.3 \\
\hline
\end{tabular}

adults, and adults were selectively hunted for meat, fat and antler. The age composition of caribou, the dominate game at the Saqqaq site of Itinnera was not analysed, however six out of 48 left mandibles (I3\%) still retained deciduous teeth (Møhl I972) and were thus younger than c. $2^{\mathrm{I}} / 2$ year. On the basis of age profiles, it is, however, difficult to compare the caribou hunting strategies at Nipisat with Itinnera directly, as preservation and excavation methods of the two sites differ and may have biased the bone assemblages against young animals in the case of Itinnera.

Sex determination based on dimensions of caribou pubic bone. According to Lie (1973) caribou can be sexed using dimensions of the pubic bone. The female long, narrow pubic bone can be distinguished from the male pubic bone, which is short and broad and there is virtually no overlap (Lie 1973). The length of the subfossil pubic bones were difficult to measure and only minimum breadth of the pubis and minimum thickness of the pubis were measured on the Nipisat sample according to the definitions of Lie (I973:80). Only pubic bones from adult individuals with completely fused sutures of os pubis, os ischium, and os illium were measured. The Nipisat sample was compared with measurements of recent caribou of known sex from the Kangerlussuaq area. The dimensions of recent caribou pubic bones show a slight overlap between females and males while the ig subfossil pubic bones fall into two distinct groups (Fig. I78). The evidence from the admittedly small sample size indicates that the sex ratio of the hunted caribou at Nipisat was I.4:I in favour of females. The sex distribution in the natural caribou population of the Kangerlussuaq area today during July and August is close to 2:I in favour of females (Meldgaard, M. 1983). The results indicate that bucks were selectively hunted at Nipisat, although the preference for bucks is not so obvious as recorded at Aasivissuit with a sex ratio of I:I (Meldgaard, M. 1983). One obvious reason for preferring 


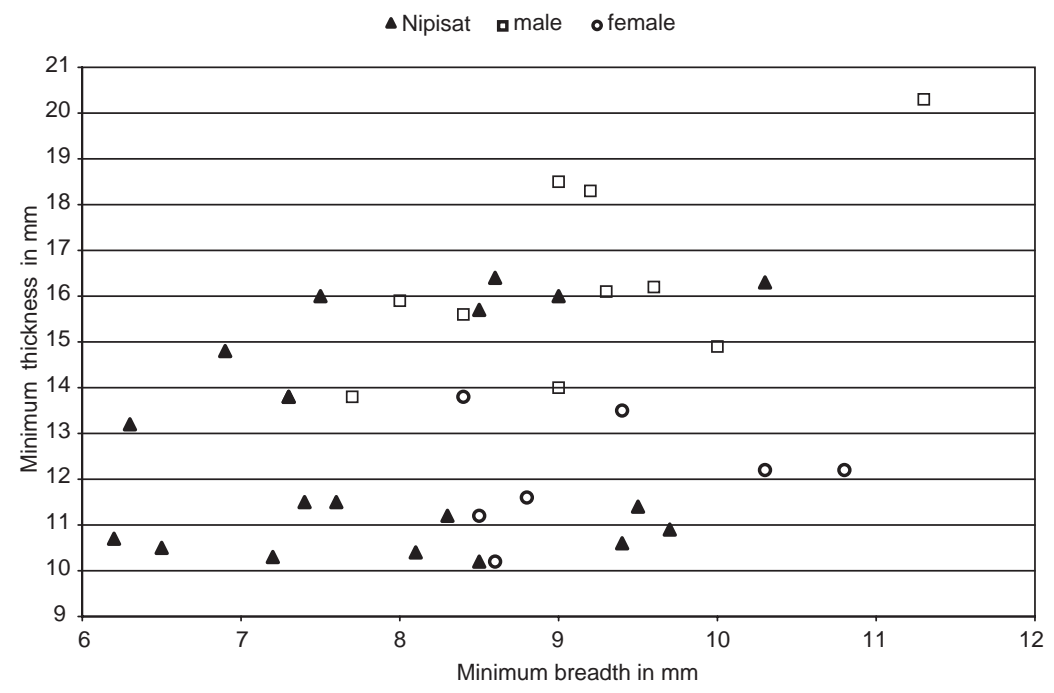

Fig. 178. Sex distribution of the Nipisat caribou based on dimensions of the pubic bone ( $\mathrm{N}=19)$. For comparison are the dimensions of pubic bones of recent caribou of known sex from the Sisimiut and Maniitsoq Districts ( $\overrightarrow{0} \hat{0}$ : $\mathrm{N}=10)$ and ( $q$ $: \mathrm{N}=7$ ).

bucks is that they have a higher percent and greater body weight than females in the autumn at least before the rut begins at the end of October (Dauphine 1976; Spiess 1979). Bucks also have the largest antlers, which were a highly appreciated resource for the inhabitants of Nipisat. Furthermore, it is easier to approach within shooting range of males than for females with their calves (Meldgaard, M. 1983).

Hunting season and strategy. From Table 44 it is seen that the young caribou calves, yearlings, and 2 year olds were killed during late summer and autumn, if we assume a date of birth on around June the first (Vibe 198I). Tooth eruption occurs primarily during the summer half of the year and development of dentition in caribou calves is retarded during winter (Edland 1969:7). Winter hunting could therefore neither be confirmed nor rejected based on tooth eruption patterns alone. It is seen that calves were a prized game and even more frequently hunted than yearlings (Fig. I76). The shorthaired soft hides from calves were well suited for summer and children's clothing, as known from historical information (H.C. Petersen pers. comm. in Grønnow et al. 1983). Besides being prized for their hides, the calves, together with yearlings and two year old subadults, are easier to hunt than adult caribou because they are still curious, inexperienced and easier to get within shooting distance of. Despite the fact that calves and yearlings are more frequent in the natural population during July/August than each successive age class (Meldgaard, M. 1983) and easier to hunt, the age distribution of the hunted caribou at
Nipisat, as documented by mandible age profiles and the post cranial skeleton indicates that adults older than c. $2^{\mathrm{I}} / 2$ years were preferred. An ethnographic example illustrating this preference for adults comes from the Nunamiut Eskimos (Binford I978:table 2.I3).

The kill-off pattern shown in Fig. 176 would not be expected for a typical drive hunt but would be more indicative of selective hunting and stalking as the dominating hunting technique. The age and sex distribution seen at Nipisat does not necessarily reflect the distribution in the hunted population but represents the hunter's choice as to which caribou carcass parts (and age groups) to bring to the island for further processing. According to Binford (1978:85-86) calves and subadults were often killed solely for their skins and hence left unbutchered at the kill site. In the case of Nipisat, the caribou bones do not seem to reflect this pattern, although we have no means of estimating the number of carcasses left on the mainland. The site was used for centuries and both drive hunting and stalking may be reflected in the caribou assemblage.

Horizontal distribution of the caribou remains. Caribou remains were scattered over the entire site although with some concentrations. The distribution of individual skeletal elements or body parts reveals no particular patterning. Fragments and splinters of long bones deriving from marrow fracturing occurred in all phases and were scattered over many squares, however, the highest numbers occurred in squares with a high score of total number of caribou bones. The gradual accumulation of caribou bones over long time spans proba- 

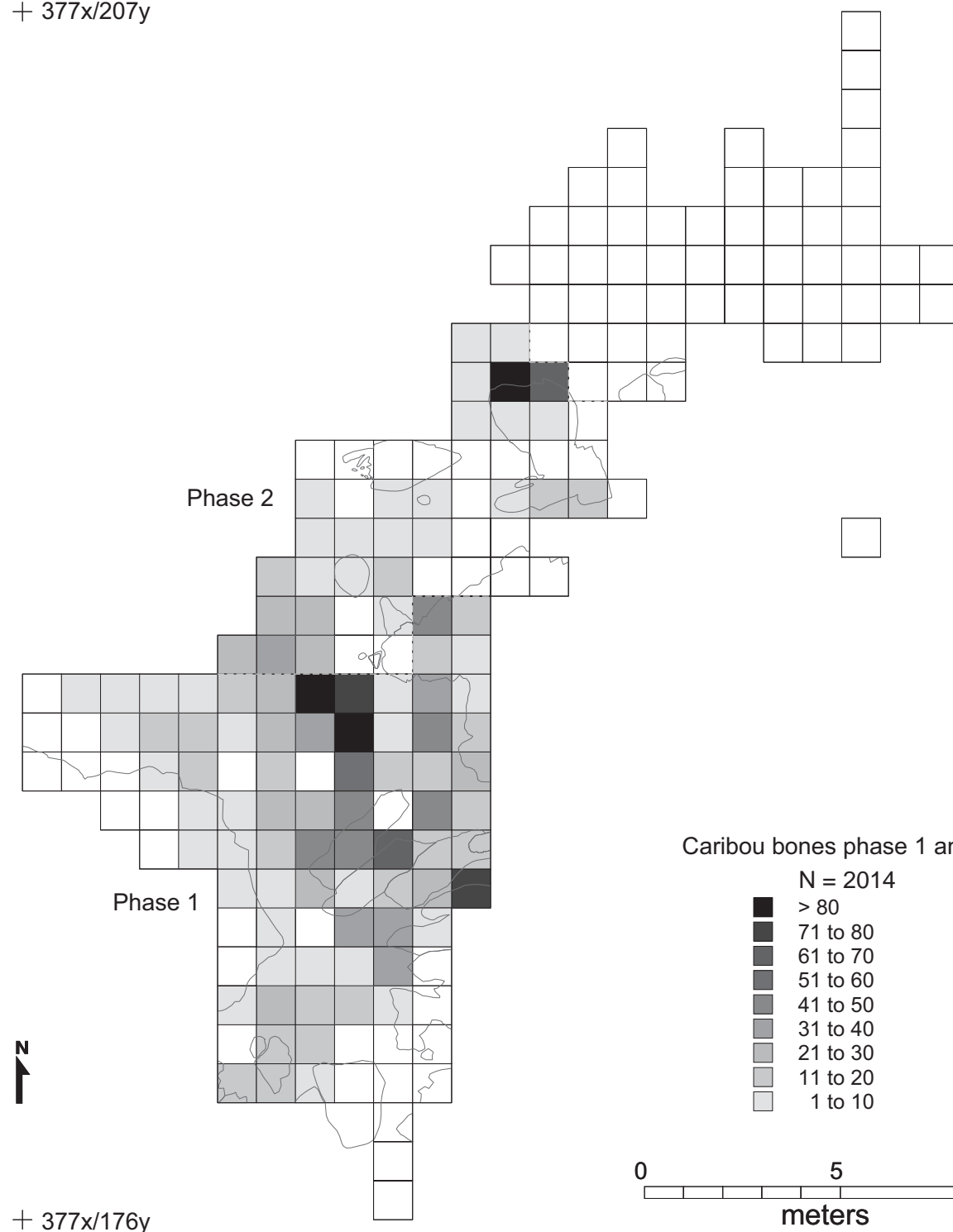

Fig. 179. Horizontal distribution of caribou bones and teeth (except antler fragments) in phase 1 and 2.

Caribou bones phase 1 and 2

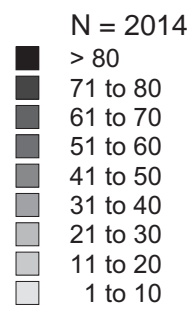

0 5 10 meters bly blurred the presence of specific processing activity areas. Consequently, the distribution of caribou remains was analysed for a) all bones and teeth (Figs I79 and I8I) and b) antler (Figs I80 and I82) respectively. The distribution plots for antler included all loose antler fragments, shed as well as broken off antlers, both worked and unworked.

In the northern part of area I, phase I, two squares yielded more than 80 bones/square with Ioo (384x/ I89y) and Io6 (385x/I88y) bones respectively. In area 2, phase 2, square 389x/I97y produced 148 bones (Fig. I79). The horizontal distribution of antler in phases I and 2 (Fig. 180) was similar to that of the other skeletal elements. No concentrations occurred close to the hearth in phase 2, area 2, although there seemed to be some scattering of antler waste products near the hearth in phase I, area I (Fig. I80). Phase 3 showed concentrations in the central part of area I, but also areas 2 and 3 exhibited squares with caribou remains in abundance (Fig. 18I). In contrast to the lower phases, the antler distribution and bone distributions differed slightly in phase 3, especially in the northern part of the site (Fig. I82). Squares 391x/I97y, 391x/ I98y, 391X/199y and 392x/197y, area 3, produced 

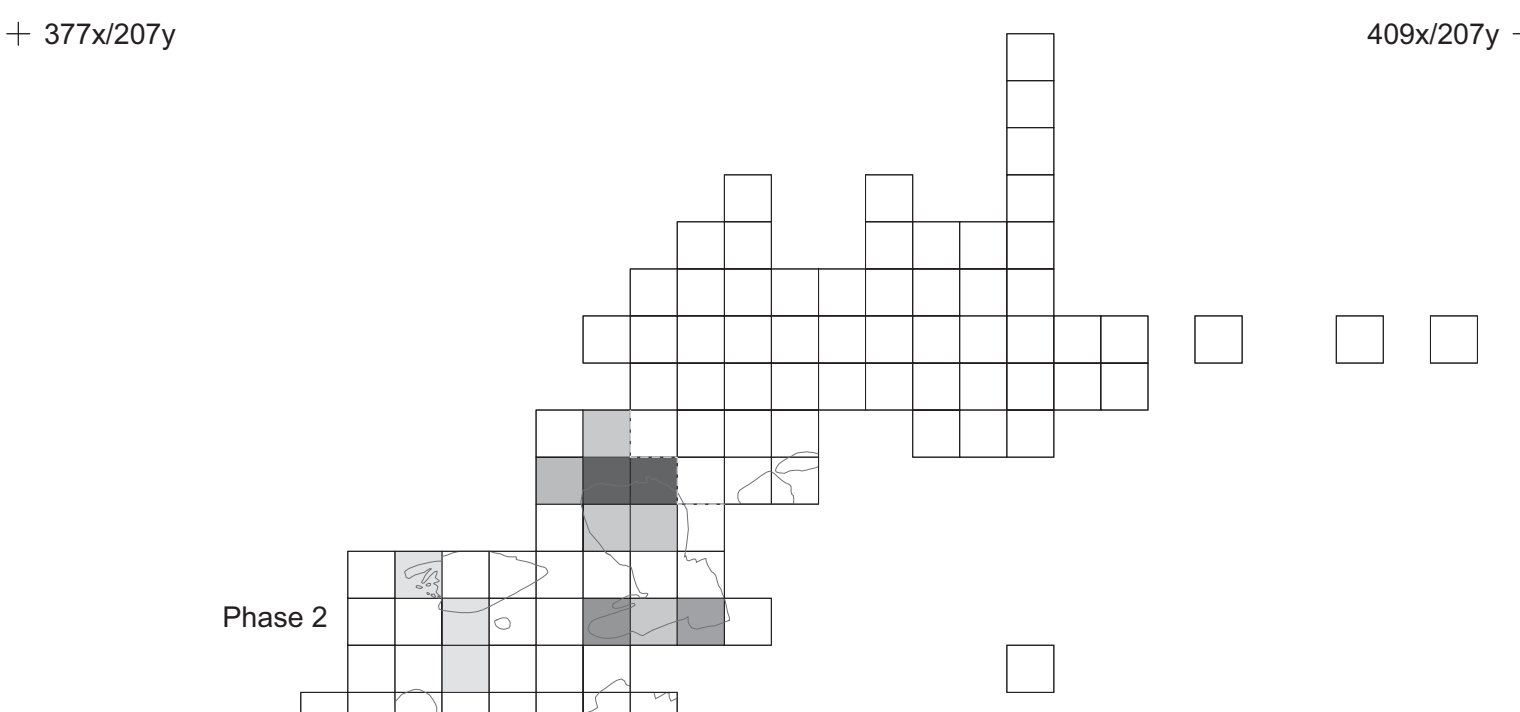

$+377 x / 176 y$

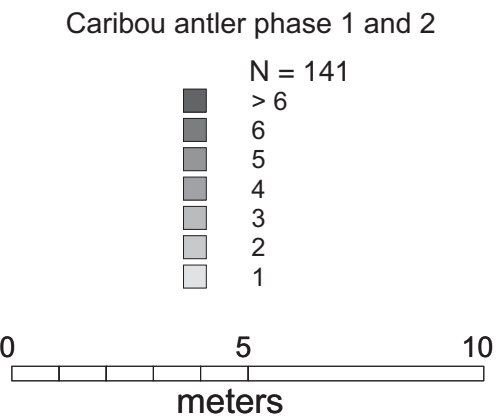

$409 x / 176 y+$

Fig. 180. Horizontal distribution of caribou antler fragments in phase 1 and 2. Both worked and unworked antler is included.

seven, fourteen, ten and eight fragments of both worked and unworked antler respectively.

Antlers were obtained by breaking or chopping them off skulls as well as through the collection of shed antlers. Phase I yielded one shed antler $(387,85 \mathrm{x} /$ 189,75y), while phase 3 yielded nine shed antlers in squares 385x/187y, 386,00x/183,80y, 386x/184y and $386 \mathrm{x} / \mathrm{I} 85 \mathrm{y}$, area I, square 389x/192y, 389x/193y and 390,62X/199,20y, area 2 and 39IX/197y and square 392X/197y, area 3. In a few instances these antler bases were made into tools (Fig. 72). Besides the loose antler fragments skulls or skull fragments with the antler base still attached were also retrieved. Phase 3 yielded one frontal bone with shed antlers (390,90x/199,25y), area 3 most likely from a female (Fig. I83, left), one with broken off antlers (386x/193y) area 2, presumably from a young male (Fig. I83, right) and one with broken off antlers $(384,20 x / 187,30 y)$ area I, from a young unsexed individual. In phase 3 , area I, five additional fragments of frontal bone with broken off antlers and one with shed antler were documented. The proportion of shed to unshed antler was, however, difficult to assess. Caribou bones and antlers were scattered all over the site, although some areas 

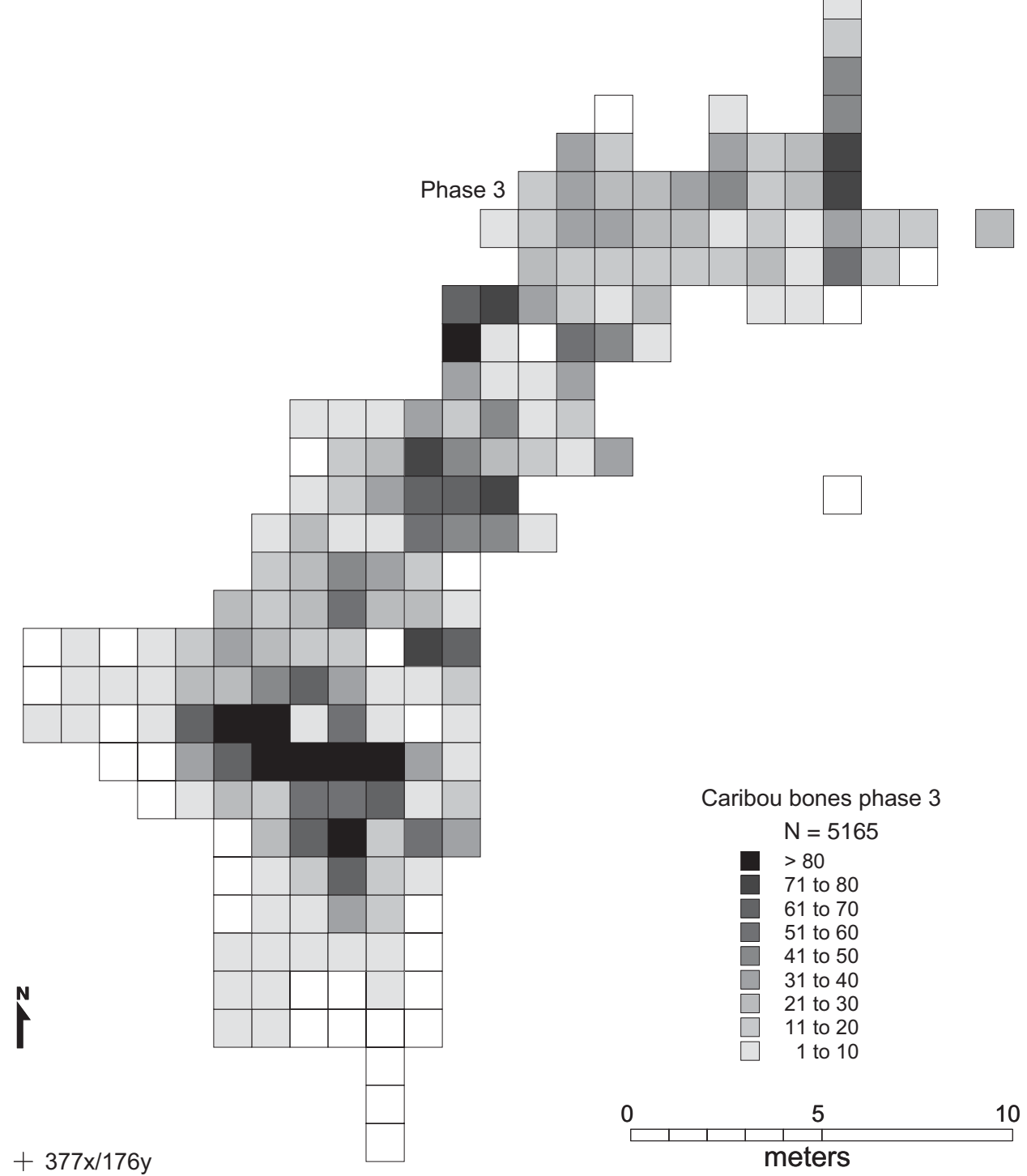

Fig. 181. Horizontal distribution of caribou bones and teeth (except antler fragments) in phase 3.

showed concentrations primarily reflecting thick midden like deposits. The scattering of long bone splinters showed that e.g. processing for marrow had occurred numerous times in different parts of the site.

Body part representation of caribou. Binford (1978) introduced utility indices of caribou carcass parts in order to explain the differential transport of skeletal parts of terrestrial mammals. They can at best serve as general guidelines only as the indices were based on very few individuals (always $\leq 4$ ) (Lyman 1996:23I). The meat and fat contents vary with age, sex and sea- son and such derived values should ideally be used on assemblages broken down into age groups. Application of utility indices requires the validity of several assumptions, i.e., that a butchering event would result in at least two assemblages, one with bones of high food value and one with bones of low food value, and that people were expected to maximize the energy output of their game animals whether in times of scarcity or not (Murray 200o). It may be argued that even though the use of utility curves may, in some cases, contribute to our understanding of the economic choices made by prehistoric people, it does not take 


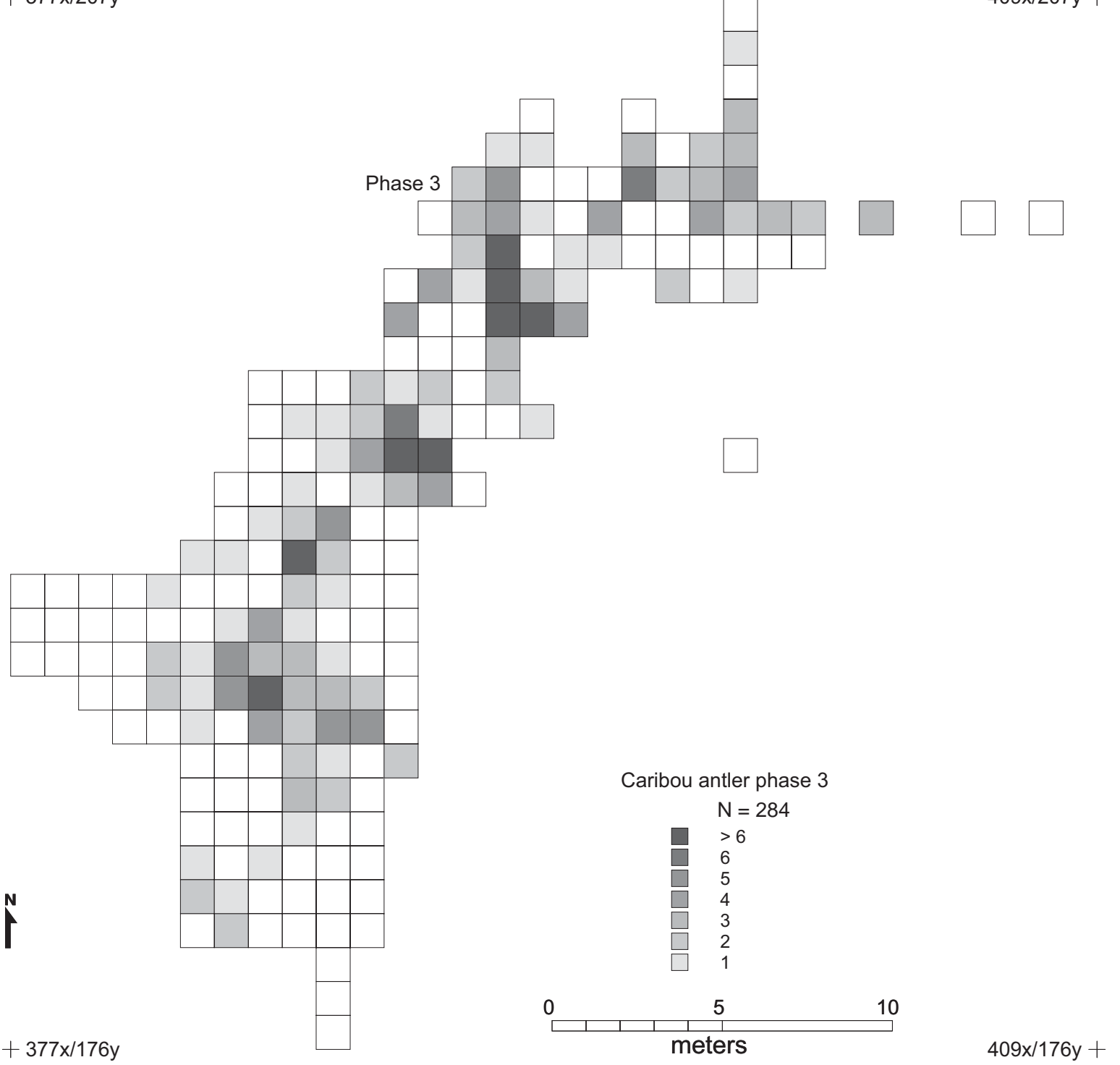

Fig. 182. Horizontal distribution of caribou antler fragments in phase 3. Both worked and unworked antler is included.

into account the fact that bone assemblages also reflect social and symbolic behaviour (Murray 2000:59).

The representation of the various skeletal parts is shown in Tables 49 and 50 and Fig. 184. Because of the small sample size, phase 2 was excluded from the MNE and MAU calculations. Antler deriving from both hunted caribou and collected shed specimens was excluded from the MNE and MAU calculations. Phases I and 3 showed an overall similar distribution of skeletal elements. The head, upper and lower portions of the front (except humerus p., phase I) and the hind leg, the pelvis and shoulder (except for scapula p., phase 3) showed \%MAU values between 26 and Ioo\%. The backbone, the rib cage, sternum (in phase I only) and the phalanges were strongly underrepresented with \%MAU values below 25\% (Fig. I84).

The apparently stronger representation of lower jaws compared to upper jaws was due to a taphonomical bias against the thin maxillary bone which is more prone to breakage and destruction than the mandible. Furthermore, the number of loose upper premolars and molars surpassed the number of loose lower teeth. These observations strongly indicate that whole skulls 
Fig. 183. Caribou skulls. Skull with shed antlers deriving from a doe killed in early summer (left) and a skull with broken off antlers deriving from a young male killed during autumn (right) (dorsal view). Photo: Geert Brovad.
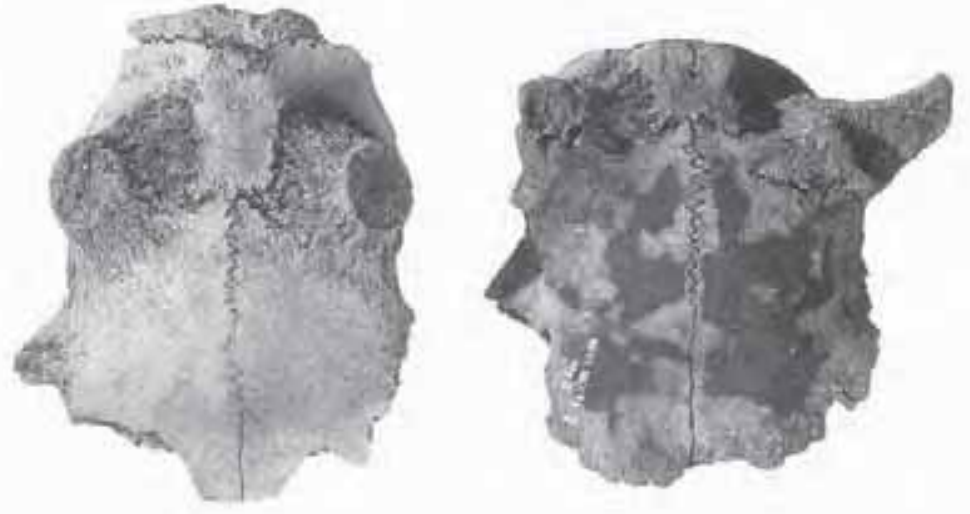

were brought to the site. Arriving at the site still articulated to the head, the atlas had a higher \%MAU value than the remaining cervical vertebrae (Table 50). Meat rich portions, as well as bones of low meat value, were brought to the site. The distal part of scapula (most likely representing whole scapulae) was quite well represented while proximal humerus had a poorer representation. This discrepancy may be explained by the low value of scapula for further use after the meat have been removed compared to humerus, which could subsequently be used for both marrow and grease extraction.

The Nipisat assemblage was dominated by skeletal elements most suitable for marrow extraction (e.g. mandibles and metapodials) while body parts with high meat yield but also usable for marrow and grease extraction (e.g. humerus, radius, femur and tibia) were only to some extent well represented. The relatively lower representation of e.g. femur d., tibia p., humerus p. may be a result of these parts being late fusing elements and thus more prone to destruction. Lower representation of these body parts could be explained by both selective destruction and selective transport, which are difficult to distinguish from each other in the archaeological record (see Lyman 1985, 1996). However, carnivore attrition was considered insignificant (see below) and in general the preservation was very good, indicating that density dependant attrition was of minor importance. The compact bones such as astragalus, calcaneus and tarsus, considered of low utility, were comparatively well represented.
However, they most likely arrived in the bone assemblage as 'riders' while still articulated to the tibia and the metatarsus (see also Binford 1978:I5I, I58) as evidenced by the high number of heel joints found in the deposits (Table 5I). The backbone, although strongly underrepresented, was in some instances disposed of on the rubbish heaps in articulated portions. Typically, a few thoracic or lumbar vertebrae were found to articulate (Table 5I, Fig. I85).

In contrast to the skeletal element distribution at Nipisat, the Thule site of Aasivissuit, interpreted as the place where coarse butchering of the carcasses took place (Meldgaard, M. 1983:80), showed a preponderance of ribs and bones of the backbone with lumbar vertebrae having MNI frequencies of $100 \%$. At the Saqqaq site of Qeqertasussuq the caribou assemblage $(\mathrm{N}=302)$ shoved a distribution with antler and bones of high food value (in particular front and hind legs) being the most frequent bone elements (Meldgaard 2004:fig. 9.36). The \%MAU of caribou at the Pita site (Fig. I, no. I7) a Pre-Dorset/Dorset Transitional site in Eastern Arctic Canada indicates that only front and hind limbs were brought to the site and that caribou were hunted elsewhere and possibly cached (Nagy 1997). At the Ohituk site (Fig. I, no. I7), another PreDorset/Dorset Transitional site, skeletal representation of caribou also indicates that limb portions, few ribs and the heads were brought to the camp (Nagy 1997:77). This is very similar to the situation seen on Nipisat. Whereas the coarse butchered caribou were probably carried to the abovementioned sites at 


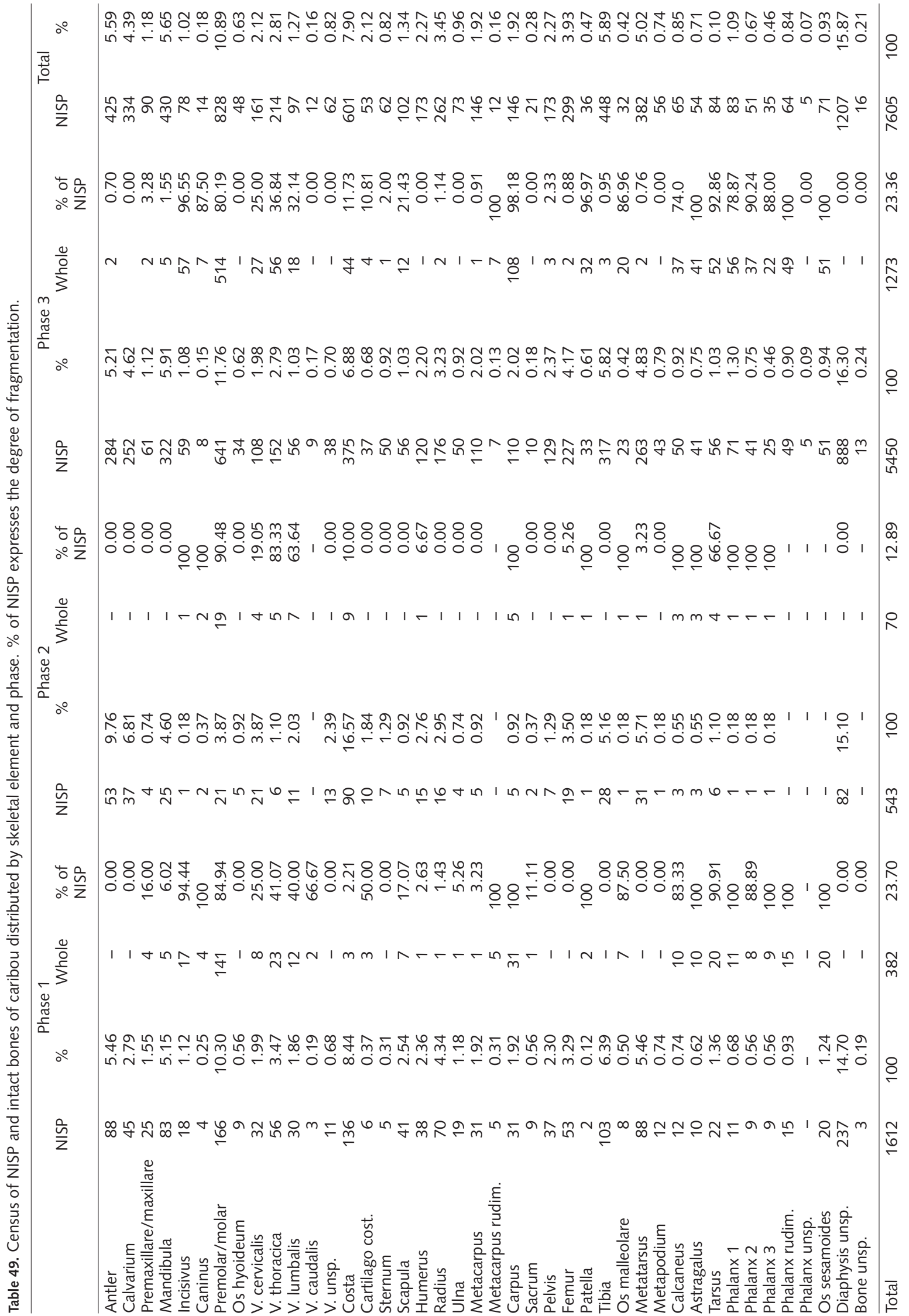


Table 50. MNE, MAU and \%MAU of caribou from phase 1 and phase 3 .

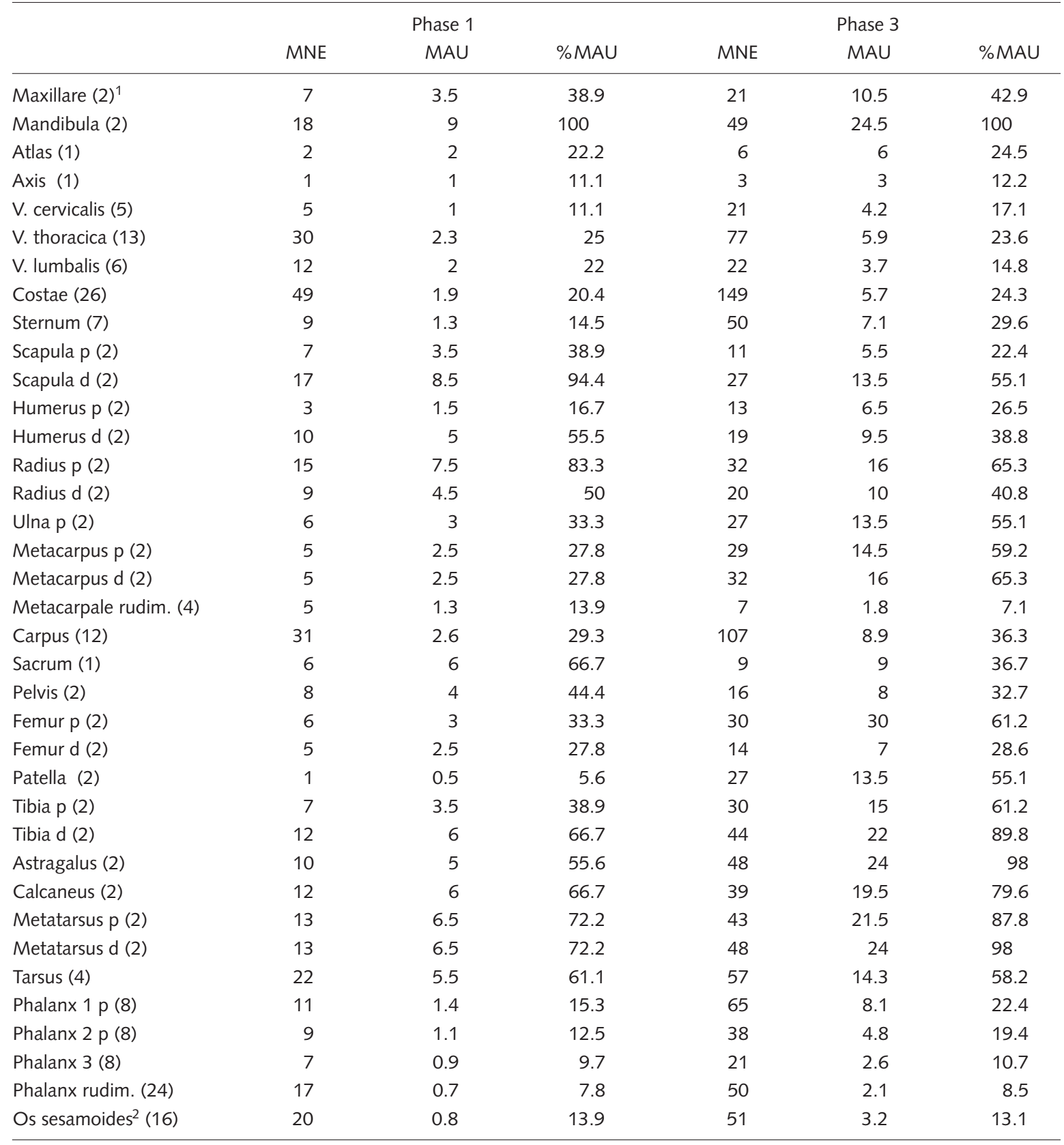

${ }^{1}$ the number of that particular skeletal element in a complete caribou skeleton.

2 only ossa sesamoidea proximales are included.

Ivujivik, it is noteworthy that the caribou at Nipisat must have been transported by boat. In that perspective it is worth noticing that heads were brought to the site in such abundance. Normally, one would expect heads to have been left behind at the kill site, to ease the burden when stalking was the primary way to hunt caribou (Meldgaard, M. 1983:78).

The destination of the bones of II caribou killed by a Nunamiut hunter was summarised by Binford (I978:table 5.I3). Mandibles, maxillary bone and, to some extent, cervical vertebra and feet were abandoned at the kill site. Quite a large proportion of the meat yielding and marrow containing bone elements (humerus, radius/ulna p, femur, tibia and metapodials but also tarsals) were abandoned at the drying camp during processing. Bones of the rib cage, verte- 


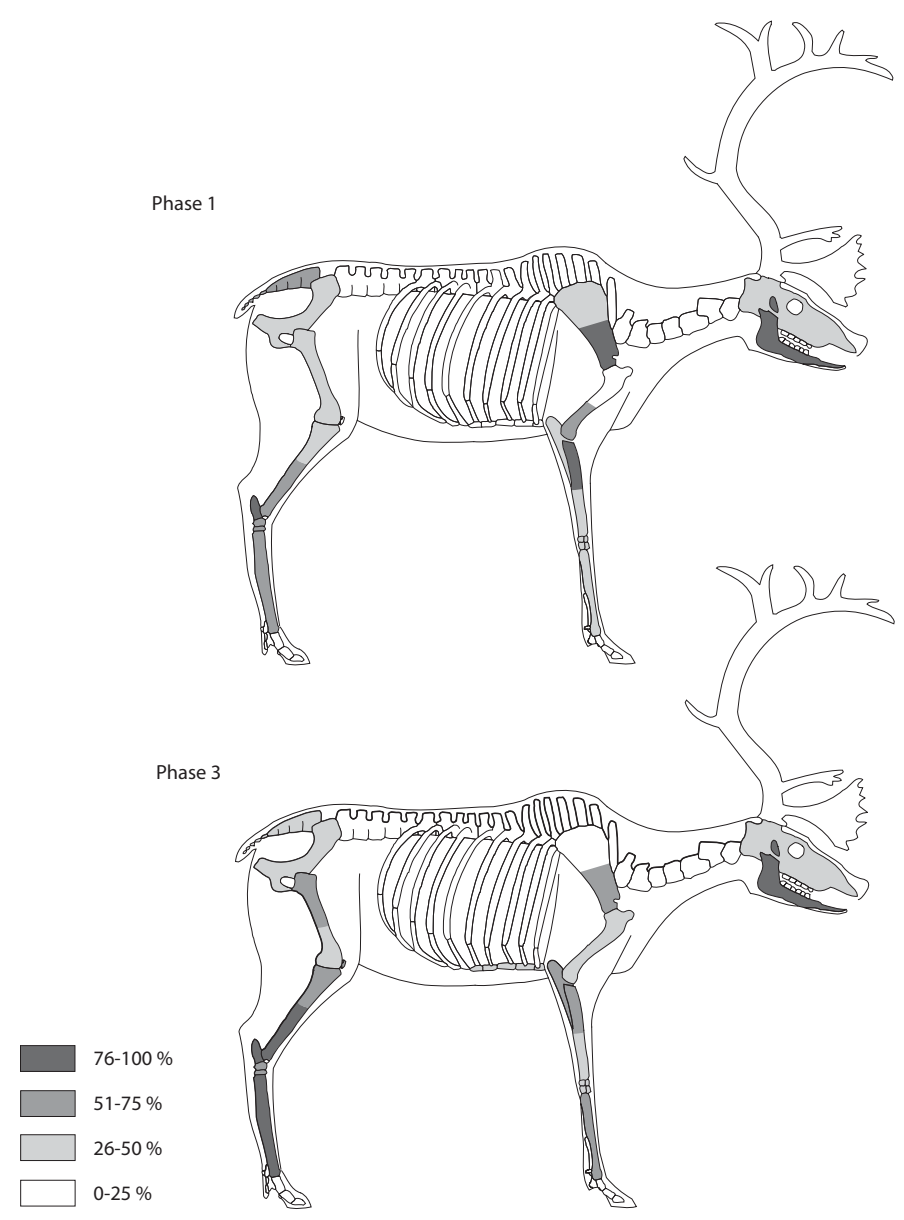

Fig. 184. Relative frequencies of caribou bone elements at Nipisat. The frequencies are \%MAU from Table 50.

brae, the scapula and the forelimb were carried to the summer base camp. This distribution of skeletal elements between various types of campsites was not applicable to the Nipisat caribou bone assemblage. The Nipisat caribou remains indicated that the head, often as whole skulls, entire hind legs including the pelvis and the fore limbs including the scapula were brought to the site, however mostly the hooves were left at the kill site (e.g. Meldgaard, M. I983:80, fig. 85).

Taking into account that the Nipisat assemblage comprised body parts known to have been abandoned at the kill site when transportation was a problem (Binford 1978:47ff) it might be speculated that caribou hunting took place on the mainland but not necessarily far inland and that all usable parts were brought to the campsite for further processing (Gotfredsen I996: I07, I998). The caribou bones are leftovers from several activities comprising filleting for immediate consumption and possibly drying for storage. After fillet- ing of the fore and hind legs the bones were not discarded as whole articulated portions as observed elsewhere (Binford I98I:fig. 4.35; Grønnow I985:I40) but further processed for marrow and grease extraction. Hides and stomach and intestine contents were most likely also used. Tool manufacturing took place with antler as the most important raw material but metapodials and scapula were also used (Fig. I92).

Fragmentation patterns. At Nipisat the caribou bones were heavily fragmented and almost all long bones were marrow fractured (Table 49 and Fig. I86). The intact long bones in Table 49 were in most cases from very young calves and only one whole metacarpus, phase I, and one radius, phase 3 derived from adults. The metatarsals were marrow fractured in a characteristic pattern often leaving three recognizable fragment types, a proximal part, the diaphysis and a distal part (Fig. I87, see also Gotfredsen I996:I08). All other mar- 
Table 51. Articulated bones of caribou at Nipisat distributed by body part and phases. It is seen that the heal joint and portions of the backbone are the most frequently occurring articulated parts. Number of bone elements is given in brackets.

\begin{tabular}{|c|c|c|c|c|}
\hline & Phase 1 & Phase 2 & Phase 3 & Total \\
\hline Backbone & $\begin{array}{l}383 x / 189 y \text { four } v \text {. thoracales } \\
385 x / 184 y \text { three } v \text {. thoracales } \\
385,57 x / 188,70 y \text { three } v \text {. } \\
\text { caudales } \\
387 x / 191 y \text { five } v \text {. lumbales }\end{array}$ & $382 x / 190 y$ two v. lumbales & $\begin{array}{l}383 x / 187 y \text { two } v . \text { lumbales (subadult) } \\
389 x / 198 y \text { two v. thoracales } \\
391 x / 198 y \text { three } v \text {. thoracales } \\
398 x / 204 y \text { four v. thoracales } \\
392 x / 200 y \text { six v. thoracales (subadult) }\end{array}$ & $10(34)$ \\
\hline Fore limb & $\begin{array}{l}385,53 x / 189,44 y \text { two carpales } \\
\text { (dex) }\end{array}$ & $384 x / 194 y$ two carpales & $\begin{array}{l}385 x / 186 y \text { proximal part of } \\
\text { radius and ulna (dex) }\end{array}$ & $3(6)$ \\
\hline Hind limb & $\begin{array}{l}385,14 x / 187,15 y \text { centrotarsale } \\
\text { and tarsale (dex) } \\
387 x / 189 y \text { distal tibia and } \\
\text { unfused distal epiphysis, } \\
\text { astragalus, calcaneus, } \\
\text { centrotarsale, tarsale and os } \\
\text { malleolare (dex) }\end{array}$ & $\begin{array}{l}389 x / 197 y \text { astragalus, } \\
\text { calcaneus, centrotarsale, } \\
\text { tarsale (sin) }\end{array}$ & $\begin{array}{l}383 x / 186 y \text { astragalus, calcaneus, } \\
\text { centrotarsale and tarsale (sin, } \\
\text { juvenile) } \\
384 x / 188 y \text { calcaneus, centrotarsale, } \\
\text { tarsale (sin) } \\
384 x / 190 y \text { distal tibia, astragalus, } \\
\text { calcaneus, tarsale and os malleolare (sin) } \\
387 x / 193 y \text { astragalus, calcaneus } \\
\text { and centrotarsale (sin) } \\
387 x / 194 y \text { astragalus, calcaneus, } \\
\text { tarsale and os malleolare (dex, juvenile) } \\
397 x / 202 y \text { distal tibia, astragalus, } \\
\text { calcaneus and centrotarsale (dex) }\end{array}$ & $9(35)$ \\
\hline Foot & 386x/185y phalanx I, II and III & & $\begin{array}{l}384 x / 183 y \text { phalanx I, II and III } \\
388 x / 197 y \text { phalanx I and phalanx II } \\
\text { (pullus) }\end{array}$ & $3(8)$ \\
\hline Total & $8(28)$ & $3(8)$ & $14(47)$ & $25(83)$ \\
\hline
\end{tabular}

row containing long bones were cracked open for marrow extraction. Most mandibles were marrow fractured leaving three (to four) typical fragments; the aboral part, the tooth bearing part and a basal part of the corpus mandibulae (Fig. I88). Blow marks were often noticed along the corpus mandibulae ventral to the tooth row both on the buccal and lingual side (Fig. I88). Calvaria were also heavily smashed and no whole brain cases were retrieved. The phalanges occurring in low frequencies were in most cases intact (Table 49).

In his study of the Nunamiut Eskimos, Binford (1978:470) noticed that there was a tendency for marrow fracturing of pelves, mandibles and phalanges to increase if resources were scarce. The intensive use, meaning marrow fracturing of almost all marrow containing bones, of the caribou bones at Nipisat seemed to be rather consistent for the whole period of occupancy. It would thus be too simplistic to infer that the intensive exploitation of selected parts brought to the site by boats is indicative of resource stress.

In contrast to the situation at Nipisat, the mandibles were in most cases whole at the contemporary site of Itinnera, Nuuk District (Møhl I972:I6), although other marrow-bones were smashed, indicating a different and possibly more extensive use of caribou at the hunting station in the Nuuk inland. At Itinnera the hunting season was very brief (Møhl I972:I6) and nearly $95 \%$ of the bone assemblage were caribou (see Table 54). According to Møhl (I972:I6) the very easy access to marrow and fat in other readily accessibly parts of the animal explained the large proportion of whole mandibles. The two Saqqaq sites Nipisat and Itinnera had different functions and therefore left different caribou assemblages. According to Binford (I98I) marrow splitting was a typical camp activity and good marrow-bones could be carried to the hunting camp. Systematic marrow fracturing was, howev- 


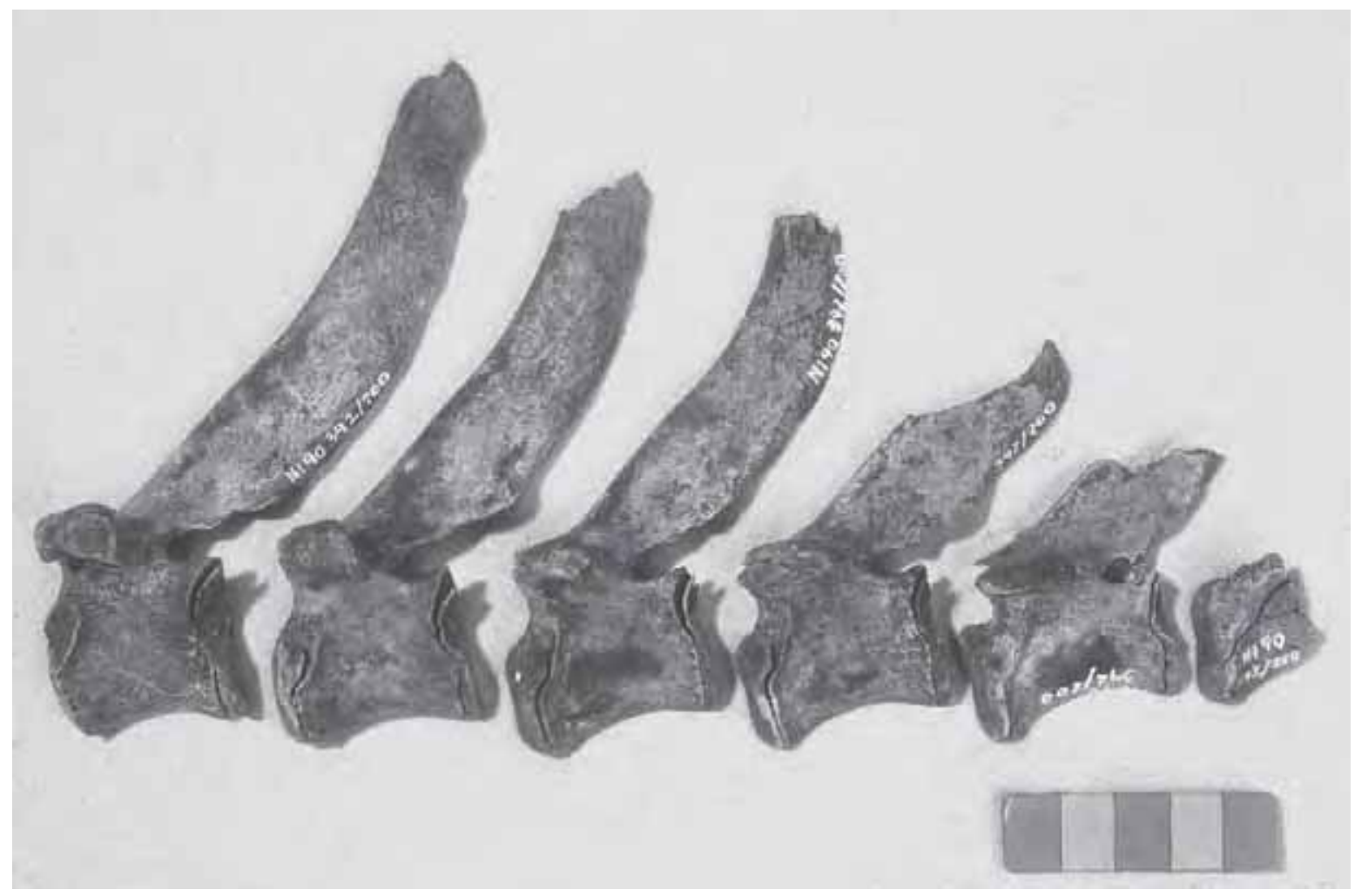

Fig. 185. Caribou thoracic vertebrae found in correct anatomical order. A part of the caribou backbone was thrown on the midden. Photo: Geert Brovad.

er, carried out by women at the base camp. At Nipisat, marrow fracturing was an activity carried out along with other activities associated with the exploitation of caribou.

Based on analyses of bone fragmentation and bone fracture types Outram (I999) claimed that Palaeo-Eskimos were less resource stressed than e.g. the Norse inhabitants of South Greenland. His conclusions were based on the fact that marrow extraction and grease rendering at Itinnera, Nuuk District, was less exhaustive than at the two Norse sites Sandnes and Niaquusat, Nuuk District. Methods for assessing degree of fragmentation outlined by Outram (1999) were not applied to the Nipisat assemblage. It is however evident that the bones, especially long bones and mandibles, were extremely fragmented and heavily smashed. Therefore it must be stressed that, even though analyses of fracture and fragmentation can be a useful palaeoeconomic measuring device, the question of site type is too important a parameter to be ignored.
Bone alterations. The damage inflicted to the caribou bone assemblage is summarized in Table 52. Unequivocal gnawing marks were observed in low frequencies for the three phases with an average of $\mathrm{.} .6 \%$ (Table 52). Most of the damage is ascribed to fox and dog/wolf and was observed primarily on bones with much soft and cancellous tissue such as vertebrae, ribs, pelvic bones and articular ends of long bones (Fig. 189). The low incidence of gnawing was in accordance with observations from other Palaeo-Eskimo sites, e.g. the Crane site with $2.5 \%$ carnivore damage. At Aasivissuit carnivore damage occurred in very low frequencies too, presumably because little meat was left on the bones (Meldgaard, M. 1983:77). At Nipisat, the caribou bones were leftovers from various processes, intensively exploited and discarded either in a raw or boiled condition and hence expected to have retained little meat and fat. The scarcity of fly puparia in the Nipisat assemblage supports this explanation. The main reason why carnivore attrition was so relatively low may, however, be because the Saqqaq peo- 


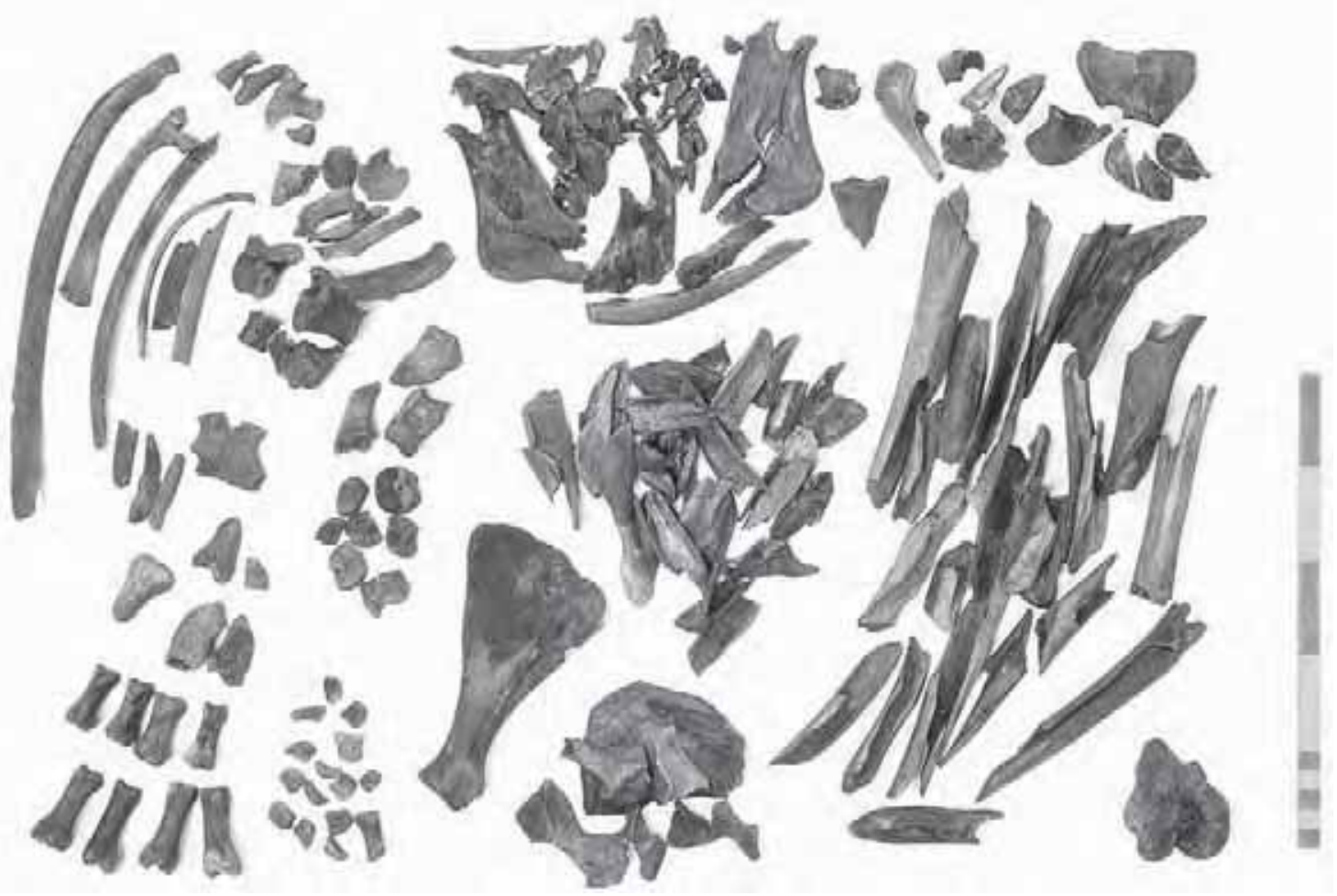

Fig. 186. Typical fragment types of caribou bones from square 383x/186y, layer 2, phase 3. Photo: Geert Brovad.

ple visited Nipisat for only brief periods at a time and that sediments partly covered the bones quickly.

Cut marks were observed on I.2\% of the bones, most frequently occurring on mandibles, ribs and femora (Table 52). The interpretation of the cut marks agrees with the results obtained from the avian remains. Most marks were made during the filleting and defleshing process. Cut marks at the hyoid bone and the lateral face of the ramus mandiblae were inflicted when the tongue and the masseter muscle were removed. Impact marks were not assessed systematically and only very clear impact scars were recorded. As expected, impact marks occurred on the shafts of long bones and mandibles (Table 52). Only one charred fragment of an unspecified long bone (395x/200y), phase I was recovered. Only three caribou bones exhibited signs of pathology all deriving from phase 3. A distal part of a left metatarsus (402X/200y) showed thickening of the medial face (Fig. 190), besides one left diaphysis of metatarsus $(385,82 \mathrm{x} / \mathrm{I} 88,80 y)$ and one alveoli of $\mathrm{P}_{4}$ showed pathological tissue. No healed lesions were observed.

Size of the Nipisat caribou. Because the majority of long bones were cracked open for marrow extraction (Fig.

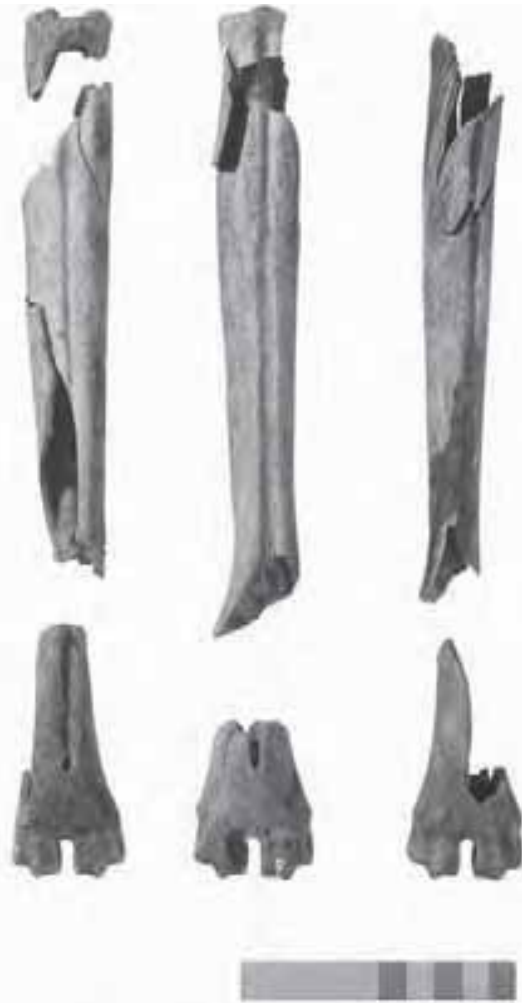

Fig. 187. The caribou metatarsals at Nipisat were marrow fractured in a characteristic manner known from contemporary sites and Neo-Eskimo sites in Greenland. Photo: Geert Brovad. 

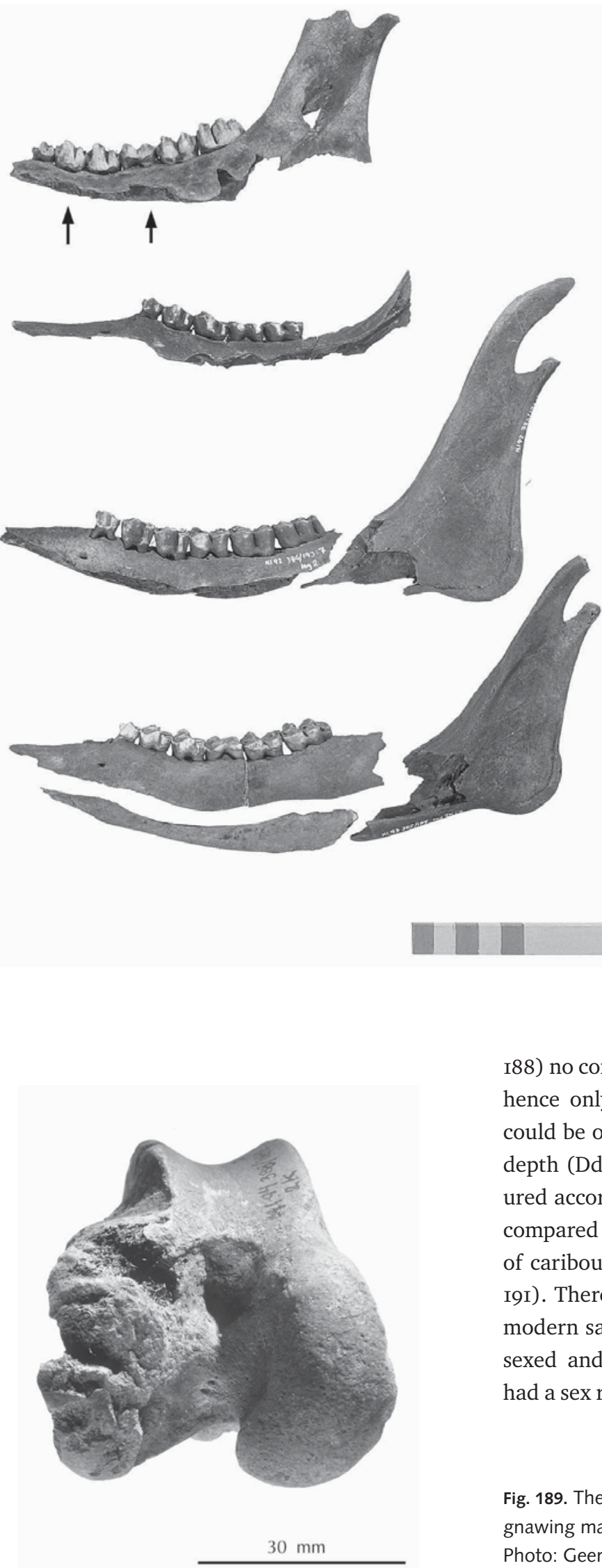

$30 \mathrm{~mm}$
Fig. 188. A collection of typical fragments derived from marrow fractured caribou mandibles at Nipisat. To extract the nutritious marrow, the mandibles were broken into three or four fragments. Note impact scars (arrow). Photo: Geert Brovad.

Anne Birgitte Gotfredsen \& Tinna Møbjerg: 
Table 52. Summary of alteration on caribou bones from the Nipisat site (NISP=7605).

\begin{tabular}{|c|c|c|c|c|c|c|c|c|c|c|c|c|}
\hline & \multicolumn{4}{|c|}{ Gnawing } & \multicolumn{4}{|c|}{ Cut marks } & \multicolumn{4}{|c|}{ Blow marks } \\
\hline & Phase 1 & Phase 2 & Phase 3 & Total & Phase 1 & Phase 2 & Phase 3 & Total & Phase 1 & Phase 2 & Phase 3 & Total \\
\hline Calvarium & - & 1 & 1 & 2 & - & - & 1 & 1 & - & - & - & - \\
\hline Mandibula & - & - & 1 & 1 & 1 & - & 10 & 11 & 2 & 1 & 16 & 19 \\
\hline Os hyoideum & - & - & - & - & 1 & - & 6 & 7 & - & - & - & - \\
\hline V. cervicalis & 1 & 1 & 3 & 5 & - & - & 1 & 1 & - & - & - & - \\
\hline V. thoracica & 2 & - & 9 & 11 & - & - & 3 & 3 & - & - & - & - \\
\hline V. lumbalis & - & - & 3 & 3 & - & - & - & - & - & - & - & - \\
\hline V. unspc. & - & - & 1 & 1 & - & - & - & - & - & - & - & - \\
\hline Sacrum & 1 & - & 1 & 2 & - & - & - & - & - & - & - & - \\
\hline Costa & 6 & 1 & 7 & 14 & 8 & - & 11 & 19 & - & - & - & - \\
\hline Sternum & 1 & - & 8 & 9 & - & - & 2 & 2 & - & - & - & - \\
\hline Scapula & 2 & 1 & 4 & 7 & 2 & - & 1 & 3 & - & - & - & - \\
\hline Humerus & 2 & 1 & 1 & 4 & 2 & 1 & 3 & 6 & - & - & 2 & 2 \\
\hline Radius & - & - & 2 & 2 & - & 1 & 1 & 2 & 2 & - & 3 & 5 \\
\hline Ulna & 1 & 1 & 3 & 5 & 1 & - & - & 1 & - & - & - & - \\
\hline Metacarpus & - & - & - & - & - & - & 2 & 2 & 1 & - & 4 & 5 \\
\hline Carpus & 1 & - & - & 1 & - & - & - & - & - & - & - & - \\
\hline Pelvis & 4 & 1 & 9 & 14 & 1 & - & 2 & 3 & - & - & - & - \\
\hline Femur & 4 & 1 & 8 & 13 & 3 & 1 & 6 & 10 & 1 & - & 1 & 2 \\
\hline Patella & - & - & 6 & 6 & - & - & - & - & - & - & - & - \\
\hline Tibia & 1 & 1 & 5 & 7 & 2 & - & 4 & 6 & 1 & - & 2 & 3 \\
\hline Metatarsus & 1 & - & 1 & 2 & - & - & 4 & 4 & - & - & 7 & 7 \\
\hline Calcaneus & - & - & 6 & 6 & - & - & - & - & - & - & - & - \\
\hline Tarsus & 1 & - & 1 & 2 & - & - & - & - & - & - & - & - \\
\hline Diaphysis unspc. & - & - & 1 & 1 & 5 & - & 9 & 14 & - & - & 1 & 1 \\
\hline Phalanx & - & - & 4 & 4 & - & - & - & - & - & - & - & - \\
\hline Total & 28 & 9 & 85 & 122 & 26 & 3 & 66 & 95 & 7 & 1 & 36 & 44 \\
\hline$\%$ NISP & 1.7 & 1.7 & 1.6 & 1.6 & 1.6 & 0.6 & 1.2 & 1.2 & 0.4 & 0.2 & 0.7 & 0.6 \\
\hline
\end{tabular}

from data on pubic bones (Fig. 178). The Nipisat caribou had a lower mean and the range falls slightly below that of the extant caribou. This may be explained by the presumed preponderance of females in the material.

The site of Itinnera (Nuuk District), comparable in age to Nipisat, yielded remains of a very small Rangifer tarandus peariy sized caribou (Meldgaard I986:figs 48 and 49, p. 50). Besides being extremely small, they also differ morphologically from modern populations by having an absent or rudimentary posterior lobe of the lower third molar $\left(\mathrm{M}_{3}\right)$ (see Degerbøl and Krogh I959; Møhl I972). It was argued that the caribou represented at Itinnera differed genetically from present day caribou populations (Meldgaard I986:I5, 50). The size range of the Nipisat and the Itinnera sample overlap (Table 53), although the mean at Itinnera $(\mathrm{N}=\mathrm{II})$ is lower than at Nipisat $(\mathrm{N}=39)$. All examined lower third molars at Nipisat have a normally developed posterior lobe supporting Meldgaard's suggestion (I986:50) that there was a genetically based difference between the two contemporary caribou populations of the Sisimiut and the Nuuk areas and that the Sukkertoppen Ice Cap may have acted as a physical barrier between the two populations.

The caribou hunted during the occupation of Nipisat were, by and large, of a size comparable to recent caribou from the Sisimiut area and to caribou from e.g. Malmquist site dated to c. $400 \mathrm{BC}$ and Aasivissuit dating to c. I650-I750 AD (see Table 53).

In conclusion, caribou were hunted during late summer and autumn and possibly spring supposedly on the mainland where the coarse butchering took place. Although caribou are known to expand their 


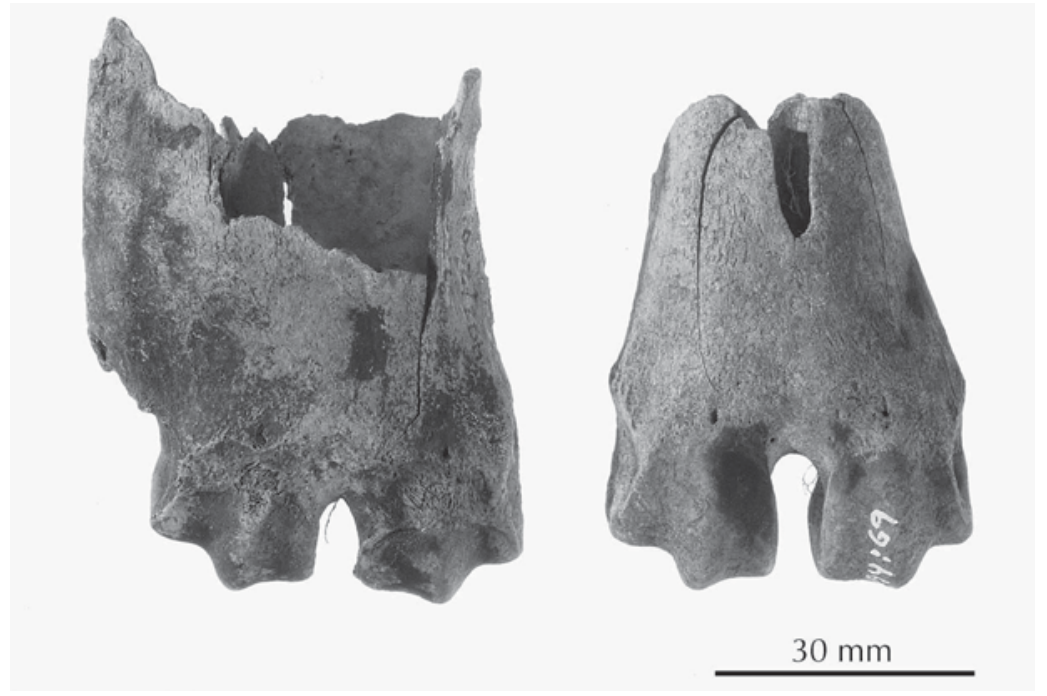

Fig. 190. Caribou metatarsal distal ends. Pathological (left) and normal (right) metatarsal (cranial view). Photo: Geert Brovad.

range to marginal territories e.g. off shore islands during caribou maxima the distribution of skeletal elements does not indicate that Nipisat was the primary kill site. Furthermore tools for skin preparation and other kinds of processing dominate the tool inventory at Nipisat while only few hunting weapons are present (see Chapter 4). The body parts preferably brought to the site were fore and hind limbs and the skull. The scattering and the degree of fragmentation of the bones indicate intensive use of all parts of the animals. Through all three phases, the caribou was an important component of the faunal assemblage, and the age and sex distribution of the caribou remains indicates that stalking might have been the prevailing hunting technique. The Nipisat caribou were of the same general body size as those hunted by the Thule Eskimo and the extant caribou of the Sisimiut District.

\section{Temporal trends in the mammalian fauna}

There seem to be no major general temporal trends in the exploitation of mammals at Nipisat. The number of species present and the relative distribution of mammalian species seemingly changed only little throughout the occupation of the site. At least io, 8 and is taxa are represented from phases I, 2 and 3 respectively. The

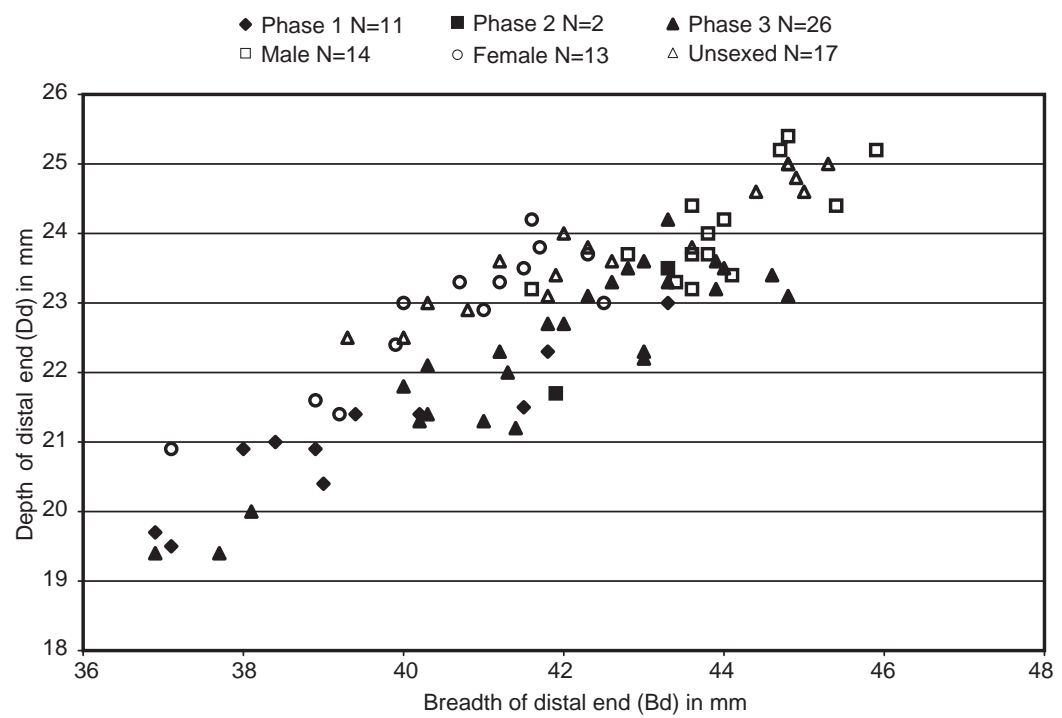

Fig. 191. Size distribution of metatarsal distal ends of caribou. Open symbols are recent caribou from the Sisimiut and Maniitsoq Districts, filled symbols are the Nipisat caribou. (Data of recent caribou were partly from Meldgaard 1986). 
Fig. 192. In addition to skin, meat, fat and sinew, the caribou provided antler and bones for tool production.

Drawing: Jørgen Mürhmann-Lund.

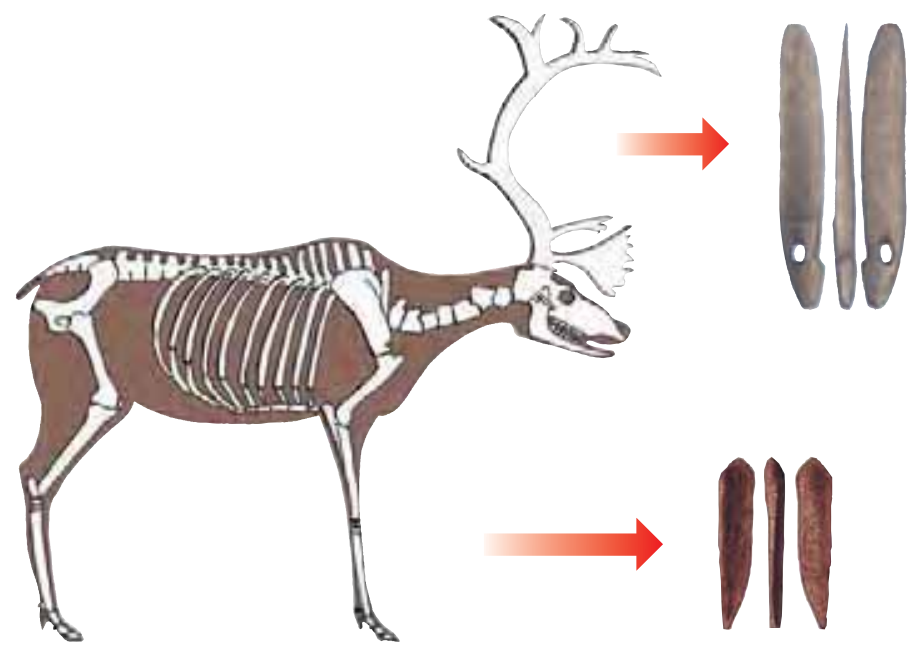

differences in diversity are primarily ascribed to sample size. Caribou played an important role through the entire occupation period comprising $45 \%$ in phase I while apparently decreasing to $36 \%$ in phase 2 and increasing to $55 \%$ in phase 3 . In the two oldest phases, marine mammals contributed more than 50\% while this dominance switched in favour of the terrestrial resource of caribou in phase 3 (Table 35 and Fig. I54).

The group of other marine mammals (Fig. I54) comprising polar bear, walrus, Phoca spp., large seals,

Table 53. Measurements of caribou distal metatarsals from Nipisat compared with measurements of a recent population of caribou and three prehistoric samples. Aasivissuit and Malmquist site of the Sisimiut District and Itinnera, Nuuk District (data from Meldgaard 1986). All measurements were according to Driesch (1976) and in mm.

\begin{tabular}{|c|c|c|c|c|c|c|}
\hline & & Mean & Min & Max & $\mathrm{Sd}$ & \\
\hline \multirow[t]{2}{*}{ Ni phase 1} & $\mathrm{Bd}$ & 39.5 & 36.9 & 43.3 & 2.0 & $N=11$ \\
\hline & $\mathrm{Dd}$ & 21.1 & 19.5 & 23.0 & 1.0 & $N=11$ \\
\hline \multirow[t]{2}{*}{ Ni phase 2} & $\mathrm{Bd}$ & 42.7 & 42.0 & 43.3 & 0.9 & $\mathrm{~N}=2$ \\
\hline & $\mathrm{Dd}$ & 22.6 & 23.5 & 21.7 & 1.3 & $\mathrm{~N}=2$ \\
\hline \multirow[t]{2}{*}{ Ni phase 3} & $\mathrm{Bd}$ & 41.8 & 36.9 & 44.8 & 2.1 & $\mathrm{~N}=26$ \\
\hline & $\mathrm{Dd}$ & 22.3 & 19.4 & 24.2 & 1.3 & $\mathrm{~N}=26$ \\
\hline \multirow[t]{2}{*}{ Ni total } & $\mathrm{Bd}$ & 41.2 & 36.9 & 44.8 & 2.1 & $N=39$ \\
\hline & $\mathrm{Dd}$ & 22.3 & 19.4 & 24.2 & 1.3 & $N=39$ \\
\hline \multirow[t]{2}{*}{ Itinnera } & $\mathrm{Bd}$ & 37.3 & 34.7 & 41.4 & 2.1 & $\mathrm{~N}=13$ \\
\hline & $\mathrm{Dd}$ & 20.1 & 17.4 & 22.3 & 1.4 & $\mathrm{~N}=13$ \\
\hline \multirow[t]{2}{*}{ Malmquist site } & $\mathrm{Bd}$ & 44.2 & 42.0 & 47.2 & 2.2 & $N=5$ \\
\hline & $\mathrm{Dd}$ & 24.4 & 23.0 & 25.8 & 1.3 & $\mathrm{~N}=5$ \\
\hline \multirow[t]{2}{*}{ Aasivissuit } & $\mathrm{Bd}$ & 43.2 & 40.3 & 46.6 & 1.8 & $N=21$ \\
\hline & Dd & 24.0 & 22.4 & 26.2 & 1.0 & $\mathrm{~N}=20$ \\
\hline \multirow[t]{2}{*}{ Recent males } & $\mathrm{Bd}$ & 43.9 & 41.6 & 45.9 & 1.1 & $\mathrm{~N}=14$ \\
\hline & $\mathrm{Dd}$ & 24.1 & 23.2 & 25.4 & 0.8 & $\mathrm{~N}=14$ \\
\hline \multirow[t]{2}{*}{ Recent females } & $\mathrm{Bd}$ & 40.6 & 37.1 & 42.5 & 1.5 & $\mathrm{~N}=13$ \\
\hline & $\mathrm{Dd}$ & 22.8 & 20.9 & 24.2 & 1.0 & $\mathrm{~N}=13$ \\
\hline \multirow[t]{2}{*}{ Recent, total ${ }^{1}$} & $\mathrm{Bd}$ & 42.4 & 37.1 & 45.9 & 2.1 & $\mathrm{~N}=44$ \\
\hline & $\mathrm{Dd}$ & 23.6 & 20.9 & 25.4 & 1.0 & $\mathrm{~N}=44$ \\
\hline
\end{tabular}

\footnotetext{
${ }^{1}$ Includes unsexed specimens.
} 
Table 54. Relative frequencies of mammalian taxa at large West Greenland Saqqaq sites. Numbers in parentheses indicate taxon rank and bold values highlight the first and second ranked taxon.

\begin{tabular}{|c|c|c|c|c|}
\hline & Qeqertasussuk $^{1}$ & Qajaa² $^{2}$ & Nipisat & Itinnera ${ }^{3}$ \\
\hline Arctic hare & $0.25(7)$ & $0.01(8)$ & $0.23(8)$ & $0.02(5)$ \\
\hline Domestic dog/wolf & $0.02(9)$ & $0.13(5)$ & $0.11(9)$ & $0.01(6)$ \\
\hline Arctic fox & $10.65(3)$ & $0.16(4)$ & $0.39(6)$ & $0.21(3)$ \\
\hline Polar bear & - & - & 0.03 & - \\
\hline Walrus & + & - & $1.76(4)$ & - \\
\hline Common seal & + & $0.21(3)$ & $41.41(2)$ & - \\
\hline Ringed seal & $36.15(2)$ & $25.83(2)$ & 0.06 & - \\
\hline Harp seal & $51.60(1)$ & $73.57(1)$ & $2.98(3)$ & $4.69(2)$ \\
\hline Bearded seal & $0.46(5)$ & $0.01(8)$ & $0.07(10)$ & $0.02(5)$ \\
\hline Hooded seal & $0.48(4)$ & - & 0.01 & - \\
\hline Caribou & $0.31(6)$ & $0.07(6)$ & $50.97(1)$ & $94.93(1)$ \\
\hline Whales & $0.06(8)$ & $0.01(8)$ & $0.37(7)$ & $0.01(6)$ \\
\hline Sperm whale & + & - & - & - \\
\hline Killer whale & + & - & - & - \\
\hline White whale & - & - & 0.01 & - \\
\hline Narwhal/white whale & + & $0.01(7)$ & - & - \\
\hline Harbour porpoise & + & - & $1.54(5)$ & $0.13(4)$ \\
\hline Minke/sei whale & + & - & - & - \\
\hline Bowhead/right whale & + & - & - & - \\
\hline Sample size & 20230 & 14005 & 14945 & 9551 \\
\hline $\mathrm{N}$ taxa & $9[16]^{4}$ & 10 & 14 & 8 \\
\hline $\begin{array}{l}+ \text { The taxon is present at } t \\
\text { sieving results. } \\
1 \text { Data compiled from Me } \\
2 \text { Data compiled from Mø } \\
3 \text { Data compiled from Mø } \\
4 \text { The number of identifiec }\end{array}$ & $\begin{array}{l}\text { included in the quan } \\
9.1 \text { and } 9.2 \text { ), sieved. } \\
\text { (pers. comm. 2002) }\end{array}$ & nple of 4 sque & nat had correc & lues obtainec \\
\hline
\end{tabular}

Cetacea spp., white whale and harbour porpoise were numerically more important in the early phase than the two subsequent phases. The importance of harbour porpoise decreased through time while walrus became more important (Table 35). There might be several factors accounting for this trend. The slight cooling of the climate (Fig. 2) during the last occupation phase may have led to an earlier build-up of ice cover. This in turn may have caused walrus populations to arrive earlier and depart later from the coastal waters in the Sisimiut area, thus shortening the summer period where they stayed off shore. It might also be possible that the Saqqaq people focused more on walrus because of the need for more blubber. We see new types of weapons suited for walrus hunting appearing in phase 3 (Figs 90 and 9I) and, at the same time presence of soapstone sherds and absence of hearths (see Chapter 9), indicating the use of an alternative fuel than wood. Seals and whales have on aver- age a blubber content of $40 \%$ (Born 200I), however walruses with their larger body size would provide larger quantities of blubber than would harbour porpoises. It was hardly the need for ivory for tool production that induced more focus on walrus hunting, because antler was still plentiful and the relative importance of caribou even rose during phase 3 .

Despite these tendencies, it must be concluded that no dramatic shift in the exploitation of mammalian game animals seems to have taken place. In combination with fishing and fowling, Nipisat was used mainly during summer for catching juvenile common seals on skerries and in the neighbouring fjords, and in early autumn caribou were most likely hunted on the mainland and brought to the island. During some periods, the site was also visited in spring, possibly for walrus hunting but also polar bear and white whale may have been hunted at that time of year. Allthough there might have been short-term fluctua- 
tions in the populations of the mammalian species exploited by the Nipisat inhabitants, the slight changes in the distribution of game animals through the three phases might primarily reflect shifts in the preferred period of visiting the site. There is a great consistency in the selected age groups, both for sea mammals and caribou, as well as in the skeletal elements represented through the entire occupation of the site. 


\section{Chapter 9}

\section{Cultural position of the Nipisat site}

Around 2500 BC, Greenland was occupied for the first time by the cultural complex called the Arctic Small Tool Tradition. This is known all over the Arctic, from the Bering Strait and Alaska in the west, to Canada and Greenland in the east. Many terms have been used for the first settlers: The Denbigh Flint complex, PreDorset, Independence I or Saqqaq and many attempts have been made to define similarities or differences between the different "cultures" (Helmer 1994).

Several researchers have worked on the earliest occupation of this area and a comprehensive review is given in Giddings (1964, 1967), Damas (1984), McGhee (1996). For more specific information concerning the research in Alaska see Anderson (1988) and in the Eastern Arctic see Maxwell (1976a, I985), Morrison and Pilon (1994) and Schledermann (I990, 1996). In Gulløv (I986a, I986b), Grønnow (I996b), and Møbjerg (1986c) a very detailed description of the research in Greenland is presented. For a more theoretical discussion see Hood (I998).

The occupation took place very quickly, as traces of the Arctic Small Tool Tradition appear all over Greenland at nearly the same time. Up to now this culture (called Independence I in Northeast Greenland and Saqqaq Culture in West Greenland) has been regarded as very homogeneous. At the time of its arrival, technology for exploiting both marine and terrestrial animals was already fully developed and the culture has been regarded as extremely conservative, with only minor changes occurring over more than I,50o years.

\section{Nipisat and other sites in the Sisimiut area}

The analysis of Nipisat has, however, revealed some new trends. Three different phases of the Saqqaq Culture can be seen in the Sisimiut area (Kramer I996a, I996b). At present Nipisat is the only site where all three phases can be identified. Phase 2 is weakly represented but, in many ways, it is transitional between phase I and 3 in terms of lithic raw material choice, the use of game animals and site position above sea level.

\section{${ }^{14} \mathrm{C}$-dating the phases of the Saqqaq Culture}

At Nipisat phase I is dated to 2020-1745 BC (cal). Phase 2 is dated to I860-I325 BC (cal) and phase 3 to at least I370- 8Io BC (cal) as seen from table 4. The youngest date (AAR-3574) of $520 \mathrm{BC}$ (cal) coincides with an area of the calibration curve where there are many oscillations resulting in a "plateau" stretching from 7604IO $\pm s t d v . ~ B C$. It is therefore not possible to achieve a more precise date for the final phase of the Saqqaq Culture than to within this c. 300 year time period (Table 3).

Excavations at Asummiut (Fig. 193, nos. I73 and 90o) revealed the presence of phase I at two separate localities (Fig. 194). (Møbjerg I998:I04; Møbjerg and Grummesgaard-Nielsen I997b:256-57). SIK 900 is dated to I970 BC (cal) and the three dates from SIK I73 are 1940 , I900 and 1670 BC (cal) (Table 55). The youngest date could represent phase 2 , but because of the matrix of the soil it was not possible to distinguish between layers $2 \mathrm{~A}$ and $2 \mathrm{~B}$ stratigraphically throughout the site (Fig. 195).

Finn Kramer's excavations, test pits and surface collections carried out between 1988-1993 revealed phase I on several sites in the Sisimiut area. In addition to Nipisat, he succeeded in obtaining ${ }^{14} \mathrm{C}$-dates from four sites (Fig. 193, nos. 49I, 526, 538 and 539). The dates range between 2550 - $1790 \mathrm{BC}$ (cal) (Kramer I996a:63, appendix 2). The two dates from Tingit (Fig. I93, no. 92) (2200 and I750 BC (cal)), excavated by J. Meldgaard in 1977 , are included in his publication. All six datings are on charcoal from locally grown species such as Betula nana or Salix spp. Angujaartorfik (Fig. I93, no. KNKI877), in the municipality of Maniitsoq, is dated by four ${ }^{14} \mathrm{C}$-samples of caribou bones to $\mathrm{I} 860$ I440 BC (cal) (Table 56). The site is outstanding in several aspects. First of all, it is the only known Early Saqqaq site with such a large number of dwelling 


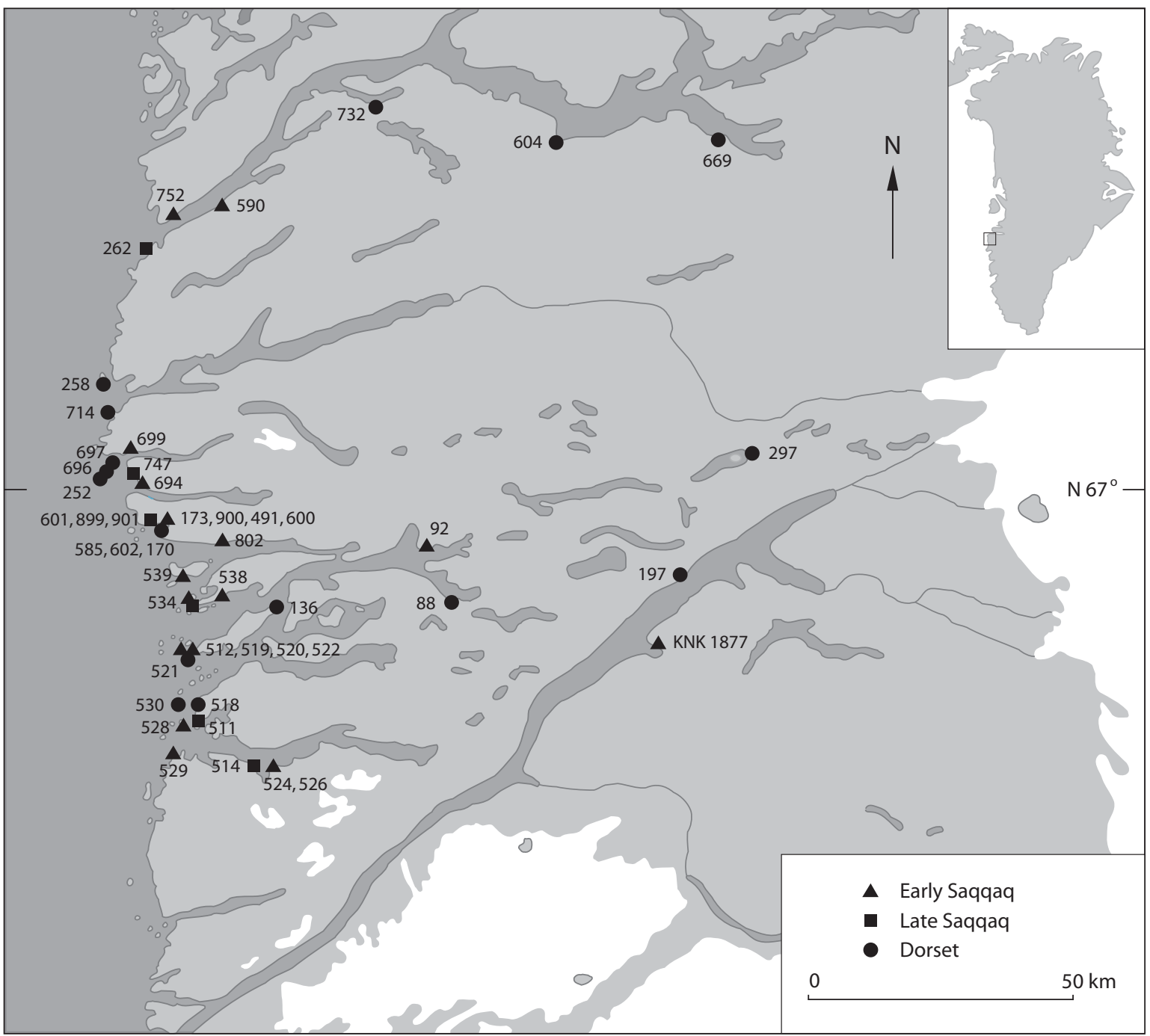

Fig. 193. Map of Sisimiut District with Palaeo-Eskimo sites from Early Saqqaq, Late Saqqaq and Dorset culture. Numbers refer to the archives at Sisimiut Museum. KNK 1877 refers to the archives at the Greenland National Museum and Archives. The map is partly after Kramer (1996a:42-45, figs 5.2-5.4).

\section{Early Saqqaq:}

SIK 092. Tingit

SIK 173. Asummiut SIK 491. Akia

SIK 512. Umiatsiavilinnguaq SIK 519. Saqqarmiormiut SIK 520. Tinoqqassaq SIK 522. Siorarliit kangiat SIK 526. Qivittup nuua SIK 528. Qaqulluit II SIK 529. Allagartalik SIK 534. Nipisat
SIK 538. Amitsuarsuk

SIK 539. Maniitsorsuaq SIK 590. Qeqertarsuup SIK 600. Aniap quia SIK 694. Nerukinnera II N SIK 699. Kangaarsuk II SIK 752. Tasiusap nua SIK 802. Toornaviarsuaqqat SIK 900. Asummiut KNK 1877. Angujaartorfik

\section{Late Saqqaq:}

SIK 262. Taseralik SIK 511. Uiffaq III SIK 514. Tununngasoq II SIK 534. Nipisat SIK 601. Asummiut SIK 747. Saqqaria II SIK 899. Asummiut SIK 901. Asummiut

\section{Dorset:}

SIK 088. Eqalugaarsuit SIK 136. Ikerasaarsuk SIK 170. Sallersuaq SIK 197. Saattorsuaq SIK 252. Illulissuaq SIK 258. Ukiivik SIK 518. Uiffaq II SIK 521. Siorarliit kangiat SIK 530. Tasilik SIK 585. Kussangasoq SIK 602. Asummiut SIK 604. Seersinnilik SIK 669. Sannerut SIK 696. Talue SIK 697. Qeqertarsuaq SIK 714. Umiatsialivik 
structures (more than 30) distributed at different levels, and there are no apparent chronological trends in the height above sea level (Kapel 1996:I23, fig. 9.4). The dating of the site implies that it was occupied during phases I and 2. Secondly, it is one of the first sites located so far from the outer coast so, although not an inland site, it might indicate exploitation of inland resources. This is supported by the new discovery of an inland site, Siorartalik, in the central part of Angujaatorfiup Nunaa. A ${ }^{\mathrm{I}} \mathrm{C}$-sample (AAR-7376) (Table 56) from a circular hearth in structure 2 is dated to I862-I773 BC (cal) (Odgaard 2003).

Nipisat is the only site where it has been possible to ${ }^{14} \mathrm{C}$-date phase 3 . 16 dates, all on caribou bone, provide a firm basis for the definition of this youngest phase, despite problems with the youngest one due to the "plateau" on the calibration curve (Table 4). The lack of organic material at the vast majority of sites in the Sisimiut area means that ${ }^{\mathrm{I} 4} \mathrm{C}$-dates cannot be used. It is therefore only possible to date such sites using beach ridge chronology, choice of raw material, on a typological basis, or by the type of dwelling structures.

\section{Beach ridge chronology}

From 1988-1993, Finn Kramer carried out reconnaissance for Sisimiut Museum and more than Ioo PalaeoEskimo sites were registered. Apart from the few sites mentioned above, the localities only yielded surface collections of lithic artefacts made of different raw materials. Dating these sites has therefore been highly problematic. In analysing the height above sea level in the same way as Meldgaard (1960) at Igloolik (Fig. I, no. 13), rather than counting the number of beach ridges as Giddings (1964, 1967) at Cape Krusenstern (Fig. I, no. 4), Kramer managed to separate Saqqaq and Dorset sites. He put forward this theory tentatively because marine-oriented hunters do not necessarily always settle down close to the shore (Kramer I996a:44-45; Møbjerg 1986b:22-29). His analysis shows that the Saqqaq and Dorset Cultures occupied different levels. Saqqaq people settled between 2I-I2 $\mathrm{m}$ and Dorset people between 8-4 $\mathrm{m}$ above sea level. New investigations by Hoch and Strand Petersen in the Sisimiut area support Kramer's theory that some Dorset sites could be submerged today (Appendix 2, Fig. 220).

The investigation at Nipisat and Asummiut can shed light on the apparent gap between the Saqqaq and the Dorset occupation. At Nipisat, the phase I inhabitants settled on a terrace between I2 and I3 metres above sea level. In phase 2 they followed the retreating sea and settled on the II to $\mathrm{I} 2 \mathrm{~m}$ a.s.l. terrace. During the youngest phase the situation altered. The inhabitants still used the II-I3 $\mathrm{m}$ a.s.l. area, at the same time as a new area between 9-II $\mathrm{m}$ a.s.l. (Fig. I96) was taken into use.

At Asummiut there are four discrete units with SIK 900 situated 140 meters from the coast at I4 $\mathrm{m}$ a.s.l. and SIK I73 situated I2O from the present coast at I2-I3 $\mathrm{m}$ a.s.l. SIK 899 is located $40 \mathrm{~m}$ from the coast at $\mathrm{II} .5 \mathrm{~m}$ a.s.l. The last unit SIK $90 \mathrm{I}$ is located $60 \mathrm{~m}$ from the present coast at Io.5 $\mathrm{m}$ a.s.1. (Fig. 194).

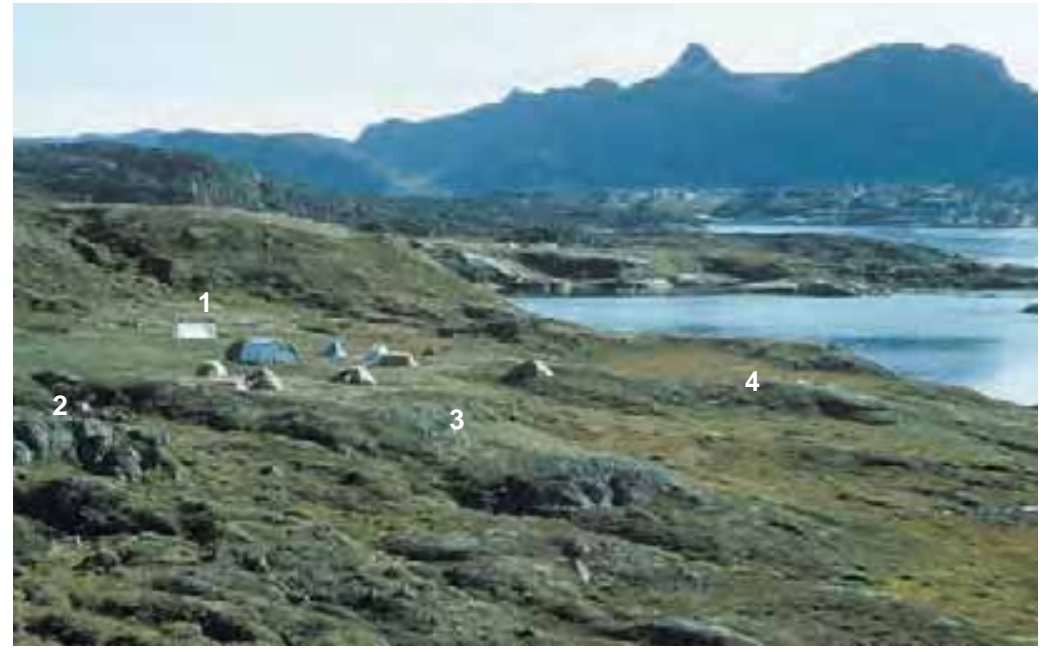

Fig. 194. Asummiut, view from the west. The archaeologists' camp can be seen in the foreground. 1. The site SIK 173. 2. SIK 900. 3. SIK 899. 4. SIK 901. Centre of the picture: historical Asummiut. Background: the town of Sisimiut with the mountain Kællingehætten. Photo: Jens Jørgen Kærgaard. 
Table 55. ${ }^{14} \mathrm{C}$ datings from Asummiut dated at the AMS Laboratory, Aarhus University (AAR). ${ }^{14} \mathrm{C}$ ages are given in conventional radiocarbon years BP, calibrated age and calibrated age \pm 1 standard deviation (Stuiver and Pearson 1993).

\begin{tabular}{lcccccc}
\hline Laboratory no & Site nr. & Asummiut layer no. & $\begin{array}{c}14 \text { C age } \\
\text { BP }\end{array}$ & $\begin{array}{c}\text { Calibrated } \\
\text { age BC }\end{array}$ & $\begin{array}{c}\text { Cal }+1 \\
\text { stdv. BC }\end{array}$ & Sample type \\
\hline AAR-3027 & SIK 900 & 2 & $3630 \pm 80$ & 1970 & $2130-1880$ & Charcoal/Salix glauca \\
AAR-3030 & SIK 173 & 3A & $3605 \pm 65$ & 1940 & $2030-1880$ & Charcoal/Betula nana \\
AAR-3029 & SIK 173 & 2B & $3575 \pm 65$ & 1900 & $2010-1780$ & Charcoal/Betula nana \\
AAR-3028 & SIK 173 & 2A & $3370 \pm 65$ & 1670 & $1740-1530$ & Charcoal/Salix species \\
\hline
\end{tabular}

Phase 3 at Nipisat, and Asummiut (SIK 899 and 90I) are interpreted as falling within the so-called "gap" between the Saqqaq (phase I-2) and Dorset occupation. However, as mentioned by Kramer (I996a:46), beach ridge chronology should not be used as the sole method of determining site cultural affiliation but, when combined with choice of raw material, it can provide a reasonable cultural indicator.

\section{Choice of lithic raw material}

As can be seen from Fig. 4I and I24, the choice of raw material for tools and flakes at Nipisat is not identical in all phases. The relative proportions of raw material types used for flakes vary depending on whether the flakes are counted or weighed. This is particularly clear from phase 2 at Nipisat (Fig. 43) and serves as a reminder of the need for analysing lithic waste material in terms of both weight, number and size. As seen from these tables, killiaq is the overall preferred raw material at Nipisat, but its importance decreases from phase I (c. $90 \%$ ) to phase 3 (c. 70\%). Agate decreases too (phase 2 is an outlier concerning agate because of the small number of tools). Quartz crystal does not appear to have played an important role at Nipisat as seen from Fig. 4I, although some quartz crystal tools occur in all three phases (Fig. I24). In phase I the quartzite frequency for flakes is identical for both weight and number (c. $2 \%)$. In phase 3 the use of quartzite increases to c. $25 \%$.

At Asummiut the same trend can be seen. SIK 900 and SIK I73 have c. $90 \%$ killiaq decreasing to below $80 \%$ for SIK 899 and c. $50 \%$ for SIK 90 or. Quartz crystal is more frequent at Asummiut (c. $15 \%$ at SIK 899) than at Nipisat. Quartzite played a minor role at SIK 9oo, I73 and 899 but was favoured at SIK 9oI with more than $30 \%$. However, the range of variation is greater concerning tools (Figs I97 and 198).

It is remarkable that even at the beginning of phase I at Nipisat the killiaq used originates from both Qaarsut at the Nussuaq peninsula (northern part of Qeqertarsuup Tunua) and from Angissat, a little island in Sydostbugten (Jensen 200oa; Jensen et al. 1999). Five samples from the same $1 / 4 \mathrm{~m}^{2}$ (387,5X/189y layer $2 \mathrm{~K}$ ) are all comparable in terms of thin section analysis, to material from Angissat. Three samples from layer $2 \mathrm{~K}$ and one from layer 2 from nearly the same area resemble killiaq from Qaarsut, but thin sectioning showed different crystalline properties not comparable to the Qaarsut type. They are therefore categorised as having an unknown source.

Thin sectioning of five samples from SIK 90I showed that killiaq from Qaarsut (N:2) was still used at the same time as killiaq from Angissat (N:I) and killiaq from an unknown source (N:2). As a whole, killiaq

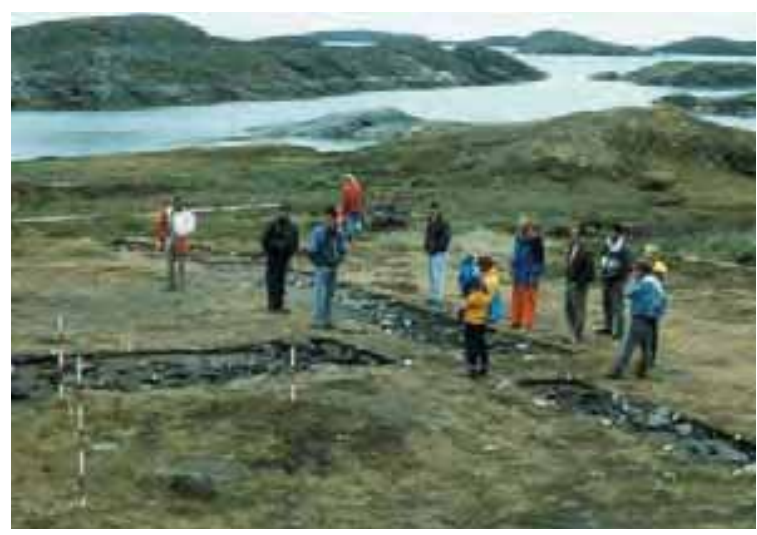

Fig. 195. The excavation at Asummiut seen from the north. In the background the archipelago at the mouth of Kangerluarsunnquaq (Ulkebugten). Photo: Jens Jørgen Kærgaard. 
Table 56. ${ }^{14} \mathrm{C}$ datings from Angujaatorfik and Sioralik dated at the AMS Laboratory, Aarhus University (AAR) and the ${ }^{14} \mathrm{C}$ laboratory, National Museum of Denmark, Copenhagen (K). ${ }^{14} \mathrm{C}$ ages are given in conventional radiocarbon years BP calibrated age and calibrated age \pm 1 standard deviation (Stuiver and Pearson 1993). (Hans Kapel and Ulla Odgaard, The National Museum, Copenhagen kindly permitted the datings).

\begin{tabular}{lclcccc}
\hline Laboratory no & Site nr. & \multicolumn{1}{c}{ Site Name } & $\begin{array}{c}\text { 14C age } \\
\text { BP }\end{array}$ & $\begin{array}{c}\text { Calibrated } \\
\text { age BC }\end{array}$ & $\begin{array}{c}\text { Cal }+1 \\
\text { stdv. BC }\end{array}$ & Sample type \\
\hline K-5191 & KNK 1877 & Angujaartorfik structure A 5 & $3370 \pm 80$ & 1670 & $1740-1520$ & Bone (Rangifer tarandus) \\
K-5192 & KNK 1877 & Angujaartorfik structure B 2 & $3490 \pm 80$ & $1860-1770$ & $1890-1690$ & Bone (Rangifer tarandus) \\
K-5193 & KNK 1877 & Angujaartorfik structure B 8 & $3190 \pm 75$ & 1440 & $1520-1400$ & Bone (Rangifer tarandus) \\
K-5194 & KNK 1877 & Angujaartorfik structure B 21 & $3440 \pm 80$ & 1740 & $1880-1730$ & Bone (Rangifer tarandus) \\
AAR-7376 & & Siorartalik structure 2 & $3486 \pm 38$ & $1862-1773$ & $1880-1742$ & Charcoal (local grown) \\
\hline
\end{tabular}
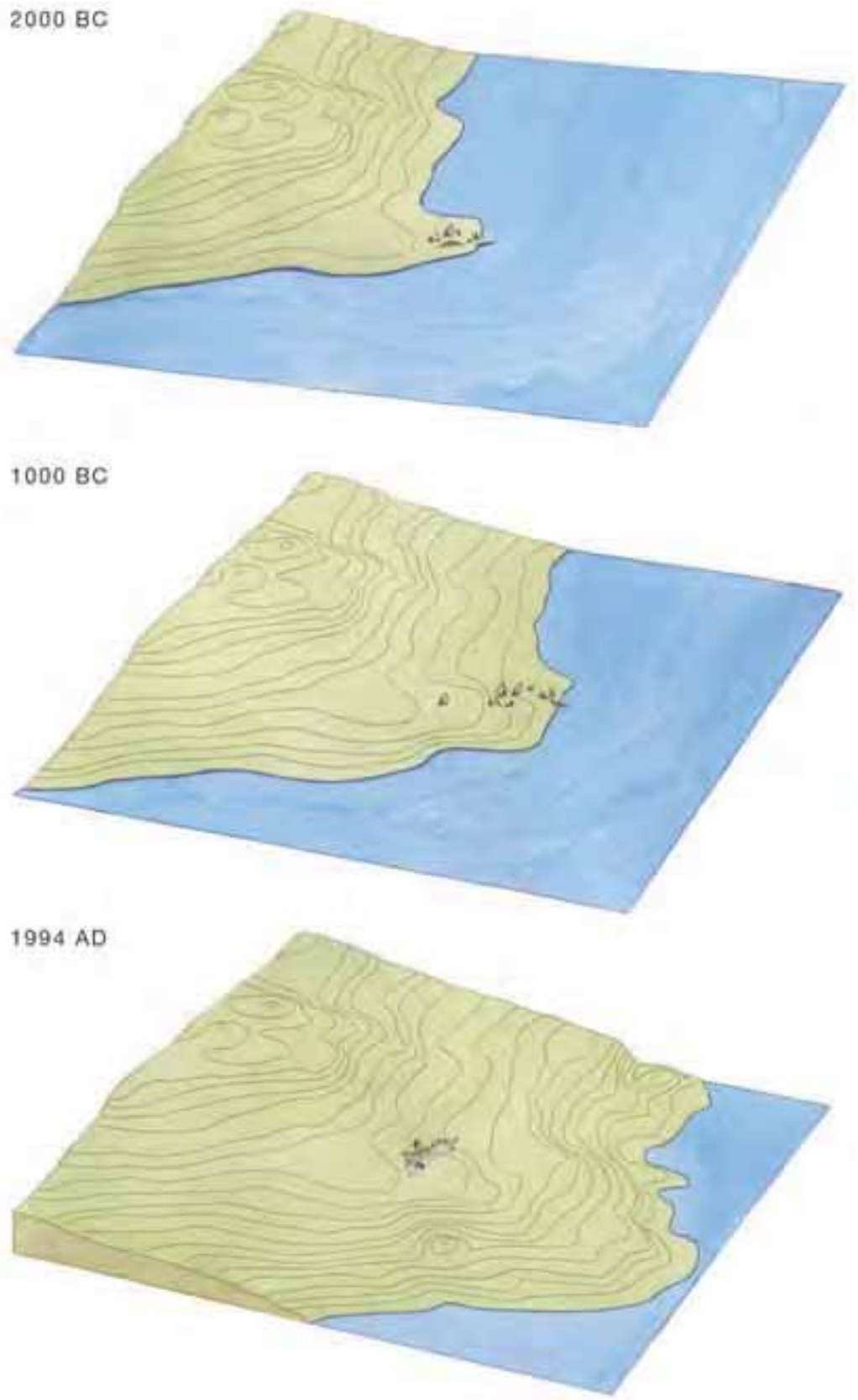

Fig. 196. Because of isostatic movements, the shape of the island Nipisat has changed remarkably through time. When the first people arrived around 2000 BC, the island was fairly small and they settled close to the water on a little promontory. The island was still "growing", however, and 1000 years later the occupation area was enlarged. The Saqqaq people thus still lived on the terrace their ancestors had occupied but, at the same time, they also lived on the new established promontory. At present (1994) the abandoned site is located nearly $50 \mathrm{~m}$ from the sea, at a level between 10 to $13 \mathrm{~m}$ above sea level. 
Fig. 197. Frequency distribution of lithic $\square$ Killiaq $\square$ Agate

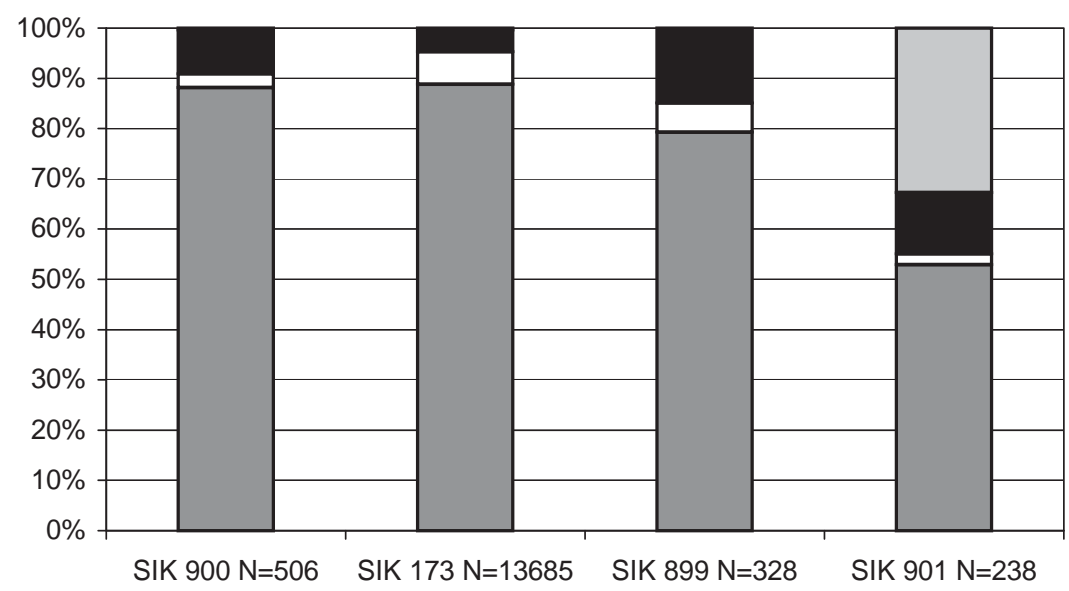

from Angissat is dominant at SIK 90I (Jensen I998: I49; J.F. Jensen pers. comm. 2003).

Comparing Nipisat and Asummiut with the investigation at Akia (Kramer 1996a, I996b) it is clear that sites with an early ${ }^{14} \mathrm{C}$ date have a high frequency of killiaq (c. 90\%) and a low frequency of quartzite (below $5 \%$ ). Agate and quartz crystal vary more, but the two materials make up c. Io\% at sites from phase I (Fig. 198).

The choice of raw material at Angujaartorfik is different. Here killiaq is only represented by $53 \%$, agate $39 \%$ and quartzite and quartz crystal have low frequencies ( $4 \%$ each). Unfortunately there are only few artefacts (N:279) which were collected very selectively because of lack of time for reconnaissance (Kapel 1996:I26-I28). This means that the sample can- not be seen as representative and there is no published information concerning the distribution of artefacts from the different structures.

Nipisat phase 3 is the only ${ }^{14} \mathrm{C}$-dated site, but the correlations between a high percentage of quartzite and a location 9-Io $\mathrm{m}$ a.s.l. might be used as evidence of a Late Saqqaq site.

\section{Typology - presence and absence of types}

Because few sites have organic material preserved, the following description is based mostly on lithic artefacts. From Nipisat there is one small harpoon blade, bifacially flaked and then polished (Fig. III) and a
Fig. 198. Frequency distribution of lithic raw materials used for tools from Asummiut SIK 900, 173, 899 and 901.

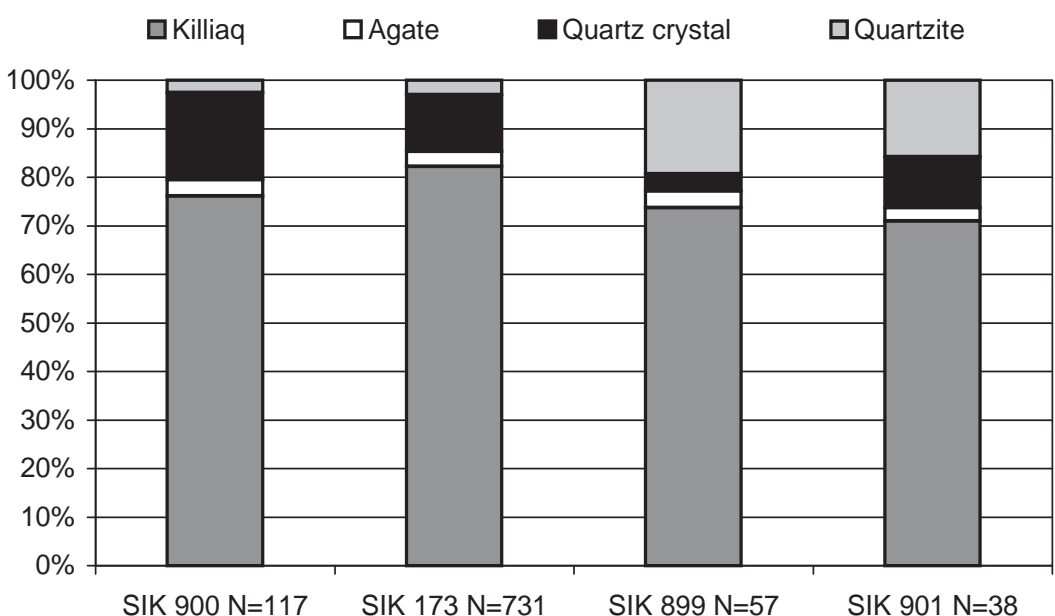


口Killiaq $\square$ Agate

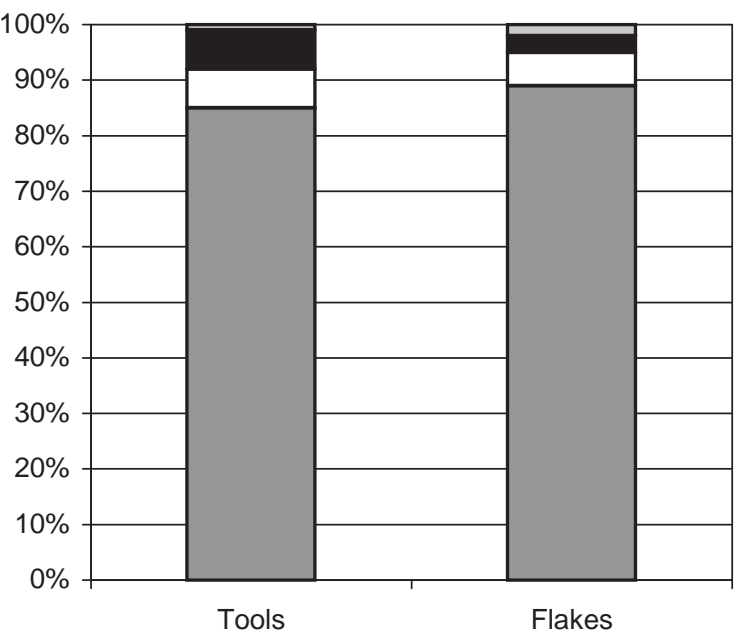

Fig. 199. Frequency distribution of lithic raw materials used for flakes and tools from Akia SIK 491. The graph is constructed from Kramer's data (Kramer 1996b:72 fig. 6.8). stemmed projectile point. Together with knife blades with transverse edges, these are types which only occur in phase I. In terms of organic material, the presence in phase I of small toggled and tanged harpoon heads (Fig. 89) should be mentioned, together with fragments of a bow (Fig. I03).

From Asummiut SIK 900 and I73, the presence of stemmed projectile points, small serrated harpoon blades and polished awls of killiaq (Fig. 200, 20I), and knife blades with transverse edges shows that the site belongs to the oldest phase (Møbjerg and Grummesgaard-Nielsen I997b: 252 fig 2I upper row). The same types are also known from Akia (Kramer 1996b:88 fig. 6.IA-I and fig. 6.2A-H)

Angujaartorfik has "old types" such as stemmed arrow points and knives with transverse edges, but the ${ }^{14} \mathrm{C}$ dates indicate an occupation from phase I to 2 . The analysis of artefact distribution at the site is still too preliminary to be used in a chronological interpretation (Kapel I996:I26).

Phase 2 at Nipisat produced so few tools (N:23)

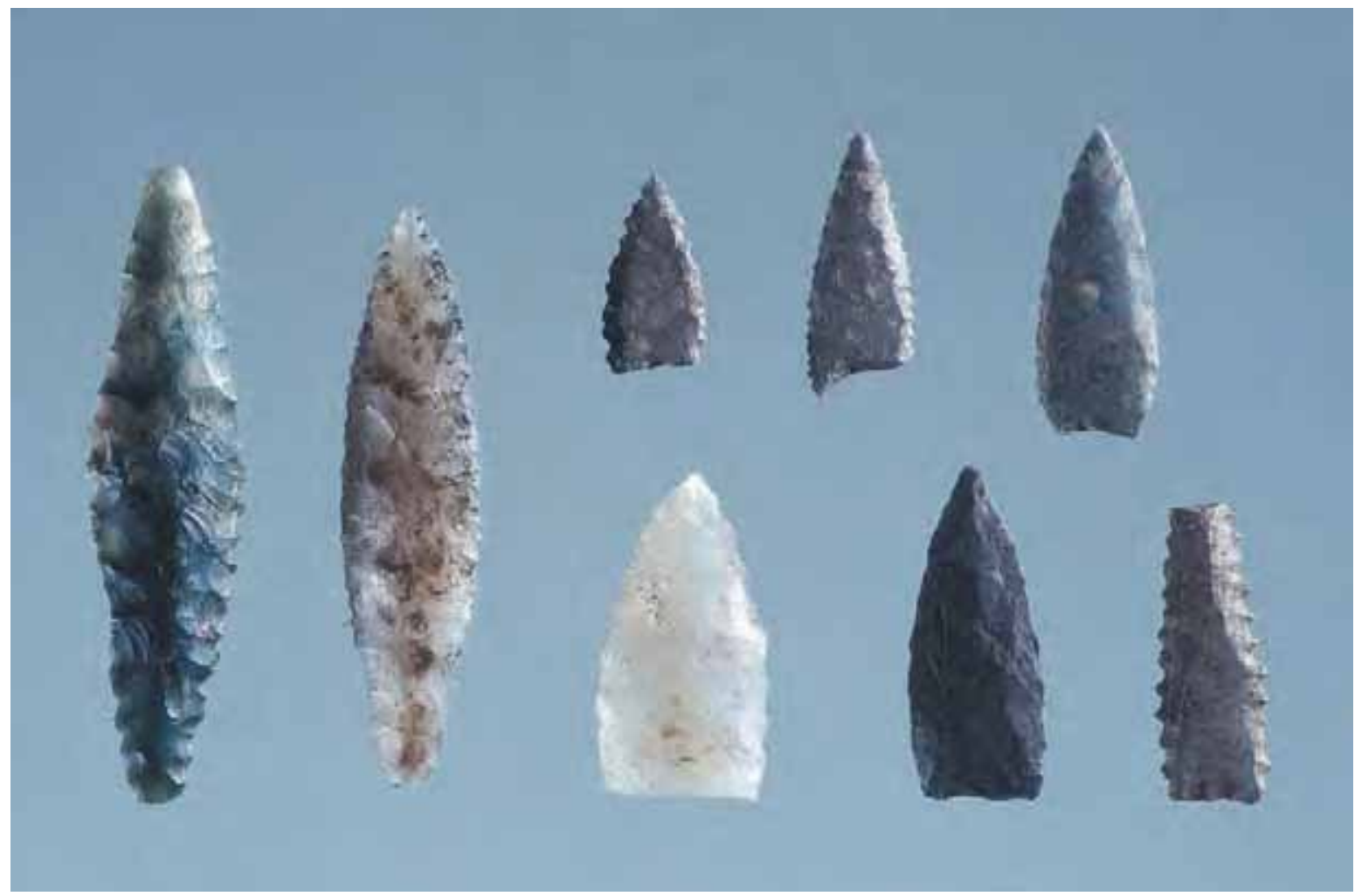

Fig. 200. Tools from the Early Saqqaq culture. From the left: Two arrow points of agate SIK173×1794 and 1392. To the right six harpoon blades. Upper row SIK173× 511, 165 and 1304 of killiaq, beneath SIK173×1327 of quartzite, SIK173×1386 and 2002 of killiaq. Size: range between $36 \mathrm{~mm}$ and $11 \mathrm{~mm}$. Photo: Preben Delholm. 
that analysis is difficult. There are, however, no small harpoon blades, stemmed projectile points or knife blades with transverse edges.

Phase 3 at Nipisat is characterised by the absence of all tool types mentioned above. Instead the presence of bevelled harpoon blades, bevelled projectile points and bevelled knife blades defines this late phase (Fig. II2). Besides these new types, the bifacially flaked projectile points found have a greater range of variation, as seen from fig II5. In addition, totally new types now appear in the archaeological record, namely lamps and cooking pots along with weights, sinkers and small gaming pieces, all made of soapstone (Fig. II6, II7 and I2I). The sherds are from two types of containers. The first type are from the well-known small thin-walled circular lamp and the second type are thick-walled sherds from larger vessels.

The bow and arrow and the small tanged and toggled harpoon heads have disappeared and instead very heavy tanged harpoon or lance heads are found (Figs 9I, 92). In addition, several organic tool types not previously seen in a Saqqaq context were also found, including different forms of barbed spears or leisters (Figs 97-I02).

There are no ${ }^{\text {I4 }} \mathrm{C}$ dates from SIK 899 and 9or at Asummiut. However, the tool inventory so closely resembles that of Nipisat phase 3 that they must be contemporary. From SIK 899 more than 800 small worked sherds of soapstone along with bevelled tools (Fig. 202) were found. At SIK 9oI four sherds of soapstone were revealed, two of them are shown in Fig. 203. None of the "old" types known from SIK 900 and I73 are registered at these two sites.

\section{Dwelling structures}

From Nipisat phase I there is one well defined boxhearth with a surrounding stone dwelling structure 4 $\mathrm{m}$. in diameter (Figs 27 and 33). There is an activity area at the hearth inside the dwelling as seen from Figs 84, 86, 88, I27, I42, I69, I79, I80.

From phase 2 there is a box-hearth, but the stone structure around it is poorly defined (Figs 27 and 29). It is noteworthy that no artefacts at all were found around this hearth and only very few bones.

From phase 3 there are no hearths and only very few stone features relate to the period (Fig. 28).

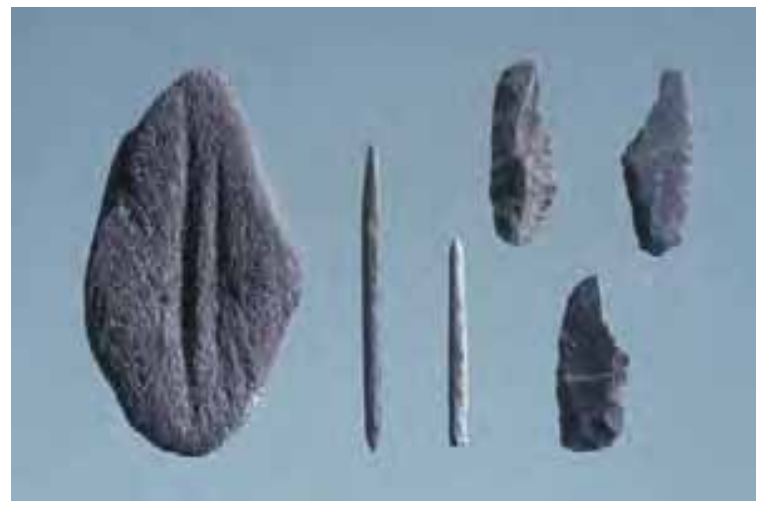

Fig. 201. Tools from the Early Saqqaq culture, Asummiut. From the left: A whetstone made of pumice SIK173×465 (56 mm). Two polished stone awls made of killiaq, SIK173×337 (46 mm) and $\times 638$. To the right three burins made of killiaq, SIK173x 418, 526 and 169 (33-35 mm). Photo: Preben Delholm.

Instead many soapstone sherds were found, indicating that fuel sources for heating and cooking had changed from drift wood or locally grown scrub to blubber from sea mammals.

The same trends are seen on Asummiut. From SIK 900 there is a dwelling structure with a form of midpassage marked by large amounts of charcoal and small pebbles (Møbjerg 1998:I05, fig. I2). At SIK I73, more than eight dwelling structures could be seen. Some of them had a clear box-hearth, others were disturbed by later inhabitants (Fig. 207).

At Akia two distinct features were recorded. In the western part, a pile of fire-cracked stones and large amounts of charcoal were found in a $3 \mathrm{x} \mathrm{I} \mathrm{m}$ area. $3 \mathrm{~m}$ to the east, a regular box-hearth filled with fire-cracked stones and surrounded by a sub-rectangular ring of stones was found (Kramer 1996b:67-68, fig. 6.3 and 6.4). The distribution of artefacts revealed a concentration around the box-hearth, but an empty area to the left. The high number of artefacts in the area around the pile of fire-cracked rocks indicates that it could be a midden area (Kramer 1996b:68-69, fig. 6.5). Olsen (I998:IO3-IO5) interpreted this feature as a mid-passage dwelling, because of similarities with his dwelling structures from Tupersuai, at Qeqertarsuup Tunua (Disko Bay). Kramer rejected this interpretation and reconfirmed his own view that it is a form of midden, based on the mixture of fire-cracked stones, charcoal and artefacts present. (F.E. Kramer pers.comm. 2003).

From Qivittup Nuua (Fig. I93, SIK 526) dwelling structures indicated by a box-hearth were recorded 


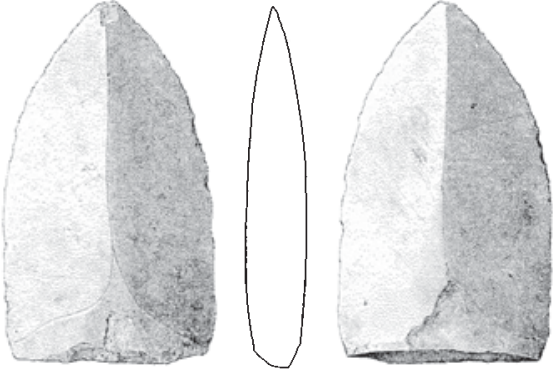

$899 \times 151$

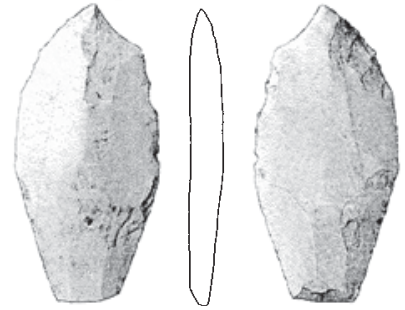

$899 \times 114$

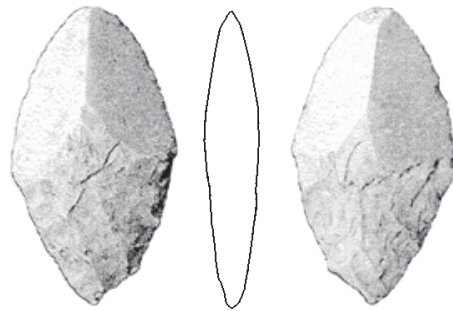

$899 \times 143$

Fig. 202. Bevelled tools from Asummiut SIK 899. Drawing: Jørgen Holm. 1:1.

during a visit in 1994 at a wind-eroded area. At Toornaviarsuaqqat (Fig. I93, SIK 802) similar dwelling structures were also recorded.

The structures recorded at Angujaartorfik consist of tent rings, sometimes with a double row of stones. None of the published structures have a box-hearth although some have central stone features (Kapel I996:I24-I27 fig. 9.5-II).

From Asummiut SIK 899 and 90I there are no clear hearths and therefore very little charcoal was found. As mentioned above, soapstone sherds, indicating the use of blubber for cooking and heating, were found.

\section{Concluding remarks on the cultural history of the Sisimiut area}

In combining the investigations by Kramer (I996a,b) with new investigations in 1994 and 1995 in the Sisimiut area, it has been possible to look at the development of the Saqqaq Culture from a much broader perspective.

The oldest phase of the Saqqaq Culture is ${ }^{\mathrm{I}} \mathrm{C}$ dated to 2550-I740 BC (cal) based on Nipisat phase I, Asummiut 900 and I73, Akia 49I, Tingit 92, Qivittup nuaa 526, Amitsuarsuk 538 and Maniitsorsuaq 539 (Fig. 193). The rest of the sites belonging to Early Saqqaq are also shown in Fig. 193. They have been dated to Early Saqqaq because of their location at a high level above the sea, c. 90\% use of killiaq, and the presence of small harpoon blades, stemmed arrow points, stone awls, knives with transverse edges or box-hearth structures.

Phase 2 at Nipisat is ${ }^{\mathrm{I}} \mathrm{C}$-dated to $\mathrm{I} 860$-1325 BC (cal). The youngest dates from Asummiut SIK I73 (Table 5I) and the dates from Tingit Square A (Kramer I996a:63) also correspond to this phase. Unfortunately, we have no information concerning raw material and the presence/absence of tool types at Tingit. According to ${ }^{\mathrm{I} 4} \mathrm{C}$-dates at Angujaartorfik, structure $\mathrm{A}_{5}$ and $\mathrm{B} 8$ may also be from phase 2. Phase 2 is further characterised by a placement at a slightly lower level above sea than phase $\mathrm{I}$, a decrease in the use of killiaq (c. 80\%), an increase in the use of quartzite, the absence of harpoon blades, stemmed arrow points, awls and knife blades with transverse edges and the presence of box-hearths. This phase is very difficult to identify without organic artefacts and without ${ }^{14} \mathrm{C}$-dates. Phase 2 is here interpreted as being part of the Early Saqqaq and not as a distinct intermediate period.

The only ${ }^{14} \mathrm{C}$-dated phase 3 site is Nipisat, dated to I370-8Io BC (cal). Judging by their height above sea level, choice of raw material (quartzite increasing and killiaq decreasing to c. $70 \%$ ), and the presence of soapstone artefacts and polished and bevelled tools, eight sites (Nipisat included) are interpreted as dating to this late phase of the Saqqaq Culture (Fig. 193). There are no clearly defined box-hearths from the sites and the amount of charcoal is limited.

The last group of sites (seen in Fig. 193) belong to the Dorset Culture. The sites are dated by ${ }^{\mathrm{I}} \mathrm{C}$-samples (Kramer 1996a:4Iff and appendix 2), decreasing use of killiaq, increasing use of agate and quartz crystal, their location close to sea level and by the presence of diagnostic tool types such as the burin-like tool. It is noteworthy that more Dorset sites are found inland along the deep fjords than both the Early and Late Saqqaq. 
Fig. 203. Sherds of soapstone from Asummiut SIK 901. Drawing: Jens Jørgen Kærgaard. 1:1.

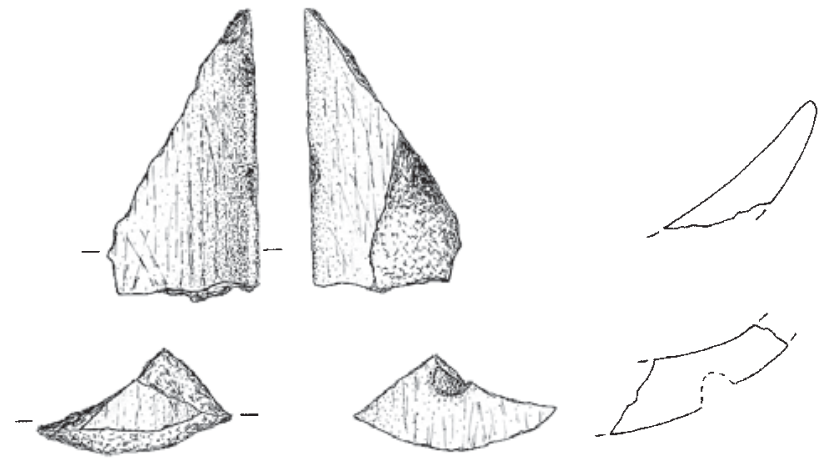

\section{Nipisat compared to sites in other regions of Greenland}

It is problematic to make interregional comparisons for several reasons. One of the greatest problems is that most of our knowledge of the Palaeo-Eskimos comes from reconnaissance and a few test pits. Apart from the excavation and mapping carried out at sites in North Greenland (Fig. I, nos. 27-32) (Knuth I952, I967, I968, 1978, I98I, 1983), in Qeqertarsuup Tunua (Disko Bay) (Fig. I, nos. 40-46) (Mathiassen I958; Larsen and Meldgaard 1958; Meldgaard 1952; Møbjerg I986b) and in the Nuuk area (Fig. I, nos. 37-38) (Meldgaard 196I; Appelt 1995; Appelt and Pind 1996; Gulløv I983, I986a; Gulløv and Kapel I988), our knowledge from excavations is minimal. Due to the small numbers of excavated sites, there is a great risk of comparing nonequivalent units, i.e. sites with highly incomparable functions and formation processes.

During the last 20 years there has, however, been an increase in Palaeo-Eskimo research programs (Grønnow I996b:I-7). Most regions have been at least partially surveyed and our understanding of the cultural history of the first inhabitants of Greenland has been deepened in many ways.

The Saqqaq Culture was originally defined based on investigations in Qeqertarsuup Tunua and research has continued up to the present (Grønnow I988a, I988b, I994, I996a, I996b, I996c, I997; Grønnow and Meldgaard I991a, I99Ib; Jensen 1995, I998, 2000a; Jensen and Brinch Petersen 1998; Hansen and Jensen I99I; Meldgaard 199I; Møhl I986, I997b; Andreasen, T.N. I998; Olsen I998).

Collaboration between local museums in Ilulissat, Aasiaat and Qasigiannguit and universities in Den- mark and Norway has resulted in the excavation of several sites from the Saqqaq and Dorset Cultures. Most noteworthy are the sites of Qajaa and Qeqertasussuk, due to their excellent preservation conditions for organic material. At Qeqertasussuk it was possible to define five stratigraphical units, components 5 to I. Component 5 is older than Nipisat, components 2-4 are contemporary with phase I at Nipisat, and component I corresponds to Nipisat phase 2 (Grønnow 1994:203, I996c:20-2I and fig. 3.4). Qeqertasussuk was thus already abandoned when phase 3 started at Nipisat. In terms of raw material, similar trends are observed at Qeqertasussuk, Akia, Asummiut and Nipisat. In the early period (Qeqertasussuk component 4-5, Akia, Asummiut I73 and Nipisat phase I) killiaq together with agate dominate the lithic assemblages. The use of agate diminishes though time, as seen from Qeqertasussuk component I-3 and Nipisat phase 2, only to increase again in phase 3 at Nipisat. Qeqertasussuk was abandoned before quartzite increased in importance, as seen at Asummiut 899, 90I and Nipisat phase 3. The presence/absence of lithic tool types such as projectile points, harpoon blades, burins, knives, scrapers etc at Qeqertasussuk and Nipisat phase I are nearly identical (Grønnow 1996c:22-23, fig. 3.5 and 3.6; Grønnow and Meldgaard 1991b:I33, I35). The permafrost at Qeqertasussuk, preserving items of wood, baleen and skin, makes it difficult to compare the two sites in terms of organic tools. If bone, antler and ivory tools such as wedges, needles, awls, flint flakers, foreshafts and some harpoon types are compared, however, no major differences can be seen (Grønnow I996c:23-24, fig. 3.7). Nevertheless, it is important to bear in mind that Qeqertasussuk was abandoned before the introduc- 
tion of bevelled polished tools, artefacts made of soapstone and the heavy tanged harpoon or lance heads known from Nipisat phase 3.

The site of Qajaa has been dated by more than 20 ${ }^{14} \mathrm{C}$ samples. The oldest is $1975 \pm 85 \mathrm{BC}$ (cal) and the youngest is $925 \pm 75 \mathrm{BC}$ (cal) (Meldgaard, J. 1983, I99I: 204-205). Qajaa was thus occupied at the same time as Nipisat phases I and 2 and during the first half of phase 3. Excavations at Qajaa yielded a vast amount of faunal material, dominated by harp and ringed seal. The site is interpreted as having been used year round (Møhl 1986, 1997b). Unfortunately, from the existing publication, it is not possible to see the correlation between tool types and stratigraphy and any comparisons with Nipisat are therefore problematic. It would have been interesting to see when soapstone was introduced and the presence/absence of other diagnostic types.

Although more than 50 years have passed since Sermermiut was excavated, the results are still of interest. For the first time it was possible to ${ }^{\mathrm{I}} \mathrm{C}$ date and distinguish between the Saqqaq and Dorset Cultures stratigraphically. Sermermiut reveals the same chronological sequences as seen at Qajaa, with a hiatus between Saqqaq and Dorset (Mathiassen I958; Larsen and Meldgaard 1958). The 198I investigation at Sermermiut confirmed the results. The Saqqaq Culture was dated by K-3768 to 2I45 BC (cal) and K-3769 dated the Dorset Culture to 405 BC (cal) (Møbjerg I986b:29). The artefacts from the Saqqaq and the Dorset Cultures were well known types (Møbjerg I986b:3I, fig. 8). There is, however, a remarkable similarity between the bevelled polished tools dated to the Dorset Culture at Sermermiut (Mathiassen I958:19, fig. 7.I9-20 and 3I, fig 8.8-9; Larsen and Meldgaard 1958: plate 5, 26-28) and those from the Saqqaq Culture seen at Nipisat phase 3 and Asummiut SIK 899 (Figs II2 and 202).

It has recently been questioned whether Sermermiut and Qajaa actually were occupied during the Late Saqqaq phase, as the youngest dates are based on turf and not on cultural artefacts (Fredskild 1973; Jensen et al. 1999:I).

In 1994, the joint Nordic "Sydostbugt project" was initiated by Aasiaat and Qasigiannguit museums with focus on elucidating variability in Palaeo-Eskimo dwelling styles. The investigations have continued up to the present and have contributed new knowledge of both Saqqaq and Dorset Cultures. The artefact material has not yet been published, so it is only on a general level that comparison with Nipisat is possible.

Because of the focus on dwelling styles, it has been possible to see a gradual development from Early Saqqaq, to Late Saqqaq, to Early Dorset. Olsen (I998) has analysed dwelling structures from Qeqertarsuup Tunua and compares them to dwelling structures in the Sisimiut and Nuuk areas. He sees the axial features as the oldest type, dated to $2500-2000$ BC (cal). This type is known from Qajaa, Qeqertasussuk, Tupersuai II (Fig. I, nos. 42-44) and Olsen includes the feature at Akia in the same category, although this has been rejected by Kramer (pers. comm. 2003).

Olsen's oldest type differs from those at Nipisat, phase I and Nunnguaq (Fig. I, no. 37). The latter appears as a regular tent ring with a central boxhearth and a form of mid-passage. The variation in the dating of this type is large, and more investigations and dates are required. Another type are tent rings with a central hearth or a box-hearth filled with boiling stones. This type is well known from Qeqertarsuup Tunua in the north to the Nuuk area in the south. Angujaartorfik is slightly different because of the diffuse character of the hearth. The type is very rare after I40o BC (cal) (Olsen I998:I06). Olsen notes that a new type has been recorded in Qeqertarsuup Tunua: a platform dwelling at present only known from Niiversussannguaq II and Tupersuai V. The type is dated to 2I0O-I700 BC and is regarded by Olsen as a replacement for the axial features (Olsen I998:Ior table I).

Investigations of the Dorset Culture in Sydostbugten has revealed interesting aspects, especially from Annertusuaqqap Nuua. Here a well defined dwelling structure with a paved floor and a raised platform at the back has been found. There is no trace of a hearth, instead there were 12 fragments of soapstone found in areas which were saturated with oil/blubber. There are two dates from the site: AAR2343 and AAR-235I at 770-4Io BC (cal \pm Istd.) and 800-520 BC (cal \pm Istd.) respectively (Rasch and Jensen I997:105, table I; Jensen 1998:70, table 2; Jensen et al. 1999:2). These dates are problematic in the same way as the youngest from Nipisat (AAR3574), because the oscillations on the calibration curve create a plateau continuing for 300 years. Remarkable too are the three artefacts collected on the beach as stray finds (Jensen 1998:68-69, fig. 6). They are not 
identical to the bevelled tools from Nipisat (Fig. II2) but look very similar. The last ten years of investigations in Qeqertarsuup Tunua have indicated that bevelled polished tools belong to both Saqqaq and Dorset Cultures (J.F. Jensen pers.comm. 2003; E. Brinch Petersen pers.comm. 2003). However, some differences can be seen. The Saqqaq types do not have a bifacially flaked tang or side-notches.

A general trend from the southern part of Qeqertarsuup Tunua is that, despite the great similarity between dwelling structures from Saqqaq and Dorset Cultures, one clear difference exists. The box-hearth and the use of boiling stones are only related to the Saqqaq Culture. The Dorset cooking and heating activities involved the use of soapstone vessels and blubber (Jensen 1998:76). From the Sisimiut area we can see that the shift occurred around I300 BC. At that time the Saqqaq Culture had already disappeared from Qeqertarsuup Tunua.

The "Sydostbugt project" project has yielded 22 dates from five Saqqaq and four Dorset sites. These show that the main occupation period for the Saqqaq Culture is between 2300 and $\mathrm{I} 500 \mathrm{BC}$ and that there are only very sporadic visits to the area after that period. The Dorset Culture spans the period from 840 to I70 BC. The discontinuity between Saqqaq and Dorset observed in the northern part of Qeqertarsuup Tunua at Sermermiut and Qajaa is thus also valid for this area. Despite problems with the calibration curve from 700-40o BC, the oldest Dorset dating (K-6992) falls before that period at $800 \mathrm{BC}$, making it contemporary with the dates from Nipisat (K-6I94) (Jensen et al. 1999).

Very little research has been carried out between Sisimiut and Nuuk (Petersen 1988). In the Nuuk area, only few Palaeo-Eskimo sites have recently been excavated. The best known are Itinnera, Nunnguaq and Tuapassuit, excavated between I958-I968. Itinnera and Tuapassuit are only preliminarily published (Gulløv 1983, I986a; Gulløv og Kapel 1988; Meldgaard I96I; Rosing 1958). Nunnguaq has been published recently (Appelt 1995; Appelt and Pind 1996). From Tuapassuit there are more than 25 hearths and only 77 artefacts. Nunnguaq has seven structures and 7178 artefacts and Itinnera around ro structures and more than 15,00o artefacts. Some of the differences are caused by chronology, others by seasonality and the number of people visiting the site. In spite the differ- ences between the sites, some comparisons to the Sisimiut area will be drawn.

The low numbers of artefacts from Tuapassuit mean that the material cannot be regarded as representative. Killiaq and quartz/quartz crystal each account for c. $40 \%$, and the remainder is made up of quartzite and chalcedony. The lithic raw materials were analysed using categories differing from those employed at Nipisat, which makes direct comparisons problematic (Gulløv and Kapel 1988:54). The published material from Itinnera does not permit a study of how the distribution of flakes made of various raw materials relates to the structures at the site. It is thus only a general overview, lacking in the information that "horizontal" stratigraphy can provide. At Itinnera, killiaq accounts for $47.1 \%$, quartzite for $44.4 \%$, and quartz crystal and agate $9.2 \%$. At Nunnguaq the following general pattern can be seen: killiaq: $72.5 \%$, quartzite: 18.4\%, quartz crystal and agate: $8.5 \%$. However, when the structures are analysed individually, a rather different pattern emerges, for example killiaq accounts for $87.3 \%$ in area B3 but only $45.6 \%$ in area 7 (Appelt and Pind 1996:I35) This could indicate that the structures differ chronologically.

Individual tool types differ greatly in terms of raw material. Burins are most often made of killiaq while sidescrapers and microblades are made of agate or quartz crystal. At Itinnera a large percentage of projectile points are made of quartzite. No lamps made of soapstone are recorded from Tuapassuit, although they occur at both Nunnguaq and Itinnera. In addition to the small circular lamps from Ittinera (Meldgaard I96I), larger lamps were found with 2-6 smaller lamps in sets at Nunnguaq (Appelt 1995; Appelt and Pind 1996:I39-I42). No gaming pieces, weights or sinkers like those from Nipisat were found at Nunnguaq.

Tuapassuit has one ${ }^{\mathrm{I} 4} \mathrm{C}$ date of 2020-I980 BC (cal) (K-I537) and Itinnera is dated by two to I425 BC (cal) (K-II93) and I250 (cal) BC (K-588) (Gulløv I983; Gul$1 \varnothing \mathrm{v}$ and Kapel 1988:55). There is only one from Nunnguaq, dated to I880-I79o BC (cal) on charcoal from the hearth in structure I (Appelt 1995:60). The relative frequencies of the various lithic raw material types and the presence of soapstone lamps at Nunnguaq would seem to point to a more recent date than is the case. This can be explained in two ways: either the date could be too early due to contamination, or there is a great regional difference between the Nuuk and 
the Sisimiut areas in terms of the relative frequencies of lithic raw materials (incl. soapstone).

The dates indicate that Tuapassuit is contemporary with Nipisat phase I. The dwelling structures at the site are similar to that at Nipisat and those from other Early Saqqaq sites. Nunnguaq is more spectacular because some of the tool types appear to be early, such as the harpoon blade (Appelt and Pind 1996:137, fig. I0.5), but the presence of soapstone and the low percentage of killiaq are factors indicating a later date. However, the lack of stratigraphic information and the fact that we only have one date from the site complicate the situation. Furthermore, choice of raw material may have been different in the Nuuk area compared to Sisimiut. Itinnera is contemporary with the oldest part of phase 3 at Nipisat. Unfortunately, there is no information available concerning the spatial relation between the distribution of soapstone lamps and the boxhearth with cooking stones. Such hearths disappeared in the Sisimiut area around I300 BC, long before soapstone lamps appear in the archaeological record.

From other parts of Greenland there are only sporadic traces of the Saqqaq Culture, as seen from the research in Southwestern Greenland (Raahauge and Appelt 2002) and Southeastern Greenland (Jensen I996; Gulløv and Jensen I99I; Gulløv et al. 1992, 1993).

At Ikaasap Ittiva (Fig. I, no. 36) in Ammassalik District both Saqqaq and Dorset Cultures have been recorded. Two ${ }^{14} \mathrm{C}$-samples (K-3938B and K-3939) date the Saqqaq Culture to 1885 BC (cal) and 106o BC (cal). Traces of the Saqqaq Culture are found all over the district but no dwelling structures have yet been recorded (Gulløv and Lange 1987; Mathiassen 1934; Møbjerg I986a, I986b, I988a; Møbjerg and Robert-Lamblin I990). Noteworthy is the presence of a bevelled polished tool (Møbjerg 1988a:87, fig. 4d) identical to the one from Annertusuaqqap Nuua (Jensen 1998:67, fig. 6). The raw material most often used by the Saqqaq people is a kind of killiaq which occurs $500 \mathrm{~km}$ north of the Ammassalik area. In addition, they used agate which might be from the Nussuaq peninsula in West Greenland. There is an increasing use of local quartzite in the Dorset Culture.

Between the Ammassalik and Illoqqortoormiut areas, there are very few traces of Palaeo-Eskimos (Andersen 198I; Kapel 1989). This is also true for the Illoqqortoormiut area itself where Cape Tobin (Fig. I, no. 35) is among the easternmost known Palaeo-
Eskimo sites. Although both reconnaissance and excavations have been carried out in the Kangertittivaq (Scoresby Sund), no traces of Palaeo-Eskimo settlements have been found. On the contrary, all agate flakes found related to later Neo-Eskimo habitation, dating from $\mathrm{I} 400 \mathrm{AD}$ to $\mathrm{I} 850 \mathrm{AD}$ (Møbjerg I988b).

More recent investigations at numerous localities carried out by Tuborg and Sandell between 1989-95 have, however, considerably altered our understanding of settlement along the outer coasts (Sandell and Sandell 1996; Tuborg and Sandell 1999). One site, Aappalaartaajik (Røde Hytte), is of particular interest. Apart from the well known tool inventory from the earliest phase of the Saqqaq/Independence, this site has also produced two outstanding bifacial endblades. Both are of grey agate and are meticulously bifacially flaked leaving them rhombic in cross section with serrated edges. One is broken but the other measures II9 $\mathrm{mm}$ in length and is $16 \mathrm{~mm}$ wide (Tuborg and Sandell I999:49, fig. 4,I9). The site has been ${ }^{\mathrm{I}} \mathrm{C}$ dated to 2490 BC (cal) (AAR-II82) and 2560-2500 BC (cal) (AARII84) on samples of locally grown willow from a mid passage hearth. No comparable artefacts are yet known from elsewhere in Greenland and the closest parallel comes from Helge Larsen's excavations at Trail Creek (Fig. I, no. 2), where he dates this type to the Denbigh flint complex (Larsen 1968:69). Information from Aappalaartaajik, combined with other dates from the area, provides a clear picture of two distinct phases, an Early Saqqaq/Independence I dated to 2500-200o BC and a later Dorset element at around 400-o BC (Tuborg and Sandell I999:I42). For a more detailed discussion of the relationship between Independence I and Saqqaq see Appelt (1997) and Elling (I996).

Recent investigations in Northeast Greenland have revealed discontinuity between the initial Independence I settlement (Adam C. Knuth Site, Pearylandville and Deltaterasserne (Fig. I, nos. 29-30)) and the arrival of Independence II (Cape Holbæk and Eigil Knuth Site (Fig. I, nos. 32-33)) (Andreasen 1996, 1997, I998; Andreasen and Elling I99I). The earliest phase (Independence I) dates to $2400-2000$ BC (cal) followed by a hiatus until Independence II dated at 8oo400 BC (cal). Further south there appears to have been a time lapse in that the Independence II settlement in Dove Bugt occurs later, dated to 500-200 BC (cal) (Andreasen 1998:20I). The entire basis for dating 
Independence II is, however, problematic due to oscillations of the calibration curve creating a "plateau" at precisely this point covering a time span of some 300 years, as has already been mentioned in connection with dating the final phase of the Saqqaq Culture in Sisimiut and the early Dorset Culture in both Sisimiut and Qeqertarsuup Tunua. There is, therefore, no basis for ${ }^{\mathrm{I}} \mathrm{C}$ dating Independence II. We can only conclude that the area may have been settled throughout the entire period or merely sporadically but that the issue cannot be settled by ${ }^{\mathrm{I}} \mathrm{C}$ dating. Although large numbers of sites have been found, the assemblages indicate that occupation was of a short and sporadic nature. The Independence II locality on Ile de France, on the other hand, has been interpreted as a form of PalaeoEskimo Aasivik (summer gathering place) with its over 500 recorded dwelling structures (Jensen 20oob).

During recent years, several investigations have been carried out in Northwestern Greenland (Diklev and Madsen 1992), although more intensive research of the oldest cultures such as that known from Nuulliit in particular (Fig. I, no. 27) (Knuth 1967) are needed. These studies reveal the same discontinuous sequence as known from Northeast Greenland, with an early wave of occupation between 2400-2000 BC, followed by a brief period of occupation around I80o-160o BC. The subsequent early Dorset occupation dates to the problematic period from 800-200 BC (Andreasen 2000:82). The main emphasis of research has recently focussed on the late Dorset Culture between 800-I300 AD (Appelt, Gulløv and Kapel 1998; Appelt and Gulløv I999; Bendix 2000).

Our knowledge of Palaeo-Eskimo settlement in the area between Qaanaaq and Uummannaq is minimal, due to lack of research in this area.

In conclusion, given present day knowledge, it has not been possible to isolate parallels to the cultural sequences observed in the Sisimiut area elsewhere in Greenland. Although similarities do exist, no other areas exhibit the same pattern of continuity covering nearly 2000 years.

\section{Nipisat's relation to sites in Canada and Alaska}

Localities exhibiting clear similarities to the earliest phase of the Saqqaq Culture are known from Elles- mere Island (Fig. I, nos. 25-26) (Schledermann I990; Sutherland 1996; Knuth 1967), Devon Island (Fig. I, nos. 23-24) (Helmer I99I; McGhee 1979), Baffin Island (Fig. I, nos. I4-I5, I9), the Igloolik area (Fig. I, no. I3) (Maxwell 1985; Meldgaard 1960) and all the way to the northern coast of Nunavik (Fig. I, nos. I6-I7, 20) (Nagy 1997; Taylor 1968; Tuck 1976). To the west, similar assemblages have been found at North Knife River sites on the west coast of Hudson Bay (Fig. I, no. 22). The western Canadian sites (Fig. I, nos. 6,8) (Harp 1958, 1997; Maxwell 1985) and the earliest Alaskan localities (Fig. I, nos. I-5) (Giddings 1964, 1967) reveal many characteristics similar to those seen from Greenland, despite the vast distances involved.

Nevertheless, there are major differences in the cultural sequences observed in Canada and Alaska when compared with Nipisat and the Sisimiut area as a whole. The High Arctic areas reveal the same discontinuity as seen in North Greenland. Localities in the Igloolik region such as Alarnerk, Kaleruserk and Kapuivik (Meldgaard I960) do, however, show signs of continuity from the earliest phases from 2000 BC and up to the arrival of the Thule culture some 3000 years later. In the analysis of these sites, however, research has focussed more on the Pre-Dorset/Dorset transition, rather than on the internal development of the Pre-Dorset itself. South of this area, preservation conditions for organic materials on Pre-Dorset sites are extremely poor, thus complicating comparative studies (Nagy 1997, 2000). Nevertheless, the striking similarities between the lithic artefacts at the Saglek Bay sites in Labrador and the tool inventory from the Sisimiut area are remarkable (Tuck 1976:90, fig. I).

It is much more difficult to find parallels to the Late Saqqaq Culture, perhaps due in part to the lack of organic material at many localities.

The closest parallels to the Nipisat material currently available are the organic materials from Taylor's I965 excavations on Banks Island and Victoria Island, far to the west in the Canadian Arctic archipelago (R. McGhee pers. comm. 1996). The dates from the sites of Wellington Bay (I-2057: I230BC (cal)), Menez (I2058:930 BC (cal)), Buchanan (I-2053 and 2054:960 BC (cal) and Io40 BC (cal)) (Fig. I, no. II) (Taylor I967:228) are very close to the youngest occupation at Nipisat.

At around I50o BC, major changes appear to have taken place throughout the Arctic area. 
In Northern Alaska the Arctic Small Tool Tradition changes: the Denbigh Flint Complex shifts to the Choris tradition. In addition to flaked bifaces, polished slate knives (presumably for cutting through the skin and blubber of sea mammals) and ceramics are introduced. Artefacts such as heavy notched stones, indicating the use of nets for fishing, appear at the same time (Anderson 1988:86; Giddings 1964). From Nipisat there are tools which could be used for net making (P. Plumet pers. comm. 1996), and one piece of soapstone is notched as if it was used as a sinker. The bevelled, polished tools and artefacts such as heavy harpoons or lances are also interpreted as having been used for hunting sea mammals.

The geographical distance between the classic Choris localities in Alaska, and the Sisimiut area is, however, enormous. Recent studies in the Mackenzie Delta at Satkualuk (Sutherland 1997), revealing ceramics, have extended the range of the Choris Culture Iooo $\mathrm{km}$ eastwards. Other items from this site are even more eastern in origin. The tool inventory at this site, like those from Crane (Fig. I, no. 7) (Le Blanc 1994) at Cape Bathurst Peninsula and Lagoon (Fig. I, no. 9) (Arnold I98I) on Banks Island, exhibit both Choris and Pre-Dorset features. Furthermore, elements from the Dorset and possibly also the Norton Cultures, not previously recorded outside Alaska, are also present (McGhee 1996:I78-I79). These late sites have been dated to between $700-400 \mathrm{BC}$, i.e. the period where the calibration curve is problematic. Meldgaard's research in the Igloolik area (Fig. I, no. I3) at Alarnerk, Kaleruserk and Kapuivik (Fig. I, no. I4) is relevant in this context (Meldgaard 1960, 1977). On raised beach terraces, he found traces of settlement spanning over 4000 years. Meldgaard sees a continuous development from the Pre-Dorset to the Dorset, but has interpreted the transition between the $22 \mathrm{~m}$ and $23 \mathrm{~m}$ terraces as a "stressed" period dating to between 850 and 400 BC (Maxwell 1997:206) i.e. contemporary with the youngest date from Nipisat. Taylor
(1968) also regards the development from Pre-Dorset to Dorset as a continuum, as exemplified at the two sites of Arnapik (Fig. I, no. I6) and Tyara (Fig. I, no. I8). Although Tyara is interpreted as early Dorset, similarities to phase 3 at Nipisat can be seen (Taylor I968:II9, fig. 23). The earliest Palaeo-Eskimo locality at Port au Choix, Newfoundland was investigated by Renouf (1990, 1994, 1999) and named the Groswater Phase (Fitzhugh 1972, 1976, 2003). Renouf sees it as transitional between Pre-Dorset and Dorset. Calibrating the available dates from Philips Garden East (Renouf I994:table I) the range is from II30-8Io to $360-60 \mathrm{BC}$, which means that it is contemporary with the youngest phase at Nipisat and the earliest Dorset dates in the Sisimiut area (The youngest date from Nipisat dates to 520 BC calibrated to $760-400$ $\mathrm{BC})$. Again, we run into problems with dates at this point with the "plateau", spanning some 300 years, on the calibration curve. For this reason, the PreDorset/Dorset transition cannot be dated using ${ }^{14} \mathrm{C}$, as was also the case for the Saqqaq/Dorset transition in Greenland.

In conclusion, clear affinities between Nipisat in Greenland and a number of early sites in Canada and Alaska can be seen. Simultaneously with the shift between phases 2 and 3 at Nipisat, dramatic changes occur throughout the Arctic. These changes are clearly reflected in the tool inventories with the introduction of ceramics or soapstone, the presence of fully polished stone tools and the increasing dominance of quartz at the expense of chert or killiaq. The exploitation of sea mammals intensified, probably due to an increasing need for blubber. Perhaps most significant of all is the evidence for well developed communication networks, where information concerning artefact style, use of raw materials, types of dwelling structure, and most importantly, ways of exploiting natural resources was shared over thousands of kilometres within a relatively short period of time. 


\section{Chapter 10}

\section{Discussion and conclusions}

\section{Climatic and cultural sequences}

Although the climatic optimum during which the sea temperature off West Greenland was higher than today had already peaked at about 3,500 BC (Fig. 2), the initial migrations of the Arctic Small Tool did not take place until some Iooo years later. These pioneer groups populated the Arctic very rapidly and from $2500 \mathrm{BC}$, traces of their occupation can be found from Alaska in the west to Greenland in the east. This is also the case for the Sisimiut area, where the site of Qivittup Nuua dates to this early pioneer phase.

At around $\mathrm{I} 800 \mathrm{BC}$ a gradual climatic cooling set in, although it was still warmer than today. Temperatures approached present day levels from around I300 BC, but between 700-400 BC the climate became cooler and more humid. It is within this period that the youngest phase of the Saqqaq disappears at Nipisat and the Dorset is first recorded both in Qeqertarsuup Tunua (Disko Bay) and in the Sisimiut region (Bundgaard 1977). Remarkably, cultural shifts, climatic changes and major oscillations of the calibration curve often coincide, making it impossible to ${ }^{\mathrm{I} 4} \mathrm{C}$ date the transitions precisely.

As the climate changed, so did the sea/land ratio (Kramer 1996a:40; Appendix 2). When the Saqqaq population settled in the Sisimiut area, the sea/land configuration was different than that of the present: i.e. the straits were wider, the islands were smaller and many of the small skerries, today forming part of the archipelago, were submerged. The effect of the isostatic upheaval at the site on Nipisat is illustrated in Fig. 196. The ratio between the eustatic and the isostatic movements was not constant, however, and at one point the sea rose faster than the land, leaving some Dorset sites either submerged or situated within the tidal zone today (Appendix 2, Fig. 220).

In this study it has not been possible to examine in detail the precise ways in which the varying land/sea ratio and climatic changes affected the Saqqaq populations. Nevertheless, the changes appear to have been more dramatic in Qeqertarsuup Tunua, where a drop in temperature of a few degrees had a greater effect upon open water hunting (due to increasing ice cover and decreasing open water) than in Sisimiut, which still has an open water area even if the temperature drops. Because open water hunting was important for the Saqqaq people, occupation continued in the Sisimiut area 500 years longer than in more northern regions.

\section{Interaction between humans and the environment}

Nipisat was obviously a very attractive place to stay, at least at certain times of year (Fig. 204), as it was used for more than a millennium, although not continuously. The presence of hatchlings of divers, geese, eiders, gulls, medium sized auks (presumably both Brünnich's guillemot and razorbill) and black guillemot, combined with the occurrence of medullary bone particularly in geese, documents that the site was visited during the nesting and brooding period. At that time of year the main option was probably egg collecting and breeding birds were certainly disturbed at their breeding grounds. The common seal was exploited in a similar manner with pups and young seals constituting the majority of the hunting bag (Figs I62-I66). Given the extremely long time span covered by the ${ }^{\mathrm{I} 4} \mathrm{C}$ dates and the comparatively crude three phase stratigraphy, it is impossible to determine how detrimental the impact of being hunted during the breeding season was for the breeding birds and common seals. The practice of taking geese primarily during their staging and nesting period seems to have occurred throughout the entire period of occupancy, and the relative importance of geese even seems to have increased through time. Despite the possible negative impact on the breeding populations caused by disturbance at the breeding sites, it made good sense for the Saqqaq people to hunt immature birds and mammals. Their inexperience and lack of timidity makes them easy prey and they are a predictable and highly concentrated resource: e.g. immature gulls gathering in the fjords during autumn or 


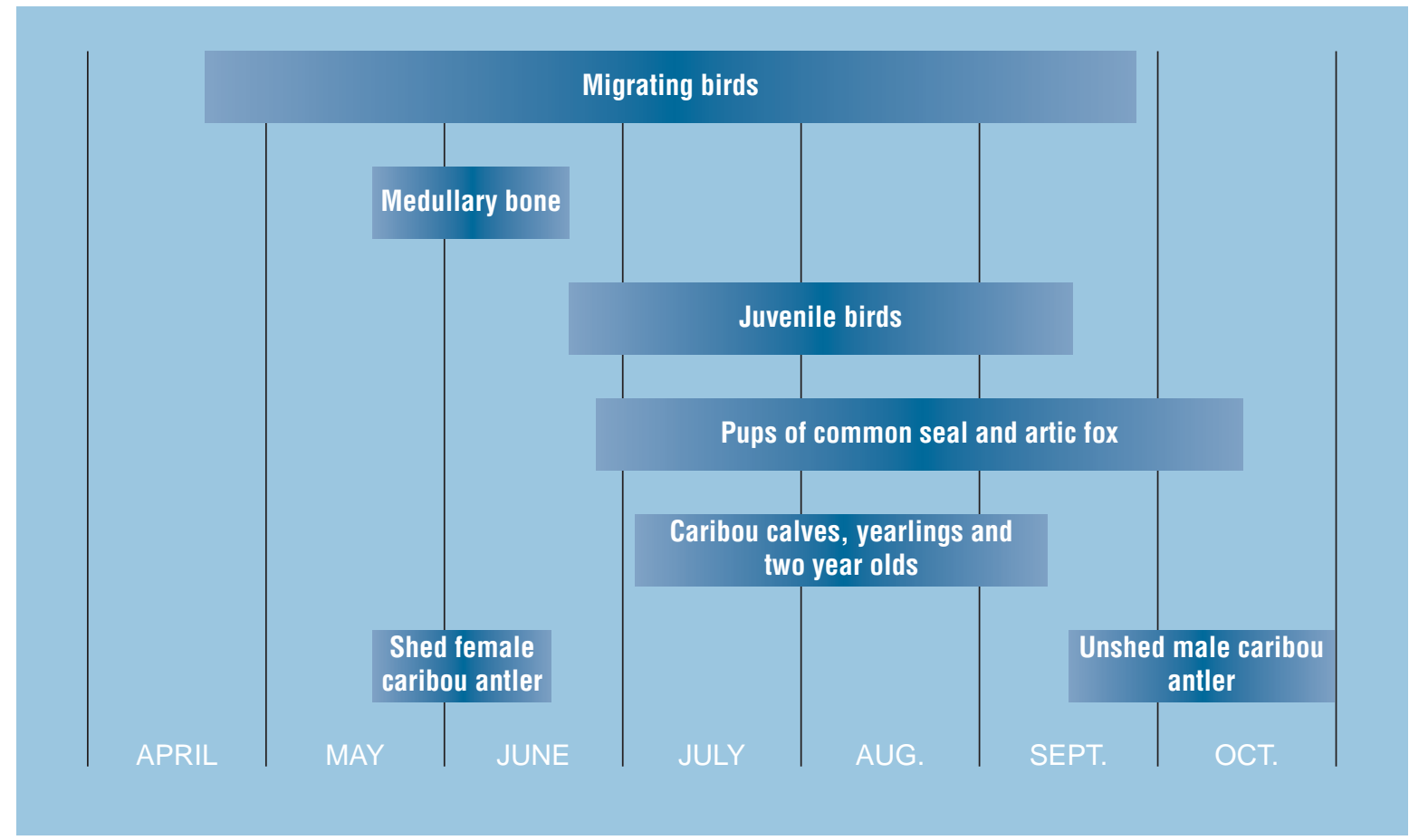

Fig. 204. Summary diagram showing the season of occupation at Nipisat. Documented by presence of medullary bone in bones of breeding birds, juvenile bones of birds and mammals and presence of migrating species. Information from all three phases was similar and therefore lumped.

common seals hauling out on sand banks during the summer months. Furthermore, taking a certain toll of juveniles or subadults does not harm the breeding population of species with a slow reproduction capacity such as e.g. walrus and guillemot.

At Nipisat it seems that a combination of terrestrial game and marine resources were exploited for centuries without major changes. The resolution of the three chronological phases does not allow detection of any fluctuations in the caribou populations. Caribou populations of West Greenland are known to have been subject to fluctuations in historic and prehistoric times (Meldgaard, M. 1983, I986). It is not possible to estimate the hunting pressure on the caribou population as neither the time lapses between hunting activities or the number of people inhabiting Nipisat can be ascertained. Although the dates (more than $80 \%$ of the ${ }^{\mathrm{I} 4} \mathrm{C}$ dates are on caribou bone) indicate a more or less continuous occupation for at least I200 years, the island may have been deserted for decades, e.g. during caribou lows. Caribou may not even have been exploited during certain periods, while people focussed on common seals and fowling. An efficient pattern of ex- ploitation is the optimum exploitation without endangering the survival of the resource (Münzel 1987b: 99). The Saqqaq population in the Sisimiut District probably never endangered the local breeding populations to any serious degree. When one resource became scarce, e.g. due to environmental/climatic changes; the Saqqaq people switched their focus towards other resources.

Despite small temporal trends in the game composition at Nipisat, the overall impression is one of stability and the island had by and large the same function during the entire occupation period. The breeding populations were apparently not depleted, due to the mobility and low numbers of the human groups.

\section{Exploitation of non-living resources}

When Saqqaq people arrived in the Sisimiut area, they brought with them knowledge of lithic raw materials such as killiaq, agate and quartz crystal, which were not available locally. The vast majority of these materials occur on the Nussuaq Peninsula c. $500 \mathrm{~km}$ north of 
Sisimiut. Thin-section analysis of individual flakes reveals, however, that even during the earliest phase, killiaq from Qaarsut on Nussuaq and from Angissat (Grønne Ejland) a small island in Sydostbugten was used. In addition, a type of killiaq from an unknown source was also used. The ratio between distance to raw material source and size/number of cores and preforms varies inversely, i.e. the greater the distance to source, the smaller the size and number of cores and preforms (Jensen et al. 1997:147), so that cores of killiaq do not in fact occur outside of Qeqertarsuup Tunua. The lithic material from Nipisat shows that there were cores at the site, but these were totally used in such a way so that only the remaining large flakes and core tools such as axes, large bifaces etc. indicate the presence of cores in the material. The great amount of small debitage (Figs 54-58) also indicates that primary flint knapping occurred on the site.

During the late Saqqaq, from about I30o BC, focus appears to shift away from Nussuaq as a raw material source towards Angissat (Jensen and Brinch Petersen I998:I49). This coincides with an increased use of quartzite and a corresponding decrease in the use of killiaq and agate. The exploitation of quartz crystal remains more or less stable throughout the entire period.

In several respects, focus is seen to shift from Qeqertarsuup Tunua and this corresponds well with the abandonment of Qeqertasussuk in around I40o BC. It has recently been questioned (Jensen et al. I999:I) as to whether Sermermiut and Qajaa were indeed occupied during the late Saqqaq, as dates here originate from turf rather than items with clear cultural affiliation. It has therefore been concluded that only sporadic visits of the Saqqaq Culture occurred after I300 BC in Qeqertarsuup Tunua.

At this time, soapstone, used for lamps, cooking vessels, containers and items of fishing equipment, was introduced in the Sisimiut area. This could reflect of the development of trade connections to the soapstone quarries in Nuuk, facilitating the acquisition of the raw material. Furthermore, the use of soapstone could be an indication that driftwood was becoming a seriously depleted resource, following more than Iooo years of exploitation. Initially, the amounts of driftwood available would have been overwhelming (Grønnow I996a), but intensive use for both tool manufacture and as firewood, can have seriously exhausted supplies. An increased emphasis on walrus hunting, for example, would have facilitated the use of blubber as fuel rather than wood. This is supported by the disappearance of box-hearths and the negligible amounts of charcoal found during the late Saqqaq, together with the numerous soapstone sherds occurring at Nipisat and Asummiut.

\section{Technology}

The earliest settlers in the Sisimiut area brought with them a highly complex technology for the exploitation of both marine and terrestrial resources. Despite the apparent stability in resource exploitation, changes in tool technology can be seen. Many of these changes occurred gradually as new types were introduced and earlier types dispensed with. The most striking change, however, occurred around I300 BC, when a new tool inventory was taken into use, including large heavy tanged antler harpoon or lance heads with an elongated line hole for fastening to the foreshaft along with several types of bevelled harpoon and lance blades (Figs 90, 9I and II2). These types have been interpreted as indicating a greater emphasis on the exploitation of marine mammals such as walrus and whale. At the same time, the well-known Saqqaq harpoon, both tanged and toggled, and the associated small triangular killiaq harpoon blades disappear from the archaeological record. Bows and arrows, which had been used for hunting caribou among other things (Fig. 205), were abandoned and replaced by various forms of lance or spear (Fig. 206). Great variation is also seen in the associated stone points (Fig. II4). During the final phase, a wide range of barbed leisters used for hunting birds or fishing (Figs 97-IO2) can be seen. At the same time we see the introduction of soapstone for lamps and as well as a range of artefacts probably used for fishing.

Tool types such as scrapers, burins, needles, or pressure flakers remained apparently unaltered, however, throughout a period of nearly 2000 years. The morphological differences, which are observed in these tool types, are interpreted as being functional, rather than chronological in origin.

When comparing technological change with resource exploitation it is interesting that, despite changes in the tool inventory, hunting strategies remained more or less constant. The minor variations 

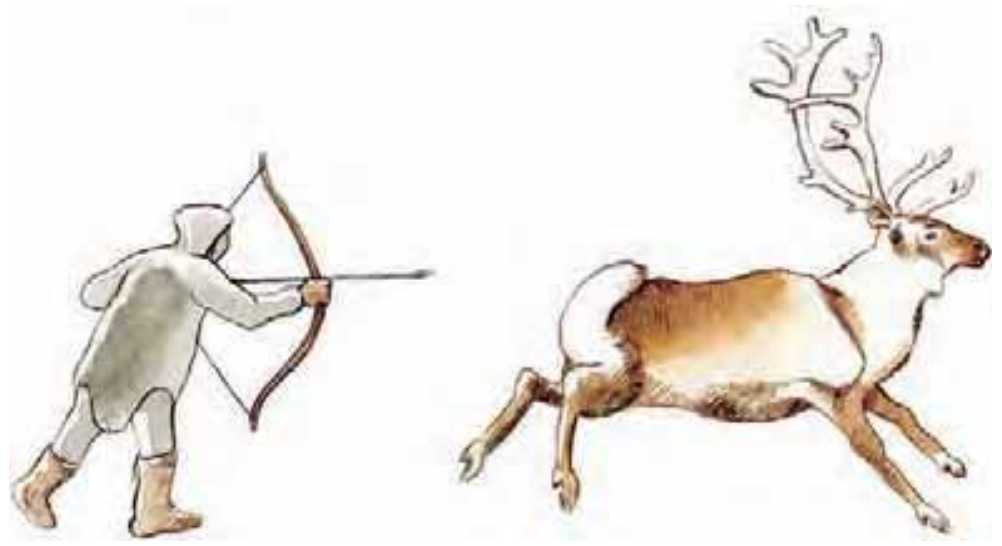

Fig. 205. The Saqqaq people from Nipisat were hunting caribou with bow and arrow in the oldest phases. Drawing: Jørgen Mürhmann-Lund. observed could indicate that the site was not necessarily visited at the same time each year, or that climatic changes may have caused a slight shift in annual game migration routes and/or periods.

\section{Settlement patterning}

Nipisat is a seasonal site and thus played its part within a network of sites in the Sisimiut area. Although the dates indicate continuous use throughout the entire period, the stratigraphy at Nipisat is not sufficiently detailed to permit a determination of just how often the site was occupied. Nor is it possible to see whether we are dealing with new groups or the same families returning again and again (Møbjerg and RobertLamblin 1990:235-39).

Although the faunal assemblage seems extensive, it is in fact rather limited, considering that Iooo-I50o years of seasonal visits are supposed to be reflected.
The proportion of game removed from the site as provisions, that only small groups used the site and that it must have been completely abandoned periodically are possible explanations for this.

The small number of dwelling structures is also surprising, considering the long period of time in which the site was in use. It is interesting that new arrivals respected and reused the old hearths although some disturbances and pits dug into older layers are seen, e.g. in the northern part of area I (Figs 26 and 30).

Although blurred, due to the long period of use, it is nevertheless still possible to discern distinct activity areas. In phase I, an activity area can clearly be seen around the hearth within what is assumed to be a dwelling structure. Here large numbers of tools (Figs 84,86 and 88) were found along with numerous bones from fish, great auk, seal and caribou (Figs I27, I42, I69 and I79) and antler (Fig. I80). A further concentration of artefacts and bones was located in the north-
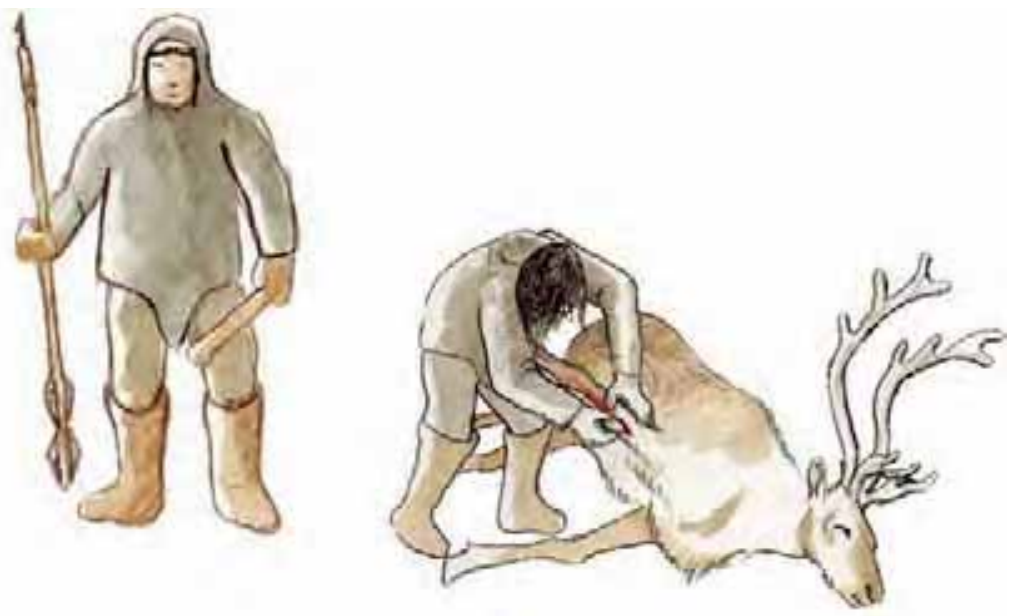

Fig. 206. The Saqqaq people from Nipisat were hunting caribou with light spears or lances in the youngest phases. Drawing: Jørgen MürhmannLund. 
ern part of area I where gulls and porpoise were also well represented (Figs I39 and I72). This area is interpreted as midden because of the mixture of stone, charcoal, thick deposits and many different bones with cut-marks (Appendix I). The horizontal distribution of fish and porpoise remains differs from that of other species, in that they lie partly on the protruding bedrock (Figs I27 and I72). Bones and flakes (Figs 44, $45,48,50$ ) are generally more evenly distributed than tools throughout area I with the exception of the far west. Here it is important to note the $4 \mathrm{~m}^{2}$ in the centre of area I for which the faunal analysis is not entirely completed (see Chapter 5)

The distribution of finds in phase 2 is entirely different. Apart from a few bones, no finds were recovered from the area around the hearth. A possible small activity area to the southwest and a midden in the far north of area 2 were also found (Figs 82, 84, 86, I27, I39, I69, I79 and I80).

Although phase 3 is characterised by a much more even distribution of flakes, tools and bones (Figs 46, $47,85,87$, I28, I40, I59, I60, I70, I8I and I82), a large concentration of bones and artefacts in the far north of area 3 is interpreted as a midden area. Further concentrations were found in the central parts of areas I and 2. Unlike the other species, swan remains were found in three distinct concentrations (Fig. I50). Similarly, porpoise bones were found concentrated in the southern part of the settlement area (Fig. 173). As no dwelling structures were found in this phase, only the distribution of soapstone sherds may perhaps provide an indication of a structure outline (Fig. II9). Three concentrations can be seen: in the north western part of area I, in the western part of area 2 and, more dispersed, in the central part of area 3. However, the fragmentary nature of the soapstone makes it difficult to ascertain whether we are dealing with a dwelling or a midden.

Interestingly, very few bones or artefacts show signs of having been affected by fire. This is interpreted as an indication that meat was generally boiled or dried rather than roasted. On the other hand, there is a clear similarity between the horizontal distribution of burins and that of caribou antler/bone for all phases (Figs 86, 87, I79, I80 and I82). A connection can similarly be seen between the amounts of antler/ivory and the large numbers of burins recorded from phases I, 2 and 3. Furthermore, the numerous needles at Nipisat clearly indicate that skins from the many birds, young seals and caribou calves were processed on site (Figs 84 and 85 ).

Fig. 193 illustrates that Nipisat was part of a network of sites in use for over Iooo years. There are nearly twice as many Early Saqqaq sites than those from the Late Saqqaq. This may be due to interpretational factors, as lack of organic material complicates the recognition of Late Saqqaq sites. If organic material, other than charcoal, had not been preserved at Nipisat, our interpretation of the site would have been entirely different. It would not have been possible to distinguish between phases I, 2 and 3 stratigraphically and there would have only been two ${ }^{14} \mathrm{C}$ dates $(2020$ and I430 BC). This would have placed the site in the same time period as e.g. Qeqertasussuk (Grønnow 1994). The few bevelled killiaq points would perhaps have been interpreted as Dorset intrusions and the soapstone sherds would have been dated to the earliest phase, thus reminiscent of Nunnguaq (Appelt 1995) in the Nuuk area.

The disparity between the number of sites known from the Early and Late Saqqaq respectively can, however, reflect a genuine difference. Environmental change may have resulted in a smaller population during the later period, as suggested by Maxwell (1985). The situation at Nipisat, where the thickest deposits occur in phase 3 , does not support this theory however.

Nipisat, along with other sites in the Sisimiut area, played a role in the local annual cycle. Nipisat was only occupied for a short period of the year, stretching from early summer to early autumn. The rest of the year was spent elsewhere in the area, perhaps in more protected bays as those at Akia or Asummiut. The latter provides evidence of a more permanent settlement in the form of numerous hearths and dwelling structures (Fig. 207), although the site was occupied for a shorter period of time (I970-I670 BC (cal) (Table 55)). This site is interpreted as a base camp (Fig. 208), to which families returned following visits to Nipisat or a fishing expedition to streams further inland. Nevertheless, we are dealing with a small, highly mobile population, which exploited the entire Sisimiut area, with their detailed knowledge of the various locally and seasonally concentrated resources.

The resources available at Nipisat must have been attractive since the site was visited repeatedly over 


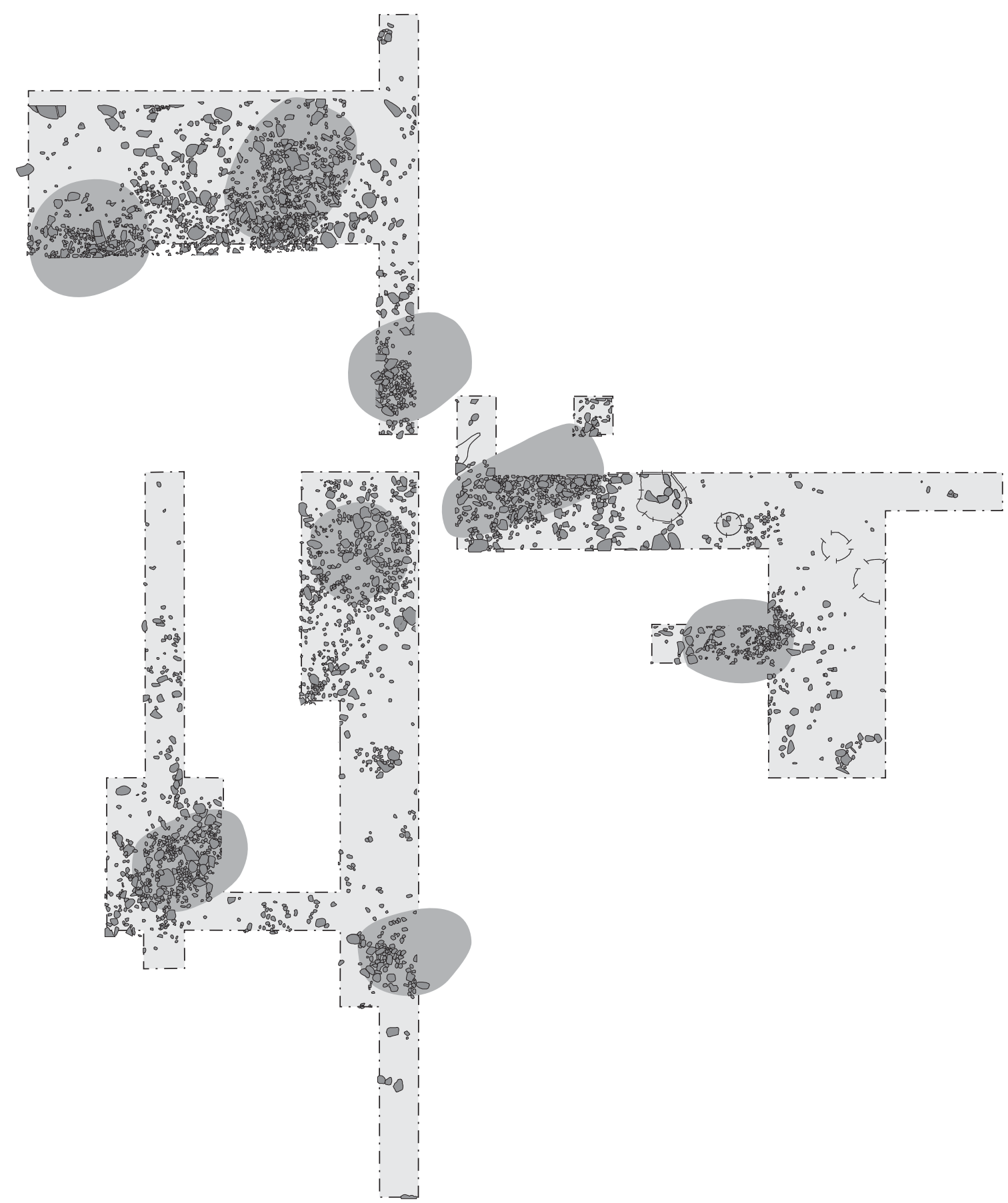

Fig. 207. Sketch map of the excavated area at SIK173. Asummiut. Dark grey circles indicating dwellings structures as seen in the field in 1995. Drawing: Stig Grummesgaard-Nielsen.

such a long time period. This could have been due to the occurrence of stable resources, which could also be stored (eggs or meat for drying), or for trading purposes (skins, antler, ivory or driftwood). The Nipisat inhabitants may thus have been part of an interregional exchange network, perhaps with groups from areas such as Qeqertarsuup Tunua or Nuuk. Given the data currently available, it is difficult determine the nature of this contact, but some form of direct procurement or indirect exchange system may well have existed (Jensen et al. 1997:I46; Jensen and Brinch Petersen 1998:I50). 


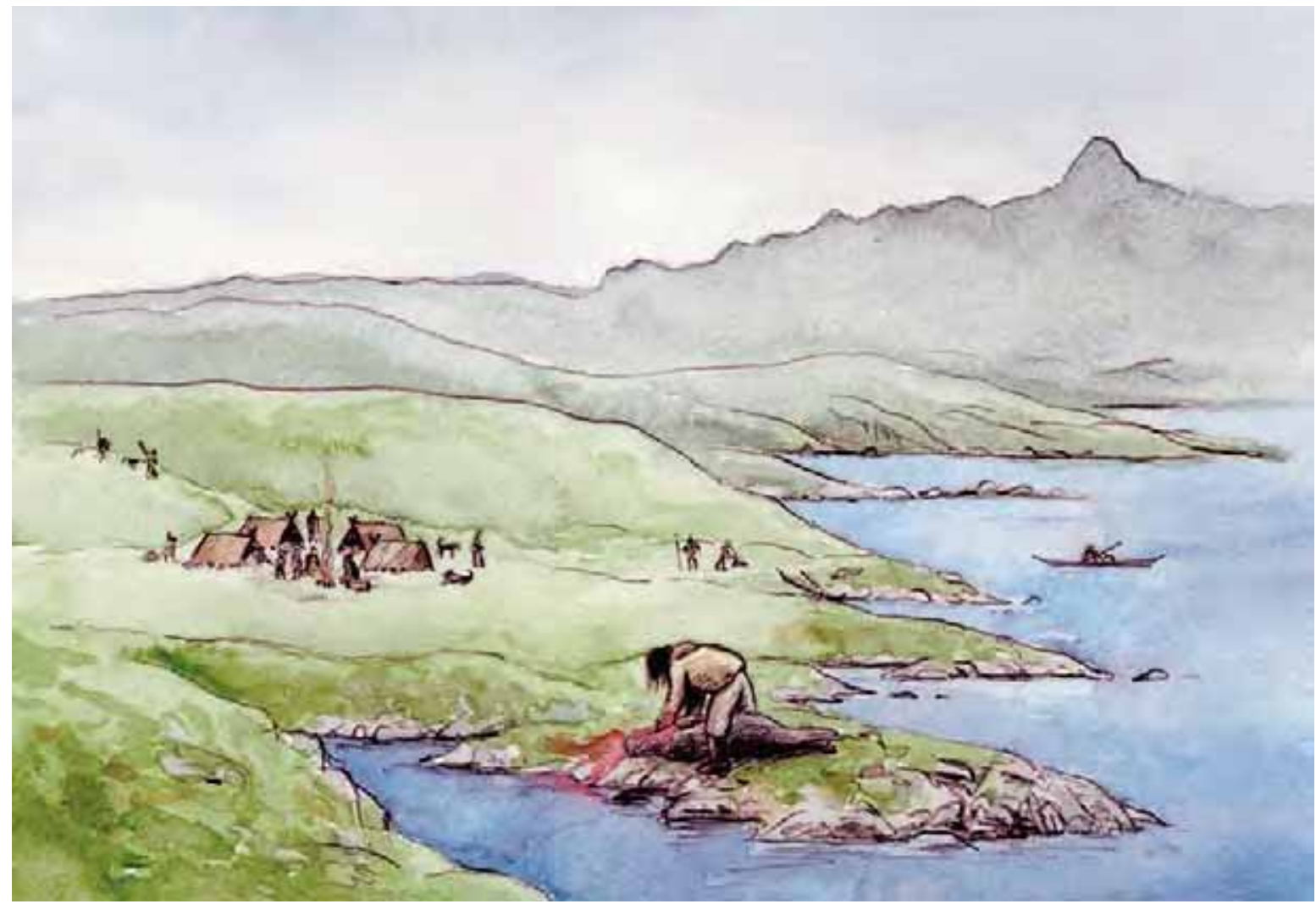

Fig. 208. Asummiut SIK173 is interpreted as a base camp used more or less year round for 4-8 families. Drawing: Jørgen Mürhmann-Lund.

Such mechanisms may also have changed through time. Contact with Nussuaq appears to have broken down before the final phase of the Saqqaq Culture and was replaced by Angissat as a source of raw materials. The issue as to whether the latter reflects a more direct procurement system or not can only be determined by a detailed analysis of the reduction sequences in the lithic production and through the construction of a "chaine opératoire". Selected localities such as Qeqertasussuk and Itinnera are currently subject to just such an analysis (Mikkel Sørensen pers. comm. 2003).

It is however clear that the population was small, mobile and appears to have covered great distances.

\section{Social organisation}

The earliest phase of the Saqqaq Culture is characterised by well-defined dwelling structures with boxhearths and an internal layout and size suggesting that one or two families lived together under the same roof.
Akia and Asummiut are typical examples. Dwelling structures were subject to seasonal variation, however. At Nipisat (phase I) there is no distinctive central passage but instead a lighter structure with a central boxhearth (Fig. 209). In phase 2 there is a more isolated box-hearth. The Late Saqqaq Culture (phase 3) sees the complete disappearance of the mid-passage dwelling and soapstone lamps replaces box-hearths.

The transition from Early to Late Saqqaq does not seem to have been marked by major changes in social organisation. We are still dealing with highly mobile, small family units moving throughout the entire Sisimiut area. This is supported by the fact that hunting strategies appear to have remained virtually unchanged for more than Iooo years.

It is always problematic to make statements concerning social organisation based on archaeological evidence (Møbjerg and Robert-Lamblin I990:258-260), nevertheless, the composition of the tool inventory has led us to interpret Nipisat as a family site rather than a hunting station used only by men (Fig. 209). 

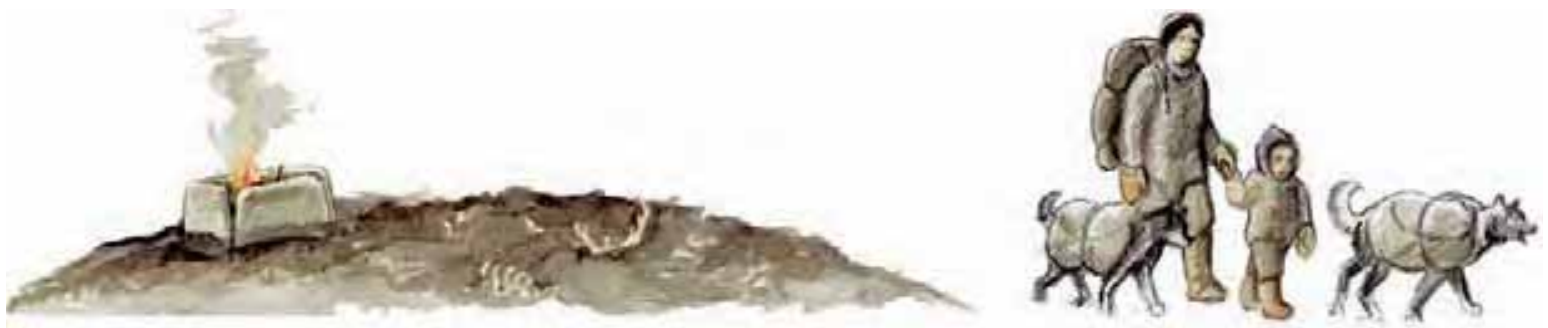

Fig. 209. Nipisat is interpreted as seasonal camp, used on several occasions in the spring, summer and autumn by one or two families. In phase 1 and 2 there is traces of hearths, but none is identified in phase 3. Dog remains were scarce at the site. The few dogs accompanying the Saqqaq people presumably served as individual pack animals or assisted during hunting. Drawing: Jørgen Mürhmann-Lund.

\section{Concluding remarks}

Investigations at Nipisat have contributed to a more detailed and solid understanding of the various phases of the Saqqaq Culture than has previously been achieved. Although very few Dorset sites have yet been found, recent studies in the Sisimiut area have served to bridge the temporal gap between the Late Saqqaq and the Early Dorset Cultures, as several elements, previously interpreted as Dorset, occur during the most recent occupational phase at Nipisat. Nevertheless, many characteristic tool types from the Dorset culture, such as burin like tools, side-notched endblades and large numbers of micro blades are not recorded in the Late Saqqaq Culture. The Saqqaq/ Dorset transition is difficult to ${ }^{14} \mathrm{C}$ date due to the presence of a "plateau" on the calibration curve covering some 300 years. Nevertheless, Nipisat has provided the first dating of the Saqqaq Culture (76o-4Io BC (cal \pm I std)) within this period. This final date from Nipisat could thus serve to indicate an overlap between the Saqqaq and Dorset Cultures.

In Qeqertarsuup Tunua the Saqqaq/Dorset transition is also problematic due to a hiatus between the latest Saqqaq and the earliest Dorset sites (Jensen et al. I999:I) The Late Saqqaq phase, as known from Sisimiut, appears not to exist here. This also implies that Greenland must be regarded as comprising of many different regions where cultural sequences may have differed considerably at any given point in time. A detailed chronology for each individual region must therefore be established before interregional comparisons can be made.

On the other hand, it is remarkable that developments such as the introduction of soapstone or ceramics occur throughout the Arctic more or less simultaneously. Some cultural features can be interpreted as responses to environmental factors, whilst others must imply communicative links across the Arctic, so that technological innovations from Alaska and Canada were transmitted to the Greenlandic cultures and vice versa. Greenland must be regarded as an additional resource area, sought out during optimal periods and abandoned if changing environmental conditions proved detrimental. Greenlanders were therefore not starving, freezing victims; on the contrary, they actively selected or rejected areas of occupation, based on their evaluation of current hunting potential. 


\section{Appendix 1}

\section{Description and position of cut marks on bird bones and their interpretation}

$(\mathbf{F})=$ filleting traces $(\mathbf{D})=$ dismemberment traces

(S) $=$ skinning traces

\section{Eider}

Phase I. v. cervicalis (384x/I88y) with two c. I mm long faint cut marks dorsally $(\mathbf{F})$, left branch of furcula (385,98x/187,96y) with a distinct cut mark placed on the ventral face $(\mathbf{F})$, left coracoid (383x/I88y) with bundles of several $3 \mathrm{~mm}$ long cut marks placed distally on the mediocaudal face (F), one right coracoid (387X/19oy) with a I mm distinct cut mark placed distally on the medial face (D) and in addition it showed pathological tissue on the caudal face, right coracoid (384x/I89y) with several faint 2-4 mm long cut marks placed on the mediocaudal face (F), left subadult humerus $(385,65 \mathrm{x} / \mathrm{I} 87,60 \mathrm{y})$ with two $3 \mathrm{~mm}$ long and one $4 \mathrm{~mm}$ long distinct cut marks placed on the ventral face perpendicular to the long axis at the middle of the diaphysis (F), left diaphysis of humerus (385,34X/ I89,04y) with cut marks placed distally on the lateral face perpendicular to the long axis $(\mathbf{F})$, right diaphysis of humerus $(385 \mathrm{x} / \mathrm{I} 86 \mathrm{y})$ with two distinct $3 \mathrm{~mm}$ long cut marks placed on the ventral face perpendicular to the long axis on the middle of the diaphysis $(\mathbf{F})$, right humerus $(384 \mathrm{x} / \mathrm{I} 88 \mathrm{y})$ with several sub-parallel $3 \mathrm{~mm}$ long faint cut marks placed on the medial face perpendicular to the long axis at the middle of the shaft $(\mathbf{F})$, left humerus (384x/I86y) with fine sub-parallel $3 \mathrm{~mm}$ long cut marks perpendicular to the long axis on the dorsal face (F), right shaft of humerus (384x/186y) with three bundles of fine sub-parallel cut marks perpendicular to the long axis placed on the ventral face (F), left diaphysis of humerus (387x/189y) with several sub-parallel $2 \mathrm{~mm}$ long cut marks placed on the medial face $(\mathbf{F})$, radius (385x/I86y) with several I mm long faint cut marks proximally on the shaft $(\mathbf{F})$.

Phase 2. v. cervicalis with cut marks ventrally (F), left subadult coracoid (383x/I9oy) with a $2 \mathrm{~mm}$ distinct cut mark placed distally on the medial face (D), left femur (389x/195y) with a c. $3 \mathrm{~mm}$ long cut mark placed ventrally of caput femoris (D), right tibiotarsus (383x/19oy) with a $2 \mathrm{~mm}$ long distinct cut mark on the lateral condyle (D).

Phase 3. right scapula (383x/186y) with two bundles of c. $2 \mathrm{~mm}$ long cut marks placed dorsolaterally (S), left coracoid (387x/193y) with several $2 \mathrm{~mm}$ long cut marks placed proximally on the cranial face $(\mathbf{F})$, right coracoid (387x/193y) with two bundles of I-2 $\mathrm{mm}$ long cut marks placed distally on the laterocaudal face (F), one left coracoid (388x/192y) with two distinct I $\mathrm{mm}$ long cut marks placed proximally on the medial face (F or D), left coracoid (392x/194y) with several $3 \mathrm{~mm}$ long cut marks placed cranially at the middle of the corpus coracoidea (F), distal part of a right subadult humerus (386x/I86y) with cut marks placed proximally on the medial face of the diaphysis (F).

\section{Gulls}

Phase I. maxillary bone (385x/I85y) with a few 2-4 $\mathrm{mm}$ long cut marks placed orally on the dorsal face (S), cranial fragment of furcula (382x/I89y) with cut marks placed cranially (F), right subadult humerus (382X/I79y) with cut marks on the diaphysis placed proximally on the lateral face $(\mathbf{F})$, right subadult femur (385x/185y) with several c. $3 \mathrm{~mm}$ long cut marks perpendicular to the long axis placed mid shaft on the caudal face $(\mathbf{F})$, right tibiotarsus $(385,57 \mathrm{X} /$ I88,70y) with cut marks placed on the cranial and caudal face (F), right tibiotarsus (385x/I88y) with cut marks placed on both the cranial and the caudal face (F).

Phase 2. juvenile proximal part of humerus (390x/ I97y) with cut marks on the lateral face (F), right radius (384X/191y) with cut marks placed proximally (D).

Phase 3. right coracoid with cut marks placed distally on the cranial face (F), right shaft of humerus with cut marks placed proximally on the medial face (F), one left humerus (387x/197y) with cut marks proximally on the medial face (F). 


\section{Geese}

Phase I. left diaphysis of humerus (385x/I85y) with fine 4-5 $\mathrm{mm}$ long sub-parallel scrape marks in an oblique angle to the long axis placed proximally on the lateral face (F).

Phase 2. right scapula (388x/197y) with bundles of several $4 \mathrm{~mm}$ long shallow cut marks placed on the medial side (F), left femur (390x/197y) with few $2 \mathrm{~mm}$ long cut marks placed perpendicular to the long axis on the laterocaudal face mid shaft $(\mathbf{F})$.

Phase 3. cranial fragment of furcula (390x/198y) with 2-3 mm long sub-parallel cut marks on the on the ventral face (F), furcula (385x/193y) with two distinct $2 \mathrm{~mm}$ long and several faint cut marks placed on the ventral face and several sub-parallel $4 \mathrm{~mm}$ long faint marks dorsally (F), cranial fragment of sternum (394x/20oy) with two bundles of sub-parallel $3 \mathrm{~mm}$ long cut marks placed cranially on the crista sterni $(\mathbf{F})$, coracoid (402x/20oy) with cut marks (F?), left coracoid (392X/I97y) with several $2 \mathrm{~mm}$ long sub-parallel cut marks placed on the middle of the corpus on the lateral face (F), left coracoid (390x/r98y) with few 5 $\mathrm{mm}$ long transverse shallow cut marks placed on the mediocranial face (F), left coracoid (388x/r95y) with several 2-3 mm long cut marks placed perpendicularly to the long axis of the bone along the entire lateral face (F), three right humeri (388x/195y, 388x/197y, 392x/ I97y) with several 4-5 $\mathrm{mm}$ long transverse cut marks placed on the lateral face of caput humeri (F), two left humeri (both from 389x/198y) with 4-5 mm long transverse cut marks placed on the lateral face of caput humeri (F), left humerus (383x/187y) with several sub-parallel 2-4 $\mathrm{mm}$ long cut marks placed proximally on the lateral face of the diaphyis (F), left humerus (384X/187,60y) with several $2 \mathrm{~mm}$ long subparallel cut marks perpendicular to the long axis placed on the medial face (F), left proximal part of humerus (39IX/20Iy) with several $2 \mathrm{~mm}$ long sub-parallel cut marks perpendicular to the long axis placed on the medial face (F), left humerus (392X/197y) with several longitudinal fine scratch marks on the lateral face and $2 \mathrm{~mm}$ long cut marks perpendicular to the long axis proximally on the medial face $(\mathbf{F})$, proximal right humerus (382x/190y) with cut marks placed on the craniolateral face $(\mathbf{F})$, right humerus $(388 \mathrm{x} / \mathrm{I} 96 \mathrm{y})$ with several $2 \mathrm{~mm}$ long sub-parallel cut marks perpendicular to the long axis placed on the cranial face (F) and two distinct $3 \mathrm{~mm}$ long cut marks placed cranially on the caput humeri (D), right humerus (388x/196y) with a few transverse c. $4 \mathrm{~mm}$ long cut marks placed proximally on the medial face of the shaft $(\mathbf{F})$, left humerus (388x/197y) with two bundles of $2 \mathrm{~mm}$ long cut marks placed perpendicularly to the long axis on the medial face (F), three left humeri (383x/I9oy, $388 \mathrm{x} / \mathrm{I} 95 \mathrm{y}$ and $392 \mathrm{x} / \mathrm{I} 97 \mathrm{y})$ with several 2-3 $\mathrm{mm}$ long sub-parallel cut marks placed distally on the medial face (F), right humerus (384X/19oy) with 2-3 mm long sub-parallel cut marks placed distally on the medial face (F), right humerus (385x/194y) with cut marks placed proximally on the lateral face (F), left distal part of humerus (386x/190y) with cut marks on the medial face of the diaphysis (F), right humerus (388x/195y) with two bundles of sub-parallel 2-3 mm long cut marks placed on the ventral face of the diaphysis (F), right diaphysis of humerus (386x/194y) with cut marks on the lateral face (F), proximal part of humerus (39IX/200y) with cut marks on the lateral face (F), distal part of humerus (393X/20oy) with cut marks (F?), fragment of humerus (393x/200y) with cut marks (F), right femur (382x/189y) with 2-5 mm long transverse cut marks placed along the diaphysis on the cranial face (F), right femur (385x/193y) with cut marks on the cranial face (F), left femur (390x/ I99y) with 3-5 $\mathrm{mm}$ long transverse cut marks placed along the cranial and the medial face of the diaphysis (F), left femur (390x/199y) with bundles of sub-parallel $2 \mathrm{~mm}$ long transverse cut marks placed along the diaphysis on the medial face (F), left femur (382x/ I88y) with two bundles of sub-parallel 2-3 $\mathrm{mm}$ long transverse cut marks placed on the cranial face $(\mathbf{F})$, left femur (392X/197y) with cut marks placed on the cranial face (F), right femur (388x/197y) with several $2 \mathrm{~mm}$ long cut marks perpendicular to the long axis of the bone placed proximally on the cranial face $(\mathbf{F})$, diaphysis of a left femur (382x/189y) with two bundles of transverse 4-5 mm long sub-parallel cut marks placed on the craniomedial face (F), diaphysis of a left femur (39IX/196y) with two $3 \mathrm{~mm}$ long transverse cut marks placed proximally on the medial face $(\mathbf{F})$, right femur (382/187y) with several transverse 3-4 mm long cut marks placed along the medial face of the diaphysis (F), right femur (385x/19ry) with several sub-parallel transverse 2-4 $\mathrm{mm}$ long cut marks placed along the diaphysis on the cranial face (F), left femur (387X/I84y) with several sub-parallel transverse 2-4 $\mathrm{mm}$ long cut marks placed along the diaphysis on the 
cranial face (F), right femur (385x/184y) with several $2 \mathrm{~mm}$ long cut marks perpendicular to the long axis placed distally on the caudal face and 3-4 $\mathrm{mm}$ long transverse cut marks placed along the shaft on the cranial face (F), left diaphysis of tibiotarsus (386x/19oy) with cut marks placed proximally on the caudal face (F), left tibiotarsus (387x/I95y) with several $2 \mathrm{~mm}$ long sub-parallel cut marks perpendicular to the long axis placed on the cranial and caudal face $(\mathbf{F})$, left tibiotarsus (390x/200y) with bundles of sub-parallel
2-3 $\mathrm{mm}$ long cut marks placed proximally on the cranial and the medial face (F), right diaphysis of tibiotarsus (391x/199y) with several sub-parallel transverse 2-3 $\mathrm{mm}$ long cut marks placed proximally on the mediocaudal face (F), left tibiotarsus (39IX/I95y) with several 3-4 mm long sub-parallel transverse cut marks placed distally on the mediocaudal face $(\mathbf{F})$, distal part of a right tibiotarsus (388x/193y) with one distinct and one faint I mm long cut mark on the lateral condyle (D). 


\title{
Appendix 2
}

\section{Holocene marine fauna and shoreline studies in the Sisimiut Area}

\author{
Kaj Strand Petersen and Ella Hoch
}

The opportunity to study the raised beaches and their faunas presented itself as the construction work for the airport at the foot of Præstefjeld at Asummiut started. A general introduction to the geological work in the area in connection with the archaeological activities has been given by Petersen and Hoch (1997; I998). Here the focus will be on mollusc faunas, both recent and subfossil, and the changing shoreline through time during the Holocene.

The study area is in Sisimiut between Ulkebugt $\left(66^{\circ} 57^{\prime} \mathrm{II} " \mathrm{~N}\right)$ and Nipisat $\left(66^{\circ} 48^{\prime} 53^{\prime \prime} \mathrm{N}\right)$. In the eastwest direction, it extends from Sisimiut ( $53^{\circ} 4 \mathrm{I}^{\prime} 4 \mathrm{I}^{\prime \prime} \mathrm{W}$ ) into Amerloq at Ataamiut $\left(53^{\circ} 25^{\prime} 23^{\prime \prime} \mathrm{W}\right)$, still however in the outer part of the fjord system. Sampling was partly carried out through surface collections of shells, as seen in Figure 3 in Petersen and Hoch (1998), and partly through taking bulk samples, i.e. both sediment and shells together. Recent fauna has also been considered through collection within the tidal zone (tidal amplitude is up to $4.5 \mathrm{~m}$ in this region).

The elevation of the sampling localities was meas- ured with an adjusted altimeter. Repeated measurements were most kindly taken the following summer by a group of students from the Technical University of Denmark. It was shown, that the measurements taken by us were of the same order of magnitude, except the one from "Sandy Beach", which was corrected by no less than $+\mathrm{I} 9 \mathrm{~m}$. All elevations are used together with ${ }^{14} \mathrm{C}$ dates in the construction of the sea-level curve. The former Copenhagen ${ }^{\mathrm{I}} \mathrm{C}$ laboratory run by Geological Survey of Denmark and Greenland and the Danish National Museum and the AMS ${ }^{14} \mathrm{C}$ dating laboratory at the University of Aarhus conducted the dating of the samples.

The collection of recent shells for this study was limited to the tidal zone.

Some comments are given on the changes in the faunal communities which are said to peak with temperate species in the middle of the Holocene approximately 5000 years ago, when species such as Panopaea

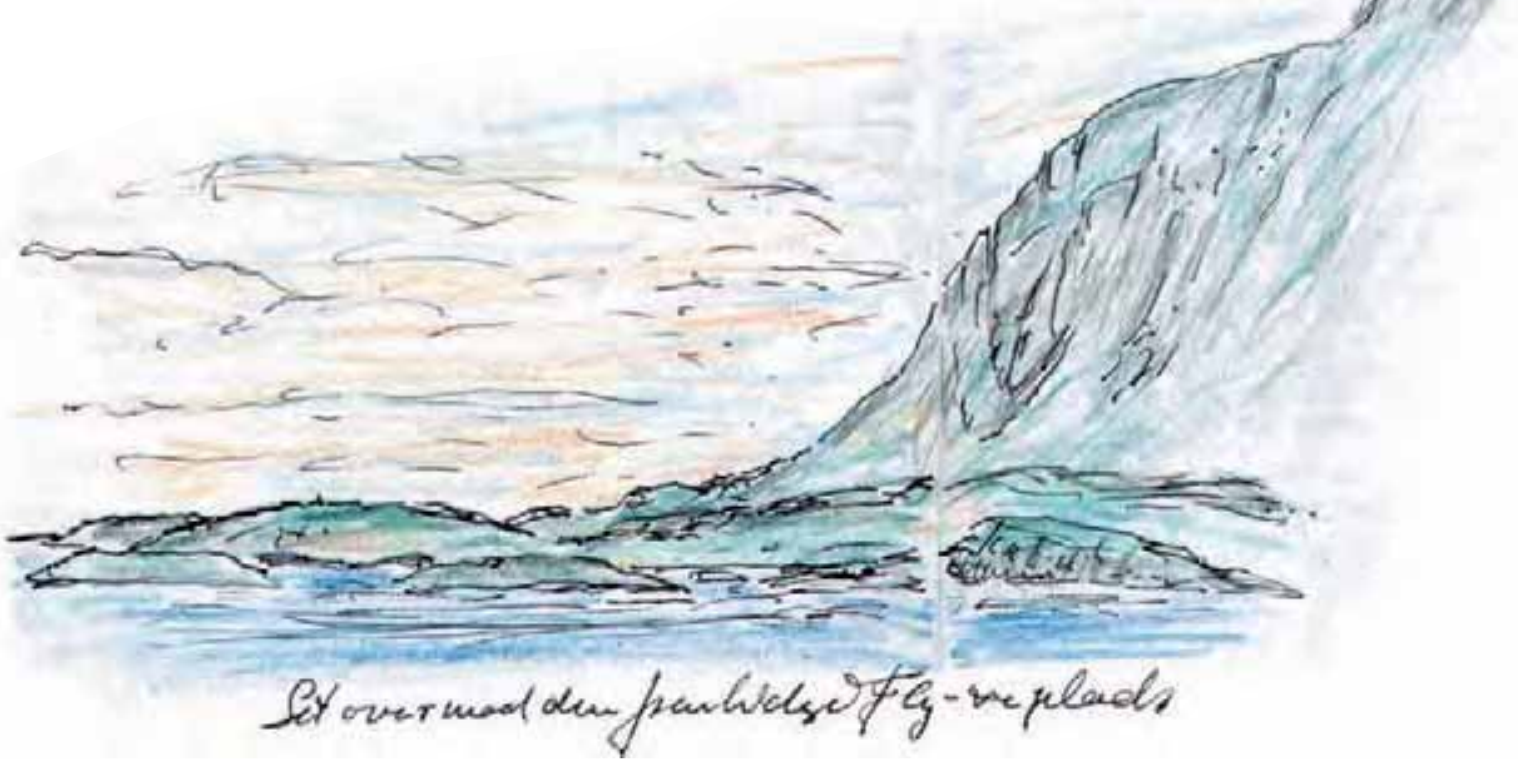

Præstefjeld seen from Sisimiut. 
Table 57. A list of dates specimens (nos 1-31) from localities around Sisimiut. Elevation indicates height above present mean sea-level.

\begin{tabular}{|c|c|c|c|c|c|c|}
\hline No. & Locality & Elevation & C-14 no. & Species & $\begin{array}{l}\text { Calibrated } \\
\text { age BP }\end{array}$ & Sample no. \\
\hline 1 & Vejsende & $80 \mathrm{~m}$ & $K-6720$ & Mya truncata & 9450 & 00645 \\
\hline 2 & Vejsving & $35 \mathrm{~m}$ & $K-6721$ & Mya truncata & 9380 & 00641 \\
\hline 3 & Sandy Beach & $26 \mathrm{~m}$ & K-6722 & Mya truncata/Hiatella arctica & 7690 & 00638 \\
\hline 4 & Sandy Beach & $26 \mathrm{~m}$ & K-6723 & Mytilus edulis & 7910 & 00637 \\
\hline 5 & Ataamiut & $25 \mathrm{~m}$ & K-6724 & Serripes groenlandicum & $7370-7290$ & 00629 \\
\hline 6 & Ataamiut & $25 \mathrm{~m}$ & $K-6725$ & Mya truncata & 7220 & 00627 \\
\hline 7 & Lille $\varnothing$ & $4 \mathrm{~m}$ & K-6726 & Mytilus edulis & 2340 & 00622 \\
\hline 8 & Nipisat & $20 \mathrm{~m}$ & K-6727 & Mytilus edulis/ Mya truncata & $6170-6110$ & 00619 \\
\hline 9 & Nipisat & $3 \mathrm{~m}$ & K-6728 & shell fragments & $6630-6570$ & 00618 \\
\hline 10 & Nipisat & $35 \mathrm{~m}$ & K-6729 & Mytilus edulis & $6280-6220$ & 00617 \\
\hline 11 & Nipisat & $30 \mathrm{~m}$ & $\mathrm{~K}-6730$ & Mytilus edulis & $5440-5320$ & 00612 \\
\hline 12 & Ataamiut & $35 \mathrm{~m}$ & K-6731 & Mya truncata/Mytilus edulis & $8480-8440$ & 00607 \\
\hline 13 & Nipisat & $12 \mathrm{~m}$ & AAR-3580 & Littorina saxatilis & 3690 & $\mathrm{Ni93}$ a \\
\hline 14 & Nipisat & $12 \mathrm{~m}$ & AAR-3581 & Hiatella arctica & 3765 & $\mathrm{Ni93} b$ \\
\hline 15 & Nipisat & $12 \mathrm{~m}$ & AAR-3582 & Mytilus edulis & 3840 & $\mathrm{Ni93} \mathrm{c}$ \\
\hline 16 & Nipisat & $12 \mathrm{~m}$ & AAR-3583 & Mytilus edulis & 3210 & $\mathrm{Ni93} d$ \\
\hline 17 & Ataamiut & $25 \mathrm{~m}$ & AAR-3584 & Mytilus edulis & 5580 & 00629 \\
\hline 18 & Vejsende & $80 \mathrm{~m}$ & AAR-3585 & Mytilus edulis & 8600 & 00645 \\
\hline 19 & Nipisat & $3 \mathrm{~m}$ & AAR-3586 & Mytilus edulis & 7660 & 00618 \\
\hline 20 & Asummiut & $10 \mathrm{~m}$ & AAR-3587 & Hiatella arctica & 3910 & 00633 \\
\hline 21 & Asummiut & $10 \mathrm{~m}$ & AAR-3588 & Mytilus edulis & 3960 & 00633 \\
\hline 22 & Nipisat & $10 \mathrm{~m}$ & AAR-3570 & Rangifer tarandus & 3305 & Ni94k \\
\hline 23 & Nipisat & $10 \mathrm{~m}$ & AAR-3571 & Rangifer tarandus & 3230 & Ni94l \\
\hline 24 & Nipisat & $10 \mathrm{~m}$ & AAR-3572 & Rangifer tarandus & 3293 & Ni94m \\
\hline 25 & Nipisat & $12 \mathrm{~m}$ & AAR-3573 & Rangifer tarandus & 3090 & $\mathrm{Ni93e}$ \\
\hline 26 & Nipisat & $12 \mathrm{~m}$ & AAR-3574 & Rangifer tarandus & 2470 & Ni93f \\
\hline 27 & Nipisat & $12 \mathrm{~m}$ & AAR-3575 & Rangifer tarandus & 2900 & Ni93g \\
\hline 28 & Nipisat & $12 \mathrm{~m}$ & AAR-3576 & Rangifer tarandus & 3785 & Ni93h \\
\hline 29 & Nipisat & $12 \mathrm{~m}$ & AAR-3577 & Rangifer tarandus & 3738 & Ni93i \\
\hline 30 & Nipisat & $12 \mathrm{~m}$ & AAR-3578 & Rangifer tarandus & 3710 & Ni93j \\
\hline 31 & Nipisat & $13 \mathrm{~m}$ & AAR-3630 & Charcoal & 3950 & $\mathrm{Ni94n}$ \\
\hline
\end{tabular}

norvegica (Sprengler, I793) and Zirfaea crispata (L., I758) increased in numbers (Funder and Weidick I99I).

\section{The molluscan assemblages - recent and subfossil}

The sampling activities were concentrated to six localities, however some localities were sampled at several levels. On Nipisat, faunas as well as ${ }^{14} \mathrm{C}$ dates were recorded at five levels: 3, IO-I3, 20, 30 and $35 \mathrm{~m}$ (Table 57).

Nipisat must be considered the main locality as sampling here included specimens of marine molluscs from the I2 $\mathrm{m}$ terraces upon which the Saqqaq people settled (Ni93a-d, Table 57).

The settlement activities are documented, among other things, by the AMS dated bones of Rangifer tarandus and charcoal from the Io-I3 m level (Table 57). The dates span I500 years, from 3950 to $2470 \mathrm{BP}$, i.e. 2000 to $520 \mathrm{BC}$, covering the major part of the Saqqaq Culture period, according to the chronology of the Sisimiut area.

The oldest dated mollusc is Mya truncata, 9450 BP, from the locality "Vejsende", which at $80 \mathrm{~m}$ a.s.l. also represents the highest level of the six localities. However, the lowermost, found at a level of $3 \mathrm{~m}$, as at Nipisat, is fairly old with ages up to 7660 years BP (Table 57, no. 9 and i9). 


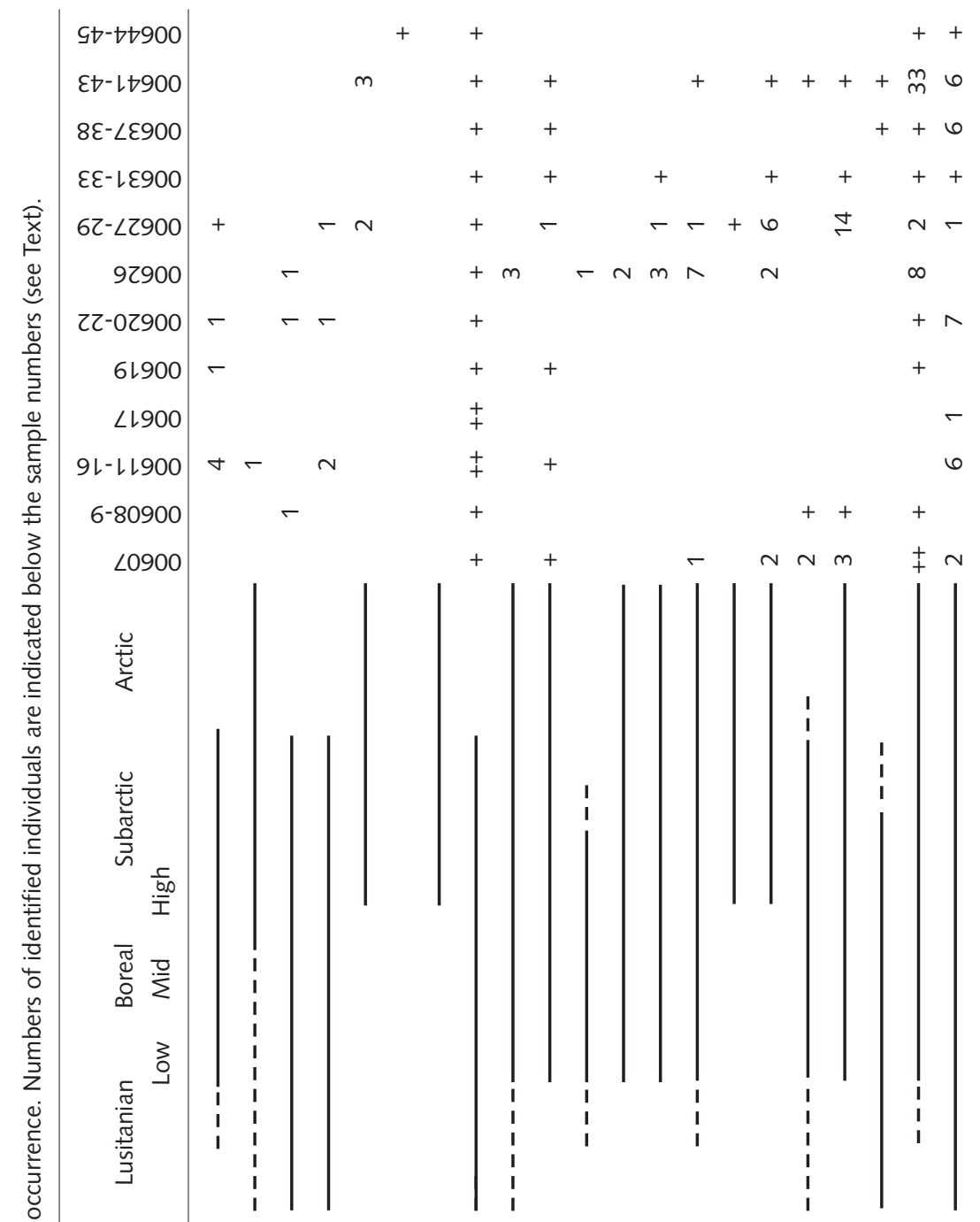

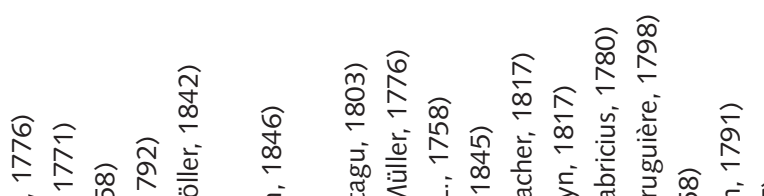

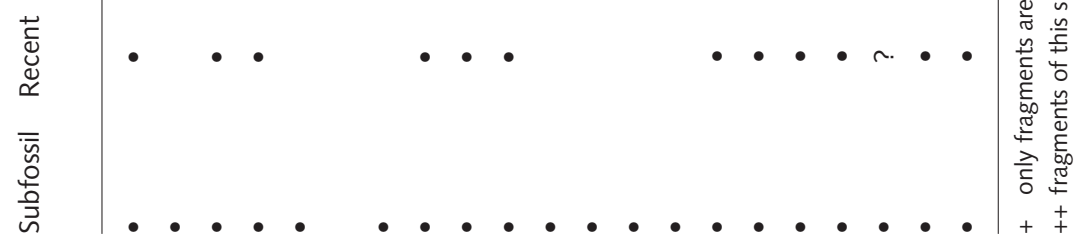


Such old dates at low levels can be explained by looking into the state of preservation of the dated shells which, in this case, must be regarded as reworked.

Before entering into more detail on the samples, the recorded molluscan species will be presented.

Table 58 presents the molluscs recorded in this study, following the taxonomy used by Petersen (2004).

\section{Acmaea tessulata (Müller, 1776)}

Distribution: East Greenland, around Iceland (Thorson I94I) and Scandinavia according to Petersen (I888). Extends southwards to the north of the British Isles and Northern Ireland.

Habitat: Lower part of the intertidal zone. According to Posselt (1899), however, along the coast of Greenland Acmaea tessulata occurs deeper, often to depths of 55-75 m.

Limpets are called "ajuak" or "ajuaursak" in Greenlandic meaning "one resembling an abscess". The Greenlandic names often describe the nature of the shells and will henceforth be given when known to the authors.

\section{Puncturella noachina (L. 1771)}

Distribution: Spitsbergen and around Iceland (Thorsen I94I), Scandinavia south to Portugal, however mainly from the Arctic down to the high Boreal. In the southern part of Portugal, this species shows the so-called tropical submerge.

Habitat: Between Io and $200 \mathrm{~m}$ on rock and stones. Off the coast of Greenland it is rather common from 30 to I9o m (Posselt I899).

\section{Littorina obtusata (L. 1758) (Fig. 210)}

Distribution: W Greenland, S and W Iceland (Thorsen I94I), Scandinavia north of Lofoten and south to the Mediterranean.

Habitat: Intertidal, lives in weeds.

Posselt (I899) recorded that Littorina palliata alias $L$. obtusata is called "siuterursak" which means ear, however, Mörch (I857) includes other genera as well, quoting the term "siuterungoak" for small snails and "siuterursoak" for large snails such as Fusus.

\section{Littorina saxatilis (Olivi, 1792)}

Distribution: From Greenland, Spitsbergen around Iceland and the Atlantic coasts of Europe.

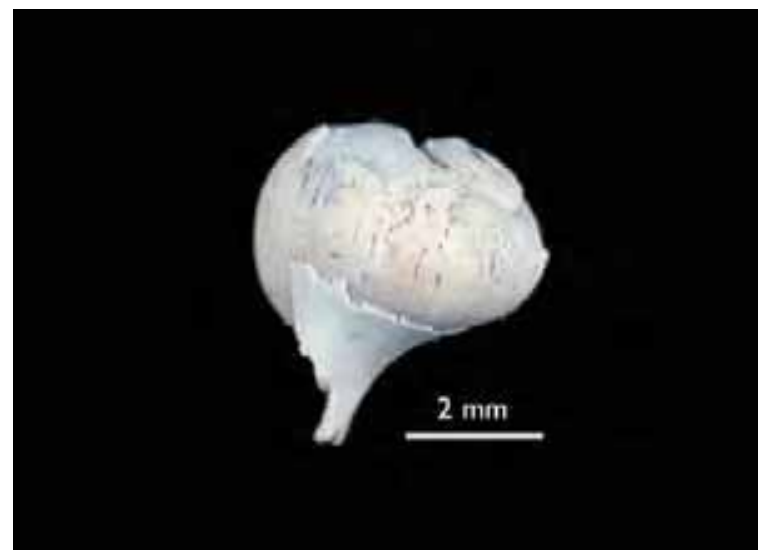

Fig. 210. Fragment of Littorina obtusata.

Habitat: Intertidal, and according to Posselt (I899: 232) many finds at greater depths.

In Greenlandic called "siuterok".

Boreotrophon fabricii (Möller, 1842) (Fig. 211)

Distribution: Greenland, Spitsbergen and around Iceland (Thorson I94I).

Habitat: On a bottom of clay and stones from to to 50 $\mathrm{m}$ in depth, but many finds at greater depths.

In Greenlandic called "korotungoak" as another species of this genus Boreotrophon truncatus (Strøm, I768) which is also found in the low Boreal and Lusitanean regions.

Mytilus edulis (L. 1758) (Fig. 212)

Distribution: W and E Greenland, however only at the southeastern coast (Ockelmann I958), around Iceland, the Faeroes, Norway north of Lofoten, and south to the Mediterranean.

Habitat: Intertidal to $40 \mathrm{~m}$ deep, however, common as an epifaunal eulittoral element.

This mussel is eaten by Greenlanders, cooked or raw in whale oil (Posselt 1899). The Greenlandic names are "uilok" and "killiortout". The latter name "kiliutaq" means a scraping implement (especially a mussel shell), while the former name also applies to bivalves in general. "Uilorak" means "little bivalve".

\section{Crenella decussata (Montagu, 1803)}

Distribution: E and W Greenland, around Iceland, Norway north of Lofoten and south to the British Isles (Madsen 1949; Petersen 1968). 


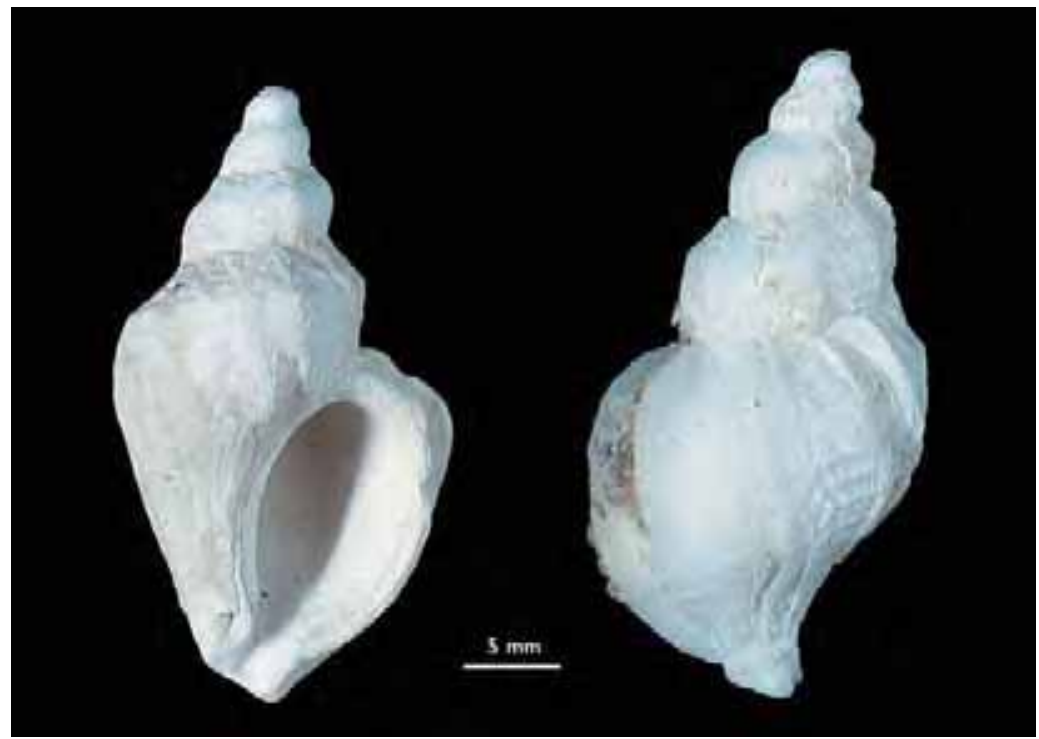

Fig. 211. Two specimens of Boreotrophon fabricii.

Habitat: From 4-20o m deep on all kinds of bottoms except mud (Poppe and Goto I993). Most common at depths of 40 to Ioo m (Posselt I899).

Chlamys islandica (C. F. Müller, 1776) (Fig. 213, no. 1) Distribution: SE and W Greenland, around Iceland, Spitsbergen, Norway north of Lofoten, and south to the Shetlands and Orkney Islands (rare) (Petersen 1968).

Habitat: In Icelandic areas one of the most common

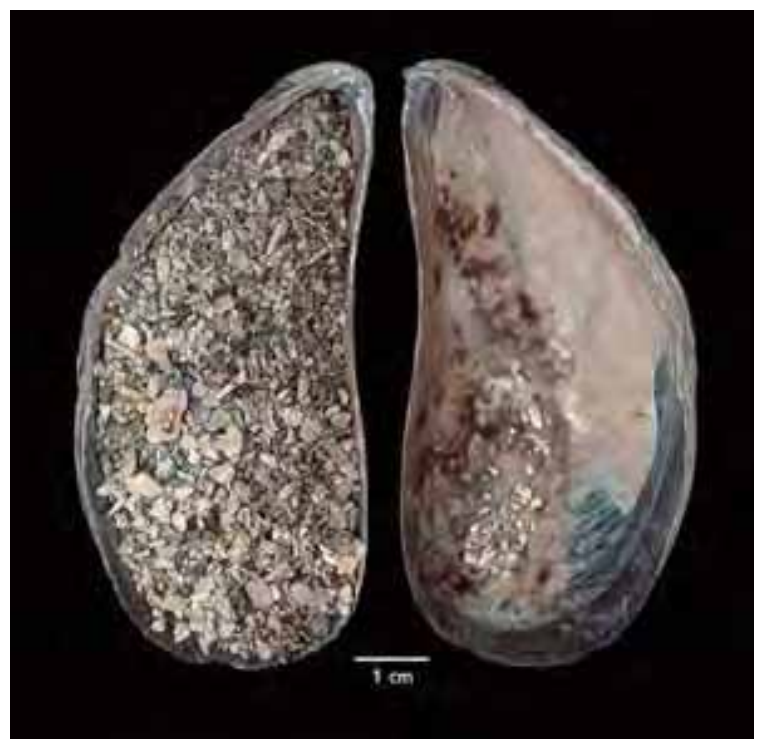

Fig. 212. Mytilus edulis. Notice the shelly gravel in the left valve. From "Lille $\varnothing$ ". bivalves at depths from a few metres to $300 \mathrm{~m}$ (Madsen 1949). Lives part of its time attached to hard substrates with its byssus.

In Greenlandic it is called "kirksoaursak" according to Mörch (I857), i.e. before the extended edition of Samuel Kleinschmidt's dictionary in I87I. It is not found in the West Greenlandic dictionary by Schultz-Lorentzen (I927). According to Mörch (I857:28), "kirksoaursak" derives from "kirkserpok" meaning "jump down". This is an accurate picture of the way that Chlamys islandica can move out of the water when someone tries to boil it.

Heteranomia squamula (L., 1758) Fig. 214

Distribution: Around Iceland, the Faeroes, Norway north of Lofoten, and south to the Bay of Biscay. Mainly an Atlantic boreal species.

Habitat: From 5-IIo m deep fixed on hard substrates, but also on algae and crustaceans (Poppo and Goto I993).

Thyasira gouldi (Philippi, 1845)

Distribution: West and East Greenland, around Iceland, the Faeroes and W Norway (Ockelmann I958).

Habitat: Common off East Greenland at depths of a few metres down to $385 \mathrm{~m}$. By far the majority of the finds originate from depths of less than 50 metres. It is an infralittoral species living mostly on clay bottoms (Posselt I899). 


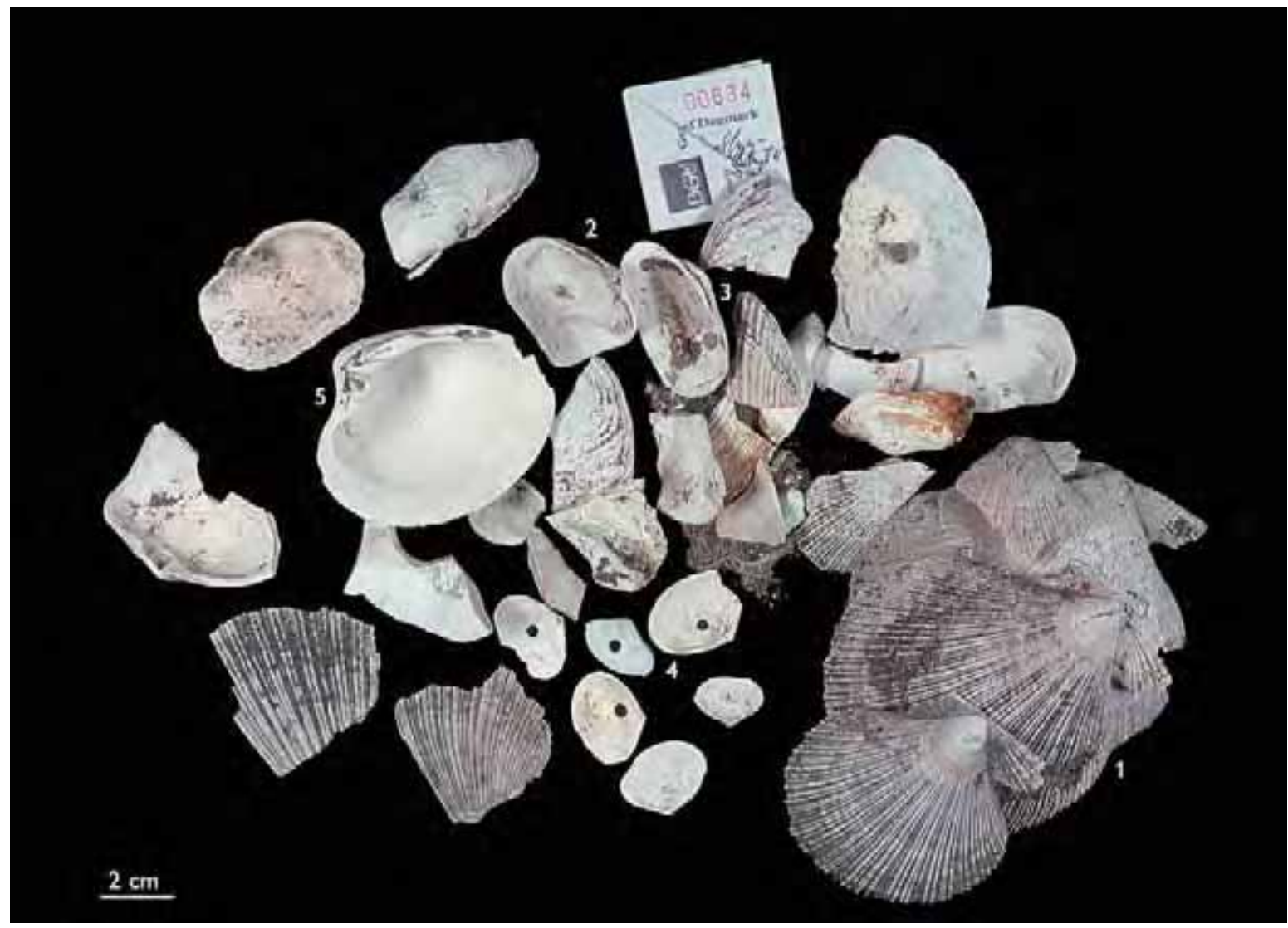

Fig. 213. Sample collected in the tidal zone, Ulkebugt, comprising: 1) Chlamys islandica, 2) Mya truncata, 3) Hiatella arctica, 4) Macoma calcarea with a hole made by a predatory gastropod, and 5) Arctica islandica.

Tridonta borealis (Schumacher, 1817)

Distribution: This species is found in all regions of the north Atlantic except the British Isles (Madsen I949). According to Petersen (I968), the species has not been recorded from the Faeroes. In Danish waters the species extends from the deeper part of the northern North Sea into Kattegat becoming very common in the Baltic. However, as Posselt already mentioned in I899, "Astarte borealis occurs in West Greenland in forms which overlap with each other to such an extent that functional definitions of the varieties cannot even be compiled". On this topic Petersen (200I) has presented "Studies on some Arctic and Baltic Astarte species" introducing several new species. However, our material does not allow further taxonomical considerations.

Habitat: off the Westcoast of Greenland, according to Posselt (I899) Tridonta borealis is found especially on hard bottoms from Io-9o m deep.
Tridonta montagui (Dillwyn, 1817)

Distribution: E and W Greenland, around Iceland, Spitsbergen, the Faeroes, Norway from north of

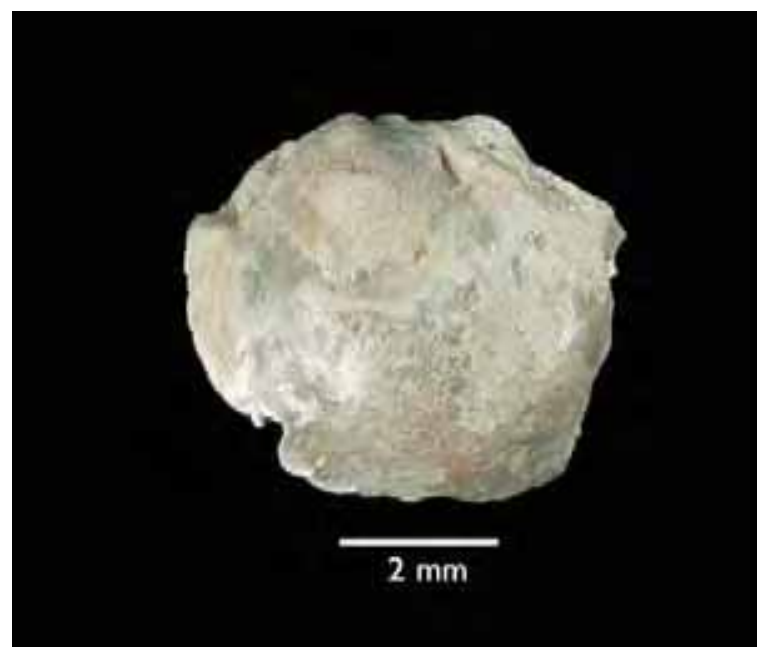

Fig. 214. Left valve of Heteranomia squamula. 


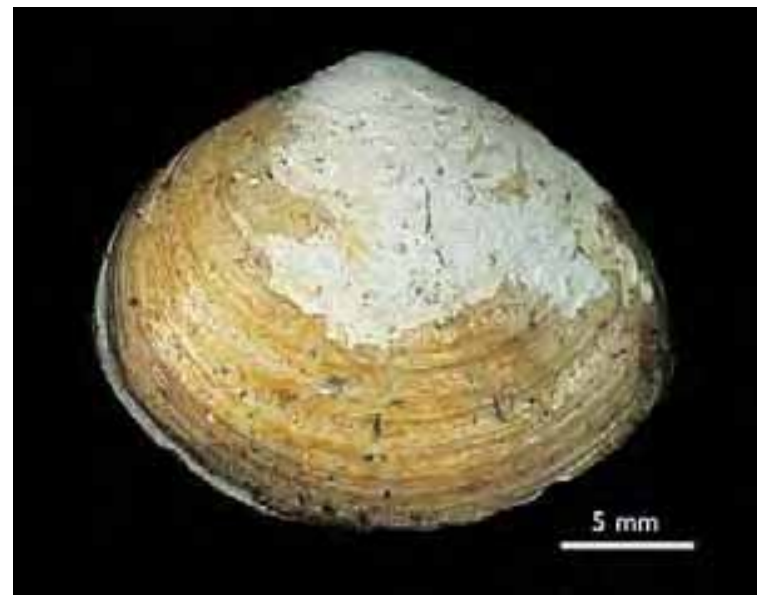

Fig. 215. Macoma balthica, seen from the left.

Lofoten and south to the Clyde Sea and Isle of Man (Petersen 1968), also recorded from the Bay of Biscay.

Habitat: Off Sisimiut this species has been recorded at nearly 250 metres deep on mixed bottom of clay, sand and stones (Posselt I899). According to Madsen (I949) the vertical range off Iceland is 7I50 $\mathrm{m}$.

Here too, Posselt (1899:72) is reluctant to define new species: "Where species vary and overlap to such an extent as seen here with the Nordic forms of Astarte".

Clinocardium ciliatum (Fabricius, 1780)

Distribution: W and E Greenland, Spitsbergen,

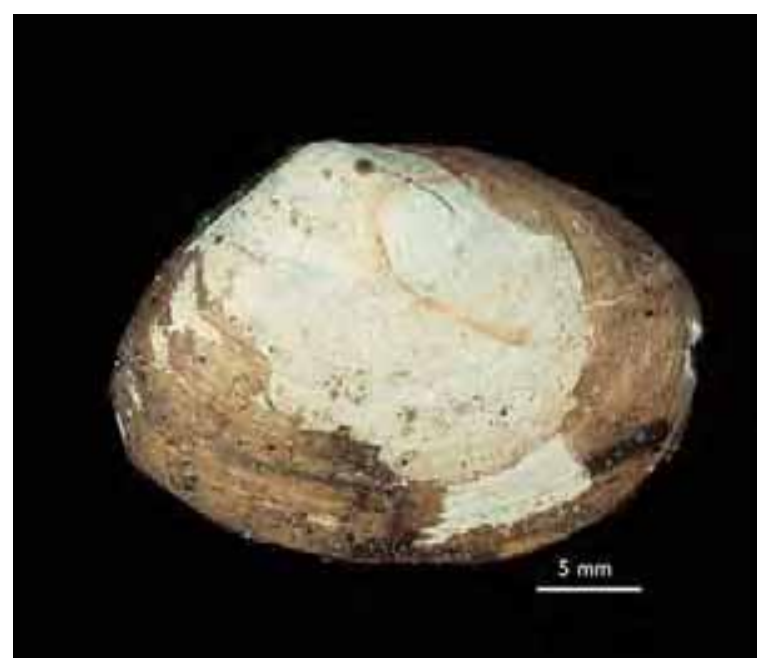

Fig. 216. Macoma calcarea, seen from the right. around Iceland and Norway north of the Lofoten islands. From the Faeroes only at depths exceeding $400 \mathrm{~m}$ (Petersen 1968).

Habitat: From the tidal zone to $700 \mathrm{~m}$, off Iceland occurring on ooze, mud, clay, sand and mixed bottoms (Madsen 1949). Mainly found in the Arctic Macoma community (Ockelmann I958) which is in shallow water.

Posselt (1899) records that the Greenlandic name is "kirksoaursak" which, according to Mörch (I857), comes from "kirkserpok" meaning "jump down" as mentioned above for Chlamys islandica. Here, however, the name does not fit the behaviour of Clinocardium ciliatum, which is a shallow infauna animal, not occassionally free living as Chlamys.

\section{Serripes groenlandicus (Bruguière, 1798)}

Distribution: W and E Greenland, Spitsbergen, around Iceland and Norway north of Lofoten. From the Faeroes only at depths exceeding 400 $\mathrm{m}$, reminiscent of Clinocardium ciliatum.

Habitat: From o-I m to I2o m deep on clay and mud, however, also sand and gravel are recorded (Madsen 1949). According to Posselt, it is one of the most common bivalves off the coast of $\mathrm{W}$ Greenland especially at depths from 20-90 metres.

Being common, big and living in tidal zone it has a Greenlandic name "ipigsaunak" meaning bivalve "af Hjerteskælsslægten" = cockle (Mörch 1857).

Macoma balthica (L., 1758) (Fig. 215)

Distribution: W Greenland, Norway from north of Lofoten and south to the British Isles (Petersen I968) and Spain (Poppo and Goto I993).

Habitat: This is a shallow water species, however, in Disko Bay it is found at depths of $35 \mathrm{~m}$ on sand and clay (Posselt I898).

In Greenlandic it is called "imennek" because it sprays water, "imeq". The same name is used for other bivalve species.

Macoma calcarea (Gmelin, 1791) (Fig. 216)

Distribution: E and W Greenland, Spitsbergen, around Iceland, the Faeroes, Norway from north of Lofoten (Madsen 1949) and south into the North Sea

Habitat: From the intertidal zone down to several 
hundred metres in the southern part of the distribution area. The species is the characteristic animal of the Arctic Macoma community (Thorson 1957). In Ikertook Fjord it is found at a depth of 30 metres on bottoms with stones and algae (Posselt I899:85).

\section{Arctica islandica (L. 1767) (Fig. 217)}

Distribution: Around Iceland, the Faeroes, Norway north of Lofoten and south to the Bay of Biscay. However, the species tends to live deeper in the southern part of its range (Poppo and Goto 1993). It is a typical Atlantic Boreal species.

Habitat: Intertidal to $480 \mathrm{~m}$ in mud, sand or gravel bottoms. According to Badarsson (I920) the fishermen from Iceland report, that the species occurs in very shallow water, just below the low water mark. Posselt (I899:6I) says that Arctica islandica is, or seems to be, very rare at the coast of Greenland and gives two records, one from the Ilulissat area and the other from Davis Strait. We found fresh looking specimens with periostracum in Ulkebugt (Fig. 2I7).

Mya truncata (L., 1758), (Fig. 213, no. 2)

Distribution: $\mathrm{W}$ and E Greenland, Spitsbergen, around Iceland, the Faeroes, Norway from north of Lofoten and south to the Bay of Biscay

(Madsen 1949; Poppe and Goto 1993).

Habitat: From the intertidal zone down to about $75 \mathrm{~m}$

(Poppe and Goto 1993). In East Greenland the species belongs to the Arctic Macoma community (Ockelmann 1958). However, according to Jensen (I900), the typical Mya truncata is not in the

Arctic (G. H. Petersen, pers. comm. 1998).

At Sisimiut it is found at a depth of $2 \mathrm{~m}$ in sand. It is a deep-burrowing bivalve with long fused siphons which form the background for the Greenlandic name "usursak" from usuk = penis. It is eaten and the large shells are used as spoons (Posselt I899).

Hiatella arctica (L., 1758) Fig. 218

Distribution: W and E Greenland, Spitsbergen, around Iceland, the Faeroes, Norway from north of Lofoten and south to the Mediterranean (Madsen 1949).

Habitat: "From the intertidal zone down to almost I400 $\mathrm{m}$ fixed by its byssus on or in all kinds of

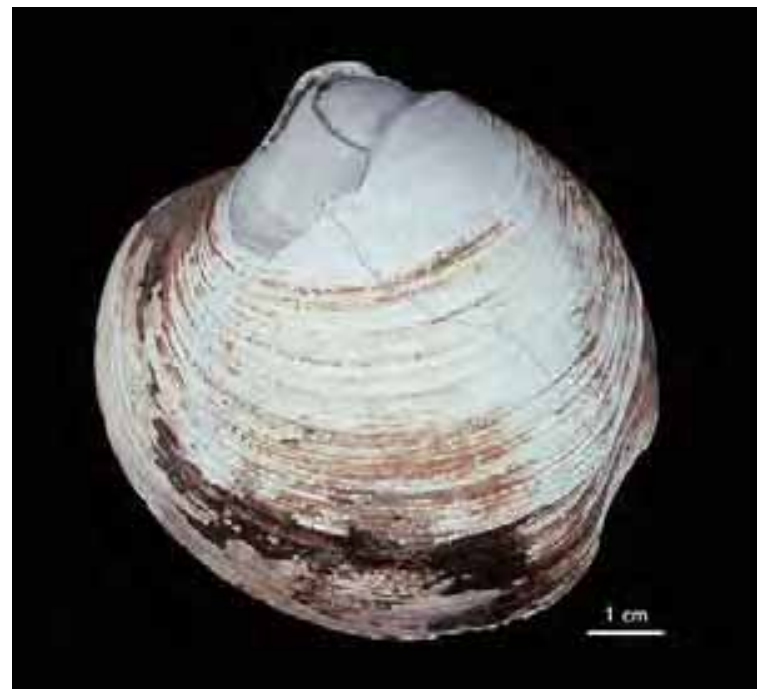

Fig. 217. Left valve of Arctica islandica. Notice the periostracum (thin coat of horny material covering calcareous part of shell). Taken together with the sample shown on Fig. 213.

substrate on all types of bottoms. Also found in holes previously bored by other species" (Poppe and Goto I993:130). However, Petersen (I977: 228) states that: "Both the systematic and nomenclature are insufficiently investigated for this genus". Species determination of the subfossil hiatellas from the Sisimiut area is difficult, as seen from Petersen (I986:figs 2 and 3), where forms with different habitat as Hiatella cf. byssifera are found fixed on a stone taken as a grab sample in Kejser Franz Joseph Fjord, E Greenland, and as traces of Hiatella arctica in the

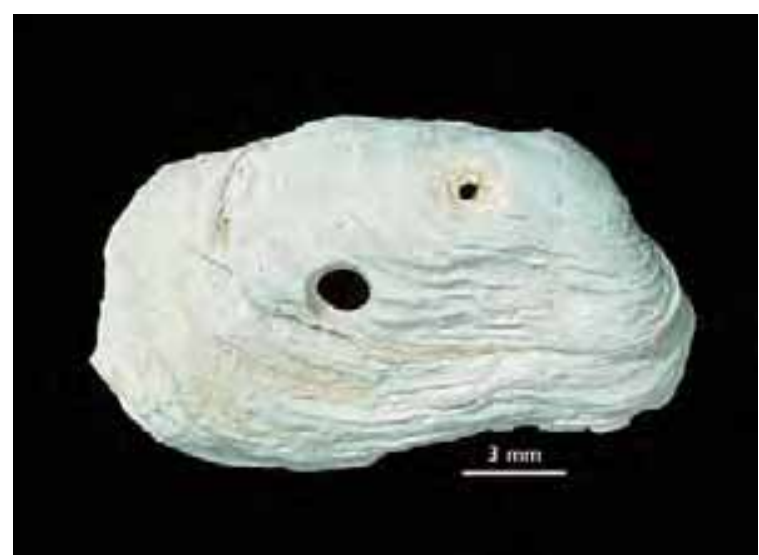

Fig. 218. Right valve of Hiatella arctica. Notice the hole made by a predatory gastropod. 


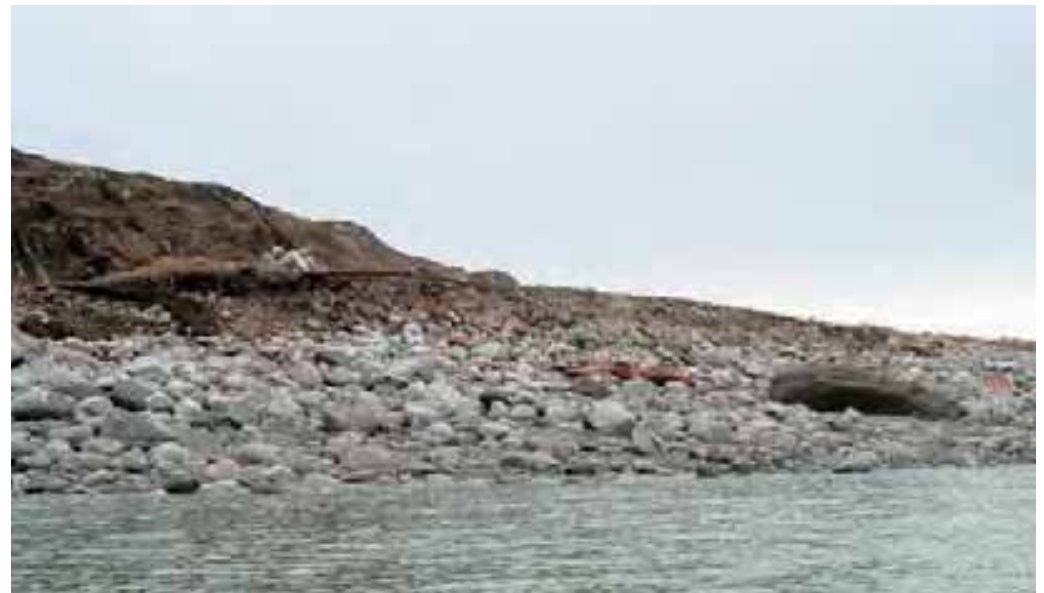

Fig. 219. From the shores of "Lille $\varnothing$ ". To the right, a carcass of a minke whale (seen at close quarters in fig. 221).

Saxicava Sand of Late Weichselian age in Vendsyssel, Denmark. Here Simonarson et al. (1998) is followed, employing the more widely used and less specific name Hiatella arctica.

In Greenland this species was called "imennek" and "imenningoak" according to Posselt (I899:96). According to Mörch (1857:27) however, "imenningoak" means the small "imennek" and applies to Nuculana minuta (Müller, I776) which it resembles Hiatella. "Imennek" is also the name for another bivalve, see Macoma balthica.

\section{The subfossil molluscan assemblages}

All dated localities are listed in Table 57, from I to 3I. The sample numbers oo6o8-9 are bulk samples, supplementary to 00607 No. I2 Ataamiut on the $35 \mathrm{~m}$ level. Sample 00626 is a bulk sample supplementary to the random collection of samples 00627-29 at Ataamiut on the $25 \mathrm{~m}$ level. In this way, the best representation of small specimens is ensured.

In Table 58, the sampling localities are listed according to sampling number/numbers. A total of 20 species have been recorded. Some of the samples were collected from the surface and some taken in combination with bulk samples.

Ataamiut; 35 m; 00607-09; No. 12

Nine species were found dominated by Mya truncata. Mytilus edulis only occurred in fragments, so it is safe to say that the assemblage of these species indicates that deposition took place off the eulittoral zone, where Mytilus would have dominated, in the upper part of the infralittoral zone.

Nipisat; 30 m; oo6II-I6; No II

Six species were found, totally dominated by Mytilus edulis. Five of the recorded species are found in the tidal zone of today. Here we are therefore dealing with the eulittoral zone.

Nipisat; 35 m; 006I7; No. Io

Only two species were identified in this random collection. However, Mytilus edulis was so common on the surface that we feel safe to say that this is a former littoral zone.

Later it will be shown that the dating of this level to $c$. $6250 \mathrm{BP}$ fits well with the $5 \mathrm{~m}$ lower level dated to c. $538 \mathrm{o} \mathrm{BP}$, when both of these levels are taken as littoral zones, reflecting isostatic rebound.

Nipisat; 20 m; 006I9; No. 8

From this bulk sample only four species in a fragmentary state of preservation are recorded, three Barnacles dominate, and all shellparts are well rounded.

Considering the $15 \mathrm{~m}$ higher terrace here on Nipisat, mentioned above, a hundred years older, and this sample lacking in typically infralittoral species, the dated shell material seems to be reworked/downwashed from higher level.

"Lille Ø”; 4 m; 00620-22; No. 7. Fig. 219

The six molluscan species recorded from this locality all indicate the shallow water zone, and the domi- 
nance of Mytilus edulis is typical for an eulittoral deposit. Furthermore, all three species of gastropods were found in the tidal zone.

Ataamiut; 25 m; 00627-29; No. 5, 6 and I7

Twelve species were recorded in these three randomly collected shell samples. When compared to the bulk sample from the same level at Ataamiut 0o626, another four species appear on the list i.e. Littorina obtusata, Crenella decussata, Heteranomia squamula and Thyasira gouldi giving a total of sixteen species from this level with five species not recorded from the tidal zone.

Therefore, the deposits from this level seem to have been deposited at some depth, surely in the infralittoral zone. However, the dating of No. 5 and 6 on Serripes groenlandicum and Mya truncata are very much of the same age i.e. $7300 \mathrm{BP}$, but the AMS-dating of a Mytilus edulis fragment No. I7 gives an age I70o years younger. As we shall see later when drawing up the sea-level curve of this region, it appears that the material with the younger Mytilus is close to the littoral zone of that time.

In this way, it seems that the random collection (sample o0629) contained fragments of much younger material, deposited when the littoral zone was close to the $25 \mathrm{~m}$ level.

Mytilus edulis was presented in the foregoing section as having a vertical range from the tidal zone down to $40 \mathrm{~m}$ deep, being gregarius only in the littoral zone. As shown in Table 58, Mytilus was found in all samples, although only regarded as being from the littoral zone when occurring numerously. But in this sample we have an indication of the lowering, relative sea level, when the shoreline passed the $25 \mathrm{~m}$ level I70o years later than the species from No. 5 .

Asummiut; Io m; 0063I-33; No. 20 and 2I

Seven species are recorded from this locality north of Sisimiut and Ulkebugt. The sampling is a combination of random collection and bulk samples. The shell material is in a fragmentary state of preservation and rounded.

The AMS-dates were carried out on fragments of Hiatella arctica and Mytilus edulis. It should be noted that the settlement unit at Asummiut lies on these terraces at the $\mathrm{I} 3$ to Io $\mathrm{m}$ level.

Calibrated dates of four charcoal samples from the
Saqqaq Culture (Møbjerg 1998: Fig. II) are contemporary or younger by only 300-500 years. This tells us that the Saqqaq people settled close to the water.

"Sandy Beach"; 26 m; 00637-38; No. 3 and 4

Both samples consist of shells collected randomly. The seven recorded species are all in fragments, except six Hiatella arctica. Ages range around $7800 \mathrm{BP}$.

The old dates at the relatively low level, together with the few fragments of Mytilus edulis, show that deposition must have occurred in deeper water.

"Vejsving"; 35 m; oo64I-43; No. 2.

Shells were collected randomly and as bulk samples. As seen from Table 58, Mya truncata is the dominant mollusc and Boreotrophon fabricii is the sole occurring gastropod. This species belongs to the infralittoral group.

"Vejsende"; 80 m; oo644-45; No. I and I8.

Both samples were collected randomly and shells of barnacles dominated.

The dating of Mya truncata gives the oldest date from this study, namely $9450 \mathrm{BP}$. The other date from the same site on Mytilus edulis is younger by 850 years.

Balanus balanus dominates the shell material indicating that the water depth was moderate (Balanus balanus lives at moderate depths in the North).

\section{The relative sea-level curve from the Sisimiut area}

The molluscan assemblages recorded from the different levels at the localities mentioned in the foregoing section are evaluated according to the following categories:

- The eulittoral deposits where Mytilus edulis is the dominant mollusc with a gregarious occurrence, and in some areas followed by littoral forms such as Littorina snails.

- The infralittoral deposits where the deeper living molluscs are recorded and the Mytilus edulis specimens no longer dominate.

- The reworked shells where shells occur in fragments and all fragments are well rounded. We are 


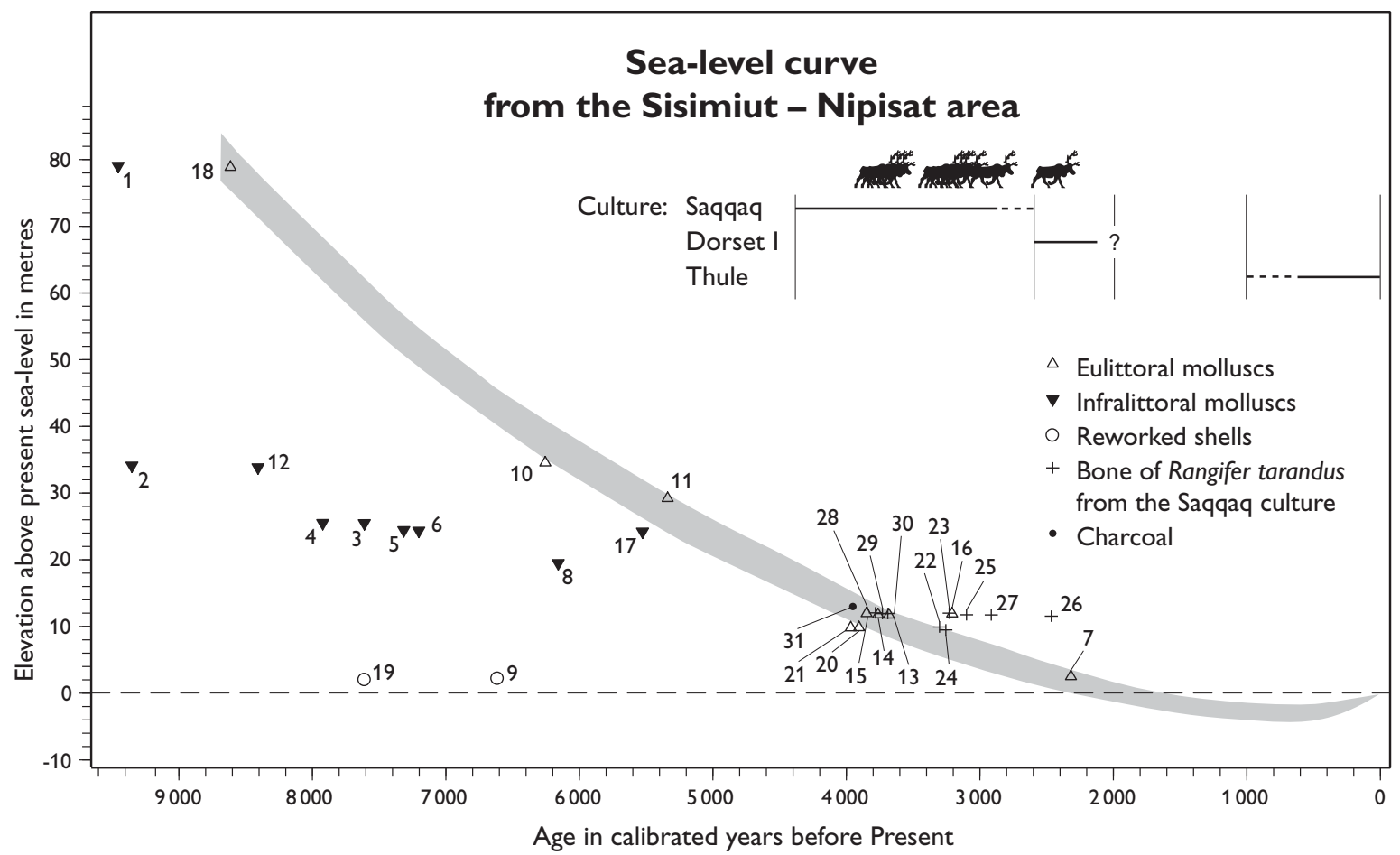

Fig. 220. The sea-level curve based on Table 57 and 58. Cultural sequences modified after Møbjerg (1998:fig. 2).

therefore not dealing with deeper water deposition.

The evaluation of the different assemblages seen in Table 58 according to their habitat allows us to draw up the relative sea-level curve from this region using the ${ }^{14} \mathrm{C}$ dated material as shown in Table 57 plus the dated bones of Rangifer tarandus and charcoal from the Nipisat site (Fig. 220).

The sea-level curve, or rather zone, is drawn through the dated molluscan assemblages with affinity to the eulittoral zone. In this way, assemblages of an infralittoral affinity will appear under this zone, and their depths of living at the time of dating are given in the vertical range from their elevation to the curve.

However, in this connection the lowermost samples dated to an age between six and eight thousand years and marked by circles, No. 9 and I9, are regarded as reworked, although it is hard to see such a long lasting downwashing of this relatively soft material.

Taking a closer look at the data between 4000 and 2000 BP covering most of the Saqqaq and Dorset Culture periods, it appears that the shoreline "fell" more than Io meters during this time. However, the
Saqqaq people stayed on the Io $\mathrm{m}$ terraces at Nipisat as well as at Asummiut, see Table 57 and Fig. 220.

Specimen from locality No. 7 "Lille Ø", midway between Sisimiut and Nipisat, is as young as 2340 BP and at a level of $4 \mathrm{~m}$. It is one of the eulittoral deposits as seen from the occurrence of Mytilus edulis with Littorina obtusata and Littorina saxatilis. These gastropods are characteristic for the littoral zone. Therefore we feel safe in letting the sea-level curve pass under the present sea-level around the time of Christ (2000 BP) leaving us with the situation that some Dorset coastal sites could now be submerged.

According to Kuijpers et al. (1999) "various indications show that after mid-Holocene times the initial glacio isostatic rebound of Greenland was followed by increased subsidence". It seems that the younger part of the sea-level curve from the Sisimiut area may be explained in this way, resulting in a relative sea-level rise up towards present time.

It has long been known that part of the Norse settlements in Southwest Greenland were submerged by the rising sea. Also in the Disko area north of Sisimiut similar situations have been recorded for some Inuit sites (Rasch and Jensen 1997). 
Fig. 221. Beached skull and anterior vertebral column of minke whale (Balaenoptera acutorostrata), the smallest of the fast-swimming finwhales. The large, triangular supraoccipital bone forming the back of the braincase faces the observer, the facial bones and jaws are still covered by remnants of soft tissue. The whale was killed and flensed and the fatty carcass left on the beach or washed ashore by the waves, in either case indicating the higher intertidal zone. Large parts of whale skeletons found in prehistoric geological deposits may be used as indicators of former beach lines. Smaller parts, such as single bones may well have been carried by man. The size and the particular structure of various whale bones made them useful in a world of no artificial materials.

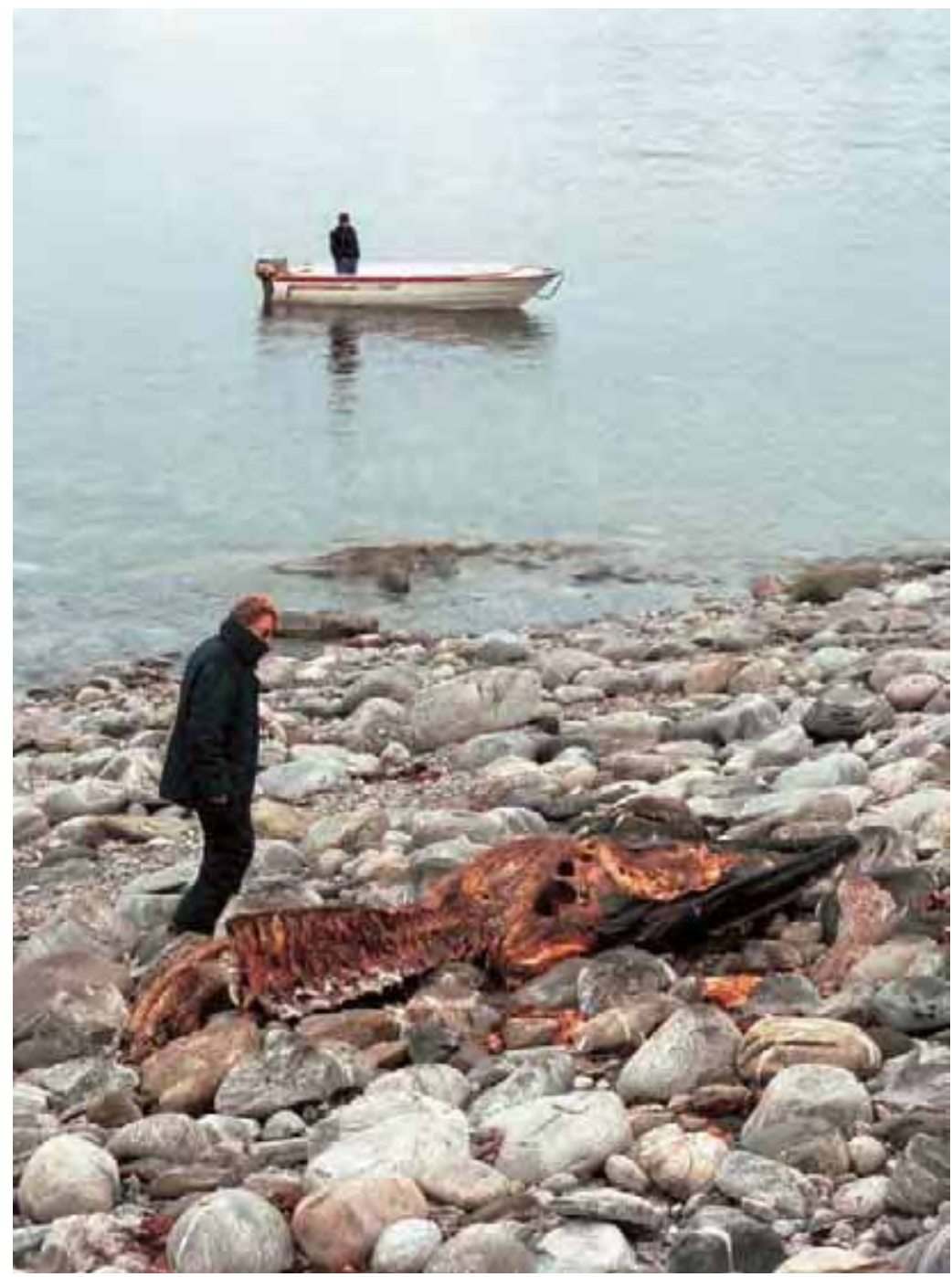

The question arises as to whether this submergence is entirely or partly caused by eustatic rise of sea-level. During the Holocene the outer fjord region of West Greenland was far from the ice margin. Therefore the area is more likely to have been influenced by upheaval as it lies within the forebulge area.

Another possibility is an eustatic rise of sea-level. It has been argued that a sea-level rise in the Mediterranean, from at depth of $\sim 2 \mathrm{~m}$ up to the present sea level, is taking place up to the present time, as concluded from a substantial bioerosion (Petersen 2000:fig. 54).

Kuijpers et al. (1999:64) state "that the average late Holocene relative sea level rise is in the order of about (at least) $3 \mathrm{~m}$ pr. Iooo years" in Southwest Greenland. Such a high rise of sea level is not recorded elsewhere around the globe, which would be the case if this rise was based on eustatic movement.

New studies on a model of glacio isostatic movements from West Greenland (Kelly 1980), show that the forebulge mentioned above is situated further away from the ice, so that the Sisimiut region should be also regarded as part of the downpressed area.

All in all there seems to be a general sea-level rise on the west coast of Greenland, although the main cause is difficult to ascertain. However, we might say that glacio-isostatic movements could be the main part varying from place to place along the coast. This could be influenced by a minor eustatic sea level rise of a magnitude like the one observed in the Mediterranean. 


\section{Comments on the records of boreal molluscs in Greenland}

Considering the limited number of material in this study compared to the study of Funder and Weidick (I99I), we will only give a few comments from our work in the outer part of the fjord region in the Sisimiut area.

Among the boreal molluscs mentioned by Funder and Weidick we encountered Heteranomia squamula within a dated timespan from 7400 to $5500 \mathrm{yr}$ BP. This is within the period from 8400 to 4900 yr BP mentioned as the "marine optimal period".

Arctica islandica was recorded from around 7800 and 9380 - the latter being older than the "optimal period". We may also have a record of an extant species (Table 58, fig. 2I7).

On Panopea norvegica we have no record from our own material, but Panopea has been recorded from Norse settlements of West Greenland in types of middens. However, the quantities of shellfish are generally low, and the Norse deposits are in no sense "shell middens" as mentioned by McGovern (1985).

In this way it seems to be clear that Panopea norvegica has had a more or less continuous existence on the West coast during the Holocene - considering the observation of V. Nordmann from Nordre Strømfjord in I9II, quoted by Jensen (I942).

Finally it is worth pointing to the observation by Andersen (1995) from the inner part of Ikertooq. Here three living specimens of Zirfaea crispata were found.

It should be concluded that the so-called "marine optimal periods" which are said to be characterised by boreal molluscs, now extinct in Greenland waters (Funder and Weidick 199I), should instead be taken as periods where these species increased in number.

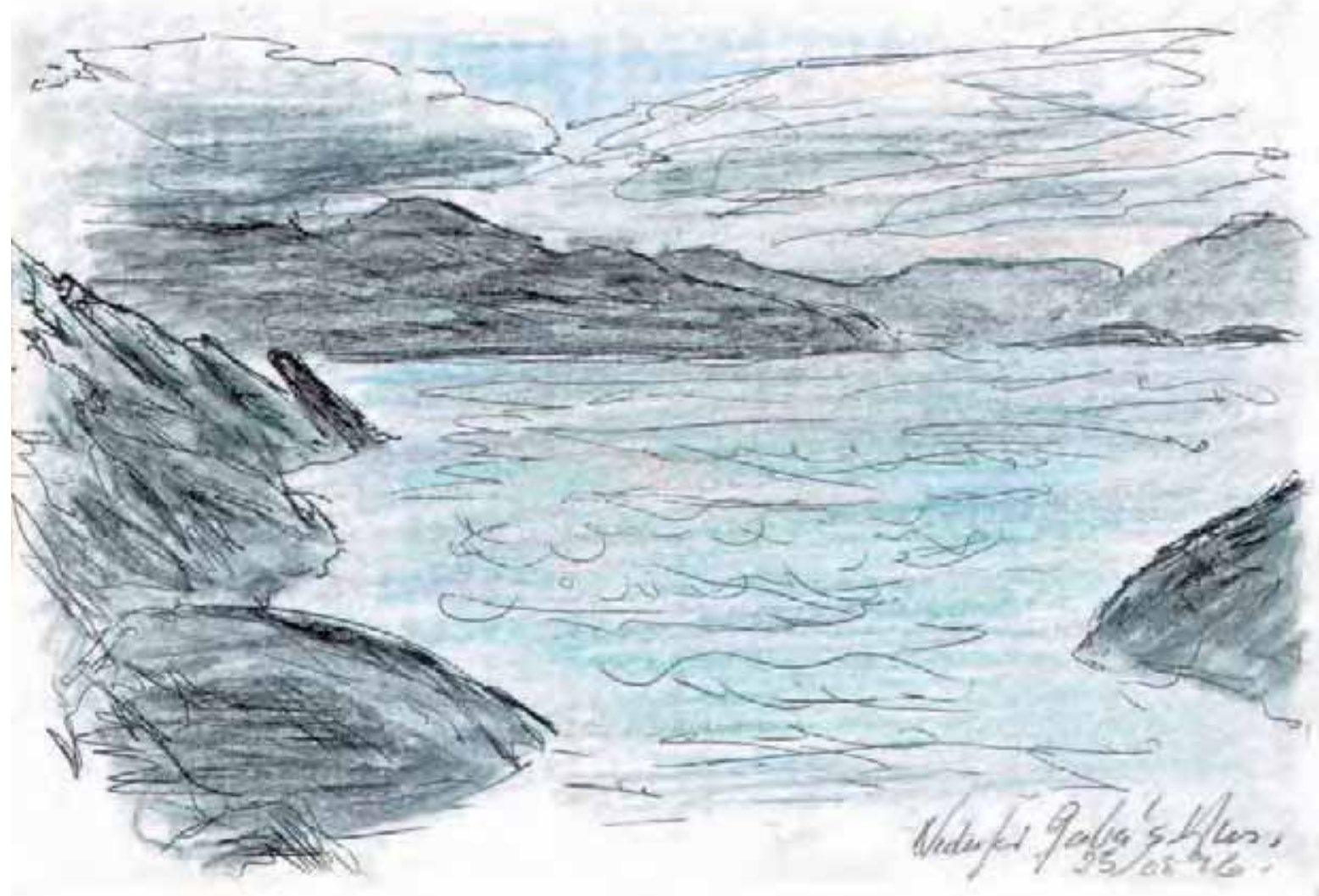

Amerloq seen from the northern shore. 


\section{References}

Allison, E.P. 1985. An archaeozoological study of bird bones from seven sites in York. - Unpublished Doctoral Thesis, University of York.

Amorosi, T., Woollett, J., Perdikaris, S. and McGowern, T.H. 1996. Regional zooarchaeology and global change: Problems and potentials. - World Archaeology 28 (I): I26-I57.

Andersen, D., Kinze, C.C. and Skov, J. 1992. The Use of Pelvic Bones in the Harbour porpoise Phocoena phocoena as indication of sexual maturity. - Lutra 35: I05-II2.

Andersen, J. 198I. Kaptajn Ejnar Mikkelsens Mindeekspedition, 1980. Scoresbysund-Angmagsalik. - Report on file at Kalaallit Nunaata Katersugaasivia. Nuuk: I05 p.

Andersen, R.W. I995. Holocæn palæoceanografi, isotopkemi og fauna i Vestgrønland. - Dissertation. University of Copenhagen, Institute of Geology. 94 p.

Anderson, D.D. 1988. Onion Portage: The archaeology of a stratified site from the Kobuk River, Northwest Alaska. Anthrological Papers of the University of Alaska 22 (I-2): I63 p.

Anderson, D.D. 1984. Prehistory of North Alaska. - In: Damas, D. (ed.). Arctic. Handbook of North American Indians Vol. 5. - Smithsonian Institution, Washington: 80-93.

Andreasen, C. 1996. A Survey of Paleo-Eskimo Sites in Northern Eastgreenland. - In: Grønnow, B. (ed.). The Paleo-Eskimo Cultures of Greenland - New Perspectives in Greenlandic Archaeology. Danish Polar Center Publication no. I, Copenhagen: I77-I90.

Andreasen, C. I997. Independence II in Northeast Greenland: some new aspects. - In: Gilberg, R. and Gulløv, H.C. (eds.). Fifty Years of Arctic Research. Anthropological Studies from Greenland to Siberia: Department of Ethnography, The National Museum of Denmark, Copenhagen: 23-32.

Andreasen, C. I998. NEWland: settlement patterns, social organization and economic strategies at a High Arctic polynya. - In: Arneborg, J. and Gulløv, H.C. (eds.). Man, Culture and Environment in Ancient Greenland. Danish Polar Center Publication no. 4, Copenhagen, Danish National Museum and Danish Polar Center: 198-2I2

Andreasen, C. 200o. Palaeo-Eskimos in Northwest and Northeast Greenland. - In: Appelt, M., Berglund, J. and Gulløv, H.C. (eds.). Identities and Cultural Contacts in the Arctic. Proceedings from a Conference at Danish National Museum Copenhagen, November 30 to December 2 I999. Danish Polar Center Publication No. 8. Copenhagen, Danish National Museum and Danish Polar Center: 8292.
Andreasen, C. and Elling H. I99I Archaeological Studies. - In: Egede, I. (ed.). Nature Conservation in Greenland. Atuakkiorfik: 54-65.

Andreasen, T.N. I998. Niivertussannguaq - a survey of the faunal remains from a Saqqaq settlement in the Disko Bay area of western Greenland. - Acta Borealia i5 (2): I29-I38.

Appelt, M. 1995. Nunnguaq - en Saqqaq-plads fra Godthåbsfjorden. En gammel udgravning i nyt perspektiv. - Unpublished master thesis, Department of Ethnology and Archaeology. University of Copenhagen: 85 pp.

Appelt, M. 1997. The Construction of an Archaeological "Culture". Similarities and differences in early PaleoEskimo cultures of Greenland. - In: Gilberg, R. and Gulløv, H.C. (eds.). Fifty Years of Arctic Research. Anthropological Studies from Greenland to Siberia. Department of Ethnography, The National Museum of Denmark, Copenhagen: 33-38.

Appelt, M., Hansen, L.W., Lai, L., Pind, J. and Schilling, H. 1992. Den palæoeskimoiske bosættelse i det vestgrønlandske indland. Rapport fra rekognosceringer og prøvegravninger i Pingo-dalen og på Tasersuaq East, sommeren I99I. - Institut for forhistorisk og klassisk arkæologi, Copenhagen: $37 \mathrm{p}$.

Appelt, M. and Pind, J. I996. Nunnguaq - a Saqqaq Site from Godthåbsfjorden. - In: Grønnow, B. (ed.). The PaleoEskimo Cultures of Greenland - New Perspectives in Greenlandic Archaeology. Danish Polar Center Publication no. I Copenhagen: I29-I42.

Appelt, M., Gulløv, H.C., Kapel, H. 1998. The gateway to Greenland. Report on the Field Season I996. - In: Arneborg, J. and Gulløv, H.C. (eds.). Man, Culture and Enviroment in Ancient Greenland. Danish Polar Center Publication no. 4, Copenhagen, Danish National Museum and Danish Polar Center: 136-197.

Appelt, M. and Gulløv, H.C. 1999. Late Dorset in High Arctic Greenland. Final report on the Gateway to Greenland project. - Danish Polar Center Publication no. 7, Copenhagen, Danish National Museum and Danish Polar Center: $\mathrm{I}-83$.

Arnold, C.D. I98I. The Lagoon Site (OjRI-3): Implications for Paleoeskimo Interactions. - Archaeological Survey of Canada, Mercury Series paper I7. National Museum of Man. Ottawa: 223 p.

Badarsson, G.G. I920. Om den marine Molluskfauna ved Vestkysten af Island. - Det Kgl. Danske Videnskabernes Selskab Biologiske Meddelelser II, 3: I39 p.

Bacher, A. 1967. Vergleichend morphologische Untersuch- 
ungen an Einzelknochen des postcranialen Skeletts in Mittleeuropa vorkommender Schwäne und Gänse. Dissertation University of München: II9 p.

Bendix, B. 200o. Late Dorset Faunal Remains from Sites at Hatherton Bay, Thule District, Greenland. - In: Appelt, M., Berglund, J. and Gulløv, H.C. (eds.). Identities and Cultural Contacts in the Arctic. Danish Polar Center Publication No. 8. Copenhagen, Danish National Museum and Danish Polar Center: 77-8I.

Bendixen, O. I92I. Holsteinsborg Distrikt. - In: Amdrup, G.C., Bobé, L., Jensen, A.S. and Steensby, H.P. (eds.). Grønland i Tohundredeaaret for Hans Egedes Landing. - Meddelelser om Grønland 6I (2): I-86.

Bennike, O. I990. Observations of geese and other birds in West Greenland, 1989 and I990. - Dansk Ornitologisk Forenings Tidsskrift 84: I45-I50.

Bertelsen, A. I92Ia. Fuglene i Umánaq distrikt. - Meddelelser om Grønland 62 (2): I39-2I4.

Bertelsen, A. I92Ib. Umánaq Distrikt. - In: Amdrup, G.C., Bobé, L., Jensen, A.S., and Steensby, H.P. (eds.), Grønland i Tohundredeaaret for Hans Egedes Landing - Meddelelser om Grønland 60 (I): 367-375.

Bertelsen, A. 1932. Meddelelser om nogle af de i Vestgrønlands distrikter mellem $60^{\circ}$ og $77^{\circ} \mathrm{N}$ br almindeligere forekommende fugle, særlig om deres udbredelsesomraade, deres yngleomraade og deres træk. - Meddelelser om Grønland 9I (4): I-75. (Danish, with English summary).

Binford, L.R. 1978. Nunamiut Ethnoarchaeology. - Academic Press. New York: 509 pp.

Binford, L.R. 198I. Bones. Ancient men and modern myths. Academic Press. London: 320 pp.

Bliss, L.C. and Matveyeva, N.V. I992. Circumpolar arctic vegetation. - In: Chapin III, F.., Jefferies, R.L., Reynolds, J.F., Shaver, G.R. and Svoboda, J. (eds.). Arctic ecosystems in a changing climate. An ecophysiological perspective. Academic Press. San Diego: 59-89.

Bobé, L. (ed.) I9I4. Thorhallesen: Beskrivelse over Missionerne i Grønlands Søndre Distrikt, Hvilke han som Viceprovst visiterede i Aarene I774-I775 - - Det Grønlandske Selskabs Skrifter i: II6 p.

Bobé, L. I9I6. Grønlands Genopdagelse og James Halls Rejser. - Det grønlandske Selskabs Aarskrift 19I6: 7I-92.

Bobé, L. I92I. Holsteinsborg District. - In: Amdrup, G.C., Bobé, L., Jensen, A.S. and Steensby, H.P. (eds.). Grønland i Tohundredeaaret for Hans Egedes Landing. - Meddelelser om Grønland 6I (2): 87-94.

Boertmann, D. 1994. An annotated checklist to the birds of Greenland. - Meddelelser om Grønland, Bioscience 38: $64 \mathrm{p}$.

Boertmann, D. 20oI. Sea Birds. - In: Born, E.W. and Böcher, J. (eds.). The Ecology of Greenland. - Ministry of Environment and Natural Resources. Ilinniusiorfik. Nuuk: I70I84.
Boertmann, D. and Mosbech, A. 1997. Breeding distribution and abundance of great cormorant Phalacrocorax carbo carbo in Greenland. - Polar Research I6 (2): 93-Ioo.

Boertmann, D. and Glahder C.M. 1999. Grønlandske gåsebestande - en oversigt. - Faglig rapport fra DMU, 276: 59 p.

Born, E.W. 20oI. Marine Mammals. - In: Born, E.W. and Böcher, J. (eds.). The Ecology of Greenland. - Ministry of Environment and Natural Resources. Ilinniusiorfik. Nuuk: I85-202.

Born, E.W, Heide-Jørgensen, M.P. and Davis, R.A. I994. The Atlantic Walrus (Odobenus rosmarus rosmarus) in West Greenland. - Meddelelser om Grønland, Bioscience 40: I-33.

Brown, R.G.B. 1985. The Atlantic Alcidae at sea. - In: Nettleship, D.N. and and Birkhead, T.R. (eds.). The Atlantic Alcidae, Academic Press, London: 384-425.

Bryden, M.M. I972. Growth and development of marine mammals. - In: Harrison, R.J. (ed.). Functional Anatomy of Marine Mammals. Academic Press, London and New York, I: I-79.

Bundgård, J. I977. Enestående dobbeltfund ændrer Grønlands historie. - Berlingske Tidende (I8. september I977): 32.

Böcher, J. I997. Insektrester fra Asummiut. - In: Møbjerg, T. (ed.). Asummiut før og nu. Tidsskriftet Grønland 45 (57): 260-262.

Böcher, J. I998. Insect remains from Asummiut. - In: Arneborg, J. and Gulløv, H.C. (eds.). Man, Culture and Environment in Ancient Greenland. Danish Polar Center Publication no. 4, Copenhagen, Danish National Museum and Danish Polar Center: I33-I34.

Böcher, J. and Fredskild, B. I993. Plant and arthropod remains from the palaeo-Eskimo site on Qeqertasussuk, West Greenland. - Meddelelser om Grønland, Geoscience 30: 35 p.

Casteel, R.D. 1976. Fish remains in archaeology and Paleoenvironmental Studies. - Academic Press. New York: I80 p.

Choinière, L. and Gauthier, G. 1995. Energetics and reproduction in female and male greater snow geese. - Oecologia I03: 379-389.

Cramp, S. and Simmons, K.E.L. (eds.) I977. The Birds of the Western Palearctic, Vol. I. Ostrich to Ducks - Oxford University Press, Oxford: 722 p.

Cramp. S. and Simmons, K. E.L. (eds.) I980. The Birds of the Western Palearctic, Vol. 2. - Oxford University Press, Oxford: $695 \mathrm{pp}$.

Crantz, D. I77o. Historie von Grönland, Theil I. - Leibzig: 400 p.

Damas, D. (ed) I984. Handbook of North American Indians 5: Arctic. - Smithsonian Institute, Washington: 829 p.

Darwent, C.M. I999. Interpreting the subsistence of the first high Arctic occupants. - In: Gillespie, J., Tupaka, S., and de Mille, C. (eds.). On being first: Cultural and environmental consequences of first peopling. Proceedings of 
the $3 \mathrm{I}^{\text {st }}$ Annual Chacmool Conference. Calgary, Alberta: The Archaeological Association of the University of Calgary: II9-I32.

Darwent, C.M. 20oI. High Arctic Paleoeskimo Fauna: Temporal Changes and Regional Differences. - Unpublished Ph.D-thesis. The Faculty of the Graduate School University of Missouri-Columbia: 203 p.

Dauphiné, T.C. Jr. 1976. Biology of the Kaminuriak population of barren-ground caribou. Part 4: Growth, reproduction and energy reserves. - Canadian Wildlife Service, report series 38: 69 p.

Dawes, P.R., Elander, M. and Ericson, M. 1986. The wolf (Canis lupus) in Greenland. A historical review and present status. - Arctic 39: II9-I32.

Degerbøl, M. 1936. Animal remains from the West Settlement in Greenland with special reference to livestock. Meddelelser om Grønland 88 (3): 54 p.

Degerbøl, M., Hørring, R. and Pfaff, I.R. I93I. Animal Bones from the Sukkertoppen District, 1930. - In: Mathiassen, T. (ed.), Ancient Eskimo Settlements in the Kangaamiut Area. - Meddelelser om Grønland 9I (I): I34-39.

Degerbøl, M. and Krogh, H. I959. The reindeer (Rangifer tarandus L.) in Denmark. - Biologiske Skrifter fra Danske Videnskabernes Selskab io (4): I65 p.

Dekin, A.A. 1976. The Arctic Small Tool Horizon: A Behavioural Model of the Dispersal of Human Population into Unoccupied Niche. - In Maxwell, M.S. (ed.). Eastern Arctic Prehistory. Paleoeskimo problems. Memoirs of the Society for American Archaeology 3I: I56-I63.

Diab, M.C. 1998. Economic Utility of the Ringed Seal (Phoca hispida): Implications for Arctic Archaeology. - Journal of Archaeological Science 25: I-26.

Diklev, T. and Madsen, B. I992. Arkæologisk berejsning i Thule I99I. - Report on file Avanersuup Katersugaasivia/ Thule Museum. Qaanaaq: $42 \mathrm{p}$.

Driesch, A. von den 1976. A Guide to the Measurement of Animal Bones from Archaeological Sites. - Peabody Museum Bulletin I. Harvard: I37 p.

Ebbinge, B.S. and Spaans, B. 1995. The importance of bodyreserves accumulated in spring staging areas in the temperate zone for breeding of dark-bellied brent geese Branta bernicla bernicla in the High Arctic. - Journal of Avian Biology 26: I05-II3.

Edland, H. 1969. Tenner hos reinsdyr, Bedømmelse ved Tannskifte og Tannfrembrud. - Norges Veterinærhøgskole, Institut for Anatomi, Olso: $32 \mathrm{p}$.

Egede, H. I74I. Det Gamle Grønlands Nye Perlustration eller Naturel-Historie. - Copenhagen: I3I p.

Egede, P. I74I. Continuation af Relationerne Betreffende Den Grønlandske Missions Tilstand og Beskaffenhed. Anno I734-I740. - In: Ostermann, H. (ed.). [I939]. Poul og Niels Egede: Continuation af Hans Egedes Relationer fra Grønland samt Niels Egede: Beskrivelse over Grønland. Meddelelser om Grønland I20: 5-I22.
Elling, H. 1992. De palæoeskimoiske kulturer i Nordgrønland og Nordøstgrønland i relation til de vestgrønlandske. - In Jacobsen, B. (ed.). Cultural and social research in Greenland 95/96. Essays in Honour of Robert Petersen. Ilisimatusarfik/Atuakkiorfik Nuuk: 50-69

Elling, H. I996. The Independence I and Old Nuulliit Cultures in Relation to the Saqqaq Culture. - In: Grønnow, B. (ed.). The Paleo-Eskimo Cultures of Greenland - New Perspectives in Greenlandic Archaeology. Danish Polar Center Publication no. I. Copenhagen: I9I-I98.

Enghoff, I.B. 1994: Fishing in Denmark during the Ertebølle Period. - International Journal of Osteoarchaeology 4: 65-96.

Enghoff, I.B. 2003. Hunting, fishing and animal husbandry at the Farm beneath the Sand, Western Greenland. An archaezoological analysis of a Norse Farm in the Western Settlement. - Meddelelser om Grønland, Man and Society 28: $104 \mathrm{p}$.

Eriksen, B.V. 200o."Chaîne opératoire". - In: Eriksen, B.V. (ed.) Flintstudier. En håndbog i systematiske analyser af flintinventarer. Aarhus University Press: 75-Ioo.

European Commission I998. Multilingual illustrated dictionary of aquatic animals and plants. Second edition. Fishing News Books and Office for Official Publications of the European Communities, Luxemburg: 548 p.

Fabricius, O. 1793. Om den pukkelnebbede Edderfugl (Anas spectabilis) og Grønlændernes Edderfuglefangst Skrivter af Naturhistorie-Selskabet 2 (2): 56-83.

Fabricius, O. 1808. Zoologiske Samlinger, eller Dyrebeskrivelser, tid til anden forfattede efter egen Betragtning ved Otto Fabricius fra Aar 1768, og her bragte i Samling fra Aar 1808. - The Manuscript Collection, New Royal Collection, No $322 \mathrm{~d}$ in quarto. The Royal Library, Copenhagen.

Fabricius, O. I8I8. Nöiagtig Beskrivelse over Grönlændernes Landdyr-Fugle-Fiskefangst med dertil hörende Redskaber. - Det kongelige danske Videnskabernes Selskabs Skrivter 6 (2): 23I-272.

Falk, K and Durinck, J. 199I. The by-catch of Thick-billed Murres in salmon drift nets off West Greenland in I988. In: Gaston, A. J. and Elliot, R.D. (eds.). Studies of highlatitude seabirds. 2. Conservation biology Thick-billed Murre in the Northwest Atlantic. - Canadian Wildlife service, Occasional paper no 69: 23-28.

Falk, K. and Durinck, J. 1992. Thick-billed Murre Hunting in West Greenland, I988-89. - Arctic 45 (2): I67-I78.

Fay, F.H. I98I. Walrus Odobenus rosmarus (Linnaeus, I758). In: Ridgway, S.H., and Harrison, R.J. (eds.). - Handbook of Marine Mammals, Volume I The Walrus, Sea Lions, Fur Seals and Sea Otter. Academic Press, New York: I-23. Fitzhugh, W.W. I972. Enviromental archaeology and cultural systems in Hamilton Inlet. Labrador: A survey of the central Labrador Coast from $3000 \mathrm{BC}$ to the present. - 
Smithsonian Contributions to Anthropology no. 16, Smithsonian Institution, Washington: 299 p.

Fitzhugh, W.W. 1976. Paleoeskimo occupations of the Labrador Coast. - In: Maxwell, M.S. (ed.). Eastern Arctic Prehistory. Paleoeskimo problems. - Memoirs of the Society for American Archaeology 3I: IO3-II8.

Fitzhugh, W.W. 2003. Nukasusutok 2 and the Paleoeskimo Tradition in Labrador. - In: Fitzhugh, W.W., Loring, S. and Odess, D. (eds.). Honouring our Elders. A History of Eastern Arctic Archaeology. Arctic Studies Center, National Museum of Natural History, Smithsonian Institution, Washington: I33-I62.

Fox, A.D., Glahder, C.M., Mitchell, C.R., Stroud, D.A., Boyd, H., Frikke, J. 1996. North American Canada Geese (Branta canadensis) in West Greenland. - The Auk I3 (I): 23I-233.

Fox, A.D. and Stroud, D.A. 1988. The breeding biology of the Greenland White-fronted Goose (Anser albifrons flavirostris).- Meddelelser om Grønland, Bioscience, 27: I4 p.

Fredskild, B. 1973. Studies in the vegetational History of Greenland. Paleobotanical investigations of some Holocene lake and bog deposits. - Meddelelser om Grønland I98 (4): $245 \mathrm{p}$.

Freuchen, P. I92I. Om Hvalrossens Forekomst og Vandringer ved Grønlands Vestkyst. - Videnskabelige Meddelelser Dansk Naturhistorisk Forening 72: 237-249.

Freuchen, P. and Salomonsen, F. I96I. Det arktiske År. - Gyldendal, København: 382 p.

Frimer, O. and Nielsen, S. I990. Bird observations in Aqujarua - Sullorsuaq, Disko Island, West Greenland, I989. Dansk Ornitologisk Forenings Tidsskrift 84: I5I-I58.

Funder, S. and Fredskild, B. I989. Paleofaunas and floras (Greenland). - In: Fulton, R.J. (ed.). Quaternary geology of Canada and Greenland. - Geological Survey of Canada, Geology of Canada r: 775-783.

Funder, S. and Weidick, A. I99I. Holocene boreal molluscs in Greenland - palaeoceanographic implications. - Palaeogeography, Palaeoclimatology, Palaeoecology 85: I23-I35.

Gabriel, M., Grønnow, B., Odgaard, U, Pasda, C. and Pasda, K. 2002. Bosættelsesmønstre i det centrale Vestgrønland. Rapport om undersøgelserne i Angujaartorfiup Nunaa, Manitsoq kommune, sommeren 200I. - SILA, Nationalmuseets Center for Grønlandsforskning, Feltrapport 4: 5I p.

Gad, F. 1967. Grønlands Historie, I. Indtil I700. - Nyt Nordisk Forlag Arnold Busck, Copenhagen: 46I p.

Gad, F. I969. Grønlands Historie, II. I700-I782. - Nyt Nordisk Forlag Arnold Busck, Copenhagen: $760 \mathrm{p}$.

Gad, F. 1976. Grønlands Historie, III. I782-I808. - Nyt Nordisk Forlag Arnold Busck, Copenhagen: 6I5 p.

Gad, F. 1984. Grønland. Politikens Danmarkshistorie. - Politikens Forlag, Copenhagen: 336 p.

Galatius, A. and Kinze, C.C. 2003. Ankylosis patterns in the post-cranial skeleton and hyoid bones of the harbour por- poise (Phocoena phocoena) in the Baltic and North Sea. Canadian Journal of Zoology 8I (II): I85I-I86I.

Gaston, A.J. and Jones, I.L. I998. The Auks. Alcidae. - Oxford University Press. Oxford New York Tokyo: 349 p.

Giddings, J.L. I964. The archaeology of Cape Denbigh. Brown University Press, Providence, Rhode Island: 33I p.

Giddings, J.L. I967. Ancient Men of the Arctic. - Alfred A. Knopf. New York: 39I p.

Gilbert, B.M., Martin, L.D. and Savage H.G. 1996. Avian Osteology. - Missouri Archaeological Society, Columbia: $252 \mathrm{p}$.

Glahder, C.M., Fox, A.D., Stroud, D.A. and Mitchell, C.R. I996. North American Canada Geese in West Greenland. - Wetlands International Goose specialist Group Bulletin 7: 23-25.

Glahn, H.C. I77I. Anmærkninger over de tre første Bøger af Hr. David Crantzes Historie om Grønland. - København: $388 \mathrm{p}$.

Godfrey, W.E. I986. The birds of Canada. Revised edition. National Museum of Canada, Ottawa: 595 p.

Gotfredsen, A.B. 1992. Nyt fra Saqqaq kulturen. - Tusaat/ Forskning i Grønland 1992 (I): 39-45.

Gotfredsen, A.B. I996. The Fauna from the Saqqaq Site of Nipisat I, Sisimiut District, West Greenland: Preliminary Results. - In: Grønnow, B. (ed.). The Paleo-Eskimo Cultures of Greenland - New Perspectives in Greenlandic Archaeology. Danish Polar Center Publication no. I. Copenhagen: 97-Iıo.

Gotfredsen, A.B. 1997a. Sea bird exploitation on coastal Inuit sites, west and southeast Greenland. - In: Serjeantson, D. (ed.). Subsistence and Symbol. Papers from the International Council for Archeaozoology Bird Group Meeting, I995. International Journal of Osteoarchaeology. Special Issue 7: 27I-286.

Gotfredsen, A.B. I997b. Fangstgrundlaget i Sisimiut distrikt udfra arkæologiske og historiske kilder. - In: Møbjerg, T. (ed.). Asummiut før og nu. Tidsskriftet Grønland 45 (57): 262-273.

Gotfredsen, A.B. I998. The faunal material of the Saqqaq site Nipisat I, Sisimiut district, west Greenland. - In: Arneborg, J and Gulløv, H.C. (eds.). Man, Culture and Environment in Ancient Greenland. Report on a research programme. Danish Polar Center. Publication No 4. The Danish National Museum and Danish Polar Center, Copenhagen: I24-I32.

Gotfredsen, A.B. 1999. The Avifauna of Greenland in a quaternary zoological perspective. An analysis of the zoogeography of selected bird species and prehistoric bird hunting in low arctic Greenland. - Unpublished Ph. D.-thesis. Department of Vertebrates, Faculty of Science, University of Copenhagen: I29 p.

Gotfredsen, A.B. 2002. Former occurrences of geese (Genera Anser and Branta) in ancient West Greenland: morphological and biometric approaches. - In: Bochénski, Z. M., 
Boche 'nski, Z. and Stewart, J. Proceedings of the 4 th Meeting of the ICAZ Bird Working Group, Kraków, Poland, II-I5 September, 20oI. - Acta Zoologia Cracoviensia, 45 (special issue): I79-204.

Grayson, D.K. 1984. Quantitative zooarchaeology: Topics in the analysis of archaeological faunas. - Academic Press, New York: 202 p.

Grønnow, B. I985. Meiendorf and Stellmoor revisited. An analysis of Late Palaeolithic Reindeer Exploitation. Acta Archaeologica 56: I3I-I66.

Grønnow, B. I988a. Nye Perspektiver i Saqqaq-forskningen. In: Møbjerg, T., Grønnow, B. and Schultz-Lorentsen, H. (eds.). Palæoeskimoisk forskning i Grønland. Aarhus University Press: 2I-38.

Grønnow, B. 1988b. Prehistory in Permafrost. Investigations at the Saqqaq Site, Qeqertasussuk, Disco Bay, West Greenland. - Journal of Danish Archaeology 7: 24-39.

Grønnow, B. 1994. Qeqertasussuk - the Archaeology of a Frozen Saqqaq Site in Disko Bugt, West Greenland. - In: Morrison, D. and Pilon, J.-L (eds.). Threads of Arctic Prehistory: Papers in honour of William E. Taylor, jr. Archaeological Survey of Canada. - Mercury Series paper I49. Canadian Museum of Civilization: 197-238.

Grønnow, B. 1996a. Driftwood and Saqqaq Culture Woodworking in West Greenland. - In: Jacobsen, B. (ed.). Cultural and Social Research in Greenland 95/96. Essays in honour of Robert Petersen. Ilisimatusarfik/Atuakkiorfik Nuuk: 73-89.

Grønnow, B. I996b. The Paleo-Eskimo Cultures of Greenland - Current Research. - In: Grønnow, B. (ed.). The PaleoEskimo Cultures of Greenland - New Perspectives in Greenlandic Archaeology. Danish Polar Center Publication no I, Copenhagen: I-8.

Grønnow, B. I996c. The Saqqaq Tool Kit - Technological and Chronological Evidence From Qeqertasussuk, Disko Bugt. - In: Grønnow, B. (ed.). The Paleo-Eskimo Cultures of Greenland - New Perspectives in Greenlandic Archaeology. Danish Polar Center Publication no I, Copenhagen: I7-34.

Grønnow, B. 1997. The Saqqaq Harpoon: An Analysis of Early Paleo-Eskimo Harpoon Heads from Qeqertasussuk, West Greenland. - In Gilberg, R. and Gulløv, H.C. (eds.). Fifty Years of Arctic Research. Anthropological Studies from Greenland to Siberia. Department of Ethnography, The National Museum of Denmark, Copenhagen: II9-I3o.

Grønnow, B and Meldgaard, M. I988. Boplads i dybfrost. Naturens Verden II-I2: 409-440.

Grønnow, B. and Meldgaard, M. (eds.) I99Ia. Qeqertasussuk. De første mennesker i Vestgrønland. - Tidsskriftet Grønland 39 (4-7): 97-224.

Grønnow, B., Meldgaard, M. and Nielsen, J.B. I983. Aasivissuit - The Great Summer Camp. Archaeological, Ethnological and Zooarchaeological Studies of a Caribou- unting Site in West Greenland. - Meddelelser om Grønland, Man and Society 5: 99.

Grønnow, B and Meldgaard, M. I99Ib. De første Vestgrønlændere. - In: Grønnow, B. and Meldgaard, M. (eds.) Qeqertasussuk.- De første mennesker i Vestgrønland. Tidsskriftet Grønland 39 (4-7): IO3-I44.

Gulløv, H.C. I983. Fortidsminder i Nuuk Kommune - Inuit kulturens bopladser. - Grønlands Nationalmuseum, Nuuk and Nationalmuseet. Copenhagen: 245 p.

Gulløv, H.C. 1986a. Grønland I945-I985. Kulturhistorisk Forskningsoversigt. -Report from Kalaallit Nunaata Katersugaasivia and Ilisimatusarfik. Nuuk: 20I p.

Gulløv, H.C. I986b. Introduction. - Arctic Anthropology 23 (I2): I-I8.

Gulløv, H.C. 1997. From Middle Ages to Colonial Times. Archaeological and ethnohistorical studies of the Thule culture in South West Greenland I300-I80o AD. - Meddelelser om Grønland, Man and Society 23: 494 p.

Gulløv, H.C. and Lange, H. 1987. Ammassalik - arkæologiske undersøgelser i Tasiilaq Kommune. - Report from Kalaallit Nunaata Katersugaasivia. Nuuk: II5 p.

Gulløv, H.C. and Kapel, H. I988. De palæoeskimoiske kulturer i Nuuk Kommune. - In: Møbjerg T., Grønnow, B. and Schultz-Lorentsen, H. (eds). Palæoeskimoisk forskning i Grønland. Aarhus University Press: 39-58.

Gulløv, H.C. and Jensen, J.F. I99I. Rapport om de arkæologiske registreringer og undersøgelser i Sønder Skjoldunge Sund, Ammassalik Kommune, Sydøstgrønland sommeren I990. - Danish Polar Center, Copenhagen: 99 p.

Gulløv, H.C., Felbo, M., Jensen, J.F., Gotfredsen, A.B. 1992. Rapport om det arkæologiske arbejde i Skjoldungen, Ammassalik Kommune, Sydøstgrønland sommeren I99I. - Danish Polar Center, Copenhagen: iı6 p.

Gulløv, H.C., Felbo, M., Gotfredsen, A.B., Kapel, H. and Koch, A. 1993. Rapport om det arkæologiske arbejde i Illuluarsuk regionen syd for Bernstorffs Isfjord, Ammassalik Kommune, Sydøstgrønland, sommeren 1992. - Danish Polar Center, Copenhagen: I54 p.

Gynther, B. and Meldgaard, J. I983. 5 kapitler af Grønlands forhistorie. Illustreret af L. Larsen og J. Rosing. - Pilersuiffik: II3 p.

Haarløv, N., Jacobsen, N.K., Meldgaard, J and Petersen, H.C. (eds.) I980. Holsteinsborg. Sisimiut kommune. Naturog kulturforhold. - Udvalget vedrørende Fredningslov for Grønland: Ministeriet for Grønland. Copenhagen: 88 p.

Habermehl, K.-H. I96I. Altersbestimmung bei Haustieren, Peltztieren und beim jagdbaren Wild. - Paul Parey, Berlin and Hamburg: 223 p.

Habermehl, K.-H. I975. Die Altersbestimmung bei Haus- und Labortieren. - Paul Parey, Berlin and Hamburg: 2I6 p.

Hansen, E.S. 20oI. Lichens. - In: Born, E.W. and Böcher, J. (eds.). The Ecology of Greenland. - Ministry of Environ- 
ment and Natural Resources. Ilinniusiorfik. Nuuk: 27I275 .

Hansen, K. and Jensen, J.F. I99I. Orpissooq- en sommerfangstplads fra Saqqaq-kulturen. - Tidsskriftet Grønland 39 (4-7): I8I-190.

Harp, E. 1958. The Prehistory of the Dismal Lake area. - Arctic II (4): 2I7-249.

Harp, E. I997. Pioneer Settlements of the Belcher Islands, N.W.T. - In: Gilberg, R. and Gulløv, H.C. (eds.). Fifty Years of Arctic Research. Anthropological Studies from Greenland to Siberia. Department of Ethnography, The National Museum of Denmark, Copenhagen: I57-I68.

Heide-Jørgensen, H.S. and Johansen, I. I997. Ecosystem Vulnerability to Climate Change in Greenland and the Faroe Islands. - Danish Environmental Protection Agency, Copenhagen. - Working Report No. 97: 266.

Heide-Jørgensen, M.P. 1994. Distribution, exploitation and population status of white whales (Delphinapterus leucas) and narhwals (Monodon monoceros) in West Greenland. - In: Born, E.W., Dietz, R. and Reeves, R.R. (eds.). Studies of white whales (Delphinapterus leucas) and narwhals (Monodon monoceros) in Greenland and adjacent waters. - Meddelelser om Grønland, Bioscience 39: I35-I49.

Helmer, J.W. I99I. The Palaeo-Eskimo of the North Devon Lowlands. - Arctic 44 (4): 30I-3I7.

Helmer, J.W. 1994. Resurrecting the Spirit(s) of Taylor's Carlsberg Culture: Cultural Traditions and Cultural Horizons in Eastern Arctic Prehistory. - In: Morrison, D. and Pilon, J.-L. (eds.). Threads of Arctic Prehistory: Papers in honour of William E. Taylor, Jr. Archaeological Survey of Canada. - Mercury Series paper 149. Canadian Museum of Civilization: $15-34$.

Helms, O. I92I (ed.). Otto Fabricius: Fauna Groenlandica. Pattedyr og Fugle. I780. - Det Grønlandske Selskabs Skrifter 6: 168.

Helms, O. 1926. Birds of Angmagssalik. - Meddelelser om Grønland 58 (4): 205-274.

Holbøll, C. I843. Ornithologiske bidrag til den Grønlandske Fauna. - Naturhistorisk Tidsskrift I. Række 4: 36I-457.

Holm, G. I887. Ethnologisk Skizze af Angmagsalikerne. Meddelelser om Grønland. København I888. Io (2): 43-I82.

Holthuis, L.B. I987. The scientific name of the sperm whale. Marine Mammal Science 3: 87-89.

Hood, B. I998. Theory on ice: the discourse of eastern Canadian Arctic Paleoeskimo archaeology. - Acta Borealia I5 (2): 3-56.

Hufthammer, A.K. I995. Age determination of Reindeer (Rangifer tarandus L.). -ArchæoZoologia 7(2): 33-42.

Härkönen, T. and Heide-Jørgensen, M.P. I99o. Comparative life histories of East Atlantic and other harbour seal populations. - Ophelia 32 (3): 2II-235.

Høiris, O., Møhl, J. and Hansen, K. 2002. Kajakjagt. Fra myte til virkelighed. - Tidsskriftet Grønland 50 (8): 26I-276.
Jensen, A.S. I90o. Studier over nordiske Mollusker I Mya. Videnskabelige Meddelelser fra den naturhistoriske Forening i København: I33-I58.

Jensen, A.S. I942. Two new West Greenland localities for deposits from the ice age and the post-glacial warm period. - Det Kgl. Danske Videnskabernes Selskab Biologiske Meddelelser I74, 4: $35 \mathrm{p}$.

Jensen, J.A.D. I885. Undersøgelse af Grønlands Vestkyst fra $64^{\circ}$ til $67^{\circ}$ N.B. - Meddelelser om Grønland 8 (2): 33-I2I.

Jensen, J.F. I995. Annertusuaqqap Nuua - en Dorset-boplads i Sydostbugten, Vestgrønland. - Tidsskriftet Grønland 43 (6): 225-240.

Jensen, J.F. I996. Paleo-Eskimo sites in Skjoldungen District, South East Greenland. - In: Grønnow, B. (ed.). The Paleo-Eskimo Cultures of Greenland - New Perspectives in Greenlandic Archaeology. Danish Polar Center Publication no. I, Copenhagen: I43-I59.

Jensen, J.F. I998. Dorset dwellings in West Greenland. - Acta Borealia I5 (2): 59-80.

Jensen, J.F. 200oa. West Greenland Palaeo-Eskimo Raw Material Procurement Elucidated by Geological Analysis. - In: Appelt, M., Berglund, J. and Gulløv, H.C. (eds.). Identities and Cultural Contacts in the Arctic. Proceedings from a Conference at Danish National Museum Copenhagen, November 30 to December 2 1999. Danish Polar Center Publication No. 8. Copenhagen, Danish National Museum and Danish Polar Center: 7I-76.

Jensen, J.F. 20oob. Kap St. Jacques - en ruinby ved Polhavet. - In: Jacobsen, B. H., Böcher, J., Nielsen, N., Guttesen, R., Humlum, O. and Jensen, E. (eds.): Topografisk Atlas Grønland, Copenhagen. Det Kongelige Danske Geografiske Selskab og Kort and Matrikelstyrelsen: 202-203.

Jensen, J.F., Brinch Petersen, E. and Johansen, L. I997. Grønlands Ældste Minedrift. - Tidsskriftet Grønland 45 (4): I37-I49.

Jensen, J.F. and Brinch Petersen, E. I998. Raw Material Distribution - Social Interaction. - Acta Borealia I5 (2): 139I52.

Jensen, J.F., Brinch Petersen, E. and Olsen, B. 1999. "Sydostbugt Projektet". New Datings of the Paleo-Eskimo Settlements in Qeqertarsuup Tunua (Disco Bay), Greenland. Copenhagen University. The School of Prehistoric Archaeology, Archaeological Notes 2: 2-4.

Johnstrup, F. I878. Giesecke, K.L. I806-I8I3. Bericht einer mineralogischen Reise in Grönland, in Form eines Tagesbuchs. Gieseckes Mineralogiske Rejse i Grønland, I878. København: $372 \mathrm{p}$.

Kampp, K., Fox, A.D. and Stroud, D.A. 1988. Mortality and Movements of the Greenland White-fronted Goose Anser albifrons flavirostris. - Dansk Ornitologisk Forenings Tidsskrift 82: 25-36.

Kampp, K. and Falk, K. I994. The birds of Ydre Kitsissut (Kitsissut Avalliit), Southwest Greenland. - Meddelelser om Grønland, Bioscience 42: 25. 
Kapel, F.O. 1977. Catch of belugas, narwhals and harbour porpoises in Greenland, I954-1975, by year, month and region. - Report of the International Whaling Commission 27: 507-520.

Kapel, H. I984 Kortlægning af kulturhistoriske interesser i forbindelse med vandkraftprojekt i, Sisimiut Kommune. Report on file at the Greenland National Museum and Archives. Nuuk: 34 p.

Kapel, H. 1986. Kortlægning af kulturhistoriske og arkæologiske interesser i forbindelse med vandkraftprojekt Tasersuaq, Sisimiut/Holsteinsborg 1984-85. Afsluttende rapport. - Report on file at the Greenland National Museum and Archives. Nuuk: $33 \mathrm{p}$.

Kapel, H. I989. Kulturhistorisk forskning omkring Kangerlussuaq - tilbageblik og perspektiver. - Tusaat/Forskning i Grønland I989 (I-2): 65-74.

Kapel, H. I996. Angujaartorfik - a Paleo-Eskimo Caribou Hunting Camp. - In: Grønnow, B. (ed.). The PaleoEskimo Cultures of Greenland - New Perspectives in Greenlandic Archaeology. Danish Polar Center Publication no. I, Copenhagen: II9-I28.

Kelly, M. I980. The status of the Neoglacial in Western Greenland - The Geological Survey of Greenland. - Report 96: $24 \mathrm{p}$.

King, J.E. I983. Seals of the World. - Oxford University Press, London: $240 \mathrm{p}$.

Kinze, C.C. I994. Phocoena phocoena (Linnaeus, I758) Schweinswal oder Kleintümmler (auch Braunfisch). - In: Robineau, D., Duguy, R. and Klima, M. (eds.) Handbuch der Säugetiere Europas 6/I A: Whale und Delphine I: 242-264.

Kinze, C.C. 1995. Exploitation of Harbour Porpoises (Phocoena phocoena) in Danish Waters: A Historical Review. Report of the International Whaling Commission I6 (Special Issue): I4I-I53.

Knuth, E. I952. An Outline of the Archaeology of Peary Land. - Arctic 5 (I): I7-33.

Knuth, E. 1967. Archaeology of the Musk-Ox Way. École Pratique des Hautes Études. Contributions du Centre d'Etudes Arctiques et Finno-Scandinaves 5: 70.

Knuth, E. 1968. The Independence II Bone Artifacts and the Dorset-evidence in North Greenland. - Folk Io: 6I-80.

Knuth, E. 1978. The "Old Nûgdlit Culture" Site af Nûgdlit Peninsula, Thule District, and the "Mesoeskimo" Site Below it. - Folk 19-20: 15-48.

Knuth, E. I98I. Greenland News from between $81^{\circ}$ and $83^{\circ}$ North. - Folk 23: 9I-III.

Knuth, E. I983. The Northernmost Ruins on the Globe. - Folk 25: 5-2I.

Kramer, F.E. 1993. Field notes from the excavation at Nipisat I in I989, I990, I992 and I993. - Report on file at Sisimiut Museum.

Kramer, F.E. I994. På sporet af Forhistorien. - Tidsskriftet Grønland 42 (7): 2I7-226.
Kramer, F.E. 1996a. The Paleo-Eskimo Cultures in Sisimiut District, West Greenland. Aspects of Chronology. - In: Grønnow, B. (ed.). The Paleo-Eskimo Cultures of Greenland - New Perspectives in Greenlandic Archaeology. Danish Polar Center Publication no. I, Copenhagen: 3964.

Kramer, F.E. 1996b. Akia and Nipisat I: Two Saqqaq sites in Sisimiut District; West Greenland. - In: Grønnow, B. (ed.). The Paleo-Eskimo Cultures of Greenland - New Perspectives in Greenlandic Archaeology. Danish Polar Center Publication no. I, Copenhagen: 65-96.

Kramer, F.E. and Jones, H. 1992. Nipisat I - en boplads fra den yngre Saqqaq kultur. - Tusaat/Forskning i Grønland 1992 (I): 28-38.

Krogh, K.J. 1965. Thjodhildes kirke på Brattahlid. - Nationalmuseets Arbejdsmark 1963-I965: 5-18.

Kuijpers, A., Abrahamsen, N., Hoffmann, G., Hühnerbach, V., Konradi, P., Kunzendorf, H., Mikkelsen, N., Thiede, J. and Weinrebe, W. 1999. Climate Changes and the Vikingage fjord environment of the Eastern Settlement, South Greenland. -Geology of Greenland Survey Bulletin I83: 6I-67.

Larsen, H, 1968. Trail Creek. Final Report on the Excavation of two caves on Seward Peninsula, Alaska. - Acta Arctica I5: $79 \mathrm{p}$.

Larsen, H. and Meldgaard, J. I958. Paleo-Eskimo Cultures in Disko Bugt, West Greenland. - Meddelelser om Grønland I6I (2): 75 .

Le Blanc, R.J. I994. The Crane Site and the Palaeoeskimo Period in the Western Canadian Arctic. - Archaeological Survey of Canada, Mercury Series paper I48: I-I30.

Le Moine, G.M. and Darwent, C.M. I998. The Walrus and the Carpenter: Late Dorset Ivory Working in the High Arctic. - Journal of Archaeological Science 25: 73-83.

Lepiksaar, J. I958. Fossilfynd av stormfåglar (Procellariformes) från Sveriges västkust. - Zoologisk Revy 4: 77-85. Lie, R.W. 1973. Sex-determination as a Multivariate Problem. - Norwegian Archaeological Review 6 (2): 79-83.

Lockyer, C., Heide-Jørgensen, M.P., Jensen, J., Kinze, C.C. and Sørensen, T.B. 200I. Age, length and reproductive parametres of harbour porpoises Phocoena phocoena L. from West Greenland. - ICES Journal of Marine Science 58: I54-I62.

Lyman, R.L. I985. Bone Frequencies: Differential Transport, in situ destruction, and MGUI. - Journal of Archaeological Science I2: 2II-236.

Lyman, R.L. I994. Quantitative units and terminology in zooarchaeology. -American Antiquity 59 (I): 36-7I.

Lyman, R.L. 1996. Vertebrate Taphonomy: Cambridge manuals in Archaeology. - Cambridge University Press, Cambridge: $524 \mathrm{p}$.

Lyngs, P. 1994. Gejrfuglen. Et I50 års minde. - Dansk Ornitologisk Forenings Tidsskrift 88: 49-72.

MacGregor, A. 1985. Bone, Antler, Ivory and Horn: The Techn- 
ology of Skeletal Materials since the Roman period. Croom Helm, London: 245 p.

Madge, S. and Burn, H. I988. Wildfowl: an identification guide to the ducks, geese and swans of the world. - Christopher Helm, London: 298 p.

Madsen, F.J. I949. Marine Bivalvia. The Zoology of Iceland IV, Part 63: iı6 p.

Madsen, J. I989. Gæs. - In: Meltofte, H. and Fjeldså, J. (eds.) Fuglene i Danmark. Gyldendal, Copenhagen: Io2I23.

Marshall, F. and Pilgrim, T. I99I. Meat versus within bonenutrients: another look at the meaning of body part representation in archaeological sites. - Journal of Archaeological Science I8: I49-I63.

Marshall, F. and Pilgrim, T. I993. NISP vs. MNI in Quantification of Body-part Representation. - American Antiquity 58: 26I-269.

Mary-Rousseliére, G. I976. The Paleoeskimo in Northern Baffinland. - In Maxwell, M.S. (ed.). Eastern Arctic Prehistory. Paleoeskimo Problems. - Memoirs of the Society for American Archaeology 3I: 40-57.

Mathiassen, T. I958. The Sermermiut Excavations 1995. Meddelelser om Grønland I6I (3): 52 p.

Maxwell, M.S. (ed.) 1976a. Eastern Arctic Prehistory. Paleoeskimo Problems. - Memoirs of the Society for American Archaeology 31: I70 p.

Maxwell, M.S. I976b. Pre-Dorset and Dorset Artifacts: The view from Lake Habour. - In Maxwell, M.S. (ed.). Eastern Arctic Prehistory. Paleoeskimo Problems. Memoirs of the Society for American Archaeology 3I: 5878.

Maxwell, M.S. I985. Prehistory of Eastern Arctic. - Academic Press. New York: 327 p.

Maxwell, M.S. 1997. The Canadian Arctic in Transition: PreDorset to Dorset. - In: Gilberg, R. and Gulløv, H.C. (eds.). Fifty Years of Arctic Research. Anthropological Studies from Greenland to Siberia. Ethnographical Series, I8. Department of Ethnography, The National Museum of Denmark, Copenhagen: 205-208.

McGhee, R. I970. Excavation at Bloody Falls. N.W.T., Canada. - Arctic Anthropology 6 (2): 53-72.

McGhee, R. I979. The Palaeoeskimo Occupations at Port Refuge, High Arctic Canada. - Archaeological Survey of Canada, Mercury Series paper 92. National Museum of Man. Ottawa: 176 p.

McGhee, R. I980. Individual Stylistic Variability in Independence I Stone Tool Assemblages from Port Refuge. N.W.T. - Arctic 33 (3): 443-453.

McGhee, R. I996. Ancient People of the Arctic. University of British Columbia Press. Vancouver: 244 p.

McGovern, T.H. I979. The paleoeconomy of Norse Greenland: adaptation and extinction in a tightly bounded ecosystem. - Unpublished Ph.D. dissertation, Columbia University: 395 p.
McGovern, T.H. 1985. Contributions to the Paleoeconomy of Norse Greenland. - Acta Archaeologica 54: 73-I22.

McGovern, T.H., Bigelow, G.F., Amorosi, T., Woollett, J. and

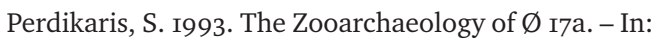
Vebæk, C.L. (ed.). Narsaq - a Norse landnáma farm. Meddelser om Grønland, Man and Society I8: 58-74.

McGovern, T.H., Amorosi, T., Perdikaris, S. and Woollett, J. I996. Vertebrate Zooarcheaeology of Sandnes V5I: Economic Change at a Chieftain's Farm in West Greenland. - Arctic Anthropology 33 (2): 94-I2I.

Meldgaard, J. I952. A Paleo-Eskimo Culture in West Greenland. - American Antiquity I7 (3): 222-230.

Meldgaard, J. I960. Prehistoric Culture Sequences in the Eastern Arctic as elucidated by stratified Sites at Iglulik. In: Wallace, A.F.C. (ed.). Men and Cultures. Selected Papers of the Fith International Congress of Anthropological and Ethnological Sciences. 1956. University of Pennsylvania Press, Philadelphia: 588-595.

Meldgaard, J. I96I. Sarqaq-folket ved Itivnera. Nationalmuseets undersøgelser i sommeren I960. - Tidsskriftet Grønland 9 (9): 15-23.

Meldgaard, J. 1977. Prehistoric Cultures in Greenland, Discontinuities in a Marginal Area. - In: Kylstra, H.P. and Liefferink, L.H. (eds.). Continuity and Discontinuity in the Inuit Cultures of Greenland. Proceedings from Danish-Netherland Symposium 1976, Arctic Center, Groningen: 19-52.

Meldgaard, J. I980. Den forhistoriske bebyggelse. - In: Haarløv, N., Jacobsen, N.K., Meldgaard, J. and Petersen, H.C. (eds.). Holsteinsborg. Sisimiut kommune. Natur- og kulturforhold. Udvalget vedrørende Fredningslov for Grønland. Ministeriet for Grønland. Copenhagen: 56-59.

Meldgaard, J. I983. Qajâ, en køkkenmødding i dybfrost. Feltrappport fra arbejdsmarken i Grønland. Nationalmuseets Arbejdsmark. Copenhagen: 83-96.

Meldgaard, J. I991. Bopladsen Qajaa i Jakobshavn Isfjord. Rapport om udgravninger I87I og I982. - Tidsskriftet Grønland 39 (4-7): 19I-205.

Meldgaard, M. 1983. The bone material. - In: Grønnow, B., Meldgaard, M. and Nielsen, J. B. (eds.), Aasivissuit - The Great Summer Camp. Archaeological, ethnographical and zooarchaeological studies of a caribou-hunting site in West Greenland. - Meddelelser om Grønland, Man and Society 5: 68-80.

Meldgaard, M. 1986. The Greenland caribou - zoogeography, taxonomy, and population dynamics. - Meddelelser om Grønland, Bioscience 20: 88 .

Meldgaard, M. I988. The Great Auk, Pinguinus impennis (L.) in Greenland. - Historical Biology I: I45-I78.

Meldgaard, M. I995. Resource pulses in a marine environment: a case study from Disko Bugt, West Greenland. In: Fischer, A. (ed.), Man and Sea in the Mesolithic. Coastal settlement above and below present sea level. Oxbow Monograph 53: 36I-370. 
Meldgaard, M. 2004. Ancient Harp Seal Hunters of Disko Bay. Subsistence and Settlement at the Saqqaq Culture Site Qeqertasussuk (2400-I40o BC), West Greenland. Meddelelser om Grønland, Man and Society 30: I86 p.

Miller, F.L. 1974. Biology of the Kaminuriak population of barren-ground caribou. Part 2: Dentition as an indicator of age and sex composition and socialization of the population. - Canadian Wildlife Service Report Series 3I: 88 p.

Mitchell-Jones, A.J., Amori, G., Bogdanowicz, W., Krystufek, B., Reijnders, P.J.H., Spitzenberger, F., Stubbe, M., Thissen, J.B.M., Vohralík, V. and Zima, J. I999. - The Atlas of European Mammals. - Academic Press, London: 484 p.

Morey, D.F. and Aaris-Sørensen, K. 2002. Paleoeskimo Dogs of the Eastern Arctic. - Arctic 50 (I): 44-56.

Morrison, D and Pilon J.-L. I994. Threads of Arctic Prehistory: Papers in honour of William E. Taylor, Jr. - Archaeological Survey of Canada, Mercury Series paper I49. National Museum of Man. Ottawa: 422 p.

Murray, M.S. I992. Beyond the laundry list. The analysis of faunal remains from a Dorset dwelling at Phillip's Garden (Eebi-I), Port au Choix, Newfoundland. - Unpublished Master's thesis, Department of Antropology, Memorial University of Newfoundland. St. John's.

Murray, M.S. 200o. A zooarchaeological approach to Arctic prehistory. - In: Rowley-Conwy, P. (ed.). Animal Bones, Human Societies. Oxbow Books, Oxford: 58-64.

Muus, B.J. I98I. Fisk. (Pisces) - In: Muus, B.J. et al. (eds). Grønlands fauna. Fisk Fugle Pattedyr. - Gyldendal, Copenhagen: 23-I58.

Muus, B.J. and Nielsen, J.G. I998. Havfisk og Fiskeri i Nordvesteuropa. - Gads Forlag, Copenhagen: 338 p.

Müller, R. 1906. Vildtet og jagten i Sydgrønland. Universitetets Bogtrykkeri, København: 519 p.

Müller-Bech, H. (ed.) 1977. Excavations at Umingmak on Banks Island, N.W.T., I970 and 1973. Preliminary Report. - Verlag Archaeologica Venatoria. Institut für Urgeschichte der Universität Tübingen I: I62 p.

Münzel, S.C. I987a. Umingmak ein Moschusochsenjagdplatz auf Banks Island, N.W.T., Canada. - In: Müller-Beck, H. and Hahn, J. (eds.). - Archaeologische Forschungen auf Banks Island 1970-I975. Verlag Archaeologica Venatoria. Institut für Urgeschichte der Universität Tübingen 2: 358 p.

Münzel, S.C. I987b. Arctic America: Umingmak, a Muskox Hunting Site on Banks Island, N.W.T., Canada. - Early Man News I2/I3: 93-I08.

Møbjerg, T. I986a. Den palæoeskimoiske ressourceudnyttelse, som den kommer til udtryk gennem bopladsplacering og knoglefund. - In: Vort sprog - vor kultur. Foredrag fra symposium afholdt i Nuuk oktober I98I arrangereret af Ilisimatusarfik og Kalaallit Nunaata Katersugaasivia. Pilersuiffik. Nuuk: 47-62.

Møbjerg, T. I986b. Contribution to Paleo-Eskimo Archaeology in Greenland. - Arctic Anthropology 23 (I-2): 19-56.
Møbjerg, T. 1988a. De palæoeskimoiske kulturer i Ammassalik distrikt. - In: Møbjerg T., Grønnow, B. and Schultz-Lorentsen, H. (eds.). Palæoeskimoisk forskning i Grønland. Aarhus University Press: 8I-94.

Møbjerg, T. I988b. A "Deathhouse" at Sydkap, Scoresbysund. - Folk 30: 20I-2I4.

Møbjerg, T. 1988c. Préhistorie du Groënland. - L'Anthropologie 92 (3): 949-952.

Møbjerg, T. I995a. Sidste nyt fra Nipisat I. - Tidsskriftet Grønland 43 (2): 45-54.

Møbjerg, T. 1995b. Nipisat I. A Saqqaq site in Sisimiut District, West Greenland. - In: Bertulli, M., Berglund, J. and Lange, H. (eds.). Archaeological Field Work in the Northwest Territories in 1994 and Greenland in 1993 and 1994. - Prince of Wales. Northern Heritage Centre, Archaeology Reports I6: 88-94.

Møbjerg, T. (ed.) I997a. Asummiut før og nu. - Tidsskriftet Grønland 45 (5-7): 173-284.

Møbjerg, T. I997b. New aspects of the Saqqaq Culture in West Greenland. - In: Gilberg, R. and Gulløv, H.C. (eds.). Fifty Years of Arctic Research. Anthropological Studies from Greenland to Siberia. Ethnographical Series I8, Department of Ethnography, The National Museum of Denmark, Copenhagen: 227-236.

Møbjerg, T. I998. The Saqqaaq culture in the Sisimiut municipality elucidated by the two sites Nipisat and Asummiut. - In: Arneborg, J. and Gulløv, H.C. (eds.). Man, Culture and Environment in Ancient Greenland. Danish Polar Center Publication no. 4, Copenhagen, Danish National Museum and Danish Polar Center: 98-ı18.

Møbjerg, T. I999. New adaptive strategies in the Saqqaq culture of Greenland, c. I600-I40o BC. - World Archaeology 30 (3): 452-465.

Møbjerg. T. and Robert-Lamblin. J. I990. The settlement Ikaasap Ittiva, East Greenland. An ethno-archaological investigation. - Acta Archaeologica 60: 229-262.

Møbjerg, T. and Grummesgaard-Nielsen, S. 1996. Excavations at Asummiut, West Greenland. - In: Kenny, V., Bertulli, M. and Berglund, J. (ed.). Archaeological Field Work in the Northwest Territories, Canada and Greenland in I995. Prince of Wales. Northern Heritage Centre, Archaeology Reports I7. Yellowknife: 54-60.

Møbjerg, T. and Grummesgaard-Nielsen, S. I997a. Kulturhistorien ved Ulkebugten. - Tidsskriftet Grønland 45 (57): I77-I82.

Møbjerg, T. and Grummesgaard-Nielsen, S. 1997b. Saqqaqkulturen på Asummiut. - Tidsskriftet Grønland 45 (5-7): 238-59.

Møhl, J. I982. Ressourceudnyttelse fra norrøne og eskimoiske affaldslag belyst gennem knoglematerialet. - Tidsskriftet Grønland 30 (8-9): 286-295.

Møhl, J. I986. Dog Remains from a Paleoeskimo Settlement in West Greenland. -Arctic Anthropology 23 (I-2): 8I-89.

Møhl, J. I997a. Faunal Remains from Illorpaat. - In: Gulløv, 
H.C. (ed.). From Middle Ages to Colonial Times Archaeological and ethnohistorical studies of the Thule culture in South West Greenland I300-I80o AD. - Meddelelser om Grønland, Man and Society 23: 495-50I.

Møhl, J. I997b. Greenland - A Quaternary Zoological View. In: Gilberg, R. and Gulløv, H.C. (eds.). Fifty Years of Arctic Research. Anthropological Studies from Greenland to Siberia. Ethnographical Series I8. Department of Ethnography, The National Museum of Denmark, Copenhagen: 237-242.

Møhl, U. 1972. Animal bones from Itivnera, West Greenland. A Reindeer hunting site of the Sarqaq Culture. - Meddelelser om Grønland I9I (6): 5- 23.

Mörch, O.A.L. I857. Fortegnelse over Grønlands Bløddyr. - In: Rink, H. Grønland, geographisk og statistisk beskrevet. Kjøbenhavn, Louis Kleins Bogtrykkeri: 28 p.

Nagy, M.I. 1997. Paleoeskimo Cultural Transition: A Case Study from Ivujivik, Eastern Arctic. - Nunavik Archaeological Monograph Series I, Avataq Cultural Institute. Québec: I87 p.

Nagy, M.I. 200o. From Pre-Dorset foragers to Dorset collectors: Paleo-eskimo cultural change in Ivujivik, eastern Canadian Arctic. - In: Appelt, M., Berglund, J. and Gulløv, H.C. (eds.). Identities and Cultural Contacts in the Arctic. Proceedings from a Conference at Danish National Museum Copenhagen, November 30 to December 2 1999. Danish Polar Center Publication No. 8., Copenhagen, Danish National Museum and Danish Polar Center: I43-I48.

Nelson, D.E. and Møhl, J. 2003. Radiocarbon Dating Caribou Antler and Bone: Are They Different? - Arctic 56 (3): 262-265.

Nelson, E.W. 1899. The Eskimo about Bering Strait. - Eighteenth Annual Report of the Bureau of American Ethnology, 1896-97. Smithsonian Institute. Washington: $997 \mathrm{p}$.

Noe-Nygaard, N. 1989. Man-made trace fossils on bones. Human Evolution 4: 46I-49I.

O'Brien, S.R., Mayewski, P.A., Meeker L.D., Meese D.A., Twickler M.S. and Whitlow, S.I. 1995. Complexity of Holocene Climate as Reconstructed from a Greenland Ice Core. - Science, 270: 1962-I964.

Ockelmann, W.K. I958. Marine Lamellibranchiata. The Zoology of East Greenland. - Meddelelser om Grønland I22,4: $256 \mathrm{p}$.

Odgaard, U. 2003. Bosættelsesmønstre i det central Vestgrønland. Rapport om undersøgelserne i Angujaartorfiup Nunaa, Maniitsoq Kommune, sommeren 2002. - SILA. Nationalmuseets Center for Grønlandsforskning. Copenhagen: $96 \mathrm{p}$.

Ogilvie, M.A. 1978. Wild Geese. - T. and A.D. Poyser, Berkhamsted: $350 \mathrm{p}$.

Ogilvie, M.A., Doertmann, D., Cabot, D., Merne, O., Percival, S.M. and Sigfusson. I999. Barnacle goose (Branta leucop- sis): Greenland. - In: Madsen, J., Cracknell G. and Fox T. (eds.) - Goose populations of the western Palearctic. Wetlands International Publication 48. National Environmental Research Institute, Denmark: 246-256.

Oldendow, K. I933. Fugleliv i Grønland. - Det grønlandske Selskabs Aarsskrift I932-I933: I7-224.

Oldendow, K. 1935. Naturfredning i Grønland. - Det grønlandske Selskabs Skrifter 9: 389 p.

Olsen, B. I998. Saqqaq housing and settlement in southern Disko Bay, West Greenland. - Acta Borealia I5 (2): 8I-I28.

Olsen, H. I967. Varanger - Funnene IV. Osteologisk materiale Innledning - Fisk - Fugl. - Tromsø Museums skrifter 7 (4): $190 \mathrm{p}$.

Olsen, K. (ed.) I958. Sisimiut. Holsteinsborg. I756-I956.- Det grønlandske Forlag. Nuuk: iıo p.

Ostermann, H. 192I. Henric Christopher Glahns miss. ord.: ved Holsteinsborg og Amertlok. Dagbog fra I. Julii I966 til sidste Junii 1967 and Dagbog fra I. Jul: 1967 til sidste Jun: I768. Missionær i Grønland Henric Christopher Glahns Dagbøger for Aarene I763-64, I766-67 og I767-68. - Det Grønlandske Selskabs Skrifter 4: 36-I24 and I27239.

Outram, A.K. 1999. A comparison of Paleo-Eskimo and Medieval Norse Bone Fat Exploitation in Western Greenland. - Arctic Anthroplogy 36 (I-2): IO3-II7.

Owen, F.R.S., F.Z.S. I865. Description of the Skeleton of the Great Auk, or Garfowl (Alca impennis, L.). - Transactions of the Zoological Society of London 5 (4): 3I7-335.

Owen, M. I980. Wild geese of the world. - B.T. Batsford Ltd. London: 236 p.

Owen, M., Drent, R.H., Ogilvie, M.A. and Spanje T.M. van. 1978. Numbers, distribution and catching of Barnacle Geese (Branta leucopsis) on the Nordenskioldkysten Svalbard, in 1977. - Norsk Polarinstituts Aarbok 1977: 247-258.

Petersen, C.G.J. I888. Om de skalbærende Molluskers Udbredningsforhold i de Danske Have indenfor Skagen. Kjøbenhavn: $162 \mathrm{p}$.

Petersen, G.H. I968. Marine Lamellibranchiata. Zoology of the Faroes III, I, LV: 80 p.

Petersen, G.H. 1977. The Density, Biomass and Origin of the Bivalves of the Central North Sea. - Meddelelser fra Danmarks Fiskeri- og Havundersøgelser Ny serie 7: 22I273.

Petersen, G.H. 20or. Studies on some Arcthic and Baltic Astarte species (Bivalvia Mollusca). - Meddelelser om Grønland, Bioscience 52: 7I p.

Petersen, K.S. I986. An Outline of the Present Stage of Study on Late Quaternary Marine Molluscs in the Nordic Realm. - Nordic Late Quaternary Biology and Ecology (L.-K. Königsson, ed.). Striae 24: 39-45.

Petersen, K.S. 200o. Geological Investigations in the Area of Haghia Triadha. - In: Greek-Danish Excavations in Aetolian Chalkis 1997-1998. Second Preliminary Report. 
Ed. S. Dietz et al. Proceedings of the Danish Institute at Athens 3: 269-75.

Petersen, K.S. 2004. Late Quaternary environmental changes recorded in the Danish marine Molluscan faunas. Geology of Denmark and Greenland Survey Bulletin 3.

Petersen, K.S. and Hoch, E. I998. Geology in the Sisimiut Area. - In: Arneborg, J. and Gulløv, H.C. (eds.). Man, Culture and Enviroment in Ancient Greenland. Danish Polar Center Publication no. 4, Copenhagen, Danish National Museum and Danish Polar Center: II9-I23.

Petersen, R. I988. Palæoeskimoiske fund i Maniitsoq Kommune. - In: Møbjerg T., Grønnow, B. and Schultz-Lorentsen, H. (eds.). Palæoeskimoisk forskning i Grønland. Aarhus University Press: 59-68.

Pind, J., Grønnow, B., Ipsen, J., Odgaard, U. and Schilling, H. I99I. Aasivissuit. Bopladser og rensdyrjagt i det vestgrønlandske indland. Rapport fra et feltkursus, sommeren I990. - Institut for forhistorisk og klassisk arkæologi, Copenhagen: I82 p.

Plumet, P. 1994. Some problems in Arctic Prehistory. - In: Gul1øv, H.C. (ed.). Contributions to a Franco-Danish Meeting on Recent Research in the Eskimo World. Danish National Museum and Danish Polar Center. Copenhagen: 79-8I.

Poppe, G.T. and Goto, Y. 1993. European Seashells (Scaphopoda, Bivalvia, Cephalopoda) II. - Verlag Christa Hemmen: 22I p.

Posselt, H.J. I899. Grønlands Brachiopoder og Bløddyr. Meddelelser om Grønland 23: 298 p.

Raahauge, K. and Appelt M. 2002. Itilleq og palæoeskimoerne i Sydgrønland. - Tidsskriftet Grønland 50 (4): II3-I24.

Rasch, M. and Jensen, J.F. I997. Ancient Eskimo dwelling sites and Holocene relative sea-level changes in southern Disko Bugt, Central West Greenland. - Polar Research I6 (2): IOI-II5.

Renouf, M.A.P. 1990. The Transitional Period in the Eastern Arctic: Another Mesolithic Interlude? - Paper for the session on "Original Affluence Revisited" at the Sixth International Conference on Hunting and Gathering Societies, Fairbanks, Alaska: I6 p.

Renouf, M.A.P. I994. Two Transitional Sites at Port au Choix, Northern Newfoundland. - In: Morrison, D. and Pilon, J.-L (eds.). Threads of Arctic Prehistory: Papers in honour of William E. Taylor, Jr. - Archaeological Survey of Canada. Mercury Series paper I49. Canadian Museum of Civilization: 165-196.

Renouf, M.A.P. 1999. Prehistory of Newfoundland huntergatherers: extinctions or adaptations? - World Archaeology. 30 (3): 403-420.

Riget, F. and Böcher, J. 200I. The Fresh Water Environment. In: Born, E.W. and Böcher, J. (eds.). The Ecology of Greenland. - Ministry of Environment and Natural Resources. Ilinniusiorfik. Nuuk: 22I-236.
Rink, H. I852. De danske handelsdistrikter i Nordgrønland I. København: 202 p.

Rink, H. I857. Grønland geografisk og statistisk beskrevet. Det Søndre Inspektorat. - København: 4I6 p.

Rosing, J. I958. Tanker ved et "viftested". - Tidsskriftet Grønland 6: 385-392.

Rowley-Conwy, P. and Storå, J. 1997. Pitted ware seals and pigs from Ajvide, Gotland: Methods of study and first results. - In: Burenhult, G. (ed.). Remote sensing vol I: Osteo-anthropological, economic, environmental and technical analyses. Institute of Archaeology, University of Stockholm: II3-I27.

Salomonsen, F. I950. Grønlands Fugle, The Birds of Greenland. - Munksgaard, København: 609 p.

Salomonsen, F. 1967. Fuglene på Grønland. - Rhodos. Copenhagen: 34I p.

Salomonsen, F. 1974. Fuglene i Menneskenes Land I. - Det Grønlandske Forlag: I27 p.

Salomonsen, F. 1979. Ornithological and ecological studies in S. W. Greenland ( $59^{\circ} 46^{\prime}-62^{\circ} 27^{\prime} \mathrm{N}$ Lat.). - Meddelelser om Grønland 204 (6): 2I4 p.

Salomonsen, F. 1981a. Grønlands natur. - In: Salomonsen, F. (ed.). Grønlands Fauna. - Gyldendal, Copenhagen: 8-22.

Salomonsen, F. 198Ib. Fugle (Aves). - In: Muus, B.J. et al. (eds). Grønlands Fauna. Fisk Fugle Pattedyr. - Gyldendal, Copenhagen: 159-36I.

Sandell, H.T. and Sandell, B. 1996. Paleo-Eskimo Sites and Finds in the Scoresby Sund area. - In: Grønnow, B. (ed.). The Paleo-Eskimo Cultures of Greenland - New Perspectives in Greenlandic Archaeology. Danish Polar Center Publication no. I, Copenhagen: I6I-I76.

Savelle, J.M. I994. Prehistoric exploitation of white whales (Delphinapterus leucas) and narwhals (Monodon monoceros) in the eastern Canadian Arctic. - In: Born, E.W., Dietz, R. and Reeves, R.R. (eds.). Studies of white whales (Delphinapterus leucas) and narwhals (Monodon monoceros) in Greenland and adjacent waters. - Meddelelser om Grønland, Bioscience 39: IOI-II7.

Schiffer, M.B. I972. Archaeological context and systemic context. - American Antiquity 37 (2): I56-I65.

Schilling, H. 1996. Paleo-Eskimo Utilization of West Greenland Inland Areas. - In: Grønnow, B. (ed.). The PaleoEskimo Cultures of Greenland - New Perspectives in Greenlandic Archaeology. Danish Polar Center Publication no. I, Copenhagen: III-II8.

Schledermann, P. I98I. Ellesmere Island. Eskimo and Viking finds in the High Arctic. - National Geographic I59 (5): 589.

Schledermann, P. I990. Crossroads to Greenland: 3000 Years of Prehistory in the Eastern High Arctic. - Komatic Series 2. The Arctic Institute of North America, University of Calgary: 364 p. 
Schledermann, P. 1996. Voices in Stone. A Personal Journey into the Arctic Past. - Komatic Series 5. The Arctic Institute of North America, University of Calgary: 22I p.

Schultz-Lorentzen, H. I927. Dictionary of the West Greenland Eskimo Language. - Meddelelser om Grønland 69: 303 p.

Schäfer, W. 1972. Ecology and paleoecology of marine environments. - Oliver and Boyd, Edinburgh: 568 p.

Secher, K., Böcher, J., Grønnow, B., Holt, S., Petersen, H.C. and Thing, H. I987. Arnangarnup Qoorua. Paradisdal i tusinder af år. - Pilersuiffik: 80 p.

Silver, I.A. 1969. The ageing of domestic animals. - In: Brothwell, D. and Higgs, E. S. (eds.). Science in Archaeology. Thames and Hudson, London: 250-268.

Simkiss, K. (ed.) I967. Calcium in reproduction physiology: a comparative study of vertebrates. - Reinhold Publishing Company, New York: 264 p.

Simonarson, L.A., Petersen, K.S. and Funder, S. 1998. Molluscan palaeontology of the Pliocene-Pleistocene Kap København Formation, North Greenland. - Meddelelser om Grønland, Geoscience 36: I03 p.

Spiess, A.E. 1979. Reindeer and Caribou Hunters. An Archaeological Study. - Studies in Archaeology. - Academic Press, New York: 3I2 p.

Stefànsson, V. I9I4. The Stefànsson-Anderson arctic expedition of the American Museum of Natural History. Preliminary Ethnological Report. - Anthropological Papers of the American Museum of Natural History I4 (I): 395 p.

Stewart, H. 1977. Indian Fishing: Early Methods on the Northwest Coast. - Vancouver: I8I p.

Stewart, H. I996. Stone, Bone, Antler and Shell. Artifacts of the Northwest Coast. - Vancouver: I40 p.

Storå, J. 20oI. Skeletal development in the Grey seal Halichoerus grypus, the Ringed seal Phoca hispida botnica, the Habour seal Phoca vitulina vitulina and the Harp seal Phoca groenlandica. Epiphyseal Fusion and Life History. ArchæoZoologia II: I99-222.

Strandgaard, H., Holthe, V., Lassen, P. and Thing, H. 1983. Rensdyrundersøgelser i Vestgrønland I977-82. - Report on file DMU, Kalø: 26 p.

Stuiver M., Reimer, P.J., Bard, E., Beck, J.W., Burr, G.S., Hughen, K.A., Kromer, B., McCormac, van der Plicht, G.J. and Spurk, M. I998. INTCAL98 Radiocarbon Age Calibration, 24000-o cal BP. - Radiocarbon 40 (3): IO4II083.

Sutherland, P. I996. Continuity and Change in the PaleoEskimo Prehistory of Northern Ellesmere Island. - In: Grønnow, B. (ed.). The Paleo-Eskimo Cultures of Greenland - New Perspectives in Greenlandic Archaeology. Danish Polar Center Publication no. I, Copenhagen: 27I294.

Sutherland, P. 1997. New Evidence for Links between Alaska and Arctic Canada: the Satkualuk Site in the Mackenzie
Delta. - Paper presented at the Alaskan Anthropological Association meetings in Whitehorse, Yukon: II p.

Tagliacozzo, A. and Gala, M. 2002. Exploitation of Anseriformes at two Upper Palaeolithic sites in Southern Italy: Grotta Romanelli (Lecce, Apulia) and Grotta del Santuario della Madonnaa Praia a Mare (Consenza, Calabria). - In: Bochénski, Z. M., Bochénski, Z. and Stewart, J. Proceedings of the 4th Meeting of the ICAZ Bird Working Group, Krakow, Poland, II-I5 September, 2002. - Acta Zoologia Cracoviensia, 45 (special issue): II7-I3I.

Taylor, T.G. 1970. How an eggshell is made. - Scientific American 222 (3): 89-95.

Taylor, W.E., Jr. 1967. Summary of Archaeological Field work on Banks and Victoria Islands, Arctic Canada, I965. Arctic Anthropology 4 (I): 22I-243.

Taylor, W.E., Jr. 1968. The Arnapik and Tyara sites: An Achaological Study of Dorset Culture Origins. - Memoirs of the Society for American Archaeology. 22. Salt Lake City: 129 p.

Taylor, W.E. Jr. and Swinton, G. 1967. Prehistoric Dorset Art. The Beaver 298: 32-47.

Teilmann, J. and Dietz, R. 1994. Status of the Harbour Seal, Phoca vitulina, in Greenland. - The Canadian FieldNaturalist I08 (2): I39-I55.

Thalbitzer, W. I9I4. Ethnographical Collections from East Greenland (Ammassalik and Nualik) made by G. Holm, G. Amdrup, and J. Petersen and described by W. Thalbitzer. - In: Thalbitzer, W. (ed.), The Ammassalik Eskimo. Contributions to the Ethnology of the East Greenland Natives. -Meddelelser om Grønland 39 (I): 32I- 753.

Thing, H. I984. Feeding ecology of the West Greenland caribou (Rangifer tarandus groenlandicus) in the Sisimiut/Kangerlussuaq region. - Danish Review of Game Biology I2 (3): 53 p.

Thorson, G. I94I. Marine Gastropoda Prosobranchiata. The Zoology of Iceland IV, Part 6o: I50 p.

Thorson, G. I957. Bottom communities (sublittoral or shallow shelf). - Geological Society of America Memoir 67,I: 46I534 .

Thuesen, S. I997. "At være i Asummiut er dejligt". - Tidsskriftet Grønland 45 (5-7): I83-I98.

Tuborg, H.T. and Sandell, B. I999. Paleo-Eskimo Settlements in Scoresby Sund, Northeast Greenland. - Danish Polar Center Publication no. 6, Copenhagen, Danish National Museum and Danish Polar Center: I5o p.

Tuck, J.A. I976. Paleoeskimo Cultures of Northern Labrador. In: Maxwell, M.S. (ed.). Eastern Arctic Prehistory. Paleoeskimo Problems. - Memoirs of the Society for American Archaeology 31: 89-I02.

Vibe, C. 1956. The walrus west of Greenland. - In: International Union of Protection of Nature. Proceedings of the $5^{\text {th }}$ Meeting, Copenhagen 1954: 79-84. 
Vibe, C. 1967. Arctic animals in relation to climatic fluctuations. - Meddelelser om Grønland I70 (5): 227 p.

Vibe, C. I97I. Havpattedyr. - In: Nørrevang, A., Meyer, T.J. and Christensen, S. (eds.). Danmarks Natur volume io. Danmark og Færøerne. - Politiken Press, Copenhagen: 244-266.

Vibe, C. I98I. Pattedyr (Mammalia). - In: Salomonsen, F. (ed.). Grønlands Fauna. Fisk Fugle Pattedyr. - Gyldendal, Copenhagen: 364-459.

Waterman, T.T. I920. The Whaling Equipment of the Makah Indians. - University of Washington Publications in Anthropology I (I): 67.
Wein, E.E., Freeman, M.R. and Makus, J.C. 1996. Use of and Preference for Traditional Foods among the Belcher Island Inuit. - Arctic 49 (3): 256-264.

Wheeler, A, and Jones, A.K.G. I989. Fishes. - Cambridge University Press. Cambridge: 2Iо p.

Winge, H. I898. Grønlands Fugle. - Meddelelser om Grønland 2I: 316.

Winge, H. I902. Grønlands Pattedyr. - Meddelelser om Grønland 2I (2): 3I9-52I.

Woollett, J.M., Henshaw, A.S. and Wake, C.P. 20oo. Palaeoecological Implications of Archaeological Seal Bone Assemblages: Case Studies from Labrador and Baffin Island. - Arctic 53 (4): 395-4I3. 